
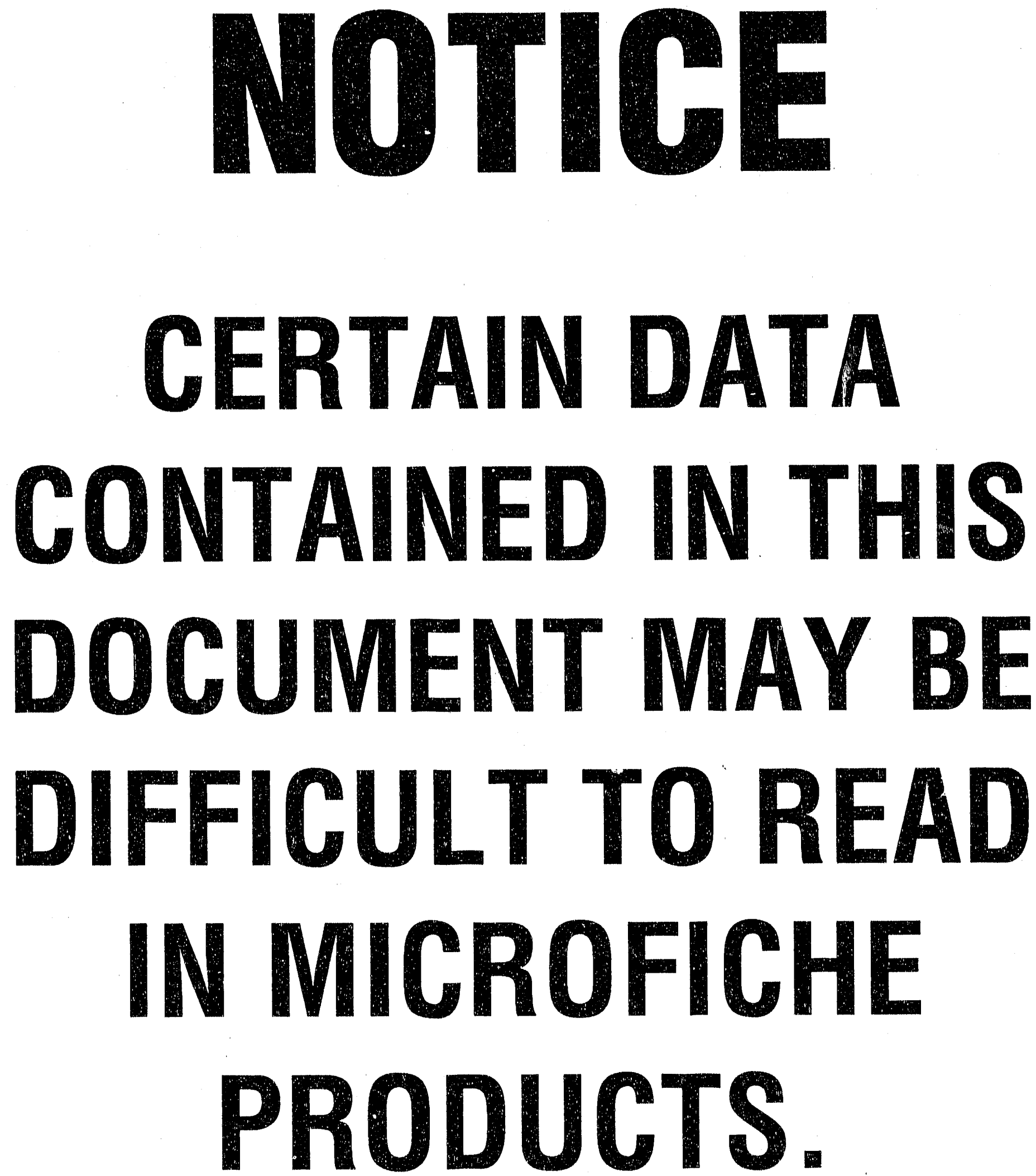


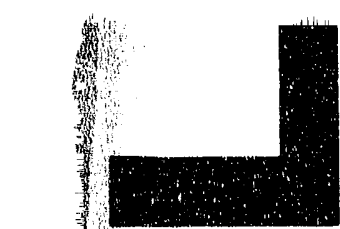

\title{
KINETICS OF COAL PYROLYSIS
}

Final Report

Volume 1-Sections 1 Through 5

\author{
By \\ D. J. Seery \\ J. D. Freihaut \\ W. M. Proscia \\ J. B. Howard \\ W. Peters \\ J. Hsu \\ M. Hajaligol \\ A. Sarofim \\ R. Jenkins \\ J. Mallin \\ B. Espindola-Merin \\ R. Essenhigh \\ M. K. Misra
}

July 1989

Work Pertormed Under Contract No. AC22-B4PC70768

For

U.S. Department of Energy

Pittsburgh Energy Technology Center

Pittsburgh, Pennsylvania

By

United Technologies Research Center

East iHartford, Connecticut 


\section{DISCLAIMER}

This report was prepared as an account of work sporisored by an agency of the United States Government. Neither the United States Government nor any agency thereof, nor any of their employees, makes any warranty, express or inplied, or assumes any legal liability or responsibility for the accuracy, completeness, or usefulness of any information, apparatus, product, or process disclosed, or represents that its use would not infringe privately owned rights. Reference herein to any specific commercial product, process, or service by trade name, trademark. manufacturer, or otherwise does not necessarily constitute or imply its endorsement, recommendation, or favoring by the United States Government or any agency thereof. The views and opinions of authors ex. pressed herein do not necessarily state or reflect those of the United States Government or any agency thereor.

This report has been reproduced directly from the best available copy.

Available to DOE and DOE contractors from the Office of Scientific and Technical Information, P.O. Box 62, Oak Ridge, TN 37831; prices available from (615)576.8401, FTS 626.8401.

Available to the public from the National Technical Information Service, U.S. Department of Commerce, 5285 Port Royal Rd., Springfield, VA 22161. 
KINETICS OF COAL PYROLYSIS

FINAL REPORT

$\mathrm{DOE} / \mathrm{PC} / 70768--\mathrm{T} 1$

DE9 1005307

VOLUME I - SECTIONS 1 THROUGH 5

Prepared by:

D. J. Seery (UTRC)

J. D. Freihaut (UTRC)

W. M. Proscia (UTRC)

J. B. Howard (MIT)

W. Peters (MIT)

J. Hsu (MIT)

M. Hajaligol (MIT)

A. Sarofim (MIT)

R. Jenkins (PSU)

J. Mallin (PSU)

B. Espindola-Merin (PSU)

R. Essenhigh (OSU)

M. K. Misra (OSU)

United Technologies Research Center

East Hartford, CT 06108

UTRC Report 956966-F

Contract No. DE-AC22-84PC70768

DOE Technical Project Officer

Mr. Phil Goldberg

July 1989 


\section{ACKNOWLEDGEMENTS}

The expert technical skills of G. Wagner and D. Santos in performing many of the experiments are gratefully acknowledged. J. Mackie of the University of Sydney and M. Colket of UTRC. Combustion Sciences, provided many helpful insights in technical discussions of results. Most importantly, the majority of the taxing work required in final text preparation was performed by $\mathrm{H}$. Hollick, with assistance from K. Wicks. Their exceptional efforts in preparing the final report and making many helpful suggestions are most thankfully acknowledged. 
R88-PC70768

\section{Kinetics of Coal Pyrolysis}

\section{TABLE OF CONTENTS}

Page

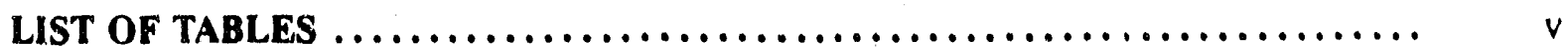

LIST OF FIGURES $\ldots \ldots \ldots \ldots \ldots \ldots \ldots \ldots \ldots \ldots \ldots \ldots \ldots \ldots \ldots \ldots \ldots \ldots \ldots$, vii

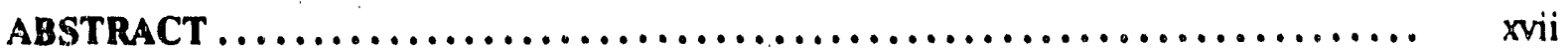

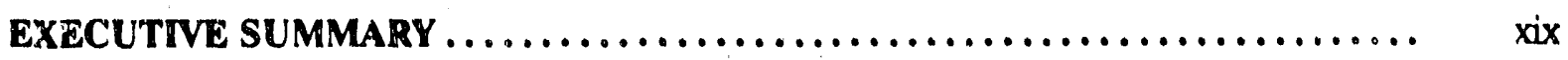

SECTION 1.0 - INTRODUCTION, STATEMENT OF THE

PROBLEM, APPROACH $\ldots \ldots \ldots \ldots \ldots \ldots \ldots \ldots \ldots \ldots \ldots \ldots \ldots \ldots, 1-1$

1.1 Significance of the Devolatilization Process .................... 1-1

1.2 Underlying Causes of Apparent Discrepancies in Conceptual

Understanding and Rate Constants $\ldots \ldots \ldots \ldots \ldots \ldots \ldots \ldots \ldots \ldots, 1-1$

1.2.1 Limitations of Simple "Mass Loss" Approach .............. 1-1

1.2.2 Limitations of Generic Product Categories Approach .......... $1-4$

1.2.3 Limitations Introduced by Variations in Tar Collection and Isolation Techniques $\ldots \ldots \ldots \ldots \ldots \ldots \ldots \ldots \ldots \ldots \ldots \ldots, 1-5$

1.2 .4 Analytical Limitations ............................. $1-5$

1.2.5 Phenomenology of Coal Devolatilization and Conceptual Model Discrepancies Related to Focusing on Limited Phenomena .. 1-5

1.2.6 Apparent Discrepancies Related to Tar Characterization Results ... 1-9

1.2.7 Difficulties in Obtaining Accurate Temperature Measurements During the Transient Devolatilization Process ............... 1-11

1.2.8 Additional Contributing Factors to Apparent Devolatilization Differences ......................................... 1-17

Section 1.0 References ..................................... 1-19

SECTION 2 - EXPERIMENTAL INVESTIGATION AND RESULTS.......... 2-1

2.1 Introduction and General Context $\ldots \ldots \ldots \ldots \ldots \ldots \ldots \ldots \ldots, 2-1$

2.1.1 Range and Characterization of Devolatilization Reactors ........ 2-1

2.1.2 Reactor Characterization and Estimated Particle Temperatures .... 2-1

2.1.3 Rationale in Devolatilization Reactor Configurations .......... 2-4

2.1.4 Order of Presentation of Results $\ldots \ldots \ldots \ldots \ldots \ldots \ldots \ldots \ldots, 2-4$ 


\section{TABLE OF CONTENTS (continued)}

Page

2.2 Devoiatilization in Reactor-to-Particle Heat Flux Rates of 50-100 Watts/sq. cm. .................................. 2-6

2.2.1 Pennsylvania State University Entrained Flow Reactor (PSU-EFR)

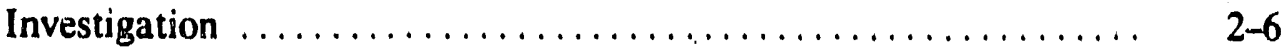

2.2.2 Sandia - MIT Entrained Flow Reactor (SMIT-EFR) Investigation . $\quad$ 2-70

2.3 Devolatilization in Reactor-to-Particle Heat Flux Rates of

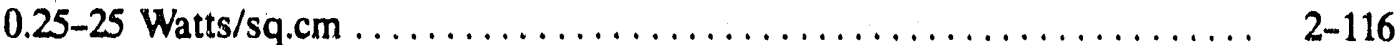

2.3.1 United Technologies Research Center Entrained Flow Reactor (UTRC-EFR) Investigation ................... 2-116

2.3.2 United Technologies Research Center Heated Grid Investigation... 2-185

2.4 United Technologies Research Center Flash Lamp Reactor (UTRC-FL):

Devolatilization in Reactor-to-Particle Heat Flux Rates of

+100 Watts/sq.cm

Section 2.0 References

3.1 General Considerations of HVA Bituminous Coal Devolatilization/Pyrolysis 3-1

3.1.1 Coal Structure Assumptions .......................... 3-1

3.1.2 Phenomenological Sequence of Coal Devolatilization/Pyrolysis of a High Volatile Bituminous Coal .................... 3-8

3.2 HVA Coal Devolatilization - UTRC Model Formulation ............. 3-8

3.2.1 Relationship to Reactor Characterization via Energy Balance Equation

3.2.2 Devolatilization/Pyrolysis Reaction Network and Mathematical Formulation ..................................... 3-15

3.2.3 Results and Kinetic Parameters ........................ 3-22

3.3 Comparison to Other Model Formulations .................... 3-51

3.3.1 One-Step Model . . . . . . . . . . . . . . . . . . . . . . . . . . . . . . . . $3-51$

3.3.2 Two-Step Model .................................... 3-51

3.3.3 Distributed Activation Energy Model (DAEM) ............. 3-52

3.3.4 Distributed-Energy Chain Model (DISCHAIN) ............ 3-52

Section 3.0 References ................................... 3-54 


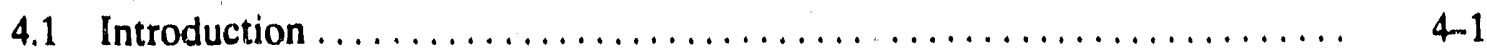

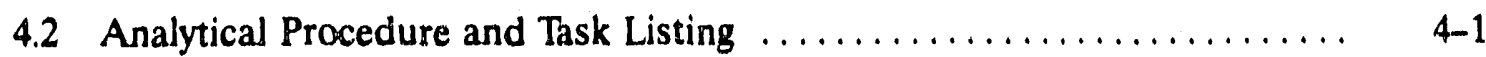

4.3 Experimental Data Base ................................. $4-3$

4.4 Physical Model for Engineering Heat Transfer Times ............. 4-22

4.5 Results I: Differential Behavior $\ldots \ldots \ldots \ldots \ldots \ldots \ldots \ldots \ldots \ldots \ldots, 4-25$

4.5.1 General Characteristics: Inert Particle ..................

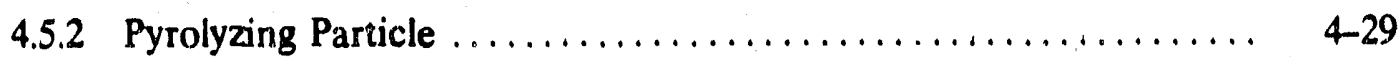

4.5 .3 Combustion $\ldots \ldots \ldots \ldots \ldots \ldots \ldots \ldots \ldots \ldots \ldots \ldots, \quad 4,38$

4.6 Results II: Integrated Behavior $\ldots \ldots \ldots \ldots \ldots \ldots \ldots \ldots \ldots \ldots \ldots, 4-42$

4.6.1 Prediction of Pyrolysis Times: (1) Influence of Diffusion and
Activation Energy ................................. $4-47$

4.6.2 Prediction of Pyrolysis Times: (2) Effect of Ambient Temperature . 4-48

4.6.3 Prediction of Pyrolysis Times: (3) Effect of Ambient Heating Rate . 4-48

4.6.4 Prediction of Pyrolysis Times: (4) Variation with Heating Rate .... $4-49$

4.6.5 Prediction of Tar Release Time $\ldots \ldots \ldots \ldots \ldots \ldots \ldots \ldots \ldots, 4-54$

4.6.6 Kinetics Constant Values ......................... $4-55$

4.7 Data and Model Evaluation ............................. $4-57$

4.7.1 Accuracy of Measurement $\ldots \ldots \ldots \ldots \ldots \ldots \ldots \ldots \ldots \ldots, \quad 4-57$

4.7.2 Captive Particle Data ........................... $4-58$

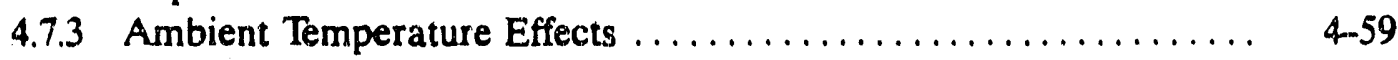

4.7.4 Effects of Coefficient Adjustment ..................... 459

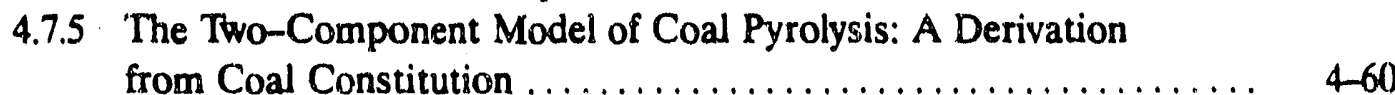

4.8 Engineering Rate Equation $\ldots \ldots \ldots \ldots \ldots \ldots \ldots \ldots \ldots \ldots, \quad 4-63$

4.8.1 Two-Component Predictive Model ...................... $4-63$

4.8.2 The Simplified Model .................................. $4-65$

4.8.3 Recommended Kinetic Equations $\ldots \ldots \ldots \ldots \ldots \ldots \ldots \ldots, 468$

Section 4.0 References $\ldots \ldots \ldots \ldots \ldots \ldots \ldots \ldots \ldots \ldots \ldots \ldots \ldots \ldots, \quad 4-69$

SECTION 5.0 - SUMMARY, CONCLUSIONS, SUGGESTIONS

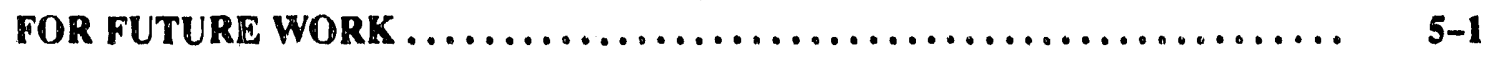


Section 1.0: Introduction, Statement of the Problem, Approach

1.1 Elemental Composition of High Volatile Bituminous Coals Utilized in Heated Grid Devolatilization Studies of Tar

Evolution

Section 2.0: Experimental Investigation and Results

2.1 Thermal Properties of Gases Utilized in the Penn State-

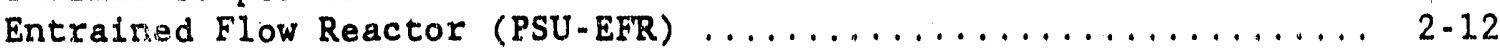

2.2 Reactor Flow Rates in PSU-EFR Operating Conditions .......... 2-13

2.3 Analyses of Coal Samples from Penn State Coal Data Base:

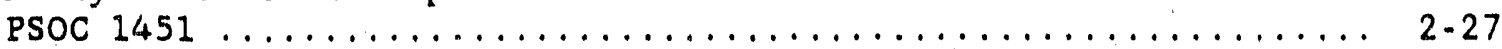

2.4 Analyses of Coal Samples from Penn State Coal Data Base:

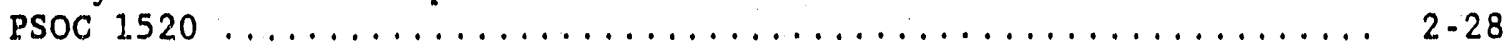

2.5 Analyses of Coal Samples from Penn State Coal Data Base:

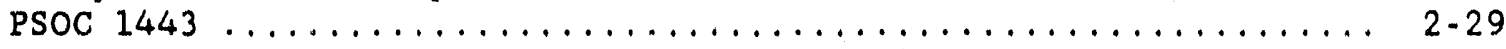

2.6 Proximate Analyses of PSOC 1451, 1520 and 1443 By Size

Fraction Utilized in PSU-EFR ..................... 2-31

2.7 Comparison of Gross Heats of Combustion for PSOC 1451 Coals and Chars Prepared in a He/N2 Atmosphere ............... 2-55

2.8 Comparison of Coal and Char Particle Sizes Prepared in a He/N2 Atmosphere ................................. 2-56

2.9 Characteristics of Ccal Used in the Sandia-M.I.T. Entrained Flow Reactor Investigation ........................ 2-79

2.10 ASTM High Tmperature Ash Analyses of PSOC 1451D ........... 2-80

2.11 Elemental Composition of PSOC XXXX D Coals Utilized in UTRC-EFR

2.12 Elemental Composition of PSOC 1451D, 20-30 Micron Sample As Utilized in UTRC-EFR: Effects of Aerodynamic Segregation of Samples By Mineral Content .........................

2.13 Structure Assignments in Absorption Spectra: Hydrocarbon Structures ................................. 2-130

2:14 Tar Filter Mass Ratios Relative to Gas Flow Split Ratio ........ 2.142

2.15 GPC Calibration Model Compound Data ..................... 2.144

2.16 Nitrogen Balance for Devolatilization of PSOC 1451D: UTRC-EFR ... 2-153

2.17 Tar Yields for PSOC 1451D, 20 - 30 Microns As a Function of Reactor Conditions and As Determined By Nitrogen and Ash

Balance : UTRC-EFR ............................. 2-153

2.18 Elemental Composition of PSOC 1451D Tars: UTRC-EFR .......... 2-155

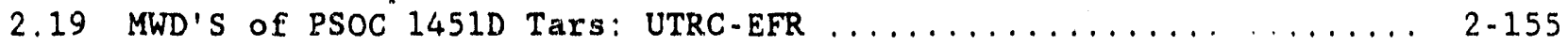

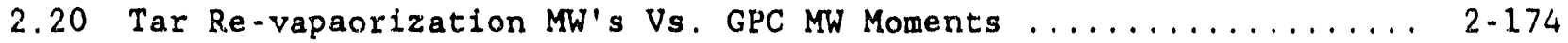

2.21 Properties of Stainless Steel Grid Material ............... 2-188

2.22 Calibration Data of the Grid Substrate Temperature in Transient Heating Conditions ................................ 2-201

2.23 Global Load Factors for Heated Grid Devolatilization of HVA Bituminous Coals ............................. 2-215

2.24 Characteristics of Delivered Flash Lanp Pulses ............ 2.224 
2.25 Characteristics of Particle Size Parameter on Particle Temperature Response in Transient Flash Lamp Pulses ........... 2-225

2.26 Flash Lamp Devolatilization Ylelds: Relative Flux Level - 0.7 , PSOC 1451, 275,325 Mesh ......................... 2-234

2.27 Flash Lamp Devolatilization Xields: Relative Flux Leve1 - 1.0, PSOC 1451, 275/325 Mesh .......................... 2-234

2.28 Flash Lamp Devolatilization Yields: Relative Flux Level - 1.5,

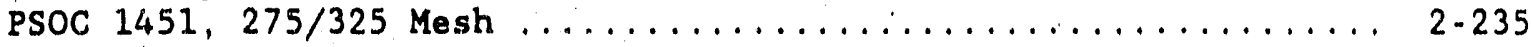

2.29 Flash Lamp Devolatilization Yields: Relative Flux Level - 2.2, PSOC 1451, 275/325 Mesh.

Section 3.0 Devolatilization Modeling

3.1 Gas Propertles Used in Reactor Modeling ................. $3-11$

3.2 Predicted Peak Particle Temperatures [C] for Flash Lamp Vacuum

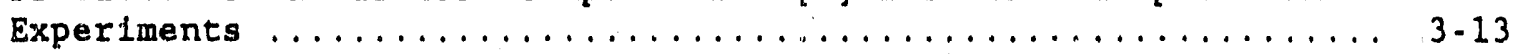

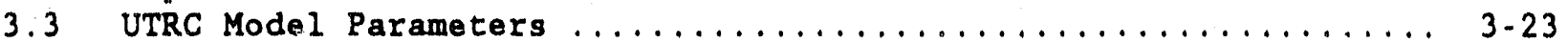

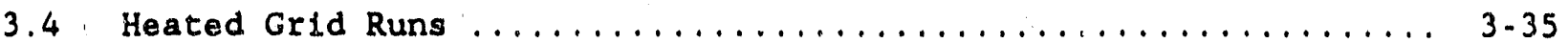

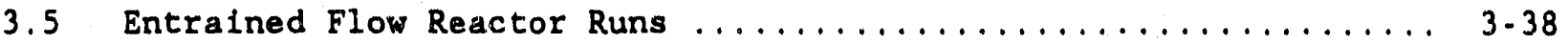

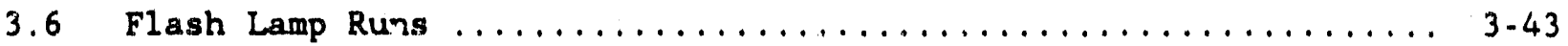

3.7 Comparison of Bond Breaking Rates in Various Models .......... 3-45

3.8 Kinetic Parameters for Tar Evolution and Pyrolys1s: Hva Bituminous 3-46

3.9 Distributed Energy Chain Model (Dischain) $\ldots \ldots \ldots \ldots \ldots \ldots \ldots \ldots$

\section{Section 4.0 Englneering Kinetics}

4.1 Single Particle Volatiles Combustion Constants (Essenhigh) ..... 4-6

4.2 Pyrolysis Times from Drop Tube, Heated Grid and Flame Experiments. 4-7

4.3 Fitting Coefficients for Prediction of Light Tar Evolution Times . 4-18

4.4 Induction and Initial Tar Evolution Times ................ 4-22

4.5 Relationship of Coalification to Pyrolysis and Phenomenology of Coal Devolatilization ............................ 4-62 
Section 1,0 Introduction, Statement of the Problem, Approach

1.1 PFC Combustion Process on a Single Particle Level .......... 1-2

1.2 Devolatilization as CPU .......................... $1-3$

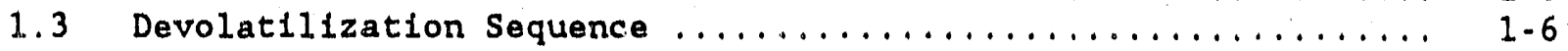

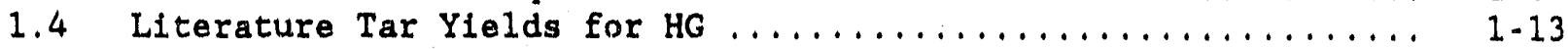

1.5 Coalification Band Plot of Coals Used in HG Tar Evolution

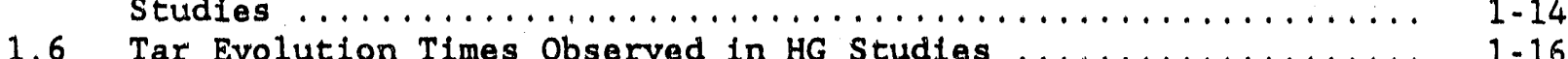

Section 2.0 Experimental Results

2.1 Heat Transfer Space of Devolatilization Reactors .......... 2-2

2.2 PFC Combustion Region of Heat Transfer Space .............. $2-3$

Penn State Entrained Flow Reactor Data

2.3 Penn State Entrained Flow Reactor .................. 2.7

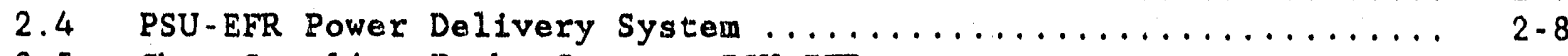

2.5 Char Sampling Probe System: PSU-EFR ................. 2-10

2.6 PSU-EFR Suction Pyrometer Probe ................... 2-11

2.7 Axial Velocity as a Function of Radial and Axial Distances

for Nitrogen at $1073 \mathrm{~K}$ Reactor Temperature (PSU-EFR) ........ 2-16

2.8 Average Axial Gas Velocity for Nitrogen at $1073 \mathrm{~K}$ as a

Function of Axial Distance (PSU-EFR) ................ 2-18

2.9 Dimensionless Boundary Layex Thickness for Nitrogen at $1073 \mathrm{~K}$

as a Function of Axial Distance (PSU-EFR) .............. 2.19

2.10 Residence Time in Nitrogen at $1073 \mathrm{~K}$ as a Function of Axial Distance for $69,81,115$ and 215 Micron Particle (PSU-EFR) ... 2-20

2.11 Axial Velocity and Silp Velocity in Nitrogen at $1073 \mathrm{~K}$ as Functions of Residence Time for 69 Micron Particles

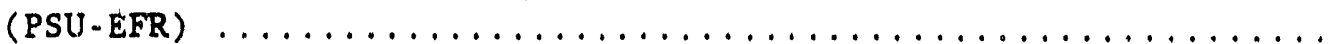

2.12 Gas Temperature Inside the EFR as a Function of Axial Distance In a He/N2 Atmosphere with a Reactor Temperature

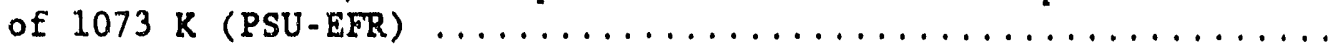

2.13 Average Temperatures for 69,81 and 115 Micron Coal Particles in a Nitrogen Atmosphere as a Function of Residence Time at Reactor Tempeiature of $1073 \mathrm{~K}$ (PSU-EFR) ............

2.14 Heat Flux and Total Heat Transferred for 69 Micron Coal Particles in a Nitrogen Atmosphere as a Function of Residence Time at Reactor Temperature of $1073 \mathrm{~K}$ (PSU-EFR) .............

2.15 Gas and Average Parificle Temperature for 69 Micron Coal Particles in a Nicrogen Atmosphere as a Function of Residence Time at a Reactor Temperature of $1073 \mathrm{~K}$ (PSU-EFR) ...........

2.16 Particle Size Distributions of Raw Coals: PSOC 1520 Mesh

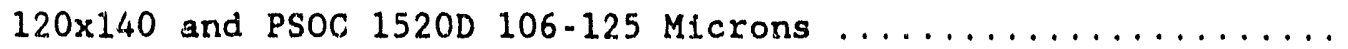


2.17 Particle Size Distributions of Raw Coals: PSOC 1520 Mesh

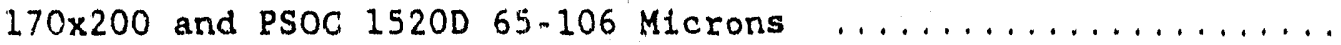

2.18 Particle Size Distributions of Raw Coals: PJ̈OC 1520 Mesh

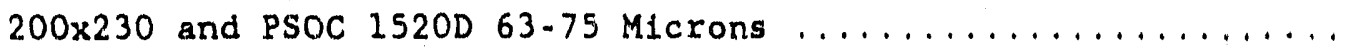

2.19 Effect of Particle Slze on Weight Loss for PSOC 1451 (B1t.) at $1073 \mathrm{~K}$ in a $\mathrm{N} 2 / \mathrm{N} 2$ Atmosphere ................... 2-38

2.20 Effect of Particle Size on Welght Loss For PSOC 1.443 (Lig.) at $1073 \mathrm{~K}$ in a $\mathrm{N} 2 / \mathrm{N} 2$ Atmosphere .................... 2.39

2.21 Effect of Reactor Atmosphere on Weight Loss for $170 \times 200$ Mesh Particles of PSOC 1451 (Bit.) at $1073 \mathrm{~K} \ldots \ldots \ldots \ldots \ldots \ldots .2 .40$

2.22 Effect of Reactor Atmosphere on Weight Loss for $170 \times 200$ Mesh Particles of PSOC 1451 (HVA B1t) at $1273 \mathrm{~K} \ldots \ldots \ldots \ldots \ldots 2.41$

2.23 Effect of Reactor Atmosphere on We1ght Loss for $120 \times 140$ Mesh Particles of PSOC 1451 (HVA Bit.) at 1073X ............ 2-42

2.24 Effect of Reactor Atmosphere on Weight Loss for $170 \times 200$

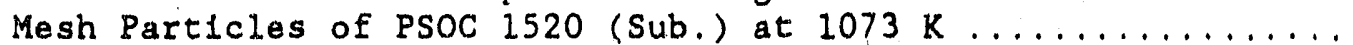

2.25 Effect of Reactor Atmosphere on Weight Loss for $170 \times 200$ Mesh Particles of PSOC 1443 (Lig.) at 1073k .............. 2.44

2.26 Effect of Temperature on Welght Loss for $170 \times 200 \mathrm{Mesh}$ Particles of PSOC 1451 (Bit): 81 Microns .............. 2-45

2.27 Effect of Temperature on Welght Loss for $120 \times 140 \mathrm{Mesh}$ Particles of PSOC 1451 (BLt): 115 Microns .............. 2-46

2.28 Effect of Coal Type on Weight Loss for $120 \times 140 \mathrm{Mesh}$ Particles at $1073 \mathrm{~K}$ During Pyrolysis in a He/N2

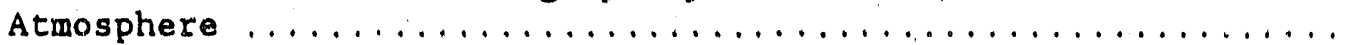

2.29 Effect of Coal Type on Weight Loss for $170 \times 200$ Mesh Particles at $1073 \mathrm{k}$ During Pyrolysis in a He/N2 Atmosphere .... 2-48

2.30 Effect of Coal Type on Weight Loss for $200 \times 300$ Mesh Particles at $1073 \mathrm{~K}$ During Pyrolysis in a He/N2 Atmosphere .............

2.31 Effect of Coal Type on Weight Loss for $120 \times 140$ Mesh

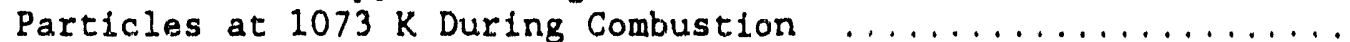

2.32 Size Distributions of $170 \times 200$ Mesh of PSOC 1451 (Bit) Coal and Char Particles. Char Prepared at $1073 \mathrm{~K}$ in He/N2 at a Residence Time of 125 Msec. .......................

2.33 Size Distributions of $120 \times 140$ Mesh PSOC 1520 (Sub.) Coal and Char Particles. Chars Prepared at $1273 \mathrm{~K}$ in $\mathrm{He} / \mathrm{N} 2$ at

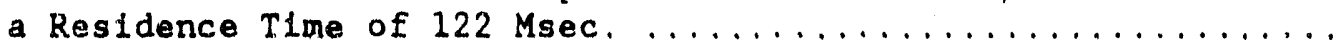

2.34 PSOC 1451 Char Prepared in He/N2 at $1273 \mathrm{~K}$, Residence Time

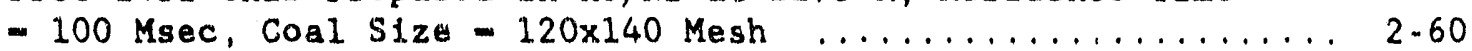

2.35 PSOC 1451 Char Prepared in $\mathrm{He} / \mathrm{N} 2$ at $1273 \mathrm{~K}$, Residence Time - $270 \mathrm{Msec}$, Coal Size $-200 \times 230 \mathrm{Mesh} \ldots \ldots \ldots \ldots \ldots \ldots \ldots \ldots . . \ldots \ldots$

2.36 PSOC 1451 Char Prepared in He/air at $1073 \mathrm{~K}$, Residen Time -m $190 \mathrm{Msec}$, Coal Size $-120 \times 140$ Mesh ....................

2.37 PSOC 1451 Char Prepared in He/air at $1273 \mathrm{~K}$, Residence. Time - $240 \mathrm{Msec}$ Coal Size - $120 \times 140$ Mesh

2.38 PSOC 1451 Char Prepared in He/CO2 at 1073, Residence Time $200 \mathrm{Msec}$, Coal Size - 120x140 Mesh .....................

2.39 PSCC 1451 Char Prepared in $\mathrm{He} / \mathrm{CO} 2$ at $1273 \mathrm{~K}$, Residence Time - 260 Msec, Coal Size $-120 \times 140$ Mesh ..................... 
2.40 PSOC 1520D Raw Coal, Fraction 106-125 Microns ............. 2-64

2.41 PSOC 1520D Raw Coal, Fraction 106-1.25 Microns ............. 2.64

2.42 PSOC $1520 \mathrm{D}$ Char Prepared in $\mathrm{N} 2 / \mathrm{N} 2$ at $1073 \mathrm{~K}$, Residence Time - $1.21 \mathrm{Msec}$, Coal Size - 106-125 Microns, 42 Magnifications ... 2-65

2.43 PSOC 1520D Char Prepared in N2/N2 at $1073 \mathrm{~K}$, Residence Time - $121 \mathrm{Msec}$, Coal Size - 106-125 Microns, 122 Magnifications ... 2-u5

2.44 PSOC 1520D Char Prepared in N2/N2 at $1073 \mathrm{~K}$, Residence Time - $183 \mathrm{Msec}$, Coal Size - 106-125 Microns, 42 Magnifications .... 2-66

2.45 PSOC 1520D Char trepared in N2/N2 at $1073 \mathrm{~K}$, Residence Time - 194 Msec, Coal Size - 75-106 Microns, 42 Magnifications ..... 2-66

2.46 PSOC 1520D Char Prepared in N2/N2 at $1073 \mathrm{~K}$, Residence Time - 194 Msec, Coal Size - 75-106 Microns, 122 Magnifications .... 2-67

2.47 PSOC $1520 D$ Char Prepared in N2/N2 at $1073 \mathrm{~K}$, Residence Time - $131 \mathrm{Msec}$, Coal Size - 63-75 Microns, 122 Magnifications .... 2-67

2.48 PSOC 1520D Char Prepared in N2/N2 at $1073 \mathrm{~K}$, Residence Time - 131 Msec, Coal Size - 63-75 Microns, 122 Magnifications ..... 2-68

2.49 PSOC 1520D Char Prepared in N2/N2 at $1073 \mathrm{~K}$, Residence Time - 198 Msec, Coal Size - 63-75 Microns, 43 Magnifications ..... 2-68

2.50 PSOC 1520D Char Prepared in N2/N2 at $1073 \mathrm{~K}$, Residence Time - $198 \mathrm{Msec}$, Coal Size - 63-75 Microns, 300 Magnifications ..... 2-69

............ M.I. Utilization of Sandia Reactor (SMIT-EFR) ........

2.51 Sandia-MIT Entrained Flow Reactor Schematic ............ 2-71

2.52 Sampling Probe: SMIT-EFR ...................... 2-73

2.53 Gas Temperature Profile in Reactor: SMIT-EFR ............ 2-81

2.54 Gas Temperatire Profile Within Probe: SMIT-EFR ........... 2-82

2.55 SEM Photographs of Raw Coal: PSOC 1451D, 106-125 Microns and 63.75 Microns ............................. 2-83

2.56 SEM Photographs of PSOC 1451D Char at $5 \mathrm{~cm}$ Position and Intermediate Tumperature Conditions (106-12b Micron Feed) .... 2-84

2.57 SEM Photograpt if PSOC 1451D Char at $9 \mathrm{~cm}$ Position and Intermediate Temperature Conditions (106-125 Micron Feed) .... 2.85

2.58 SEM Photographs of PSOC 1451D Char at $12 \mathrm{~cm}$ Position and Intermediate Temperature Conditions (106-125 Micron Feed) .... 2-86

2.59 SEM Photographs of PSOC 1451D Char at $14 \mathrm{~cm}$ Position and
Intermediate Temperature Conditions (106-125 Micron Feed) $\ldots . .2-87$

2.60 SEM Photographs of PSOC 1451D Char at $18 \mathrm{~cm}$ Position and

2.61 SEM Photographs of PSOC 1451D Char at $20 \mathrm{~cm}$ Position and $\cdots . . .2-88$ Intermediate Temperature Conditions (106-125 Micron Feed) .... 2-89

2.62 SEM Photographs of PSOC 1451D Char at $25 \mathrm{~cm}$ Position and
Intermediate Temperature Conditions (106-125 Micron Feed) ... 2-90

2.63 SEM Photographs of PSOC 1451.D Char at $5 \mathrm{~cm}$ Position alnd
Intermediate Temperature Conditions (63-75 Micron Feed) $\ldots \ldots .2-91$

2.64 SEM Photographs of PSOC 1451D Char at $6 \mathrm{~cm}$ Position and
Intermediate Temperature Conditions (63-75 Micron Fesd) ...... 2-92

2.65 SEM Photographs of PSOC 1451D Char at $9 \mathrm{~cm}$ Position and
Intermediate Tempexature Conditions $(63-75$ Micron Feled) ...... 2.93 
2.66 SEM Photographs of PSOC 1451D Char at $15 \mathrm{~cm}$ Position and Intermediate Temperature Conditions (63-75 Micron Feed) ...... 2-94

2.67 SEM Photographs of PSOC 1451D Char at $20 \mathrm{~cm}$ Position and Intermediate Temperature Conditions (63-75 Micron Feed) ...... 2.95

2.68 Schematic of Morphology Changes in a Softening Coal During

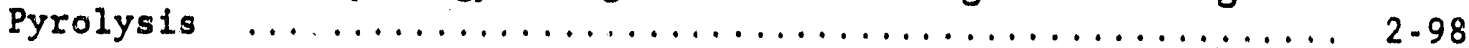

2.69 Swelling Ratio Vs. Distance at the Intermedfate Temperature Condition $(106-125$ Micron Feed) ...................... 2-39

2.70 Swelling Ratio Vs. Distance at the Intermediate Temperature Condition $(63-75$ Micron Feed) ............................ 2.100

2.71 Weight Loss Vs Distance at intermediate and Low Temperature Conditions for 106-125 and 63-75 Micron Feeds ........... 2-102

2.72 Particle Density Vs. Distance at the High, Intermediate and Low Temperature Profiles for $106-125$ and 63-75 Micron. Feeds ....................................... 2-105

2.73 Solid Density Vs. Distance at the High, Intermediate and Low Temperature Profiles for 106-125 and 63-75 Micron Feeds ... 2-106

2.74 Porosity Vs. Distance at the High, Intermediate and Low Temperature Profiles for the 106-125 and 63-75 Microns

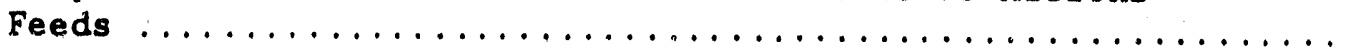

2.75 BET Surface Area Vs. Distance at the High, Intermediate and Low Temperature Profiles for 106-125 and 63-75 Micron Feeds .................................. 2-109

2.76 Cumulative Pore Volume Vs. Distance at Intermediate Temperature Condition for 106-125 Micron Feeds :.......... 2-111

2.77 Cumulative Pore Volume Vs. Distance at Intermediate Temperature Condition for 63-75 Micron Feeds ............ 2-112

2.78 Cummulative Pore Volume Vs. Distance at Low Temperature Condition for 106-125 Micron Feed ................... 2-113

2.79 Cummulative Pore Volume Vs. Distance at Low Temperature Condition for $63-75$ Micron Feed .................... 2.114

2.80 Cummulative Pore Volume Vs. Distance at High Temperature Condition for $106-125$ Micron Feed ..................... 2-115

......... United Technologies Research Center Entrained Flow Reactor (UTRC-EFR) Data ..........

UTRC-EFR Devalatilization Reactor ...................

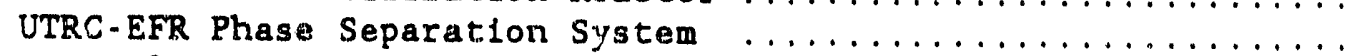
Aerosol and Char Particulate Separation Trains: UTRC-EFR ....... Total Heat Flux Rate Profiles: UTRC-EFR ................ Radiative Heat Flux Rate Profiles: UTRC-EFR Gas Temperature Profiles As a Function of Reactor Wall Temperature and Axial Position: UTRC-EFR ............. 2-122.

2.87 Estimated 25 Micron Particle Temperature Profile: UTRC-EFR at Wall Temperature of 939 C .................... 2.123

2.88 Estimated 25 Micron Particle Temperature Proflle: UTRC-EFR at Wall Temperature of $124 I$ C ...................... 2-124

2.89 Tar Distribution in Aerosol Collection System: UTRC-EFR 
2.90 Infrared Absorbance Spectra of Aerosol Arm Tar: PSOC 1451D 20 - 30 Micron Particles, Wall Temperature - 939 C ......... 2-131

2.91 Infrared Absorbance Spectra of Stage 1 Deposited Aerosols from Devolatilization of PSOC 1451D, 20 - 30 Microns At

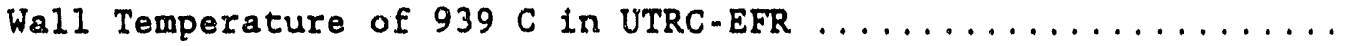

2.92 Infrared Absorbance Spectra of Stage 2 Deposited Aerosols from Devolatilization of PSOC 1451D, 20 - 30 Microns At

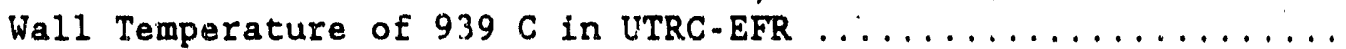

2.93 Infrared Absorbance Spectra of Stage 3 Deposited Aerosols from Devolatilization of PSGC 1451D, 20 - 30 Microns At

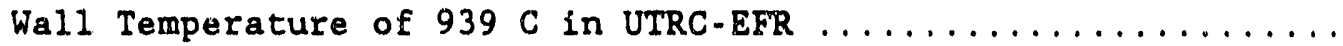

2.94 Infrared Absorbance Spectra of Stage 4 Deposited Aerosols from Devolatilization of PSOC 1451.D, 20 - 30 Microns At

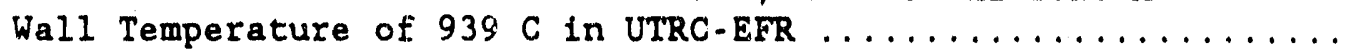

2.95 Infrared Absorbance Spectra of Stage 5 Depositled Aercsols from Devolatilization of PSOC 1451D, 20 - 30 Microns At

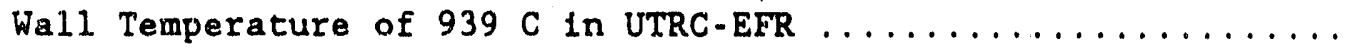

2.96 Infrared Absorbance Spectra of Stage 6 Deposited Aerosols from Devolatilization of PSOC 1451D, 20 - 30 Microns at

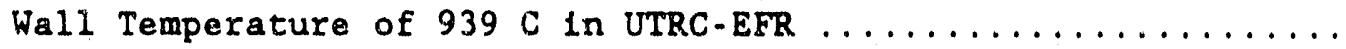

2.97 Infrared Absorbance Spectra of Stage 7 Deposited Aerosols from Devolatilization of PSOC 1451D, 20 - 30 Microns At

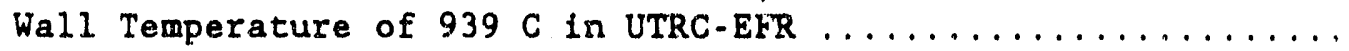

2.98 Infrared Absorbance Spectra of Stage 8 Deposited Aerosols from Devolatilization of PSOC 1451D, 20 - 30 Microns At

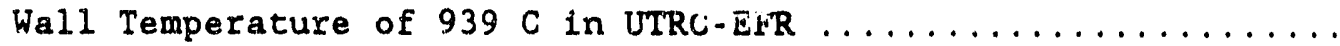

2.99 Infrared Absorbance Spectra of Aerosol Train Final Filter Deposits (Tar) from Devolatilization of PSOC 1451D, 20 - 30 Microns at Wall Temperature of $939 \mathrm{C}$ in UTRC-EFR ............

2.100 Infrared Absorbance Spectra of Cyclone Train Final Filter Deposits from Devolatilization of PSOC 1451D, $20-30$ Microns at Wall Temperture of $939 \mathrm{C}$ in UTRC-EFR ........... 2.141

2.100a Hydrocarbon Structures, IR Absorption Band Identification .... 2.140a

2.101 GPC Calibration Curve Using Model Compound Data of Table

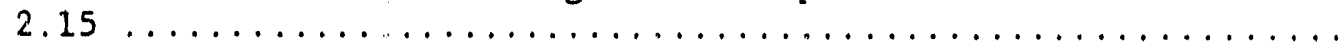

2.102 Mass Fraction Volatile Yleld for PSOC 1451D, $20 \cdot 30$

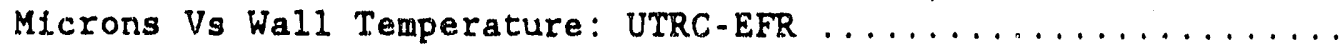

2.103 Relative Gas Yields for PSOC 1451D, 20 - 30 Microns, Vs

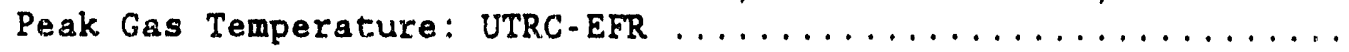

2.104 Tar Yields Vs Coal Type (PSOC XXXX D), 20 - 30 Microns

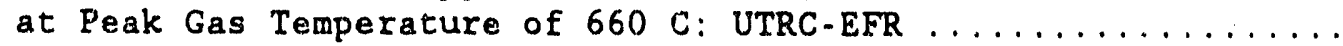

$2.105 \mathrm{H}(\mathrm{daf})$ in PSOC 1451D Tars Vs. Peak Reactor Gas Temperature

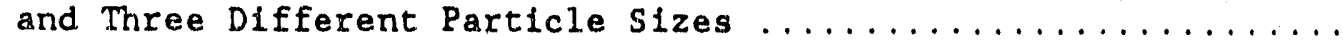

2.106 Polymethylene Associated Absorbance Intensities Vs Peak

2.107 Visual. Appearance of Inpactor Deposited Tars: PSOC 1516D

2.108 Visual Appearance of Impactor Deposited Ta.s: PSOC $1443 \mathrm{D}$ PSOC 1451D, PSOC 1508D 
2.109 H (Daf) Vs Peak Reactor Gas Temperature for All Coal

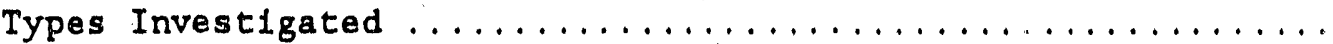

2.110 H (Daf) Vs C of Parent Coal at Peak Gas Temperature

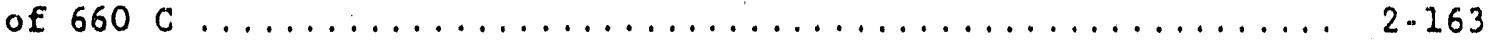

$2.1118 \mathrm{H}(\mathrm{Tar}) / 8 \mathrm{H}(\operatorname{coal})$ Vs $\& \mathrm{C}-\operatorname{cosl}$ at Peak Gas Temperature of

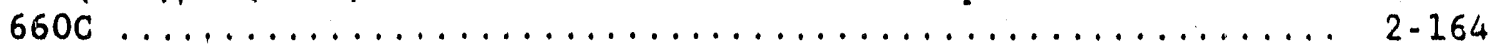

$2.112 \quad(S+0) \operatorname{tar} /(S+0)$ coal Vs $8-c o a l$ at Peak Gas Temperature of

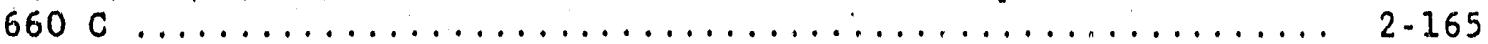

2.113 Polymethylene Absorbance Intensity Vs $\mathrm{C}$ of Parent Coal ..... 2-166

2.114 Polymethylene Absorbance Instensity Vs. H(daf) Tars Produced at 660 C Peak Gas Temporature .................. 2-167

2.115 Molecular Welght Moments of Tars Pruduced at $660 \mathrm{C}$ Peak Gas Temperature Vs. C(daf) Coals: Polystyrene Calibration .................................. 2-168

2.116 Molecular Weight Moments of Tax Produced at $660 \mathrm{C}$ Peak Gas Tempersture Vs. \& $C$ (daf) Coals: Multi-compound Calibration Vs. Polystyrene Calibration ...................... 2-171

2.117 Primary Tar Structures Vs. Parent Coal Structures ........... 2-172

2.116 WW'S Coinparisoris: Revaporization MW'S of 1443d Tars Vs GPC Determinations .......................... 2-176

2.119 MWD'S Comparisons: Revaporization MW'S of Australian Subbituminous Tars Vs GPC Determinations ......................... 2-177

2.120 MWD'S Comparisons: Revaporization MW'S of PSOC 14510 Tars Vs GPC Determinations ............................ 2-178

2.121 MWD'S Comparisons: Revaporization WW'S of PSOC 1508d Tars Vs GPC Determinations ............................ 2.179 2.122 Ash Corrected Heat of Combustion of PSOC XXXX D Coals and Tars.

2.123 Coal Devolatilization/Pyrolysis: Temperature Regimes .........

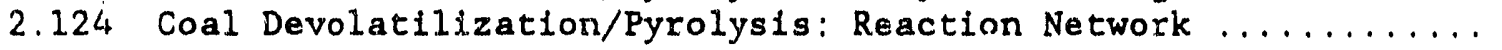

2.125 Coal Devolatilization/Pyrolysis: Physical Parameters ...........

-United Technologies Heated Grid Re tictor (UTRC-HG) Data ........

2.126 UTRC Heated Grid Devolatilization Apparatus $\ldots \ldots \ldots \ldots \ldots \ldots, 2.186$

2.127 SEM of Stainless Steel Screen Mesh and Thermocouple ......... 2.187

2.128 Folding Technique of Steel Mesh ..................... 2-189

2.129 Power Input Vs. Steady State Temperature of Grid In Vacuum or Helium Conditions: 25 C - 1100 C .............. 2-191

2.130 Power Input Vs. Steady State Temperature of Gfid in

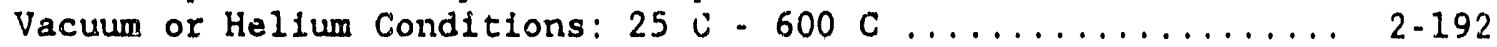

2.131 Current Through Grid Vs. Time in Various Atmospheres ......... 2.193

2.132 Voltage Across Grid Vs. Time in Various Atmospheres .......... 2.194

2.133 Temperature of Central Grid Area Vs. Time in Various Atmospheres ................................. 2-195

2.134 Temperature Traces of Grid in Contact With Calibration Samples: Bismuth and Lead ...................... 2-198

2.135 Temperature Traces of Grid in Contact With Aluminum Sample and at An Unloaded Position V's. Time .............. 2-199 
2.136 Zero-hold Time Tar Evolution Data: PSOC 1451D, $63-75$

Micron, in Context of Previously Reported Data .............. 2-202

2.137 Sample Load Effects on Transient Grid Temperatures:

Symmetric Loading About Unloaded thermocouple: PSOC 1451D ..... 2-204

2.138 Tar Yield Vs. Sample Size for Identical Power Inputs:

PSOC 1451D ................................. 2-206

2.139 Tar Yields Vs. Sample Size for Identical Power Inputs:

Asymmetric Loading About thermocouples . PSOC 1451D ......... 2-207

2.140 Transient thermocouple Traces for a Representative Asymmetric

Load (X Mg / O Mg ) Condtions Over Two Thermocouples:

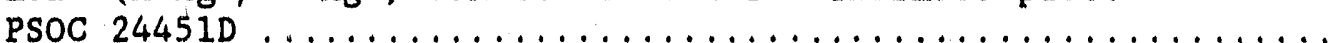

2.141 Transient Thermocouple Traces for a Representative Asymmetric Load (2/1) Over Two Thermocouple Positions: PSOC 1451D ...... 2-209

2.142 Summary of Tar Yleld Varlation With Load Factor Distribution As a Function of Peak Thermocouple Temperature: PSOC 1451D ... 2-210

2.143 Effect of Sample Load on Tar Evolution for Zero-hold Time Conditions: PSOC 1451D ........................... 2-211

2.144 Tar Yields for Varying Pressure and Hold Time Conditions Vs

Peak Grid Temperature: PSOC 1451D .................... 2-212

2.145 Tar Yields Vs. Coal Type Parameter \& $\mathrm{C}($ daf $): 10 \mathrm{Sec}$ Hold ..... 2-217

-United Technologies Flash Lamp Reactor (UTRC-FL) .........

2.146 Flash Lamp Reactor and Gas Analysis System (Top Vlew) ....... 2-219

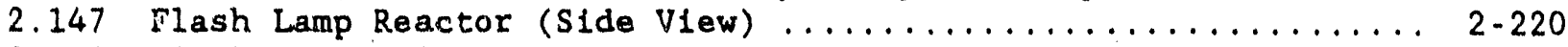

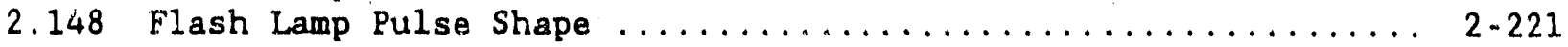

2.149 Flash Lamp Spectra ............................ 2-223

2.150 Estimated 50 Micron Particle Temperatures at Relative

Flux Level of 0.5: Vacuum, Argon, Helium Atmospheres ....... 2-226

2.151 Estimated 50 Micron Particle Temperatures at Relative

Flux Level of 0.7: Vacuum, Argon, Hellum Atmospheres ....... 2-227

2.152 Estinated 50 Micron Particle Temperatures at Relative

Flux Level of 1.0: Vacuum, Argon, Hellum Atmospheres ........ 2-228

2.153 Estimated 50 Micron Particle Temperatures at Relative

Flux Level of 1.5: Vacuum, Argon, Hellum Atmospheres ......... 2-229

2.154 Estimated 50 Micron Particle Temperatures at Relative

Flux Level of 2.2: Vacuum, Argon, Hellum Atmospheres ........ 2-230

2.155 Estimated Particle Temperatures in Vacuum: Particle

Size Effect ................................. 2-231

2.156 Estimated Particle Temperatures in Argon: Particle

Size Effect ............................... 2-232

2.157 Estimated Particle Tempertures in Helium: Particle

Size Effect ................................ 2-233

2.158 Tar Yields Vs. Peak Irradiance Levels: PSOC 1451,

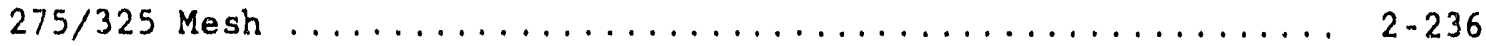

2.159 Tar and Char Ylelds Vs. Peak Irradiance Levels: PSOC 1451,

275/325 Mesh ............................. 2-237

2.160 CO, C2H2, HCN Ylelds Vs. Peak Irradiance Levels: PSOC 1451,

$275 / 325$ Mesh, Vacuum ........................... 
2.161 CO, C2H2, HCN Ylelds Vs. Peak Irradiance Leve1s: PSOC 1451 275/325 Mesh, Helium Atmosphere ................... 2.240

2.162 CO, C2H2, HCN Ylelds Vs. Peak Irradiance Levels: PSOC 1451, 275/325 Mesh, Argon Atmosphere .................... 2-241

2.163 C2H2, HCN Vs. CO Irrespective of Irradiance Leve1: PSOC 1451, 275/325 Mesh, All Conditions ...................... 2-242

2.164 C2H2, HCN Vs. CO at a Constant Irradiance Pulse Condition and for Various Size Cuts of a HVA Bituminous Coal ............ 2-243

2.165 \& CO Yields Vs Peak Irradiance in Various Ambient Gas Atmospheres (Vacuum, Argon, Helium) for PSOC 1451, 275/325 Mesh ......... 2-244

2.166 Tar Yleld Vs. Particle Size at a Constant Peak Irradiance: PSOC 1451, Various Atmosphere Conditions. ............. 2-246

2.167 Effect of Power Density of Relative MWD's of Tars ......... 2-247

Section 3: Devolatilization Modeling

3.01 Devolatilization in The Coal Combustion Sequence .......... 3-3

3.02 Coal Devolatilization Sequence Vlewed in Terms of Multiple Distribution, Multiple Distribution, Multiple Desorption Kinetic Model ....................................... 3.4

3.03 Coal Devolatilization and Physical Parameter Changes ........ 3-5

3.04 Reaction Network in UTRC Coal Devolat1lization Mode1 ........ 3.16

3.05 UTRC Model Results - $10 \mathrm{C} / \mathrm{sec}$ Heating Rate ............... 3.24

3.06 UTRC Model Results - $100 \mathrm{C} / \mathrm{sec}$ Heating Rate ............. 3.25

3.07 UTRC Model Results - $1000 \mathrm{C} / \mathrm{sec}$ Heating Rate ............. 3.26

3.08 UTRC Model Results - 10,000 c/sec Heating Rate ............ 3-27

3.09 UTRC Model Results - 100,000 C/sec Heating Rate ........... 3.28

3.10 UTRC Model Results - 1,000,000 C/sec Heating Rate .......... 3.29

3.11 Predicted Extent of Reaction for Varlous Heating Rates ....... 3.31

3.12 Detached Tar Precursor Concentrations at $1000 \mathrm{C} / \mathrm{sec} \ldots \ldots \ldots \ldots 32$

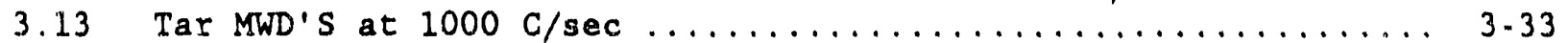

3.14 Comparison of Experimental and Predicted Heated Grid Yields for Zero-hold-time, $1000 \mathrm{c} / \mathrm{sec}$, One Atm. Helium Runs (Predictions Simulate Time-temperature History of

Each Individual Run.) ....................... 3-34

3.15 Comparison of Experimental and Predicted Heated Grid Yields for Zero-hold-time, $1000 \mathrm{C} / \mathrm{sec}$, One Atm. Helium Runs (Prediction Based on $850 \mathrm{C} / \mathrm{sec}$ Heating Rate) ........... 3.36

3.16 Predicted Primary Tar Molecular Weight Distributions for $850 \mathrm{C} / \mathrm{sec}$ heating Rate ........................ 3.37

3.17 Comparison of Experimental and Predicted Entrained Flow Reactor Yeilds for 20-30 Microns PSOC 1451D ........... 3.39

3.18 Comparison of Heated Grid and Entrained Flow Reactor Experimental

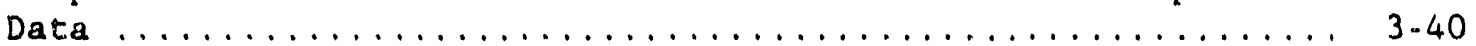

3.19 Comparison of Experimental and Predicted Glash Lamp Yields for 49 Micron PSOC 1451D in One Atm. Helium ............. $3-42$ 
3.20 Mwd Comparison - PSOC 1451, Vacuum Flash Lamp Tar and THF Extract of Raw Coal ................................ 3.44

3.21 Kinetic Regimes of Tar Evolution and Pyrolysis ........... 3-47

3.22 Light Gas Yields from UTRC-HG Devolatilization Experiments . . . 3-48

Section 4.0 Engineering Kinetics

4.01 Pyrolysis Times Vs. Particle Size (Literature Data) ......... 4-4

4.02a Phases of Devolatilization Relative to Sigmoid Mass Loss Curve .................................... 4-11

4.02b Phases of Devolatilization Relative to Chemical Nature of Mass Loss ................................. 4-12

4.03 Initial Tar Evolution Response Vs. Heating Rate Index ...... 4-16

4.04a Englneering Model Predictions of Tar Evolution Times ........ 4-19

4.04b Engineering Model Predictions of Tar Evolution Relative to Total Particle Devolatilization Process ................ 4-20

4.05 Temperature Response of Devolatilizing Coal Particle:

Gas Temperature - $1000 \mathrm{~K}$, Particle Size - 50 Micron
4.06 Temperature Rise at Particle Surface and Center: Gas Temperature $=1500$ K, Particle Size - 50 Microns ....... 4-27

4.07 Temperature Difference Between Surface and Center of a 50 Micron Particle ......................... 4-28

4.08 Varlation of Instantaneous Heating Rate With Time:

Gas Temperature - 1500K, Particle Size - 50 Microns ......... 4-30

4.09 Temperature Rise and Particle Mass Loss: 50 Micron Particle ... 4-31

4.10 Temperature Rise and Particle Mass Loss: 20 Micron Particle .. 4-32

4.11 Comparison of Experimental Volatiles Release With Prediction .. 4-34

4.12 Predicted Volative Release With Temperature: 50 Micron Particles ................................. 4-35

4.13 Variation of Reactivity Ratio With Particle Surface

Temperature for a 200 Micron Particle ................ 4-36

4.14 Effect of Heat of Devolatilization Value on Predicted Temperature Trajectory of a 100 Micron Particle ........... 4-37

4.15 Temperature Trajectory of a Burning Particle in a Gas Held

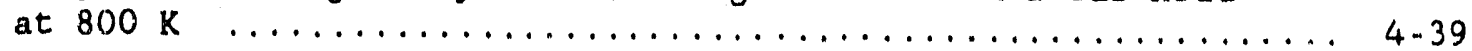

4.16 Temperature Trajectory of a Burning Particle in a Gas Held

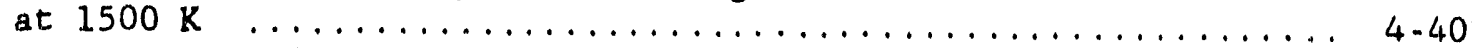

4.17 Temperature Dlfference Between Particle Surface and Center

4.18 Vuriation in Instantaneous Heating Rate With Surface $\ldots \ldots \ldots \ldots 4.41$ Temperature for a Maximum Gas Temperature of $800 \mathrm{~K} \ldots \ldots \ldots \ldots 4-43$

4.19 Comparison of Experimental Pyrolysis Times With Predictions

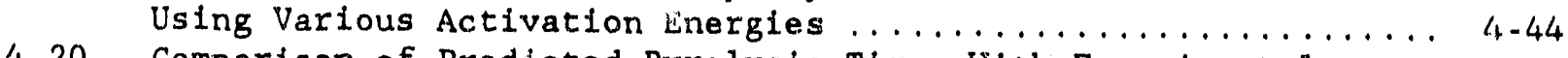
Comparison of Predicted Pyrolys is Times With Experimental

4.21 Data for Varying Ambient Gas Temperatures ............. 4-45 Effect of Characteristic Heating Time of Experiment on
Pyrolysis Time: Comparison of Experiment and Theory ....... $4-46$ 
4.22 Variation of Pyrolysis Time of Small Particles With Heating Rate: Comparison of Predictions from One-step First Order Kinetics With Experimental Times ................... 4-50

4.23 Variation of Pyrolysis Time of Small Particles with Heating Rate: Comparison of Predictions from I'wo-componenet Model With Experimental Times ......................... 4-51

4.24 Varlation of The Onset Temperature of Pyrolysis with Heating Rate .................................. 4-53

4.25 Relationship of Activation Energy to Pre-exponential Value for Pyrolysis Models ............................ 4-57

4.26 Comparison of Pyrolysis Time Data With Theoretical Predictions. 4-64

4.27 Comparison of Simplified Model Pyrolysis Times With Complete

4.28 Comparison of Predicted Times for Pyrolysis Using Total Unsteady State Analaysis and Using Simplified Equations With a Correction Factor of $2 \mathrm{~K}$ for Temperature 


\begin{abstract}
The following report contains results of a coordinated, multi-laboratory investigation of coal devolatilization. The overall objective of the investigation is to establish a coordinated, technical interaction among inclustrial, government and university laboratories actively engaged in coal devolatillzation research. Although the rapid devolatilization process has long been recognized as a critical phenomenon in pulverized coal combustion and, consequently, has been the focus of numerous experimental and theuretical investigations, the published literature in the area indicates' a paucity of agreement with respect to: controlling intrinsic or extrinsic parameters, the sequence of physical and chemical processes controlling observables, the sensitivity of the observables to changes in parameters, chemical composition of volatiles, kinetic parameters employed to describe mass loss or specific volatiles evolution, fundamental models used to describe volatiles formation and evolution. The goal of the investigation is to arrive at a common understanding of the phenomenology of rapid devolatilization by conducting a courdinated investigation using common, carefully selected and prepared coal samples and well-characterized devolatilization reactors. The underlying causes of the apparent discrepancies in understanding and reported kinetic parameters in the existing literature emerged in the process of conducting the coordinated approach.

Under DOE leadership, the participating laboratories were provided with a set of well-characterized, size-segregated samples which provided the sample basis of the experimental phases of the investigation. The following report contains data peraining to the devolatilization of these samples over three orders of magnitude in apparent heating rate (100 to $100,000+{ }^{\circ} \mathrm{C} / \mathrm{sec}$ ), over two orders of magnitude in particle size (20 to 700 microns), inal particle temperatures from 400 to $1600^{\circ} \mathrm{C}$, heat transfer modes ranging from convection to radiative, ambient pressure ranging from near vacuum to one atmosphere pressure. The heat transfer characteristics of the reactors are reported in detail to insure interested laboratories can utilize the results immediately. It is assumed the experimental results are to form the basis of a devolatilization data base.
\end{abstract}

The experimental efforts led to a comprehensive understanding of the phases of coal devolatilization, the parameters that dominate the mass loss kinetics and chemical characteristics of the volatiles release of each phase and the relative characteristic times of each devolatilization phase for bituminous coals. The data indicate a common phenomenology is followed by a wide range of coal ranks but that there are significant differences in the chernistry of coal devolatilization with coal rank. Discrepancies in reported kinetics and volatiles characterization are seen to be the result of inadequate reactor heat transfer characterization, improperly conducted experiments based on implicit assumptions regarding the structure 
of coal, the assumption that the devolatilization process is chemically invariant with the conditions of heating.

Empirical rate expressions are doveloped for each phase of devolatilization which, when coupled to an awareness of the heat transfer rate potential of a particular devolatilization reactor, indicate the kinetics emphasized by a particular system reactor plus coal sample. The analysis is derived from a multi-reactor approach and indicates the futiuty of developing or postulating comprehensive coal devolatilization models from a one-reactor data base. The analysis indicates the particular phase of devolatilization that will be emphasized by a particular reactor type and, thereby, the kinetic expressions appropriate to that devolatilization systern. Engineering rate expressions are developed from the empirical rate expressions in the context of a fundamental understanding of coal devolatilization developed in the course of the investigation.

Parallel to the experimental, empirical and engineering investigations, a fundamental investigation of coal devolatilization modeling is conducted. Such an approach is essential in establishing the validity of the empirical approaches and in guiding experimental research. It is noted that fundamental models of coal devolatilization are converging to a common understanding and mathematical approach. However, it is also noted that significant differences still exist on the importance of various parameter fields - mass transport, heat transfer, intrinsic chemical structure of the parent coal - within the various phases of devolatilization. It is suggested that the data base be expanded, but in the light of testing fundamental models having significant differences in predictions of volatiles release or the importance of specific parameters on devolatilization observables. 


\section{EXECUTIVE SUMMARY}

This investigation was not initiated to serve as a stand-alone contribution to understanding of coal devolatilization. Its necessity, conception and exectition arose naturally from historical developments in devolatilization research, as indicated by the brief historical synopsis below.

The complex structure of any one coal type, the extensive change in structural parameters with change in coal type, and the subtle, yet significant, Interplay among physical and chemical phenomena during coal devolatilization collectively present a reaction system of considerable scope. The intrinsic complexity of the process coupled to the range of parametric variations of interest preclude the probability that any single laboratory can formulate a predictive, quantitative model of coal devolatilization. This investigation represents the first formal attempt to coordinate the specific expertise that exists in a variety of laboratories Into a coordinated investigation of coal devolatilization. Its chronological position relative to developments in devolatilization understanding is evident in the following historical context synopsis.

1930 - 1960: Based on the van Krevelen view of coal structure and the slow heating, packed bed pyrolysis data that dominated this period, coal devolatilization was seen as a complex depolymerization process. Essenhigh's single particle experiments provided the one comprehensive, devolatilization study indicating physical processes exert a significant influence on rapid devolatilization.

1960 - 1980: The depolymerization concept maintains its importance in describing coal devolatilization, although the analogy is now significantly qualified by observations that many devolatilization processes of different temperature sensitivities seem to influence the mass loss process. The heated grid investigations and the concepts evolved from them dominate the frame of reference of modeling effors despite the "anomalous" heat transfer correlations being developed by some. Questions concerning the inadequacy of temperature measurements or reactor characterization are generally ignored.

1980 - 1985: A proliferation of novel experimental techniques and sophistication in reactor characterization stimulates a complete re-evaluation of our understanding of coal devalatilization, coal structure, the importance of reactor transport characteristics in determining devolatilization rates, the central role of tar evolution and characterization in developrnent of comprehensive models. As expected, the proliferation in relatively uncoordinated results and data produces a diverging proliferation of devolatilization models. 
1985 - Present: Due to a concerted effort from DOE, a coordinated multi-laboratory effort is launched. The investigation capitalizes on DOE-engineered sample control, eliminating the "different" sample arguments in rationalizing apparently disparate results. The study seeks to establish a data base for a comprehensive model of coal devolatilization, to establish the phenomenological framework for such a model, to discover the cause of the apparent discrepancies in published devolatilization data, and to develop short term engirieering kinetic models of devolatilization for combustor modeling.

As a result, the overall phenomenology of bituminous coal devolatilization is established as well as the intimate coupling between aspects of that phenomenology and reactor heat and mass transport parameters. In addition, the underlying consistency and chemical differences in the rank variant phenomenology of coal devolatilization is established using tar evolution properties as the intrinsic tracer of the devolatilization process. The discrepancies in published data and rate constants are demonstrated to be the result of oversimplified views of the structure of coal and the phenomenology of coal devolatilization and inadequate or inaccurate reactor heat transfer characterization. The convergence in understanding of coal devolatilization phenomenology has resulted in a convergence of model premises and formulations.

As detalled below, the program has been generally successful, but the underlying complexity of devolatilization has prevented development of comprehensive, a priori predictive models in the time period available. In addition, significant differences remain with respect to the relative importance of mass transfer in various stages of devolatilization. It is recommended that the data base be systematically expanded, but in the context of answering critical questions, generating fundarnental parameters for model development (MWD's, char morphology/reactivity), or combustor modeling (heat of combustion of tars and chars, char aerodynamic properties, etc.). Critical testing of model premises and predictions should commence in a coordinated manner. 


\section{Significant Findings/Developments of This Investigation}

\section{Influence of Reactor System and Experimental Technique on Devolatilization Observables}

Because of the growing realization of the importance of heat transfer conditions on observables, well characterized reactors spanning three orders of magnitude in heating rate were employed to perform the devolatilization investigations. With respect to the influence of experimental conditions on the observables of devolatilization, the following results indicate:

1. Inaccurate transient temperature measurements account for a significant fraction of the apparent discrepancy in reported devolatilization kinetic behavior of bituminous coals.

2. Particle feed characteristics can vary dynamically in entrained flow reactor systems having significant effects on apparent mass loss results.

3. A unique entrained flow reactor system with on-line gas analysis and tar separation permitted deconvolution of the tar evolution and secondary reaction networks.

4. A unique flash lamp apparatus verified the temperature regimes of tar evolution and secondary reactions indicating the underlying consistency in coal devolatilization phenomenology and previously published, apparently disparate irradiance heating results.

5. The unique capabilities of the heated grid and entrained flow reactors were utilized to develop a new, more accurate approach to characterizing molecular weight properties of coal tars.

The Phenomenology of Tar Evolution: Effect of Coal Rank, Reactor Temperature, Particle Size And Extent of Evolution on Tar Properties

Because of the central role of tars in model development, emphasis was placed on measurements of particle temperature during tar evolution, tar characterization for a range of coal ranks, extent of tar evolution and heating conditions, and the determinaticn of tar evolution kinetic parameters. With respect to the phenomenology of coal devolatilization, the major findings to date of the UTRC study are as follows:

1. For a given set of heating conditions and extent of tar evolution, the lower the rank of the parent coal the more dissimilar the "primary," immediately quenched, tars relative to the "average" parent coal structure, as indicated by elemental composition or infrared absorbance properties. In general, the lower the rank characteristics of the coal, the greater the concentration of polymethylene-like structures in the primary tars. 
2. For a given coal type and a given set of heating conditions, the primary tars evolve in a definite sequence - the earlier in the tar evolution process the more hydrogen rich, lower in molecular welght the tars.

3. For a given coal type, the yield, physical and chemical characteristics, and rate of particle mass loss as "primary" tars vary significantly with rate of hearing and peak particle temperature achieved.

4. In general, maximizing tar yields for a given coal requires transient particle heating to particle temperatures in excess of $600^{\circ} \mathrm{C}$. The higher the apparent particle heating rate, that is, the greater the transient heat flux to the particle, the larger the molecular weight characteristics of the integrated tar mass, although a distlllation-like process appears, to be followed in all but most intense heating conditions, that is when net transient flex rates are in excess of 100 watts/sq. cm. Factors such as particle size and ambient pressure appear to have second order influence on the yields or chemical characteristics of the major fraction of the potential tar yield, provided account is taken of the effect changes in these parameters have on transient heat transfer.

5. The initial $60-75 \%$ of particle mass loss as tar correlates well with the reactor to particle heat flux rate, provided particle temperatures in excess of $600^{\circ} \mathrm{C}$ are achieved. However, the nature and yield of tars can vary appreciably, indicating very different overall intraparticle chemistry and tar desorption processes are followed in different hearing conditions.

6. Tar evolution in the $550-700^{\circ} \mathrm{C}$ particle temperature range involves desorption of large molecular weight species relative to species evolved at lower temperatures. The molecular weight and thermally lablie structural characteristics of such species immediately establish competitive reaction processes that determine their fate - intraparticle pyrolysis fragmentation and/or intraparticle coking versus intact desorption. Intact desorption requires net reactor-to-particle surface heat transfer rates of the order of 100 watts $/ \mathrm{sq} . \mathrm{cm}$. 
7. Extensive heat transfer characterization of coal devolatilizatio tactor systems indicates that heat transfer rates required for non-equilibrium, intact desorption of the large. detached molecular weight species can not be achieved in conventional fixed bed reactors wire baskets, heated grids, low temperature fluid bed systems, etc. Such heat transfer rates are only achieved in high temperature flow reactors or radiation helating - flash lamp, laser desorption - experiments.

8. Gas phase, "secondary" pyrolysis reactions of primary tars from all coals initiate around $600^{\circ} \mathrm{C}$, producing mainly methane, water, carbon dioxide, carbon monoxide and ethylene between 600 and $800^{\circ} \mathrm{C}$. At $700^{\circ} \mathrm{C}$ and above, gas phase pyrolysis networks leading to the formation of acetylene, carbon monoxide, ethylene, benzene and hydrogen cyanide dominate the observable gases.

9. The change in gas phase products as a function of residence time of the prirnary tars in the hot zone of the reactor, or the particle vicinity, correlates with the change in tar properties elemental composition, infrared absol'ance, molecular weight and THF solvent solubility. By gas phase secondary reactions, "primary" tars of coals can approach average structural features similar to the parent coal.

10. Particle size studies using the heated grid and a specially designed entrained flow reactor also indicate the importance of heat transfer conditions in establishing the rate of particle mass loss as tar. Tar yields and chemical characteristics for a given reactor appear relatively insensitive to particle size, given knowledge of any maceral distribution charges with particle size.

11. Experiments performed on a conventional entrained flow reactor at PSU indicate that HVA bituminous coals show the same sensitivity to changes in heat transfer parameters as observed earlier by Maloney. However, the lower rank coals display lower initial mass loss rates than bituminous coals. The decrease in initial mass loss rate correlated with the decrease in potential tar yield the heat transfer controlled volatile fraction from lower rank coals.

12. MIT studies using the Sandia EFR indicate that intraparticle bubble formation occurs early in the devolatilization process, resulting in significant swelling during the first phase of particle mass loss. This phenomenology appears to be confirmed 
by direct visual observations made by Maloney at DOE/METC. It is important to note that these investigations involve devolatilization in heat transfer conditions of 100 watts/sq. cm and above. Intraparticle high temperature pyrolysis of heavy tars is comparable to tar evolution rates in these conditions.

13. In view of the above coupling observed among intrinsic and extrinsic parameters in determining tar evolution rates and characteristics, comparisons of mass loss kinetic rate constants over a wide range of heating conditions and without respect to observed tar characteristics is less than informative. Such comparisons can even be misleading in the sense that the underlying assumption is that the same chemical kinetic processes are followed with equal magnitude in a wide range of heating conditions.

14. Extensive heat transfer calculations performed independently by MIT and Ohio State personnel indicate that intraparticle temperature gradients were not significant in most experimental conditions, provided the initial and boundary conditions of the experiment were assumed to simulate the mathematical boundary conditions. In addition, such calculations also showed negligible temperature difference between a reactor thermocouple and a coal particle in real time, provided an idealized set of heat transfer boundary conditions could be established within an experiment and the tar evolution process is slow enough to allow the ideal boundary conditions to be established around the particle. These requirements are, of course, mathematically feasible but experimentally unrealizable in rapid heating to particle temperatures in excess of $500^{\circ} \mathrm{C}$. It is important to note that these model calculations can not simulate appreciable variations in sample distribution with batch reactor type or real inlet conditions in a flow reactor. More positively the calculations indicate if a reactor dependent tar evolution rates as abserved, it is because either the reactor is not sufficiently characterized with respect to heat transfer conditions in the early mass loss or an inadequate understanding of the kinetics of devolatilization if employed.

\section{Conceptual Understanding of Coal Structure and Devolatilization Sequence Following} From Above:

1. Comparison of data generated in this program with that generated in a wide range of heating conditions with similar HVA bituminous coals indicates the following conceptual model of tar formation, evolution and reactions provides an adequate basis for understanding the tar devolatilization process and tar properties observed in a wide range of reactor conditions: 
I. Physical Detachmerit of Tar Precursors $\left(300-450^{\circ} \mathrm{C}\right)$

II. Chemical Detachmont of Tar Precursors $\left(400-550^{\circ} \mathrm{C}\right)$

III. Intraparticle Pyrolysis/Reformation of Detached Tar Precursors $\left(450^{\circ} \mathrm{C}+\right)$

IV. Extraparticle Evolution of Tar Precursors via Vaporization, Convection, Non-equilibrium Desorption $\left(300-700^{\circ} \mathrm{C}\right)$

V. Low Temperature Secondary Reactions of Tars Coincidental with Char Degassing $\left(600-800^{\circ} \mathrm{C}\right)$

VI. High Temperature Secondary Reactions of Tars Coincidental with Char Degassing $\left(700^{\circ} \mathrm{C}+\right)$

2. The results imply that the correct view of coal structure is that of a three dimensional macromolecular entanglement containing a wide range of molecular sizes bonded throughout the entanglement by a wide range of physical and chemical bond strengths.

3. Relative to a HVA bituminous coal, lower rank coals display tar evolution and weight loss phenomenology more symptomatic of purely polymeric materials. That is, these coals have structural parameters that produce devolatilization behavior more symptomatic of polymer pyrolysis - light gas evolution is always competitive with tar evolution, the initial tar burst is not clearly heat transfer controlled.

4. Relative to a HVA bituminous coal, higher rank coals display tar evolution patterns similar to the HVA coal but tar yields are lower, indicating less material is present or is generated within the parent coal structure possessing molecular weight capable of vaporizing during the weight loss process

\section{Mass Loss Kinetics}

With respect to particle weight loss, the HVA bituminous coal devolatilization process is best unclerstood as a four phase process

I. Induction Period to Initial Tar Release

II. Initial Tar Devolatilization with Low Gas Yields

III. Residual Tar Evolution Phase with Large Gas Yields

IV. Char Degassing

Phases I and II are primarily heat transfer controlled and account for $0.5-0.6$ of the particle mass loss, that is, $20-30 \%$ of the parent coal mass. An engineering kinetics description of the Phases I and II has been 
developed which indicates a good estimate of the characteristic time of these phases can be obtained by a heat transfer correlation. The correlation is expressed in terms of net power density experienced by the coal particle injected into a hot environment, normalized to account for the thermal inertia of the particle mass. The correlation gives a first order prediction of the initial tar evolution times over nine orders of magnitude in heating rate, three orders of magnitude in particle size and changes in heat transfer mode from total irradiance to purely convective. More importantly, the fundamental aspects of the investigation indicate there are sound physico-chemicai bases for the correlation.

Phase III of the particle mass loss process is mass transfer and chemical kinetics controlled. Interphase mass transfer Inhibits the release of large molecular weight hydrocarbons associated with the late stages of tar evolution. Intraparticle pyrolysis reactions generate enough light gas and smaller molecular weight tars enabling tar escape via vaporization and convective expulsion with gases through bubble formation. Phase III is slow relative to Phase I + II and represents the change in slope of the wt. loss vs. time curve from concave up to concave down in the transition to the asymptotic approach to final weight loss. Phase IV represents the slow char degassing indicated by asymptotic nature of the final $10 \%$ weight loss in devolatilization experiments. Phase IV is very slow relative to phases I, II and III. It should be noted that the total weight loss process, irrespective of experimental configuration, is always the result of coupled chemical and transport processes. Overall kinetics will change with conditions of heating because it is the conditions of heating that amplify the importance of a particular set of tar reactions or phase of mass loss.

Kinetic parameters are derived for three major reaction processes involved in devolatilization of a HVA bituminous coal - tar evolution, tar coking, high temperature secondary reactions of tars. Respectively, these processes have activation energies of approximately 45,20 and $66 \mathrm{kcal}$. The substantial differences in temperature sensitivity produce apparently disparate pyrolysis behavior in different heating apparatuses. That is, the heat transfer field of the reactor determines the kinetic process to be emphasized during particle mass loss. 


\section{SECTION 1.0 - INTRODUCTION, STATEMENT OF THE PROBLEM, APPROACH}

\subsection{Significance of the Devolatilization Process}

The significance of rapid coal devolatiiization with respect to any coal utilization process derives from the simple fact that the parent coal is never reacted as such in the conversion device; rather, the products of coal devolatilization are those involved in the utilization process. With respect to pulverized fuel combustion (pfc), the situation is described in Fig. 1.1. The combustion system actually burns the products of rapid coal devolatilization - the char, tars and light gases produced. "Coal" combustion is in practice the combustion of devolatilization products. Without an adequate description of the products of rapid coal devolatilization and a computer-tractable kinetic description of the process, advances in understanding of pfc combustion can only be marginal.

From the point of view of understanding the complex fluid dynamic phenomena and combustion chemistry involved in a particular combustion device, an improved knowledge of rapid coal devolatilization appears essential, simply because so many important aspects of the combustion properties of coal are related to the products of coal devolatilization (Fig, 1.2). Unfortunately, despite years of research in devolatilization, the published literature shows a rather pronounced lack of agreement not only with respect to the rate of devolatilization for a given coal type, but also in conceptual understanding of the dominant mechanisms present in rapid coal devolatilization.

\subsection{Underlying Causes of Apparent Discrepancies in Conceptual Understanding and Rate Constants}

\subsubsection{Limitations of Simple "Mass Loss" Approach}

The most obvious symptom of apparent discrepancy in observable devolatilization behavior is manifested in the range of reported mass loss kinetic rate constants for the devolatilization process (Ref. 1.1). Mass loss kinetic rate constants at a given temperature are observed to vary by nearly four orders of magnitude. From the point of view of coal combustion modeling, such a wide range in particle mass loss kinetic descriptions is not acceptable. The underlying assumption in such comparisons is that the "chemical nature" of the particle mass loss is invariant with the conditions of particle heating, that is, the chemical product distribution is independent of the conditions of heating. Stated in another manner, such kinetic comparisons assume the chemical nature of the "mass released" by the particles and the mass residue in the char product of devolatilization is independent of the heating rate. The observable physical and chemical 


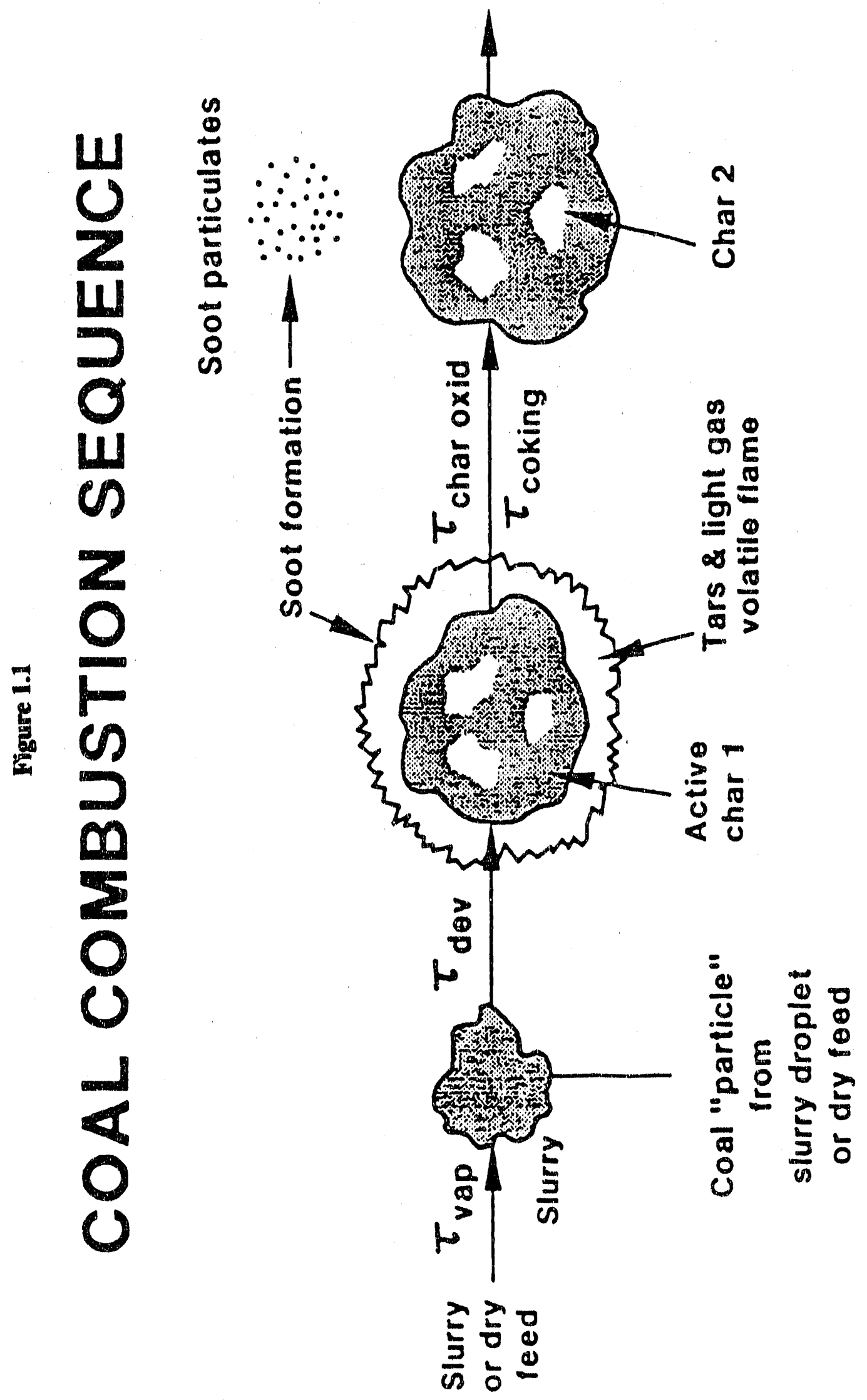




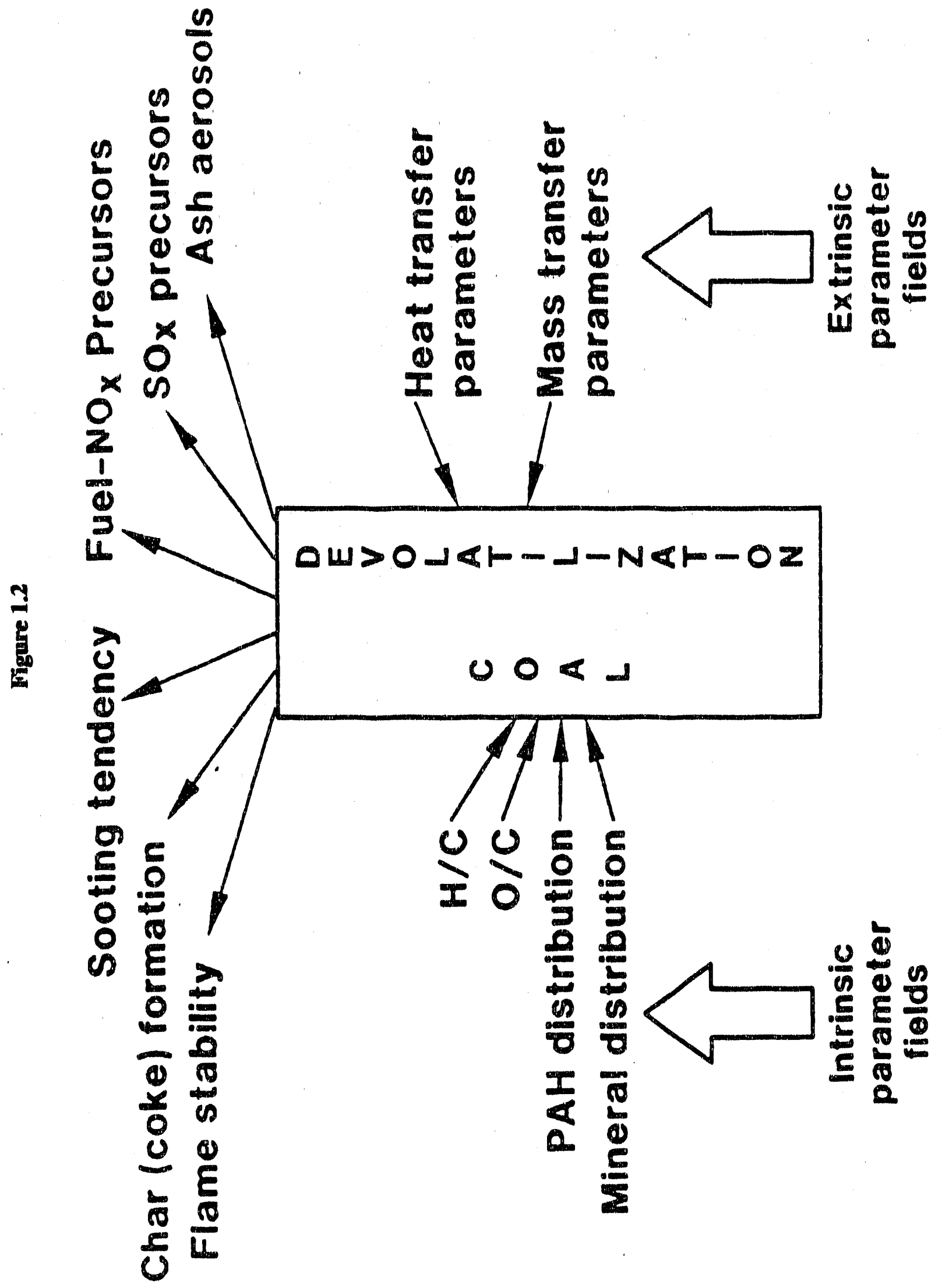


processes associated with coal particle devolatilization are assumed independent of the rate of heating and the observed products are being generated directly by invariant processes. In actuality, and as is definitively established by this investigation, the heat and mass transport parameters of a particular devolatilization system effectively serve to determine a particular route from the many devolatlization pathways avallable to a particular coal type. As a result, the observables in a devolatilization experiment always reflect a significant degree of coupling among the intrinsic chemical properties of the parent coal and the transport parameters of the devolatilization system (Fig. 1,2).

The complexity of the kinetics of coal devolatilization follows directly from the complexity of coal structure (Ref. 1.2). Any coal type consists of a range of compound types - aliphatic, allcyclic, and aromatic - that compose the coal matrix, coupled to a wide range of bonding strengths - hydrogen bonds, donor-acceptor complexing, covalent bonds - that link the compound types. Both the fractional distribution of compound types and the bonding types vary significantly with coal rank characteristics. As a consequence, the range of potential devolatilization/pyrolysis reaction pathways is nearly unllmited. A particular devolatilizaticn/pyrolysis reaction system serves to "select" or amplify a particular reaction network, relative to the others available. Changing the reactor system effectively changes the selectivity of the devolatilization/pyrolysis process by changing the heat and mass transfer conditions experienced by the coal particle and its devolatilization products. As a result, a chemically distinct mix of devolatilization products is observed relative to that observed in another system. "Mass loss" comparisons among widely different reactor types rapidly become meaningless if made irrespective of the conditions of heating and if no detail of the chemical nature of the mass "loss" is provided.

\subsubsection{Limitations of Generic Product Categories Approach}

The degree of apparent discrepancy and confusion is only slightly reduced if one attempts to deconvolute the lumped "mass loss" into major component categories: tar and light gases. "Tar" is an operational definition of the heavy hydrocarbon species released during coal devolatilization. "Tars" are those species which condense at room temperature due to their relatively high molecular weights.

However, the generic nature of "tar" and "light gas" categories again serves to obscure, in a manner similar to the "mass loss" category, the possibility of wide variations in actual product yields and characteristics. Physical and chemical characteristics of "tars" formed in heating conditions of $0.1^{\circ} \mathrm{C} / \mathrm{sec}$ may not at all be the same as those formed at $1000^{\circ} \mathrm{C} / \mathrm{sec}$. 


\subsubsection{Limitations Introduced by Variations in Tar Collection and Isolation Techniques}

Further complicating devolatilization comparisons are differences in techniques for Isolating and collecting tar species within different reactor systems. For example, tar samples collected in an entralned flow reactor system may or may not be totally isolated from char/soot specles. In addition, tar ylelds in entrained flow reactors are not generally quantified to any degres of accuracy. Tars collected in heated grid apparatuses may indeed be sufficlently isolated from char/soot particulates but small yields per experiment may require an exorbitant number of repeat runs to produce enough sample for only minimal characterization. Tars collected in flash lamp, laser devolatilization, or fluid bed pyrolysis systems may require solvent extraction for separation, leading to solvent selectivity or solvent interference in subsequent analysis. Again the nature of coal structure and the subsequent complexity of the volatile products introduce significant difficulties in making adequate comparisons of devolatilization reaction processes from one reactor to another on the basis of general categories alone. In general, Insufficient samples or insufficlent analytical resolution has been avallable to establish Invariance of dominant devolatillzation mechanism with change in reactor system on the basis of tar yields and characteristics.

\subsubsection{Analytical Limitations}

The low volatility and thermally labile nature of tar species formed in rapid heating experiments, coupled to limited sample availabillty, introduce considerable difficulties in producing reproducible analytical data. Standard infrared analysis, chromatographic techniques and elemental analyses require samples for which some preliminary information is availaple. For example, gel permeation techniques employed to determine molecular weights of large organic molecules requires some a priori knowledge of molecular structure - aliphatic chain, condensed aromatic, linear aromalic, etc. Elemental analyses generally require large sample amounts to generate reproducible results. Such amounts are seldom avallable from research scale reactors and samples available from larger systems are not generally collected in an appropriate manner or in well-defined conditions.

\subsubsection{Phenomenology of Coal Devolatilization and Conceptual Model Discrepancies Related to Focusing on Limited Phenomena}

The devolatilization of a high volatile bituminous coal follows the sequence indicated in Fig. 1.3. The formation and evolution of heavy molecular weight hydrocarbons, tars, account for more than half the total mass loss of such coals (Ref, 1.3, 1.4, 1.5, 1.6). As observed in a wide range of heating conditions, the formation of detached tar precursors (DTP) from attached complexes (ATP) and the subsequent evolution of tars dominates the initial mass loss of bituminous coal particles. In addition, gas phase, "secondary" 


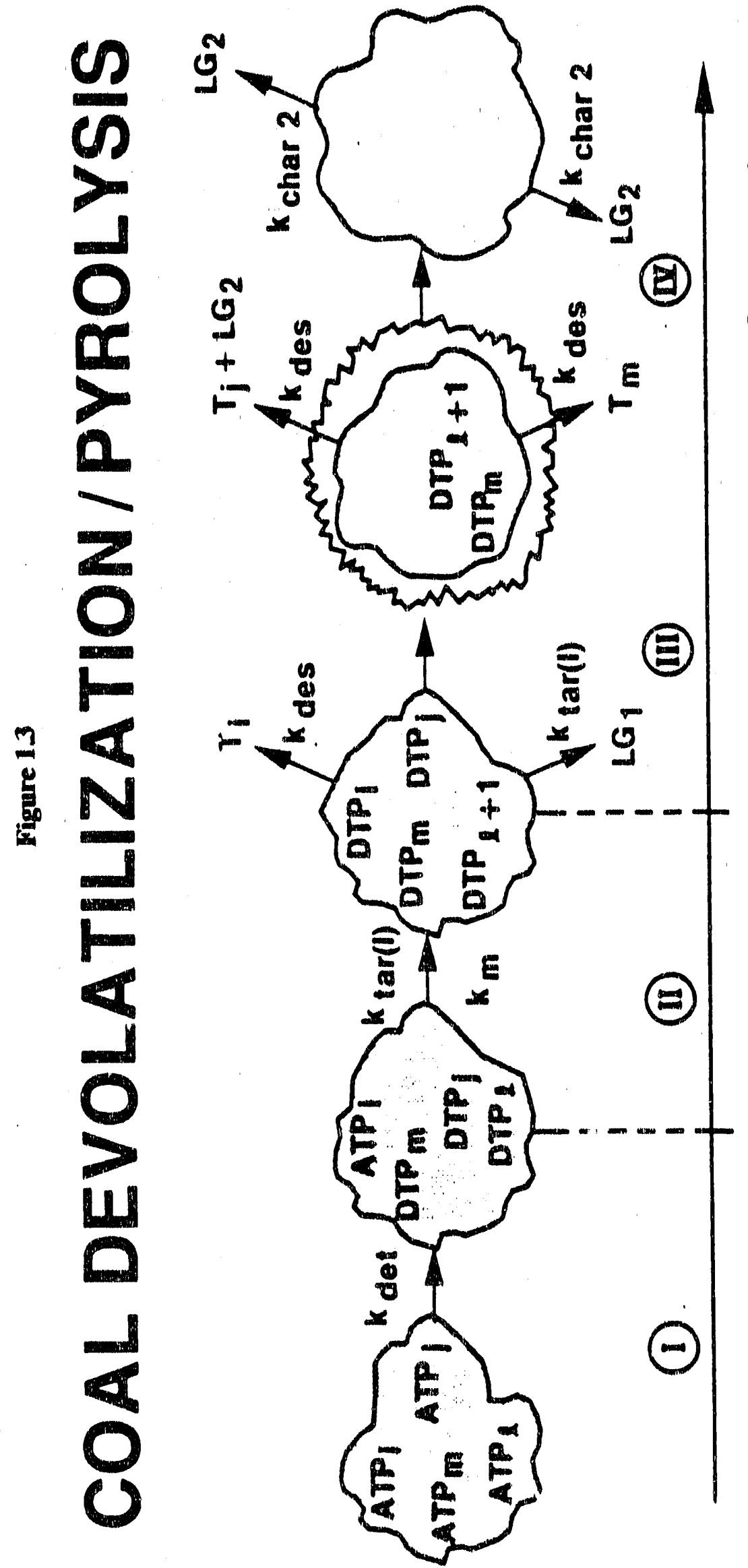

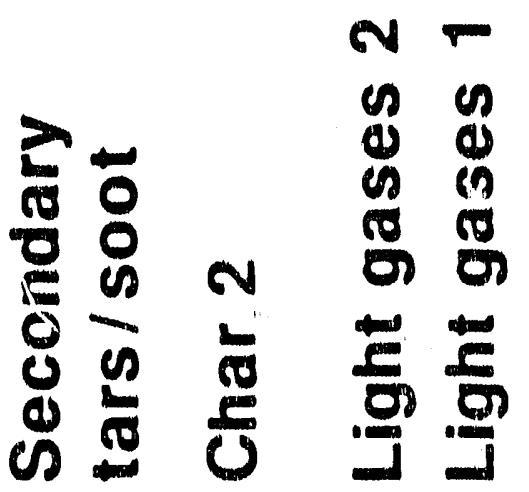
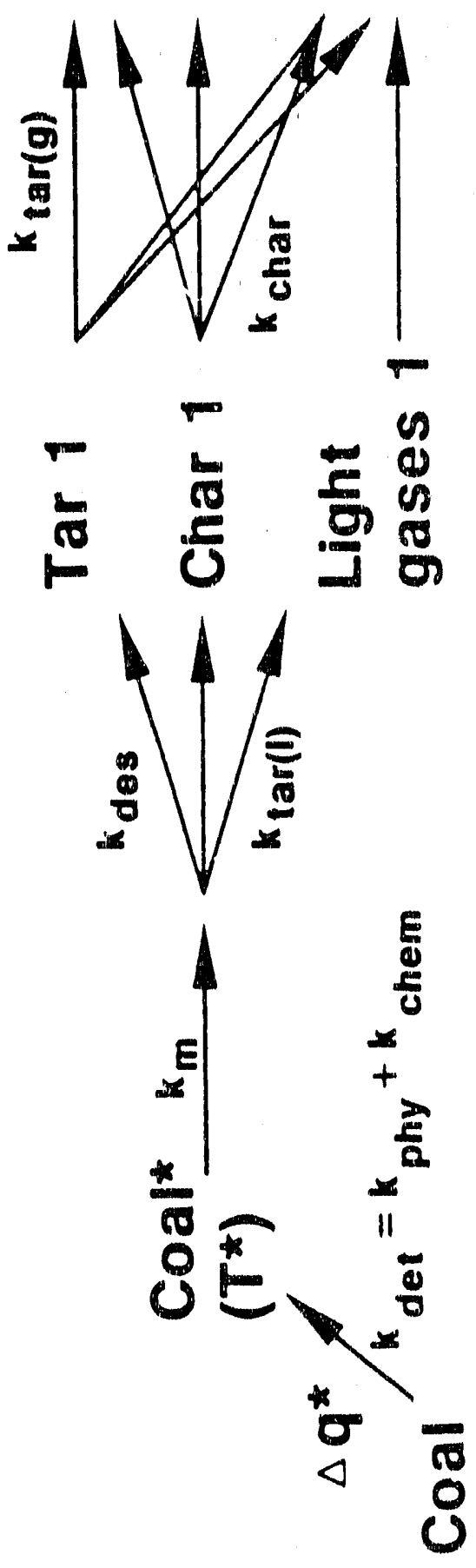
reactions of tars can account for major fractions of the light gas yields, depending on the heating condltions. The distribution of the light gases (Ref. 1.7, 1.8, 1.9) and chemical characteristics of the collected tars are dependent on both the transient particle temperature and ambient gas temperature.

A number of Investigators have observed that a range of coal types follows the same phenomenological sequerice, although the tar yields and characteristics vary significantly with coal rank characteristics (Ref. 1.10, 1.11). Some Investigators report the chemical structural characteristics of primary tars are "similar" to those present in the parent coal, that is, "primary" tar "monomers" refleot the coal "polymer", (Ref. 1.12, 1.13) ambient pressure apparently having little effect on the structure of evolved primary tars relative to the parent coal. "Primary" tars are those coliected in conditions in which intraparticle or extraparticle "secondary" reactions are thought to be minirnized.

Orning and Glefer (Ref, 1,14) noted that "under conditions of molecular distillation", the vacuum pyrolysis of coal gave a condensible solid which "resembles" the molecular configuration of coal, as justified by infrared absorption spectra." In a more comprehensive investigation. Brown, et. al. (Ref. 1.15) indicated vacuum pyrolysis of coal resulted in a kind of depolymerization followed by separation of the smaller units from the larger. The room temperature condensible volatiles "resembled" the parent coal in chemica! structure (Ref, 1.15). In attempts to formulate a general model of coal devolatilization, some of these investigators have noted that, within the limits of experimental resolution, the chemical kinetic parameters that describe tar evolution from a wide range of coals do not vary with coal type (Ref, 1.12, and 1.16). From this latter perspective, the phenomenological sequence, monomer-polymer relationship between primary tar and parent coal structural characteristics and the chemical kinetic parameters describing tar formation and evolution are invariants in coal devolatilization. These become the underlying premises of general models of tar devolatilization.

On the other hand, some investigators, while indicating the common phenomenological sequence of disperse phase devolatillzation, note tar yields and chemical characteristics, relative to other coal tars as well as to the parent coal itself, vary significantly with coal type (Ref. 1.7). In addition, secondary gas phase pyrolysis behavior varies according to chemical characteristics of the primary tars (Ref. 1.7, 1.8). Implicit in these structural observations with respect to primary tars is the implication that the underlying mechanisms of tar formation and evolution vary with coal rank characteristics, which, in turn, implies a variance in associated kinetic paraneters. In addition, the primary tar structural dlfferences make it unlikely the same homogeneous decomposition kinetics are followed by all primary coal tars. 


\section{R88-PC70768}

Still other Investigators have noted the appreclable role mass transport parameters can exer in determining devolatllization phenomena. The formation of a glass-llke "melt" as an intermecliate phase during devolatilization of a bituminous coal (Ref, 1.17, 1.18) and the observed changes in molecular weight characteristics of heavy hydrocarbons with ambient pressure (Ref, 1.19), have led some investigators into a detalled examination of Intraphase and interphase mass transport phonomena contributions in mass loss kinetics.

Yet others, ignoring the detalls of product distributions and chemical characteristics of tars with changes in pyrolysis conditions, have indicated that welght loss kinetlc behavior is determined primarily by heat transfer considerations (Ref. 1.20,1.21) and, thereby, appears independent of coal type.

As apparent from the diverse perspectives, a conceptual understarding of disperse phase coal devolatilization remains elusive and, consequently, comprehensive kinetic models remaln difficult to extrapolate to a wide range of conditions.

The range of conceptual models which have been formulated into "predictive" quantitative kinetic schemes varies from essentially chemical reaction control (Ref. 1.13, 1.16, 1.22, 1.23), to mass transfer dominant (Ref. 1.15), to heat transfer control of particle mass loss (Ref. 1.20,1.21). The differences in conceptual understanding of the dominant controlling process with respect to particle mass losi are significant. A purely chemically controlled phenomenon should display no particle size effects on volatiles properties, provided there is no change in organic composition of the particles with size cut. Mass transfer dominated models must be further distinguished on the basis of interphase or intraphase control of the mass evolution process. In any transport influenced process, a significant particle size effect on the rate of particle mass loss and/or product characteristics should be observable.

The difficulty in employing extent of mass loss or rate of mass loss as a distinguishing criterion in testing the validity of devolatilization models has been discussed above. A chemically complex organic material has a nearly unlimited number of reaction paths through which it can respond to thermal stimulation. The asymptotic mass loss and instantaneous mass loss rate may be invariant with conditions of heating, within the limits of experimental resolution, whereas the underlying mechanisms of mass loss may vary significantly. Deconvolution of the "mass loss" into tars and light gases reduces but does not eliminate the ambiguity. The chemically complex nature of "tar" must be deconvoluted to obtain furher insight into changes in controlling mechanisms with changes in heating conditions. 
Again as noted above, the difficulties involved in the analysis of small amounts of tar avallable from research reactors further compounds the difficulty in model distingulshment, and, hence, model development. The discrepancies in, ialr sharacteristics present in the llterature which have led to misconceptions and differences in conceprual formulation of the rapid devolatllization process are now discussed.

\subsubsection{Apparent Discrepancies Related to Tar Characterization Results}

The "similarity" or "resemblance" reported between the "primary" tars and the corresponding parent coal structures (Ref. 1.12,1.14,1.15) appears based on a qualitative rather than quantitative application of "similar" and "resemblance" to rather limited data. In addition, devolatilization conditions in which collected tars are considered to be "primary" are vastly different.

Orning and Griefer (Ref, 1.14) collected tars evolved in vacuum conditions from a Plttsburgh seam coal heated on an electric plate to $515^{\circ} \mathrm{C}$. They compared the Infrared absorbance of a thin film of the evolved tar to that of a thin section of vitrain ("anthraxylon") of a coal sample from the same seam. The vitrain rich spectrum was generated on a different grating instrument by a different investigator. Nevertheless, for similar tar film and vitrain section thicknesses, the transmission spectra of the two samples were "essentially Identical" with respect to "shape", "shoulders", and "relative intensities" of absorption bands. However, the spectra are reported relative to the same thickness $(20$ microns). Since the sample types undoubtedly had different mass densities, one concludes that band intensitles reported on a mass normalized basis would be very different. Indeed, the hydrogen and heteroatom mass contents of the tars are reported as $7.5 \%$ and $7.0 \%$, respectively, whereas that of the parent vitrain are repcrted as $5.8 \%$ and $12.6 \%$, respectively. Such large differences in elemental composition and, consequently, associated IR active functional group concentrations should produce striking differences in a mass normalized transmission or absorbarice spectrum, particularly in the strongly absorbing aliphatic $\mathrm{H}\left(2600-3000 \mathrm{~cm}^{-1}\right)$ stretching and moderate intensity aromatic $H$ bending $\left(760-920 \mathrm{~cm}^{-1}\right)$ regions. In short, the lack of difference in the transmission spectra of the two samples of such different elemental composition must be due to differences in techniques and assumptions employed in generating tho coal spectra in one laboratory and the tar spectra in another and/or indicative of the quantitative insensitivity of the grating instruments of the time.

Brown, et. al. (Rel. 1.15) also collected tar in a vacuum in a similar apparatus to that of Orning and Griefer and from a prime coking coal, but at a peak temperature of $400^{\circ} \mathrm{C}$. Similar to Orning and Griefer, they also observed the "volatile solids" (tars) to have a much greater hydrogen composition than the parent 


\section{R88-PC70768}

coal, $7.0 \%$ and $5.0 \%$ respectively. Contrary to the results of Orning and Griefer, however, the absorbance bands of the tar solids do not show the same absorbance intensities as those observed for the parent coal. The tar samples display more intense aliphatic stretch and bending $\left(1300-1400 \mathrm{~cm}^{-1}\right)$ tiands, aromatic hydrogen bending bands, and carbonyl bands $\left(1.650-1725 \mathrm{~cm}^{-1}\right)$, but lower broad band oxygen structures In the $1100-1300 \mathrm{~cm}^{-1}$ regton. Again, two different sampling techniques were employed to obtaln the spectra - thin film of tars vs, alkall hallde pellets for the parent coal - and again, no mass normallzation factors are reported. Consequently, quantitative band intensity comparisons between tar and coal are not possible, but qualitative differences are apparent, as expected from the significant differences in elemental composition.

Such instrumental and technique considerations, the awareness of the intrinsic broadband nature of the infrared absorbance spectra of solid samples of complex hydrocarbon mixtures, and the resulting limited sensitivity of the techniques to detect small but important changes In structure from one sample to the next, lead one to the conclusion that the authors are using the ierm "similar" more qualitatively than quantitatively. Consequently, in expressing reservations concerning the realism of his "average" coal molecule structure, Given (Ref. 1.2) notes "....My reason for believing that a molecule could be representative was chiefly the fairly close similarity of the infrared spectra of coals and their extracts. I now regard this as poor evidence. The 'close similarity' of spectra means in fact merely that the bands are centered on more or less the same frequencies. These bands are quite broad, and the shapes, including widths and intensities, are not necessarily the same for coal and extract. In general terms, the same functional groups are present, but this does not mean much when one is talking about a complex mixture. " A close inspection of the earlier work of Orning and Griefer and Brown, et. al. would support Glven's conjecture.

Relatively high polymethylene contents (Ref. 1.7, 1.9, 1.24) of the low temperature tars from a wide range of coal ranks and the dominance of such structures in all low rank coal tars to the onset of secondary reactions is observed in fluid bed reaction systems. However, as Collin et. al. (Ref. 1.7) note in a review of coal devolatilization work performed in Australia, the elemental composition of tars produced in some heated grid devolatilization investigations (Ref, 1.4, 1.25) of high volatile bituminous coals have considerably lower hydrogen concentrations than that observed in fluid bed devolatilization studies. In addition, and perhaps more importantly, the tar elemental compositions from the heated grid experiments were observed to be nearly independent of the extent of tar evolution or reported final particle temperatures between 400 and $900^{\circ} \mathrm{C}$. Analogous to the hot plate work reported above, however, tars from these early 
heated grid studies are reported to have "similar" IR absorbance bands as the parent coal. Using the computerized advantage of FT-IR instrumentation, typical mass normalized spectra as a function of peak grid temperature are reported for tars evolved from a bituminous coal (Ref. 1,12) in a heated grid system. Relative to the spectra of either the parent coal or the tar evolved at the point of maximum tar yield, the low temperature tar spectra indicate the presence of appreciable quantities of polymethylene functionality, in agreement with the observations of others (Ref. 1.7, 1.9, 1.24). However, no temperature dependence is reported in the corresponding tar elemental composition data for bituminous cuals (Ref. 1.4, 1.12). Again the authors appear to use the term "similar" in a qualitative sense with respect to either the elemental composition or infrared absorbance characteristics.

Such qualitative generalizations can serve to obscure rather systematic quantitative changes in overall tar composition as a function of the extent of tar evolution for a given coal or with coal type for a given extent of evolution. If a truly quantitative, rank-independent, monomer-polymer structural relationship existed among primary tars and the parent coal during devolatilization, such phenomenological behavior would imply a chemically controlled depolymerization process is responsible for tar formation and evolution. However, there is no consistent quantitative data supporting this view.

\subsubsection{Difficulties in Obtaining Accurate Temperature Measurements During the Transient Devolatilization Process}

The difficulties in determining the temperature of a rapidly decomposing heterogeneous particle are well known in principle but have not been fully appreciated in practice. This fact, coupled to the phenomenological observation that the rate of coal devolatilization appears to "a ljust" itself to the heating conditions of an experiment, have undoubtedly led to inaccuracies in reported particle temperatures associated with rapid devolatilization. Since the complexity of coal structure permits a wide range of devolatilization/pyrolysis reaction paths, a coal particle is able to respond to a given heat transfer field in a variety of manners. As a consequence the local finite heat transfer rate generated by a reactor to a devolatilizing particle may produce particle devolatilization with resultant transient particle temperature trajectories much different than those calculated for an inert particle, or as measured by an associated thermocouple. The temperature measurement contribution to apparent discrepancies in devolatilization behavior can best be illustrated by focusing on a particular reactor type, such as the heated grid.

The wire mesh technique has been employed for over twenty years in investigating the devolatilization of pulverized coal. The technique is useful in that it provides quantitative data on the product distribution produced in semi-disperse, rapid heating of small coal particles. However, the temperature sensitivity of tar 
yields or total volatiles in transient heating condition are not in apparent agreement. The transient, heterogeneous nature of the process and the chemical complexity of the parent material and heavy hydrocarbon volatiles establish experimental difficulties and prevent immediate interpretation of observable behavior. Heavy hydrocarbons, tars, are the major volatile species evolved during the transient particle heating to temperatures in excess of $600^{\circ} \mathrm{C}$. It is the formation and evolution of these species that are the natural references in attempts to discover the causes for the reported differences in total volatile behavior observed in a variety of clevolatilization experiments.

More specifically, it is the evolution of tars during experiments characterized by nonisothermal temperature profiles that result in the greatest differences in reported results. Figure 1.4 displays heated grid tar yields as a function of peak temperatures observed for some high volatile bituminous coals. All of these experiments were performed using "zero hold time" conditions, that is, the system thermocouple was heated to the given temperature and the electrical power immediately terminated. In each of the experiments in Fig. 1.4, thermocouple heating rates of $1000^{\circ} \mathrm{C} / \mathrm{sec}$ were obtained in one atmosphere of helium gas. In only one case (Ref. 1.26), was a carrier flow maintained over the mesh-sample surface. In some cases, natural convection and radiation cooling are the main modes of sample cooling (Ref. 1.4, 1.17, 1.19, 1.27, 1.28). In other cases an auxiliary quench was employed to increase the mesh-sample cooling rate (Ref. 1.26). Natural convection and radiation provides cooling rates of the order of several hundred degrees per second, whereas forced convection cooling produces cooling rates in excess of $1000^{\circ} \mathrm{C} / \mathrm{sec}$.

Table 1.1 lists the reported elemental compositions the coals employed and Fig. 1.5 shows their location on a coalification band plot relative to the "reference" coal of this investigation. PSOC 1451D. Inspection of Fig. 1.4 indicates asymptotic tar yields of the Pittsburgh Seam high volatile bituminous coal vary from $23 \%$ to approximately $32 \%$. The $37 \%$ tar yield observed for the UK bituminous coal consists of "heavy" tars and "light" tars, with heavy tars comprising approximately $70 \%$ of this amount. With this distinction in yield definition, the asymptotic, transient, "heavy" tar yields vary by only $33 \%$, although. temperature ranges of evolution vary considerably. 


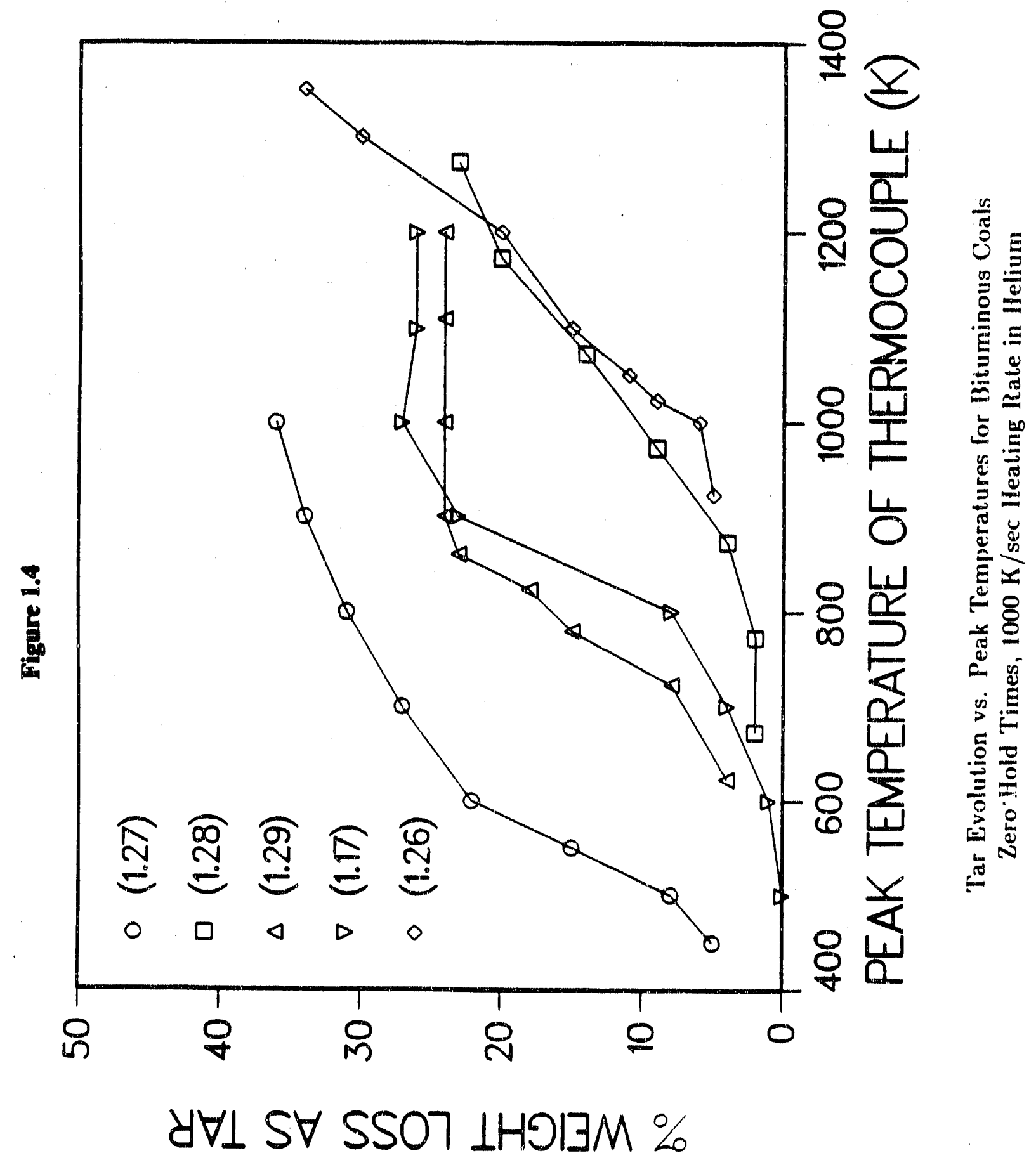




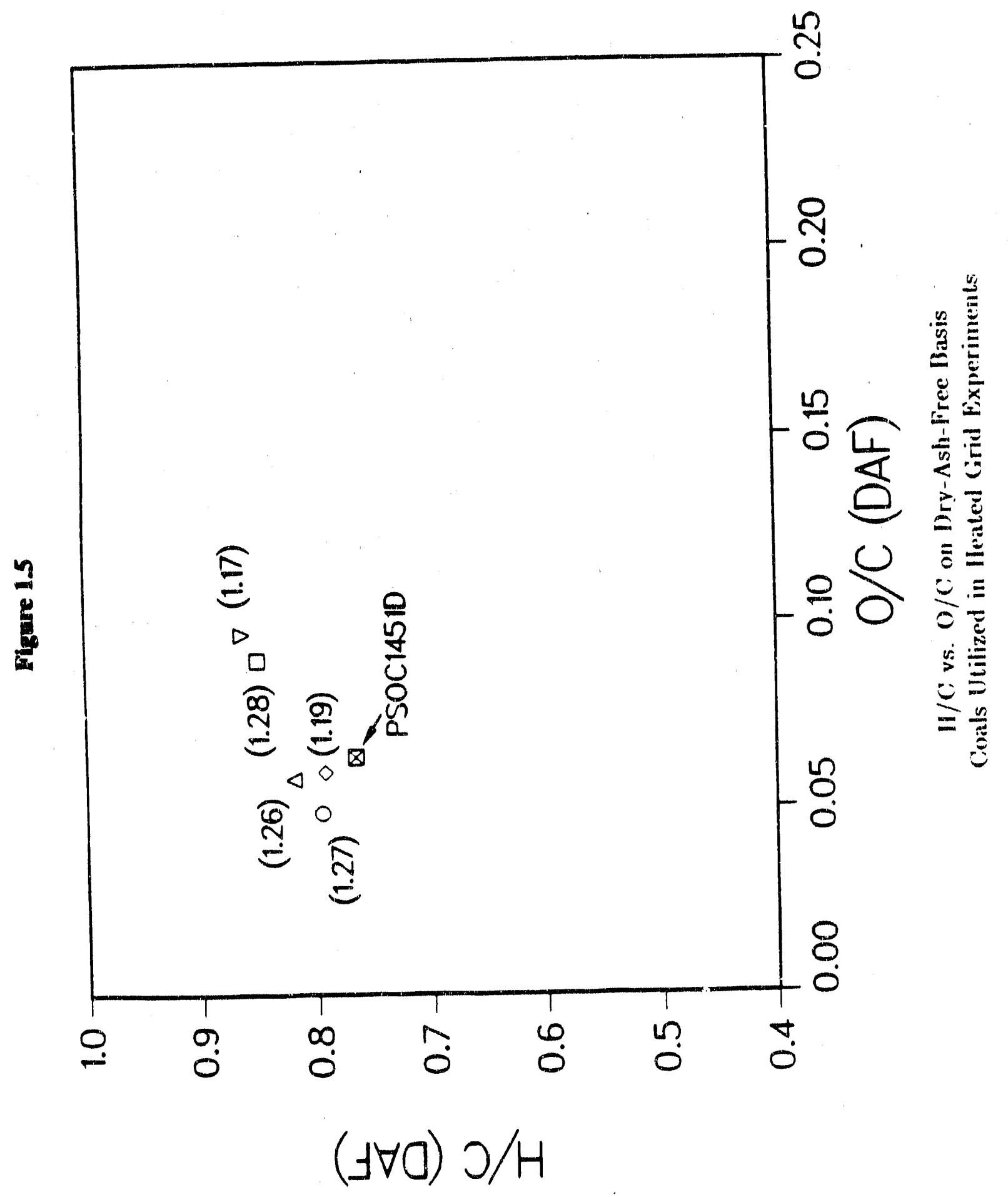




\section{TABLE 1.1 - ELEMENTAL COMPOSITION OF BITUMINOUS COALS USED IN HEATED GRID INVESTIGATIONS OF TAR EVOLUTION}

\begin{tabular}{lccccc} 
& \multicolumn{5}{c}{ DAF Composition } \\
\cline { 2 - 6 } Investigator (s) & $\% \mathrm{C}$ & $\% \mathrm{H}$ & $\% \mathrm{~N}$ & $\% \mathrm{~S}$ & $\% \mathrm{O}$ \\
\hline Desypris, et al. & 86.00 & 5.70 & 1.85 & 1.00 & 5.60 \\
Suuberg, et al. & 76.44 & 5.41 & 1.47 & 5.97 & 9.13 \\
Unger and Suuberg & 84.28 & 5.56 & 1.68 & 1.05 & 7.02 \\
Oh & 79.37 & 5.70 & 1.35 & 5.30 & 10.23 \\
Bautista & 84.50 & 5.77 & 1.73 & 1.33 & 6.50 \\
This Study & 84.70 & 5.40 & 1.71 & 0.92 & 7.26
\end{tabular}

With respect to long hold time tar yields there is less data available. Bautista, et.al. (Ref. 1.26) report approximately a $32 \%$ tar yield for $20 \mathrm{sec}$ hold times at $750^{\circ} \mathrm{C}$ after transieritly heating at a rate of $1000^{\circ} \mathrm{C} / \mathrm{sec}$, and nearly 0.9 of that yield occurs within the first 0.75 seconds of the isothermal period. Gibbins (Ref. 1.29) observed the same tar yield for 30 second hold times after heating at the same rate to $700^{\circ} \mathrm{C}$. Tar yieids make up the bulk of his total yields and the zero hold time runs to $700^{\circ} \mathrm{C}$ indicated nearly all of mass loss occurs during the transient heating process to $700^{\circ} \mathrm{C}$. Suuberg, et. al. (Ref. 1.28) report $22-25 \%$ tar yields for $2-10$ second hold times at $650^{\circ} \mathrm{C}$, with approximately one-third of the yield generated in the transient, zero hold time conditions. Considering there is some variation in coal samples, the investigators are in substantial agreement over the temperatures and tar yields expected in heating conditions in which thermal equilibrium between sample, screen and thermocouple are established during the major fraction of the heating cycle.

An alternative manner of visualizing the agreement in the data despite the obvious differences in transient temperatures is illustrated in Fig. 1.6. In this figure the empirical tar evolution times are plotted versus the reported temperatures for the midpoint of tar evolution. As implied in the discussion above, the investigators are in substantial agreement in the tar evolution times, given the cornmon heating conditions. There is essential agreement in: a) tar evolution times, b) unit change in yield per change in peak temperature achieved, c) transient asymptotic tar yields, and d) tar release temperatures in conditions where 


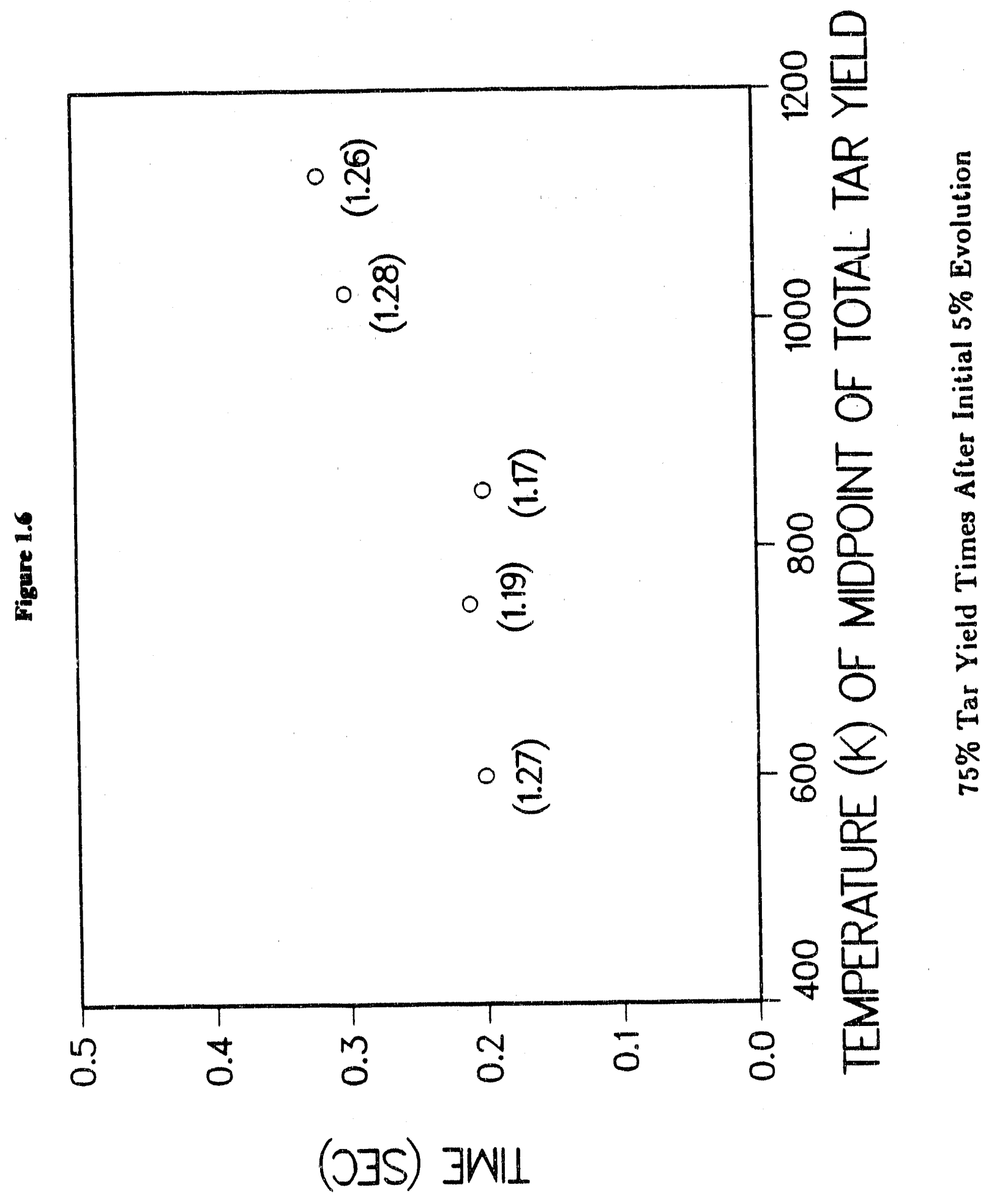




\section{R88-PC70768}

thermal equilibrium is achieved. The agreement implies the coal samples were experiencing similar heat flux rates during the main phase of tar evolution. despite the reported differences in corresponding temperatures for a given extent of tar evolution during transient heating.

From a combustion modeling perspective, the apparent discrepancy in the temperature dependence of the tar yield in transient heating conditions is an important issue. Reported temperatures for half the potential tar evolution during transient heating range from as low as $575 \mathrm{~K}$ to as high as $1125 \mathrm{~K}$. But the reported differences in zero hold time tar evolution must be considered in the context of the substantial agreements noted above. Such results imply that the measured temperature is a) not always representative of the sample temperature during the transient tar evolution process; b) only one of several important intrinsic or extrinsic parameters in determining the temperature sensitivity of the tar evolution in such an experiment; c) some combination of these two.

\subsubsection{Additional Contributing Factors to Apparent Devolatilization Differences}

Several other factors can be identified which have contributed to the apparent confusion and discrepancies in published models: 1) investigators have not used coal samples obtained from the same seams and mines and prepared in the same manner; 2) oversimplification of the nature of coal structure; 3 ) use of hidden assumptions in interpreting data; 4) misinterpretation of the significance of light gas yields and composition: 5) oversimplification of the complexity of the devolatilization/pyrolysis process.

The lack of a common set of coal samples to be used in investigations in different research laboratories has been the source of much uncertainty. Because of the complexity of coal structure and the variance in sample characteristics within a seam, an underlying uncertainty with respect to the universal applicability of results obtained using one particular coal sample always existed. Significant variations in devolatilization behavior observed for a given coal type from laboratory to laboratory has at times been dismissed as due to the peculiarities of an unusual sample. Quantitative comparisons of data under conditions of non-uniformity in sample characteristics become difficult if not impossible. More importantly, researchers are not inclined to investigate the possible experimental or mechanistic causes for such anomalous behavior if sample uniformity is not certain.

Oversimplifying the nature of coal structure by direct comparisons to covalently-bonded polymer analogs has undoubtedly confused the interpretation of associated devolatilization behavior. In addition, assuming the same types of chemical pyrolysis networks are occurring irrespective of the nature of the coal rank has resulted in added confusion and misunderstanding in interpreting devolatilization behavior. 
R88-PC70768

The assumption that devolatilization mass loss is primarily controlled by chemical bond breaking pyrolysis processes has led to distributed activation energy models as a modellng device to explain the low temperature sensitivity observed for particle mass loss in many devolatilization experiments. Mass loss by a set of parallel first order reactions that have a dlstribution of chemical bond activation energtes can be simulated by a single low activation energy process under certain heating ronditions and for a given experimental resolution. The overall low activation energy would generally be attributed to physical control of a process, rather than chemical, but since coal is assumed to be a purely covalently-bonded structure, the low temperature sensitivity observed is attributed to the parallel reaction set behavior.

While it is undoubtedly true that a given coal contains many types of covalent chemical bonds. this does not necessarily imply that the low temperature sensitivity of particle mass loss observed for a given devolatilization experiment is a reflection of a distributed activation energy process. Physical bonding of molecular species, mass or heat transpor influence of the mass loss process, and inadequate temperature measurements (see above) during the rapid devolatilization process may also contribute to the observable low temperature sensitivity. That is, the low temperature sensitlvity may indeed reflect the real controlling phenomena in that particular experiment. The real danger of these hidden assumptions is that alternative explanations of apparently anomalous behavior are not pursued.

It is now apparent that light gas yields, in a manner analogous to tar yields and characteristics, reflect not only the intrinsic chemical characteristics of the parent coal but also the conditions in which the experiment rakes place. Light gases can be derived not only from decomposition reactions at functional group sites within the parent coal matrix itself, but also from pyrolysis of tars in the gas phase outside the particle (Fig, 1.3), depending on the temperature of the surrounding gases in the devolatilization experiment. In the case of some gas phase reactions, the transform from functional group type to particular light gas species is far from straightforward (Ref. 1.7, 1.9). To simply treat the light gas evolution process as reflective of the primary coal devolatilization process is itself a gross oversimplification. 


\section{SECTION 1.0 REFERENCES}

1.1 Howard, J, B., in Chemistry of Coal Utilization, 2nd Supp, Vol, ed, by Ellioth, M. A., Wiley - Interscience, New York, 665 (1981).

1.2 Given, P. H., In Coal Sclence, III, ed, by Gorbarty, M. L., Larsen, J. W. and Wender, I., "An Essay on the Organic Geochemistry of Coal," Academic Press, Inc., 65-253 (1984).

1.3 Suuberg, E. M., Peters, W. A., Howard, J, B., Ind, Eng. Chem. Proc. Design and Dev., 17. 37 (1978).

1.4 Solomon, P. R., Colket, M. B., Seventeenth Symposium (Int.) on Combustion. The Combustion Institute, 131 (1979).

1.5 Freihaut, J, D., Zabielski, M. F., and Seery, D. J., Nineteenth Symposium (Int.) on Combustion. The Combustion Institute, 1159 (1982).

1.6 Wel-Chun Xu, and Akira, Tomita, Fuel, 66, 626 (1987).

1.7 Collin, P. J., et. al, in Coal Liquefaction Products, ed, by H. D. Shultz, 1, 86 (1983),

1.8 Doolan, K. R., Mackie, J. C. and Tyler, R. J., Fuel, 66, 572 (1987),

1.9 Calkins, W. H., Hazaman, E. and Zeldes, H., Fuel, 63, 1113 (1984).

1.10 Tyler, R. J., Fuel, 59, 218 (1980).

1.11 Nelson, P. F, and Tyler, R, J., Twenty-First Symposium (Int.) on Combustion. The Combustion Institute, 427 (1986).

1.12 Solomon, P. R. and Hamblen, D. G., AlP Conference Proceedings No. 70: Chemistry and Physics of Coal Utilization, ed. by B. Cooper and L. Petrakis, 121 (1981).

1.13 Niksa, S. and Kerstein, A. R., Combustion and Flame, 66, 95(1986).

1.14 Orning, A. A. and Griefer, B., Fuel, 35, 381 (1956).

1.15 Brown, J. K., et. al, J. Institute of Fuel, 31, 259 (1958).

1.16 Solomon, P. R., et. al, Nineteenth Symposium (Intr.) on Combustion. The Combustion Institute, 1139 (1982). 
1.17 Oh, M. S., "Softening Coal Pyrolysis", Sc, D. Thesls, Dept, of Chem, Eng, MIT, Cambridgo, MA (1985),

1.18 Suuberg, E. M. "Mass Transfer Effects in Coal Pyrolysis," In Chemistry of Coal Conversion, ed, by R, H, Schlosberg, Plenum Press, 67 (1985).

1.19 Unger, P. E, and Suuberg, E, M., Fuel, 606 (1984).

1.20 Zlelinski, E., Fuel, 46, 329 (1967).

1.21 Hertzberg, N, and Ny, Dantel, "A Microscopic and Kinetlc Study of Coal Particle Devolatilization in a Laser Beam." In Fundamentals of the Physical-Chemistry of Pulverized Coal Combustion, ed. by J, Layaye and O. Prado, NATO ASI Series, Sries E.. No. 137. 104 (1987).

1.22 Solomon, P. R., Hamblen, D. G., Carangelo, D. G., Serio, N. A. and Destipande, G. V., Combustion and Flame, 71, 137 (1988).

1.23 Grant, D. N., Pugmire, R. J., Fletcher, T. H. and Kerstein, A. R., ACS Div. of Fuel Chem. Preprints, 195th National Meeting, Toronto, Carlada, 33(2), 322 (1988).

1.24 Calkins, W, H, and Tyler, R, J., Fuel, 63, 1119 (1984),

1.25 Solomon, P. R. and Colket, M. B., Fuel, 57, 749 (1978),

1,26 Bautista, J. R., Russel, N. B. and Saville, D. A., Ind. Eng. Chem. Fundamentals, 25, 536 (1986).

1.27 Desypris, J., Murdoch, P. and Williams, A., Fuel, 61, 807 (1982).

1.28 Suuberg, E. N., Peters, W. A., and Howard, J. B., The Seventeenth Symposium (Int.) on Combustion. The Combustion institute, 117 (1979).

1.29 Gibbins, Ion., "Investigation of Primary Coal Pyrolysis Using a Variable Heating Rate Wire-Mesh Apparatus", Ph.D. Thesis, Imperial College of Science, Technology and Medicine (1988). 


\section{SECTION 2 - EXPERIMENTAI, INY'ESTIGATION AND RESULTS}

\subsection{Introduction and General Context}

\subsubsection{Range and Characterization of Devolatilization Reactors}

A major implication of coal devolatilization research within the last decade is the roallzation that the macroscopic observables of coal devolatlization - product yields and characteristics - wild the kinetic parameters derived from these time - resolved observations appoar slgnificantly coupled to the particular heating conditions employed to generate the observables. The cause of the intimate coupling relates to the nature of coal structure, as discussed above (Section 1,0),

The sheer range of reactor characteristics presents a formidable obstacle to development of a coherent understanding of coal devolatilization. Reactor systems utillzed to investigate coal devolatilization produce particle heating rates which vary from fractions of degree a second (Ref. 2,1) to rates of the order of a million degrees a second (Ref, 2,2). Particle sizes range from the order of several millimeters (Ref.2,1) to as small as several microns (Ref, 2.3). Modes of thermal delivery vary from purely gas conduction/convection (Ref. 2,1), to combined convection and radlative (Ref, 2,4), to total radiative (Ref. 2,3), Radlative heating varles from broad band (Ref. 2.3) to single wavelength laser systems (Ref. 2.5, 2.6). Figuro 2.1 displays the range of heat transfer space created by such reactor systems and the approximate location of reactor types in the space. Figure 2.2 displays the approximate location of pfc coal combustion systems in such heat transfer space. If a particular reaction system does not coinclde with the pfc domain, it does not mean investigations performed with such systerns are not useful. It does mean that extrapolations of such results, particularly kinetic expressions, must be performed with caution and proper qualification. Comparisons of derived mass loss rate constarus from such a wide range of heating conditions abplied to a complex organic substance involves a number of often unstated assumptions. The primary unsubstantiated assumption is the invariance of chemical decomposition pathway with particle heating rate.

\subsubsection{Reactor Characterization and Estimated Particle Temperatures}

Closely related to the assuruption of chemica decomposition Invariance is the assumption that the transient particle temperature can be adequately estimated from the associated, measured therrocouple measlurements within the reactor system. The discrepancies observed in attempts to measure particle temperatures during devolatilization in a single, "apparently simple device" are noted above (Section 1). Recently, several investigators have attempted to develop techniques to measure the transient particle temperature during devolatilization (Ref. 2.7, 2.8) within entrained flow reactor systerns, However, 


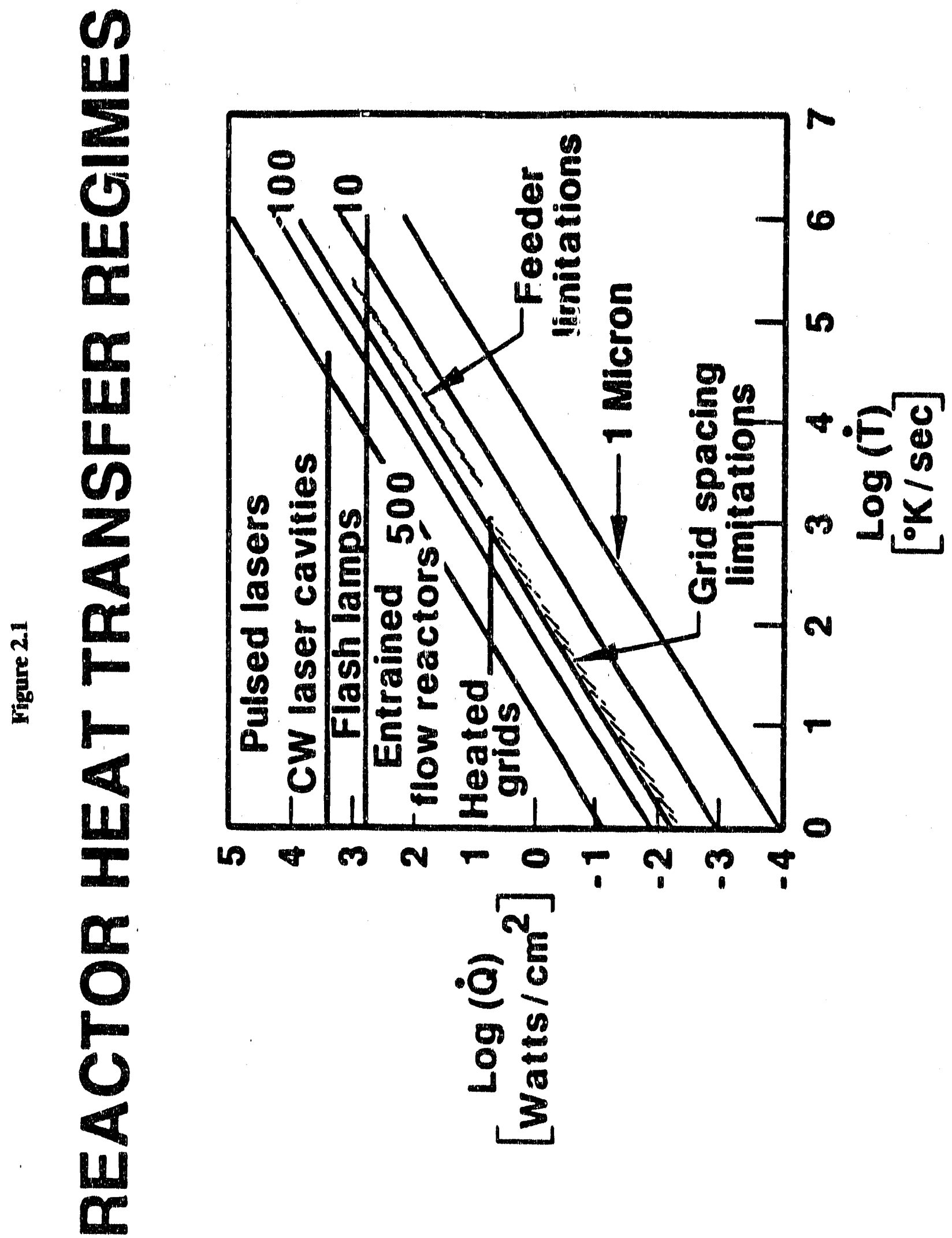




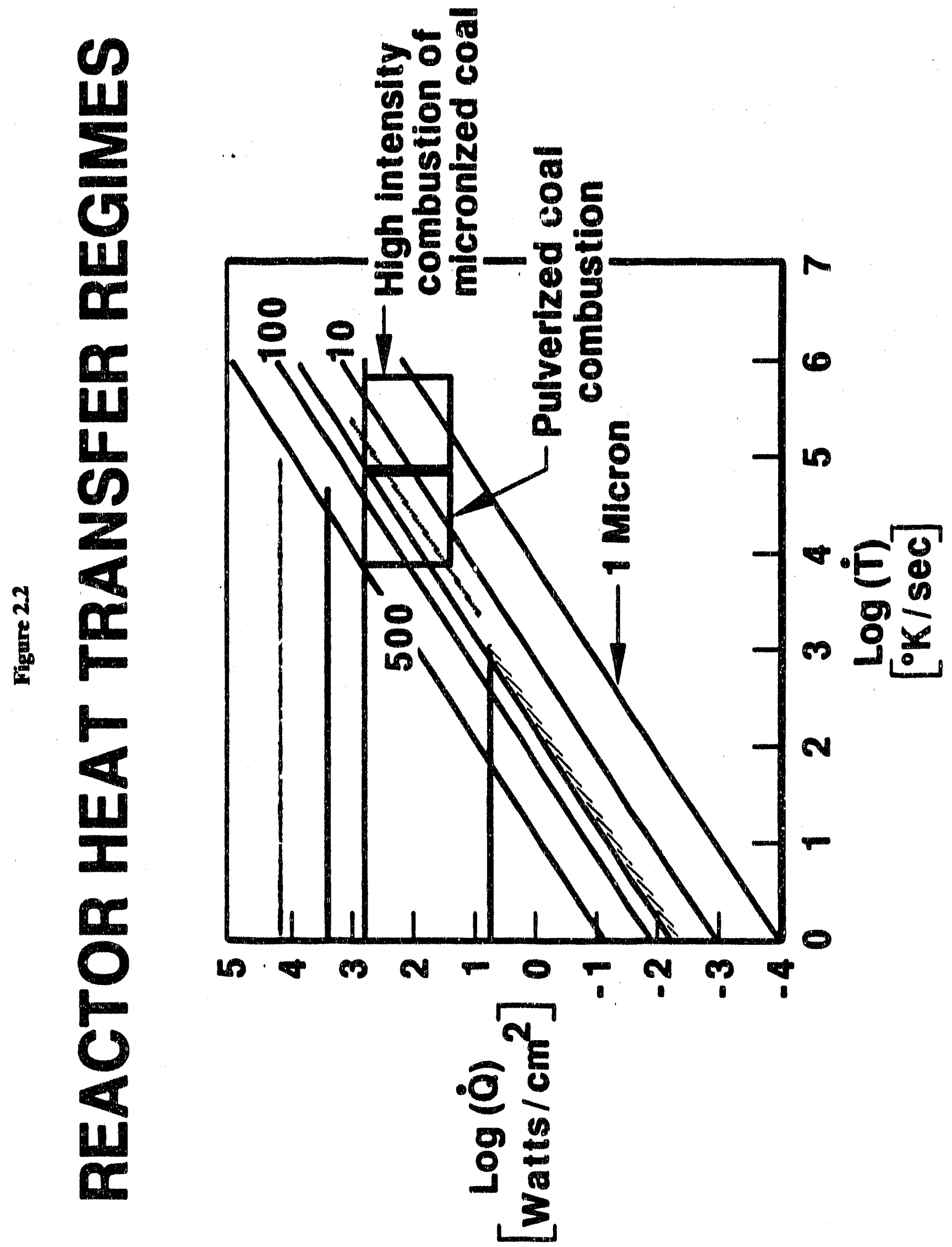


generalized laboratory transferable techniques have yet to be quantitatively established and, moreover, their extrapolation to other devolatilization reactor systems (see Fig. 2.1) is not stralghtforward.

Given: 1) the importance of devolatlization to coal combustion processes (Fig. 1.1);2) the general awareness of the couplling among heating conditions and devolatilization observables; 3 ) the Infeasiblity of making direct transient particle temperakure measurements in the range of roactor systems utilized in this investigation, the technically mandated approach is to make every effort to quantify the heat transfer conditions of each devolatilization reactor. The devolatilization reactors employed in this Investigation are unique in the level to which they have been characterized with respect to heat transfer properties. To the extent possible, the magnitude of the reactor-to-particle heat transfer rate and the mode of heat transfer were quantified. As a consequence particle temperatures are estimated from directly measured flux rates rather than associated thermocouple measurements.

\subsubsection{Rationale in Devolatilization Reactor Configura'ions}

The devolatilization experiments performed in the experimental portion of this investigation span heating rates of $100^{\circ} \mathrm{C} / \mathrm{sec}$ to $100,000^{\circ} \mathrm{C} / \mathrm{sec}$ and particle sizes ranging from 20 microns to 700 microns. The wide range of heating conditions was employed in order that results obtained under this multi-laboratory coordinated effort undertaken with a common set of samples could be related to the range of results already available in the literature. It is assumed that useful, coherent information exists in the literature but its usefulness is partially obscured by the fragmentary nature of the individial studies and ill-defined comparisons of the data on the bases of questionable assumptions. By performing devolatilization experiments over a comparable range of conditions, It is thought that a sufficient data base and phenomenological understanding of coal devolatilization could be established to show the underlying consistency in the apparently disparate behavior.

\subsubsection{Order of Presentation of Results}

The experimental system descriptions and devolatilization results are presented in terms of heat transfer rates of the reactor systems, given the importance of heating conditions on the devolatillzation process. With respect to Fig. 2.1, results obtained using "Isotnermal" entralned flow reactor results having reactor-to-particle heat transfer rates of 50-100 watts/sq. cm. during the bulk of the particle mass loss are discussed first: the Pennsylvania State University entrained flow reactor (PSU-EFR), and the MIT investigation utilizing the Sandia National Laboratories entrained flow reactor (SMIT-EFR). These reactors present heat transfer fields to the particles that are nearest those established in pfo combustion systems, and 
are characterized by entrainment gas and wall temperature fields that are matched as close as possible. These reactors are "isothermal" only in the sense that all parts of the reactor heat transfer media are kept at the same temperature to the extent possible.

These results are followed by those obtained in two different non-isothermal reaction systems of lower heat flux rates: the non-isothermal entrained flow reactor of United Technologies Research Center (UTRC-EFR) and the heated grid reactor in the same laboratory (UTRC-HG). In these reactors the heat transfer field itself is non-isothermal, forcing a particle to follow a non-isothermal trajectory in time during the devolatilization process. These experiments art characterized by reactor-to-particle heat flux rates of the order of 0.25 to 25 watts $/ \mathrm{sq}$. cm. during devolatilization.

Finally results are presented from a rcactor system in which the heat flux rate exceeds 100 watts/sq.cm., the United Technologies Research Center Flash Lamp Reactor (UTRC-FL). In these experiments in which the reactor-to-particle heat transfer rate may exceed those found in pfc combustion systems, purely radiant pulses of energy are delivered to the coal particles.

The low heat flux reactors (UTRC-EFR and UTRC-HG) and severe heat flux rate reactor (UTRC-FL) establish border or framing conditions relative to the moderate (PSU-EFR and SMIT-EFR) flux rate reactors and, thereby, become the experimental analogs to the "limiting case" studies of complex mathematical expressions or models. Their results help to deconvolute the convoluted chemical and physical behavior observed in isothermal entrained flow reactors. They also serve to link the results of this investigation to the wide range of results found in the literature. 


\subsection{Devolatilization in Reactor-to-Particle Heat Flux Rates of 50-100 Watts/sq. cm.}

\subsubsection{Pennsylvania State University Entrained Flow Reactor (PSU-EFR) Investigation \\ Entrained Flow Reactor and Ancillary Eyuipment}

A schematic diagram of the Penn State Entrained Flow Reactor (EFR) is shown in Fig. 2.3. This apparatus has been described fully by Maloney (Ref. 2.9). Briefly, coal particles are entrained in a primary gas stream at ambient temperature, and injected into the center of a cylindrical reaction chamber, electrically maintained at a specified temperature. At the same time, a secondary gas stream, preheated to the reactor temperature, is isokinetically injected around the primary gas stream. The particles travel down the center of the reactor in a pencil-like fashion. The products of pyrolysis and/or combustion are aspirated through a water cooled collector probe that quenches reactions. It has been shown (Ref. 2.10) that the hot gases can be cooled to less than $500 \mathrm{~K}$ within $50 \mathrm{msec}$ in the collector probe. Any solid products are collected in the cyclone, condensed liquids are deposited on the filter, and gaseous matter is released into an exhaust stack. The residence time of the coal particles in the reactor can be varied by changing the position of the collector probe and is typically less than $280 \mathrm{msec}$.

Equipment Modifications. The basic nature of the reactor was not changed in this study but modifications were made to both the preheater and on the cnllection systems. As shown in Fig. 2.3, the EFR and preheater are placed on a mezzanine level above the laboratory floor, and the collection train is situated on a table top directly beneath the reactor. A thermocouple readout, flowmeters, and furnace controls are mounted on a control panel attached to the table beneath the EFR. Operation of the EFR is performed while standing on ground level. The original arrangement of two secondary gas preheaters in series was abandoned because heat loss from the unheated section between the units was too great. A single, more powerful unit was installed that out-performs the old equipment. Like the old preheater, this new unit contains silicon carbide heating elements. To extend the elements' life, and to provide automatic control over heatup and cooldown, a power delivery systern was designed with a current limiting power controller (Halmar Electronics model i-2450 AD) and a programmable temperature controller (Thermo Electric Tempstar II). The typical time required to heat the preheater from ambient teinperature to $1100^{\circ} \mathrm{C}$ is 12 hours. This slow heating rate reduces thermally induced stresses on the materials of construction and heating elements. The controllers are used in conjunction with a powerstat variable voltage transformer. A block diagram of the power delivery system is shown in Fig. 2.4. 
Figure 2.3

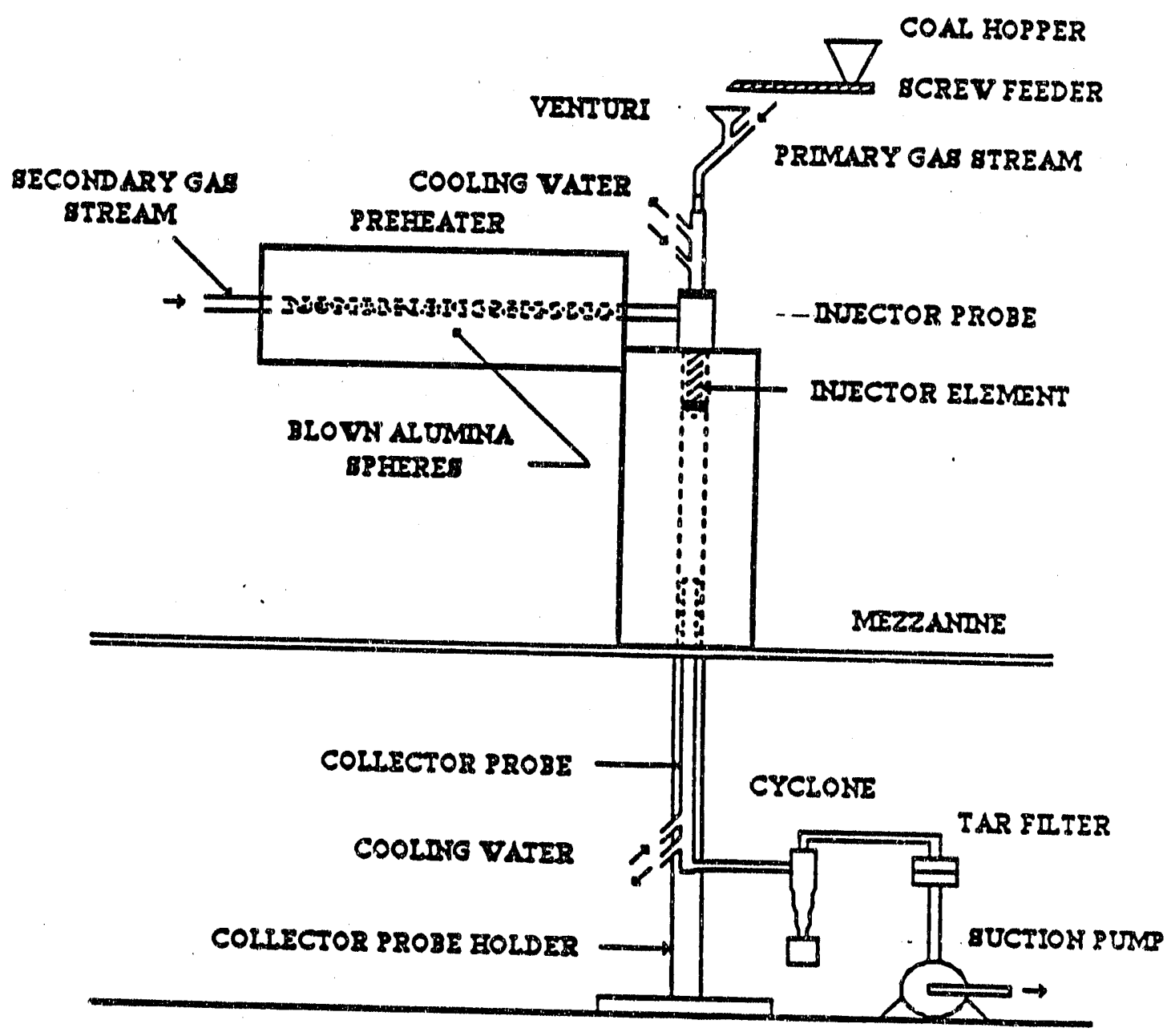

The Entrained Flow Reactor and Ancillary Equipment 
Figure 2.4

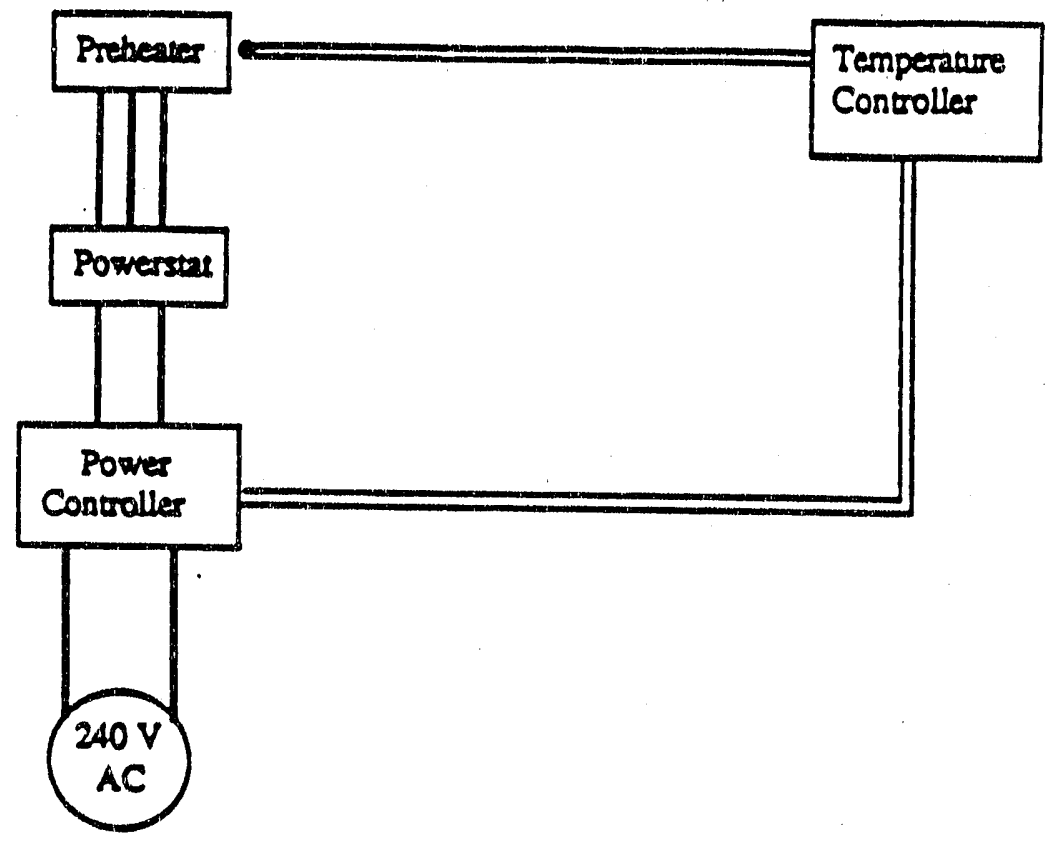

Block Wiring Diagram for the Secondary Gas Preheater 
Collector Probe Modification. By varying the position of the collector probe in the reactor, the particle residence time can be changed. The positioning was previously performed by an imprecise jacking arrangement which required great care to ensure reproducibility of placement. A new collector probe holder was designed, and built, to remedy this problem. This holder is shown schematically in Fig. 2.5. It is permanently mounted on a table top and provides fine control in two directions to ensure that the probe is positioned accurately in both 3 horizontal $( \pm 4 \mathrm{~mm})$ and vertical $( \pm 3 \mathrm{~mm})$ fashion. Since the outer dimensions of the collector probe and the suction pyrometer are identical, both can be used in the holder.

Suction Pyrometer Modification. A complete description of the suction pyrometer has been given by Maloney (Ref, 2.9). Briefly, this device is used to measure the gas temperature in the reactor without any contribution from the furnace walls. It does this in two ways. First, the thermocouple bead is shielded by concentric mullite tubes from radiation emanating from the wall. Second, gas is aspirated across the bead at a high velocity. However, the top part of the bead remained exposed to radiation originating at small angles as measured form the furnace center line, i.e. radiation from the wound element on the injector probe.

A second problem that was noticed with the pyrometer was an apparent temperature variation in the radial direction. The gas temperature was $5-10^{\circ} \mathrm{C}$ cooler near the centerline compared to positions near the wall. This discrepancy was more pronounced near the injector tip. It is believed this observation was due to the non-preheated primary gas stream flowing in the center of the furnace. When setting the furnace power levels, it is desirable to know the gas temperature averaged over the cross section, at a particular axial distance.

The two problems of radiation from the top and lack of mixing were both solved by fabricating a bullet shaped cap for the suction pyrometer's radiation shield. Fig. 2.6. This was made from a small piece of mullite and high temperature cement. Four small slits were cut in the sides to allow the gases access to the thermocouple bead. Variation in measured gas temperature with radial position was eliminated by mixing of primary and secondary gases. As the cool gas along the centerline strikes the top of the cap, the streamlines are deflected where the'/ mix with the hot gas near the wall. The combination of these gases is then drawn inside the cap, and over the thermocouple bead, to register a gas temperature that is "averaged" over the cross section.

Reactor Atroospheres. The major thrust of this particular study on the EFR was to evaluate the effect of reactor atmosphere on devolatilization kinetics. By changing the gases in the reactor, one is able to vary the heat transfer rate to the particle without changing the reactor temperature. Five atmosphere 
Figure 2.5

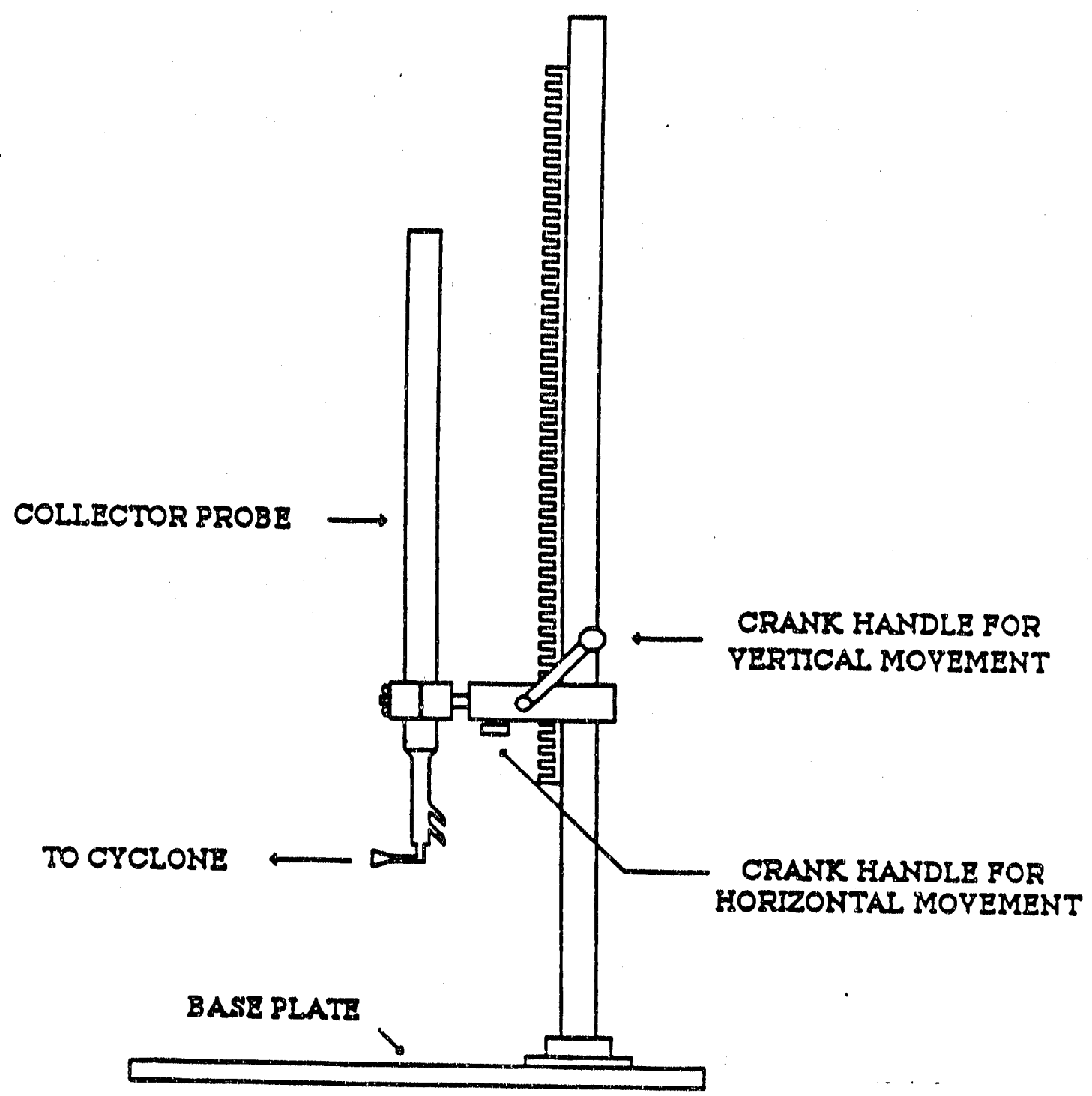

Probe Holder 
Figure 2.6

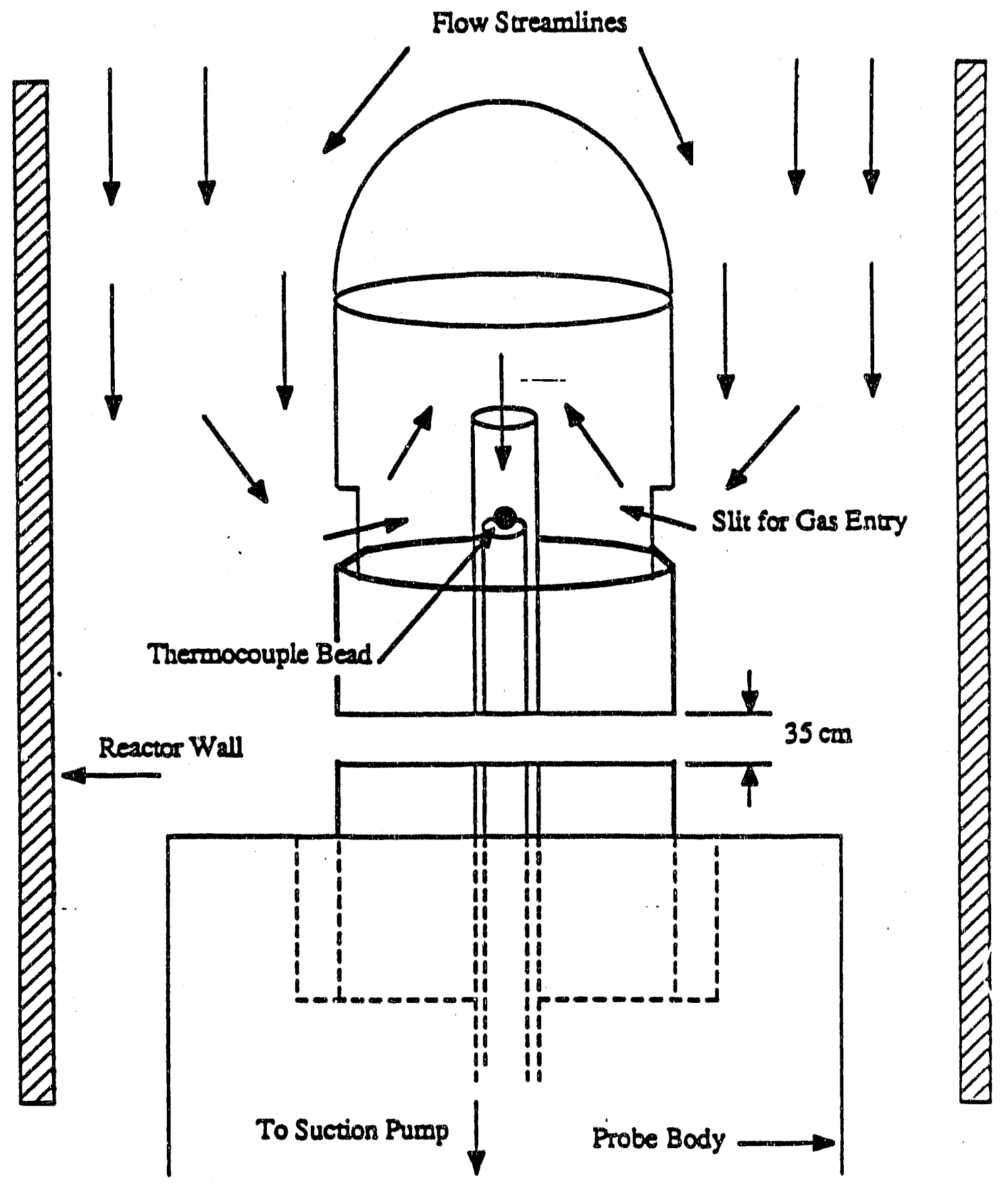

Cap for the Suction Pyrometer 
combinations were used in this research. Following the convention of primary gas/secondary gas, these combinations were $\mathrm{He} / \mathrm{N}_{2}, \mathrm{~N}_{2} / \mathrm{N}_{2}, \mathrm{He} / \mathrm{CO}_{2}, \mathrm{He} / \mathrm{air}$, and alr/air. A summary of the gases' thermal properties is displayed in Table 2.1. The most interesting features in Table 2.1 are the properties of hellum compared with the properties of the other three gases. The kinematic viscosity of Hellum is 100 times groater than that of alr. Helium's heat capacity and thermal conductivity are 5 times greater than air's values. The significance of the Prandtl number is that it expresses a ratio of thermal diffusivity to the diffusivity of momentum.

The higher the Prandtl number the quicker the thermal profile develops in relation to the velocity profile. In recent EFR projects at Penn State (Ref, 2.9, 2.10, and 2.11), and elsewhere, helium was chosen as the primary gas because of its high thermal diffusivity. Carbon dioxide is of particular interest in this work because it has only been used by one previous researcher in the Penn State EFR.

\section{TABLE 2.1 - THERMAL PROPERTIES OF GASES USED IN THE EFR}

\begin{tabular}{|c|c|c|c|c|c|c|}
\hline$\frac{\text { T.K }}{\text { Helliun }}$ & $\mathrm{R} \mathrm{K} / \mathrm{m}^{3}$ & Sa_pas & $\mathrm{Lr} \mathrm{m}^{2} / \mathrm{s}$ & CpKJ/KaK & $\mathrm{k} \omega \mathrm{W} / \mathrm{m} k$ & Er \\
\hline 1073 & $\begin{array}{l}0.0455 \\
0.0384\end{array}$ & $\begin{array}{l}48.54 \times 10^{-6} \\
54.76 \times 10^{-6}\end{array}$ & $\begin{array}{l}10.69 \times 10^{-4} \\
14.30 \times 10^{-4}\end{array}$ & $\begin{array}{l}5.193 \\
5.193\end{array}$ & $\begin{array}{l}37.82 \times 10^{-2} \\
42.75 \times 10^{-2}\end{array}$ & $\begin{array}{l}0.666 \\
0.665\end{array}$ \\
\hline
\end{tabular}

\section{Nitrogen}

\begin{tabular}{|c|c|c|c|c|c|c|c|}
\hline $\begin{array}{l}1073 \\
1273\end{array}$ & $\begin{array}{l}0.3137 \\
0.2685\end{array}$ & $\begin{array}{l}42.07 \times 10^{-6} \\
46.53 \times 10^{-6}\end{array}$ & $\begin{array}{l}13.24 \times 10^{-5} \\
17.36 \times 10^{-5}\end{array}$ & $\begin{array}{l}1.181 \\
1.215\end{array}$ & $\begin{array}{l}66.09 \times 10^{-3} \\
74.29 \times 10^{-3}\end{array}$ & $\begin{array}{l}0.752 \\
0.761\end{array}$ & $\begin{array}{l}0.1784 \\
0.2277\end{array}$ \\
\hline \multicolumn{8}{|c|}{ Carbon Dipxide } \\
\hline $\begin{array}{l}1073 \\
1273\end{array}$ & $\begin{array}{l}0.5007 \\
0.4218\end{array}$ & $\begin{array}{l}41.67 \times 10^{-6} \\
46.73 \times 10^{-6}\end{array}$ & $\begin{array}{l}83.47 \times 10^{-6} \\
11.10 \times 10^{-5}\end{array}$ & $\begin{array}{l}1.252 \\
1.293\end{array}$ & $\begin{array}{l}71.87 \times 10^{-3} \\
81.25 \times 10^{-3}\end{array}$ & $\begin{array}{l}0.726 \\
0.744\end{array}$ & $\begin{array}{l}0.11 \\
0.149\end{array}$ \\
\hline
\end{tabular}

\section{Air}

$\begin{array}{llllllll}1073 & 0.3296 & 43.7 \times 10^{-6} & 13.3 \times 10^{-6} & 1.155 & 71.6 \times 10^{-3} & 0.706 & 0.188 \\ 1273 & 0.2776 & 48.8 \times 10^{-6} & 17.6 \times 10^{-6} & 1.190 & 82.2 \times 10^{-3} & 0.705 & 0.249\end{array}$

$\begin{array}{llll}T & \text { Temperature } & k & \text { Thermal Conductivity } \\ \rho & \text { Density } & C_{p} & \text { Heat Capacity at constant pressure } \\ \mu & \text { Absolute Viscosity } & \operatorname{Pr} \text { Prandtl number, } v / \alpha \\ \nu & \text { Kinematic Viscosity } & \alpha & \text { Thermal Diffusivity, } k / \varrho C_{p}\end{array}$

Qperating Cenditions. The isokinetic velocity chosen for the primary gas and the secondary gas was $128 \mathrm{~cm} / \mathrm{s}$. This was the same velocity used by Tsai (Ref. 2.11) so comparison of his results with the results from this study could be simplified. Table 2.2 lists important sizes, flow rates, and other operating parameters in this work. Note the reactor Reynolds number is always less than 2100 indicating a laminar flow regime. Although one would seldom operate a commercial piece of equipment under laminar flow 
conditions, it was necessary In this case to avoid turbulence and have the same residence time for each particle so weight loss kinetics could be studled.

In all cases, the coal feed rate was a nominal $0.5 \mathrm{~g} / \mathrm{min}$. The feeder was callbrated to $0.50 \pm 0.02 \mathrm{~g} / \mathrm{m} / \mathrm{n}$ each time the hopper was filled. Frequently during a run, suction and coal flow were stopped, the cyclone was emptied, and the collector probe was cleared by blowing alr back through the collector probe using the flexible hose connecting the cyclone and the tar filter. The run was continued until $1.0-1.5 \mathrm{~g}$ of char was collected. The variable operating parameters were reactor atmosphere, particle size, reactor temperature, and coal type.

\section{TABLE 2.2 FLOW RATES UNDER OPERATING CONDITTONS}

$\begin{array}{lcc}\text { Temperature } & 1073 \mathrm{~K} & 1273 \mathrm{~K} \\ \text { Primary Gas Stream } & & \\ \text { Diameter, cm } & 0.3 & 0.3 \\ \text { Coal Feedrate, mg/s } & 8.3 & 8.3 \\ \text { Gas Velocity, cm/s } & 128 & 128 \\ \text { Gas Flow Rate, cm }{ }^{3 / s} \text { at STP } & 9.0 & 9.0 \\ \quad & \\ \text { Secondary Gas Stream } & & \\ \text { Diameter, cm } & 5.1 & 5.1 \\ \text { Gas Velocity, cm/s } & 128 & 128 \\ \text { Gas Flow Rate, cm }{ }^{3 / s} \text { at STP } & 665 & 561 \\ \text { Reynolds Number } & 492 & 371 \\ \text { Primary to Secondary } & \\ \quad \text { Volumetric Flow Rate at STP } & 1 / 74 & 1 / 62\end{array}$

\section{Analysis of Chars}

Both chars and tars were saved in small plastic containers. The tars were retained for analysis. Chars were characterized in five ways: proximate, trace element and particle size analyses, calorific value determination, and scanning electron microscopy.

Broximate Analysis. A proximate analysis was performed on the coal char collected from each run made in the EFR using a Leco MAC-400. In most cases, two samples of $400 \mathrm{mg}$ were run. Scaroni (Ref. 2.12) showed a char sample of this size is large enough to be representative of the char in general. Prior to loading the char in the crucibles for the MAC-4000, the total char sample for that run was riffled three times to ensure homogenelty of the char for the two crucible splits. In most cases, the analysis accepted for each run was an average of the two splits. 
Performing a proximate analysis on both a char and its parent coal permitted the weight loss to be calculated with Eq. (2.1) using ash as a tracer material, In this equation, $\Delta W$ is the welght loss on a daf basis. $A_{0}$ is the ash content of the parent coal on a dry basis, and $A^{\prime}$ is the ash content of the char on a dry basis.

$$
\Delta W=100 \%\left[1-\frac{A_{0}\left(100-A^{\prime}\right)}{A^{\prime}\left(100-A_{0}\right)}\right]
$$

This equation assumes that the mineral matter content is not transformed upon passing through the reactor. A sensitivity analysis of Eq. $(2,1)$ to the ash content found in the parent coal is presented in Appendix A.2.

Trace Element Analysis. To further validate the use of ash as a tracer in determining weight loss, 10 char samples of PSOC-145! prepared under a vartety of conditions in the EFR was ashed and analyzed for 12 trace elements. These tests were performed with a DC Plasma Spectrometer (Spectraspan III) by the Mineral Constitution Laboratory at Penn State. The results are listed in Table A.1 in Appendix A.2.

Particle Size Analysis. The results of particle size change upon passing through the EFR was Investigated with a Malvern Instruments $2600 \mathrm{c}$ droplet and particle sizer. This device employs a laser beam that. passes through a transparent sample cell containing the sample dispersed in a liquld media. The llquid chosen was acetone. Due to acetone's low surface tension, an extremely small sample size $(-10-20 \mathrm{mg})$ provides an adequate sample loading for the instrument. The Malvern provides a sample size distribution and reports a volume-averaged mean particle size. Samples of each size fraction from the different coals were tested to establish an average particle size for each cnal. These results were compared with the final average particle diameter of selected chars.

Calorific Yalue Determination. Calorific values for the coal PSOC-1451 and six selected chars were determined with a Parr 1241 Adiabatic Calorimeter. The sample weight used waș $400 \mathrm{mg}$. After the sample was placed in the stalnless steel bomb, the bomb was pressurized to $30 \mathrm{~atm}$ with oxygen. It was then depressurized and refilled to $30 \mathrm{~atm}$. This was to reduce the amount of nitrogen which, when present, forms nitric acid after ignition of the sample. An accompanying controller calculated the rise in temperature and the calorific value. The calorific values for the chars were compared to the values for the parent coal to determine the energy content of the volatile matter. 
Scanoing Electron_Microscony. Approximately 30 char samples were Wewed under a scanning electron mlcroscope (International Sclentific Instruments model III A) to investigate the char morphologies and to compare the dlameters measured from a photograph with those measured by the Malvern.

\section{PSU-EFR Computer Model}

An existing computer model last modified by Tsal (Ref. 2.11) was changed to allow th to be rin on the more advanced VM/CMS operating system residing on Penn State's 370-3090-200 mainframe computer. Aside from being much easier to edit computer code, the VM/CMS operating system offers the added advantage of the virtual machine concept. This affords the user all the interactive abillty found on a personal computer along with the power of a mainframe.

The FORTRAN source code to the four transport models was changed so they are all controlled by an interactive EXEC program written in REXX. A graphics program using the SAS/CRAPH package was written to go along with each of the four transport models. These SAS programs create labeled tables and figures of their respective transport solutions generated by the FORTRAN code. All tables are normally directed to a high speed line printer and the plots are routed to a Versatec printer/plotter.

Although these changes provide no technical improvement on the Penn State EFR computer model, they do greatly enhance the ease of interpretation of the results from different operational scenarios. To run the modifled model, the user simply answers a series of yes/no questions and enters any new numbers. All numerical output is in cgs units. The model segments are listed below.

\section{The Gas Velocity Segments}

GVEL Fortran. This program solves the gas velocity in the reactor tube as functions of both axial and radial distance. The user can choose from four secondary gasses and the reactor temperature as input variables. Subroutines evaluate viscosity as a function of temperature with expressions taken from Daubert and Danner (Ref. 2.13).

GVELRYSAS. This program generates three plots: axial velocity as a function of radial and axial distance, boundary layer thickness as a function of axial distance, and average gas velocity as a function of axial distance. The program also generates a data table. Figure 2.7 shows the axial gas velocity as a function of radial and axial distance for nitrogen at $1073 \mathrm{~K}$. Each of the curves represents different dimensionless radial distances as measured from the centerline $(R=0)$ toward the wall $(R=1)$. Tsai (Ref, 2.11) experimentally showed that the coal cloud remained in the envelope $R<0.3$. Figurc 2.7 indicates the gases 
Flgure 2.7

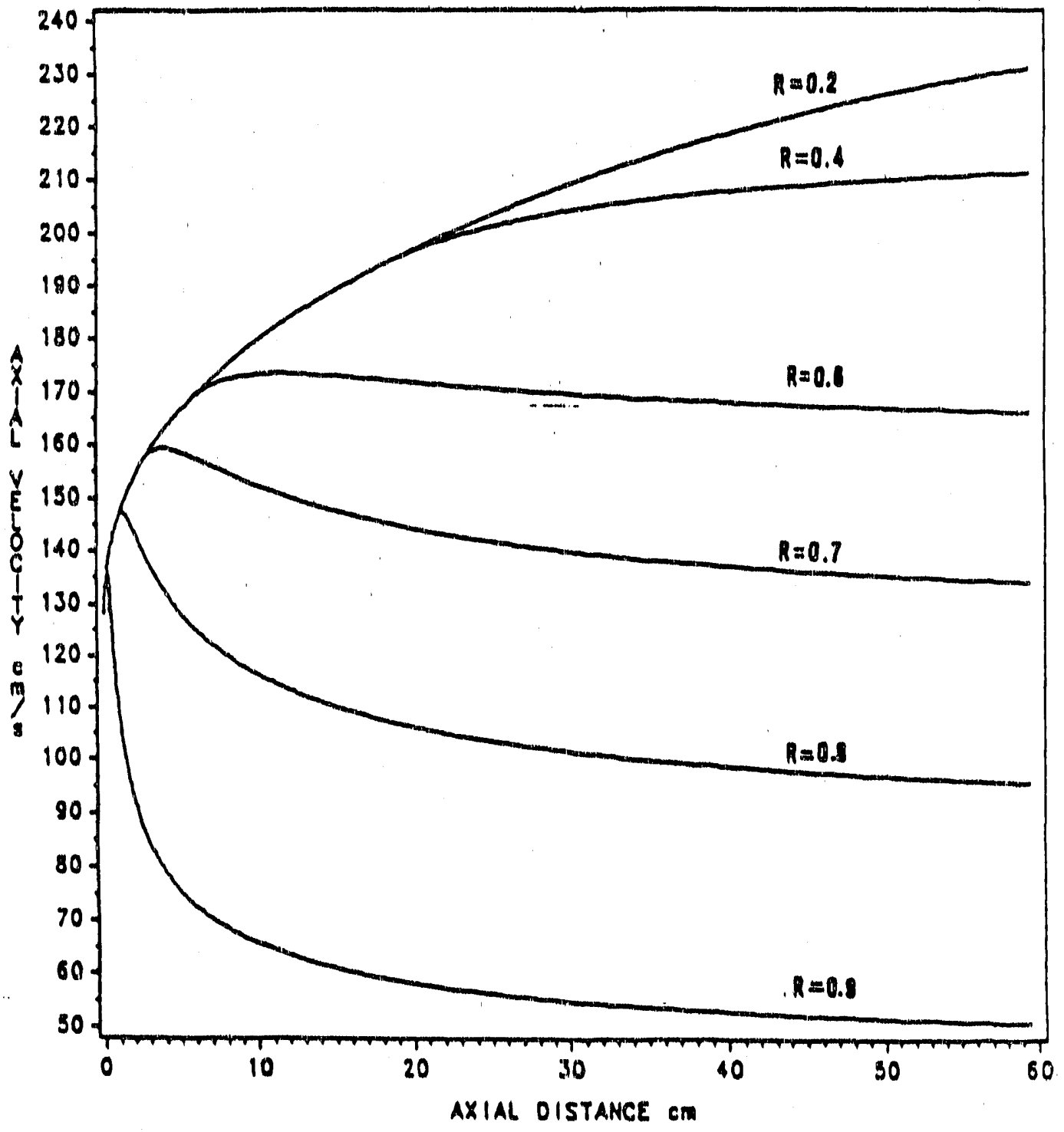

Axial v xity as a Function of Radial and Axial

Distancm for Nitrogen at $1073 \mathrm{~K}$. 
surrounding the coal particles are continuously accolerating, An average velocity taken over the entire cross section yields the curve In Fig, 2.8. The hydrodynamic boundary layer is continuously developing. This is shown In Fig. 2.9. The longest distance that char was collected from the infector was $2 \mathrm{~m} 55 \mathrm{~cm}$. At that point, the boundary layer thlckness was $80 \%$ of the fully developed value.

\section{The Particle Velocity Segments}

RVEL Eactran. This program allows the user to choose up to four partcle sizes, secondary gas type and reactor temperature as input variables. The solution output is particle residence time, particle velocity, and slip velocity for a given axjal distance.

PVELPYSAS. This program provides two plots and a data table. The plots are residence time as a function of axial distance for up to four particle sizes all superimposed on the same axes, and a plot of axial velocity and sllp velocity as functions of particle residence time for a single particle size. To get an idea of how particle size affects residence time, Fig. 2.10 was generated with the three size fractions which were actually run plus one oversize particle size, $230 \mu \mathrm{m}$; the residence time becomes noticeably shorter for a specific sampling position. L,ooking at the average gas velocity in Fig. 2.8, one would expect the particle velocity plot to appear similar. Figuro 2.11 shows this to be true. An Initial slip velocity of $15 \mathrm{~cm} / \mathrm{s}$ is first assumed. This assumption is seen not to be a critical one, since the slip velocity rapidly decays (or rises if too low an assumption is made) to the terminal sllp velocity.

\section{The Gas Temperature Segments}

GTEM Eortran. This program allows the user to input both primary and secondary gas types, reactor temperature, and amblent temperature. The constants for ideal gas he: : capacity and vapor thermal conductivity were taken from Daubert and Danner (Ref. 2.13). The output is average gas temperature as a function of axial distance and gas temperature as a function of radial and axial distance.

GTEMPY SAS. This program plots average gas temperature as a function of axial distance and gas temperature as a function of both axial and radial distance. A data table is also created. Flgure 2.12 shows the gas temperature inside the EFR as functions of both radial and axial position. Starting at the top, the three solid lines represent temperatures at $R$ values of $0.99,0.20$, and 0.10 . The dashed line is the gas temperature within the coal cloud. The sharp dips observed at small axial distances are caused by the cold primary gas and coal particles which must be heated to the temperature of the bulk gas. 
Figure 2.8

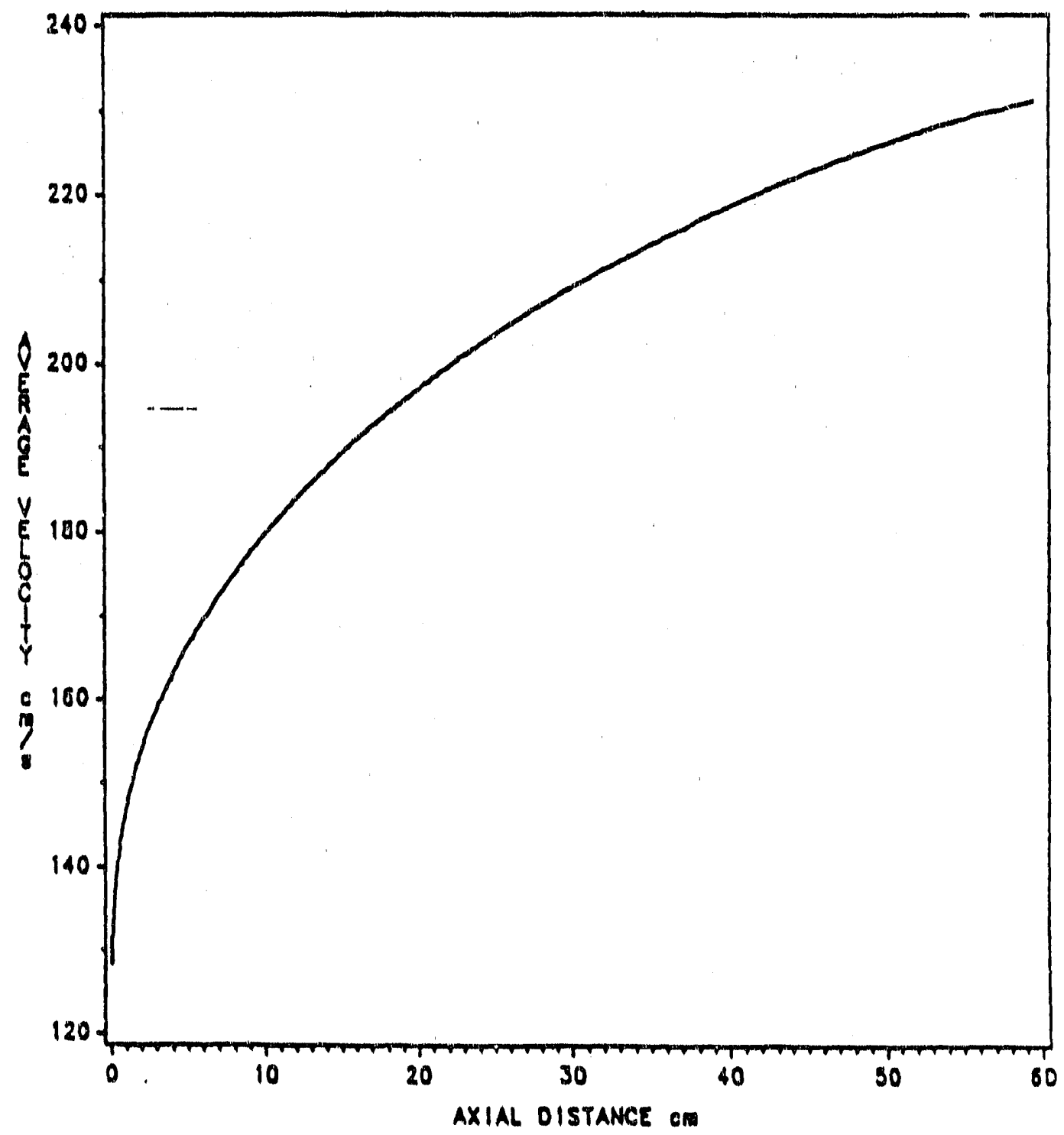

Average Axial Gas Velocity for Nitrogen at $1073 \mathrm{~K}$ as a Function of Axial Distance 
R88-PC70768

Figure 2.9

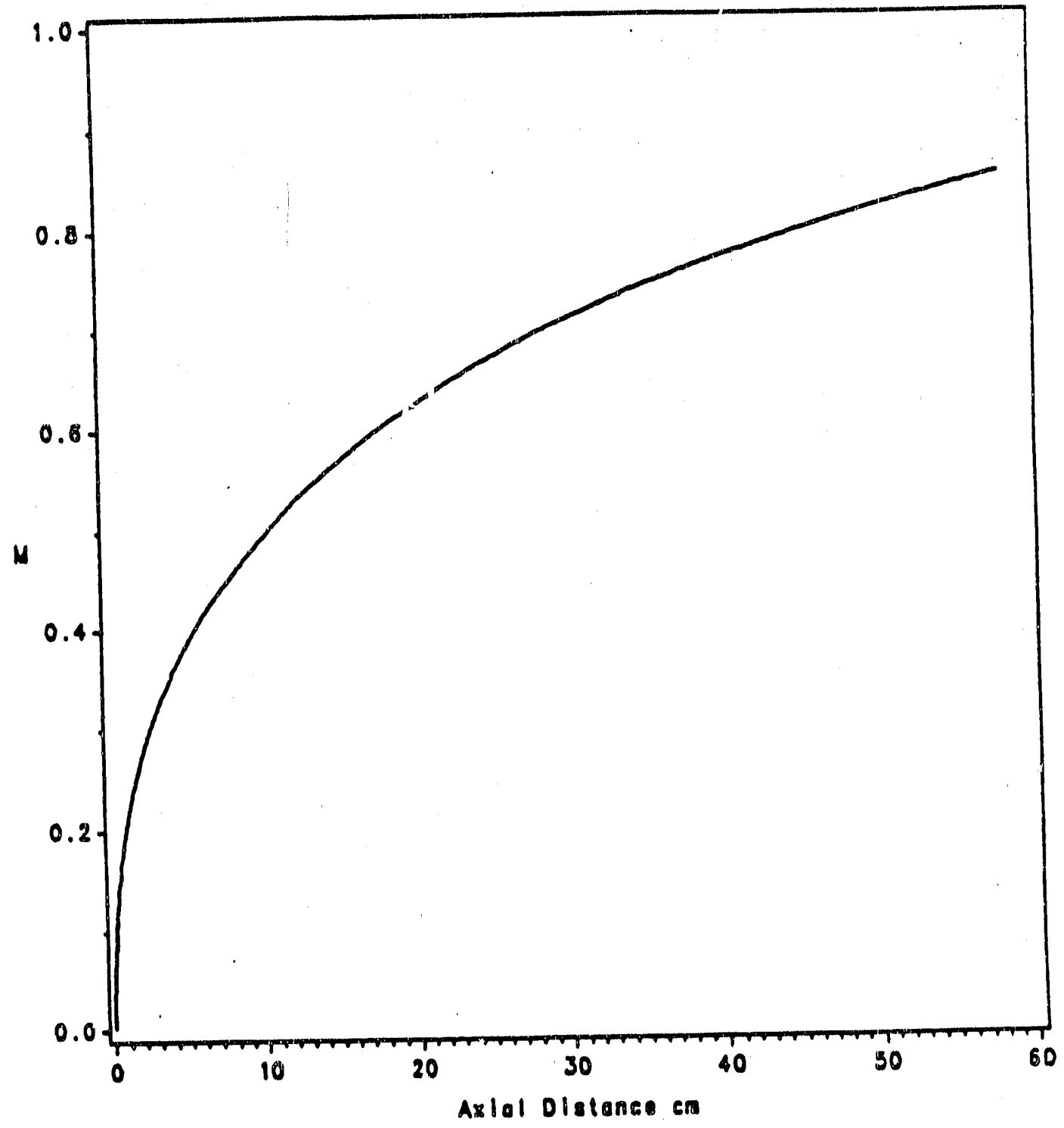

Dimensionles Roundery I.nyer Thickness for Nitrogen at $1073 \mathrm{~K}$ as a Function of Axial Distance 
Figure 2.10

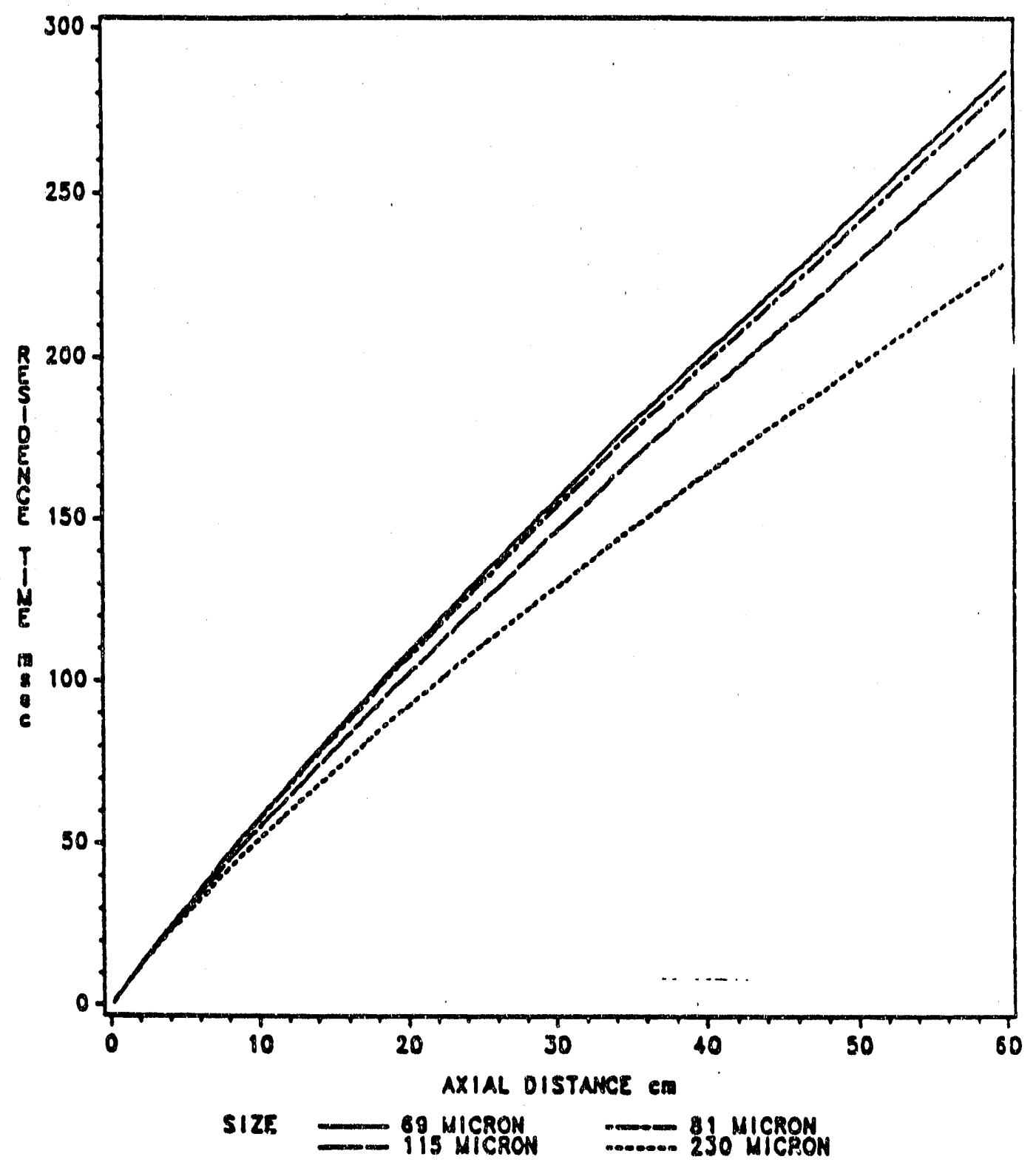

Residence Time in Nitrogen at $1073 \mathrm{~K}$ as a Function U Axial Distance for 69, 81, 115 nnd 215 표 Diameter Particles 
Figure 2.11

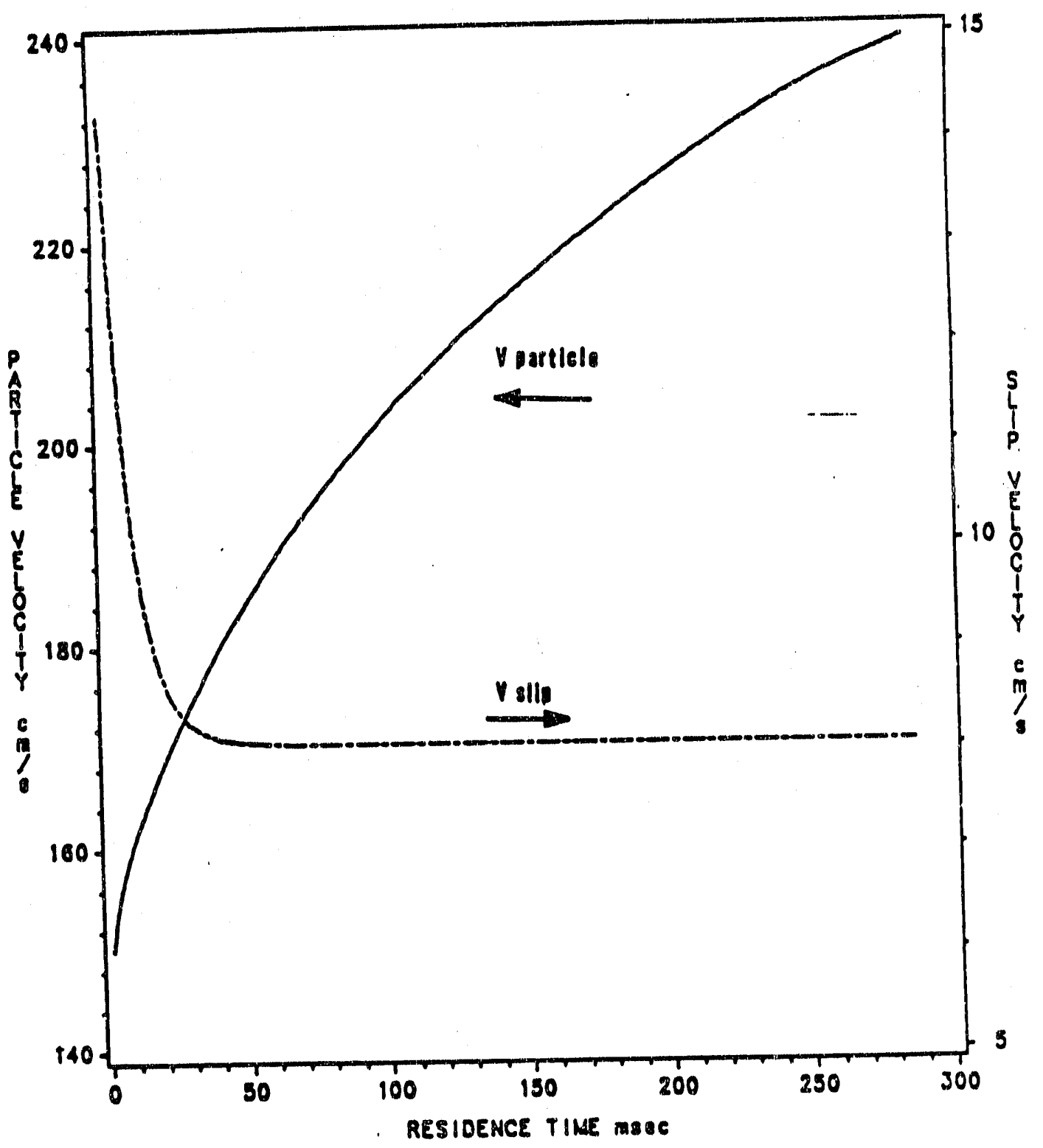

Axial Velocity and Stip Velocity in Nitrogen at $1073 \mathrm{~K}$ as Functions of Residence Time for $69 \mu \mathrm{m}$ Diameter Particies 
Figure 2.12

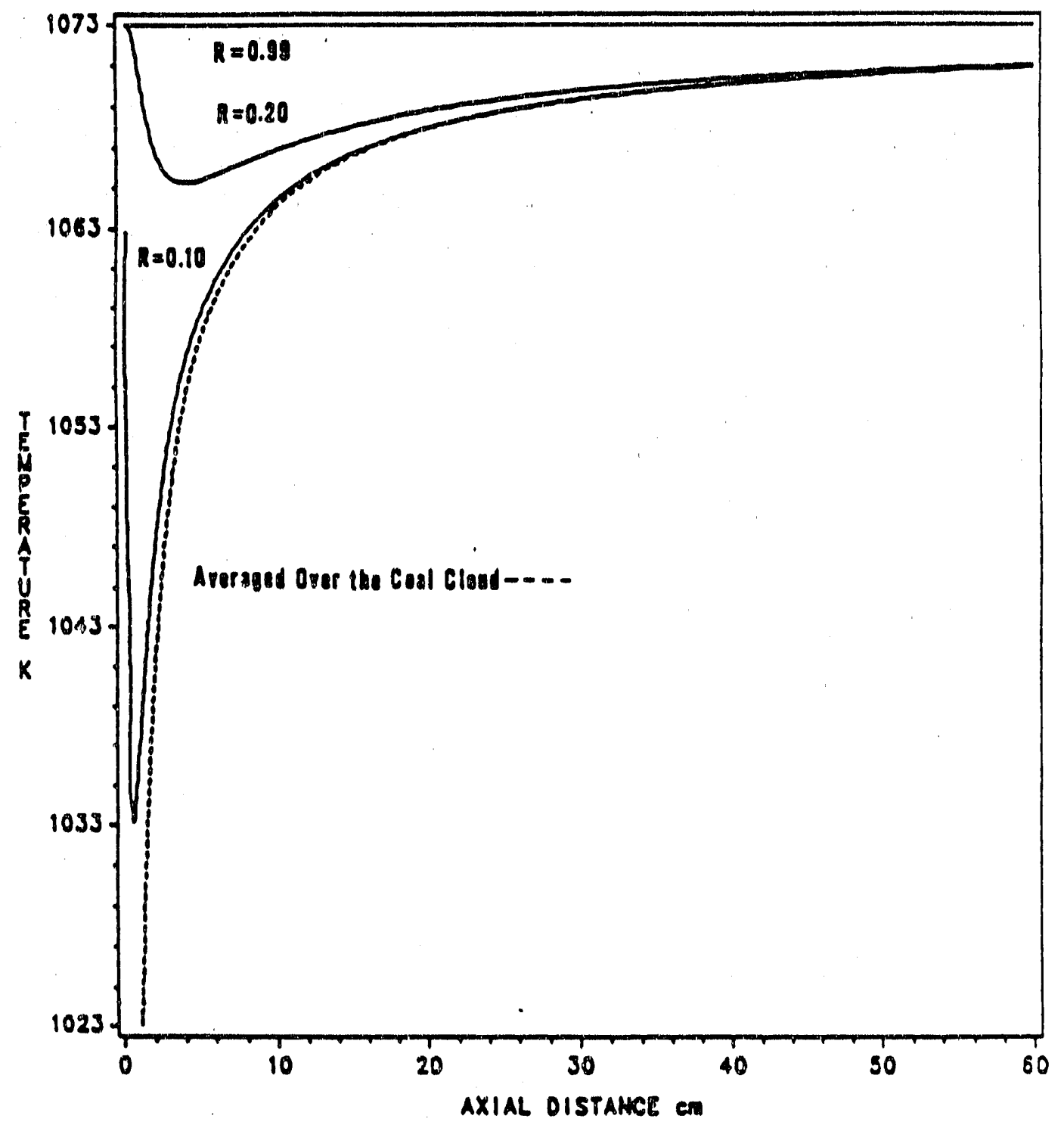

Gas Temperature Inside the EFR as a Function of Axial Distance in a $\mathrm{He} / \mathrm{N}_{2}$ Atmosphere with a Reactor Temperature of $1073 \mathrm{~K}$ 
The Particle Temperature Segments

RTEM Fertran. This program allows the user to input up to four particle sizes and the reactor temperature. The output is average particle temperature, temperature at the particle's center, temperature at the particle's skin, heat flux and total heat transferred, all as functions of residence time.

RTEMPVSAS. This program generates three plots: gas and average particle temperature as a function of residence time for a single particle size, average particle temperature for all particle sizes as a function of residence time, and heat flux and total heat transferred as a function of resident time for a single particle size. Figure 2.13 shows how rapidly the particles injected in the EFR were heated. Notice the temperature scale only covers the last 200 degrees of heating. It is intuitive that the smaller particles should be heated faster; Fig. 2.13 confirms it mathematically. Figures 2.14 and 2.15 should be considered together. Figure 2.14 shows a rapid rise in heat flux peaking at $92 \mathrm{~W} / \mathrm{cm}^{2}$. The flux then rapidly decays to a level approaching zero as the total heat transferred levels off to some finite value. This can be understood in terms of the temperature driving force shown in Fig. 2.15. As the particle temperature approaches the gas temperature, the driving force for heat transfer is greatly diminished. Consideration of the mode of heat transfer (Section 4.) indicated conventional transfer from the gas dominates at these operating temperatures.

\section{Coal Sample Selection}

Three coals were chosen for this work - one exhibiting thermoplastic properties on heating and two displaying non-thermoplastic behavior. These coals are identified by the Penn State Coal Sample Bank as PSOC-1451, PSOC-1520 and PSOC-1443, respectively. PSOC-1451 is a HVA bituminous coal from the Pittsburgh Seam. PSOC-1520 is a subbituminous coal from the Smith-Roland seam. PSOC-1443 is a lignite A from the Lower Wilcox Seam. The coals were obtained directly from Penn State's Coal Sample Bank in half pound quantities, sealed in steel cans under argon. Sample characterization provided by the Penn State Coal Data Base is presented in Tables 2-3 through 2-5. As can be observed from the Table 2.3, the bituminous coal is typical of other Pittsburgh Seam coals with the fixed carbon and volatile matter being $52 \%$ and $34 \%$ respectively. The sulfur content is average at $1.4 \%$ on a dry basis, and the ash content is slightly high at $13.7 \%$. The subbituminous coal aiso exhibits a typical behavior (Table 2.4) having intermediate values in all proximate daf data. The lignite (Table 2.5 ) contains $21 \%$ ash on a dry basis and its oxygen content is $16 \%$. Total sulfur for PSOC-1443 is $0.7 \%$ on a dry basis. It was also of interest to determine whether the different processing (grinding and sieving) conditions of the coal samples has an influence on the data. Therefore, samples of PSOC-1520 and 1443 coals were also obtained from Vortec Products Company, which provided coal samples to the other research groups involved in this project. The samples 
Figure 2.13

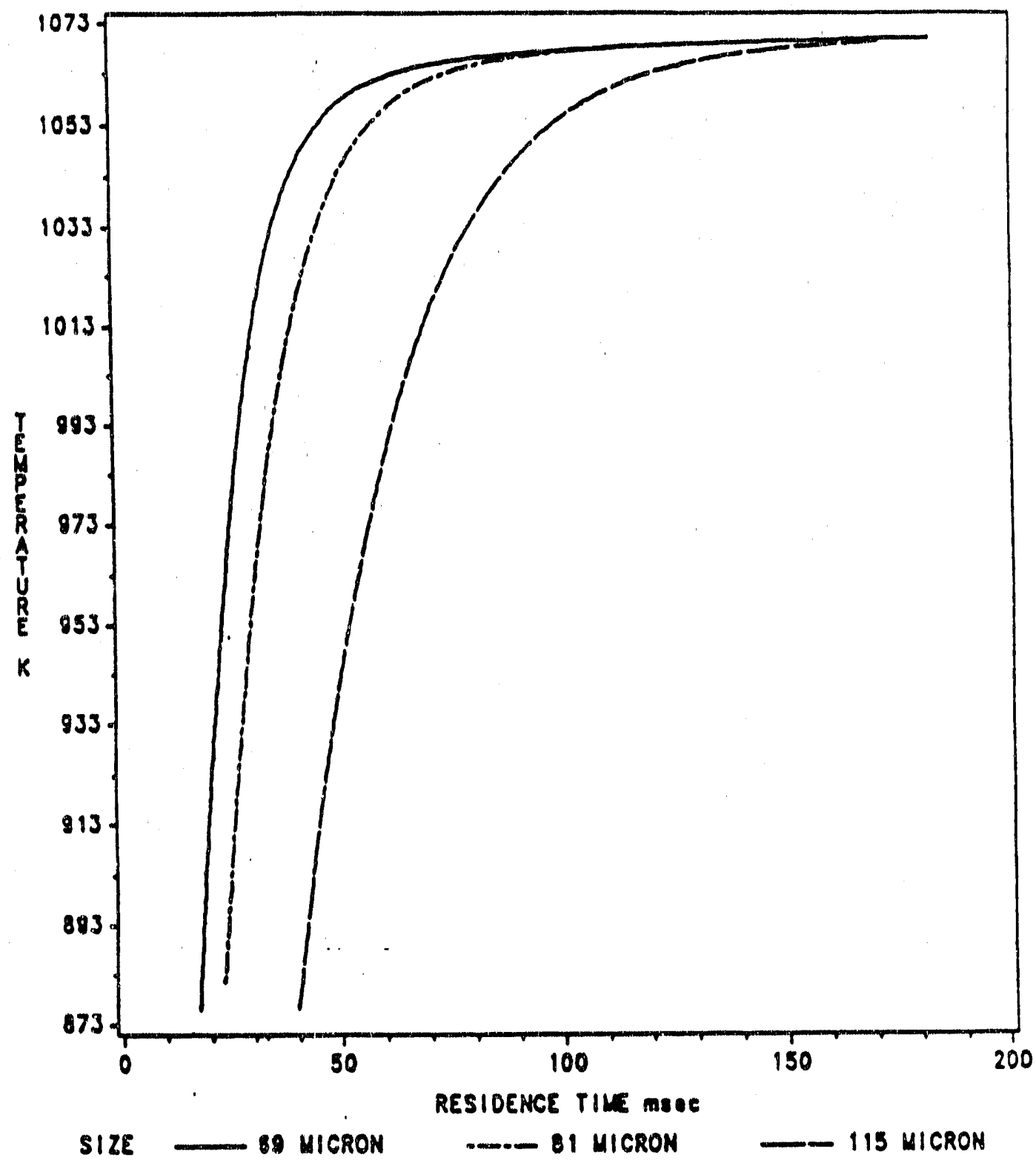

Average Temperatures for 69,81 and $115 \mu \mathrm{m}$ Coal Particles in a Nitrogen Atmosphere as a Function of Residence Time with a Reactor Temperature of $1073 \mathrm{~K}$ 
Figure 2.14

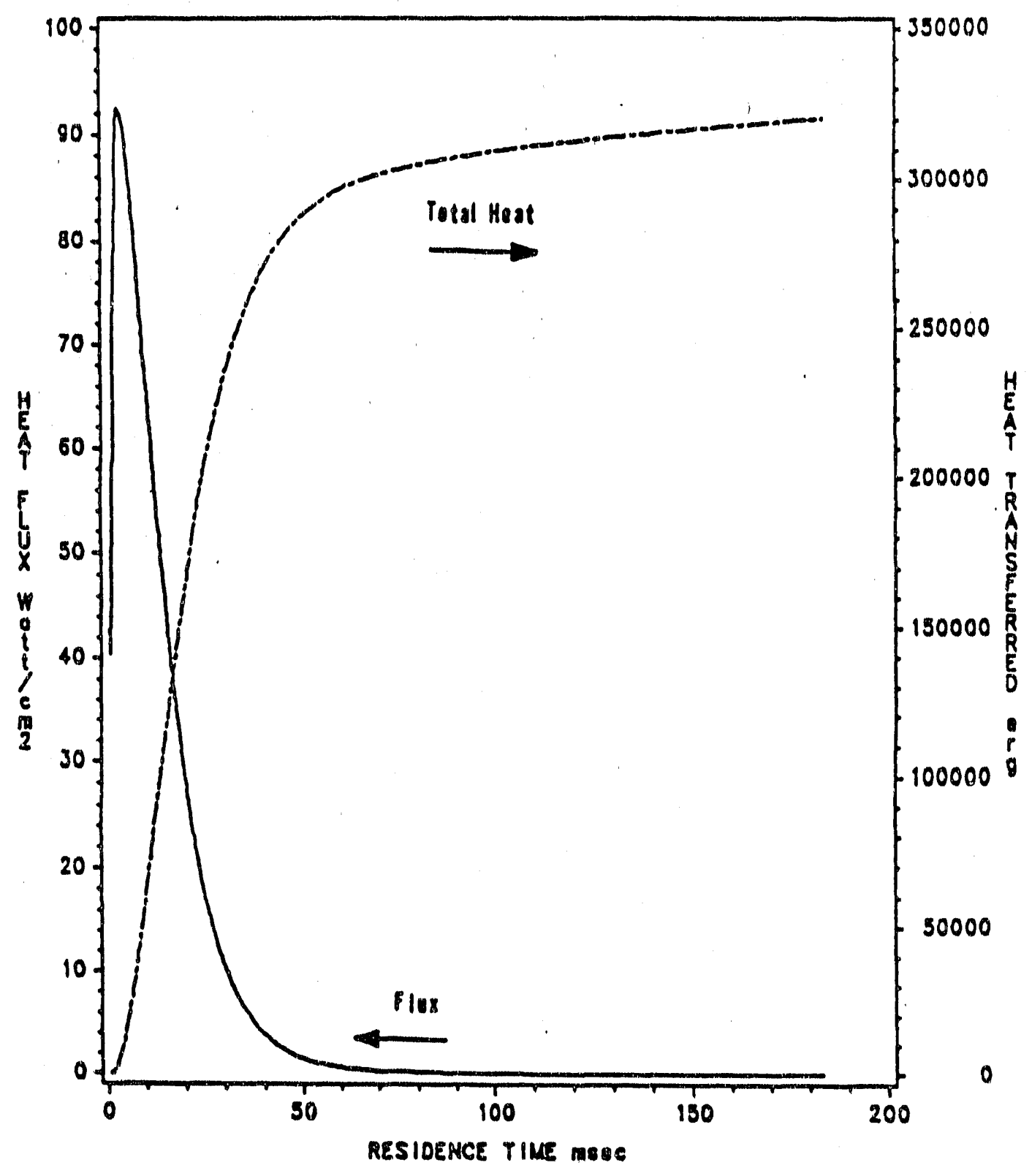

Heat Flux and Total Heat Transferred for $69 \mu \mathrm{m}$ Coal Particles in a Nitrogen Atmosphere as a Function of Residence Time with a Reactor Temperature of $1073 \mathrm{~K}$ 
Figure 2.15

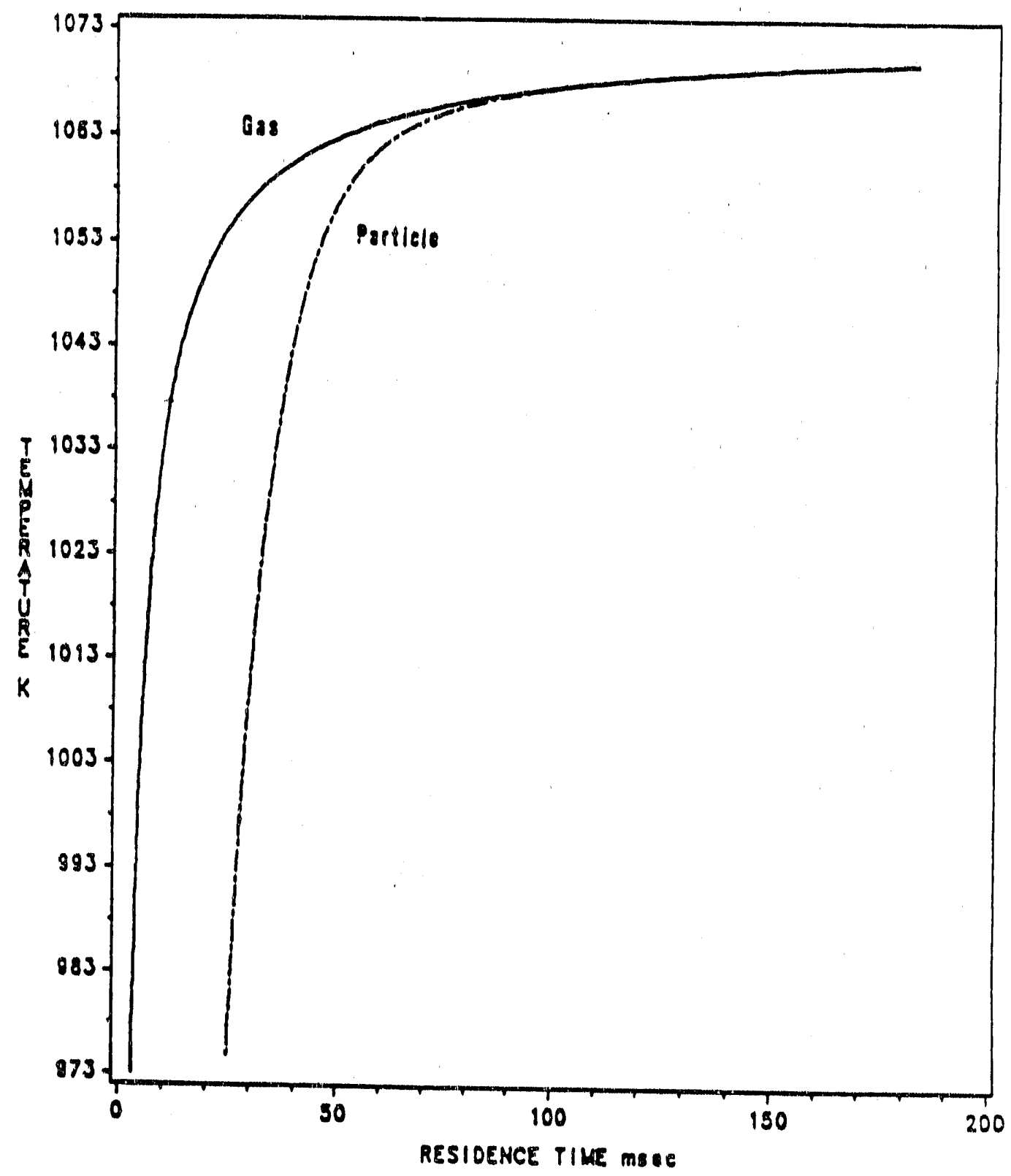

Gas and Average Particle Temperature for $69 \mu \mathrm{m}$ Coal 
came in throe different size fractions (125-106,106-75 and 75-63 microns), and arrived in $200 \mathrm{~g}$ batches sealed in Jars. In order to differentiate between the samples obtained from Penn State's Coal Sample Bank and those prepared by the Vortec Co., the latter will be designated PSOC-1520D and PSOC-14335 heretofore.

\section{TABLE 2.3 - ANALYSES OF COAL SAMPLES FROM PENN STATE COAL DATA} BASE

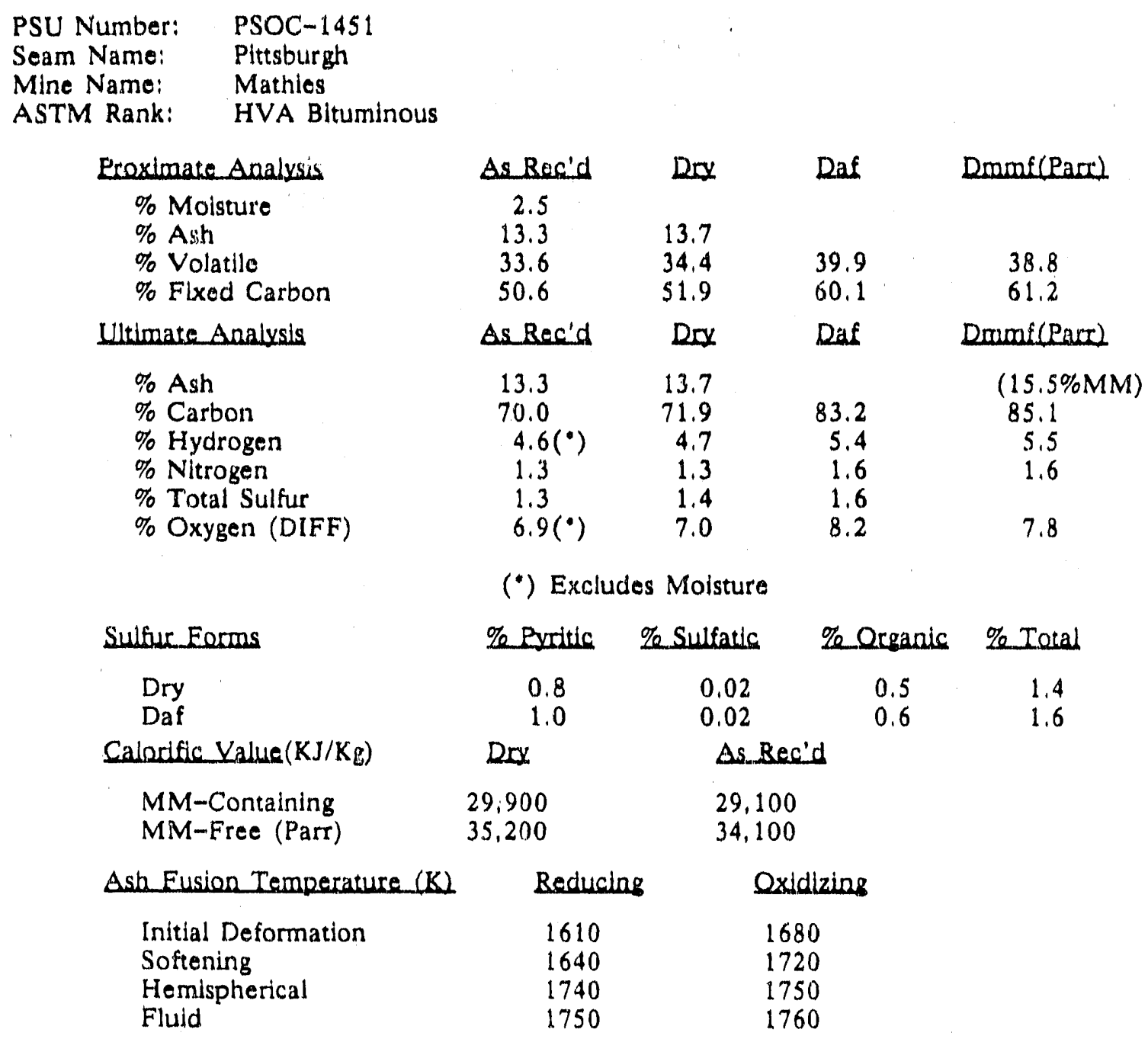




\section{TABLE 2.4 - ANALXSES OF COAL SAMPLES FROM PENN STATE COAL DATA} BASE

\begin{tabular}{|c|c|c|c|c|c|}
\hline $\begin{array}{l}\text { PSU Number: } \\
\text { Seam Name: } \\
\text { MIne Name: } \\
\text { ASTM Rank: }\end{array}$ & $\begin{array}{l}\text { PSOC- } 1520 \\
\text { Smith-Roland } \\
\text { Wyodak } \\
\text { Subbituminous C }\end{array}$ & & & & \\
\hline \multicolumn{2}{|c|}{ Broximate Analysis } & As Rec'd & Dry & Daf & Dmmf(Parr) \\
\hline \multicolumn{2}{|c|}{$\begin{array}{l}\% \text { Moisture } \\
\% \text { Ash } \\
\% \text { Volatile } \\
\% \text { Fixed Carbon }\end{array}$} & $\begin{array}{r}26.29 \\
9.08 \\
40.13 \\
24.10\end{array}$ & $\begin{array}{l}12.38 \\
54.74 \\
32.88\end{array}$ & $\begin{array}{l}62.47 \\
37.53\end{array}$ & $\begin{array}{l}61.96 \\
38.04\end{array}$ \\
\hline \multicolumn{2}{|c|}{ Ultimate_Analysis } & As_Recidd & Dry & Daf & Dmonf(Parr) \\
\hline \multicolumn{2}{|c|}{$\begin{array}{l}\% \text { Ash } \\
\% \text { Carbon } \\
\% \text { Hydrogen } \\
\% \text { Nitrogen } \\
\% \text { Total Sulfur } \\
\% \text { Oxygen (DIFF) }\end{array}$} & $\begin{array}{c}9.08 \\
47.39 \\
1.78\left(^{\circ}\right) \\
0.71 \\
0.89 \\
13.46\left(^{\circ}\right)\end{array}$ & $\begin{array}{l}12.38 \\
64.6 \\
2.43 \\
0.97 \\
1.21 \\
18.36\end{array}$ & $\begin{array}{r}73.78 \\
2.77 \\
1.11 \\
1.38 \\
20.95\end{array}$ & $\begin{array}{c}(14.04 \% \mathrm{MM}) \\
75.21 \\
2.83 \\
1.13 \\
20.84\end{array}$ \\
\hline \multicolumn{6}{|c|}{ (“) Excludes Moisture } \\
\hline \multicolumn{2}{|c|}{ Sulfur Forons } & \% Byritic & \% Sulfatic & \%e Organile & \%e Total \\
\hline \multicolumn{2}{|c|}{$\begin{array}{l}\text { Dry } \\
\text { Daf }\end{array}$} & $\begin{array}{l}0.05 \\
0.06\end{array}$ & $\begin{array}{l}0.01 \\
0.01\end{array}$ & $\begin{array}{l}1.15 \\
1.31\end{array}$ & $\begin{array}{l}1.21 \\
1.38\end{array}$ \\
\hline \multicolumn{2}{|c|}{ Calodific Value $(\mathrm{KJ} / \mathrm{Kg})$} & Dry & \multicolumn{2}{|c|}{ As_Rec'd } & \\
\hline \multicolumn{2}{|c|}{$\begin{array}{l}\text { MM-Containing } \\
\text { MM-Free (Parr) }\end{array}$} & $\begin{array}{l}26,239 \\
30,360\end{array}$ & \multicolumn{2}{|c|}{$\begin{array}{l}19,235 \\
21,327\end{array}$} & \\
\hline \multicolumn{2}{|c|}{ Ais Fusion Temperature (K) } & Reduc & \multicolumn{2}{|c|}{ Oxidizing } & \\
\hline \multicolumn{2}{|c|}{$\begin{array}{l}\text { Initial Deformation } \\
\text { Softoning } \\
\text { Hemispherical } \\
\text { Fluid }\end{array}$} & $\begin{array}{l}1466 \\
1489 \\
1508 \\
1544\end{array}$ & \multicolumn{2}{|c|}{$\begin{array}{l}1527 \\
1555 \\
1586 \\
1622\end{array}$} & \\
\hline
\end{tabular}


TABLE 2.5 - ANALYSES OF COAL SAMPLES FROM PENN STATE COAL DATA BASE

\begin{tabular}{|c|c|c|c|c|c|}
\hline $\begin{array}{l}\text { PSU Number: } \\
\text { Seam Name: } \\
\text { Mine Name: } \\
\text { ASTM Rank: }\end{array}$ & $\begin{array}{l}\text { PSOC-1 } 443 \\
\text { Lower Wilcox } \\
\text { Monticello } \\
\text { Lignite }\end{array}$ & & & & \\
\hline \multicolumn{2}{|c|}{ Broximace Analysis } & As_Roc'd & Dev & Daf & Dramf(Parr) \\
\hline \multicolumn{2}{|c|}{$\begin{array}{l}\% \text { Moisture } \\
\% \text { Ash } \\
\% \text { Volatile } \\
\% \text { Fixed Carbon }\end{array}$} & $\begin{array}{l}28.5 \\
15.3 \\
44.2 \\
12.0\end{array}$ & $\begin{array}{l}21.4 \\
61.8 \\
16.8\end{array}$ & $\begin{array}{l}78.7 \\
21.3\end{array}$ & $\begin{array}{l}78.2 \\
21.8\end{array}$ \\
\hline \multicolumn{2}{|c|}{ Uلtevate Analusis } & As_Res'd & Dry & Daf & Drmanf(Pare) \\
\hline \multicolumn{2}{|c|}{$\begin{array}{l}\% \text { Ash } \\
\% \text { Carbon } \\
\% \text { Hydrogen } \\
\% \text { Nitrogen } \\
\% \text { Total Sulfur } \\
\% \text { Oxygen (DIFF) }\end{array}$} & $\begin{array}{l}15.3 \\
40.6 \\
2.9\left({ }^{\circ}\right) \\
0.8 \\
0.5 \\
11.3\left({ }^{\circ}\right)\end{array}$ & $\begin{array}{r}21.4 \\
56.8 \\
4.1 \\
1.1 \\
0.7 \\
15.9\end{array}$ & $\begin{array}{r}72.3 \\
5.2 \\
1.4 \\
0.9 \\
20.2\end{array}$ & $\begin{array}{l}(23.6 \% \mathrm{MM}) \\
74.3 \\
5.4 \\
1.4 \\
18.9\end{array}$ \\
\hline \multicolumn{6}{|c|}{ (*) Excludes Moisture } \\
\hline \multicolumn{2}{|c|}{ Sulfur Eorros } & \%e Purdela & \%e Sulfatic & te Organic & $\%$ Total \\
\hline \multicolumn{2}{|c|}{$\begin{array}{l}\text { Dry } \\
\text { Daf }\end{array}$} & $\begin{array}{l}0.1 \\
0.1\end{array}$ & $\begin{array}{l}0.01 \\
0.01\end{array}$ & $\begin{array}{l}0.6 \\
0.8\end{array}$ & $\begin{array}{l}0.7 \\
0.9\end{array}$ \\
\hline \multicolumn{2}{|c|}{ Calorifle Value (KJ/Kg) } & $D r y$ & \multicolumn{2}{|c|}{ As_Rec'd } & \\
\hline \multicolumn{2}{|c|}{$\begin{array}{l}\text { MM-Containing } \\
\text { MM-Free (Parr) }\end{array}$} & $\begin{array}{l}23,000 \\
30,000\end{array}$ & \multicolumn{2}{|c|}{$\begin{array}{l}16,400 \\
19,700\end{array}$} & \\
\hline \multicolumn{2}{|c|}{ Ash Eusion Temperature (K) } & Beduc & \multicolumn{2}{|c|}{ Oxidizios } & \\
\hline \multicolumn{2}{|c|}{$\begin{array}{l}\text { Initial Deformation } \\
\text { Softening } \\
\text { Hemispherical } \\
\text { Fluid }\end{array}$} & $\begin{array}{l}1540 \\
1570 \\
1640 \\
1670\end{array}$ & \multicolumn{2}{|c|}{$\begin{array}{l}1550 \\
1670 \\
1690 \\
1720\end{array}$} & \\
\hline
\end{tabular}

\section{Sample Preparation}

An attempt was made to process the llgnite in the "as-received" condition, but the openings in the screen sleves immediately became plugged with coal clue to its high moisture content. In order to reduce the lignite's natural agglomerating behavior and render the coal slevable, PSOC-1443 was first dried for 1 hour under nitrogen at $105^{\circ} \mathrm{C}$. The three coals were thus ground (The Straub Co. model $4 \mathrm{E}$ ) and dry sleved twice with a sleve vibrator (Fritsch Analysette). The three narrow size fractions, $120 \times 140,170 \times 200$, and 200×.230 mesh corresponding to $125 \times 105,88 \times 74$ and $74 \times 63 \mu \mathrm{m}$ respectively, were stored in small plastic containers. To minimize low temperature oxidation of the samples, the jars were filled to the top and closed; the coals 
were used within one month after grinding. The samples provided by the Vortec Products Co., on the other hand, were used as recelved.

Portions of each size fraction of all coals were subjected to proximate analysis using Leco MAC-400 Proximate Analysis Determinator. Each sample size loaded in the proximate analyzer was $0.5 \mathrm{~g}$. The MAC-400 is an automated instrument that analyzes for molsture, volatlle matter, ash, and calculates flxed carbon by difference. Samples are placed in ceramic cruclbles which are sltuated on a rotating platform Inside the oven chamber of the MAC-400. A cruclble is weighed on every rotation and cumpared with the prevlous weighing to determine the weight loss for each segment of the analysis. The temperatures and hold times are similar to the ASTM's methods (Ref. 2,14). Oven temperatures for the MAC-400 were molsture temperature, $106^{\circ} \mathrm{C}$; volatile matter temperature, $950^{\circ} \mathrm{C}$; and ash temperature, $750^{\circ} \mathrm{C}$. The results of proximate analyses performed on all coals are shown in Table 2.6.

In an earlier portion of this study, three duplicate samples of the bituminous coal PSOC -1451 and six duplicate samples of the lignite PSOC-1 1443 were run. These results were complemented by monitoring the changes in proximate analysis data on samples of PSOC-1451D, PSOC-1520 D, and PSOC-1443D coals during a period of six to eight months. In all cases the changes were minimal, and amounted to less than $1 \%$ increase and decrease in daf ash content and volatile matter yield, respectively, with the daf \% ftxed carbon remaining essentially unchanged.

The ash content on a dry basis is a function of particle size for the bituminous coal PSOC-1451. The largest particles used, $120 \times 140$ mesh $(115 \mu \mathrm{m})$, showed an ash content on a dry basis of $12.0 \%$. An even larger size, which was not used in this study, contained $19.3 \%$ ash on a dry basis. The smallest size fraction contained $10.0 \%$ ash. This same decrease in ash content with decreasing particle size for PSOC-1451 is reported by UTRC (Appendix D). The subbituminous coal and the lignite showed no particle size dependency on the amount of ash which was present. Neither coal displayed a particle size influence on the amount of volatile matter determined by ASTM methods. 
TABLE 2.6 - PROXIMATE ANALYSES OF COAL SAMPLES BY PARTICLE SIZE

Ceal: PSOC-145\%, HVA Bituminous $120 \times 140$ Mesh (115 micron):

$\%$ Molsture
$\%$ Volatllo Matter
$\%$ Ash
$\%$ Fixed Carbon

$170 \times 200$ Mesh (81 mlcron):

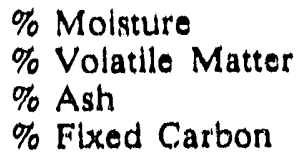

$200 \times 230$ Mesh (69 micron):

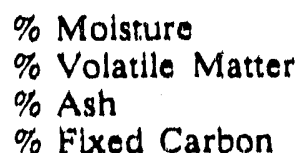

Coal: PSOC-1520, Subbituminous C $120 \times 140 \mathrm{~N}$ esh (115 micron):

$$
\begin{aligned}
& \text { \% Moisture } \\
& \% \text { Volatile Matter } \\
& \% \text { Ash } \\
& \% \text { Fixed Carbon }
\end{aligned}
$$

$170 \times 200$ Mesh (81 micron):

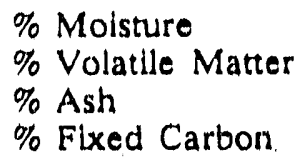

$200 \times 230$ Mesh (69 micron):

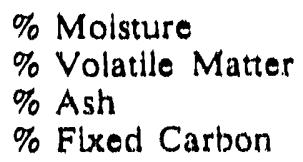

$\begin{array}{ccc}\text { As Rec'd } & \text { dry } & \text { daf } \\ 1.7 & & \\ 30.1 & 30.6 & 34.9 \\ 11.8 & 12.0 & \\ 56.4 & 57.4 & 65.1 \\ \text { As Rec'd } & \text { dry } & \text { daf } \\ 1.6 & & \\ 30.4 & 30.9 & 34.5 \\ 10.3 & 10.5 & \\ 57.7 & 58.6 & 65.5 \\ \text { As Rec'd } & \text { dry } & \text { daf } \\ 1.7 & & \\ 30.7 & 31.2 & 34.7 \\ 9.8 & 10.0 & \\ 57.8 & 58.8 & 65.3\end{array}$

$\begin{array}{ccc}\text { As Rec'd } & \text { dry } & \text { daf } \\ 23.4 & & \\ 36.1 & 47.1 & 52.8 \\ 8.3 & 10.8 & \\ 32.2 & 42.1 & 47.2 \\ \text { As Rec'd } & \text { dry } & \text { daf } \\ 24.6 & & \\ 36.0 & 47.7 & 53.2 \\ 7.8 & 10.3 & \\ 31.6 & 41.9 & 46.8 \\ \text { As Rec'd } & \text { dry } & \text { daf } \\ 21.9 & & \\ 36.9 & 47.2 & 53.1 \\ 8.7 & 11.1 & \\ 32.5 & 41.6 & 46.9\end{array}$


TABLE 2.6 (CONT'D) - PROXIMATE ANALYSES OF COAL SAMPLES BY PARTICLE SIZE

Coal: PSOC-1520D, Subbituminous $C$ $125 \times 106$ microns:

$\begin{array}{ccc}\text { As Rec'd } & \text { dry } & \text { daf } \\ 21.6 & & \\ 36.6 & 46.7 & 52.6 \\ 8.8 & 11.2 & \\ 33.0 & 42.1 & 47.4 \\ \text { As Rec'd } & \text { dry } & \text { daf } \\ 21.0 & & \\ 37.4 & 47.3 & 53.8 \\ 9.5 & 12.0 & \\ 32.1 & 40.7 & 46.2 \\ \text { As Rec'd } & \text { dry } & \text { daf } \\ 20.8 & & \\ 37.1 & 46.8 & 53.3 \\ 9.7 & 12.2 & \\ 32.6 & 41.0 & 46.7\end{array}$

Coal: PSOC-1443, Lignite A

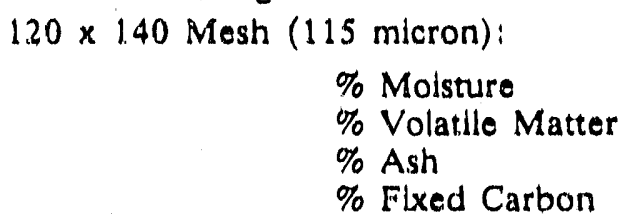

- After drying for $1 / 2$ hour in nitrogen at $105^{\circ} \mathrm{C}$ 


\section{TABLE 2.6 (CONT'D.) - PROXIMATE ANALYSES OF COAL SAMPLES BY PARTICLE SIZE}

Coal: PSOC-1443D, Lignite A $125 \times 105$ microns:

\% Moisture
$\%$ Volatile Matter
$\%$ Ash
$\%$ Fixed Carbon

$105 \times 75$ microns:

$$
\begin{aligned}
& \% \text { Moisture } \\
& \% \text { Volatile Matter } \\
& \% \text { Ash } \\
& \% \text { Fixed Carbon }
\end{aligned}
$$

$75 \times 63$ microns:

\begin{tabular}{ccc} 
As Rec'd & ury & \multicolumn{1}{c}{ daf } \\
22.3 & & \\
35.7 & 45.9 & 58.8 \\
17.0 & 21.9 & \\
25.0 & 32.2 & 41.2 \\
As Rec'd & dry & daf \\
18.3 & & \\
38.2 & 45.7 & 55.4 \\
14.2 & 17.4 & \\
29.3 & 36.8 & 44.6 \\
As Rec'd & dry & daf \\
16.2 & & \\
38.5 & 46.3 & 55.5 \\
13.8 & 16.6 & \\
30.8 & 37.1 & 44.5
\end{tabular}

\section{Analysis of Coal Samples}

The proximate analyses from the Sample Bank (Tables 2.3 through 2.5) were found to be somewhat different from the results obtained in this study (Table 2.6). On a dry hasis. PSOC-1451 was found to contain $10.8 \%$ ash and $30.9 \%$ volatile matter on average by our analysis, compared to $13.7 \%$ ash and $34.4 \%$ volatile matter fro $\mathrm{n}$ the Sample Bank, which tested -60 mesh $(250 \mathrm{\mu m})$ samples. In a recent study, Niksa et. al. (Ref. 2.15) also performed an independent proximate analysis on a bituminous coal from the Penn State Sample Bank and found the volatile matter content to be several percent lower than the value provided by the Sample Bank. Similarly, for the subbituminous coal, the average values of ash and volatile matter, $10.7 \%$ and $47.3 \%$, respectively, were smaller than the amounts given by the Sample Bank $(12.38 \%$ and $54.74 \%$, respectively). Likewise, the analyses for the lignite yielded ash and volatile matter contents below those reperted by the Sample Bank. We tound, on a dry basis, ti,e lignite contained $17.4 \%$ ash and $45.3 \%$ volatile matter The Sample Bank reports the ash content and volatile tis tter to be $21.4 \%$ and $61.8 \%$ respectively.

Tabl: 2.0 shows a proximate analysis of exch fraction run in the EFR. It is interesting to note the decrease of ash content with decreasing pa: : at for the bituminous coal. It can be hypothesized that the mineral noster becomes separated from the . . ing the extensive grinding and sieving process. Since this effect is not observed with the subbituminous coal or with the lignite, it follows that a significant fraction of 
the ash in the bituminous coal is physically trapped in relatively large deposits, and that the majority of ash in the other two coals is chemically bound, and uniformly dispersed throughout them. Of course, it is well known that a substantial part of the inorganic species in a ligs. 4 . . is directly associated with the carboxylic acids. Thus these species presumably cannot be liberated by grinding, and this argument car. also be extended to subbituminous coals, where a significant fraction of inorganic species are still likely to be bound to carboxyl groups.

It is also evident from Table 2.6 that there is good agreement between the proximate analyses from PSOC-XXXX and PSOC-XXXXD coals (XXXX $=1520$ or 1443). Therefore, the different grinding conditions do not appear to influence the data significantly. In addition, Figs. 2.16 through 2.18 show no significant variation in particle size distributions for the three PSOC-1520 and PSOC-1520D coal size fractions considered.

\section{Pyrolysis Results}

Some gaseous atmosphere combinations contain air, and hence cannot be truly called pyrolysis conditions. However, for completeness, these results will be presented and discussed in this section along with the runs in which no oxygen was present. Since many of the plots displayed in this section contain information pertinent to more than one subsection, comments about certain aspects of the data will be addressed after the table or figure in which it first appears. All weight loss data in Figs. 2.19 through 2.31 are on a dry, ash-free basis and a complete listing of the data appears in tabular form in Appendix A.1.

Effect of Particle Sizen Aside from the effect that smaller particles have longer residence times at a given probe position (Fig. 2.10), they also heat faster than the larger ones (Fig. 2.13). Along with a higher temperature comes a faster decomposition reaction and a greater weight loss.

Two examples of the effect of particle size on weight loss in pure nitrogen atmosphere are included. Figure 2.19 is for the bituminous coal PSOC-1451, and Fig. 2.20 is for the lignite PSOC-1443. As might be expected from the temperatures predicted in the Compute: Model Section, the weight losses are correlated according to the statement that the smaller the particle size, the greater the weight loss. For both coals, there is a more dramatic effect in the degree of pyrolysis between the $69 \mu \mathrm{m}$ size and $81 \mu \mathrm{m}$ size than between the $81 \mu \mathrm{m}$ particles and the $115 \mu \mathrm{m}$ particles. In most cases, the two larger sizes differ by only $1-3 \%$ and the smaller $69 \mu \mathrm{m}$ size displuys $10 \%$ higher value than the larger paricles. 
Figure 2.16

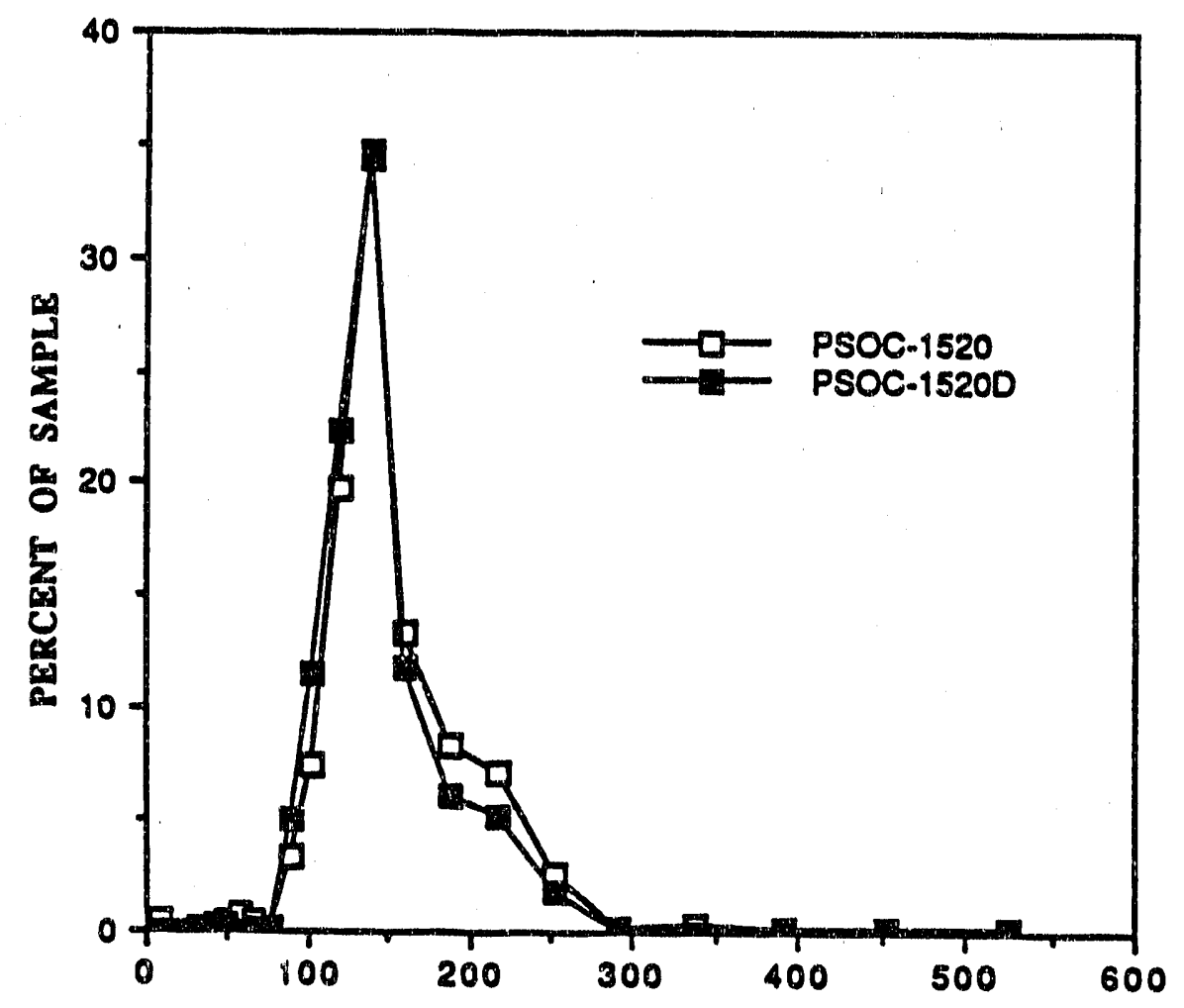

PARTICLE STZE, microns

Particle Size Distributions of Raw Coals PSOC.1520 Fraction 120x140 Mesh and PSOC-1520D Fraction 125.106 Microns 
Figure 2.17

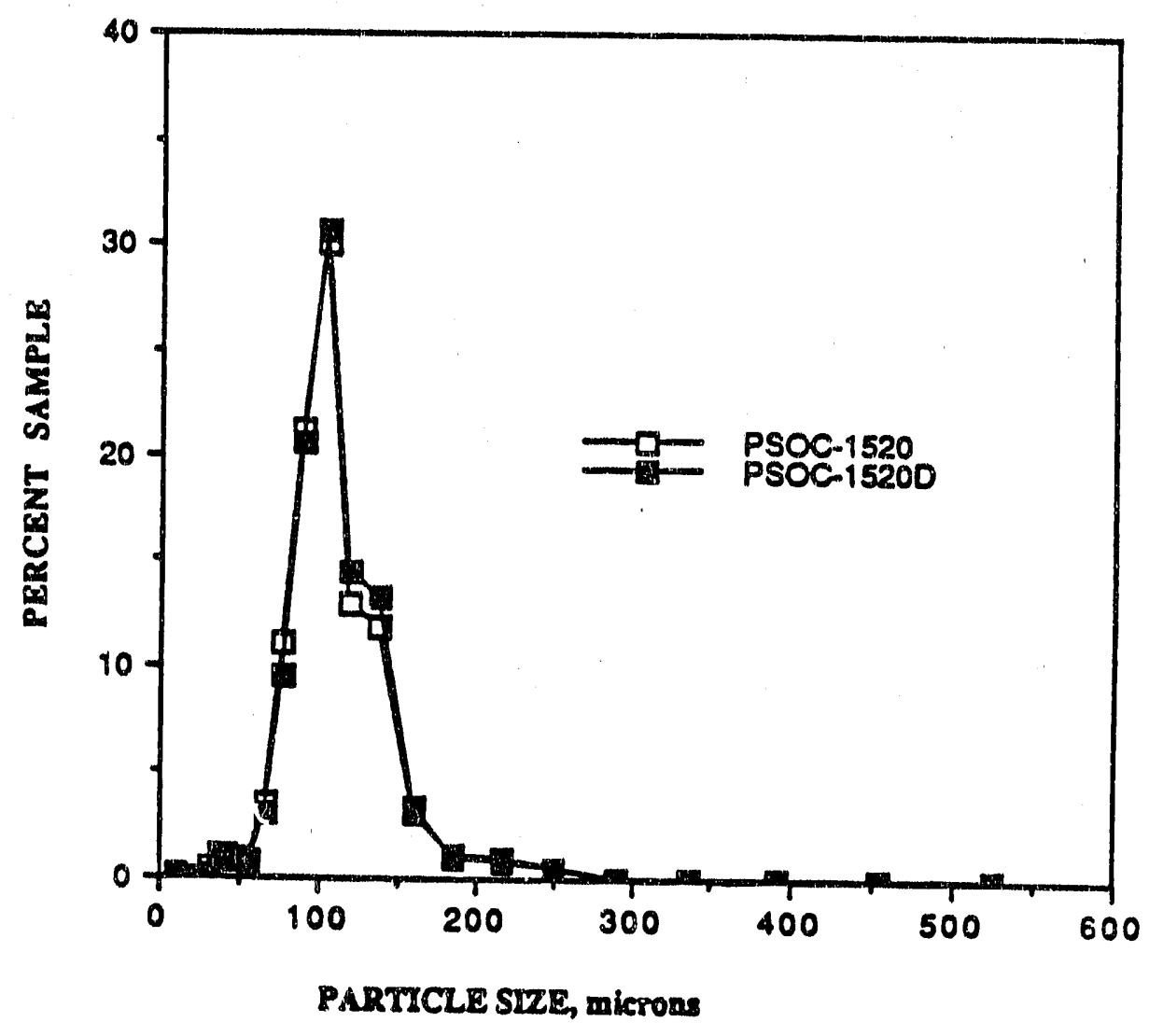

Particle Size Distributions of Raw Coals PSOC-1520 Fraction $170 \times 200$ Mesh and PSOC-1520D Fraction 106.75 Microns 
R88-PC70768

Figure 2.18

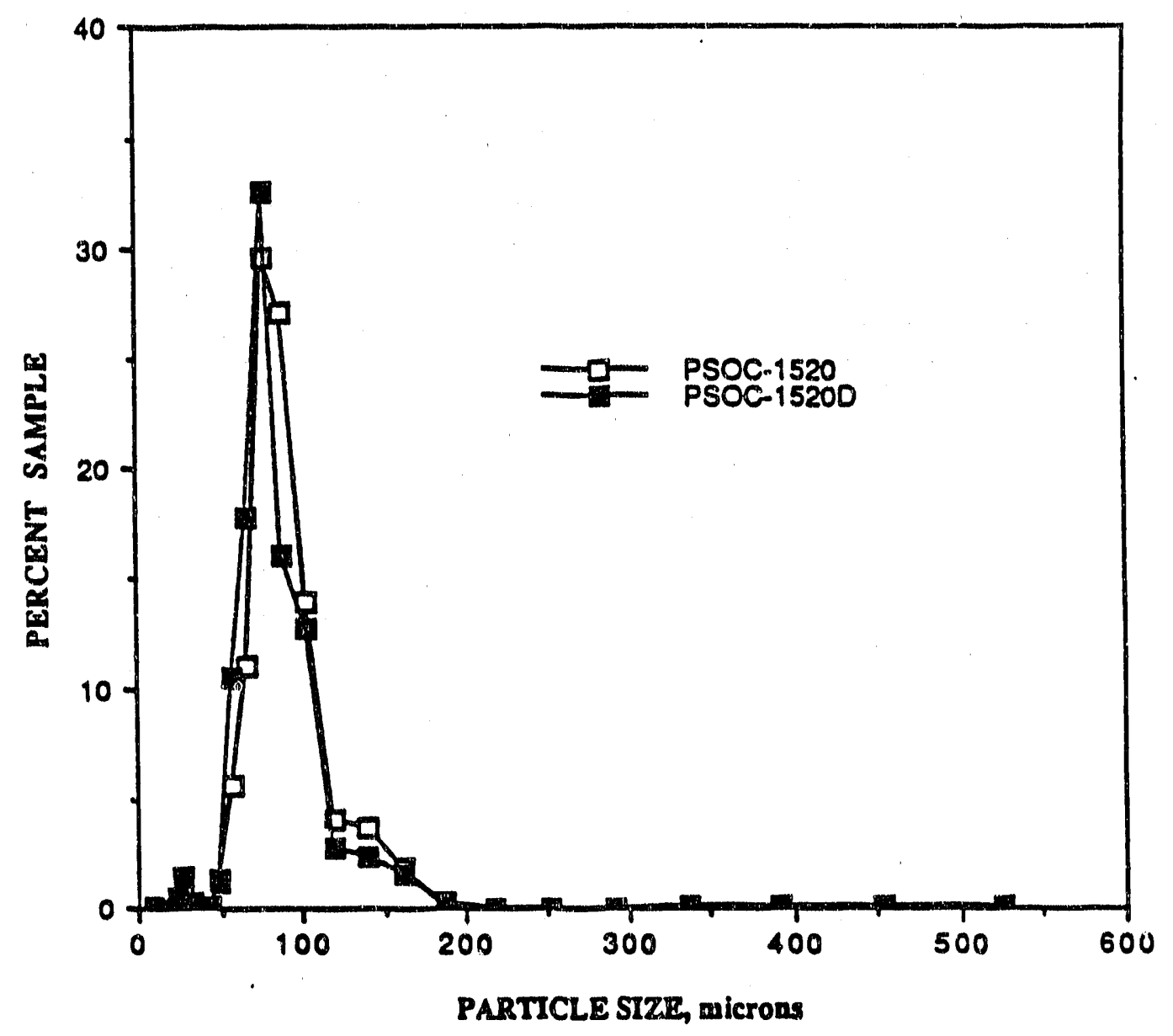

Particle Size Distributions of Raw Coals PSOC-1520 Fraction $200 \times 230$ Mesh and PSOC.1520D Fraction 75.63 Microns 
Figure 2.19

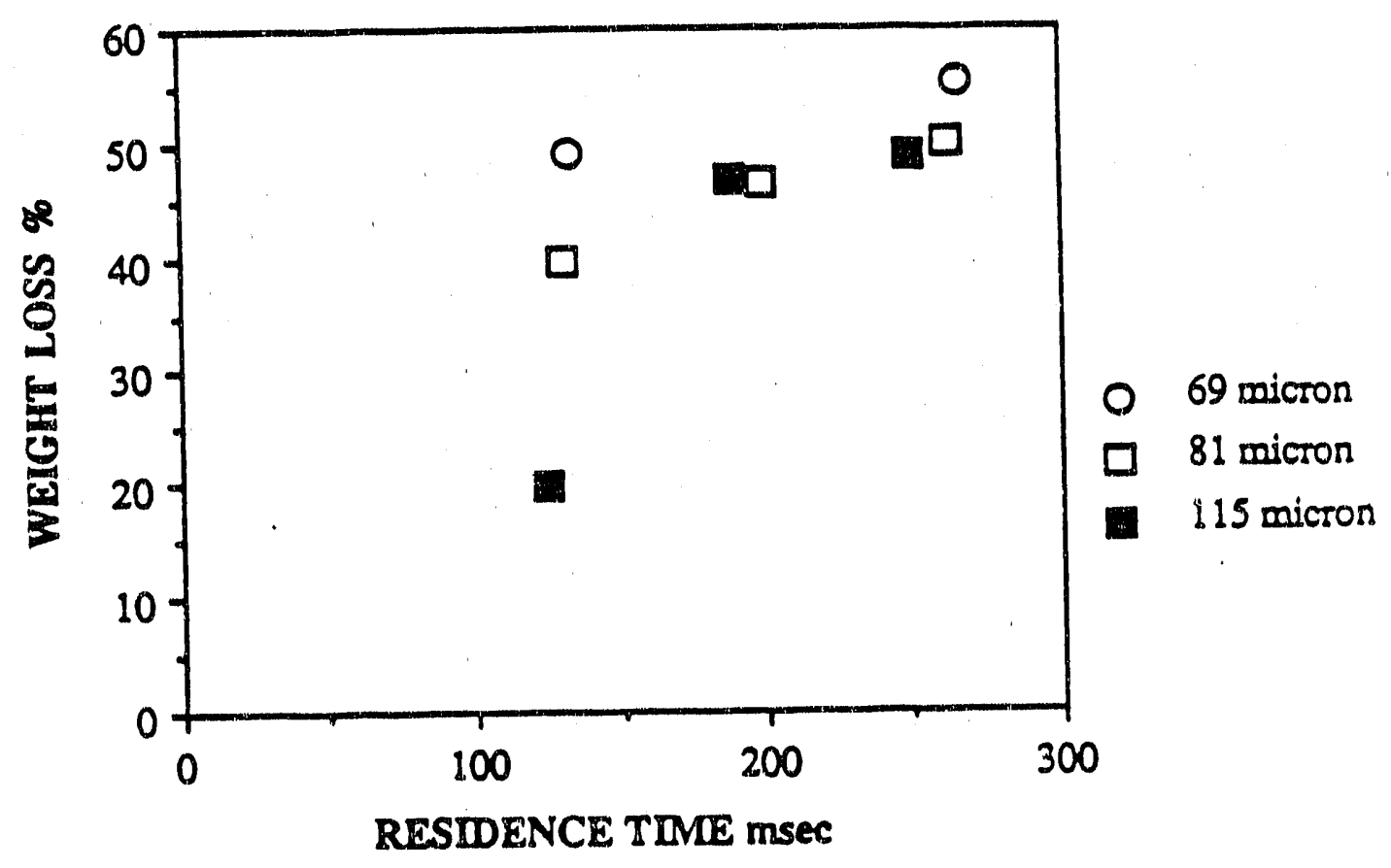

Effect of Particle Size on Weight Loss for PSOC-1451 (bit.) at $1073 \mathrm{~K}$ in a $\mathrm{N}_{2} / \mathrm{N}_{2}$ Atmosphere 
Figure 2.20

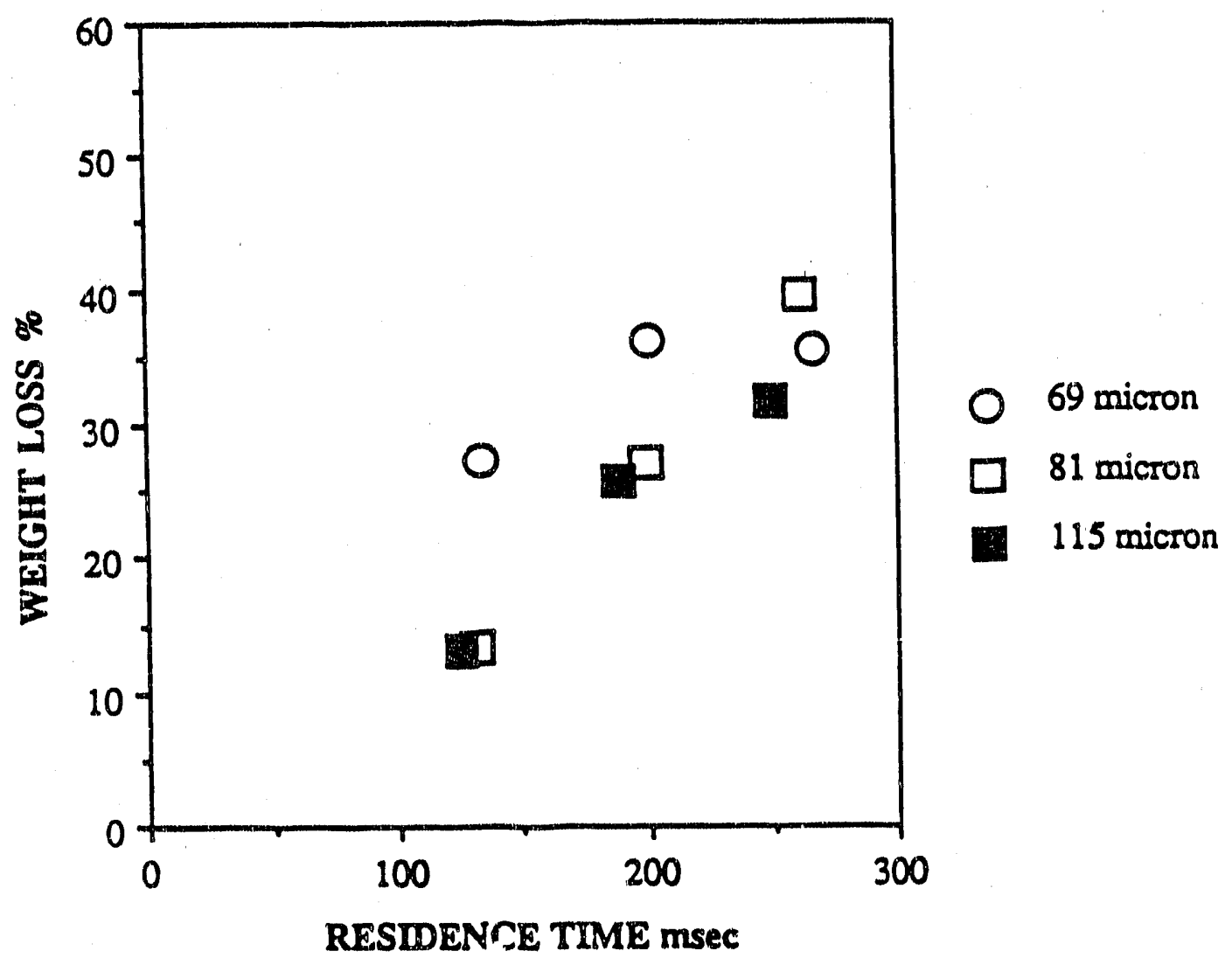

Effecf of Particle Size on Weight Loss for PSOC-1443 (lig.) at $1073 \mathrm{~K}$ in $\& \mathrm{~N}_{2} / \mathrm{N}_{2}$ Atmosphere 
Figure 2.21

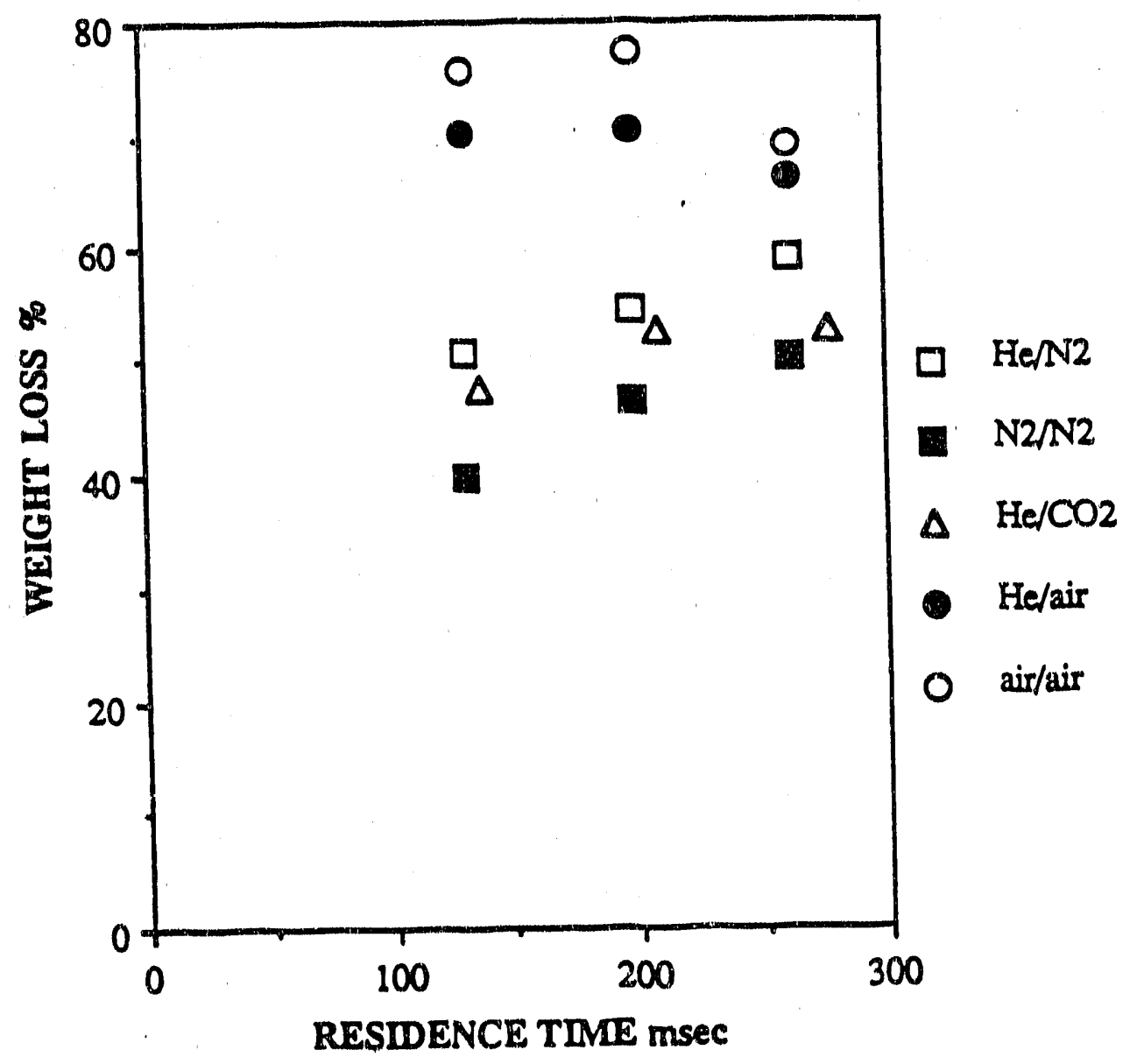

Effect of Reactor Atmosphere on Weight Loss for $170 \times 200$ Mesh Particles of I'SOC-1451 (Bit.) at $1073 \mathrm{~K}$ 
Figure 2.22

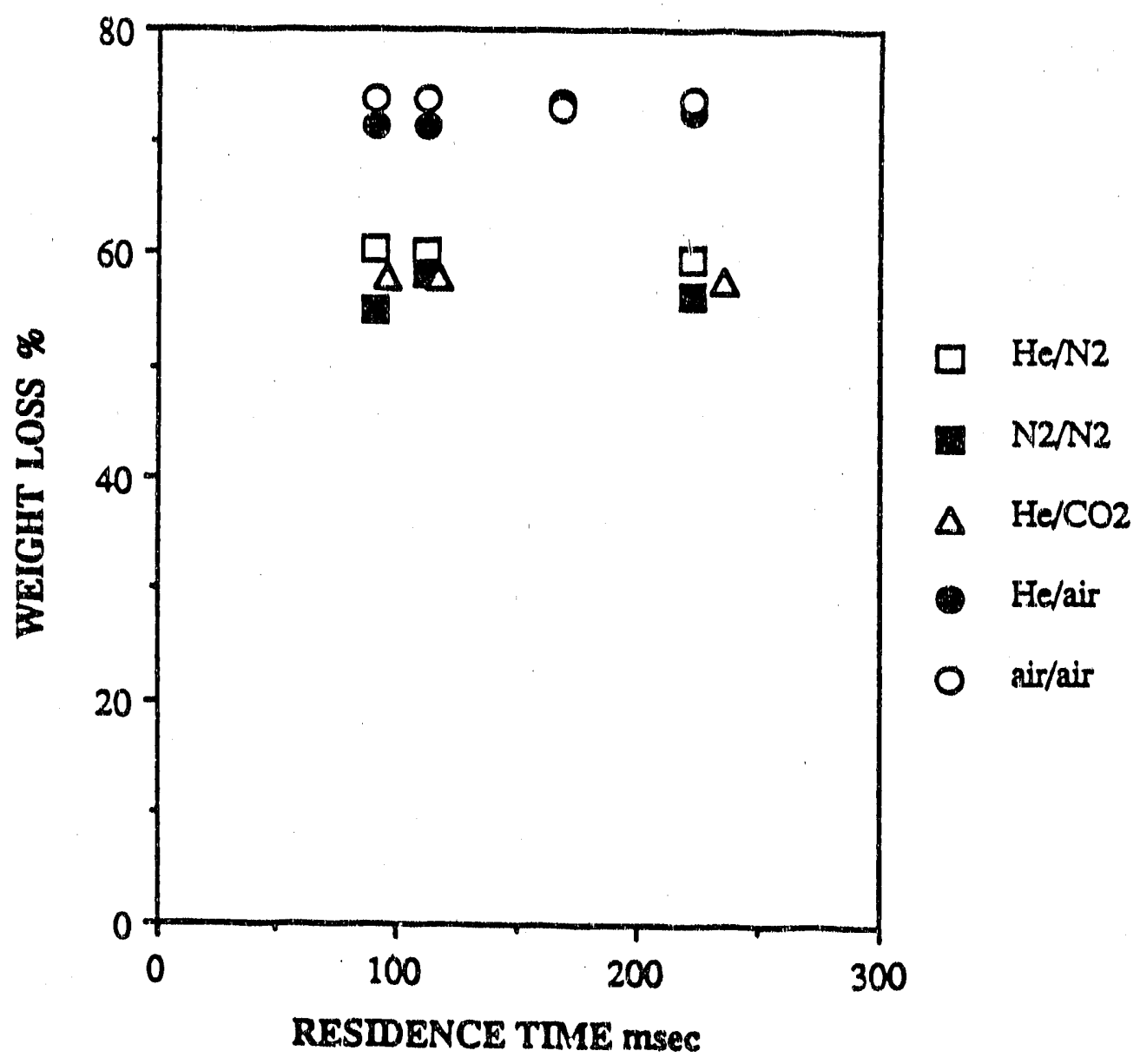

Effect of Reactor Atmosphere on Weight Loss for $170 \times 200$ Mesh Particles of PSOC.1451 (bit. hVA) at $1273 \mathrm{~K}$ 
Figure 2.23

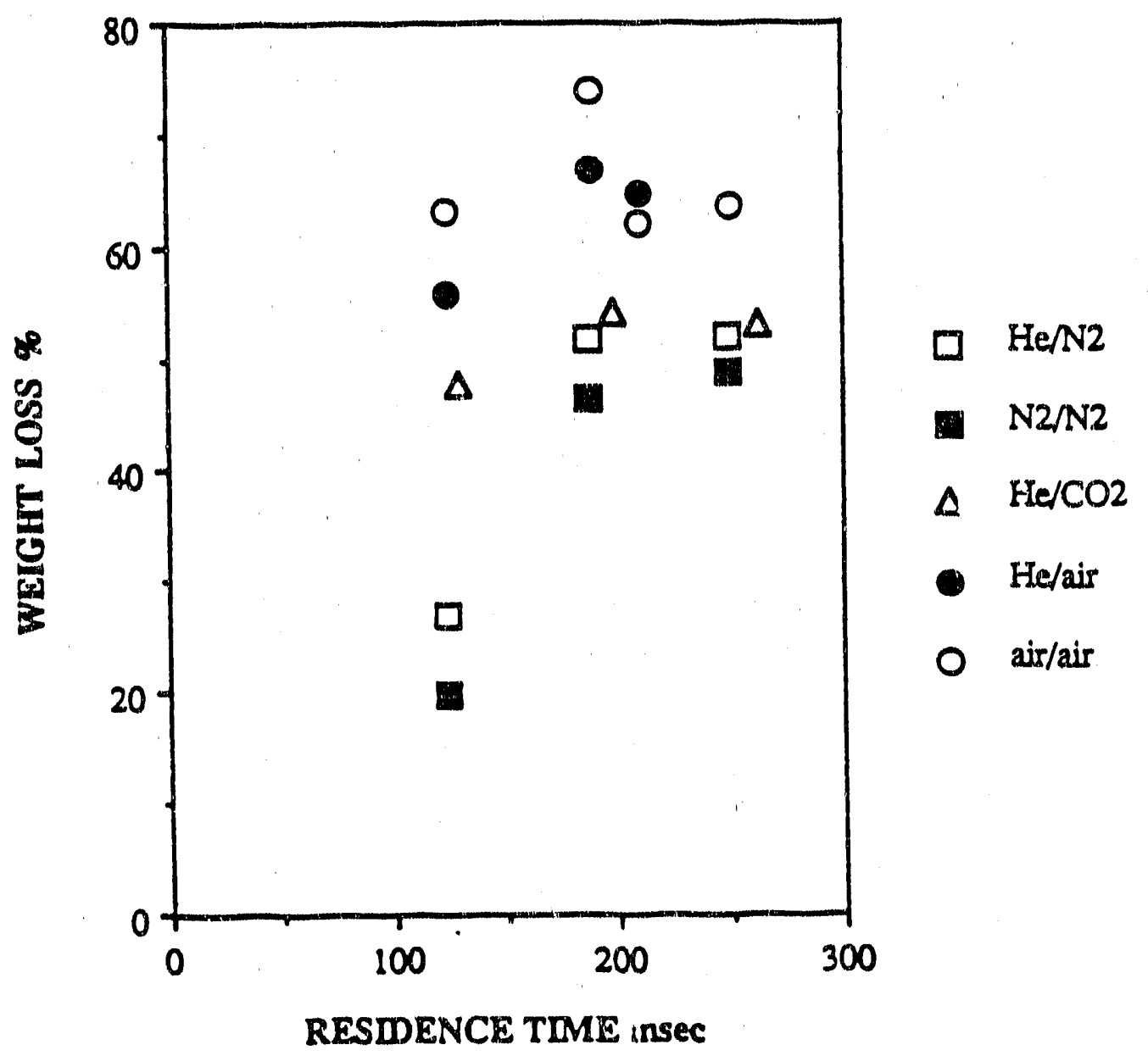

Erfect of Reactor Atmosphere on Weight Loss for $120 \times 140$ Mesh Particles of PSOC-1451 (tit. hvA) at $1073 \mathrm{~K}$ 
Figure 2.24

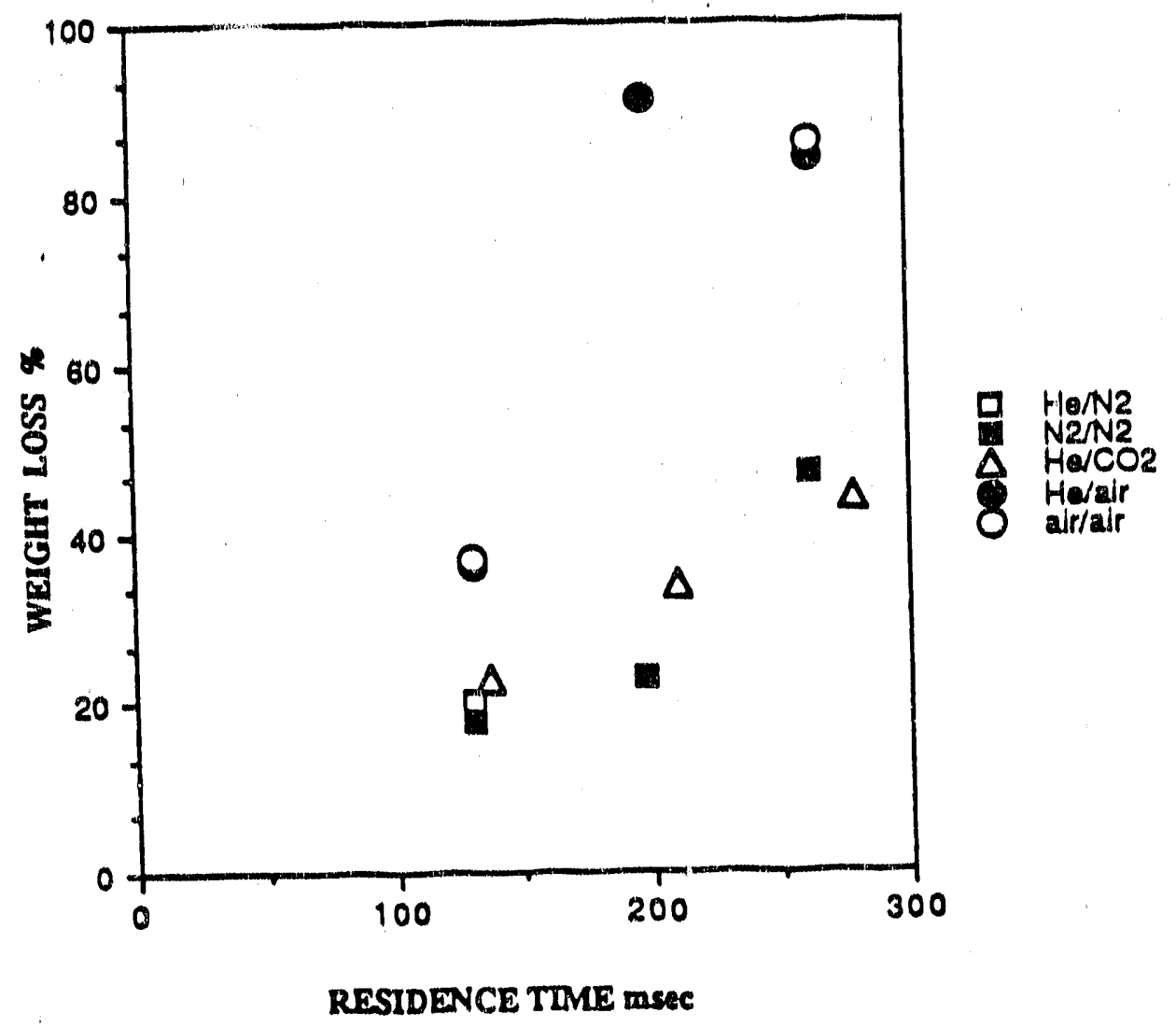

Effect of Reactor Atmosphere on Weight Loss for $170 \times 200$ Mesh Particles of PSOC.1520 (Subtit.) at $1073 \mathrm{~K}$ 
Figure 2.25

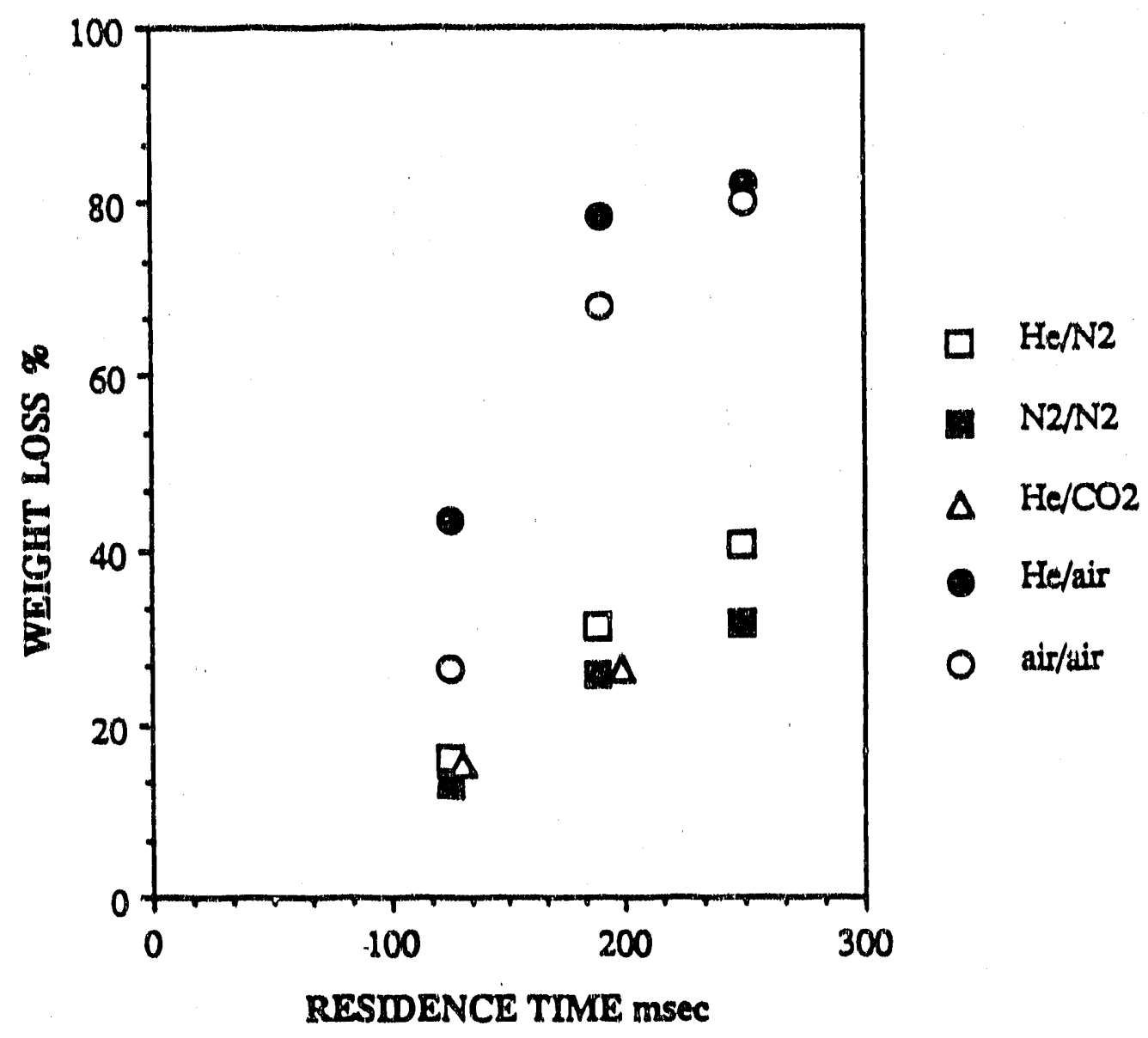

Effect of Resctor Atmosphere on Weight Loss for 170x2,00 Mesh Particles of PSOC.1443 (lignite A) at $1073 \mathrm{~K}$ 
Figure 2.26

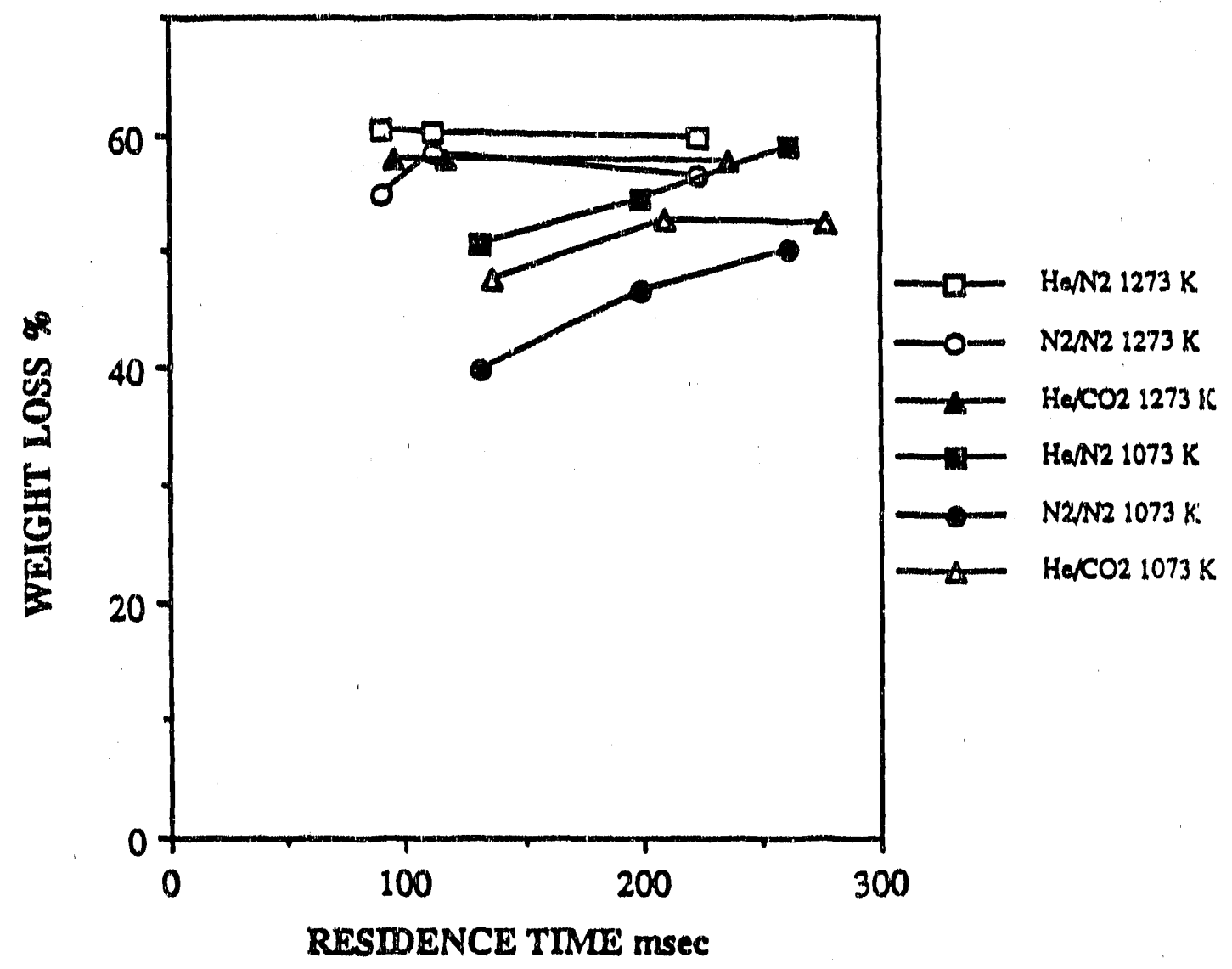

Effect of Temperature on Weight Loss for $170 \times 200$ Mesh Particles of PSOC-1451 (Bit) 
Figure 2.27

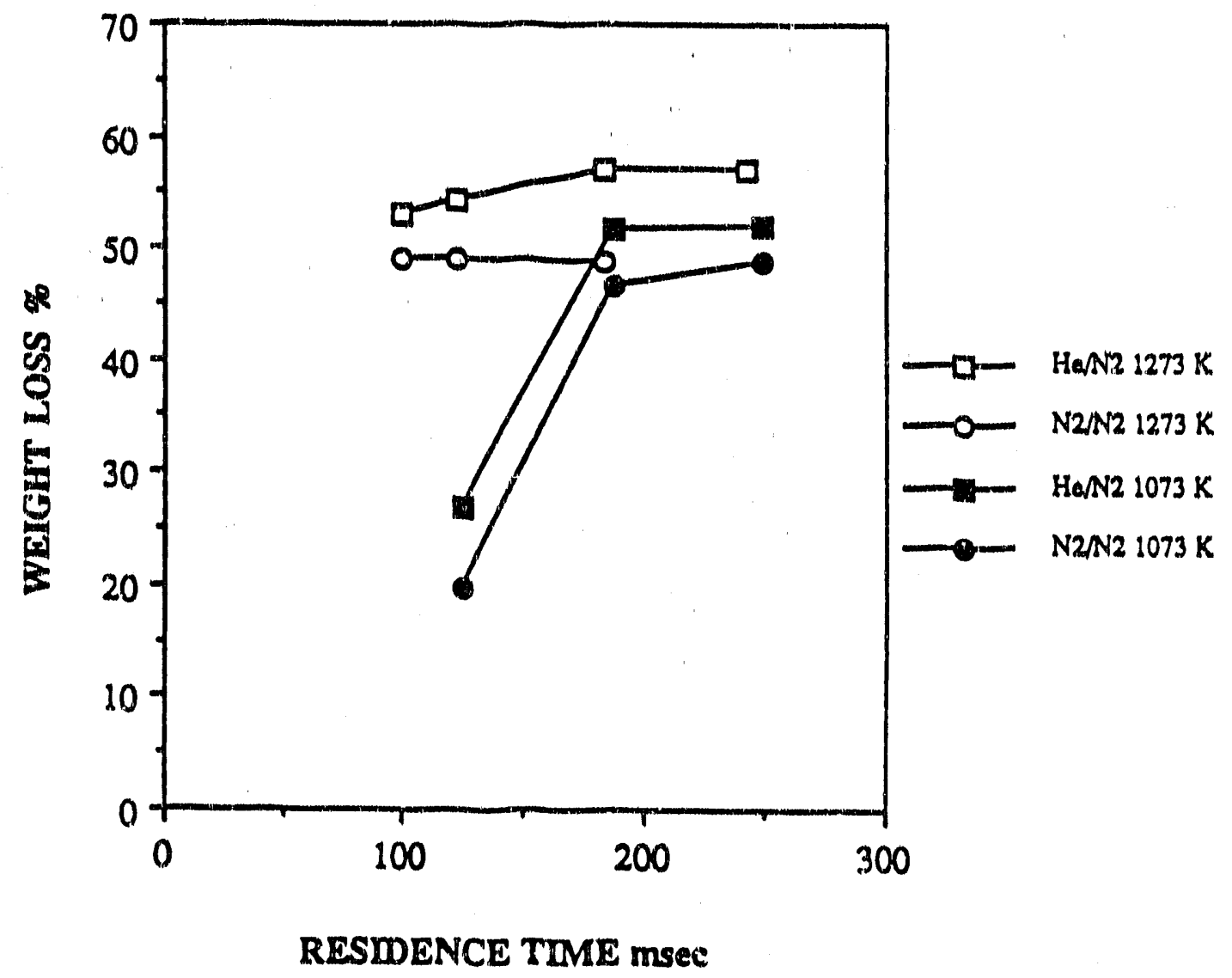

Effect of Temperature on Weight Loss for $120 \times 140$ Mesh Particles of PSOC-1451 (Bit) 
Figure 2.28

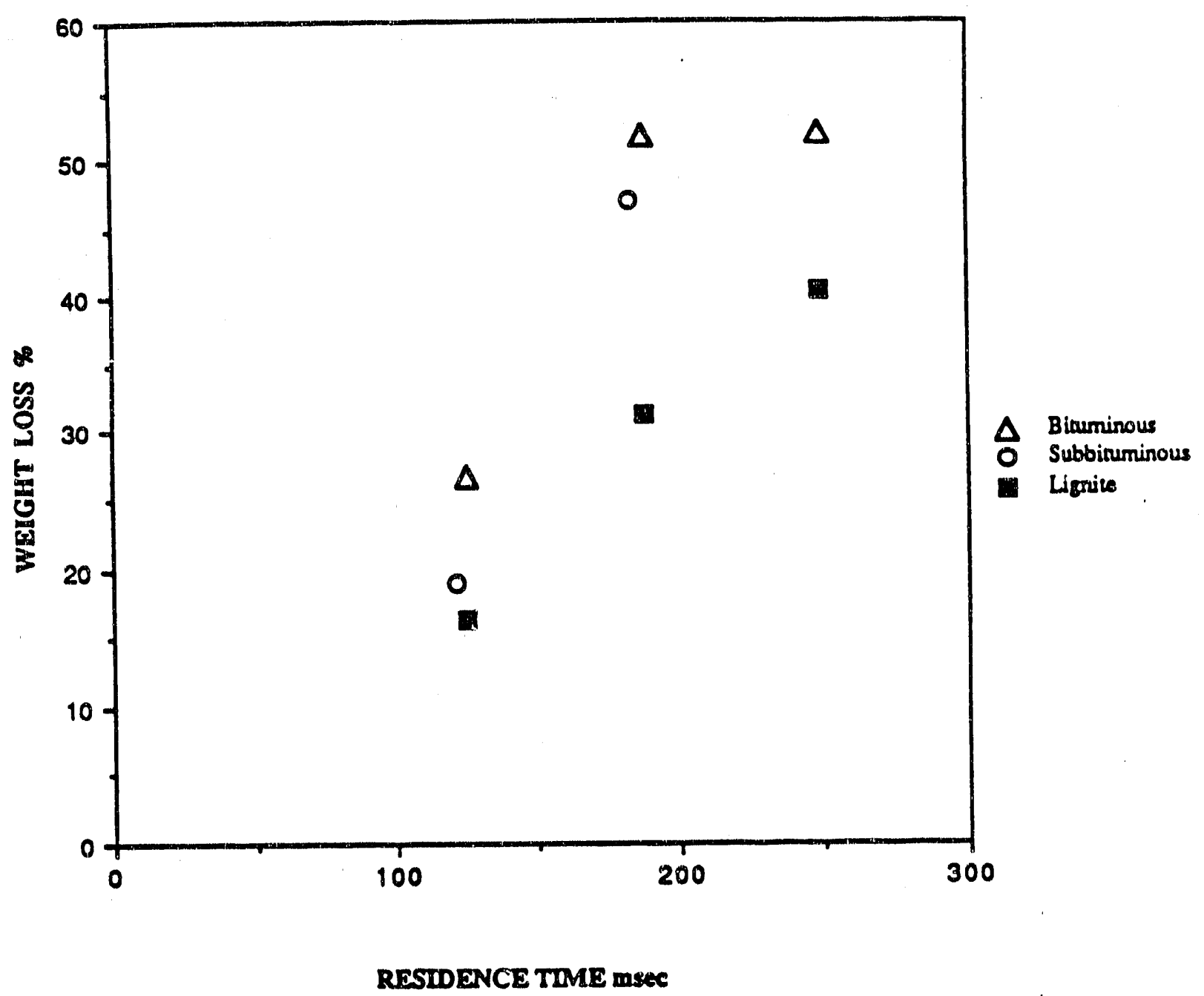

Effect of Coal Type on Weight Loss for $120 \times 140$ Mesh Particles at $1073 \mathrm{~K}$ During Pyrolysis in a He/N2 Atmosphere 
Figure 2.29

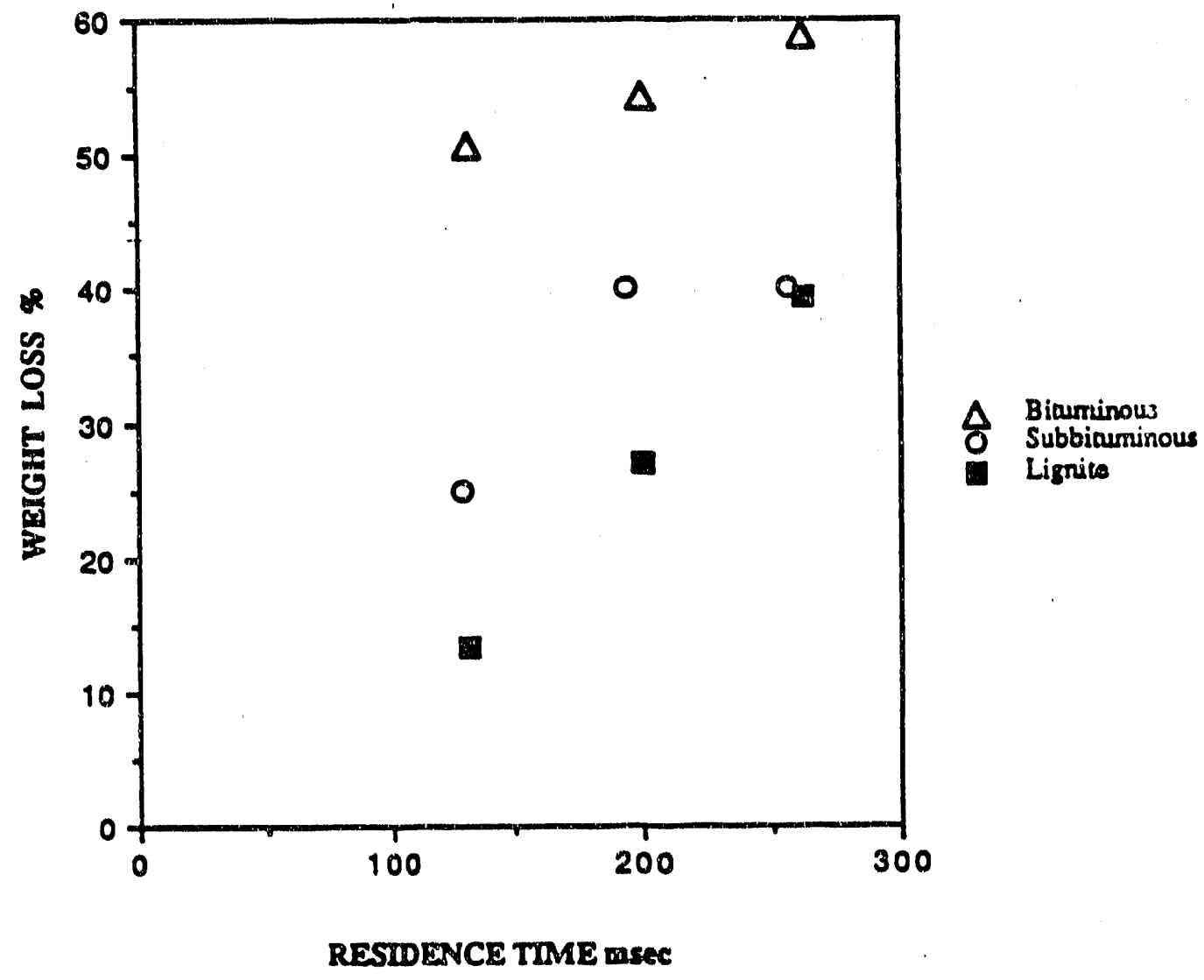

Effect of Coal Type on Weight Loss for $170 \times 200$ Mesh Particles at $1073 \mathrm{~K}$ During Pyrolysis in a He/N2 Atmosphere 
Figure 2.30

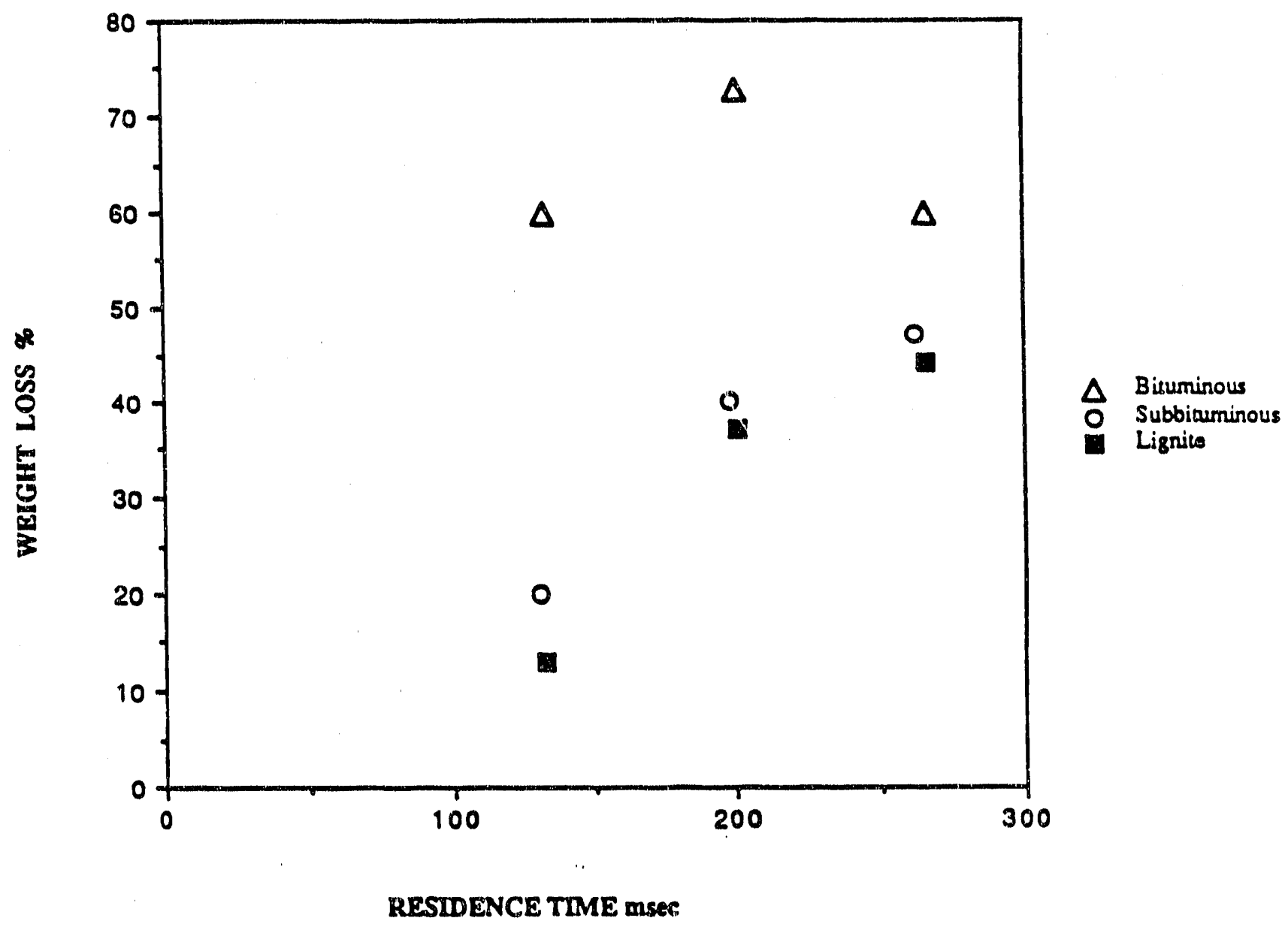

Effect of Coal Type on Weight Loss for 200x230 Mesh Particles at $1073 \mathrm{~K}$ During Pyrolysis in a He/N2 Atmosphere 
Figure 2.31

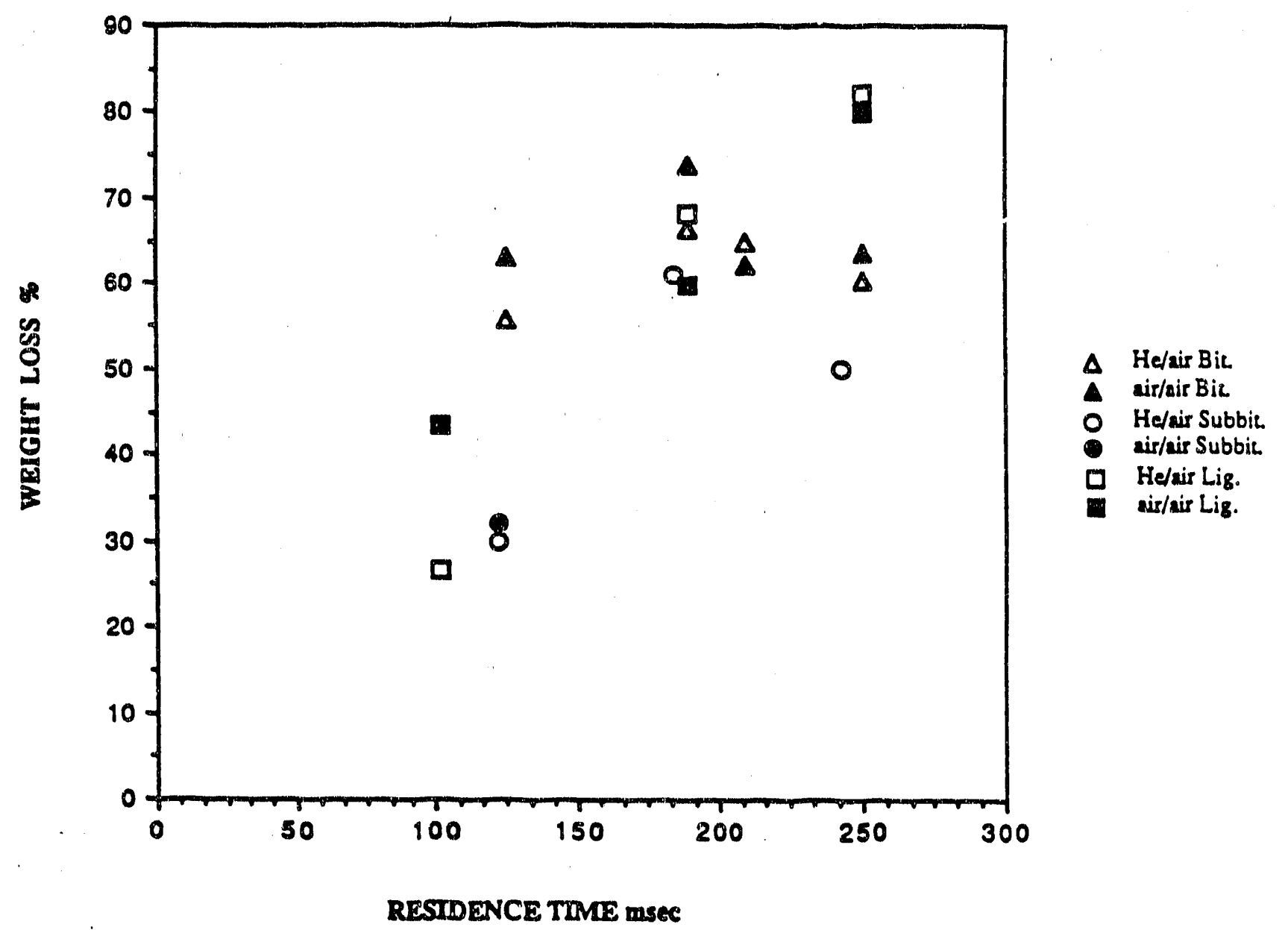

Effect of Coal Type on Weight Loss for $120 \times 140$ Mesh Particles at $1073 \mathrm{~K}$ During Combustion 
It is encouraging to note however, that the three curves in both Figs. 2.19 and 2.20 seem to be converging on one ultimate weight loss. This ultimate weight loss appears to be about $50-55 \%$ for the bituminous coal in Fig. 2.19 and about $35-40 \%$ for the lignite in Fig. 2.20.

The trend in weight loss with particle size was not as apparent for the intermediate (Subbituminous) PSOC-1520 coal studied later. The scatter in the data was unexpectedly large than those shown in Figs. 2.19 and 2.20 , respectively. Similarly, it will be shown later that there appears to be only a small correlation between weight loss and particle size for runs on air-containing atmospheres.

Effect of Reactor Atmosphere. Figures $2.21-2.25$ illustrate the effect of reactor atmosphere on weight loss data for runs performed under different operating conditions. In all five plots, the curves representing experiments in which air was present are higher than the curves representing air-free atmospheres. Therefore, the behavior of the bituminous coal (Figs. $2.21-2.23$ ) generally shows two characteristic trends: a) higher transient weight losses in air/air than in He/air, and b) a r(latively small change in asymptotic weight loss with residence time. In contrast, both the lignite (Fig. 2.25) and the subbituminous (Fig. 2.24) coals generally show a) higher weight losses in He/air than in air/air, particularly at shorter residence times, and b) a considerable increase in weight loss with increasing residence time. If one considers that the thermal diffusivity of helium is 8.5 times greater than the value for air at $1073 \mathrm{~K}$ (Table 2.1), then the question exists as to why there isn't always a greater weight loss for the He/air combination? The answer may be a consequence of two processes happening simultaneously (that is, pyrolysis and combustion). If only thermal decomposition was taking place, then the runs where the primary gas was helium would produce a higher weight loss. This implies heat transfer is not the controlling mechanism for total weight loss during combustion in this reactor. However, since oxygen is present in both the secondary and primary gases, where it is in close contact with the particles even before they enter the reactor, the effect of heterogeneous char combustion is enhanced. Air used as a primary gas helps to ignite volatiles, which heat up the pyrolyzing coal particles, causing an even more rapid volatile matter release, and yet higher temperatures and an even greater weight loss. Thus, the substitution of air for helium as the primary gas produces a greater weight loss because it produces higher transient particle temperatures and/or some char burnout. It is interesting to note that the absence of a significant trend in weight loss with particle size (or residence time) for air-containing runs on the bituminous coals (Figs. $2.21-2.23$ ) suggest that the processes responsible for the weight loss may be free of diffusion limitations.

By the same token, the fact that both the lignite and the subbituminous coal underwent lower weight losses at shorter residence times (i.e., for initially larger particles) suggests that the mass loss processes may 
be limited by diffusion effects. This is in accordance with the fact that lower rank coals are in general more porous than bituminous coals. Morgan (Ref. 2.10) reported results for a lignite in the Penn State EFR which are in qualitative agreement with the results shown in Fig. 2.25. Morgan also mentioned that the mass diffusivity of oxygen in helium is about the same as that of oxygen in air, although their thermal diffusivities are very different. Therefore, it would appear that the lower rank (mnre porous) coals lose more weight in He/air than in air/air because of the predominance of thermal decomposition over combustion under mass transfer limitations.

The other three atmospheres, $\mathrm{He} / \mathrm{N}_{2}, \mathrm{~N}_{2} / \mathrm{N}_{2}$, and $\mathrm{He} / \mathrm{CO}_{2}$, can be grouped as pyrolysis conditions even though $\mathrm{CO}_{2}$ is a potentially reactive gas. The curves in Figs. 2.21, 2.22 and 2.25 have the weight loss propensity for these atmospheres ranked as $\mathrm{He} / \mathrm{N}_{2}>\mathrm{He} / \mathrm{CO}_{2}>\mathrm{N}_{2} / \mathrm{N}_{2}$. Tamhankar (Ref. 2.16) also observed that weight loss for $358.5 \mu \mathrm{m}$ particles run in $\mathrm{N}_{2}$ was higher than for the same particles tested in $\mathrm{CO}_{2}$ or steam. Morgan (Ref. 2.10) however, reported a $9 \%$ increase in particle weight loss when runs were made with a $270 \times 400$ mesh $(53 \times 37 \mu \mathrm{m})$ fraction in $\mathrm{CO}_{2}$ instead of pure $\mathrm{N}_{2}$. Figures 2.23 and 2.24 have the atmospheres ranked $\mathrm{He} / \mathrm{CO}_{2}>\mathrm{He} / \mathrm{N}_{2}>\mathrm{N}_{2} / \mathrm{N}_{2}$.

Effects of Reactor Temperatusis. Temperature had by far the greatest effect on the degree of pyrolysis and combustion. Figure 2.26 shows the effect of reactor ternperature on $81 \mu \mathrm{m}$ particles of PSOC-1451 for three pyrolysis atmospheres $\left(\mathrm{He} / \mathrm{N}_{2}, \mathrm{~N}_{2} / \mathrm{N}_{2}\right.$ and $\left.\mathrm{He} / \mathrm{CO}_{2}\right)$, and $\mathrm{Fig} .2 .27$ shows the effects for two pyrolysis atmospheres $\left(\mathrm{He} / \mathrm{N}_{2}\right.$ and $\mathrm{N}_{2} / \mathrm{N}_{2}$ ) on $115 \mu \mathrm{m}$ particles of the same coal. In both plots, the runs made at $1273 \mathrm{~K}$ had reached a constant weight loss within $100 \mathrm{msec}$. The runs performed at the lower temperature still show developing weight loss curves. This effect is more prominent with the $115 \mu \mathrm{m}$ particle size (Fig. 2.27) than with the $81 \mu \mathrm{m}$ particles (Fig. 2.26).

Maloney (Ref. 2.9) reported the asymptotic weight losses for an HVA coal at $1073 \mathrm{~K}$ and $1273 \mathrm{~K}$ were $41 \%$ and $51 \%$ respectively. The difference in asymptotic weight loss due to temperature in these results was also about $10 \%$ but was higher than Maloney's (-50\% at $1073 \mathrm{~K}$ and $-60 \%$ at $1273 \mathrm{~K}$ in this study). Since the difference between the temperatures was similar, one can conclude that the rates of pyrolysis of Maloney's experiments were similar to the rates in the current work.

Effects of Coal Type. Figures 2.28 through 2.31 illustrate the effect of coal type on pyrolysis and combustion. Figures 2.28 through 2.30 place the pyrolysis weight loss for PSOC-1451 (bit.) higher than that of PSOC-1443 (lignite), with PSOC-1520 (subbit.) having intermediate values in all cases. This seerns surprising when one considers the rotal volatile matter plus moisture content of each coal. The average 
volatile matier plus moisture for PSOC-1451, PSOC-1520 and PSOC-1443 are $32 \%, 60 \%$ and $57 \%$ (48\% when pre-dried), respectively. However, Figs. 2.28 through 2.30 show that the bituminous coal has lost roughly between 50 and $60 \%$ of its original weight after $250 \mathrm{msec}$. The lignite lost a maximum of $50 \%$ of the original weight in the same length of time, but this is still below the value of volatile matter in the original proximate analysis. Heating rate must be an important factor in determining weight loss in the bituminous coal since some of what was found to be fixed carbon in ASTM heating was released as volatile matter. The heating rate that was used by the MAC- 400 for the proximate analysis was on the order of $10 \mathrm{~K} / \mathrm{min}$ and the volatile matter holding temperature was $950^{\circ} \mathrm{C}$. In the EFR, the particles were heated at a rate of $10^{3}-10^{4}$ $\mathrm{K} / \mathrm{s}$. The bituminous coal lost about twice as much weight under the rapid heating conditions of the EFR as it did under the slow heating conditions of the MAC-400. The additional material lost during rapid heating had to come from what was classified as fixed carbon under slow heating conditions. The lignitic coal did not lose as much weight in the short residence time under rapid heating as it did with a long residence time and slow heating.

Figure 2.31 shows the effect of coal type under conditions of incipient combustion with both He/air and air/air. Two iterns on this plot should be noted. The first is the shape for bituminous coal curves. They appear to undergo a negative weight loss or a small weight gain after $175 \mathrm{msec}$. This result is not only observed in Fig. 2.31, but could also be gathered from Figs. 2.21 through 2.23. One possible explanation for this small effect (if real) could be the redeposition of soot on the particle's internal and external surfaces. Soot was observed both with the naked eye mixed in with the char prepared both in He/air and air/air, and also with the aid of a scanning electron microscope (See above). The second salient feature in Fig. 2.31 is that the curve for the lignite appears to overtake the bituminous coal curve after $225 \mathrm{msec}$. This is thought to be caused by the higher reactivity of a lignite char once the char gasification reaction becomes significant.

Nsakala et. al. (Ref. 2.17) ran a similar Lower Wilcox Texas lignite as a $200 \times 400$ mesh size fraction in a similar entrained flow reactor, and saw weight losses that were significantly below those reported in this study. As an illustration, at $200 \mathrm{msec}$ Nsakala et. al. reported a loss of $13 \%$ daf in nitrogen at $1600 \mathrm{~K}$. Figure 2.30 shows a daf weight loss of $39 \%$, or triple Nsakala's. The half hour drying under nitrogen prior to running the PSOC-1443 caused a significant reduction in moisture and was felt to be responsible for most of this discrepancy. That is, the removal of water prior to pyrolysis would allow more heat to be devoted to endothermic pyrolysis reactions rather than to water removal itself. It should be pointed out that there were no significant differences in the behavior of analogous coals provided by the Penn State Coal Sample Bank and the Vortec Products Co. (Labeled-D), as expected from their analyses (Table 2.6). 


\section{Ash as a Tracer}

Due to the inability to collect all products of pyrolysis and/or combustion, ash must be used as a tracer material for calculating weight loss. Scaroni, Walker and Essenhigh (Ref. 2.18) determined this method could be used with less than a $6 \%$ error by comparing a direct measurement of weight loss by a coal in a crucible to measurements taken using ash as a tracer. This method can only be correct if the ash undergoes no selective loss of any constituent on heating. The higher the furnace temperature, the greater the posslbility of the ash changing (Ref. 2.19). To investigate the inertness of the mineral matter upon heating, ten bituminous coal chars were prepared under a wide variety of conditions with respect to temperature. residence time and atmosphere. These chars were then ashed and the results were compared to each other and to the hight temperature ash analysis performed on the raw coal (See Appendix A. 2 for the data). There was no selective increase or decrease in any of the ten constituents analyzed for in the ash.

\section{Changes in Heating Value}

A brief investigation in the area of changes in heating value was conducted for the bituminous coal. Table 2.7 lists the gross heats of combustion for the parent coal and for chars prepared from it in $\mathrm{He} / \mathrm{N}_{2}$. For the sake of comparison, the $\mathrm{H}_{\mathrm{g}}$ value obtained by the Sample Bank was $29,120 \mathrm{KJ} / \mathrm{Kg}$ on an as-received basis. This was slightly higher than the one reported here. The last two columns in Table 2.7 indicate the relative distribution of the parents coal's energy among the products of pyrolysis. With these four runs, the energy leaving with the volatile matter ranged between $47 \%$ and $59 \%$ of the total energy available in the parent coal. The heat of combustion for the volatile matter was, in all cases, higher than the heat of combustion for its corresponding char. Elemental analyses showed the $C: H$ ratios to be $15: 1,30: 1$ and $11: 1$ for the raw coal, char and volatile matter respectively. From these ratios, the heat of combustion was estimated to be $33,000 \mathrm{KJ} / \mathrm{Kg}$ for the coal, char and volatile matter. 
TABLE 2.7 - COMPARISON OF GROSS HEATS OF COMBUSTION FOR PSOC-1451 COALS AND CHARS PREPARED IN A HE/N 2 ATMOSPHERE

\section{Coal}

$\begin{array}{cc}\text { Mesh Size } & \begin{array}{c}\mathrm{H}_{\mathrm{B}} \text { coal, } \mathrm{KJ} / \mathrm{Kg} \\ \text { as Rec'd }\end{array} \\ 120 \times 140 & 28,040 \\ 170 \times 200 & 28,670\end{array}$

\section{Char}

\begin{tabular}{cccc} 
I. Mesh_Size & \multicolumn{2}{c}{ Weight_ess.\% } \\
& & daf & as Rec'd \\
1073 & $170 \times 200$ & 51 & 41 \\
1273 & $120 \times 140$ & 54 & 41 \\
1273 & $120 \times 140$ & 57 & 43 \\
1273 & $170 \times 200$ & 59 & 45
\end{tabular}

He_char.KJ/Kg
as Rec'd
25,740
24,860
24,650
25,740

He VMA KJ/KR
as Rec'd
39,940
32,650
38,390
38,080

\begin{tabular}{cc}
\multicolumn{3}{c}{ Energy } \\
in Products \\
$\%$ v'M & \% char \\
47 & 53 \\
48 & 52 \\
58 & 42 \\
59 & 41
\end{tabular}

\section{Structural Changes in the Coal Char}

Changes in the residual char structure were followed two ways: 1) Particle diameters were measured through laser scattering and 2) char morphologies were investigated through scanning electron microscopy.

Particle Size Changes. The coal used in this study was first ground and then separated with standard U.S. screen sieves. Table 2.8 compares the sizes of the coal particles determined by the size of the openings in the screen mesh with those determined by the scattering of laser light by the Malvern Instruments $2600 \mathrm{c}$ droplet and particle sizer. The three coals produced particles of larger diameter when measured by laser scattering. In the case of the lignite, for instance, the laser determined sizes were $24 \%, 25 \%$, and $26 \%$ larger than the screen openings on the $120 \times 140,170 \times 200$, and $200 \times 230$ fractions, respectively. 
R88-PC70768

TABLE 2.8 - COMPARISON OF COAL AND CHAR PARTICLE SIZES PREPARED IN A HE/N2 ATMIOSFHERE

\begin{tabular}{lcccc} 
Mesh Size & $\begin{array}{c}\text { Mean Mesh Size } \\
\mu \mathrm{m}\end{array}$ & \multicolumn{3}{c}{ Laser Determined Particle Size } \\
$120 \times 140$ & 115 & 134 & 1.35 & 142 \\
$170 \times 200$ & 81 & 105 & 98 & 101 \\
$200 \times 230$ & 69 & Not determined & 80 & 87
\end{tabular}

PSOC-1451 Chars Prepared in $\mathrm{He} / \mathrm{N}_{2}$

$\begin{array}{rcccccc}\text { T,K } & \text { Mesh Size } & \text { Weight Loss, \% } & \text { D', } \mu \mathrm{m}^{\prime} & \mathrm{D}^{\prime} / \mathrm{D} & \mathrm{V}^{\prime} / \mathrm{V} & \rho^{\prime} / \rho \\ 1073 & 120 \times 140 & 27 & 176 & 1.31 & 2.27 & 0.32 \\ 1073 & 170 \times 200 & 52 & 1.71 & 1.62 & 4.32 & 0.11 \\ 1073 & 120 \times 140 & 52 & 221 & 1.65 & 4.49 & 0.11 \\ 1273 & 120 \times 140 & 54 & 191 & 1.47 & 2.90 & 0.16 \\ 1273 & 120 \times 140 & 57 & 219 & 1.63 & 4.36 & 0.10 \\ 1273 & 170 \times 200 & 59 & 145 & 1.37 & 2.63 & 0.16 \\ 1273 & 170 \times 200 & 59 & 155 & 1.47 & 3.22 & 0.13\end{array}$

PSOC-1443 Chars Prepared in $\mathrm{He} / \mathrm{N}_{2}$

$\begin{array}{rcccccc}\text { T,K } & \text { Mesh Size } & \text { Weight Loss, \% } & \text { D', } \mu \mathrm{m}^{\prime} & \mathrm{D}^{\prime} / \mathrm{D} & \mathrm{V}^{\prime} / \mathrm{V} & \rho^{\prime} / \mathrm{\rho} \\ 1073 & 170 \times 200 & 28 & 96 & 0.95 & 0.86 & 0.83 \\ 1073 & 120 \times 140 & 40 & 131 & 0.93 & 0.79 & 0.76 \\ 1073 & 200 \times 230 & 44 & 75 & 0.86 & 0.64 & 0.87 \\ 1273 & 170 \times 200 & 38 & 92 & 0.92 & 0.78 & 0.78 \\ 1273 & 120 \times 140 & 46 & 131 & 0.92 & 0.79 & 0.68 \\ 1273 & 200 \times 230 & 47 & 73 & 0.84 & 0.59 & 0.90\end{array}$

One reason for this difference in sizing by the two techniques may well be a result of the non-sphericity of the particles. In the laser technique, the particles are tumbling through a liquid medium, each one sweeping out a volume that is converted to a diameter. The screen sieves however, may allow particles through the openings if they are oriented correctly on one attempt, but may deny them access if the orientation has changed to present a face that is too wide. A rod-shaped particle would be an extreme example of this effect. A second explanation for the discrepancy in sizing might be agglomeration of particles while they were in the liquid medium. A third, and more likely explanation, has to do with the different assumptions involved in the estimation of particle sizes by the different techniques. While the 
screening technique gives a linear average size in the fraction considered, it does not provide any information about particle size distribution; instead, it presumes a Gaussian distribution of particle diameters, which is clearly not the case for the coals considered (see, e.g. Figs. 2.16 through 2.18). Besides, it is known by statistics that the mean diameter derived from an "average" (screening) area will be smaller than that derived from a "volume" estimate (Laser techniques). Therefore, the observed discrepancy in mean sizes is to be expected, and the ambiguity in the definition of "mean particle size" may be its major cause.

Like most bituminous coals. PSOC-1451 swelled to form cenospheres under rapid heating conditions. Table 2.8 presents ratios of final value to original value for diameter, volume, and density. Diameter increase ranged from 1.3 to 1.6 times the original size. the corresponding increase in volume was 2.3 to 4.5 times the original coal particle's volume. Using the accompanying weight loss values, the corresponding decrease in particle density ranged from $10 \%$ to $32 \%$ of the parent coal's density. In contrast, the subbituminous and the lignite chars showed a decrease in particle diameter, but in both cases the density of the char was still less than parent coal's (e.8. $68 \%$ to $90 \%$ of the unheated lignite).

Figure 2.32 shows the particle size distributions (obtained with the Malvern) for the bituminous coal and char sample. It can be seen that the char's distribution is both spread out and shifted to the right of the parent coal's distribution. A significant portion of the coal possesses a diameter greater than $160 \mu \mathrm{m}$, giving some support to the agglomeration explanation of why the mean particle diameter is greater than the diameter measured by the sieves. Orientation alone could not account for a particle diameter that is twice as large as the sieve openings. On the other hand, Fig. 2.33 shows analogous data for the subbituminous coal and its char. The curves are better defined than those in Fig. 2.32, and show little evidence of particle agglomeration. In addition, the shift in char size distribution is to the left of the parent coal's distribution. The corresponding behaviors for other mesh fractions in air-containing atmospheres are included in Appendix A.3, and, in general, they show a small loss in average diameter after oxidation.

Ceal Char Morphologies. Studying the morphologies of coal chars with a scanning electron microscope can complement data taken by other methods. Before the technique of measuring particle sizes through laser scattering was available, particle sizes were measured from SEM photographs. Figures 2.34 through 2.39 are reproductions of fhotographs taken of bituminous coal chars prepared in the EFR. A microbar is shown in the lower right hand comer of each figure. The left-most line is the length in microns multiplied in $10^{n}$ where $n$ is the number of lines following the microbar. These six figures shiow a final size of 1.1 to 2.0 times the original particle size. This method however, is based on a very limited number of 
Figure 2.32

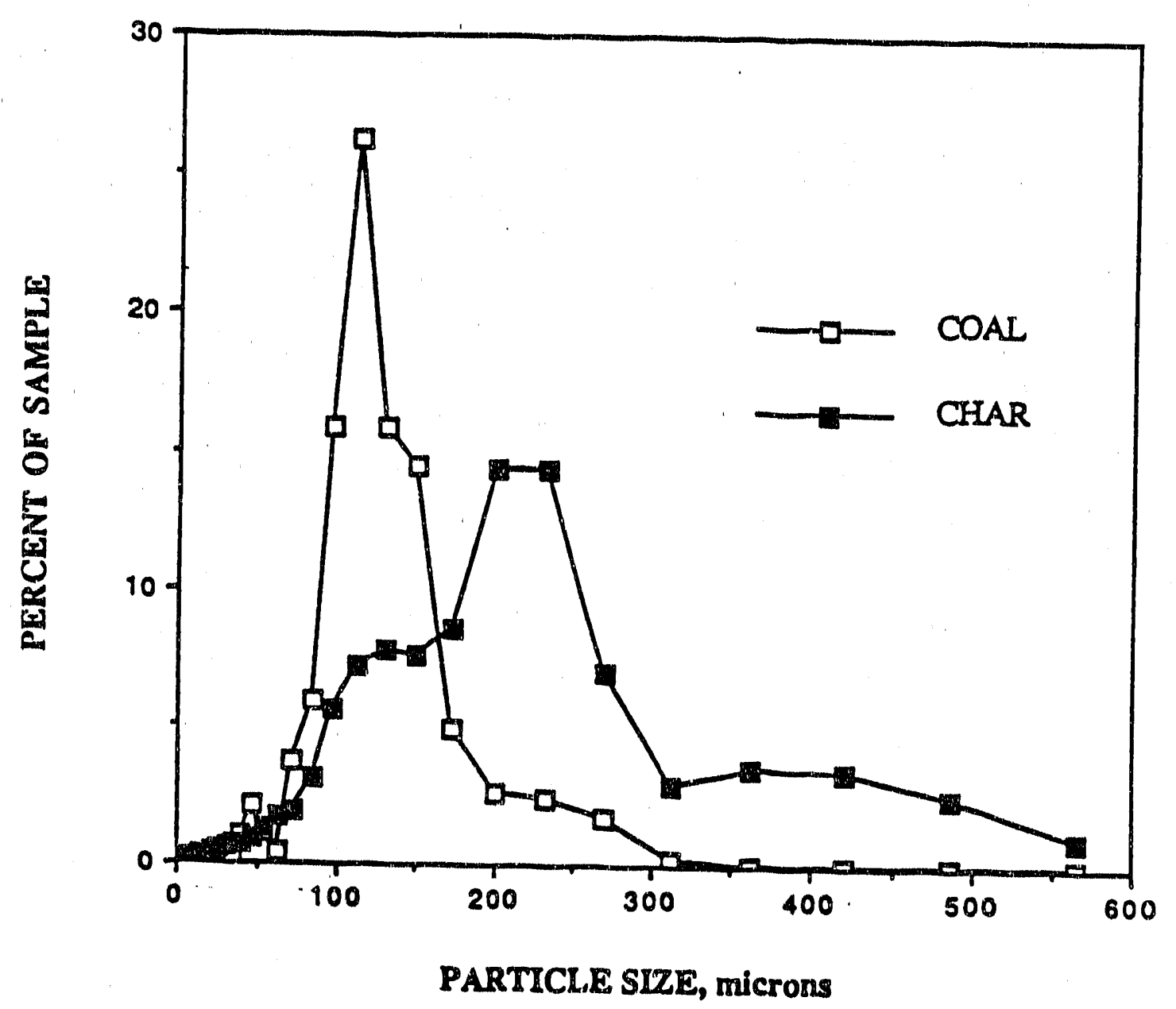

Distribution of $170 \times 200$ Mesh PSOC-1451 (Bit.) Coal and Char Particles. Char Prepared at $1073 \mathrm{~K}$ in He/N2 at a Residence Time of 125 msec. 
Figure 2.33

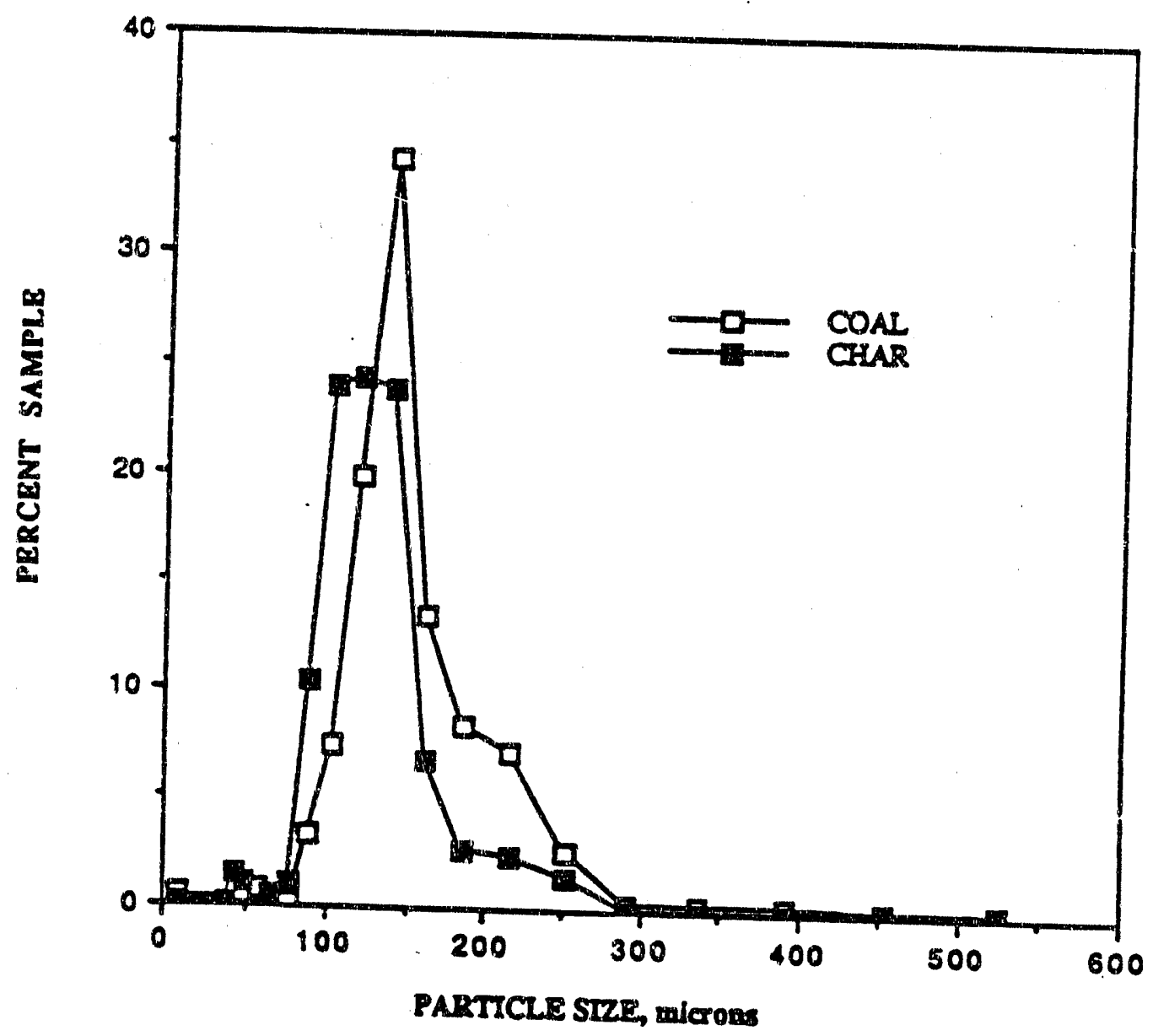

Distribution of 120x140 Mesh PSOC.1520 (Subbit.) Coal anid Char Particlea. CharsPrepared at $1273 \mathrm{~K}$ in $\mathrm{He} / \mathrm{N}_{2}$ at a
Residence Time of $122 \mathrm{msec}$. 
Figure 2.34

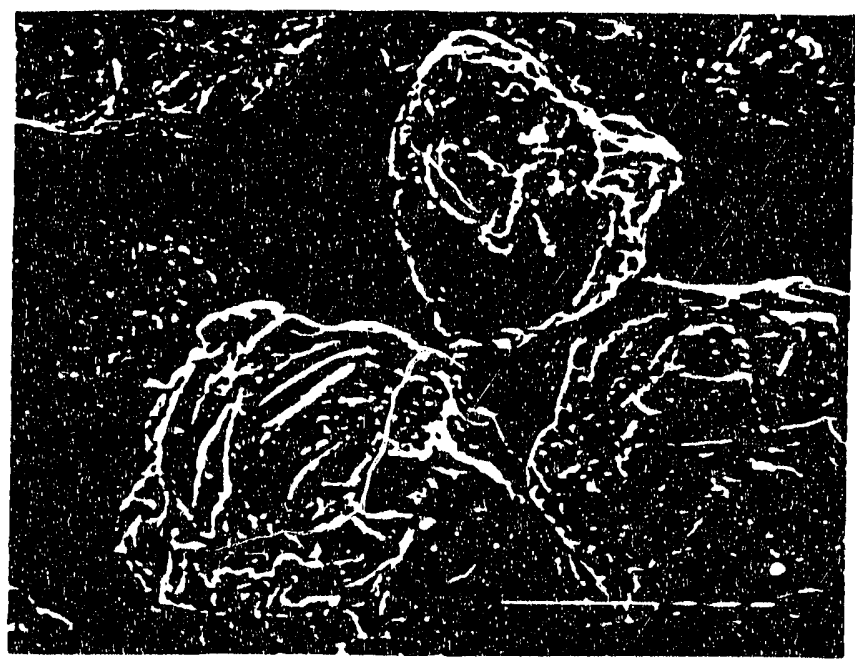

PSOC.1451 Char Prepared in He/N2 at 1273K, $:=100 \mathrm{msec}$, Coal Size $=120 \times 140$ mesh, $\mu$ bar $=100 \mu \mathrm{m}$

Figure 2.35

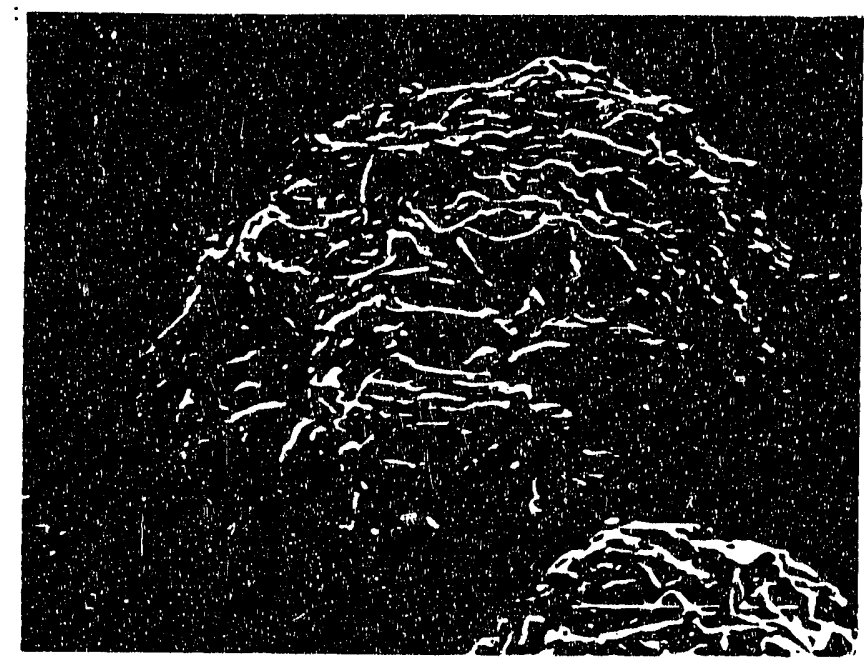

PSOC. 1451 Char Prepared in He/N2 at $1273 \mathrm{~K}_{v} q=270 \mathrm{msec}$, Coal Size $=200 \times 230$ mesh, $\mu$ bar $=100 \mu \mathrm{m}$ 


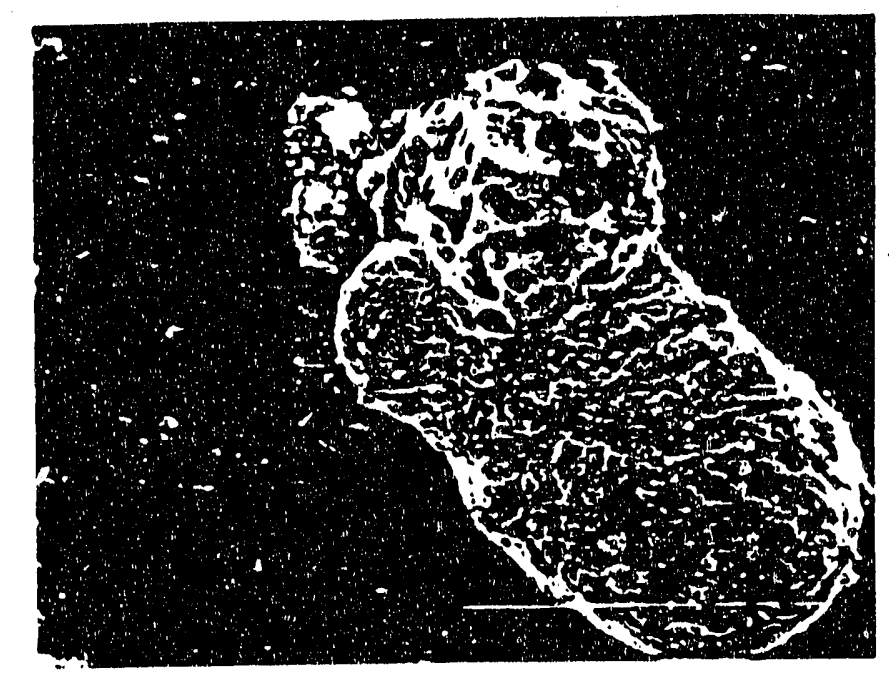

PSOC.1451 Char Prepared in He/air at 1073K, $\tau=190 \mathrm{msec}$, Coal Size $=120 \times 140 \mathrm{mesh}, \mu$ bar $=100 \mu \mathrm{m}$

Figure 2.37

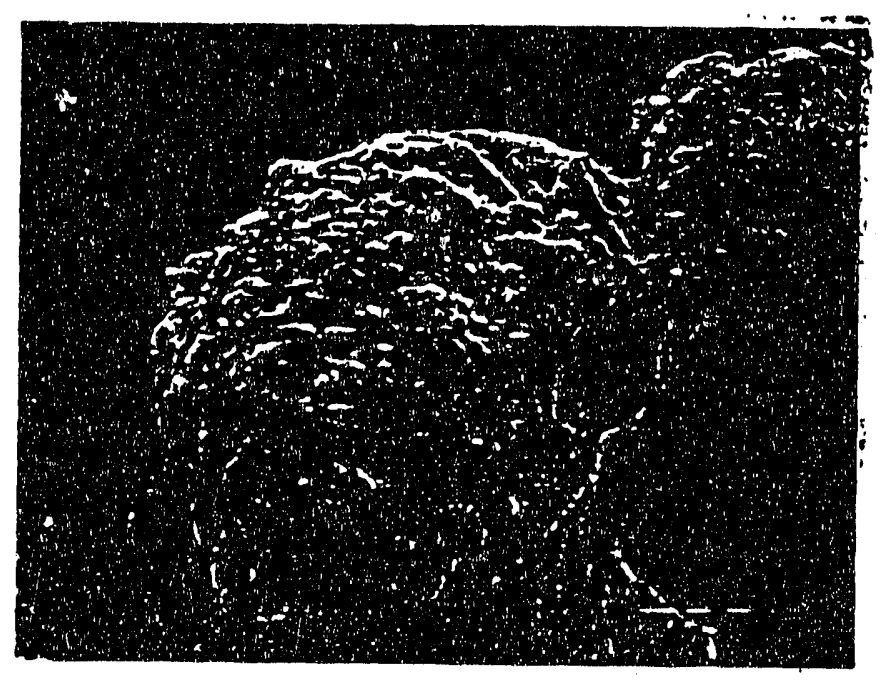

PSOC.1451 Char Prepared in He/air at 1273K, $\tau=240 \mathrm{msec}$, Coal Size $=120 \times 140$ mesh, $\mu$ bar $=10 \mu \mathrm{rn}$ 


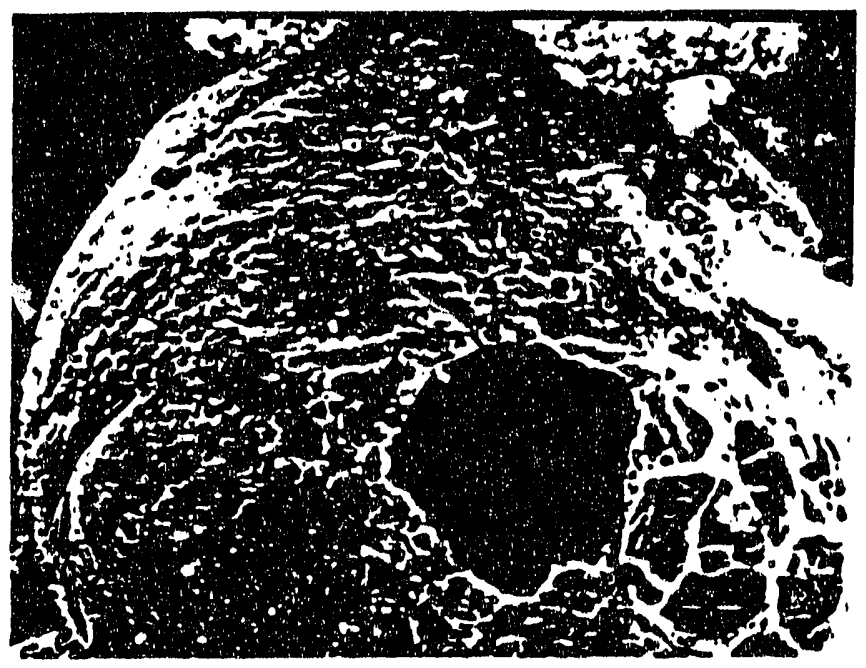

PSOC-1451 Char Prepared in $\mathrm{He} / \mathrm{CO}_{2}$ at 1073K, $\tau=200$ msec, Coal Size $=120 \times 140$ mesh, $\mu$ bar $=10 \mu \mathrm{m}$

Figure 2.39

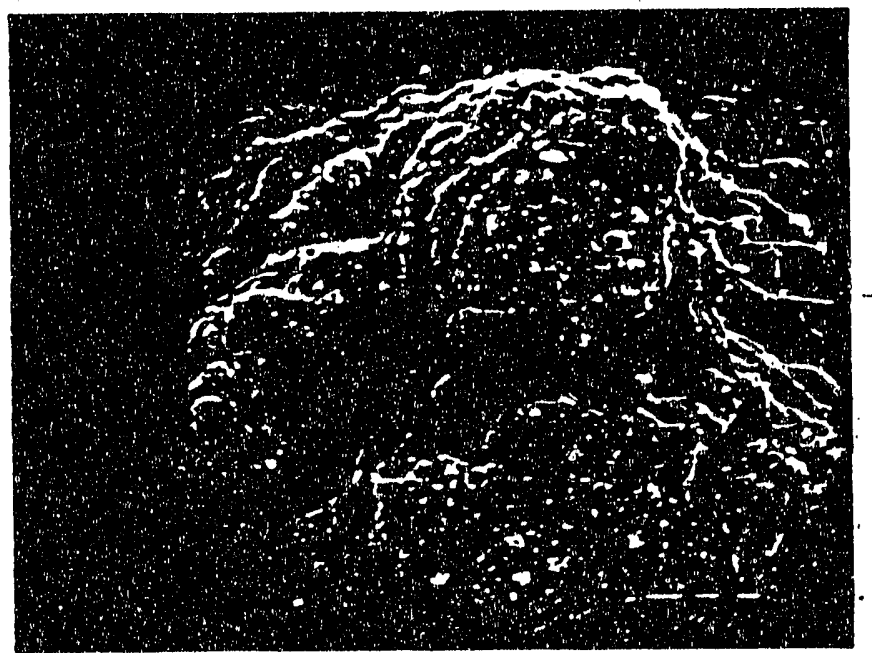

PSOC-1451 Char Prepared in $\mathrm{He} / \mathrm{CO}_{2}$ at $1273 \mathrm{~K}, \tau=260$ msec, Coal Size $=120 \times 140$ mesh, $\mu$ bar $=10 \mu \mathrm{m}$ 
particles and is not as accurate as the laser scattering technique described above. Tsail (Ref. 2.11) used the SEM photograph measuring technique and obtained swelling ratios between 1.00 and 1.3 times the original diameter. Maloney (Ref. 2.9) reported this number to be twice the original for a bituminous coal. These swelling ratios are in agreement with the laser scattering measurements of $1.3-1.6$ times the original diameter.

Figures 2.34 and 2.35 show bituminous coal char particles which were pyrolyzed in $\mathrm{He} / \mathrm{N}_{2}$ under conditions of different severity. Both chars display the cenosphere structure, and fluid ridges are visible. These ridges are most dramatic in Fig. 2.35 where the smaller coal particle size and longer residence time have enhanced the pyrolysis phenomenon.

The bituminous coal chars in Figs. 2.36 and 2.37 were prepared in He/air. Several salient features were observed. Both photographs show visual evidence of agglomeration. Figure 2.36 appears to be composed of three smaller particles and Fig. 2.37 was formed from at least two. Soot can also be seen in both figures and appears as grey-white fluffy material. the presence of soot on the char particles could serve as an explanation for the apparent weight gain or negative weight loss at about $200 \mathrm{msec}$ during all bituminous coal runs where air was present. Contrary to the pictures taken of the bituminous coal chars prepared in the $\mathrm{He} / \mathrm{N}_{2}$ atmosphere where holes in the surface were large and few in number, the pictures taken in the chars prepared in He/air atmosphere show many smaller holes spread out over the entire surface. These holes are believed to be related to sites of char oxidation.

Figure 2.38 and 2.39 show bituminous coal chars prepared in a $\mathrm{He} / \mathrm{CO}_{2}$ atmosphere. A combination of the results mentioned above can be seen. Soot is present in both figures indicating $\mathrm{He} / \mathrm{CO}_{2}$ is a reactive environment. The pattern of many small blow holes is evident in Fig. 2.38. However, the texture of the particle in Fig. 2.39 is more similar to the particle in Fig. 2.35 which was extremely fluid at some point in its history. It was previously shown that the weight losses in $\mathrm{He} / \mathrm{CO}_{2}$ were much closer to those in $\mathrm{He} / \mathrm{N}_{2}$ than those in He/air. Therefore, it might be expected that chars prepared in $\mathrm{He} / \mathrm{CO}_{2}$ should look similar to those prepared in $\mathrm{He} / \mathrm{N}_{2}$.

In order to contrast the variations in char morphology with coal rank, SEM pictures of the subbituminous PSOC-1520D coal and its chars are presented in Figs. 2.40 through 2.50. Only chars pyrolyzed in $\mathrm{N}_{2} / \mathrm{N}_{2}$ at $1073 \mathrm{~K}$ are included for comparison. These chars were not expected to show any evidence of swelling or of cenosphere formation. Indeed, by comparing the raw coal particles (Fig. 2.40) with their corresponding char particles (Fig. 2.42) at the same level of magnification (42 times, read 0.042 
Figure 2.40

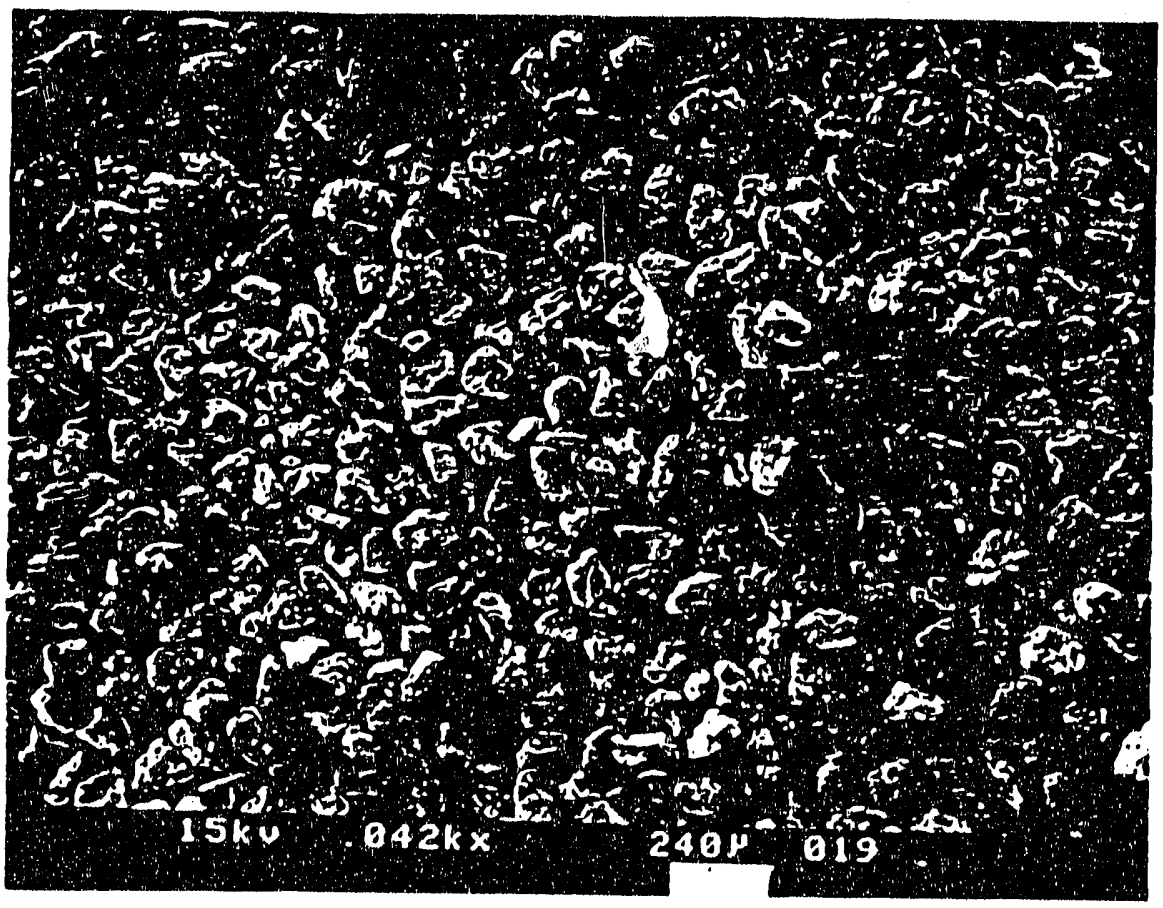

PSOC-1520D Raw Coal, Fraction $125.106 \mu \mathrm{m}$

Figure 2.41

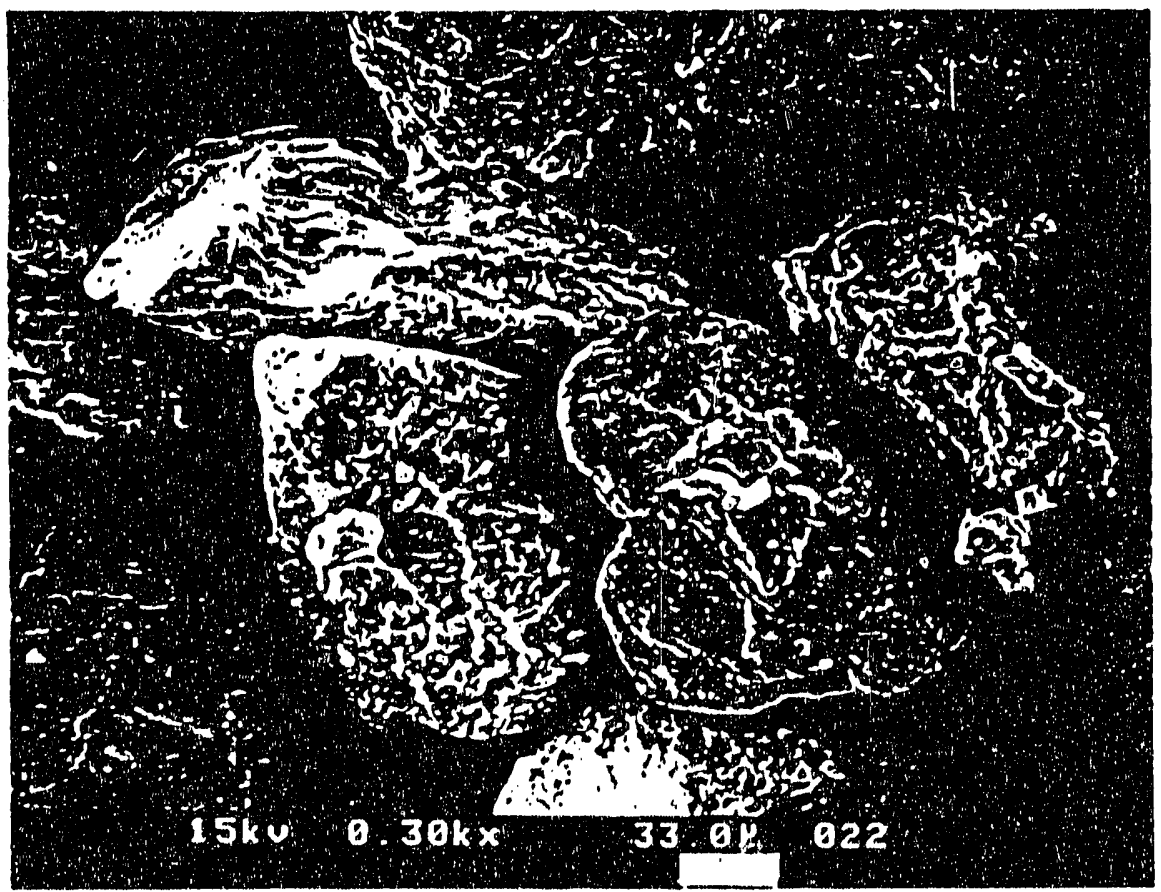

PSOC-1520D Raw Coal, Fraction 125.106 $\mu \mathrm{m}$ 
Figure 2.42

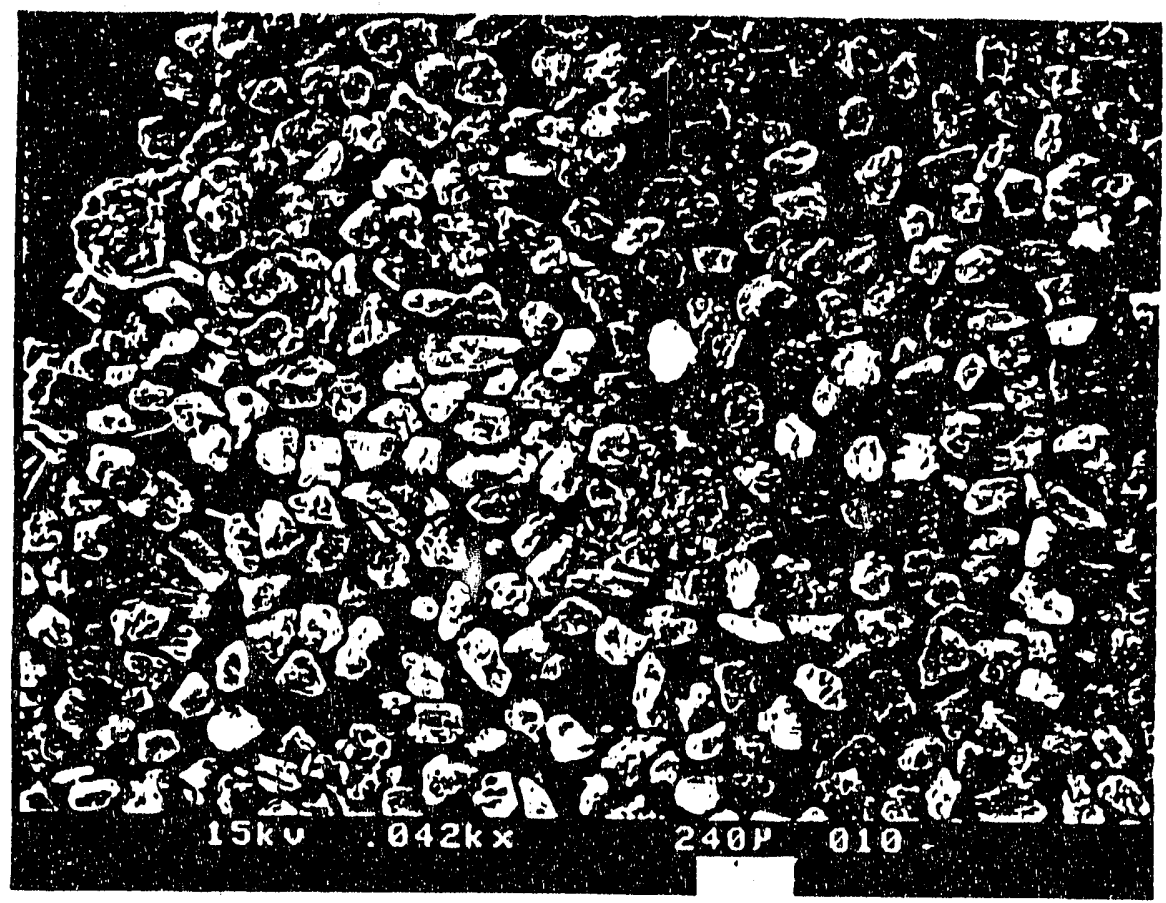

PSOC.1520D Char Prepared in $\mathrm{N}_{2} / \mathrm{N}_{2}$ at $1073 \mathrm{~K}$, Residence time $=121 \mathrm{msec}$, Coal Size $=125.106$ microns, 42 Magnifications

Figure 2.43

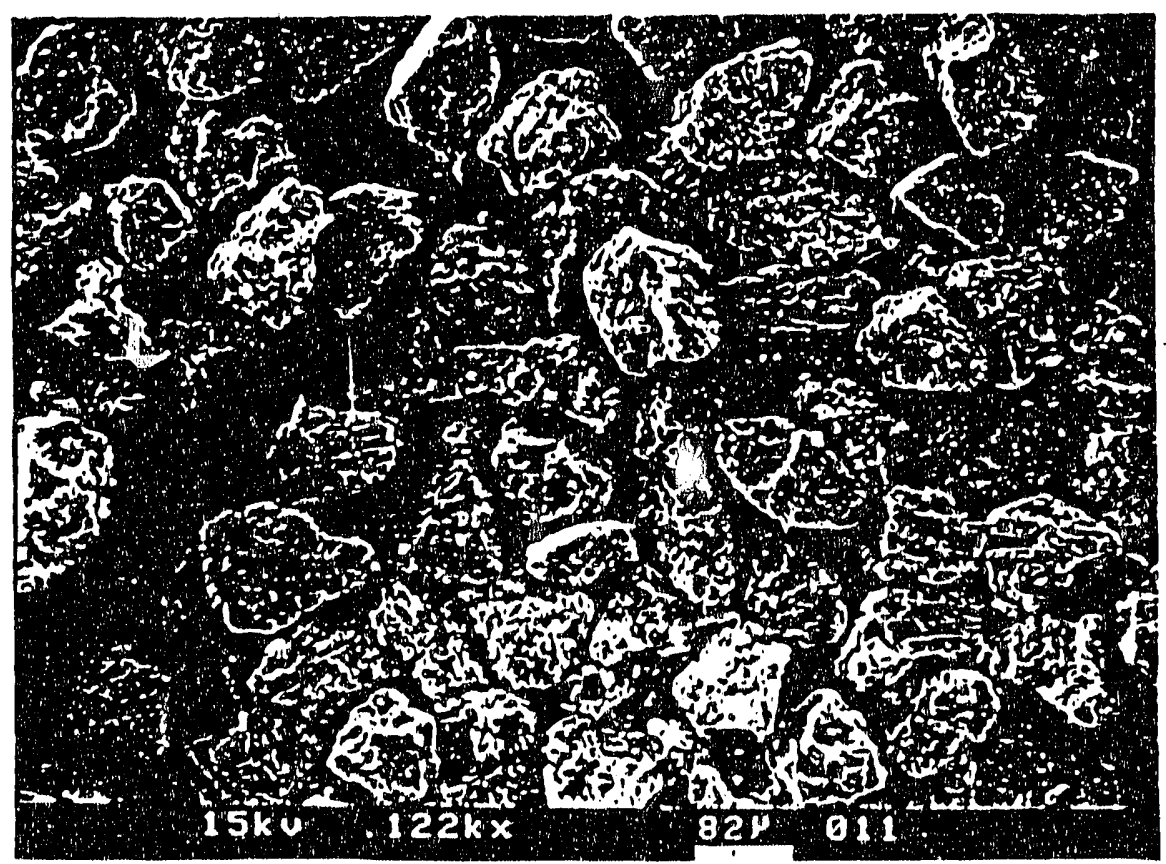

PSOC-1520D Char Prepared in $\mathrm{N}_{2} / \mathrm{N}_{2}$ at $1073 \mathrm{~K}$, Residence time $=121$ msec, Coal Size $=125.106$ microns, 122 Magnifications 
Figure 2.44

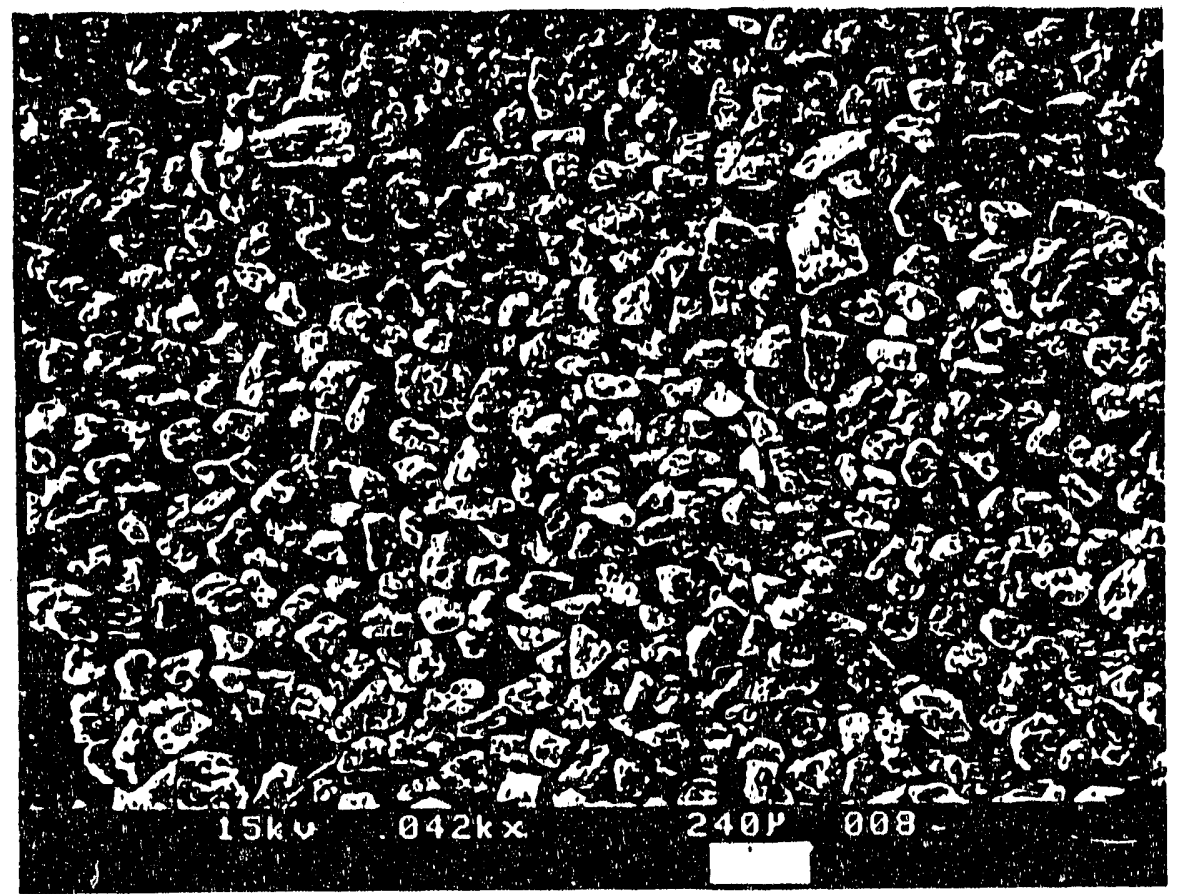

PSOC.1520D Char Prepared in $\mathrm{N}_{2} / \mathrm{N}_{2}$ at $1073 \mathrm{~K}$, Residence time $=183$ msec, Coal Size $=125.106$ microns, 42 Magnifications

Figure 2.45

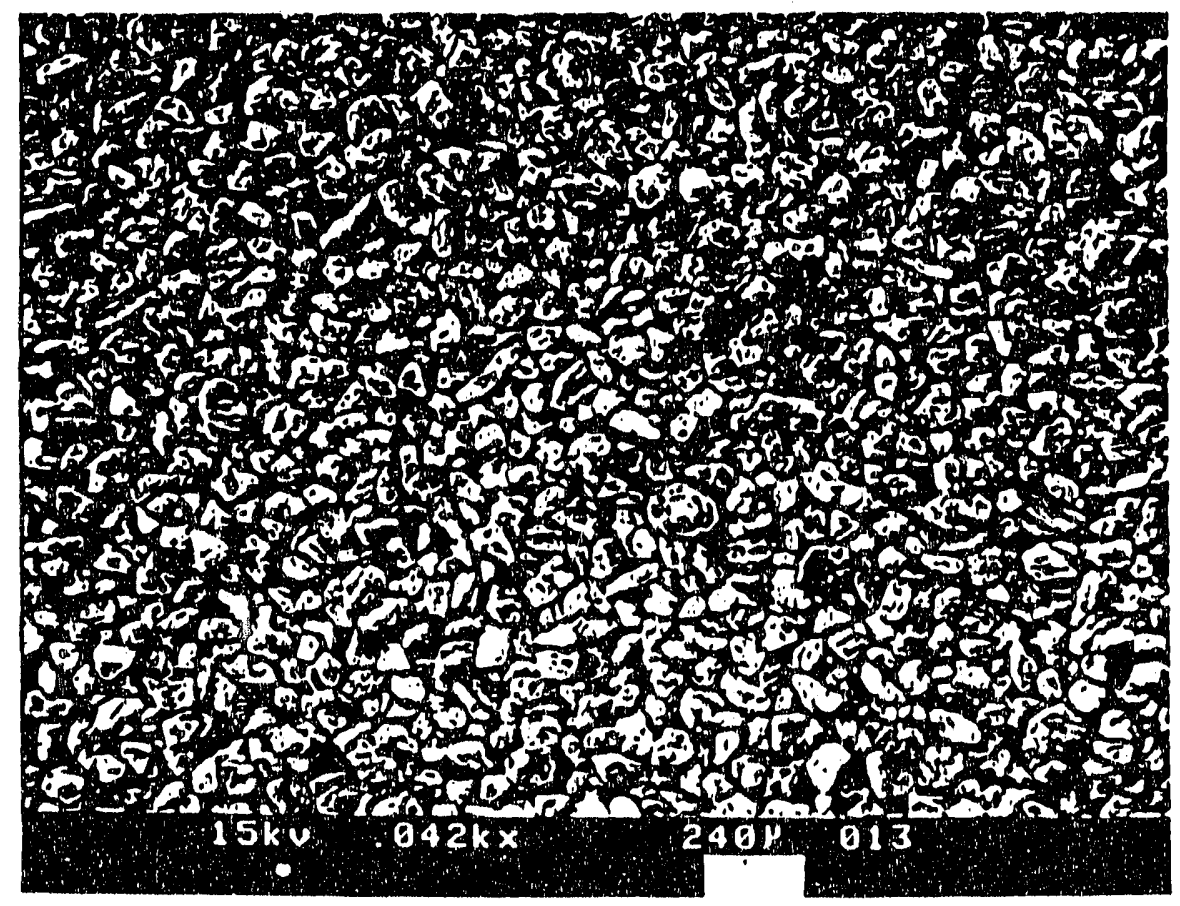

PSOC.1520D Char Prepared in $\mathrm{N}_{2} / \mathrm{N}_{2}$ at $1073 \mathrm{~K}$, Residence time $=194 \mathrm{msec}$, Coal Size $=106.75$ microns, 42 Magnifications 
Figure 2.46

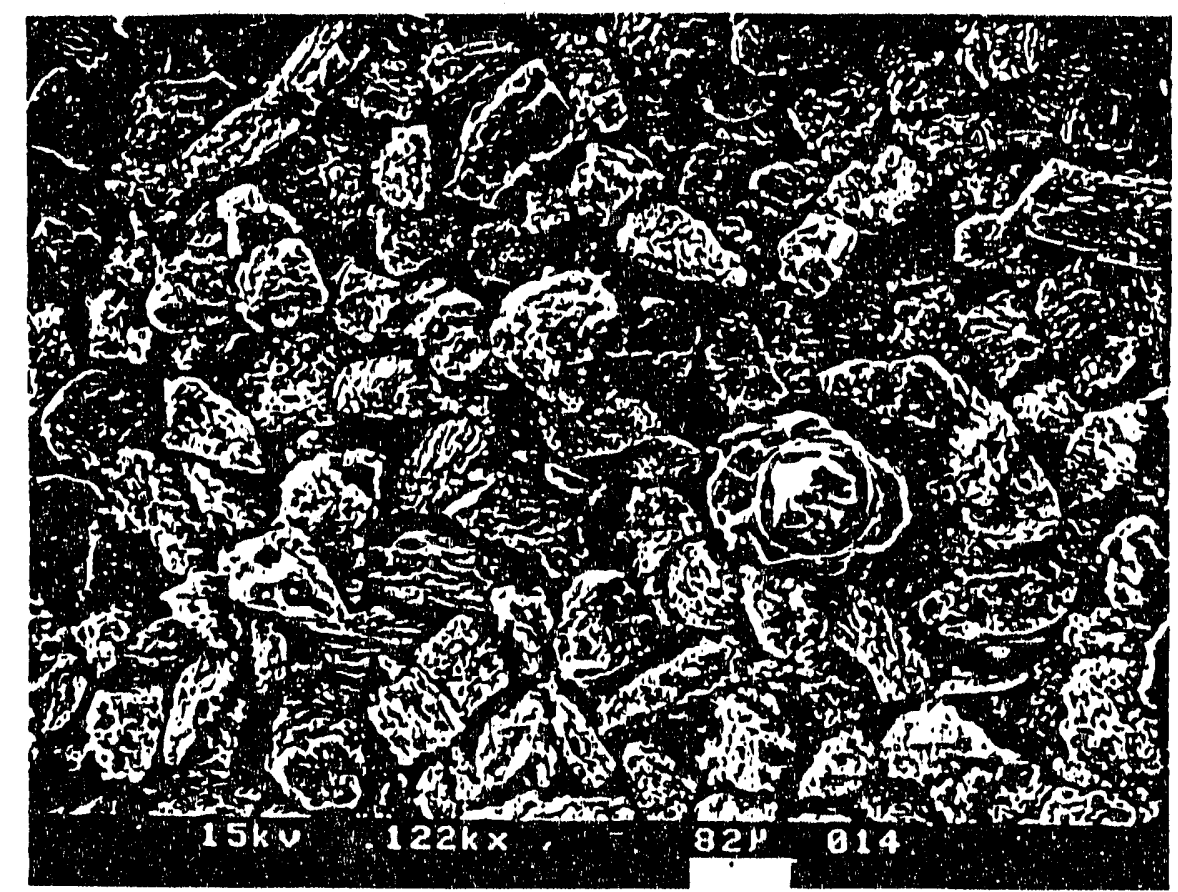

PSOC-1520D Char Prepared in $\mathrm{N}_{2} / \mathrm{N}_{2}$ at $1073 \mathrm{~K}$, Residence time $=194 \mathrm{msec}$, Coal Size $=106.75$ microns, 122 Magnifications

Figure 2.47

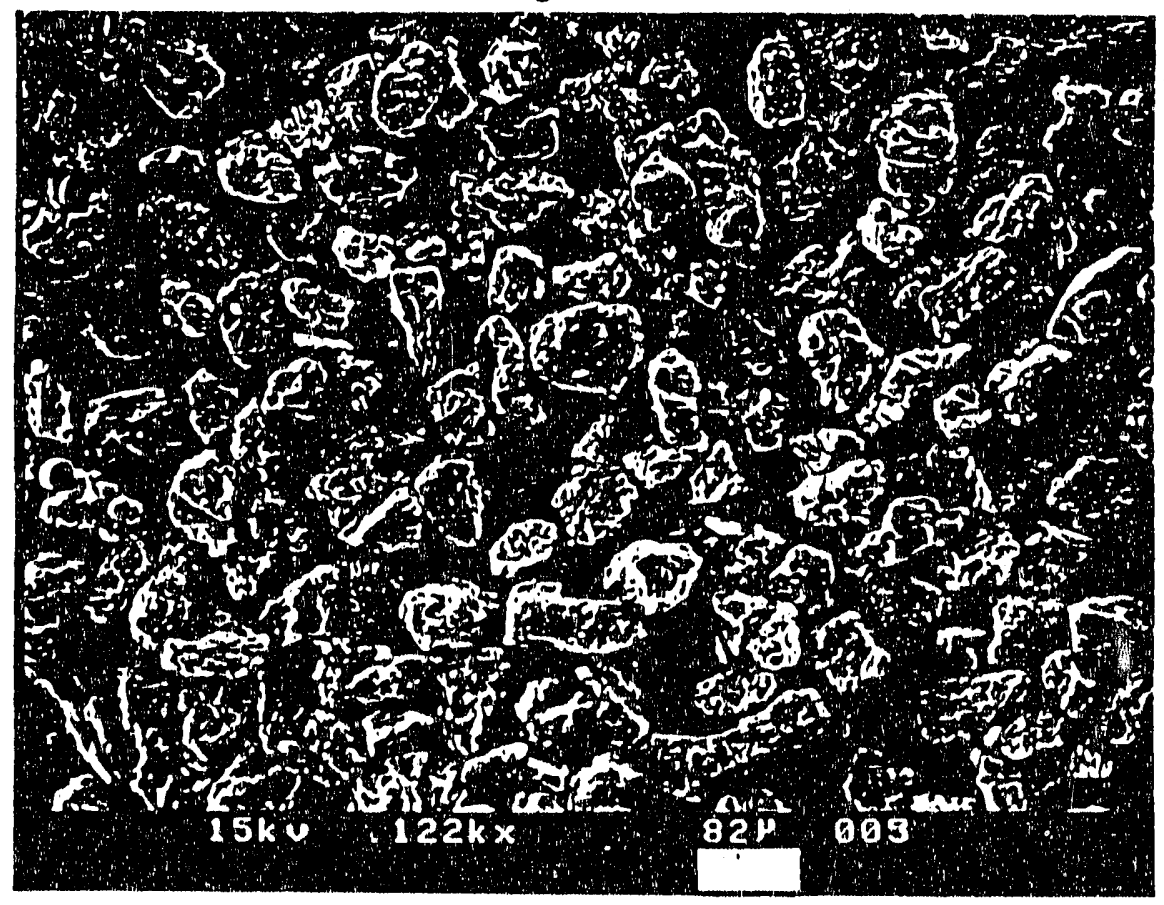

PSOC-1520D Char Prepared in $\mathrm{N}_{2} / \mathrm{N}_{2}$ at $1073 \mathrm{~K}$, Residence time $=131 \mathrm{msec}$, Coal Size $=75.63$ microns, 122 Magnifications 
Figure 2.48

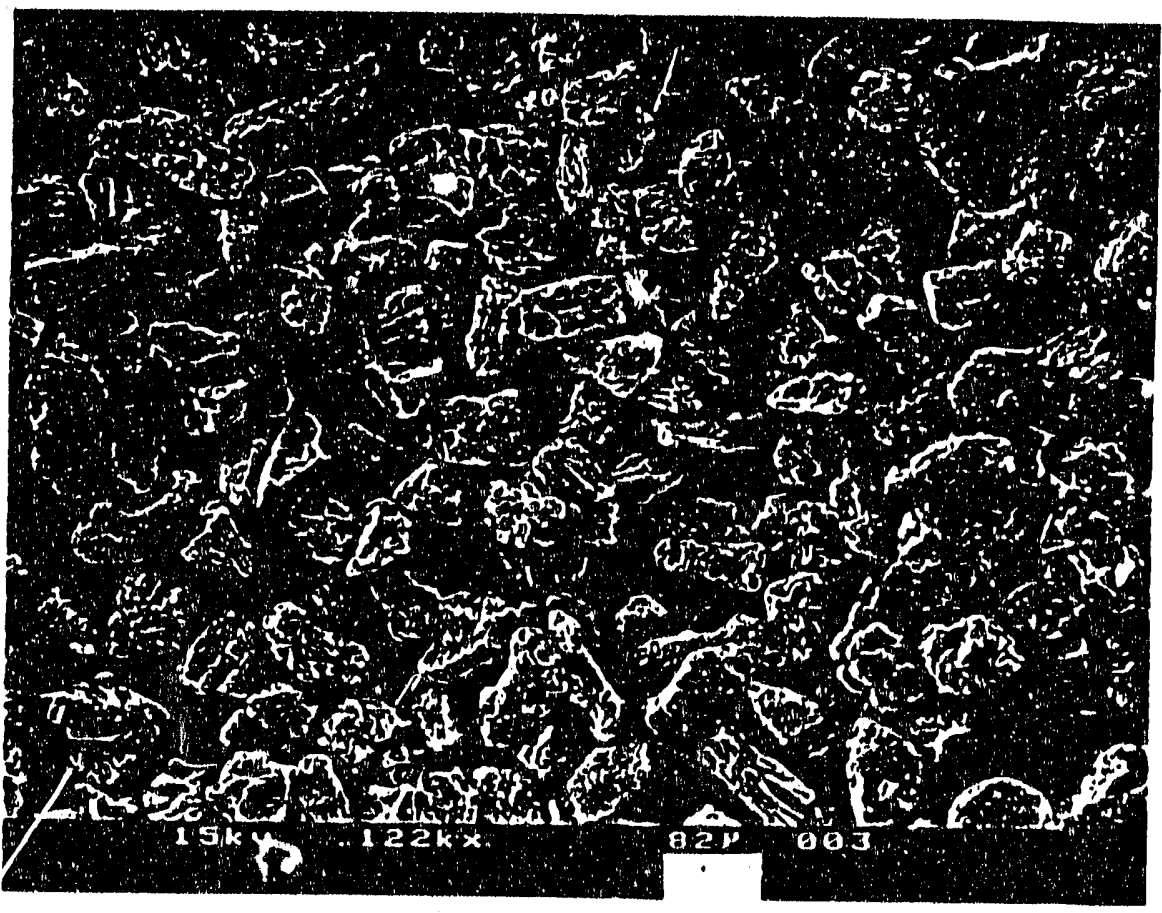

PSOC-1520D Char Prepared in $\mathrm{N}_{2} / \mathrm{N}_{2}$ at $1073 \mathrm{~K}$, Residence time $=131$ msec, Coal Size $=75.63$ microns, 12.2 Magnifications

Figure 2.49

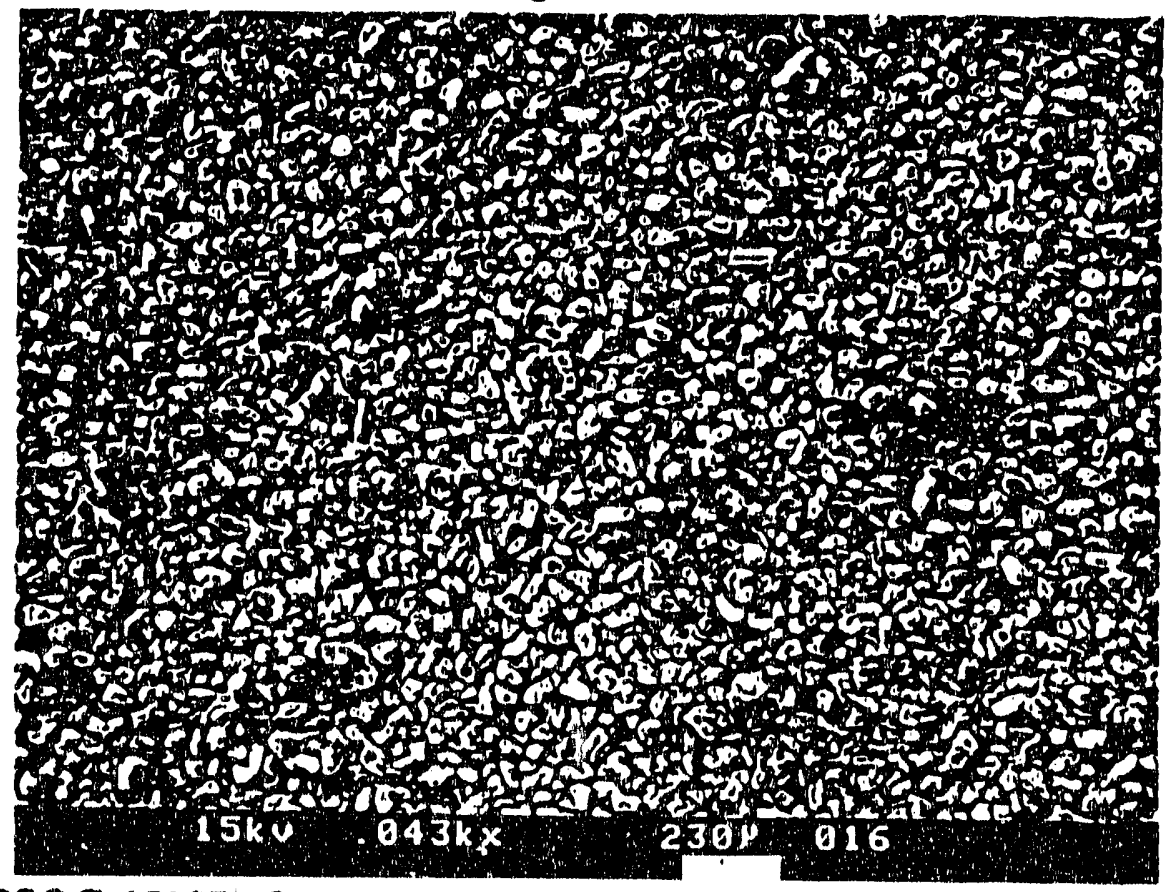

PSOC.1520D Char Prepared in $\mathrm{N}_{2} / \mathrm{N}_{2}$ at $1073 \mathrm{~K}$, Residence time $=198 \mathrm{msec}$, Coal Size $=75.63$ microns, 43 Magnifications 
Figure 2.50

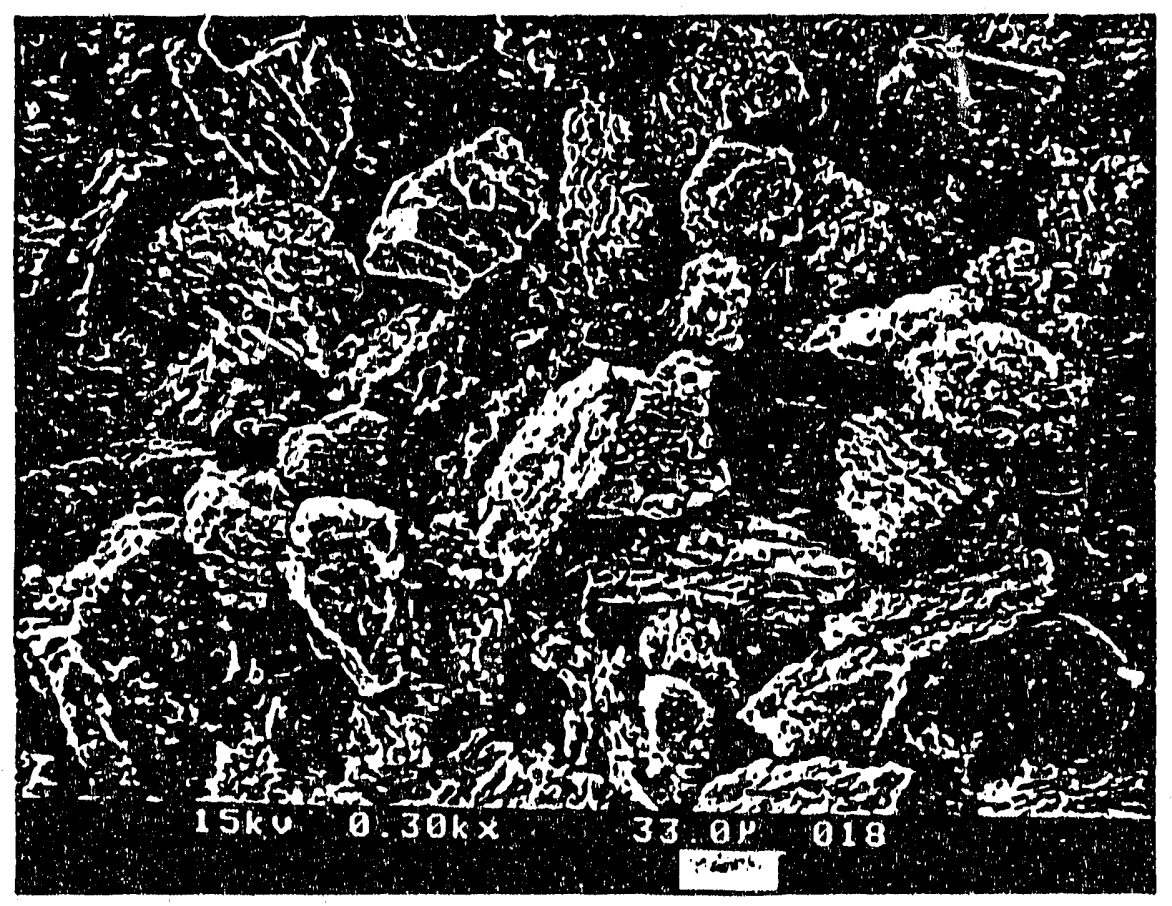

PSOC-1520D Char Prepared in $\mathrm{N}_{2} / \mathrm{N}_{2}$ at $1073 \mathrm{~K}$, Residence time $=198 \mathrm{msec}$, Coal Size $=75.63 \mathrm{microns} 300$ Magnifications 
$k x$ on each fgure), It can be seen that the particles were equal or slightly smaller at short residence times $(t=121 \mathrm{msec})$. While Fig. 2.42 shows some particles that were probably crushed during sample preparation, its magnification (Fig. 2.43) indicates that some particles are already beginning to develop a more porous structure with respect to the raw coal $(F i g, 2,41)$. The cffect is more pronounced at longer residence umes $(t=194 \mathrm{msec}$ ) for a sllghtly smaller size fraction (Figs. 2.45 and 2.46), In fact, Fig. 2.46 already shows particles which resemble those observed for pyrolyzed bltuminous coal chars (Figs, 2.34 and 2.35 ) However, the concentration of particles displaying cenosphere structural characteristics is considerably smaller for the subbituminous coal chars. This may reflect the difference In maceral compositions in the original coals.

It is somewhat surprising, nevertheless, that subbituminous coal chars may exhibit cenosphere formation under the conditions studied here. Even the smallest size fractions considered gave evidence of cenosphere formation (Flgs, 2.47 through 2.50 ), although the magnified pictures show, in addition to porous particles, smoother particles with fewer visible holes or ridges. Therefore, it appears that cenosphere formation is possibly on pyrolyzed PSOC-1520D soal chars,

\subsubsection{Sandia - MIT Entrained Flow Reactor (SMIT-EFR) Investigation}

\section{Experimental Facilities and Procedures}

The entrained flow reactor used for the sampling of char is shown in Fig. 2.51. This reactor consists of feeding, heating, cooling, and collecting systerns and a reaction zone. Coal particles are placed in a syringe plunger with a stepping mecor. Coal particles in the feeding tube should be well diluted so the agglomeration of softened coal particles does not occur in the reaction zone. This is accomplished by maintaining a slow speed of the stepping motor and by use of an entrainment gas ( $N_{2}$ in this case) and rotating brush. The feeding tube has a diameter of $0.0794 \mathrm{~cm}$ and is connected to a water-cooled injector. The entrainment gas $\left(N_{2}\right)$ served as the heating inedlum in the reaction zone and was preheated by three furnaces $\left(F_{1}, F_{2}\right.$, and $F_{3}$ ) whose temperatures are controlled.

In order to ensure a laminar flow of the entrainment gas and that the particle flow paths are located at the center of the reaction zone, mullite honeycomb flow straighteners are used in the third stage heater and the flow rate of the entrainment gas is carefully adjusted. The reaction zone is in a quartz chimney with an internal $4.73 \times 4.73 \mathrm{~cm}$ cross-section. The position of the entire heating system is adjustable to have a desired distance between the particle injector and the sampling probe. 
Figure 2.51

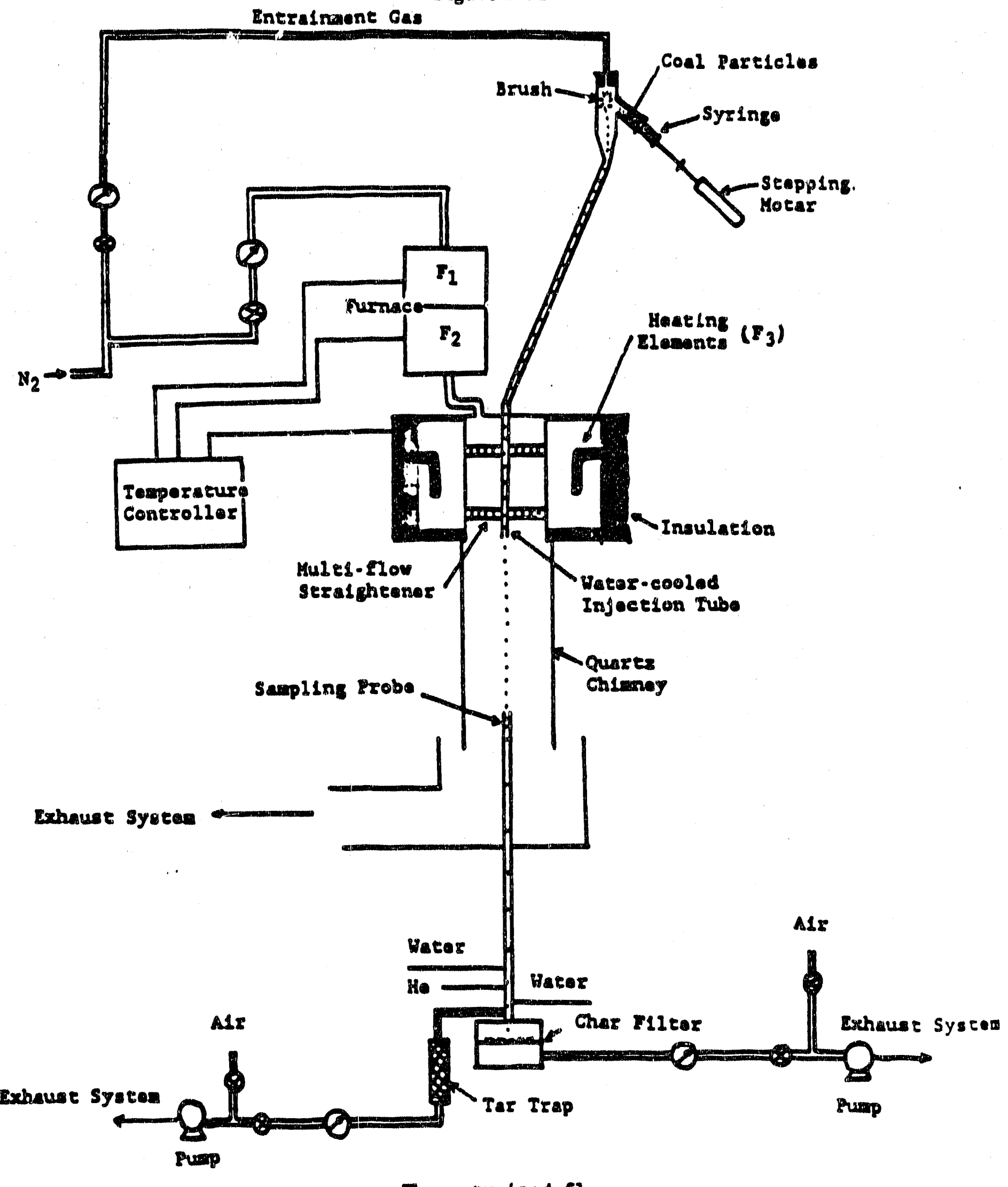

The entralned flow reactor. 
The sampling probe, shown schematically in Fig. 2.52, has an internal diameter of $3 / 8$ inch. The cross-section of the probe is much larger than the spread area of the particle stream. The probe tip is shaped so that the taper is on the probe exterior: particles therefore travel directly into the probe and do not deposit In the probe inlet. Hellum jets inside the probe tip quench both the entering gas and the particles from the reactor. The interior wall of the probe consists of a porous metal tube. Helium transpiring through this porous tube prevents deposition of tars, soot, and other aerosols in the probe. The entire probe is cooled by a water circulation.

The quenched gases and hellum then pass through a char filter (Pyrex Wool, fiberglass) and tar trap ( $76 \mathrm{~mm}$ diameter PVC membrane with $12 \mu \mathrm{m}$ pores) for the separation of char and tar (Fig. 2.51). Most of the tar and aerosols (less than $5 \mu \mathrm{m}$ diameter) follow the main flow of gas and are deposited in the tar trap. while larger char particles are collected on the char filter (Ref. 2.20). Carefully adjusting suction rates of quenched gases and helium into the exhaust system are necessary. A higher suction rate leads to more suction of hot nitrogen into the probe, hence causing a slow cooling rate and possibly a heat-up of internal section of the probe which may destroy the probe due to faster expansion of the porous tube than its surrounding water jacket. On the other hand, if the suction rate is too slow, the quenching helium may overflow into the reaction zone and the pyrolyzed coal char may never drop into the probe.

Precedures. The following procedure was used in the experimental runs:

1) Turn on the entire system and set the initial furnace temperatures, which roughly correspond to the desired gas temperatures, at least 16 hours prior to the experiments for the warm-up.

2) Open the valve of the $N_{2}$ entrainment gas, and set its flow rate. Adjust the furnace temperature to obtain the desired gas temperatures. The adjustment is by trial-and-error. The gas temperatures vs the distance between the particle injector and the sampling probe are measured by a thermocouple (Type $R,(P t)-(P i+13 \% R h)$, bead diameter $\simeq 100$ $\mu \mathrm{m})$.

3) Measure the gas temperatures inside the sampling probe vs the distance from the probe mouth, using a thermocouple ( Type $\mathrm{K}$, Chromel-Alumel Alloy, bead diameter $=1 / 16$ inch).

4) Set the desired distance between the particle injector and the sampling probe. Load coal particles in the syringe and set the speed of the stepping motor. 
Figure 2.52

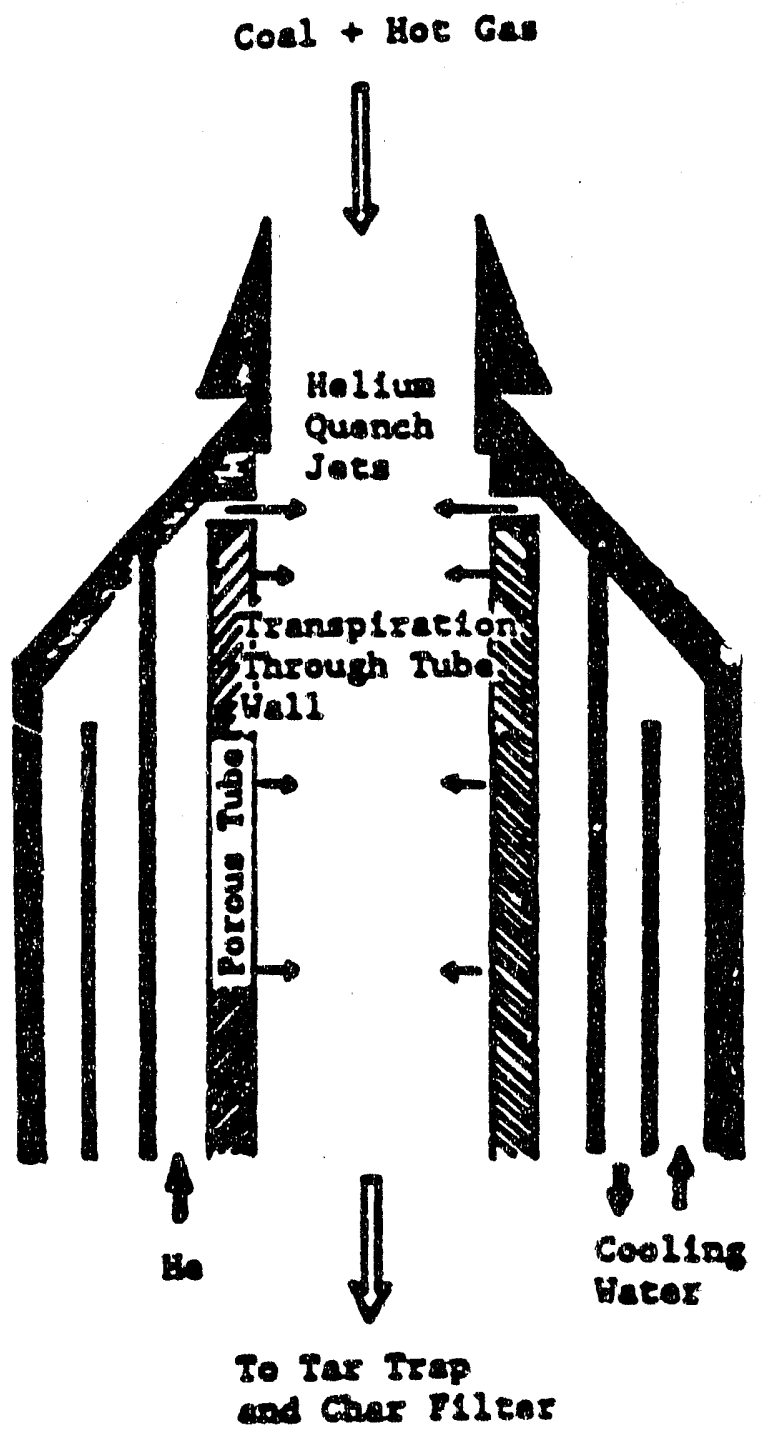

The sampline probe. 
R88-PC70768

5) Put Pyrex Wool (fiberglass) into the char trap and use PVC membrane as tar filter. During the experiments, fiberglass and membrane filter have to be changed frequently in order to avoiding blocking the flow of exhaust gases.

6) Turn on the probe quenching helium and cooling water and set their flow rates.

7) Turn on the stepping motor and start to collect char while carefully adjusting the suction rate of cooled gases.

After collection of char samples, their physical properties are measured. In this study, morphological changes, pore volume, BET surface area, density, and porosity of pyrolyzed char are the major properties of interest.

\section{Measurements}

Rhotographs from Scanning Electron Microscopy Scanning electron microscopy and optical microscopy were used to take photographs of the particle surface and the particle cross-sections. Preparation of coal char for the cross section microscopic examination consists of two methods: 1) high pressure technique (employed at SNLL) and vacuum technique (employed at M.I.T.). A small amount of char is mixed with a mixture of styrene, vinyl toluene and acrylate monomers (polyester resin) and with a hardener, MEK peroxide in dimethyl phthalate, in a mould. the volume ratio of polyester resin to hardener is about 100:1. The mixture (with char) is then placed in a high pressure $(10,000$ psia) vessel to force polyester resin into voids inside the char, or in a desiccator for further processing when using the vacuum technique.

The vacuum technique is similar to that employed by Lightman and Street (Ref. 2.21). The pressure in the desiccator is reduced several times, each time the pressure being returned to atmospheric so that after removal of air from the char paricle polyester resin can flow further into evacuated voids still remaining. When the samples bearing dispersed char are set hard, they are ground on a coarse emery wheel until char is exposed. The resin surface is then polished on a mechanized wheel using successively $240,320,600$ grade emery papers followed by $20 \mu \mathrm{m}$ aluminum powder. The well polished samples are then ready for microscopic examination.

Preparation of coal char for the particle-surface microscopic examination is quite straight forward. A thin film of colloidal graphite (mixed with alcohol) is first spread on a half-inch-diameter aluminum holder. Char particles are then scattered on top of the graphite-alcohol film. The loose particles are blown off after 
the graphite is dried and then the sample is coated with a film of gold in a vacuum evaporating unit for subsequent microscopic examination.

Swelline Ratio. The extent ar.d significance of particle swelling during pyrolysis are evaluated by measuring the swelling ratio, defined as the particle diameter at any pyrolysis time divided by the initial particle diameter. Because of the irregular external shape of the char particles, the particle diameter used here is derived by converting the projected external surface area of each particle seen in the SEM pictures to an equivalent spherical diameter.

The projected external surface areas of about 40 particles for each sample are measured by a Toyce-Loebl Magiscan II Image analyzer at M.I.T. The analyzer is sensitive to the contrast between a particle image and its background in the SEM pictures. The projected areas of analyzed particles are carefully reproduced on a transparent film, using a waterproof-black pen to guarantee uniform contrast for all measurements. Assuming a Gaussian distribution, the mean and standard deviation of the swelling ratio are obtained by best fitting the data.

BET Surface Area Rore Volume. Particle and Solid Densities, and Porosity. Samples of coals and partially reacted coal chars were analyzed at the Particle Characterization Facility (PCF) at the Lawrence Livermore Laboratory. The facility is equipped to carry out nitrogen absorption analyses for BET surface area, and mercury intrusion porosimetry for determining particle and solid densities, and void fraction. Here particle density is defined as the mass of a single particle divided by its total volume including internal voids. Solid density is defined as the mass of an individual coal particle divided by the volume of solid material only.

Prior to $t !$ = nitrogen absorption analyses and mercury intrusion porosimetry, each sample (roughly 2.5 gm) was baked under vacuurn $\left(10^{-5}\right.$ torr) at $200^{\circ} \mathrm{C}$ for several hours to remove gaseous or liquid contaminants from the particle. A Digisorb 2600 is used to analyze the particle surface area. The analysis consists of a 5-point BET calculation and the relative pressure (applied pressure/saturation pressure of adsorbate gas) is varied from 0.05 to 0.21 .

Mercury intrusion porosimetry utilizes the theory of liquid-solid contacting in capillaries to provide information on char pore size distributions. Assuming cylindrical pores, the pore diameter (D) is given by

$$
D=-\frac{4 \pi}{P} \operatorname{Cos} \theta
$$


where $\mathrm{P}$ is the applied pressure, $\tau$ the surface tension of mercury, and $\Theta$ the contact angle between the liquid (here mercury) and solid (here char). The volume of mercury ( $V$ ) penetrating the pores is measured directly as a function of applied pressures. This $D-V$ information serves as a unique characterization of pore structure. The present measurements used an Autopore 9200 mercury porosimeter with 56 intrusion points and 27 extrusion points. Pressures as high as $60 \mathrm{~K}$ psi wiere employed which according to equation 2.2 (Ref. 2.22) correspond to a minimum pore diameter of about $30 \AA$

Although pores in the char are rarely cylindrical (as observed from scanning electron microscopy), this approximation is generally accepted as a reasonable approach for data interpretation. The surface tension of mercury is usually accepted as 484 dynes $/ \mathrm{cm}$. The contact angle varies somewhat with solid composition. A value of 130 degrees is assumed in general.

Particle density $\left(\varrho_{p}\right)$ is calculated by assuming a mercury density $\left(\varrho_{m}\right)$ of $13.5335 \mathrm{~g} / \mathrm{cc}$. The following equations were employed.

$$
\begin{aligned}
& Q_{p}=\frac{\text { Sample Weight }}{\text { Sample Volume }}=\frac{W}{V_{p}}=\frac{W}{V_{p t r}-V_{m}} \\
& V_{m}=\frac{W_{2}-W_{1}}{Q_{m}}
\end{aligned}
$$

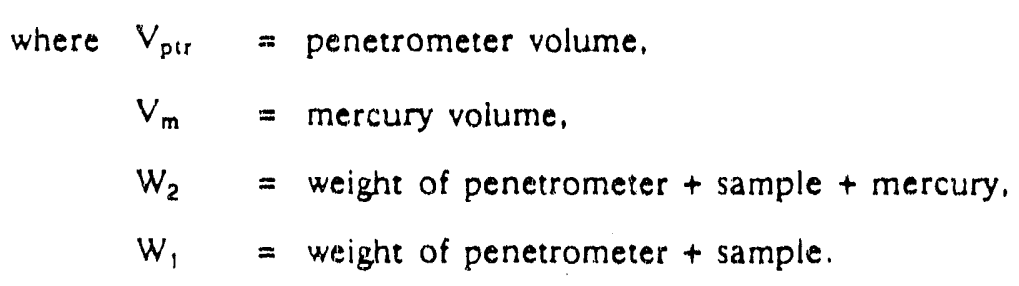

Solid density $\left(Q_{1}\right)$ is calculated by

$$
\begin{aligned}
& Q_{1}=\frac{\text { Sample Weight }}{\text { Solid (skeletal) Volume }}=\frac{W}{V_{1}} \\
& V_{1}=V_{p}-V_{1} W
\end{aligned}
$$

where $V_{1}=$ total intrusion volume of mercury per unit weight of sample (in $\mathrm{cc} / \mathrm{gm}$ ). 
The void fraction (=porosity) is defined as

$$
\% \text { Porosity }=100\left(1-\frac{\text { Particle Density }}{\text { Solid Density }}\right)
$$

The solid density defined here does not necessarily refer to the true solid density, since the solid volume obtained depends somewhat on the method of measurement. In this case, the solid volume may still include pores smaller than 30 Angstroms.

Detailed discussions of BET surface area and mercury intrusion porosimetry can be found in standard references (Ref. 2.22, and 2.23).

Weight Loss Determination. Weight loss (WL) due to pyrolysis is determined by 1) solid density, 2) ash analysis, and 3) titanium analysis. The first method approximates weight loss as

$$
W L=1-V_{s} \varrho_{3} / V_{0} \varrho_{s o} \approx 1-Q_{3} / Q_{s o}
$$

where $V_{1}$ and $Q_{s}$ are volume and density of solid material and the subscript 0 represents their initial values. The approximation assumes the volume change of solid in pyrolyzed coal is negligible. For swelling coals, this will be reasonable only when the weight loss is low."

Ash and titanium tracer techniques assume that ash and titanium mass are constant during pyrolysis. The weight loss is defined (on an as-received basis) as

$$
W=\left[:-\frac{y_{10}}{y_{i}}\right] 100 \%
$$

where $\quad y_{i o}=$ initial ash (or titanium) mass fraction in the coal particle (as received),

$y_{i}=$ ash (or titanium) mass fraction in the char particle.

The ash content is determined by the ASTM technique. The concentration of titanium, existing in coal or char in a form of $\mathrm{TiO}_{2}$, is analyzed at the Combustion Research Facility, SNLL, by an inductively-coupled plasma (ICP) optical emission spectroscopy. This instrument was selected for this work

- Furthermore, the known uncertainties in the mercury porosimetry technique contribute to uncertainties in the solid densities, and thus to uncertainties in the weight losses calculated from them. (Dr. T.H. Fletcher, private communication, May 1988.) 
because of its sensitivity down to parts per million, its ability to determine refractory elements, and the capability of simultaneous multi-element analysis, although it requires extreme care and maintenance.

Prior to the analysis, coal (char) has to be properly prepared. The sample is mixed with an aqueous solution containing 10 percent aqua regia (three parts hydrochloric acid and one part nitric acid) and 10 percent hydrofluoric acid. The sample is then put into a teflon container, covered, and placed in a laboratory microwave oven for 10 minutes to leach out the elements of interest. The HF helps dissolve silicates and refractory metals. Following cooling and filtering of insoluble solids (organic material), boric acid is added to the solution. This is to convert the HF (by forming tetrafluoboric acid) since it will attack the quartz torch of the instrument. The arnount of $\mathrm{HF}$ and $\mathrm{H}_{3} \mathrm{BO}_{3}$ employed must be the same for calibration and actual measurements.

The prepared solution is then injected into the instrument where it is heated by an argon plasma, generated by an inductively-coupled plasma technique. Temperatures of the plasma, in the range of 6000 to $10000 \mathrm{~K}$, are high enough that refractory oxides such as $\mathrm{TiO}_{2}$ are easily dissociated and provide very intense emission from both the atomic and lonized species. Every element emits its own characteristic wavelengths. Emission spectroscopy is used to determine elements present in the plasma. Calibration is required for quantitative determinations of each elenent.

Ash Proximate Analvsis. Ash content in raw coal and char is determined, according to ASTM D3172. Approximately $1 \mathrm{gm}$ of raw coal (as-received) or $0.2 \mathrm{gm}$ of char is placed in a cold furnace and gradually heated to $500^{\circ} \mathrm{C}$ in 1 hour and to the final temperature of $750^{\circ} \mathrm{C}$, in 2 hours, and held for at least 5 hours at $750^{\circ} \mathrm{C}$. The ash is then naturally cooled in a desiccator and weighed as soon as it reaches room temperature.

\section{Coal Selection}

A high-volatile bituminous coal. Pittsturgh Seam No. 8. (PSOC 1451D) was the focus of this experimental work. Particle-size ranges of 30-45, 60-75, and 106-125 $\mu \mathrm{m}$ were studied. The ultimate analysis, proximate analysis, and maceral composition for the selected coal are presented in Table 2.9. The data are taken from the Penn State Coal Data Base.

With the ASTM technique, different particle sizes show different ash contents. Table 2.10 lists the values obtained for each replicate analysis and the arithmetic average of the replicate results. The results generally agree with those obtained at UTRC( see Appendix A.1). 
R88-PC70768

TABLE 2.9 - CHARACTERISTICS OF SELECTED COAL

Data Source: Penn State Coal Data Base

Coal Type: Pitisburgh Seam No. 8 bituminous coal: PSOC 1451D

Proximate Analysis (Wt \%)

$\begin{array}{lrrr} & \text { As Rec'd } & \text { Dry } & \text { DAF } \\ \text { \% Moisture } & 2.5 \% & & \\ \text { \% A.sh } & 13.32 & 13.67 & \\ \text { \% Volatile } & 33.56 & 34.43 & 39.88 \\ \quad \text { Matter } & & & 60.12 \\ \text { \% Fixed Carbon } & 50.58 & 51.90 & \end{array}$

Ultimate Analysis (Wt \%)

$\begin{array}{lccr} & \text { As Rec'd } & \text { Dry } & \text { DAF } \\ \text { \% Ash } & 13.32 & 13.67 & \\ \text { \% Carbon } & 70.05 & 71.38 & 83.26 \\ \text { \% Hydrogen } & 4.55 & 4.67 & 5.41 \\ \text { \% Nitrogen } & 1.33 & 1.36 & 1.58 \\ \text { \% Sulfur } & 1.33 & 1.36 & 1.58 \\ \text { \% Chlorine } & 0.07 & 0.08 & 0.09 \\ \text { \% Oxygen } & 6.81 & 6.99 & 8.10\end{array}$

Maceral Composition (Vol \%)

$\begin{array}{cccr}\begin{array}{c}\text { Particle diameter } \\ (\mu \mathrm{m})\end{array} & \text { Vitrinite } & \text { Intertinite } & \text { Exinite } \\ 210-250 & 69.7 & 12.7 & 17.6 \\ 106-125 & 84.6 & 7.1 & 8.2 \\ 63-75 & 84.8 & 7.7 & 7.5 \\ 30-45 & 88.0 & 7.0 & 5.1\end{array}$




\section{TABLE 2.10 - ASTM ASH ANALYSIS OF PITTSBURGH SEAM NO. 8 BITUMINOUS COAL}

\begin{tabular}{lrrrr} 
& \multicolumn{4}{c}{ Replicate $\left(W_{t} \%\right)$} \\
\cline { 2 - 5 } Size $(\mu \mathrm{m})$ & \multicolumn{1}{c}{1} & 2 & \multicolumn{1}{c}{3} & Average \\
\hline $30-45$ & 6.3 & 6.4 & 6.7 & $6.5 \pm 0.2$ \\
$63-75$ & 4.6 & 4.3 & 4.3 & $4.4 \pm 0.1$ \\
$106-125$ & 11.6 & 11.1 & 11.5 & $11.4 \pm 0.2$ \\
$210-250$ & 22.2 & 22.3 & 24.9 & $23.1 \pm 1.2$
\end{tabular}

Results and Discussions. The experiments were designed to cover three gas-temperature profiles in the reactor and three ranges of particle diameters 30-45, 63-75, and 106-125 $\mu \mathrm{m}$. The gas-temperature profiles, corrected for radiation losses to the reactor wall, are indicated as low, intermedlate, and high temperature, in Fig. 2.53, with peak temperatures as shown. The approximate gas veiocity in the flow reactor is $1 \mathrm{~mm} / \mathrm{msec}$ (Ref. 2.24). Hence, assuming the coal particles closely follow the gas temperature, typical heating rates exceed $10^{4} \mathrm{~K} / \mathrm{sec}$. Figure 2.54 shows the quenched-gas temperatures in the probe as a function of distance from the probe mouth. The radiation correction to the thermocouple was small. The gas was quenched, for example, from $1033 \mathrm{~K}$ to $459 \mathrm{~K}$ in $4 \mathrm{~mm}$, corresponding to a gas-quenching rate of approximately $10^{8} \mathrm{~K} / \mathrm{sec}$ as calculated from a heat-transfer model (Ref. 2.24). Particle quenching time is slightly longer due to thermal inertia of the particle. The temperature profile was obtained with an entrained flow rate of $30 \mathrm{slpm}$ (standard liter per minute) $\mathrm{N}_{2}$ and suction rates of 58-61 slpm and 21-23 s/pm for tar and char flows, respectively. The particle feeding rates ranged from 7.0 to $23.0 \mathrm{mg} / \mathrm{min}$. The pyrolyzed coal char was collected at distances of 3 to $29 \mathrm{~cm}$ from the particle injector, corresponding to residence times of approximately 30 to $290 \mathrm{msec}$ in the reaction zone.

However, in this report, the analytical results will be presented as a function of distance between the particle injector and the probe mouth rather than bulk resident time, because the precise measurements $r$. particle velocity in the reactor necessary for reliable :esidence time determination were not included in these experiments.

Figure 2.55 shows the SEM photographs of initial particles with particle size $106-125$ and $63-75 \mu \mathrm{m}$. Figures 2.56 to 2.62 and 2.63 to 2.67 show subsequent changes in morphology of both the particle surfaces (upper pictures) and their corresponding cross-sections (lower pictures) at the intermediate reactor temperature profile. These figures are described and discussed in detall below. 


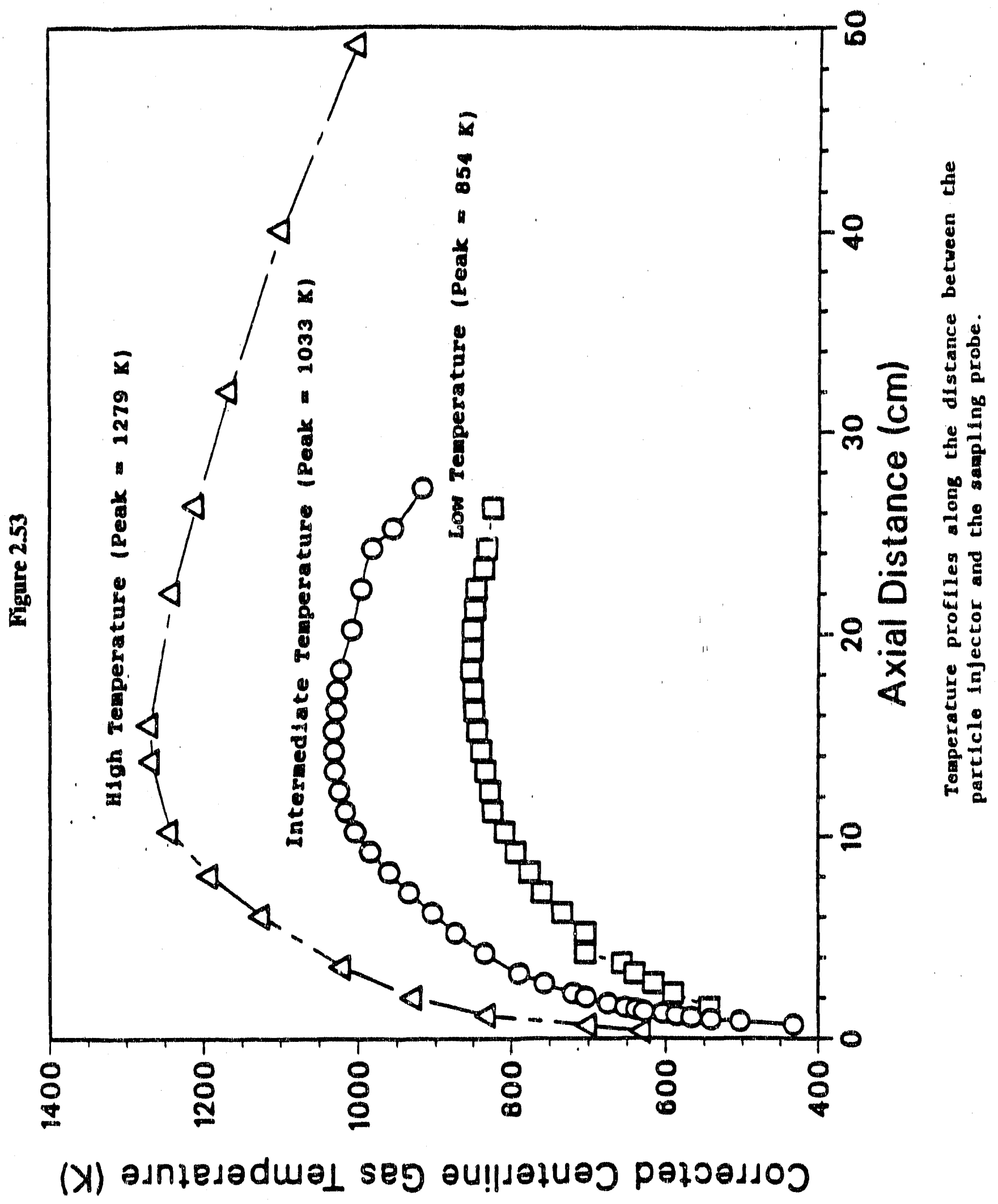




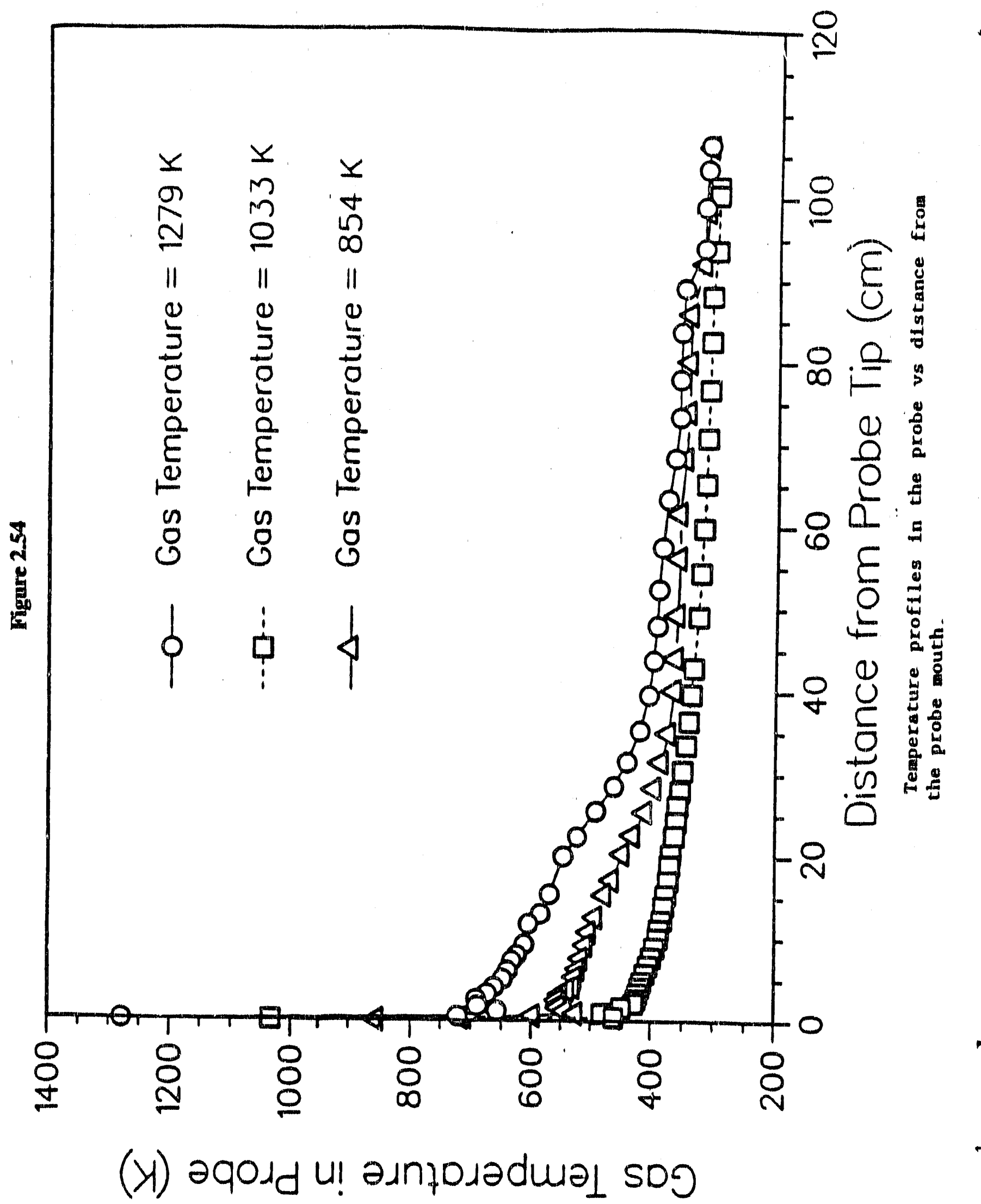


Figure 2.55
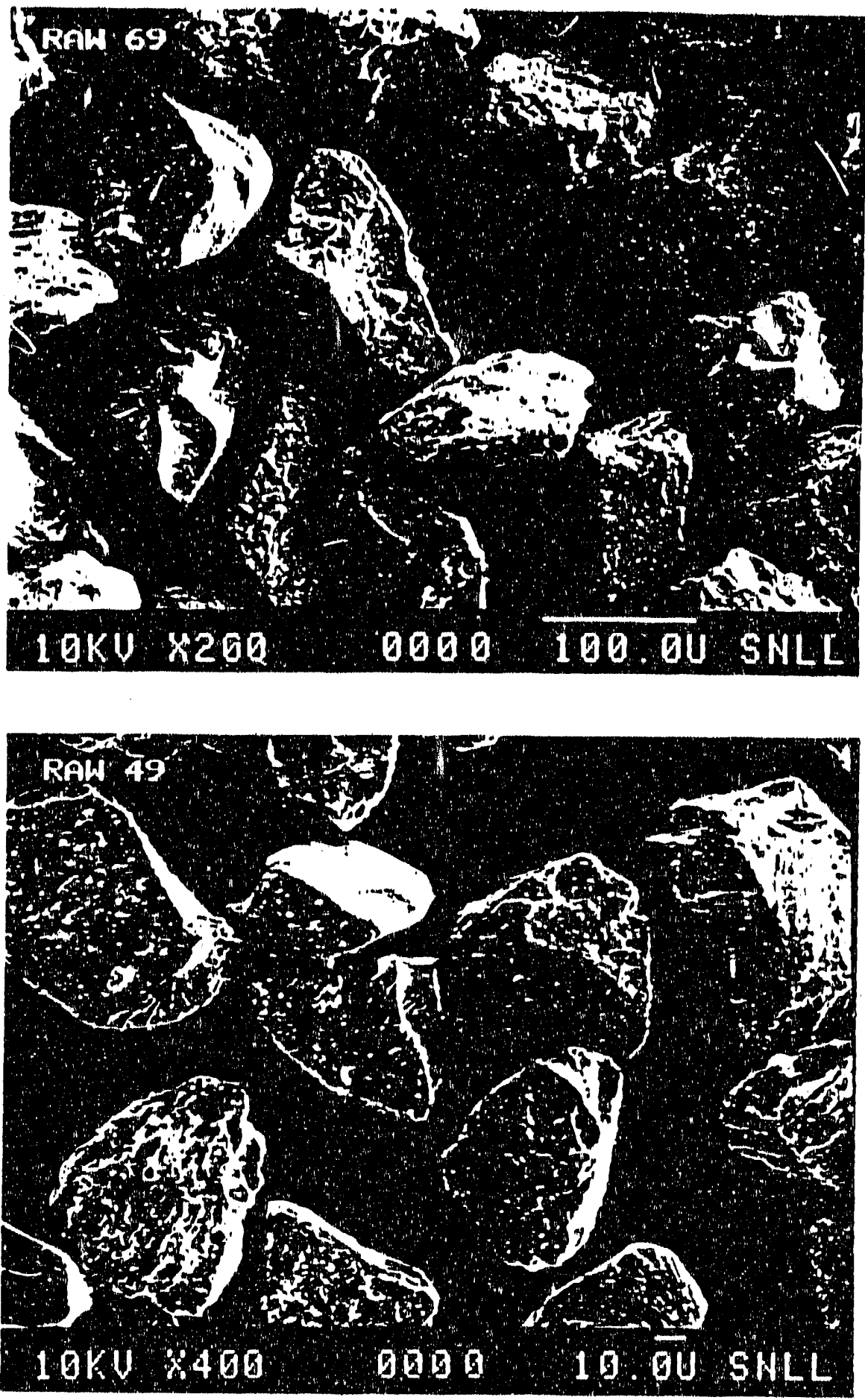

SEM photographs of raw coal. The inftial particle

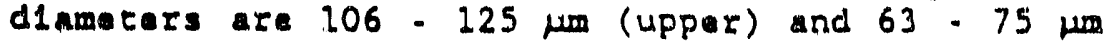
(low:r). 
Figure 2.56
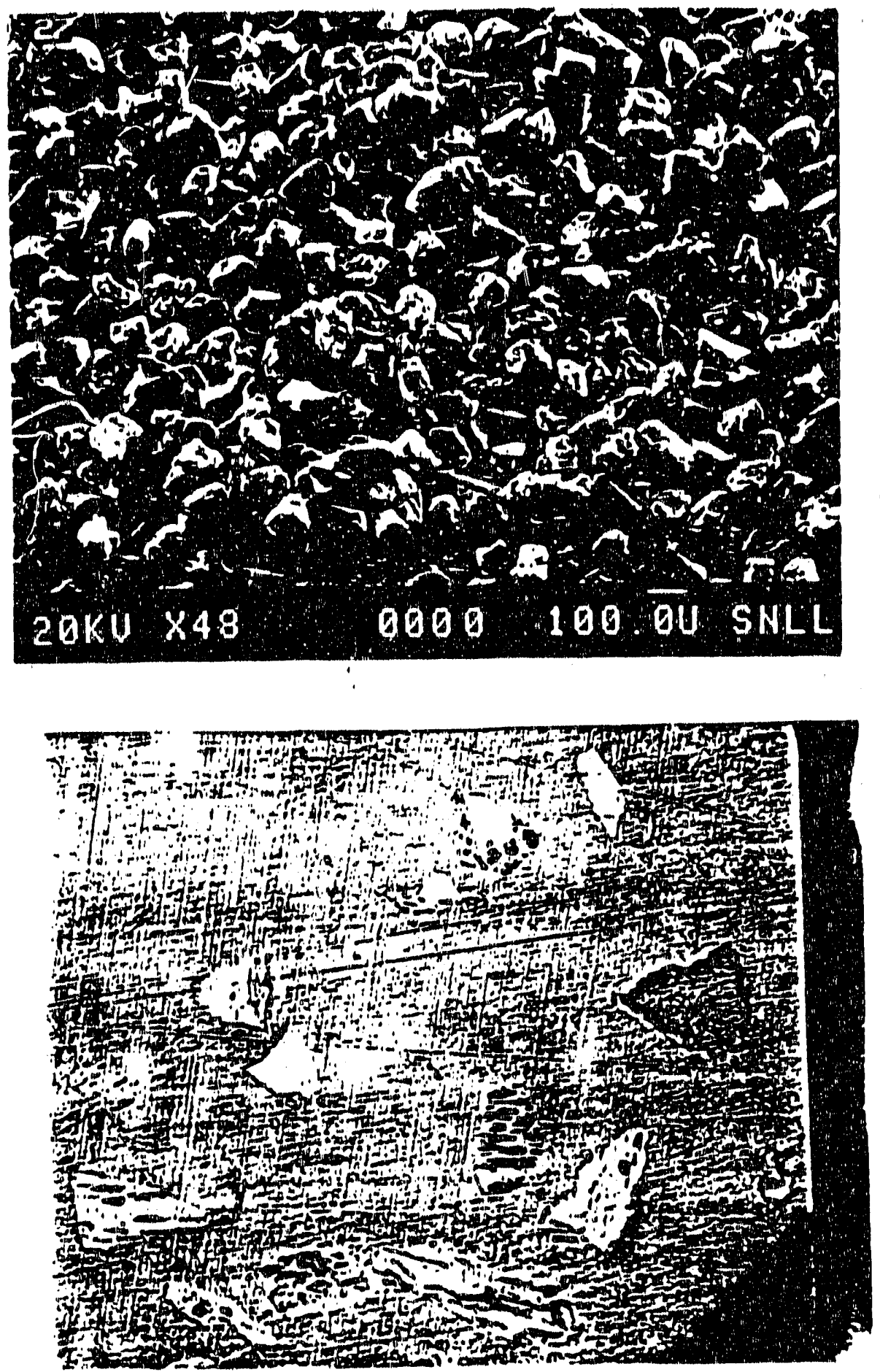

SEM photographs of char (upper) and 1 tg corrosponding cros -soction (lower) collacted at 5 cu at tho inter. mediate comperature condition: infelal particle diamer - $106-125 \mu$ magnificalion for the cross. section -100 . 
Figure 2.57
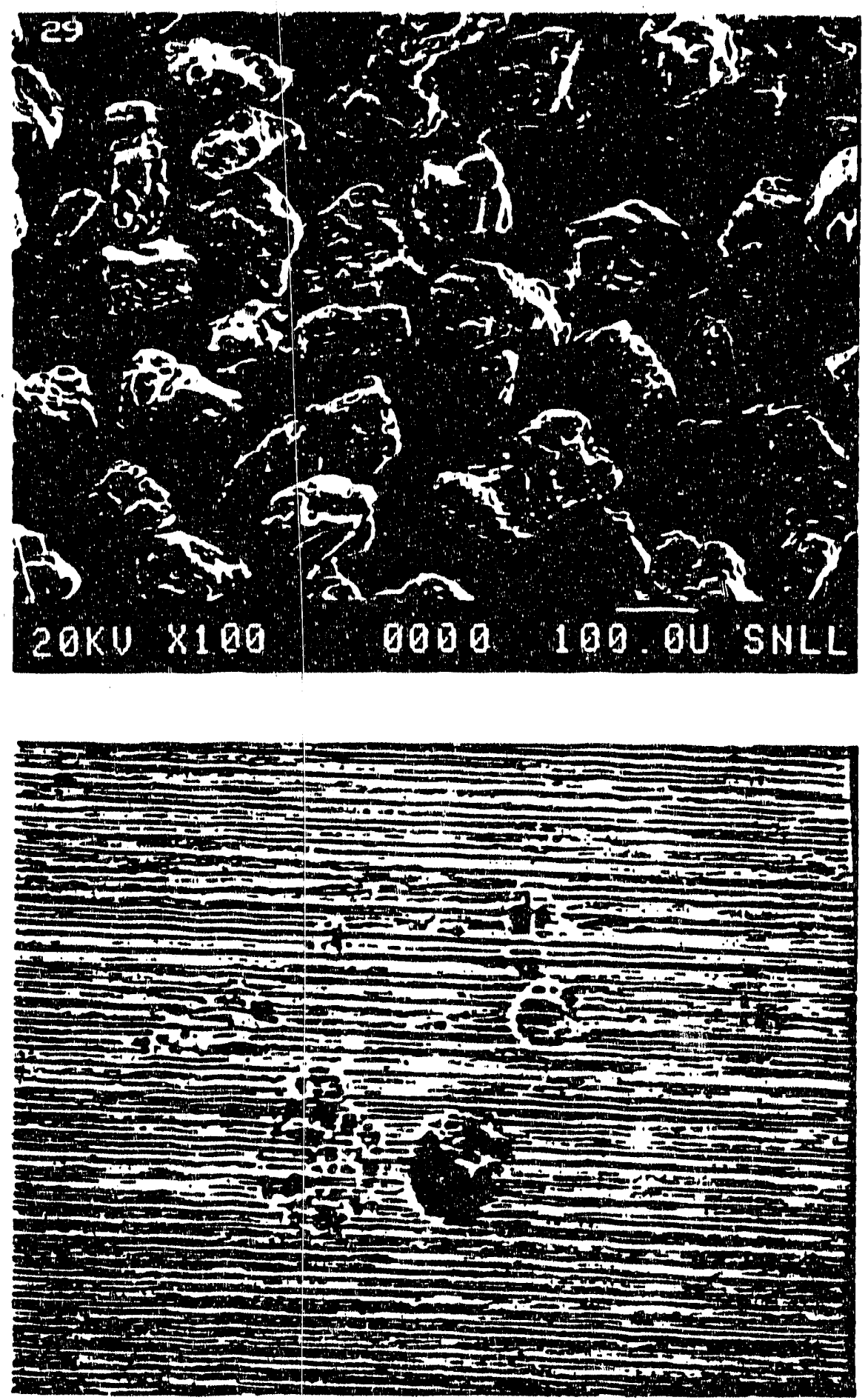

SEM photographs of shar (upper) and 1ta corrosponding crosa-section (lowar) collectud at 9 em at the lnter. aediate tomerature condlelon; latelal particlo diancter - 106 - $125 \mathrm{Hm}$; magnification for the cross$\operatorname{section}=100$. 
Figure 2.58
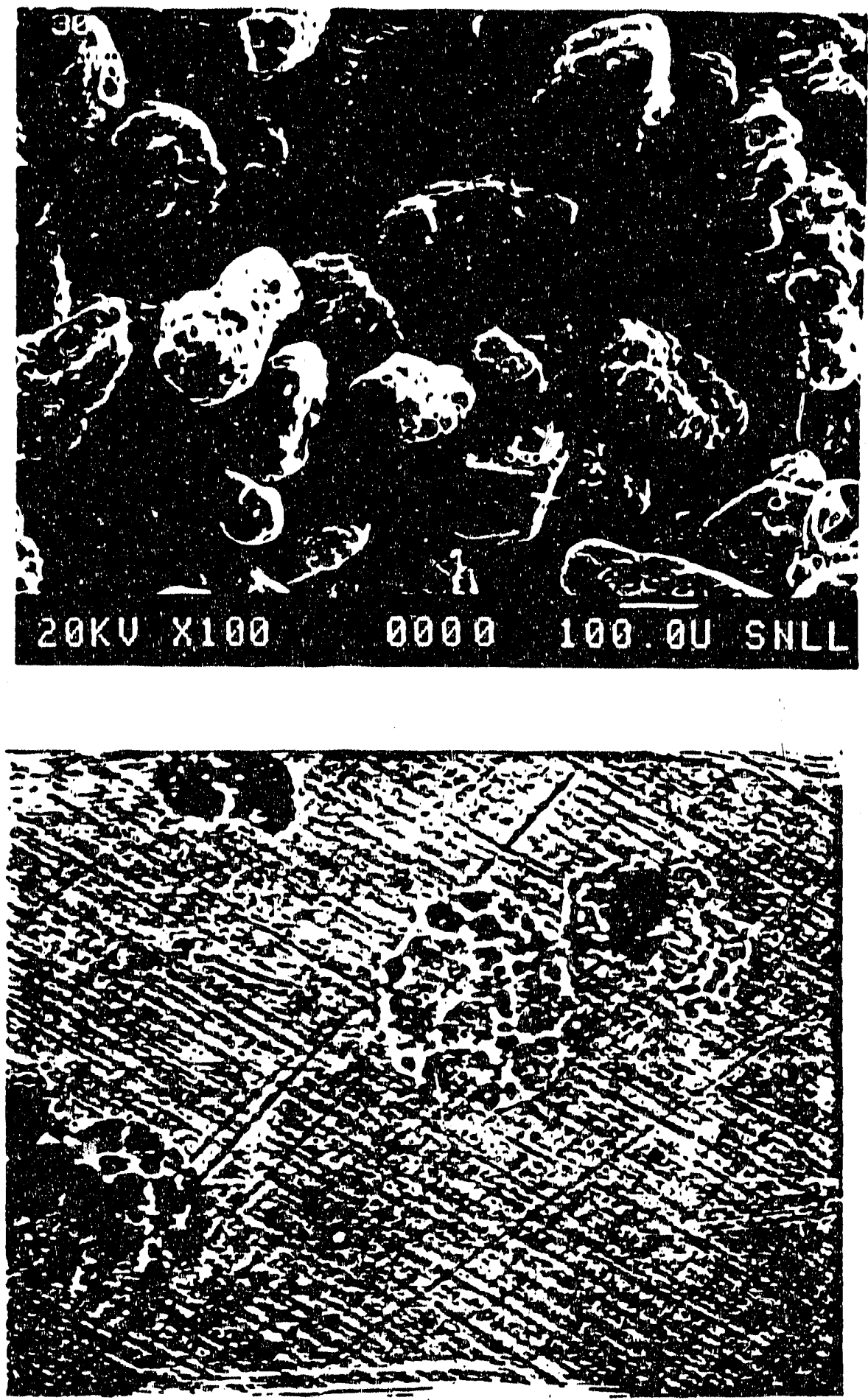

SEM photographa of char (upper) and lts corrasponding cross-gecton (lower) collected at $12 \mathrm{co}$ at the intar. medlate tomperature condition; inltial particlo diameter - 106 : $125 \mu m$; magnifleation for the cross. section -100 . 
Figure 2.59
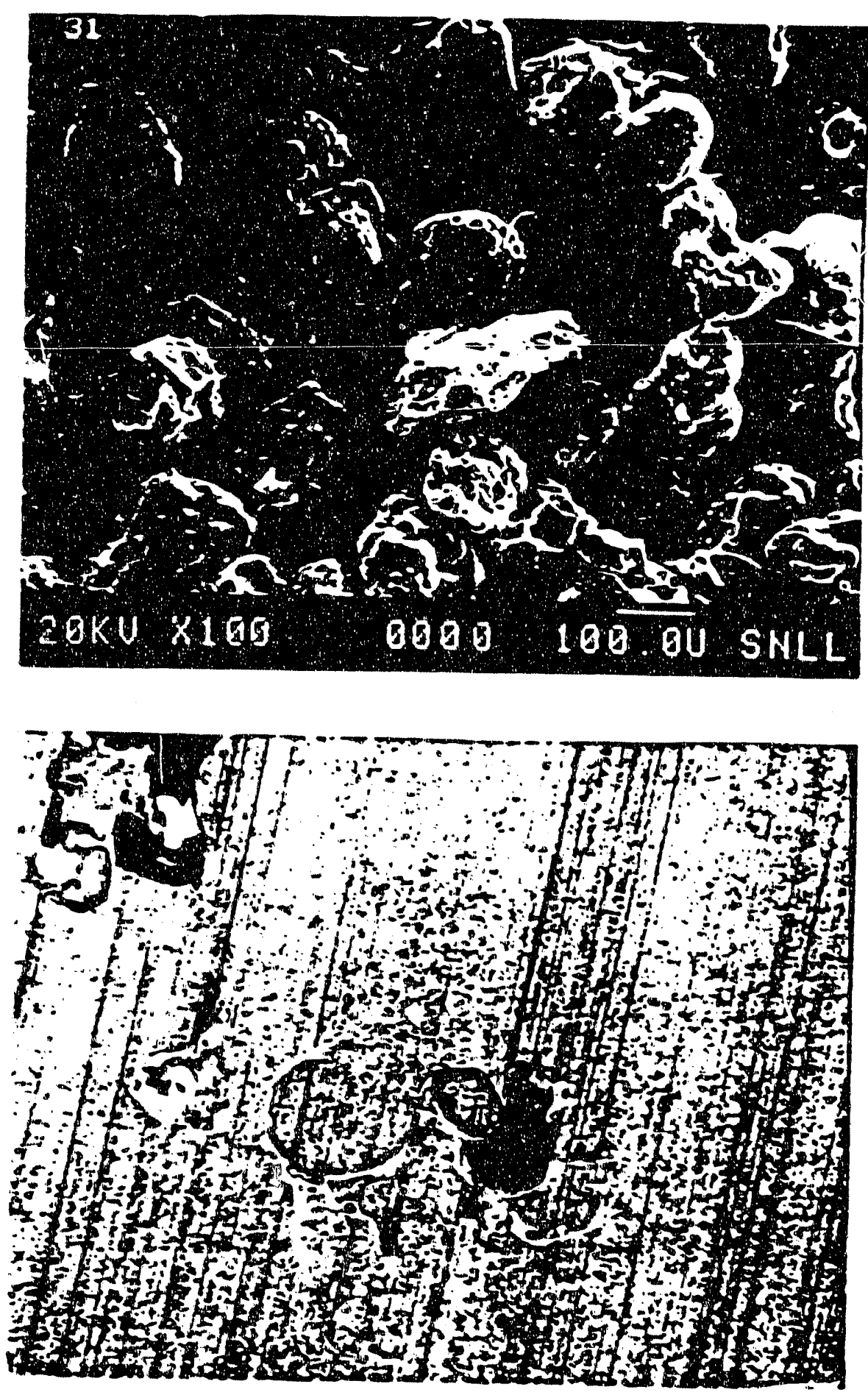

SEX pbotographs of cher (uppar) and lts corrosponding c5oss-action (lovar) collectad at $14 \mathrm{ca}$ at the inter. mediace ceaperature condtelon; latelal particle dianerer - 106 - $125 \mathrm{Ha}$; agnification for the cross. sector -100 . 
Figure 2.60

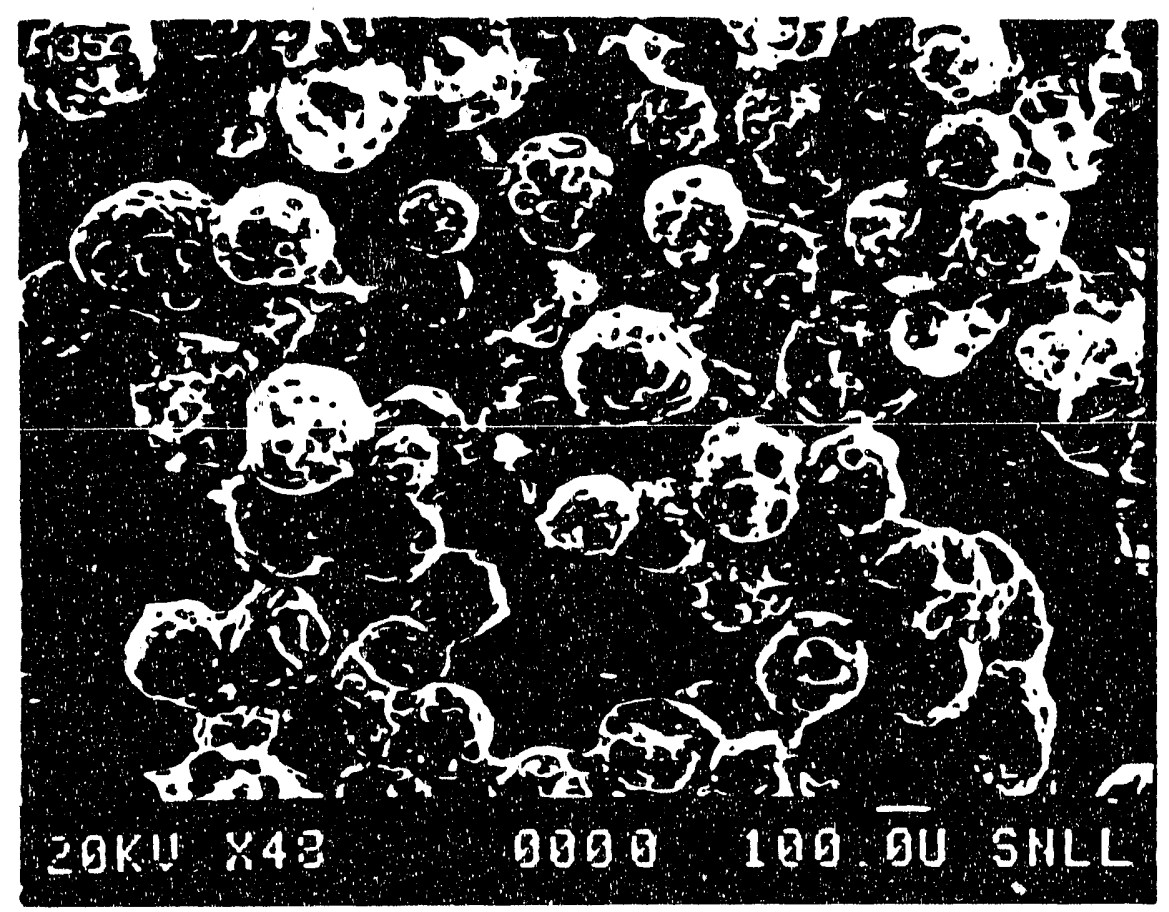

SEA pbotographs of chas collacted ac 18 ea et eho laceradiate ceaperature condlelon; latelal particle

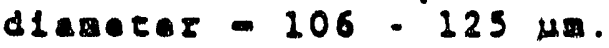


Figure 2.61
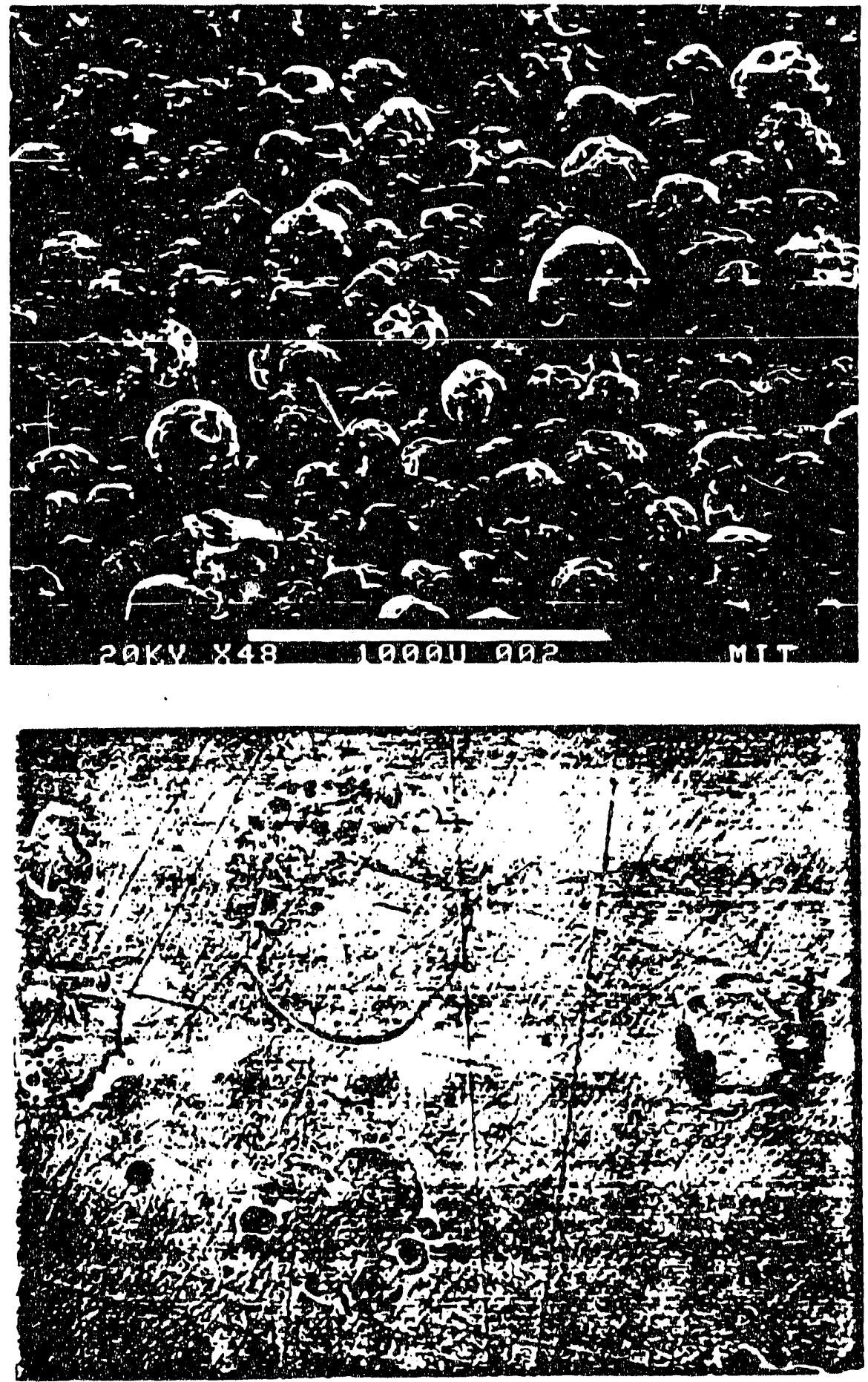

SEM photographa of char (uppor) and 1to corrosponding cros coction (lower) colloctod at $20 \mathrm{~cm}$ et the inter. Fodiate tompratura condition; Initial particlo dianetar - $106-125 \mathrm{\mu a}$; galfication for the cross. secelon - 100 . 
Figure 2.62
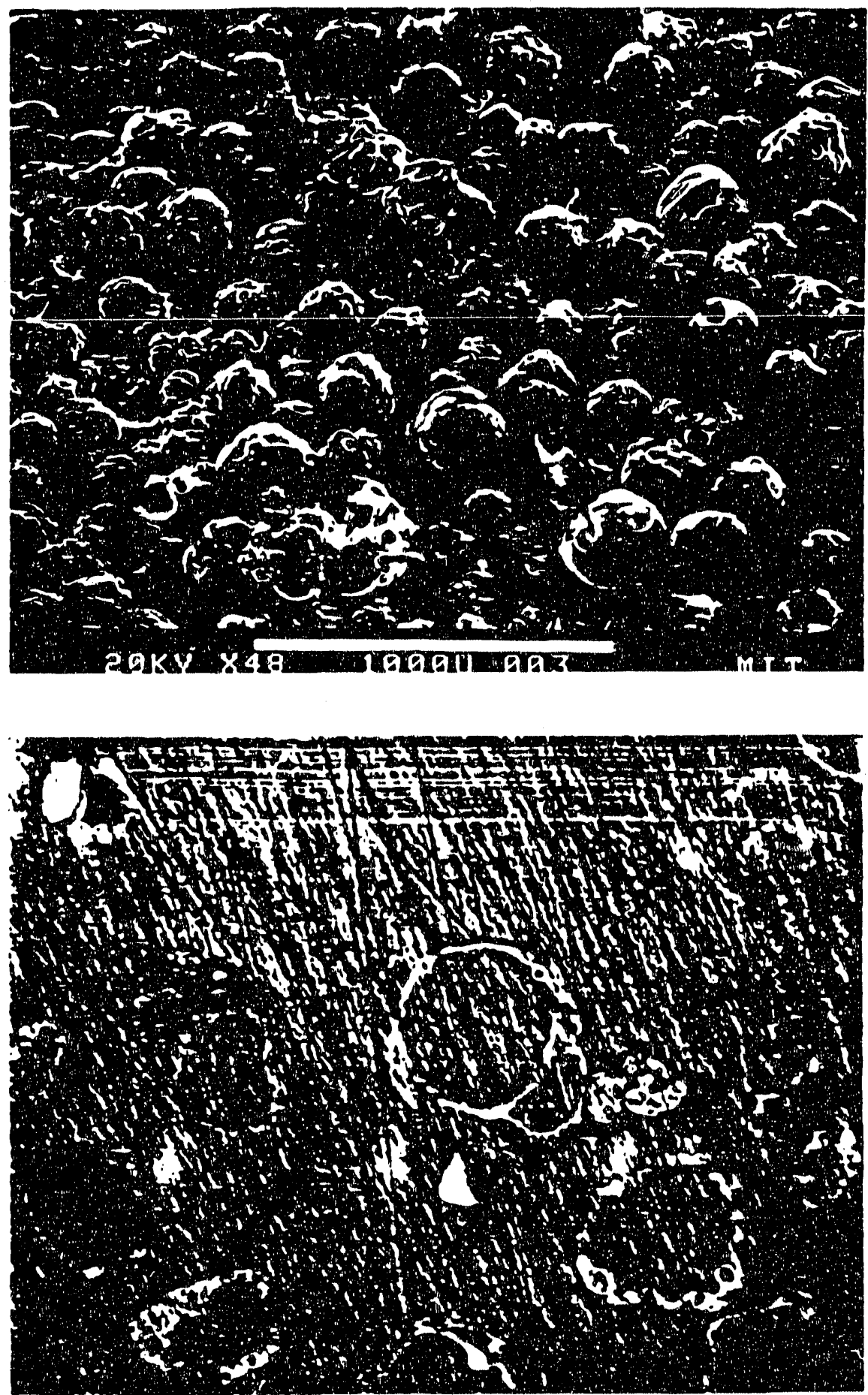

SEM photographs of char (upper) and 1ts corresponding cross-gection (lowar) collocted at $25 \mathrm{ca}$ the lnter. modiate coporature condition; initial parelclo diamerer - $106-125 \mathrm{\mu m}$; magnification for the cross. section -100 . 
Figure 2.63
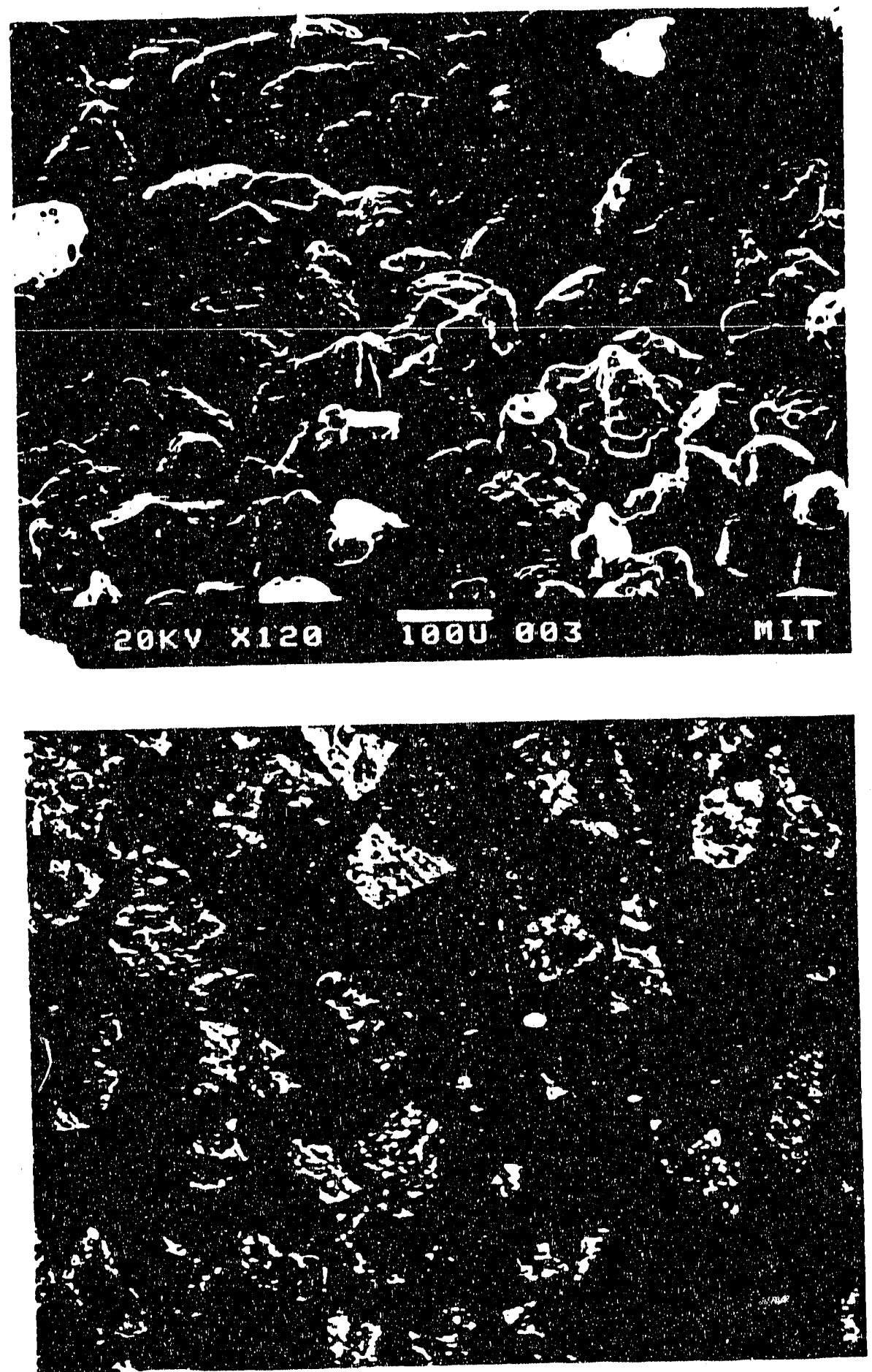

SEx phorographs of char (uppar) and $1=5$ corrosponding cros phocographa (lower) colloctod a $5 \mathrm{~cm}$ ti tha later. crodia temperaturo condition; initial partialo diameter -63 - $75 \mathrm{\mu m}$; magnification for the cross. section - 150 . 
Figure 2.64
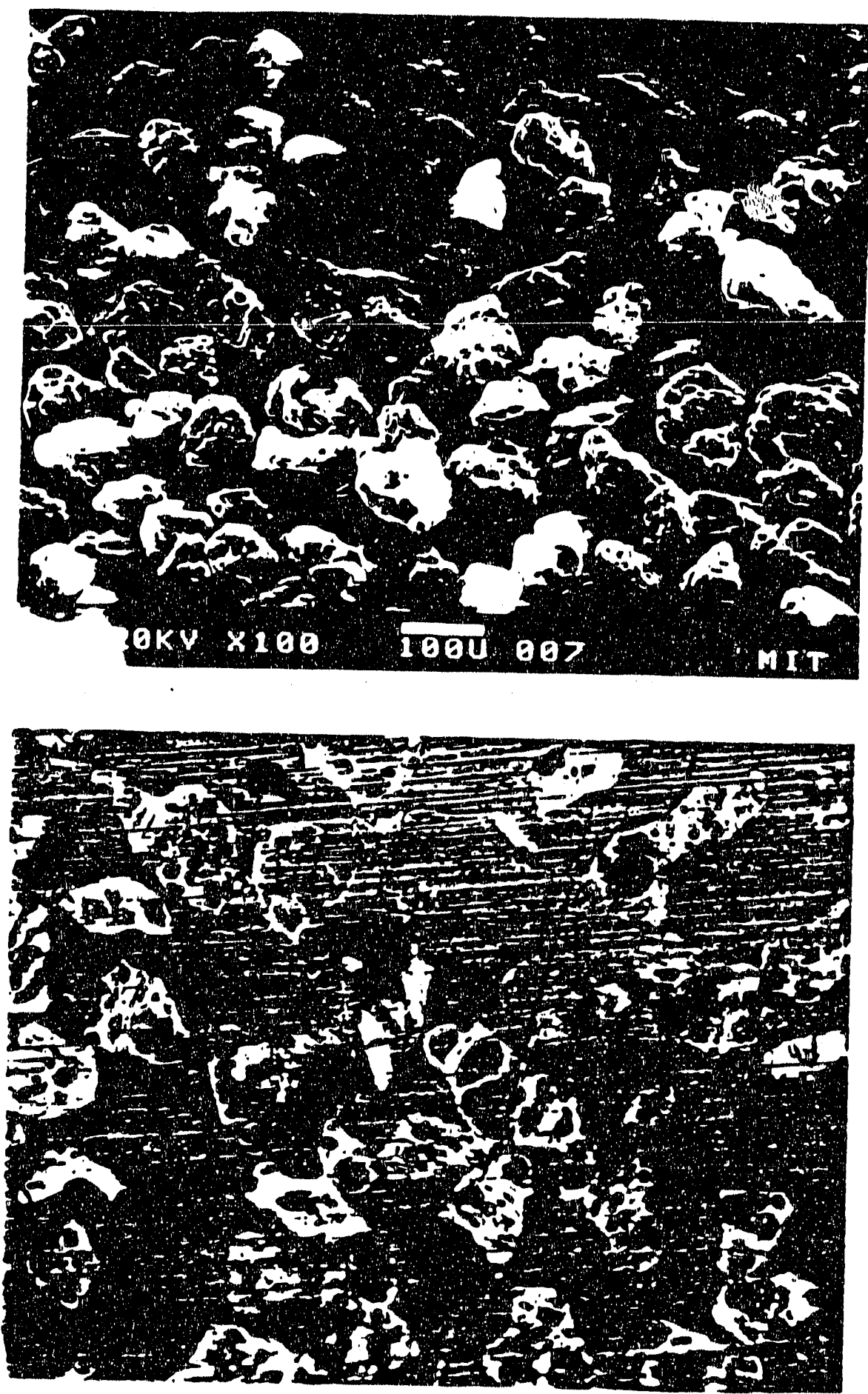

SEM photographs of char (upper) and its corresponding crosa-section (lover) collectad t 6 cal at the lneer. mediate tomperature condition: inielal particle

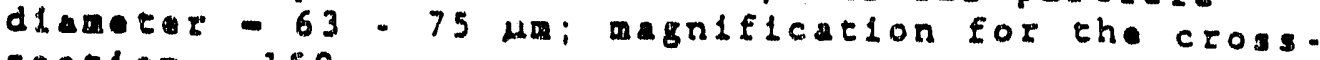
action - 150 . 
Figure 2.65
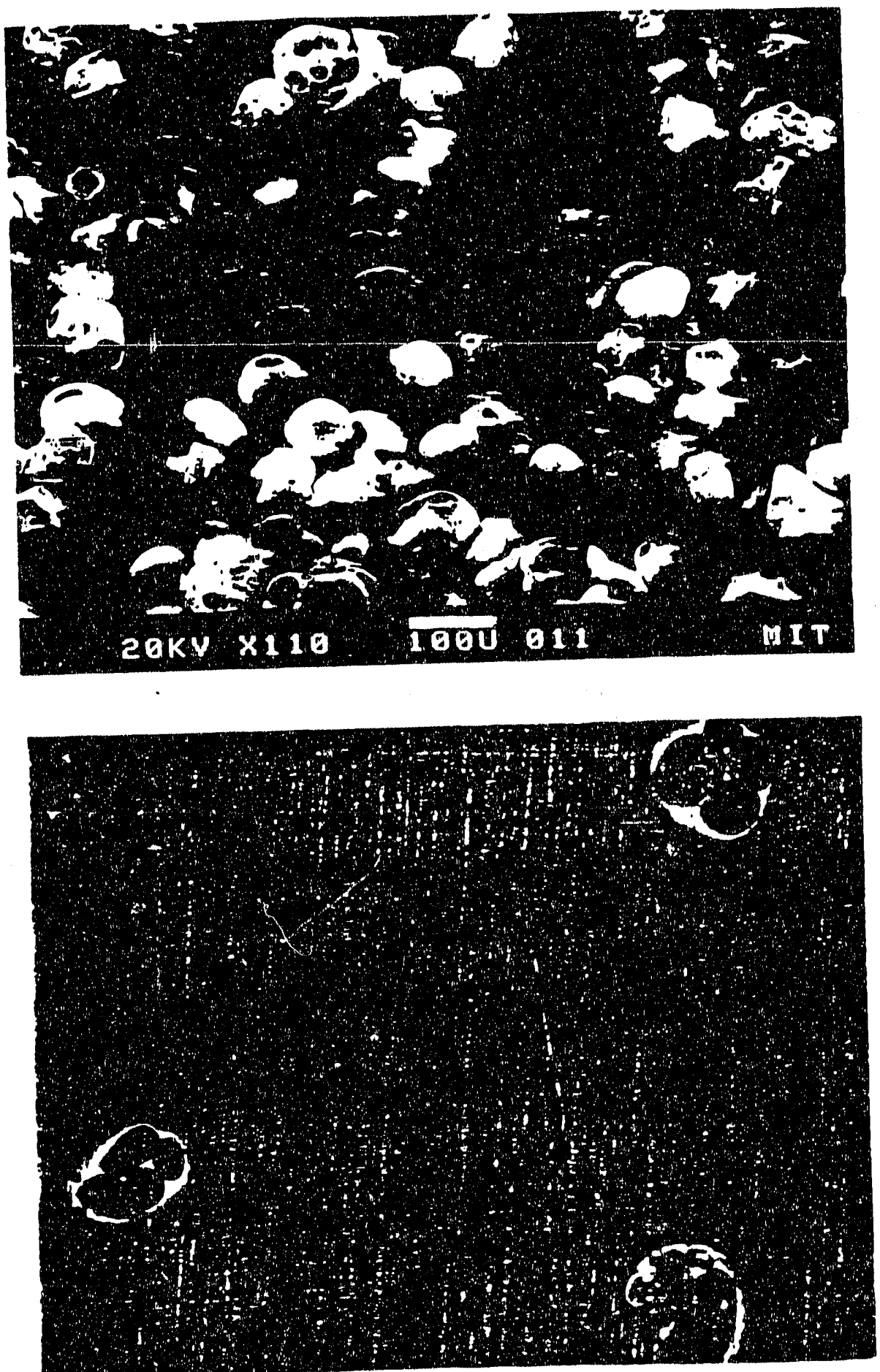

SEM photograph of cher (uppor) and 1ts corresponding crosesection (lower) collectod at $9 \mathrm{ca}$ at tha inter. - diace tomperature condition; intelal particle diancer - 63 - $75 \mu m$; magnitication for tho crosssection -150 . 
Figure $\mathbf{2 . 6 6}$
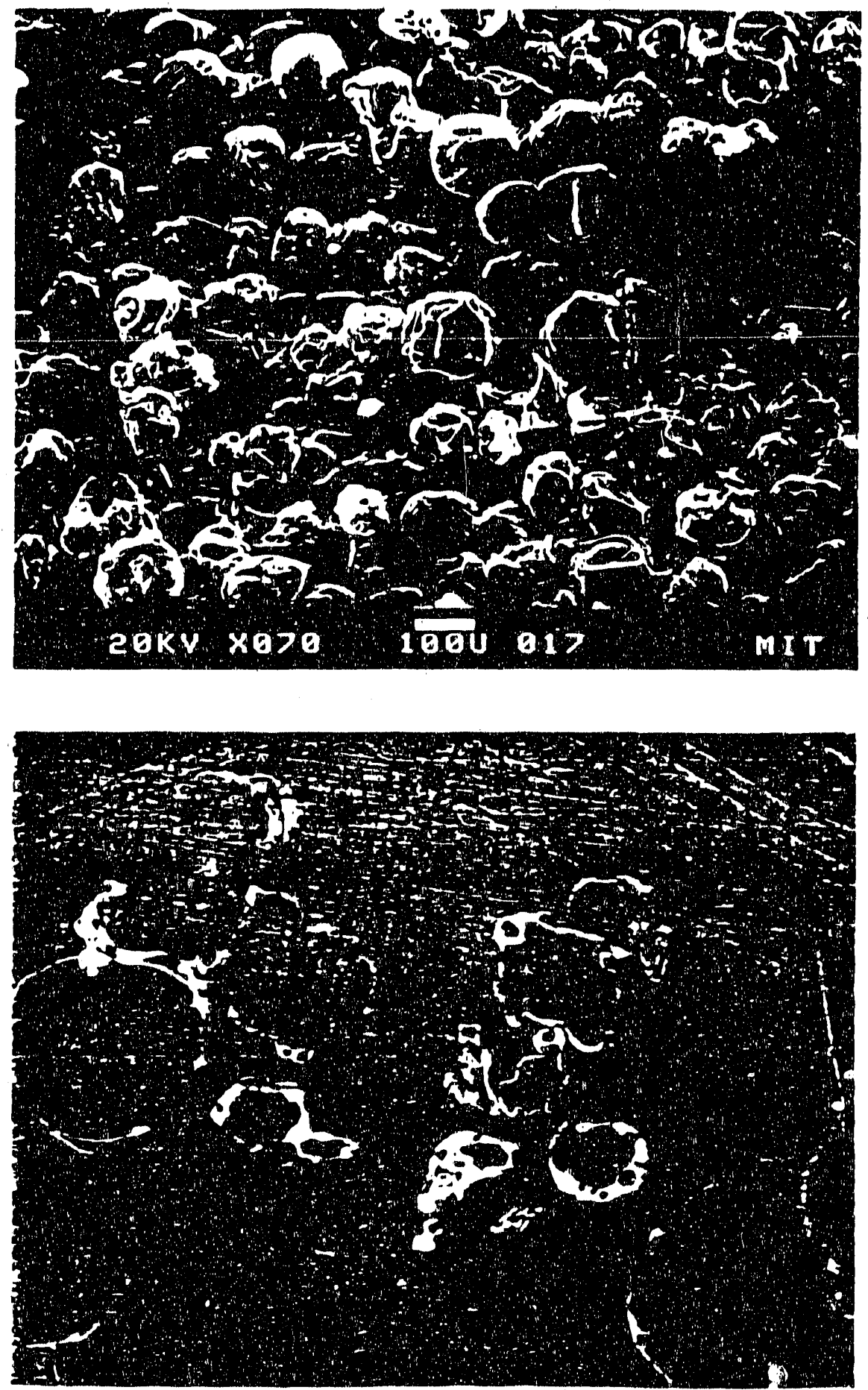

SEM photographs of char (upper) and 1ts corrosponding cross-ation (lower) collocted at $15 \mathrm{cac}$ ethe inter. modiate temperate condition: lnitlal particlo diameter - 63 - 75 Mm; magnifleation for the cross. section -150 . 
Figure 2.67
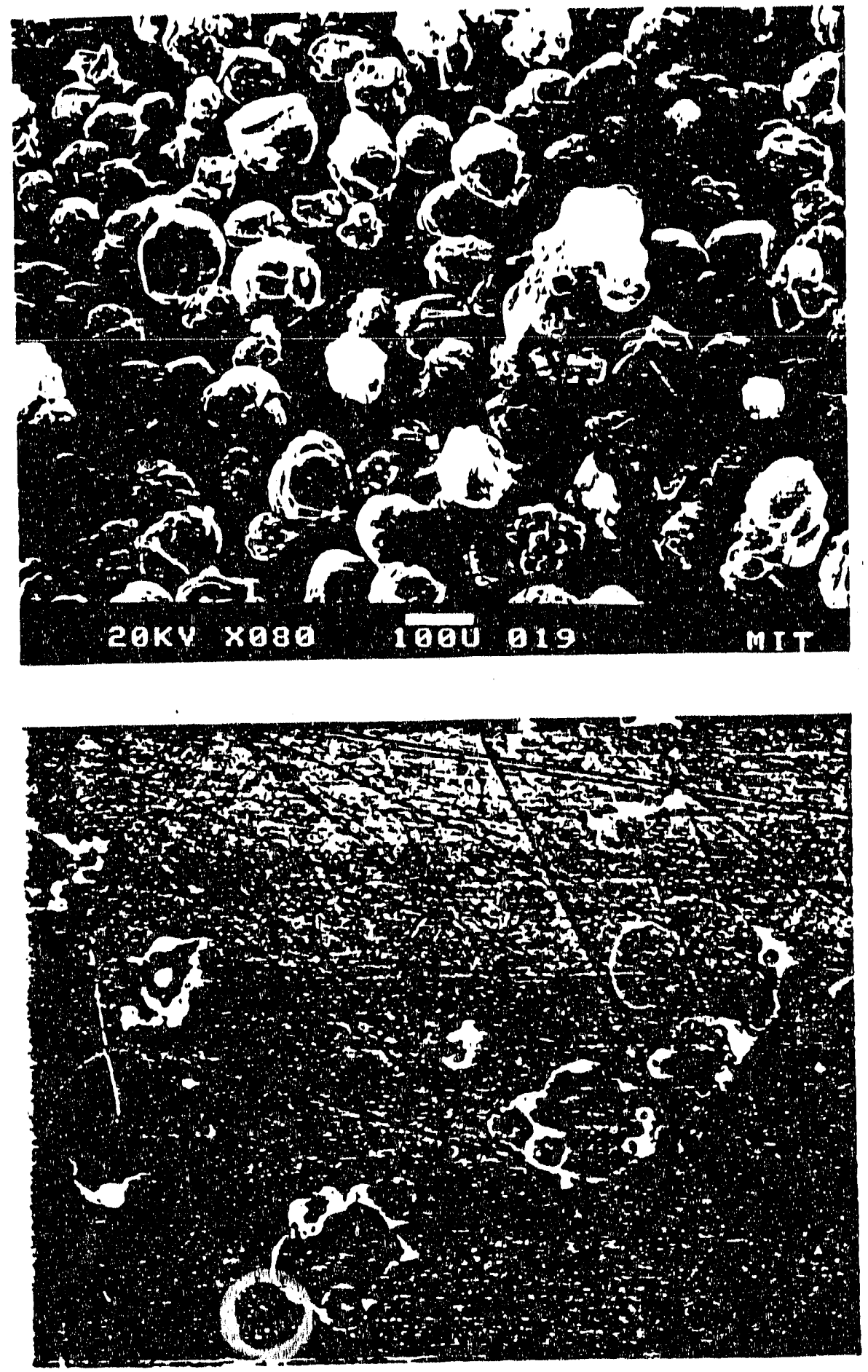

SEM photograph of char (UPpar) and itg corresponding crosasoction (lowar) collectad at $20 \mathrm{~cm}$ at tha lnter. modiate comperature condition: intelal particlo diamer- $-63-75 \mathrm{\mu m}$; magnification for the cross. secton $=150$. 
Figure 2.55: particles have Irregular shapes and external appearance with no (or very few) pores and fissures vislble.

Figure 2.56: fissures open up on the paricle surface. Blocked gas bubbles grow inside the particles, although their edges remain unsoftened. The black spots shown on the pictures could be elther poorly pollshed char or lack of polymer resins. Note that some bubbles have long and Irregular shapes. suggesting that the bubbles may be Initlated from fissures which may in turn be due either to initially existent pores or to thermal expansion of the coal during heat up.

Figure 2.57: fissures are longer and more apparent on the particle surface. A few balloon-like bubbles and few holes can also be seen on the surface, but generally the overall characteristic shapes of the original particles remain reasonably well-defined. Fissures can no longer be seen inside the particle. Instead, many smali bubbles and occasionally a few large bubbles appear. The wall thickness between bubbles seems quite uniform. Note that while many Internal bubbles have not yet broken through the particle surfaces, the appearance of crater-like punctures or 'blow holes' in the surfaces show that some bubbles have ruptured the coal particle 'skin'.

Figures 2.58 and 2.59: particles become more rounded. The surface is internally surrounded by individual bubbles and pocked with several small blowholes. Inside the particles the bubbles seem bigger. In some particles, the partitions have vanished and larger cavities obtain. Some particles in Fig. 2.59 appear llke withered puckered prunes suggesting partial contraction of the particle surface after bubble release.

Figure 2.60: no cross-sections are avallable for this sample. The particle surfaces exhibit a beehive-like appearance and the particle shell is very thin. The particle sizes vary to some extent. Some chars appear to exist in clusters in which 3 to 5 particles are interconnected by relatively planar neck-like linkages. Later analysis (see below) indicate that agglomeration of particles may occur under these pyrolysis conditions.

Figures 2.61 and $2.62:$ these figures show swollen, thin walled, quite spherical particles of high internal vold fraction, i.e. cenospheres. The figures also show big blowholes rupturing the paricle surface and some shell fragments. Again, the particle volumes exhibit greater deviations between particles. Larger individual voids are clearly more apparent, partitions are thinner and many paritions have disappeared. The puckering behavior attributed to post shell rupture and surface contraction is also evident in both figures. 


\section{R88-PC70768}

During pyrolysis, conospheres are formed and the shell continues to become thinner with time. The formation of cenospheres suggests that, before they resolldify, the coal particles go through a stage of thermal plasticity in which the molten coal (metaplast) extibits a rather low apparent viscosity (Ref, 2.20).

For the $63-75 \mu \mathrm{m}$ particles, the morphology changes are quite similar to that of the $106-125 \mu \mathrm{m}$ particles (Figs. $2.63-2.67$ ). One difference is that single, central bubbles are more likely to exist in the 63-75 $\mu \mathrm{m}$ particles during the bubble development stage. This is alsc true for $30 \mathrm{~m} 45 \mu \mathrm{m}$ particles. This may reflect more rapid depletion of the inventory of small bubbles in the sinaller particles.

Based on observations from the micrographs, varlation in particle size over the range studied in this experiment seem to have few effects on the sequentlal morphology changes during pyrolysis. The sequential morphology changes are characteristically sketched in Fig. 2.68a. With continued heating: 1) coal starts to soften at a melting temperature of $350-400^{\circ} \mathrm{C}$ (Ref. 2.25 and 2.26) and the Internal pressure increases within fissures (possibly generated by thermal stress) and in the Initially existent pores, due to the release of adsorbed moisture and weakly bounded gases. 2) The viscous fluid (liquild metaplast) flows and seals off the pore mouths and the fissures. 3) The increasing internal pressure, due to decomposed gases and evaporated

results in bubble growth and further swelling of the particles. In the early stage of swelling, a low fluidity may explain retention of the essential shape features of the original particles, 4) As devolatllization proceeds, the temperature increases, generating more softened material. The small bubbles merge and form large. central bubbles which are bounded by thin-shells of the particle surface. 5) Eventually the large bubbles break through the particle shell, allowing tar and gases to escape through the external and internal surfaces (original bubble interface).

In addition to the cenosphere sormation, other important observations are the increase of particle volume in the early stages of pyrolysis, followed by contraction of the particle surface. Figure 2.69 and 2.70 show effects of reaction distance (approximately proportional to residence time) on swelling ratios for particle size of 106-125 and 63-75 $\mu \mathrm{m}$, respectively. Here swelling ratio is defined as the diameter of a char particle collected after traveling through the reaction zone for the indicated distance divided by the mean diameter for the unpyrolyzed particles. The solld curves drawn through the data points are only to show continulty and do not represent predictions form a mathematical model or correlation. The dashed curves continuing the solid line represent uncerainty as explained later. Apparently, the 106-125 and 63-75 $\mu \mathrm{m}$ particles show maximum swelling ratios close to 1.5 and 1.25 , respectively. Both then exhibit subsequent volume reductions. Vierinite, a major composition of macerals in the coal, is believed to contribute to the swelling (Ref, $2.26,2.27,2.28$ ). The secondary increases of mean swelling ratios (solid points) at reaction 


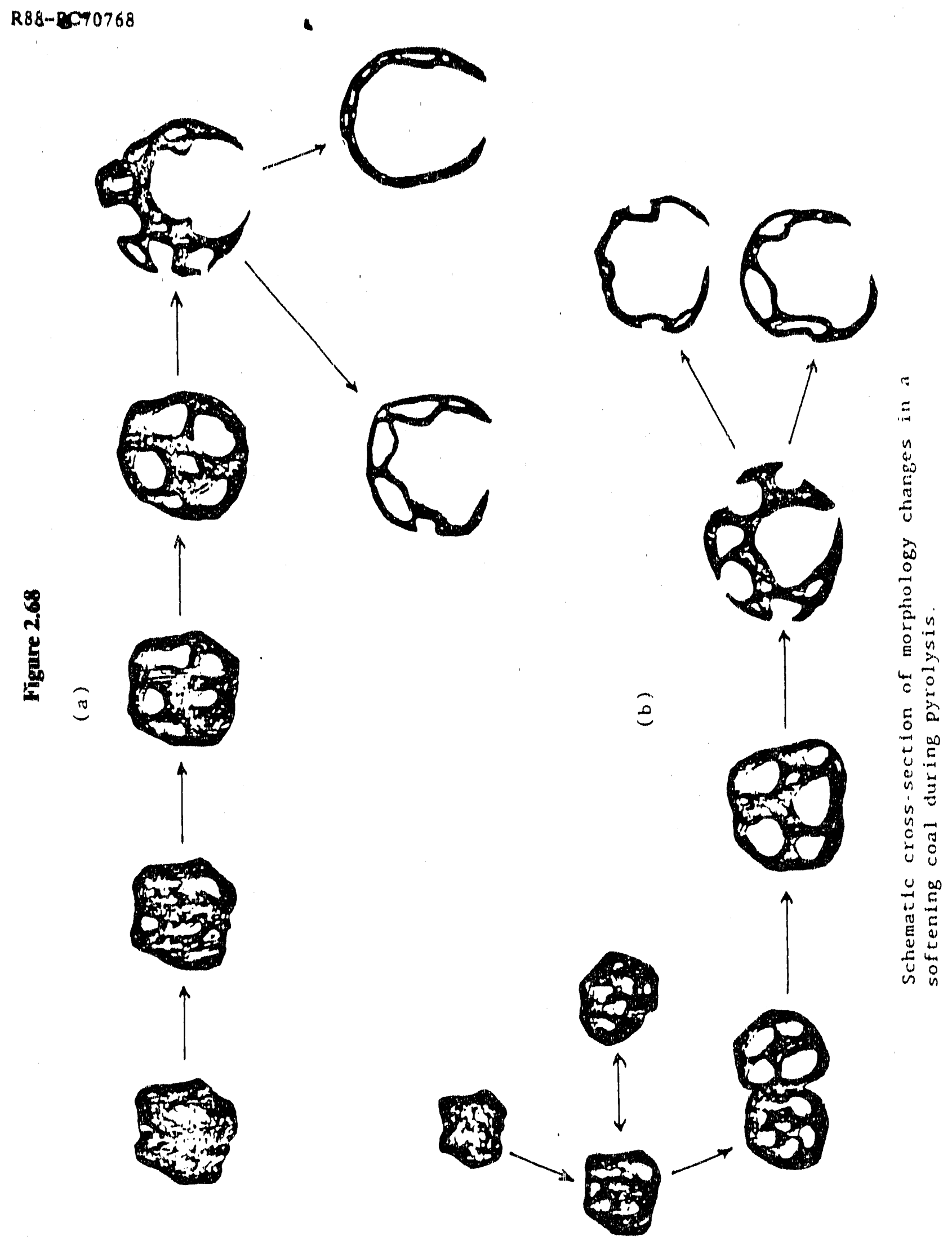


Figure 2.69

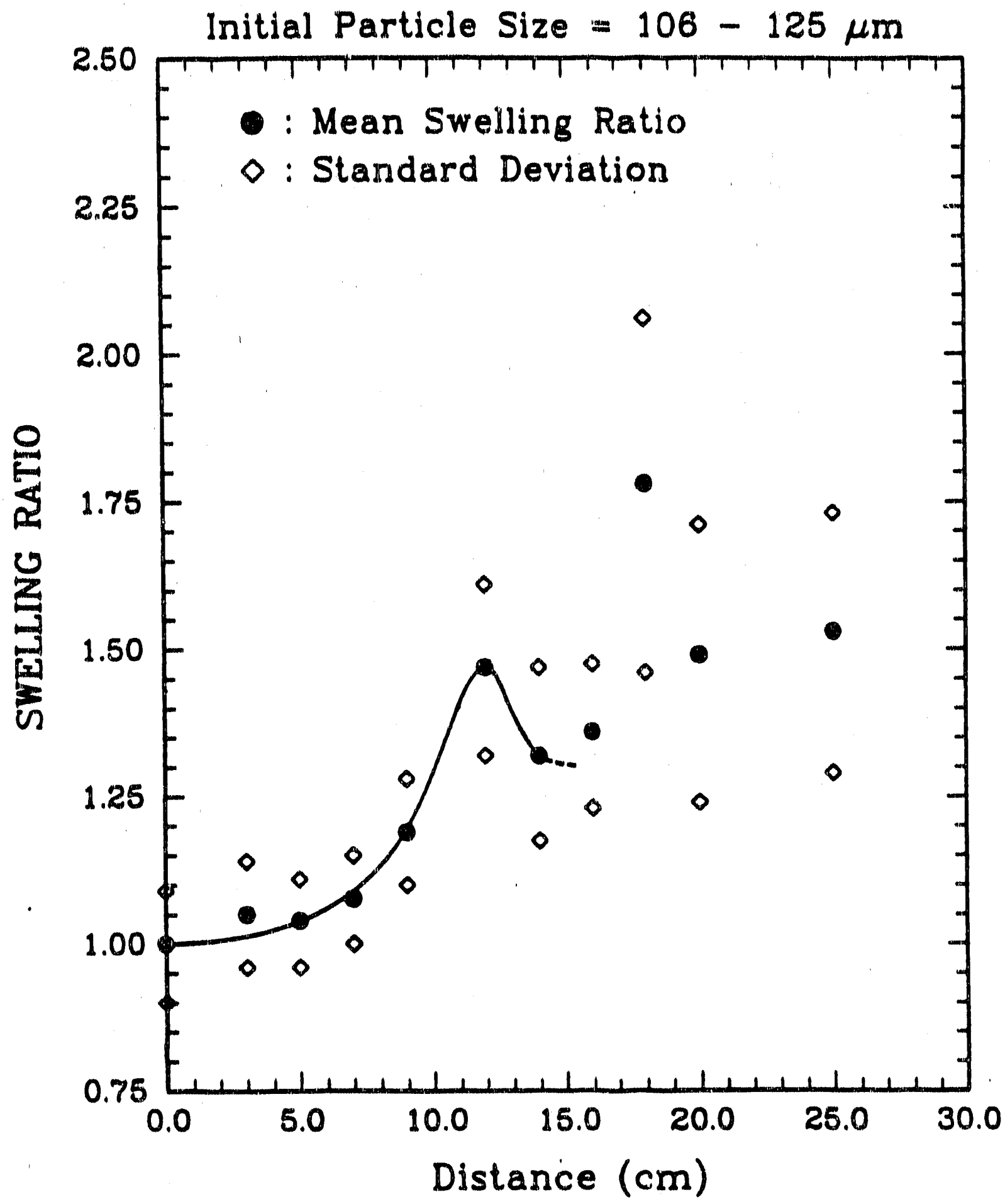

Swalling Ratio vo distance at the intermadlate tomperature condltion. 
Figure 2.70

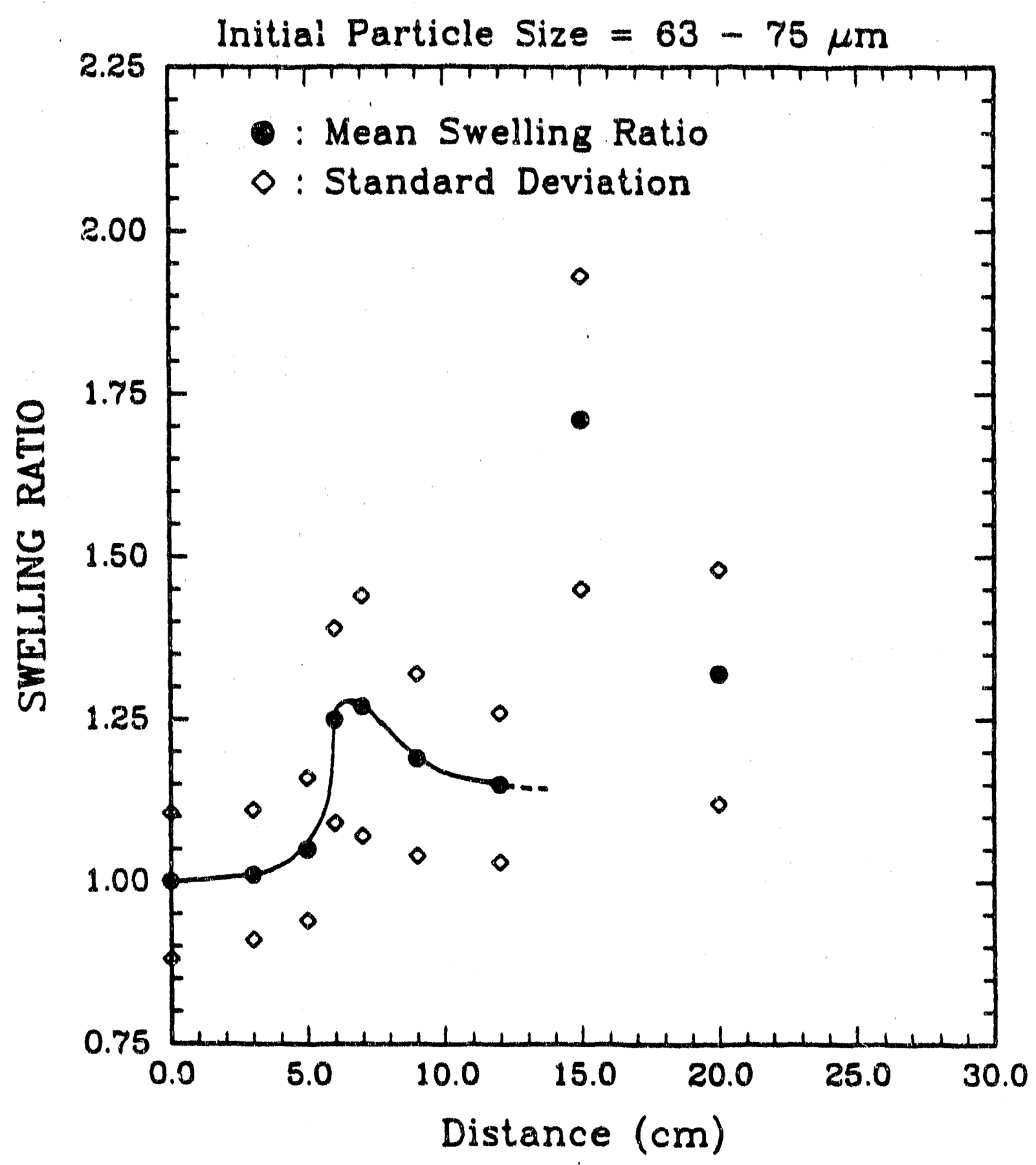

Swalling Ratio ve distance at the intoradiato tomperature condltion. 
$R 88-P C 70768$

distance above about $14 \mathrm{~cm}$ and the wide ranges of their standard deviation in $b$ th cases indicates that paricle agglomeration may have occurred if two or more particles collided and fused together duririg the sticky phase of devolatilization. "Calculations by Fong (Ref. 2.25) show that agglomeration of sticky coal particles is pussible under laminar flow conditions. The micrographs show evidence of agglomeration of the 106- $125 \mu \mathrm{m}$ particles at $18 \mathrm{~cm}$ reaction distance (Fig. 2.68b). Figure $2.68 \mathrm{~b}$ schematicizes how two particles could agglomerate and ultimately yield single particles of similar morphology to those that remain free of agglomeration. Even these agglomerated particles can also experience volume shrinkage. Other SEM pictures (not displayed) show that particle agglorneration is especially severe at high temperatures.

Weight loss data for these two particle sizes are shown in Fig. 2.71 for reaction distance representing the initial pyrolysis history. Data for higher severities are omitted, because of their wide scatter. The reasons for such scatter could be contamination of the chars used to determine weight loss by tracer techniquesi (see above). During the collection of chars. deposits including agglomerated particles and condensed tat may occasionally form on the probe tip and in the probe inlet and then drop into the probe and be collected. Efforts were made to prevent such occurrences. Since the agglomerated particles stay on the tip for a longer resident time. they may undergo additional pyrolysis, thus their collection could result in a higher calculated weight loss. Anocher, more likely, possibility for char contamination is the inadequate separation of tar and char. which increases the overall sample weight (or reduces the apparent titanium and ash concentrations in the sample), thus causing the calculated weight loss to be arificially low. Such difficulties contribute to the uncertainties in determining weight loss by these techniques.

However, in the earlier stages of pyrolysis. the weight loss results are quite acceptable, due to low weight losses in which the contamination of char as well as other potentially confounding effects such as distillation of the ash or titanium tracers are presumably less likely to occur. This is supported by visually checking tar deposizion in the tar trap. For instance, at the intermediate temperature profile, the observed ar deposition did not markedly increase until the distances between the particle injector and the probe exceed $14 \mathrm{~cm}$ and $9 \mathrm{~cm}$ for the 106-125 and 63-75 $\mu \mathrm{m}$ particles. respectively. No measurements of tar yields were made. For the intermediate temperatures. the 63-75 $\mu \mathrm{m}$ particles apparently show a more rapid

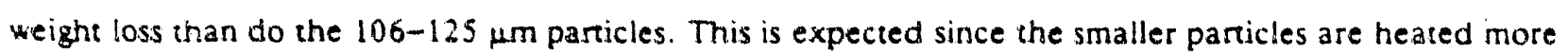

- An alternative possibility is that particle agglomeration does not occur, and that the observed increases in swelling ratio reflect contributions from individual oversize particles (Dr. T.H. Fletcher, private communication, May 1988.) 
Figure 2.71

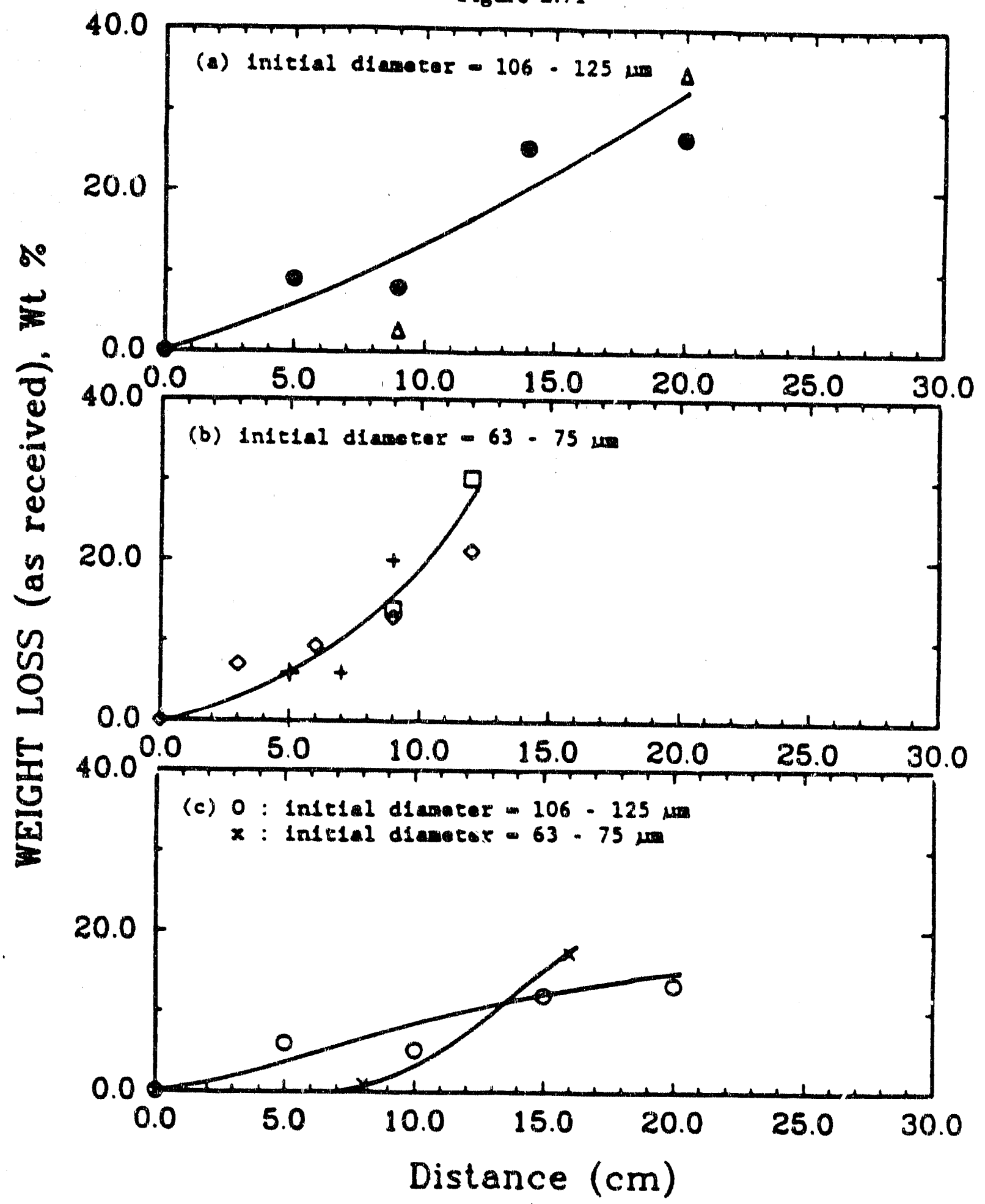

Welght 108 vo distance at the Interaediato (a and b) and lou (c) teaperatura profilos. , o, $0, x$ : deterained from olid denaley;o. 0 : obteined from ah analyals: + : obtalned froa cleaniua analyal. 
R88-PC70768

rapidly than the larger ones, and hence a given reaction distance corresponds to a higher temperatures for the smaller particles than for the larger ones.

Comparing the swelling ratio and the weight loss, it is interesting to note that the maximum swelling associated with minimum uncertainty occurs at low weight loss. For the intermediate ternperature cases, the weight loss for the $106-125 \mu \mathrm{m}$ particles is $10-15 \%$ at $12 \mathrm{~cm}$; for the $63-75 \mu \mathrm{m}$ particle, it is around $10 \%$ at $7 \mathrm{~cm}$ (Fig. 2.71). In addition, the SEM pictures show that at these reaction distances, many blowholes exist on the particle surface and bubbles have become well developed inside the particles (Figs. 2.58, 2.64). These observations indicate that cenospheres and thin shells can be formed in the softened particles during relatively early stages of devolatilization. Thus, a significant fraction of the volatiles can be lost through the broken thin coal-shell by escaping from the internal and external surfaces of the particle shell.

The retention of rather unsoftened particle edges with big bubbles in the early stages of pyrolysis, where temperature is low and chemical decomposition of coal is small, raises the question of how important pre-existing metaplast is in bubble generation and particle expansion, which, of course, also depend upon the rates of tar and gas evolution. The pre-existing metaplast (primarily vitrinite) presumably melts at low temperature via physical melting (Ref. 2.25). Fong's experiments showed that pyridine extract, representing the pre-existing metaplast, from raw Pittsburgh No. 8 bituminous coal is about $25 \%$ of the coal mass. Such a high percentage of early melting material might provide the necessary environment for bubble generation and expansion.

From the SEM pictures of particle cross-sections, the average shell thickness appears to be less than 8 microns, if locations where many blowholes cross the particle surface are accounted for. Shell thicknesses as thin as 1 to 2 microns are observed in the later stages of pyrolysis. A mass balance of solid char can give the average shell thickness, assuming the porosity inside the particle shell is negligible.

$$
\Delta r=\frac{r_{0}\left(1-\theta_{0}\right)(1-W L) Q_{\text {so }}}{3 \phi^{2} Q_{1}}
$$

where $\quad r_{0}=$ initial particle radius.

$\boldsymbol{\theta}_{0}=$ initial porosity.

$\phi=$ swelling ratio,

(Qso) $Q_{1}=$ (initial) solid density.

$\mathrm{WL}=$ weight loss.

For instance, at the intermediate temperature profile, the maximum swelling gives the 106-125 $\mu \mathrm{m}$ particle a shell thickness of $\Delta r=60 \mu \mathrm{m} \cdot(1 .-0.54) / 3 / 1.47^{2}=4.3 \mu \mathrm{m}$, assuming (1. - WL) $Q_{10} / Q_{1}$ aा 1, i.e. 
assuming the loss of solid volume due to the weight loss is negligible. The value seems quite reasonable, compared to that observed from the SEM pictures.

Another interesting observation to note is that stalagmite-like agglomeration of particles may occur on the probe tip. especially at reaction distances of $12-14 \mathrm{~cm}$ for the $106-125 \mu \mathrm{m}$ particles and at distance of 7-12 $\mathrm{cm}$ for 63-75 $\mu \mathrm{m}$ particles at the intermediate temperature profile. In order to avoid such agglomeration, the speed of the stepping motor must be as low as possible. For longer reaction distances (longer residence times) the agglomeration occurred only occasionally and the speed of the stepping motor was not reduced. Probably that is the reason why agglomerated particles can be seen in some of the micrographs. For large reaction distances agglomeration may have already occurred in the earlier stages of pyrolysis. These observations further imply that the external surfaces of the particles become solidified soon after the maximum swelling is reached, i,e. early during the shrinkage stage. This is to be expected because lighter tar and gaseous volatiles may quickly escape through the external surface, leaving less volatile metaplast which is more likely to resolldify rapidly. However, this does not mean that the internal surface of particle is equally prone to rapid resolidification. Some of the micrographs (not displayed) show that small bubbles trapped inside the particle shell tend to grow on the internal surface, while the external surface is quite smooth, and presumahly resolidified. This is also observed by Tsai and Scaroni (Ref. 2.29).

The morphological changes observed from the micrographs and the swelling measurements can be further confirmed by the determinations of particle and solid densities, porosity, BET surface area and pore volume. Figures 2.72 and 2.73 respectively show the particle and solid densities of $63-75$ and $106-125 \mu \mathrm{m}$ particles at low, intermediate, and high temperature profiles. Figure $2.72 b$ shows rapid decreases in the particle density from 0.62 to 0.30 for the $63-75 \mu \mathrm{m}$ particles and from 0.76 to 0.32 for the $106-125 \mu \mathrm{m}$ particles. corresponding to reaction distances ranging from zero to those for the maximurn extents of swelling. The minimum particle densities for both particle sizes in Fig. $2.72 \mathrm{~b}$ as well as for the single curve in the high-temperature case (Fig. 2.72a) appear to be about same $\left(0.14 \mathrm{gm} / \mathrm{cm}^{3}\right.$ ). Figure $2.72 \mathrm{c}$ shows the particle density slightly increases over the minimum value. From examination of the corresponding porosity and pore volume data (Figs. $2.74 \mathrm{c}$ and 2.79 discussed later) it is obvious that bubble shrinkage and particle wall contraction are responsible for these increases. However, the cause for bubble shrinkage at this low temperature condition is not clear.

The solid densities show less variation, especially at the high temperature (Fig. 2.73a). Comparing Figs. $2.73 \mathrm{~b}$ and $2.72 \mathrm{~b}$, the solid density has minimum values at the same distance as that for the particle density, i.e. $12 \mathrm{~cm}$ for the $63-75 \mu \mathrm{m}$ particles and $20 \mathrm{~cm}$ for the $106-125 \mu \mathrm{m}$ particles: but then the solid 
Figure 2.72

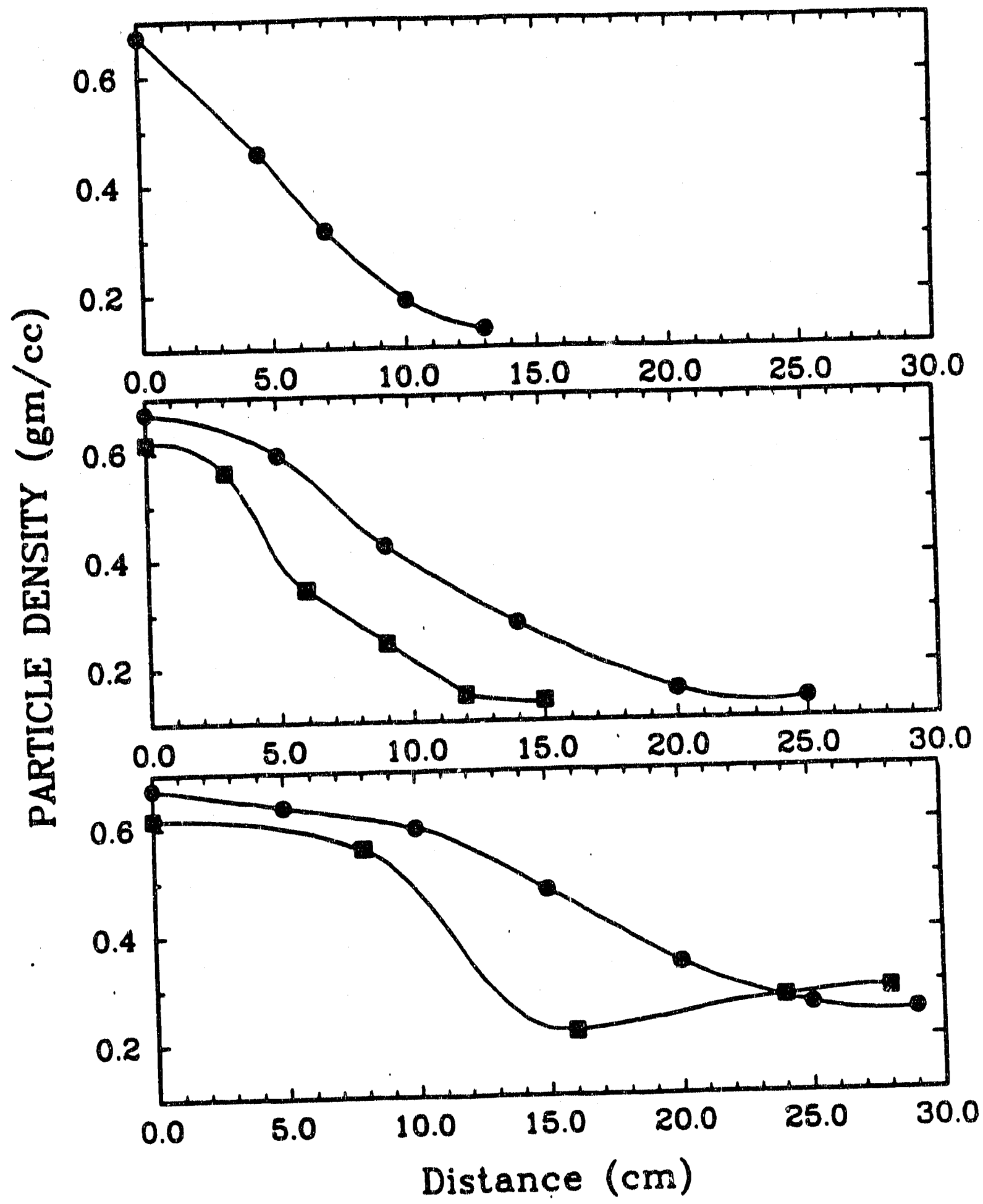

Partisle denelty $v$ distance at the high (a), intermodiate (b), and low (c) temperature profilos. : inftial dianter - 106 . $125 \mathrm{\mu m}$ : Initial diameter $-63.75 \mu \mathrm{m}$. 
Figure 2.73

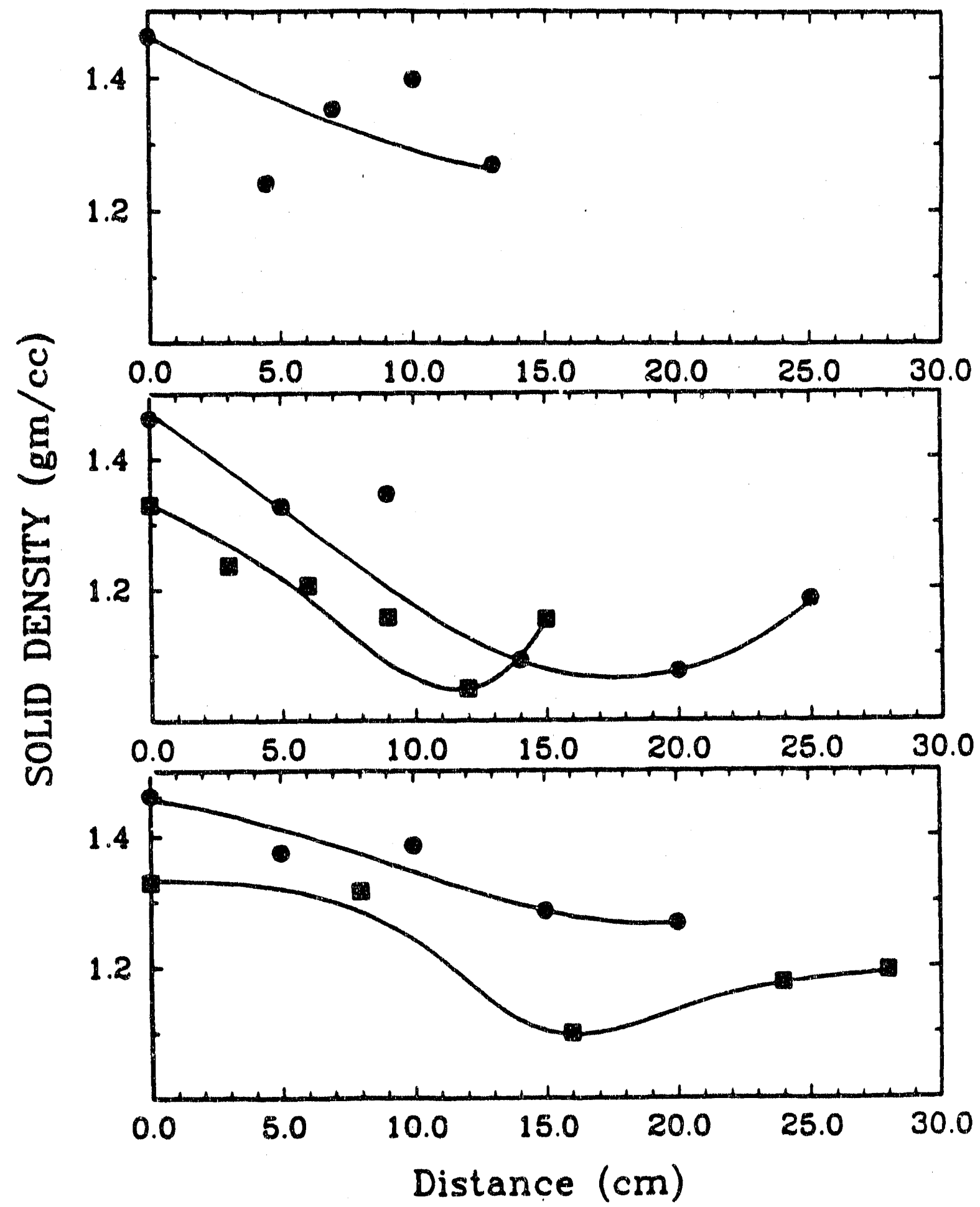

Solid density ve distance the high (a), lnter. medlate (b), and low (c) tenperacure profilas. - :

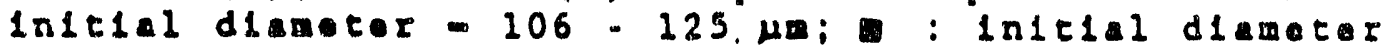
$-63.75 \mu \mathrm{m}$. 
density increases. A possible explanation is due to the presence of increased fragments and the formation of discrete ash particles and ash agglomerates as observed from the micrographs. Fragmentation may open up tiny pores which are orimally unmeasurable, resulting in a smaller true solid volume in the density determination. This explanation is reasonable especially at the high temperature (Fig. 2.73a), where the solid density is higher than that at Figs. $2.73 \mathrm{~b}$ and $2.73 \mathrm{c}$. The solid density at the low temperature is expected to be higher than at the intermediate temperature since the weight loss is lower. Figure $2.73 \mathrm{c}$ shows an increase for the 63-75 $\mu \mathrm{m}$ particles at higher reaction distance which is due to pore shrinkage as evidenced in the porosity measurements.

Figure 2.74 presents the porosity data, corresponding to the pyrolysis conditions of Figs. 2.72 and 2.73. The porosity approaches $90 \%$ for both particle sizes at intermediate temperatures (Fig. 2.74b) and for the $106-125 \mu \mathrm{m}$ particles at high temperatures.

Data on BET surface area and pore volume at different extents of pyrolysis provide further insight on the above morphological changes. Basically, the entire pyrolysis can be divided into two stages: bubble expansion and metaplast depletion. This can be distinguished easily from the BET surface area data (Fig. 2.75). The general trend for each case is that the surface area first decreases and then increases. The decreases appear to be the results of coalescence of small pores or fissures into big bubbles. Note that the minimum surface area coincides with the maximum swelling. For example, the minimum value of $1.5 \mathrm{~m}^{2} / \mathrm{gm}$ for the $106-125 \mu \mathrm{m}$ particle at the intermediate temperature condition occurs at $12 \mathrm{~cm}$ where the swelling is the highest. During the shrinkage stage, the surface area increases markedly, indicating that more new poras have been formed, reflecting loss of liquid metaplast. The increase of internal surface area was also reported by Maloney (Ref. 2.9) and Tsai and Scaroni (Ref. 2.29).

Figures 2.76 to 2.80 show the accumulated pore volume vs. distance for the same experimental conditions discussed above. In each figure the vertical separation between adjacert curves represents the total volume of pores and cavities with diameters between the two values indicated. Figures 2.76 and 2.77 show that a substantial fraction of the total pore volume resides in pores between 22 and $68 \mu \mathrm{m}$ diameter, especially after the occurrence of maximum swelling. The dominance of pores of larger diameter is even more pronounced for the particles of larger initial size (Fig. 2.76). These devolatilization-induced voids are readily seen in electron micrographs.

The absolute magnitude of the porosity increases with temperature (Figs. 2.80 vs. 2.78) with pores of $\geq 22 \mu \mathrm{m}$ apparent diameter, again making major $(-2 / 3)$ contributions to the total volume. However, even at 
Figure 2.74

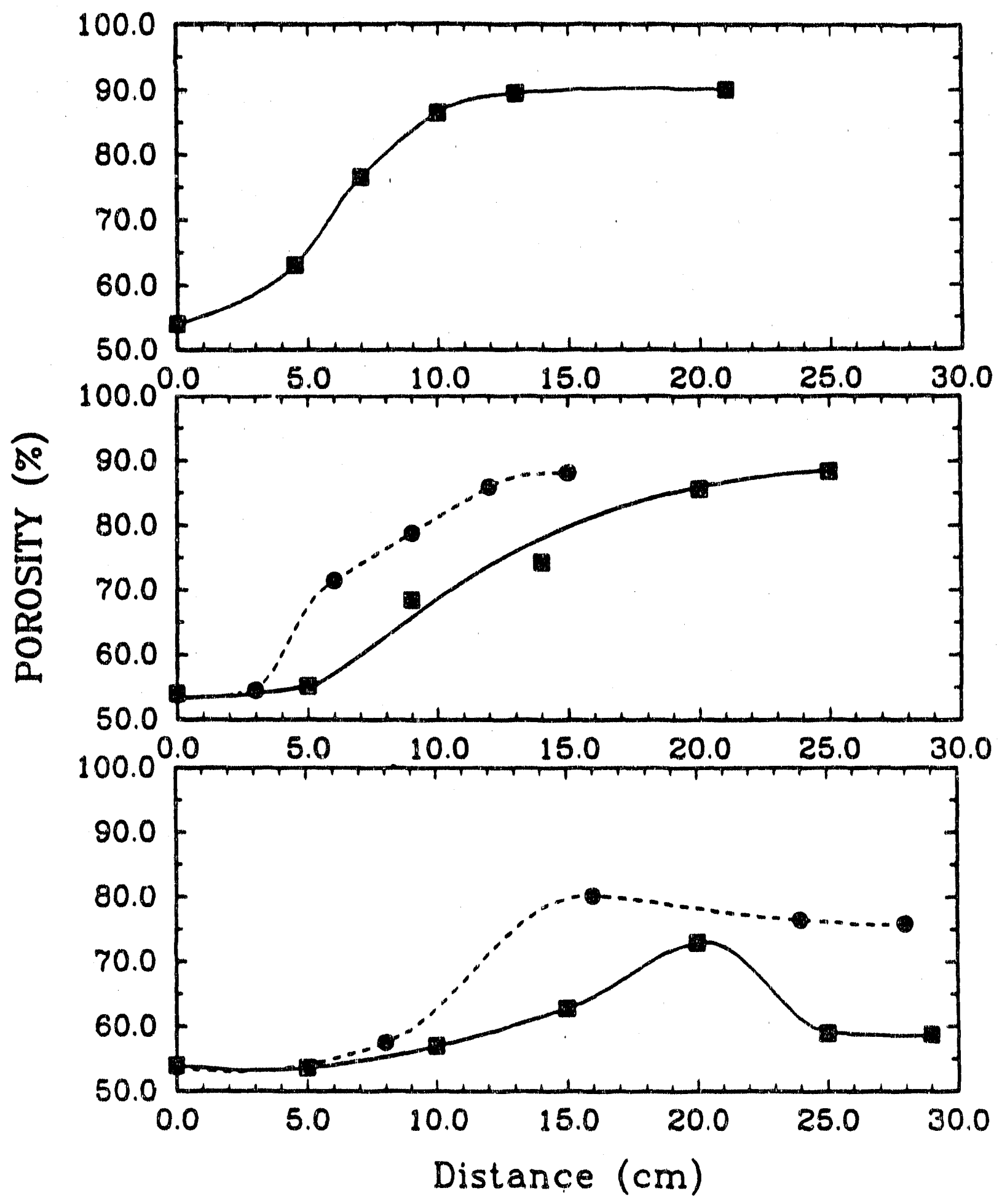

Poroalty ve dietance at the high (a), Intormodiato (b), and low (c) tomporaturo proflian. : Inicial dianeter - 106 - $125 \mathrm{\mu m}$; : infriel diameter - 63 . $75 \mathrm{\mu m}$. 
Figure 2.75

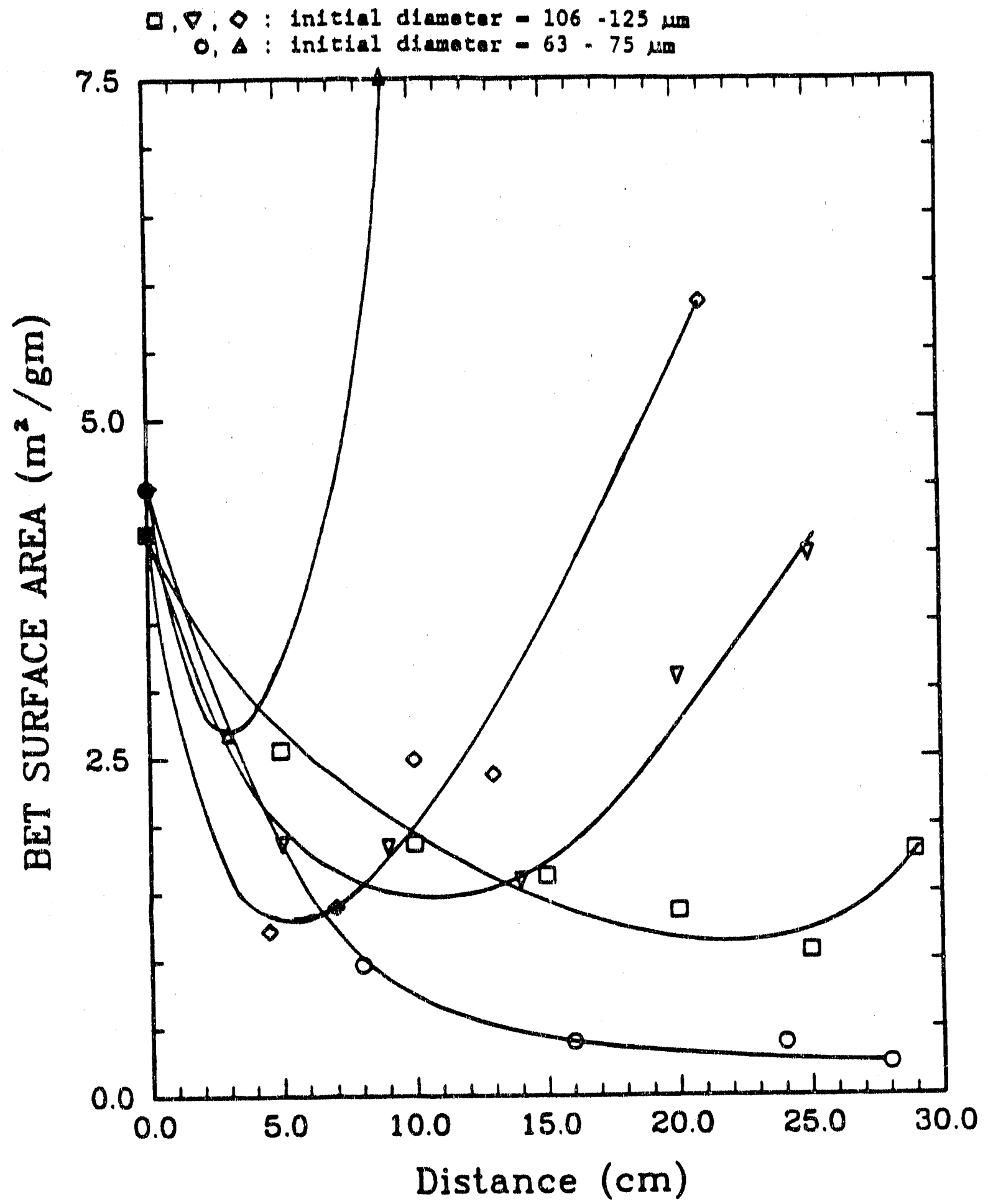

BET surface rea ve dietenve at the high (0), Inter. aedlate $(\nabla, \Delta)$. and low $(0,0)$ teaperature proflies. 
Figure 2.76

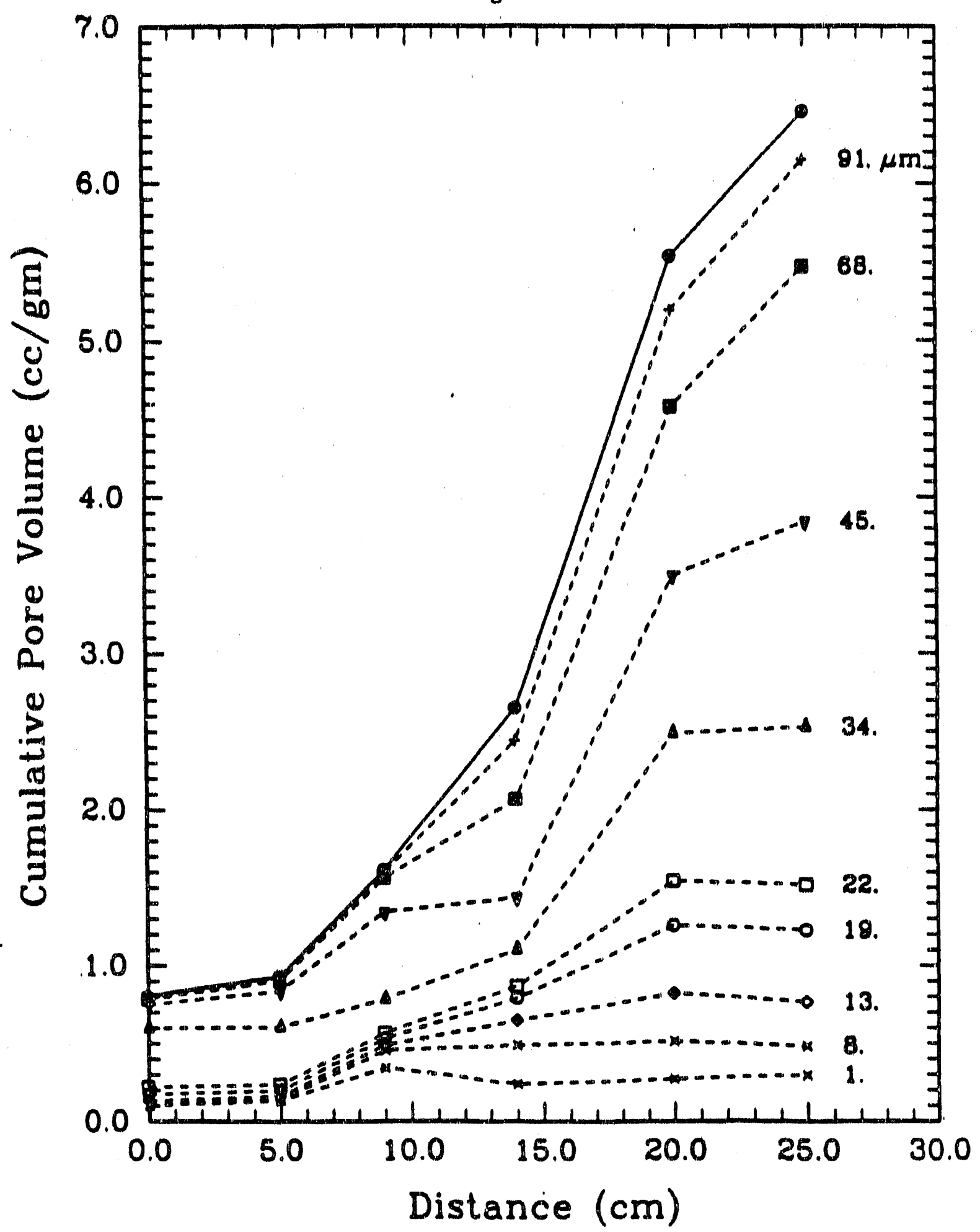

Cumulative pot volumo vo distance for particles with Inltial dianeter, 106 . $125 \mathrm{\mu m}$, at the intermediate temperatur condition. 
Figure 2.77

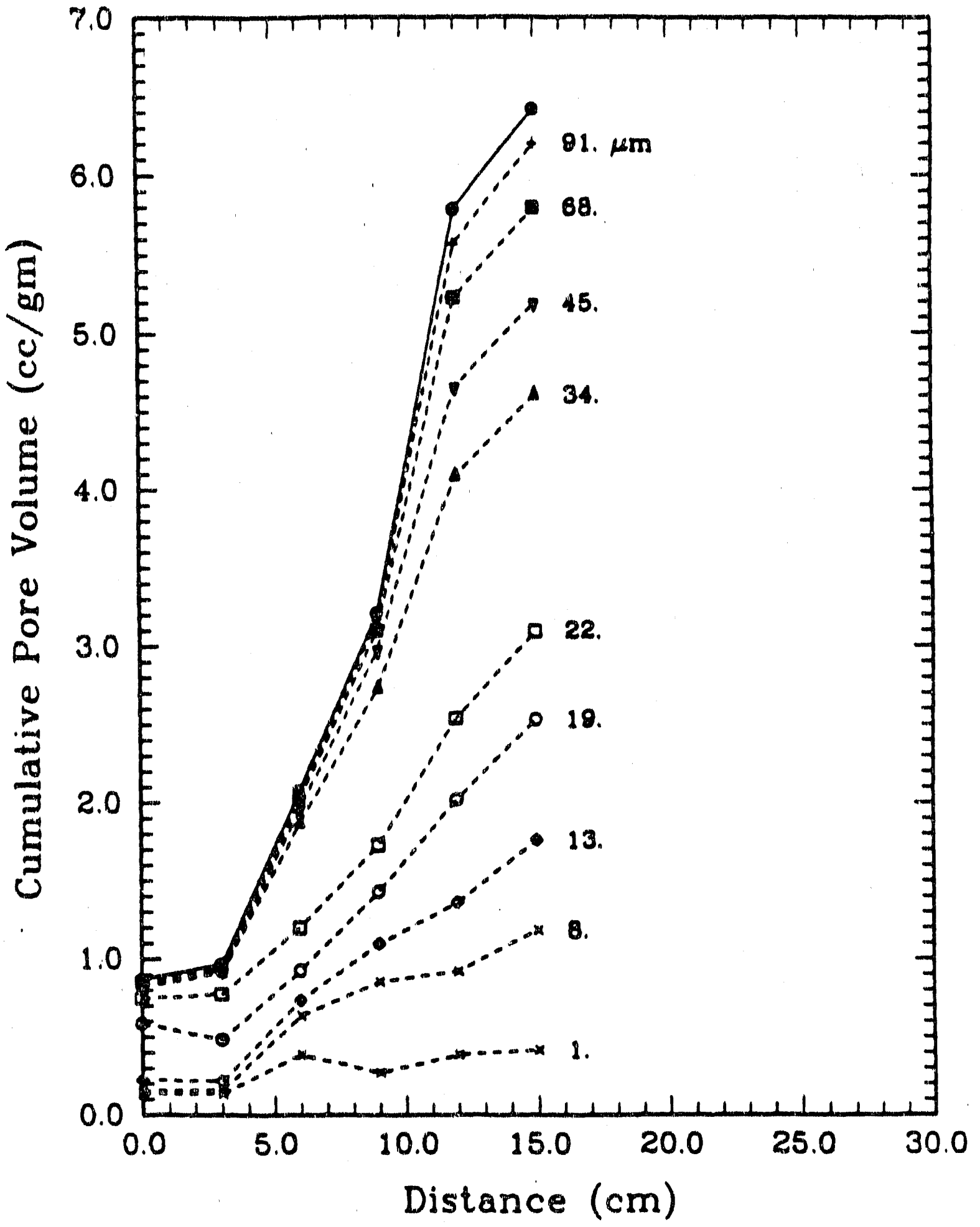

Cumulative pore volume ve dlatance far particles with

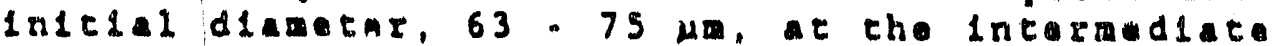
temperature condlelon. 
Figure 2.78

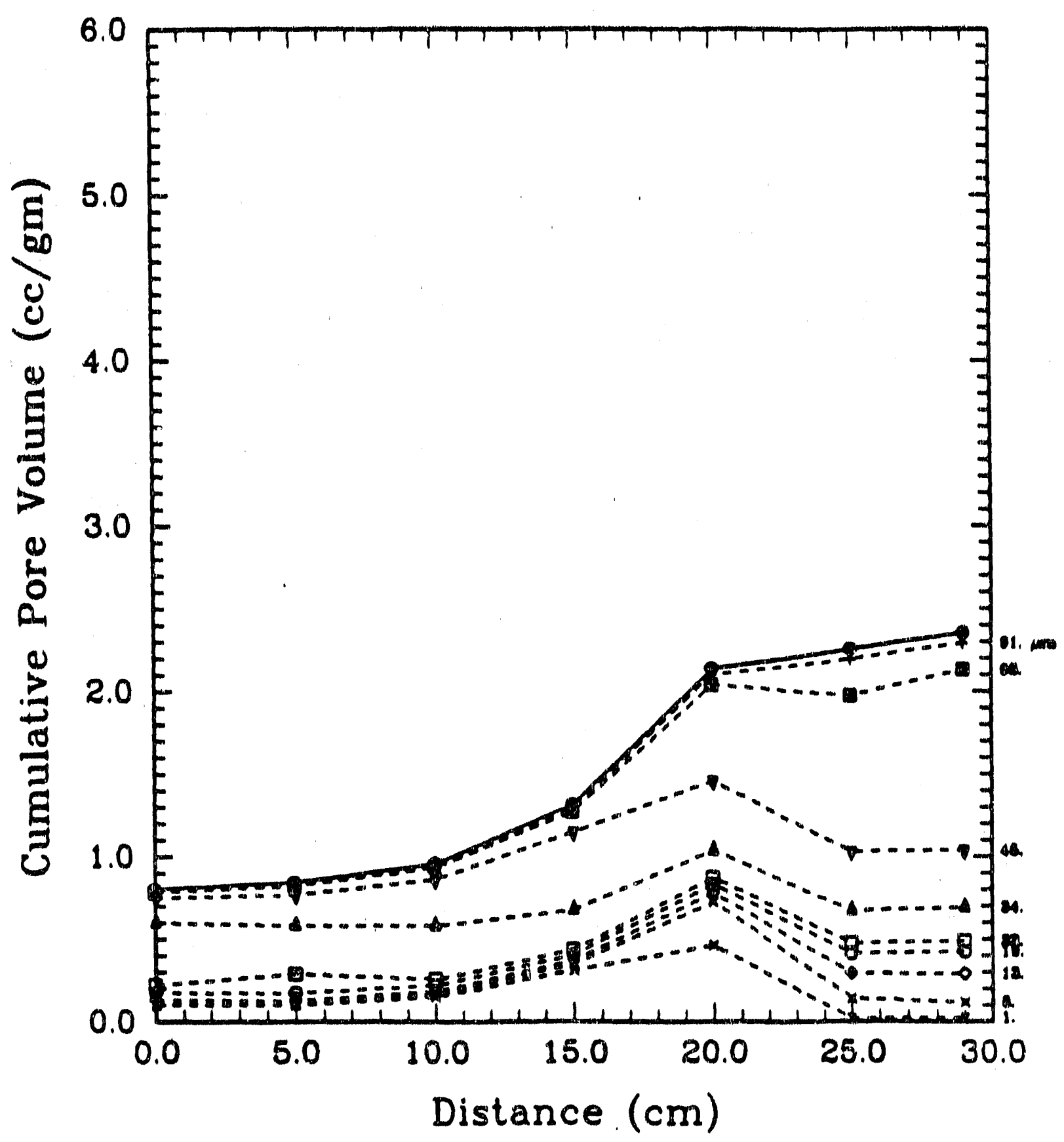

Cumulativo pore volum va dletance for particles with infelal dianter, 206 . $225 \mathrm{\mu m}$, at the low temperature condition. 
Flgure 2.79

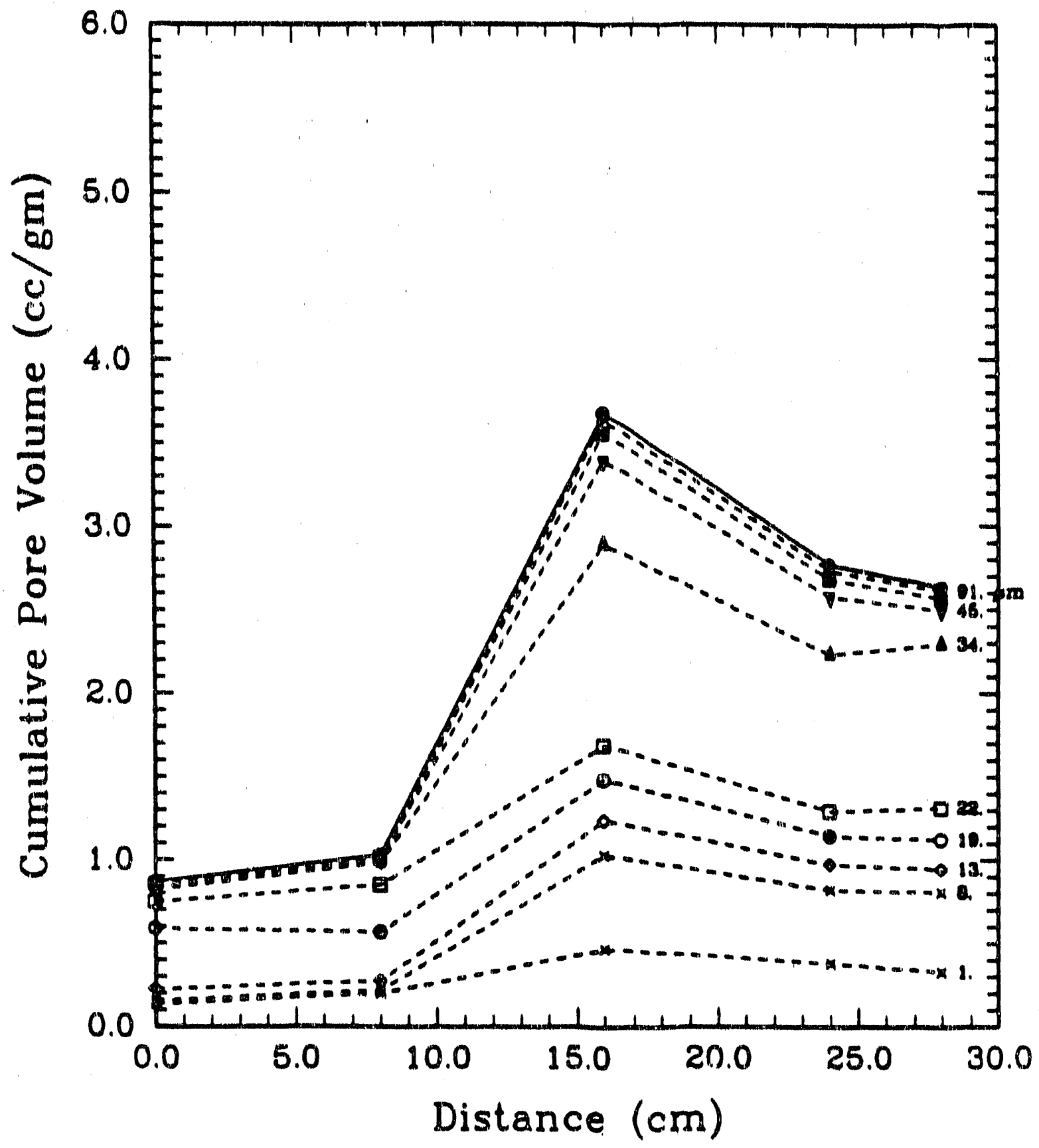

Cualative pora volume va diatance for particlan with Intelal diamater, $63.75 \mu \mathrm{m}$, at the low tomperature condle10n. 
Figure 2.80

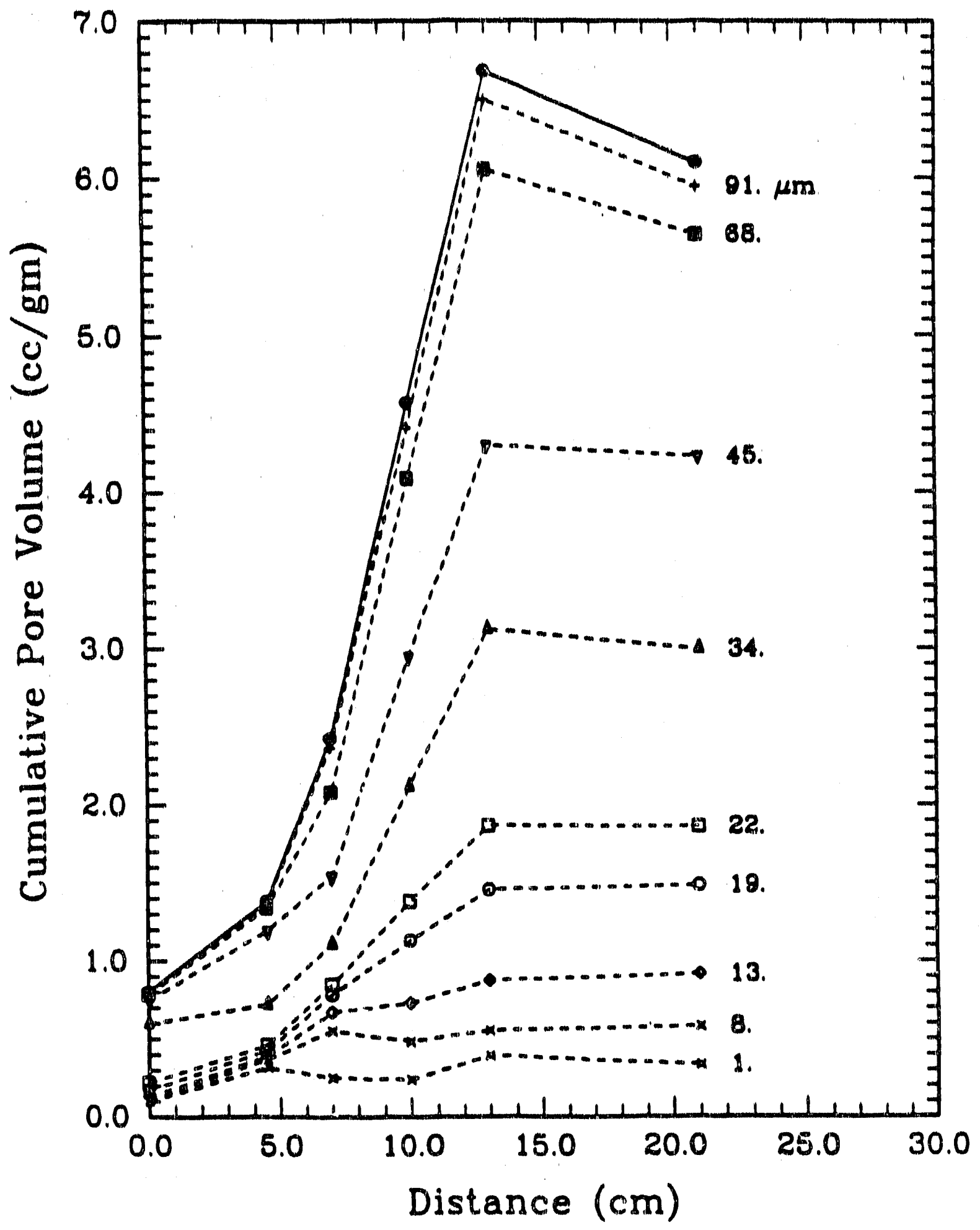

Cumulative pore volume vs distance for particlas with Intelal diametor, 106 . $125 \mathrm{\mu m}$, a the high tompera. ture condition. 


\subsection{Devolatilization in Reactor-to-Particle Heat Flux Rates of 0.25-25 Watts/sq.cm}

\subsubsection{United Technologies Research Center Entrained Flow Reactor (UTRC-EFR) Investigation}

Reactor and Product Separation System

Figures 2.81 through 2.83 display the essential components of the entrained flow reactor. product separation and gas analysis systems. Figures 2.84 through 2.86 display the total power density, radiative power density and gas temperature profiles as a function of reactor position. The flux rate profiles are measured by specially designed. calibrated probes. Incident, centerline radiative flux rates range from severai watts $/ \mathrm{sq} . \mathrm{cm}$. at wall temperatures of $700^{\circ} \mathrm{C}$ to approximately 25 watts $/ \mathrm{sq} . \mathrm{cm}$. at wail temperatures of $1241^{\circ} \mathrm{C}$. Gas temperature profiles vary as shown. Gas temperature profiles were obtained by making a series of measurements with a set of decreasing thermocouple bead sizes with the asymptotic temperatures approached defined as the "true" locai gas temperature.

The reactor creates a heat transfer field in which entrained paricles are heated by radiation to temperatures slightly above the local. axial, entrained gas temperature with :a the reactor (Figs. 2.87.2.88). The radiation flux induces an inverse diameter dependent heating rate on particles in an artempt to drive the particles to equilibrium with the radiating walls. The carrier gas imposes an inverse diameter squsared component on the particle heating rate. which in effect insures small particle temperatures are not very different fiom the local gas temperature. assuming the devolatilization process is weakly endothermic or thermally neutral.

Since an objective of this experiment is to minimize the secondary reactions of tars, the entrainment gas enters the reactor at room temperature and is heated by the hot walls as it flows through the reactor. The resulting gas temperature profiles are therefore non-isothermal. In order to operate the reactor in this inode and still allow interpretation of the results requires the careful characterization of the heat transfer field as described above. Paricle temperatures are calculated using the measured radiative fluxes and gas temperatures. a particle emissivity of 0.7 , and the Merrick model for the heat capacity of coal (Ref. 2.30) (see Section 3).

Estimated particle heating rates are of the order of $2000-5000^{\circ} \mathrm{C} / \mathrm{sec}$ in these conditions. Such heating rates are greater than that reproducibly obtainable in a heated grid apparatus operated in the same laboratory, but less than that expected in conventional entrained flow reactors wherein heating rates approaching $100.000^{\circ} \mathrm{C} / \mathrm{sec}$ (see Section 2.2 .1 and 2.2.2) are indicated with estimated transient flux rates 
Figure 2.81

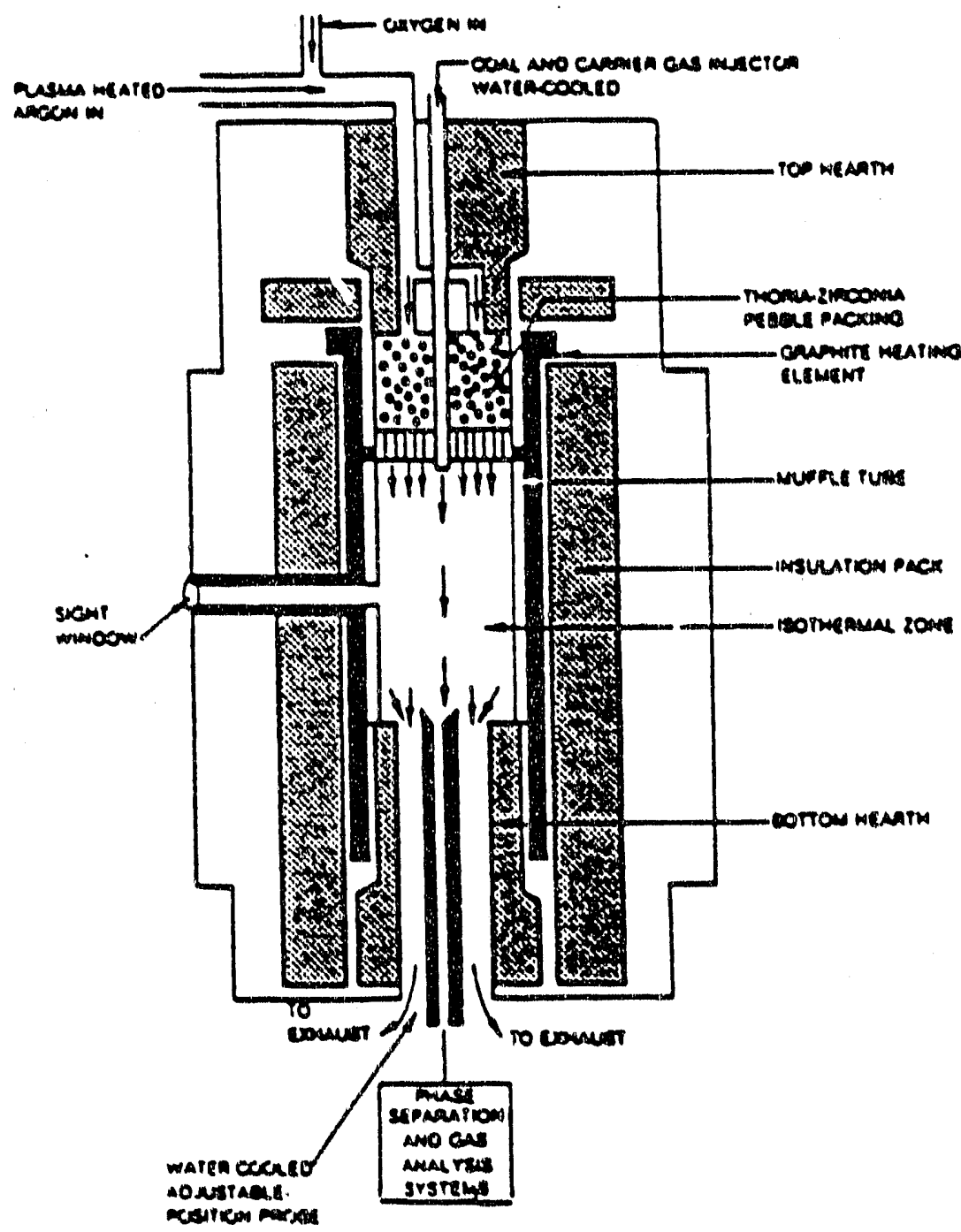




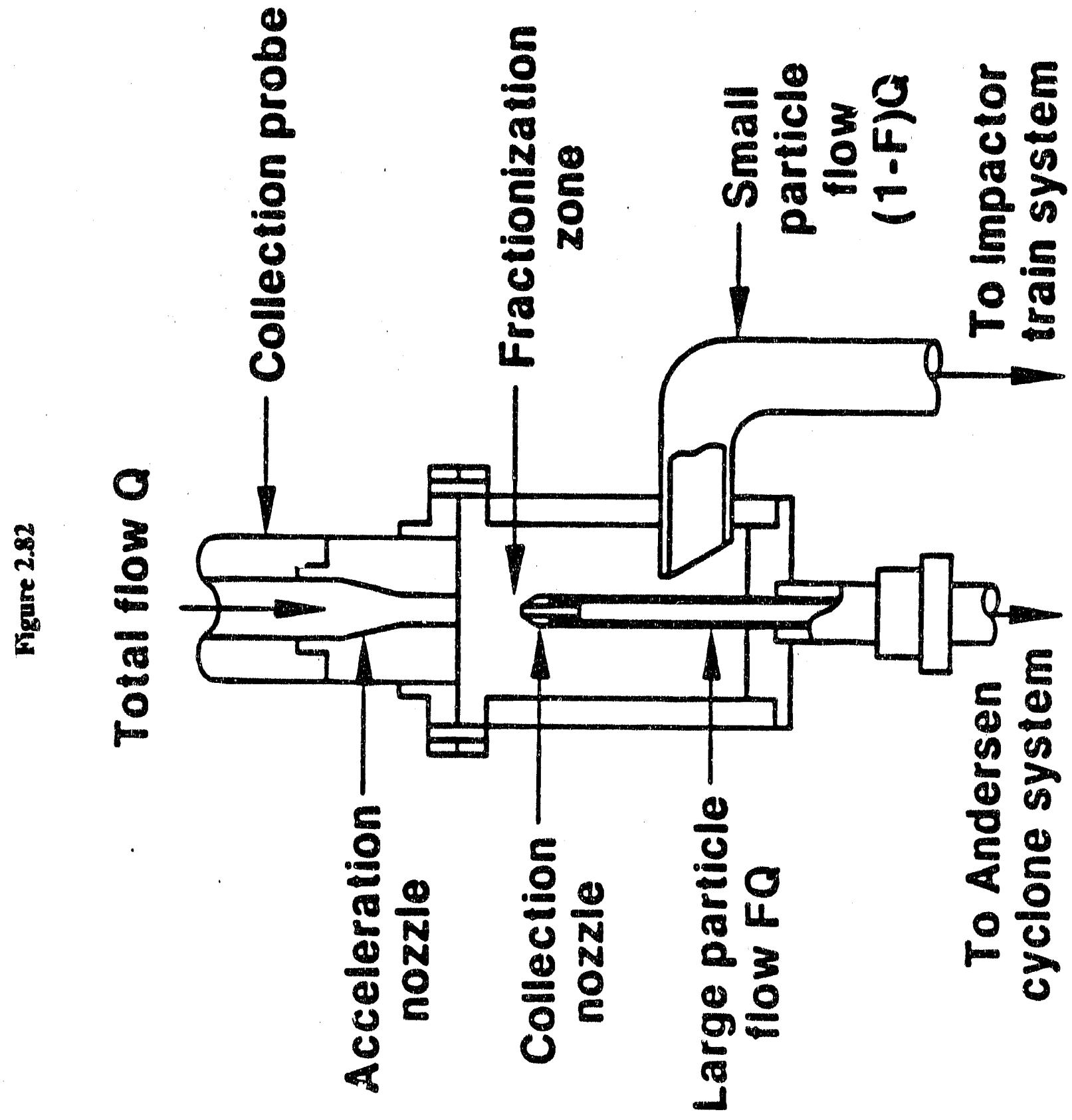




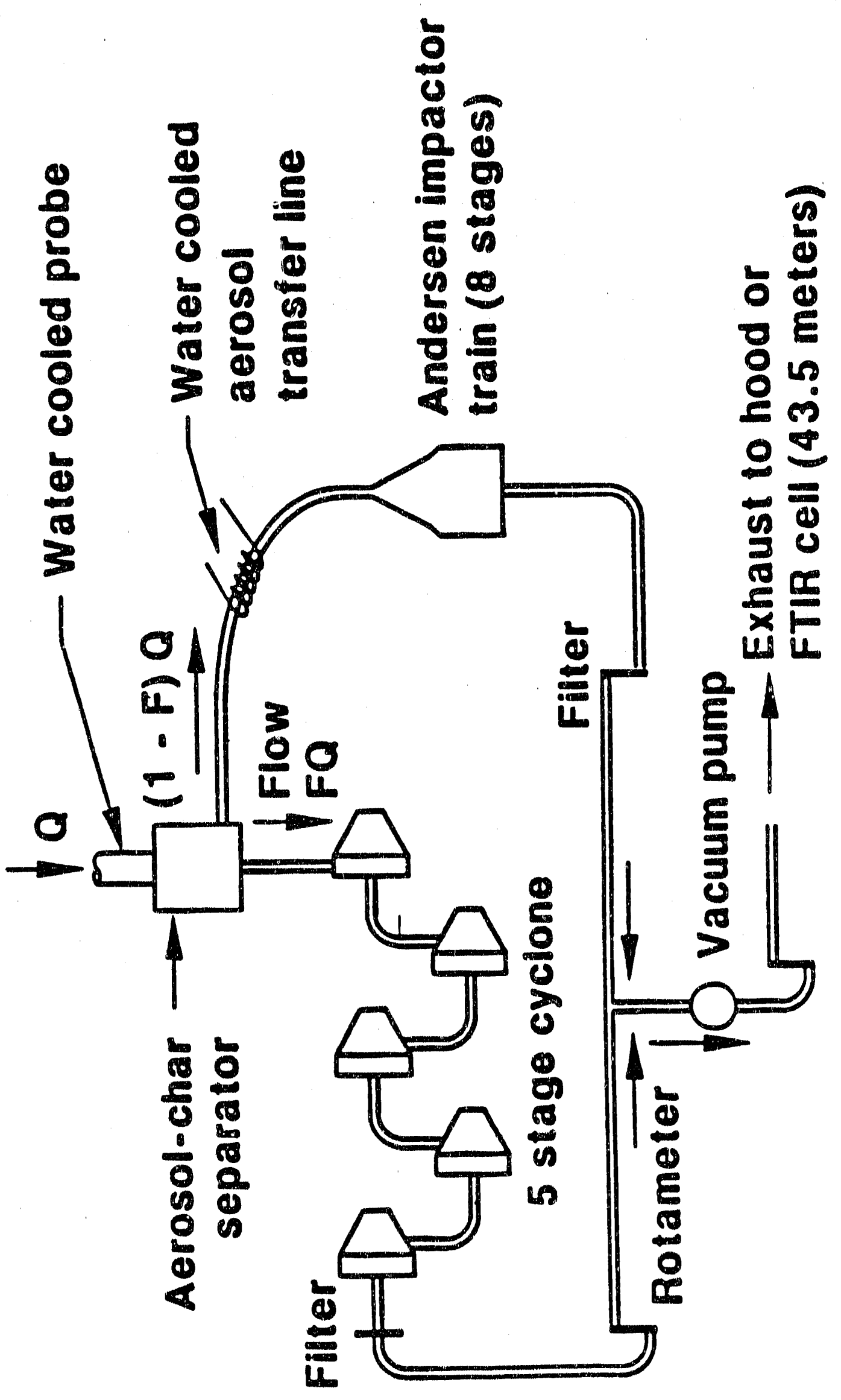




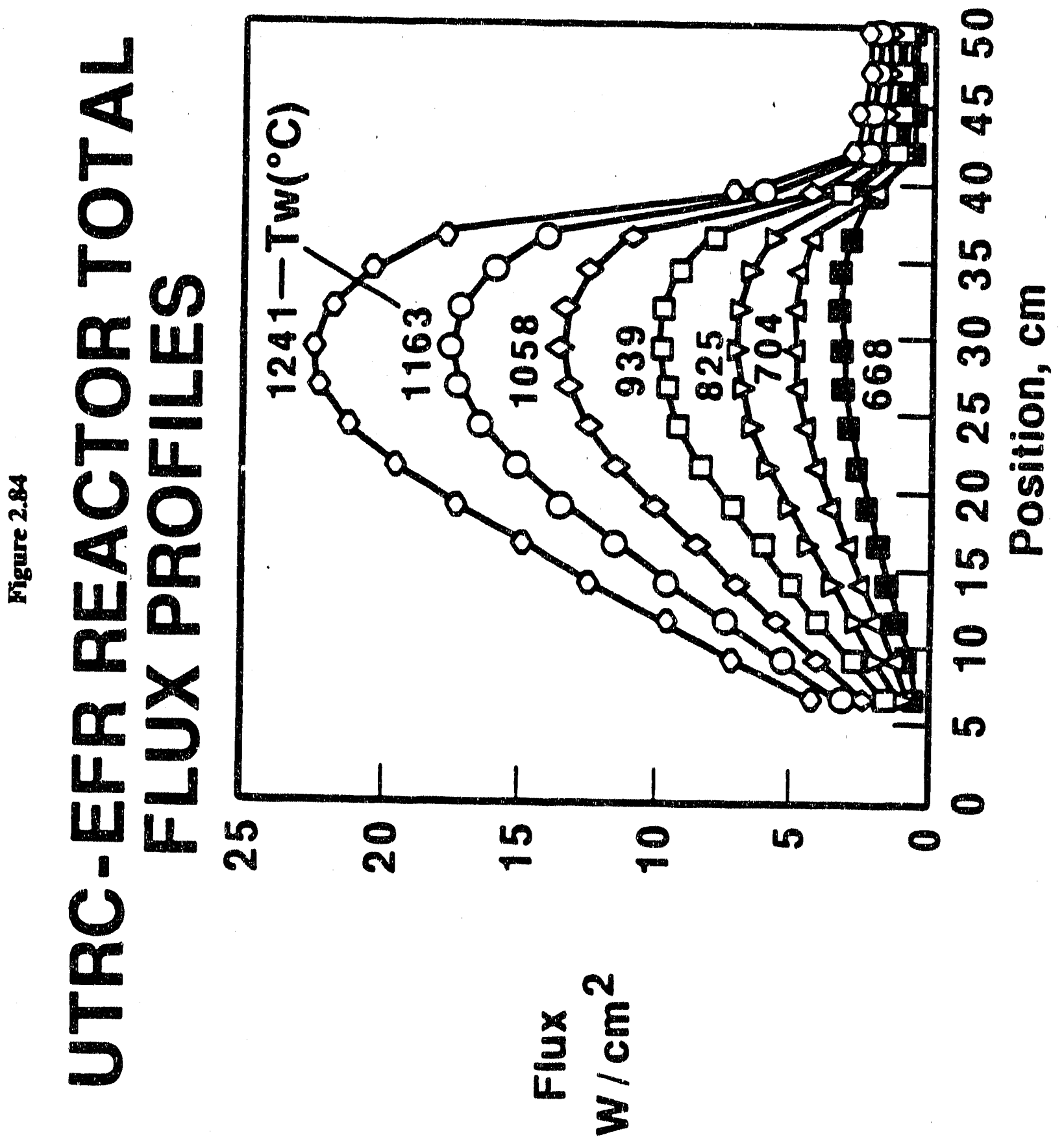




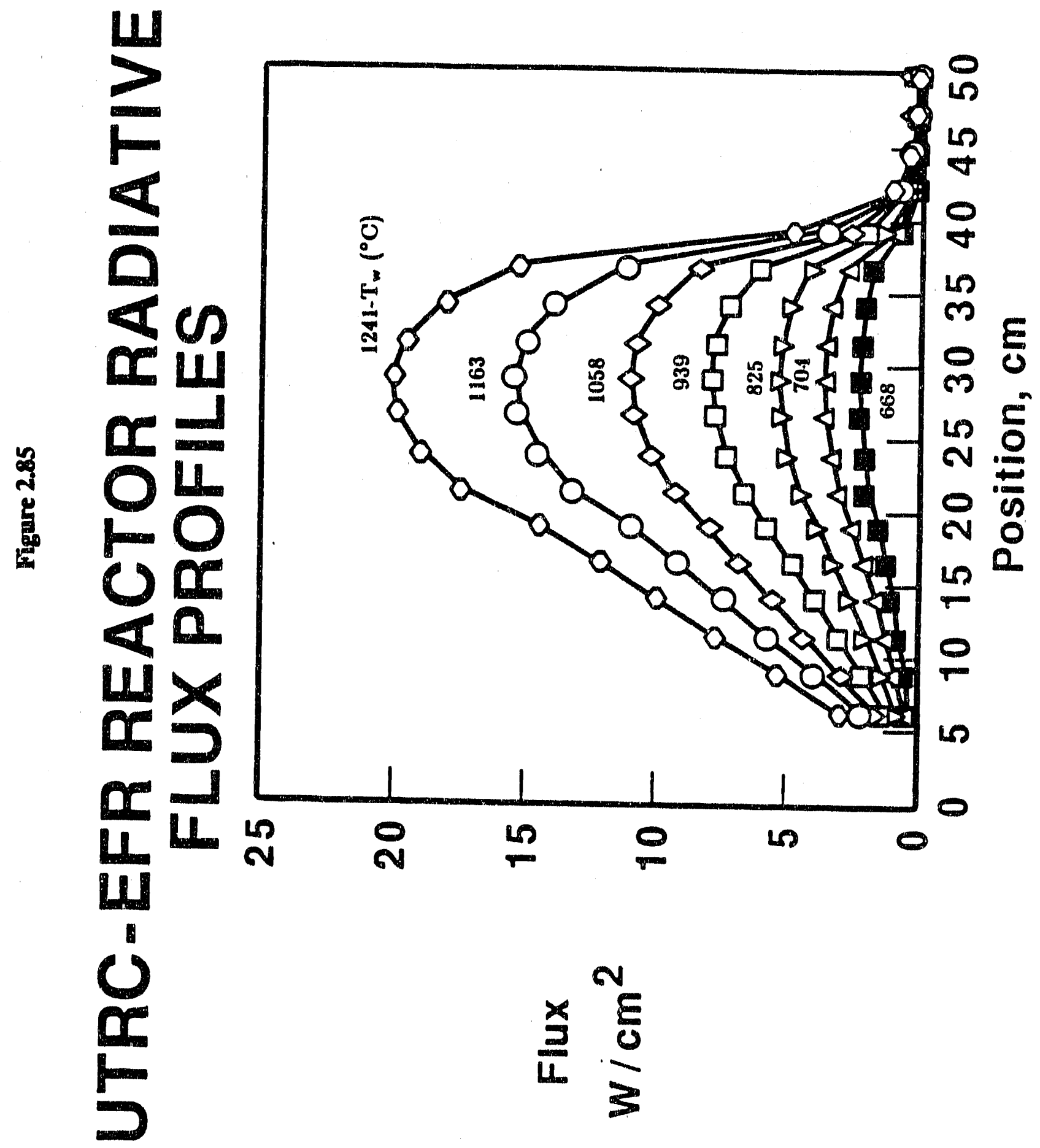




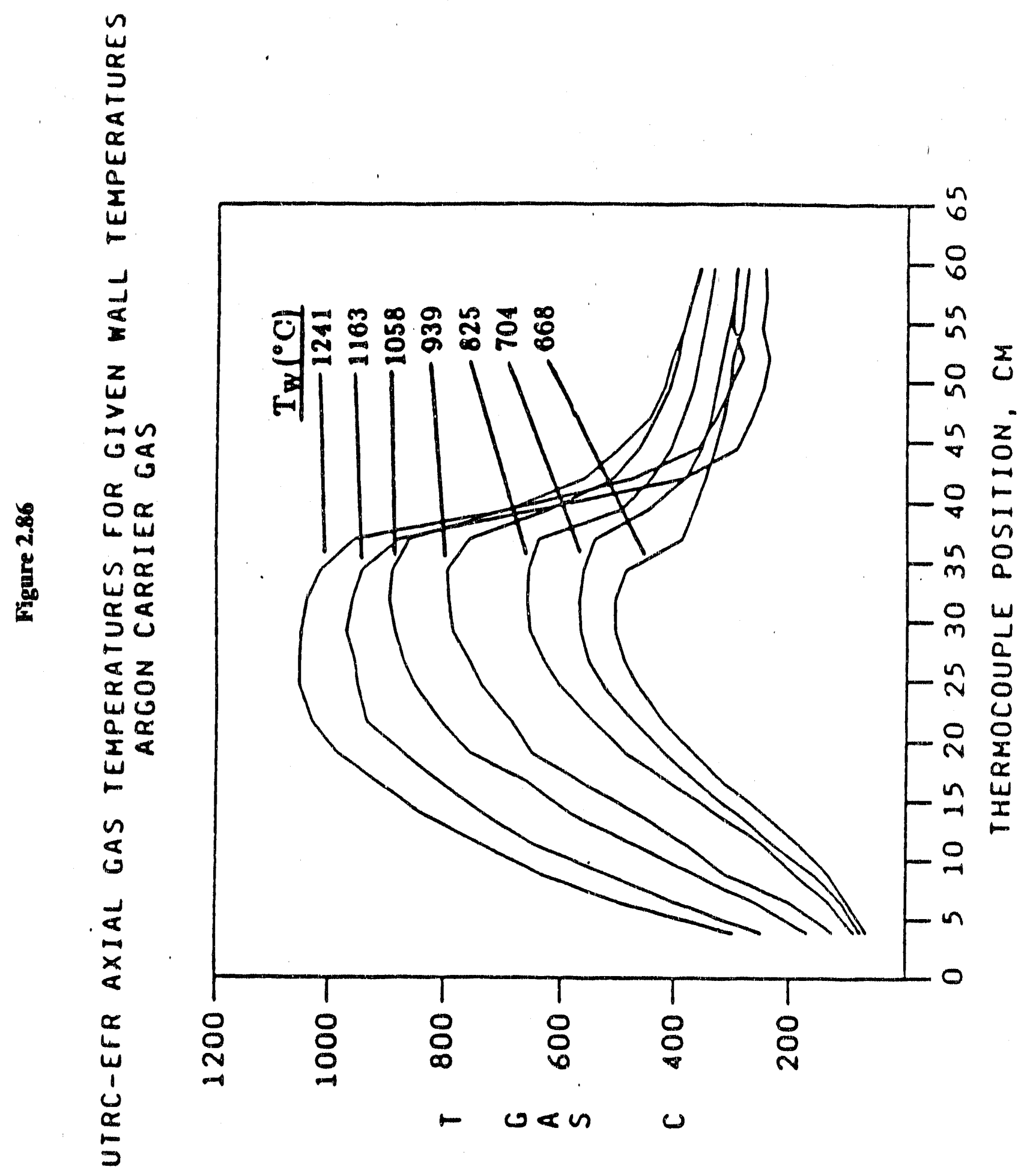


R88-PC70768

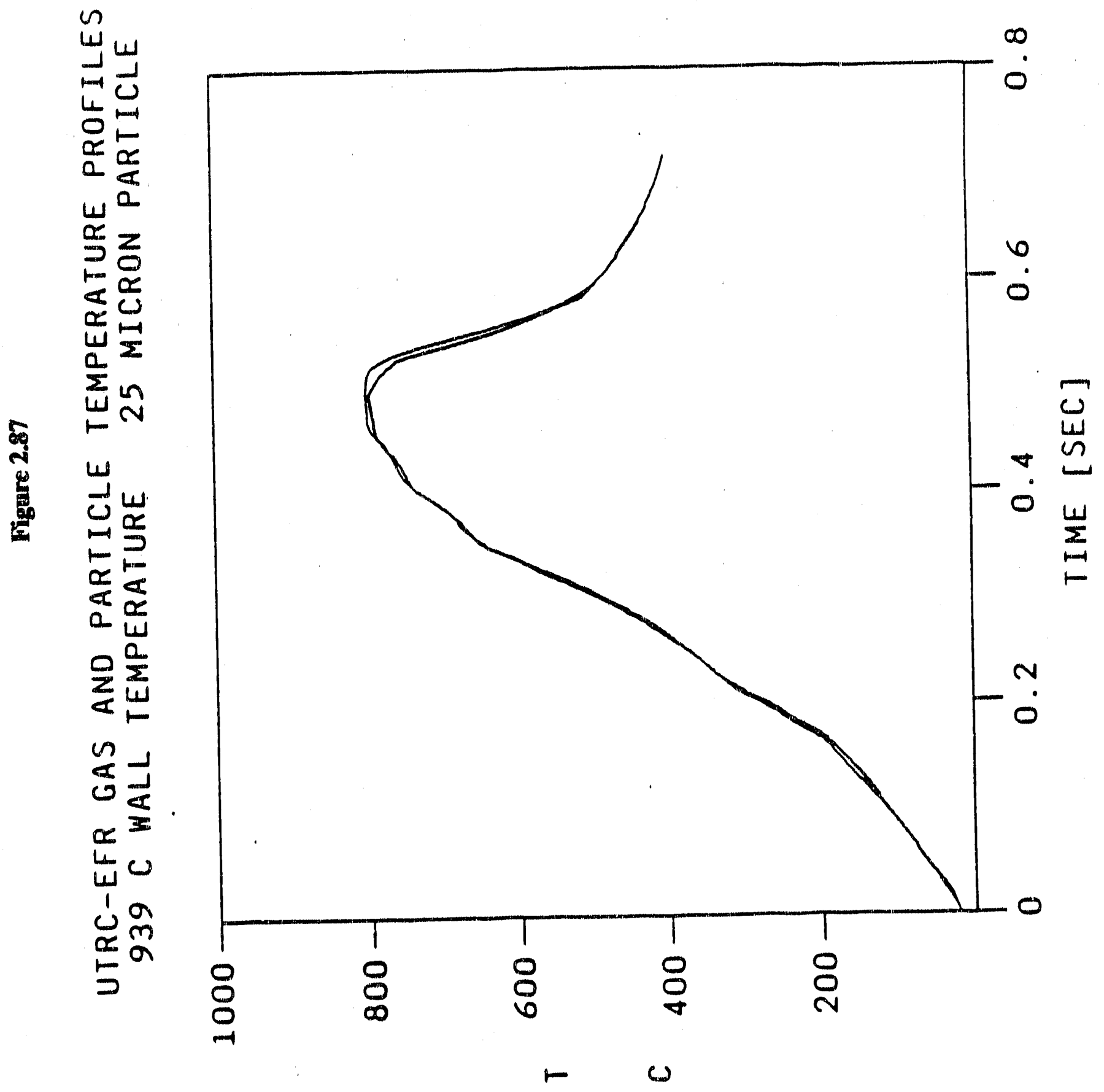




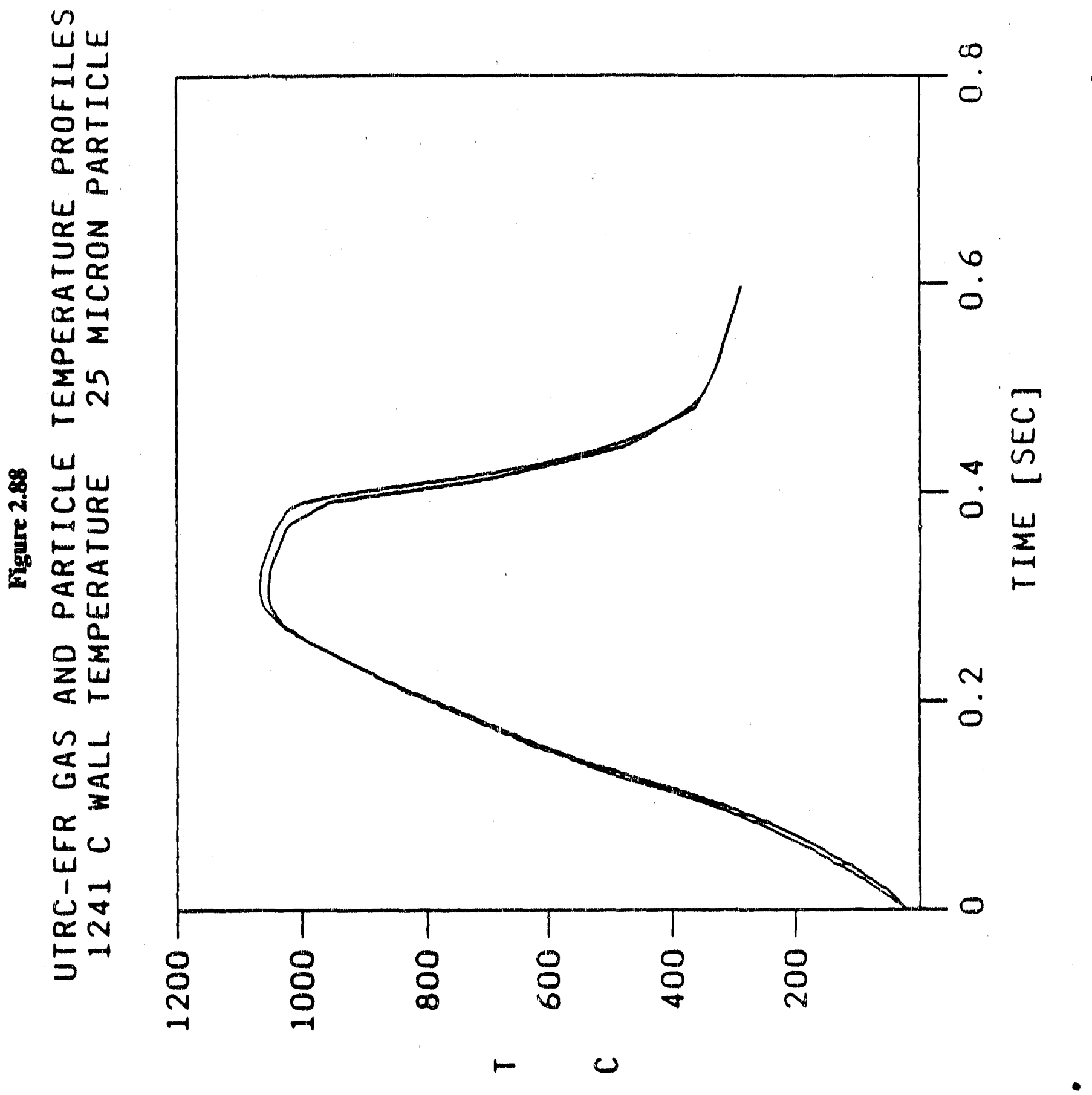


at the particle surface of nearly 100 watts $/ \mathrm{sq} . \mathrm{cm}$. Operating an entralned flow reactor in this manner minimizes gas phase pyrolysis reactions of the initial tar species and allows collection of large quantities of physically isolated tar species, thereby allowing a greater degree of deconvolution of the tar evolution process.

Normally, $60-75 \%$ of the total reactor flow is drawn through the aerosol separation (impactor traln) system, that is F of Fig. 2.82 and 2.83 is of the order $0.25-0.40$. The temperature and path length of the cooled aerosol transfer line are varied according to the nature of the tars being collected, which, in turn, varies with the parent coal characteristics and reactor heating conditions. The aerosol phase separator is designed to "pull off", in quantities proportional to the gas split, all particles or aerosols that are less than 2 microns. A qualitative check of the performance by scanning electron microscope examination of the deposits indicated that designed behavior is followed, provided proper flow rates are maintalned throughout an experiment. Inertia carries larger particles into the char separation (cyclone train) system. Both separation trains contain porous metal filters as final stages. Performance of the system is monitored by measuring the flow through the separation arms, pressure drop across the filter housings and determining the tar mass deposited on each of the filter systems, and throughout the aerosol train system.

\section{Sample Selection}

The feed system utllized is capable of sustained delivery of optically thin streams of particles at constant mass delivery rate, provided the feeder is loaded with a narrow particle size range initially. Particle sizes as low as 10 microns and as large as 300 microns have been utilized. Since the feeder operates on aerodynamic principles, aerodynamically separated samples were employed (see acknowledgements). The elemental composition of the parent coals are given in Table 2.11 .

\section{Sample Measurements}

Mass loss is determined by ash tracer techniques. It is observed that experiment specific determinations of the parent coal ash need to be determined. This is accomplished by operating the system in cold flow conditions before and after a particular hot wall devolatilization test and determining the high temperature (ASTM) ash content of the particles collected in the first stage cyclone. This value becomes the Initial, experiment specific feed ash value. It is observed that lower density particles are fed into the reactor Initially despite the rather extensive efforts to match the aerodynamic characteristics of the feeder with those of the size separated samples provided. Consequently, sustained operation over a sequence of 
devolatlization conditions leads to significant varlations tat the average density, mineral content, of the feed, which, in turn, leads to inconsistent determinations in particle mass loss via ash tracer.

\section{TABLE 2.11 - ELEMENTAL COMPOSITION OF PSOC XXXXD COALS* DRY-ASH-FREE BASIS}

\begin{tabular}{|c|c|c|c|c|c|c|c|}
\hline RSOCE & Bank & ofe & \% & $\mathscr{W N}$ & \%0 & \% & Seam/Location \\
\hline \multicolumn{8}{|c|}{$20-30$ microns } \\
\hline 1443D & Lignite & 71.42 & 5.17 & 1.35 & 21.01 & 1.06 & Lower Wilcox, TX \\
\hline $1507 \mathrm{D}$ & Lignite & 72.49 & 4.32 & 1.09 & 20.22 & 1.88 & Beulan, ND \\
\hline 1488D & Sub B & 75.48 & 5.34 & 0.94 & 17.80 & 0.44 & Dietz MT \\
\hline $1520 \mathrm{D}$ & Sub C & 73.67 & 5.90 & 1.11 & 18.22 & 1.10 & Smith Roland, WY \\
\hline $1445 \mathrm{D}$ & HVC Bit & 76.72 & 5.44 & 1.28 & 15.65 & 0.91 & Blue, NM \\
\hline $1502 \mathrm{D}$ & HVB Bit & 79.88 & 5.71 & 1.31 & 12.65 & 0.45 & Hiawatha, UT \\
\hline $1451 \mathrm{D}$ & $H^{*}$ 'A Bit & 83.98 & 5.48 & 1.67 & 7.41 & 1.46 & Pitt, $\# 8$ \\
\hline $1493 \mathrm{D}$ & HVA Bit & 78.79 & $5: 16$ & 1.48 & 10.15 & 4.42 & III. \\
\hline $1508 \mathrm{D}$ & MVB & 91.73 & 4.52 & 1.73 & 1.38 & 0.63 & Pocahontas \#3 \\
\hline $1516 \mathrm{D}$ & LVB & 90.53 & 5.11 & 1.59 & 1.50 & 1.26 & Lower Kittaning \\
\hline \multicolumn{8}{|c|}{$63-75$ microns } \\
\hline $1451 \mathrm{D}$ & & 84.70 & 5.40 & 1.71 & 7.26 & 0.92 & Pitt. \#8 \\
\hline \multicolumn{8}{|c|}{$210-250$ microns } \\
\hline & & 85.45 & 6.01 & 1.74 & 5.58 & 22 & Pitt. \#8 \\
\hline
\end{tabular}

* Analyses provided by DOE-PETC

Table 2.12 indicates the UTRC determined elemental composition of PSOC/451D, 20-30 microns as determined for the parent coal sample, the "delivered" samples during a series of UTRC-EFR runs, and the feeder "residual". The parent coal sample in this case was that extracted from the original, DOE-provided sample for insertion into the coal feeder. The "delivered" samples are those captured in the first-stage cyclone during the cold flow runs associated with a series of devolatilization runs. The "residual" samples are those remaining in the feeder after a series of runs. The segregation of coal particles by ash content is obvious. The somewhat surprising aspect of the separation is the magnitude of the effect given the fact that the original DOE-provided samples were aerodynamically prepared. 


\section{TABLE 2.12 - ELEMENTAL COMPOSITION OF PARENT, DELIVERED AND RESIDUAL PARTICLES: PSOC 1451D, 20-30 MICRON PARTICLES}

$\begin{array}{llllll}\text { Sample } & \text { \%C } & \text { \%H } & \text { \%N } & \text { \%S + O } & \text { \%ASH* } \\ \text { PARENT-1 } & 75.19 & 4.94 & 1.48 & 9.66 & 8.69 \\ \text { PARENT-2 } & 75.25 & 4.95 & 1.45 & 9.52 & 8.80 \\ \text { PARENT-3 } & 75.00 & 4.91 & 1.45 & 9.82 & 8.80 \\ \text { PARENT-4 } & 75.06 & 4.90 & 1.45 & 9.78 & 8.80 \\ & & & & & \\ \text { DELIVERED-1 } & 78.49 & 5.08 & 1.53 & 10.08 & 4.80 \\ \text { DELIVERED-2 } & 78.54 & 5.08 & 1.50 & 10.36 & 4.50 \\ \text { DELIVERED-3 } & 78.56 & 5.12 & 1.51 & 10.09 & 4.69 \\ \text { DELIVERED-4 } & 78.59 & 5.08 & 1.48 & 10.01 & 4.80 \\ & & & & & \\ \text { RESIDUAL-1 } & 74.46 & 4.91 & 1.41 & 9.49 & 9.69 \\ \text { RESIDUAL-2 } & 74.42 & 4.89 & 1.43 & 9.84 & 9.39 \\ \text { RESIDUAL-3 } & 74.45 & 4.90 & 1.45 & 9.99 & 9.19 \\ \text { RESIDUAL-4 } & 74.44 & 4.91 & 1.45 & 9.78 & 9.39\end{array}$

* Note: $\quad$ ASTM Ash Analysis of the PETC Supplied Parent Sample for this size cut was determined to be $9.2 \%$. These samples were not dried before analysis.

In any case, the data Indicate the importance of continually monitoring the characteristics of the sample feed if ash tracer techniques are employed to follow mass loss. Separation by ash concentration would be expected in any feed system which employs gravitational, aerodynamic, or coupled gravitation-aerodynamic princlples for operation - stirred jet, hopper-screw feeder, fluid beds, ets.

Elemental characteristics of evolved tars and chars are determined by use of a Perkin-Elmer 240 instrument. IR absorbance characteristics are determined by an alkali-hallde technique using a Fourier Transform - Infrared Spectrometer (FT-IR). The FT-IR is also used to determine the composition of the pyrolysis gases. The particulate free gas streams from the two separation systems are recombined and continuously passed through a multi-pass cell. The 43.5 meter path length is needed to measure the low levels of IR active llght gases generated. Concentrations are low because the Initial stages of devolatilization, 
the focus of this investigatlon, generate small amounts of such gases which are entrained in a relatively large volume of carrier gas.

\section{Tar Sampling}

The wide ranges of polarity and size properties of the molecular species that compose the tar yields lead one to consider the possibility that cerain fractions of tars may be preferentially conclensed or captured at certain stages of the separation system. Preferential entrapment of fractions of the collective tar species would then lead to an unrepresentative deposition of hydrocarbons on the final filters. To ascertain the mass fraction "represenuiveness" of the final filter tar samples, a detailed mass fraction analysis was performed of the tar mass collected at the various points of tar deposition in the separation system. Figure 2.89 displays the percent of total tar mass observed at each of the indicated deposition points of the separation system. Results are shown for coal samples of three different rank characteristlcs - HVA Bituminous (PSOC 1451D), Subbltuminous C (PSOC 1520D), and a Low Volatile Bltuminous (PSOC 1S16D). The results indicate the major fraction of the captured tar mass is found on the final filter stages of the separation-collection system. irrespective of the appreclably different chemical and volatility characteristics of the rank varying tars. The ratio of impactor train to cyclorie train filter tar masses mirrors the mass ratio of the flow separation at the phase separator stage, Indicating the tar aerosol closely follows the gas flow through the collection system. As a result, only about $15 \%$ of the deposited tar mass occurs in the prefilter stages.

Figure 2.90 displays the mid-IR absorbance spectra of the relatively small amount of species found in the water cooled elbow (Fig. 2.83) of the aerosol train (Flg. 2.90). Figure 2.91 to 2.98 show the absorbance characteristics of the small sample amounts (see Fig. 2.89) deposited on impactor plates 1 - 8 from parial devolatilization of PSOC 1451D. Figures 2.99 and 2.100 display the spectra of the tar species found on the impactor filter and the cyclone filters, respectively. Wlthin the limited sensitivity of the infrared absorbance technique, the organic functional group absorbance characteristics of the filter tars are the same (see Table 2.13 and Fig. 2-1004), but aerosol impactor plates $1-4$ show the presence of significant amounts of mineral matter and condensed aromatic $\mathrm{C}$ structures (probably char). The mineral matter is probably due to char particle fines produced during the feed or devolatilization process; the "background" absorbance due to char $\mathrm{C}$ correlates with mineral matter absorbance bands in the impactor plate samples. The latter stages of the impactor train (plates 5-8) display spectra essentially free of background absorption, char $C$, and mineral matter. The mass normalized functional group absorbance bands are essentially identical. Such results are observed for each of the coals investigated and for each devolatilization temperature 


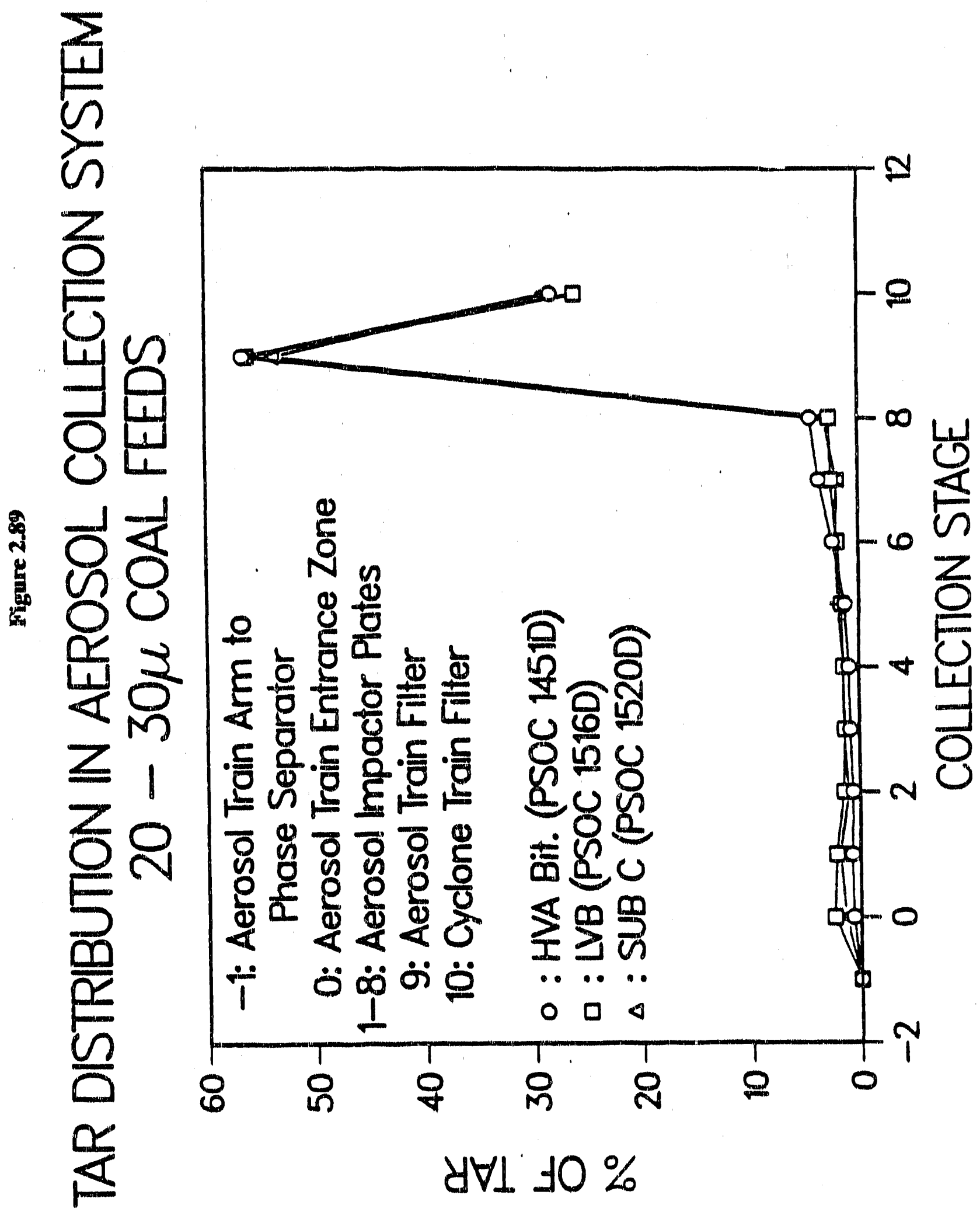


employed.although the chemical nature arid deposited amounts of the tars vary substantially with rank characteristics of the parent coal, reactor operating temperature, and paricle size characteristics of the feed.

Table 2.14 displays the mass ratio of tar deposits as collected on the cyclone and impactor filter plares relative to mass flow ratio through each arm of the separation system. As indicated, the mass ratios of he filter deposits reflect the gas mass ratio established at the phase separator.

In summary, both mass distribution and chemical characterization of the species deposited within the sampling system components indicate the tars collected on the final filters are representative of the soller aptured tar mass. The pre-filter impactor plates serve to separate the small amount of fines, that is, mineral matter/coal particles, from the entrained tar acrosol. Relatively small amounts of tars are deposited before the final filter stages.

\section{TABLE 2.13 - STRUCTURE ASSIGNMENTS IN ABSORPTION SPECTRA HYDROCARBON STRUCTURES}

BAND $\left(\mathrm{CM}^{-1}\right)$ ASSIGNMENC OF STRUCTURE

$700-900$

$3000-3100$

$2000-4000^{\circ}$

$2600-3000$

$2000-3620$
AROMATIC RING H OUT OF PLANE BENDING

AROMATIC RING H STRETCHING

CONDENSED AROMATIC RING STRUCTURES

ALIPHATIC H STRETCH

HYDROXYL AND AMIDE H IN VARYING STATES OF HYDROGEN BONDING

EEAK/SHOULDER (CM-1) ASSIGNMENT OF STRUCTURE

3560

3420

3240

2965,1385

$2860,2930,1465$

1140

$1220, \quad 2270$
HYDROXYL H IN PHENOL GROUPS

AMIDE BONDED H; PYROLE RING H

HYDROXYL H IN PHENOL GROUPS WHICH

ARE HYDROGEN BONDED TO HALIDE MATRIX

AND INTRA-MOLECIJLAR YYDROGEN BOINDED

H CONTAINED IN $-\mathrm{CH}_{3}$ CROUPS

$\mathrm{H}$ CONTIAINED IN $-\mathrm{CH}_{2}$ GROUPS

ETHER OXYGEN

HYDROXYL HI

- Broadband harkground absorption due to photo promotion of valenc" barids of molecular orbitals established in condensed aromatic ring stri

Id electrons to conduction absorption band $\left(2000-3620 \mathrm{~cm}^{-1}\right)$ "rides" on top of this band tisixes ind absorption increases with extent (number density and size distribution) of aromatic ring condensation within a sampl.. 

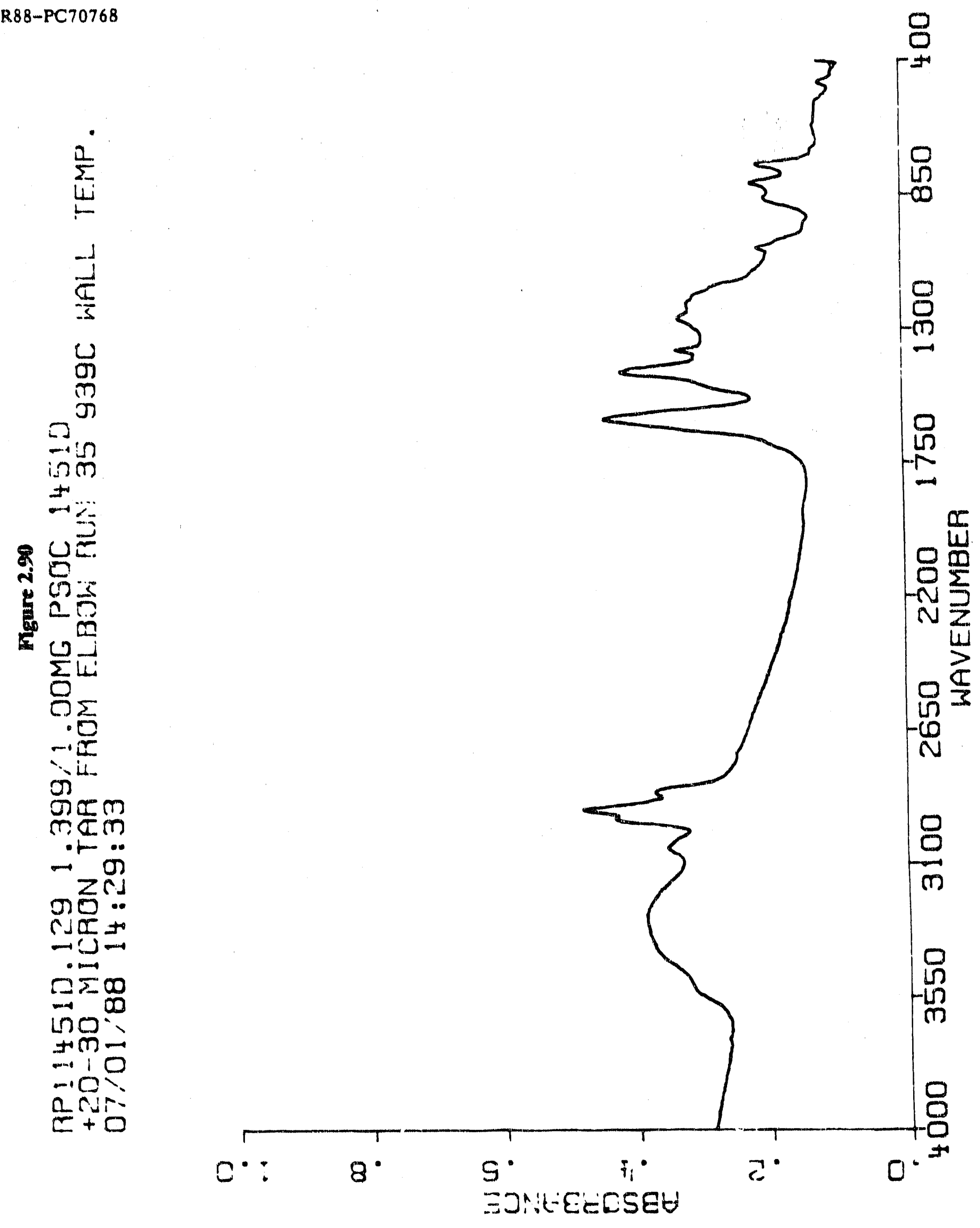


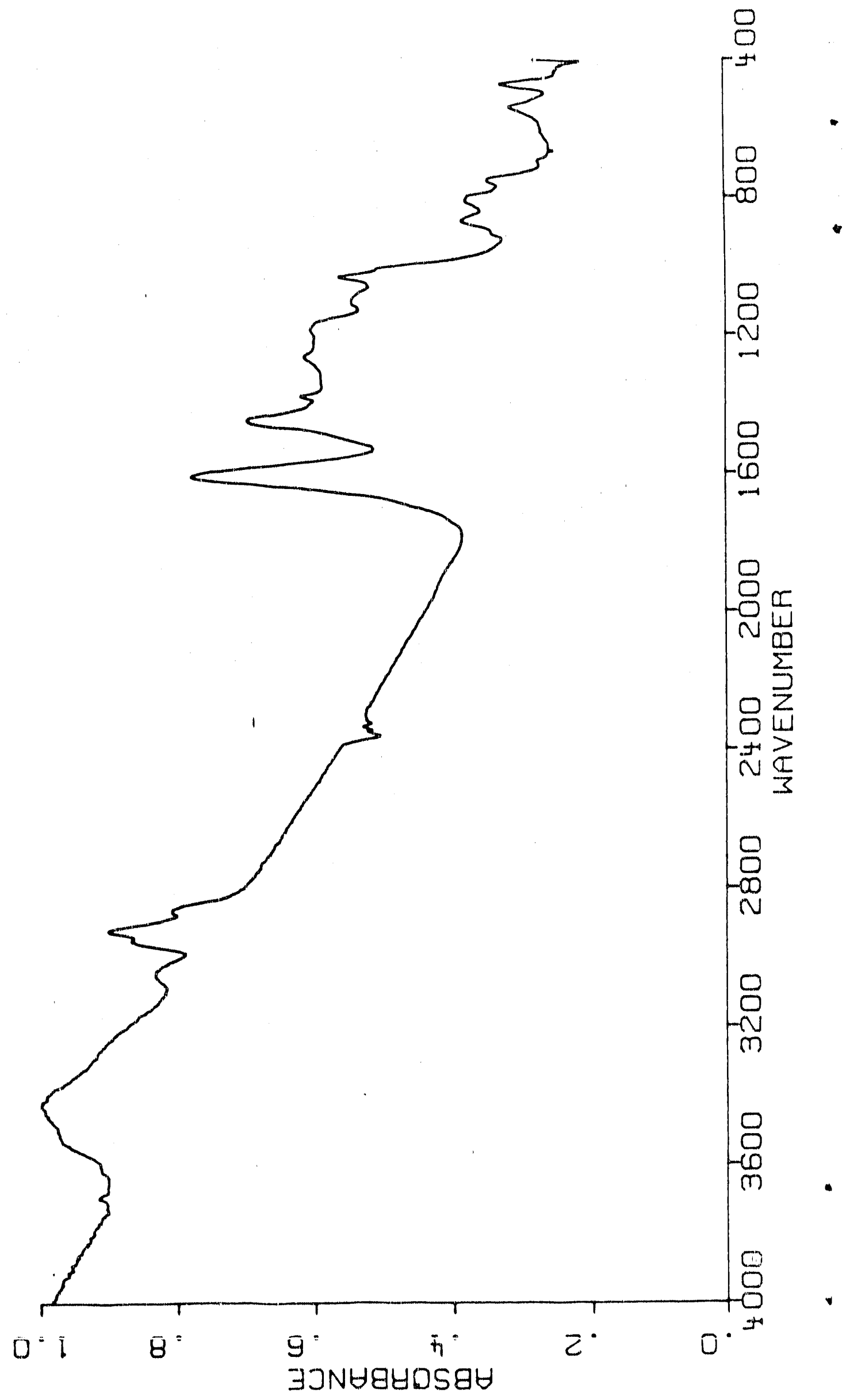



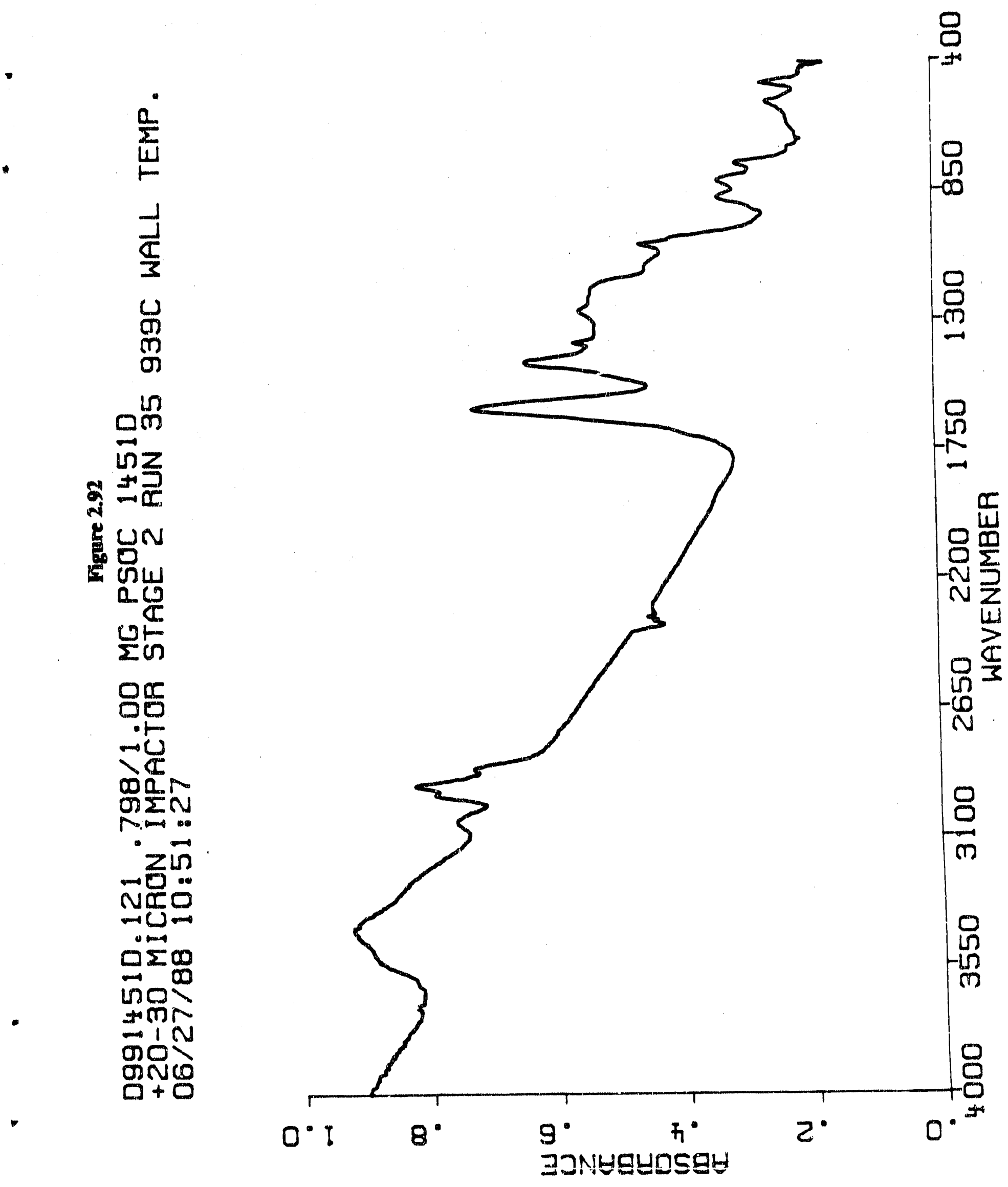

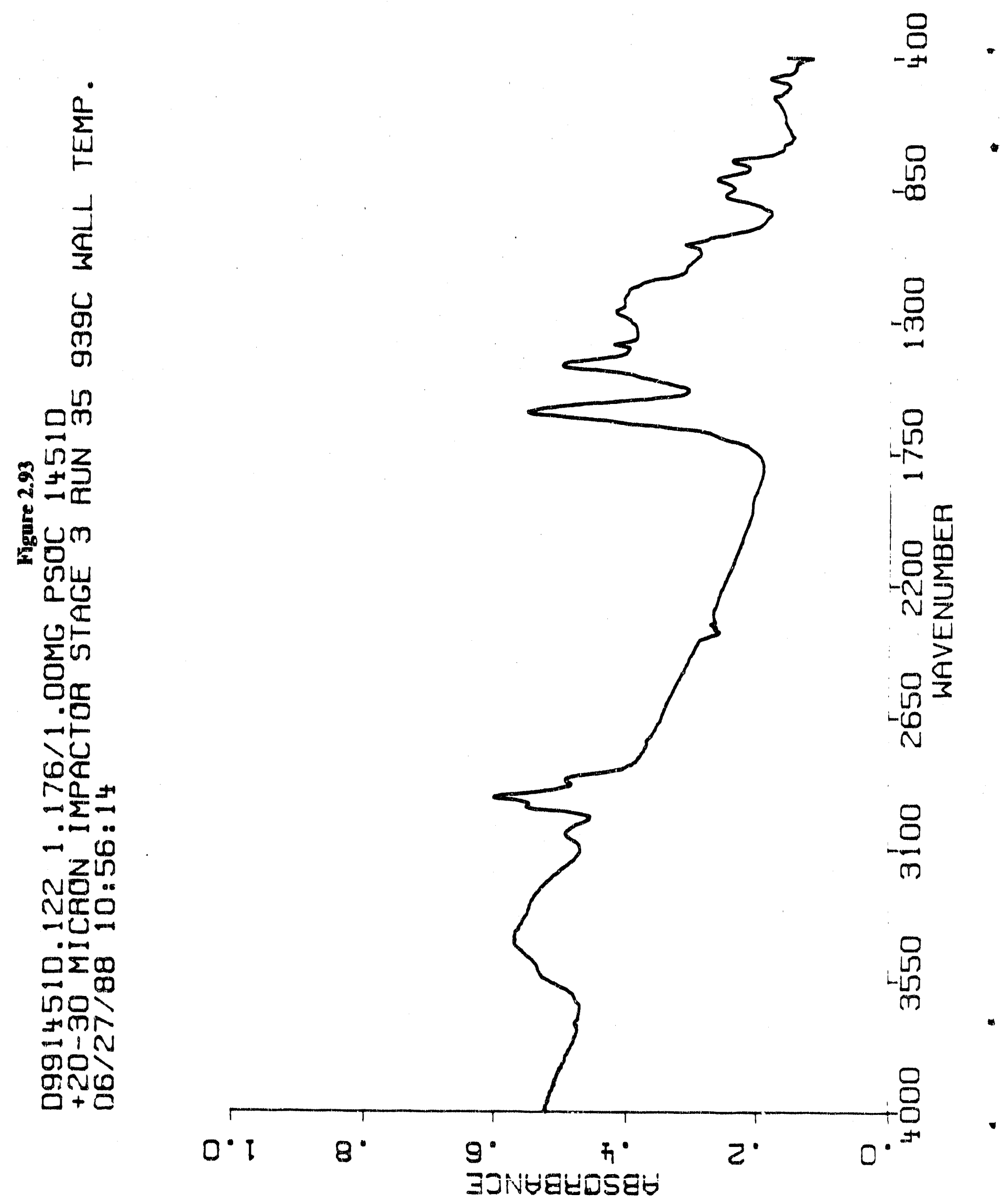

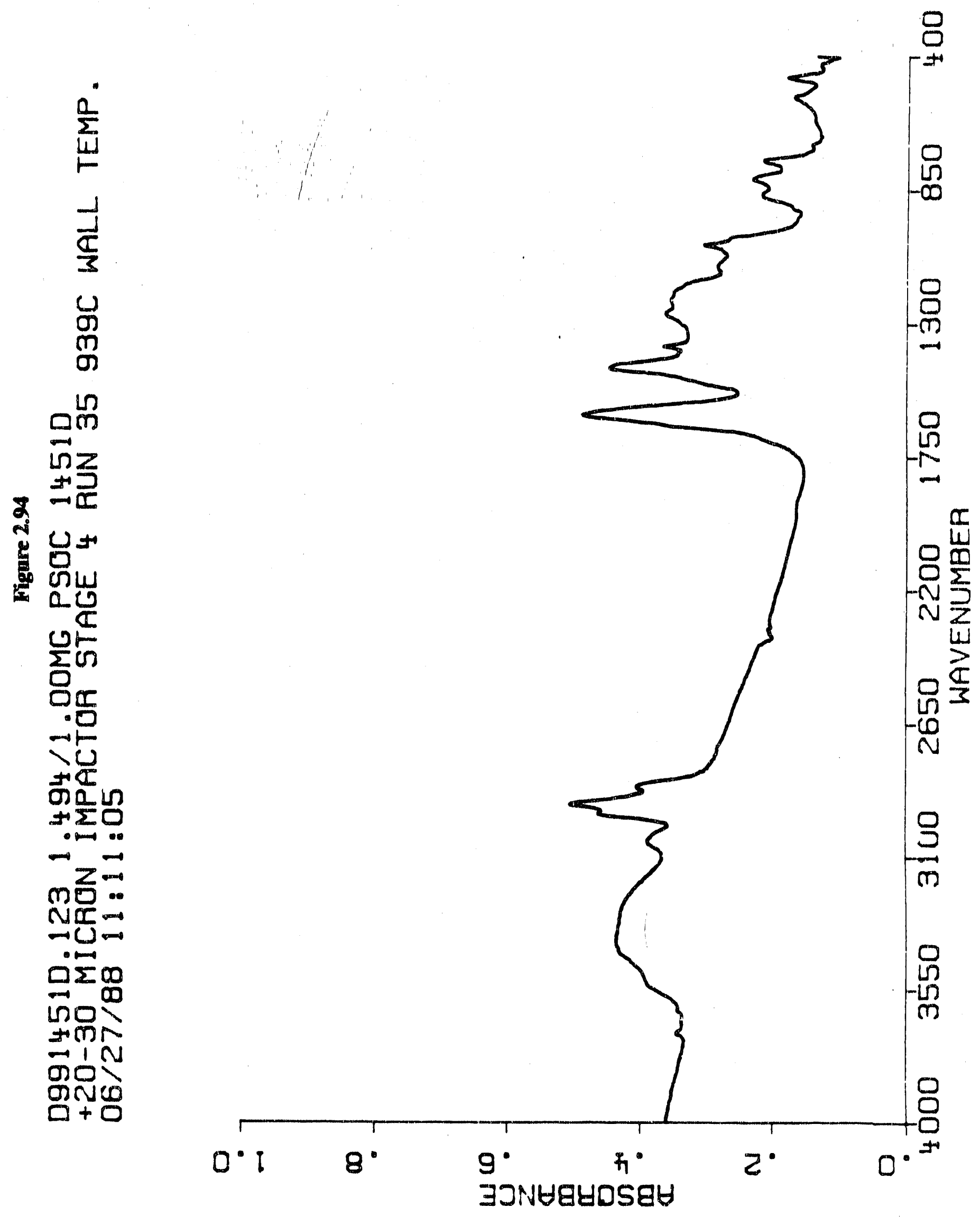

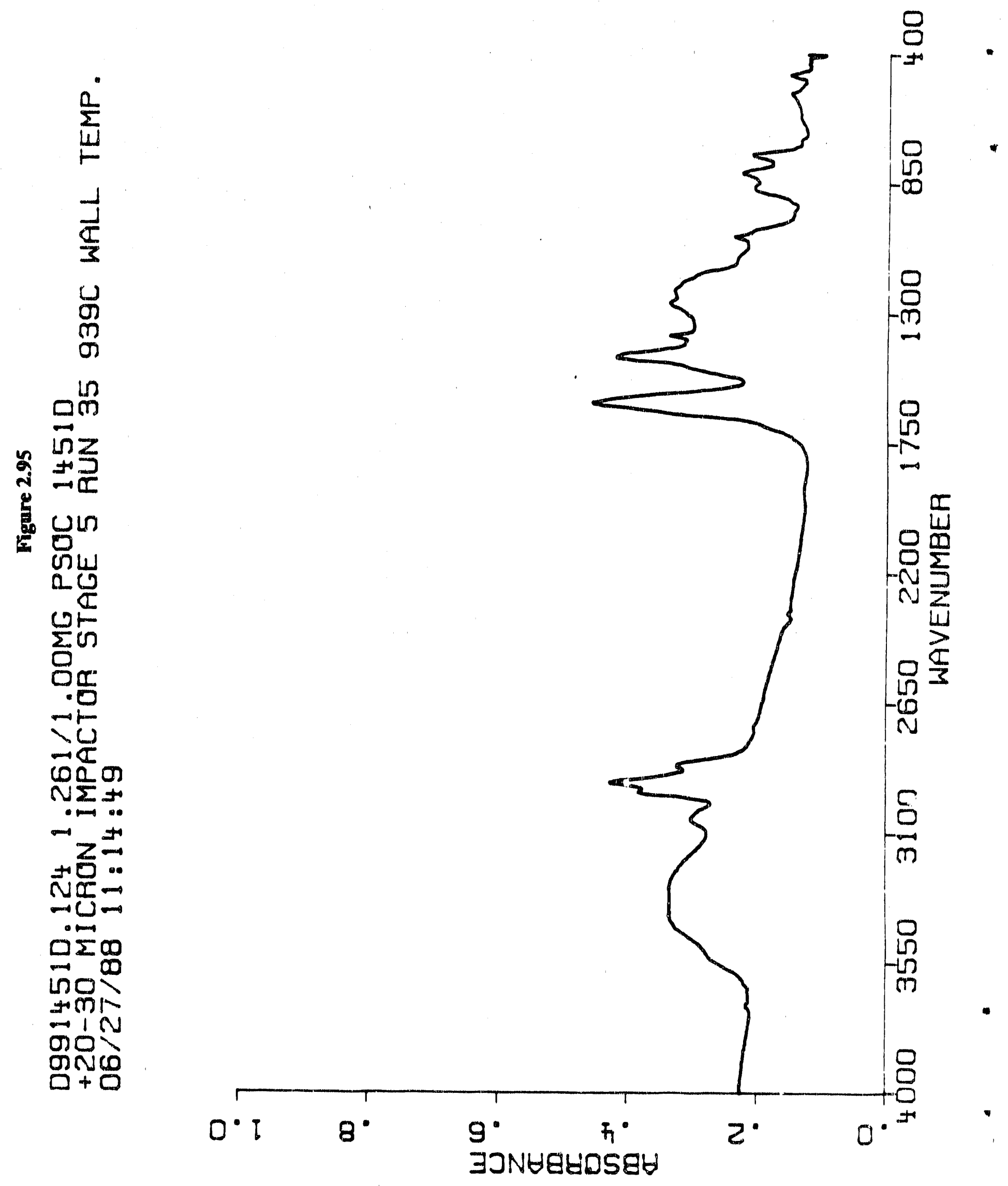


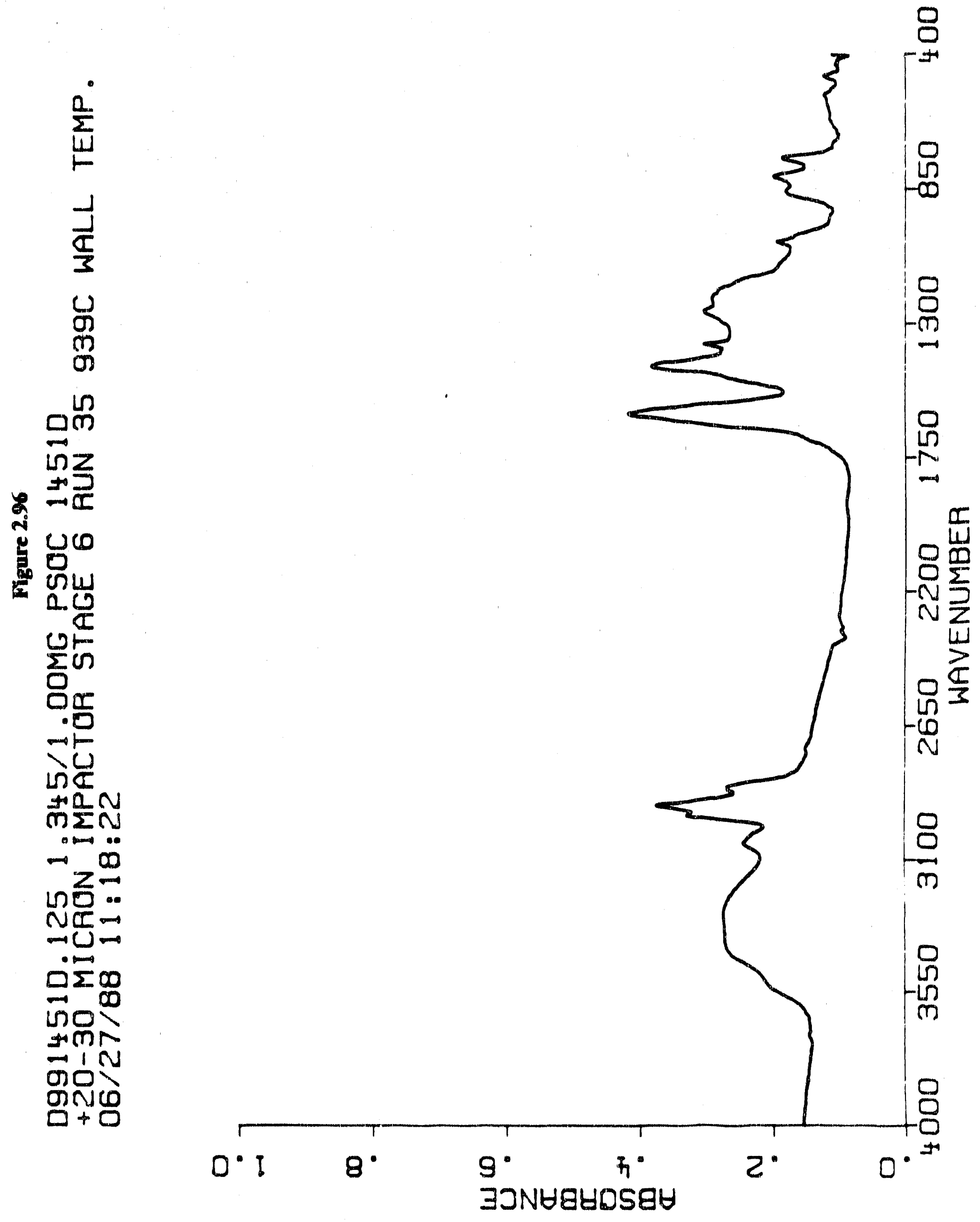




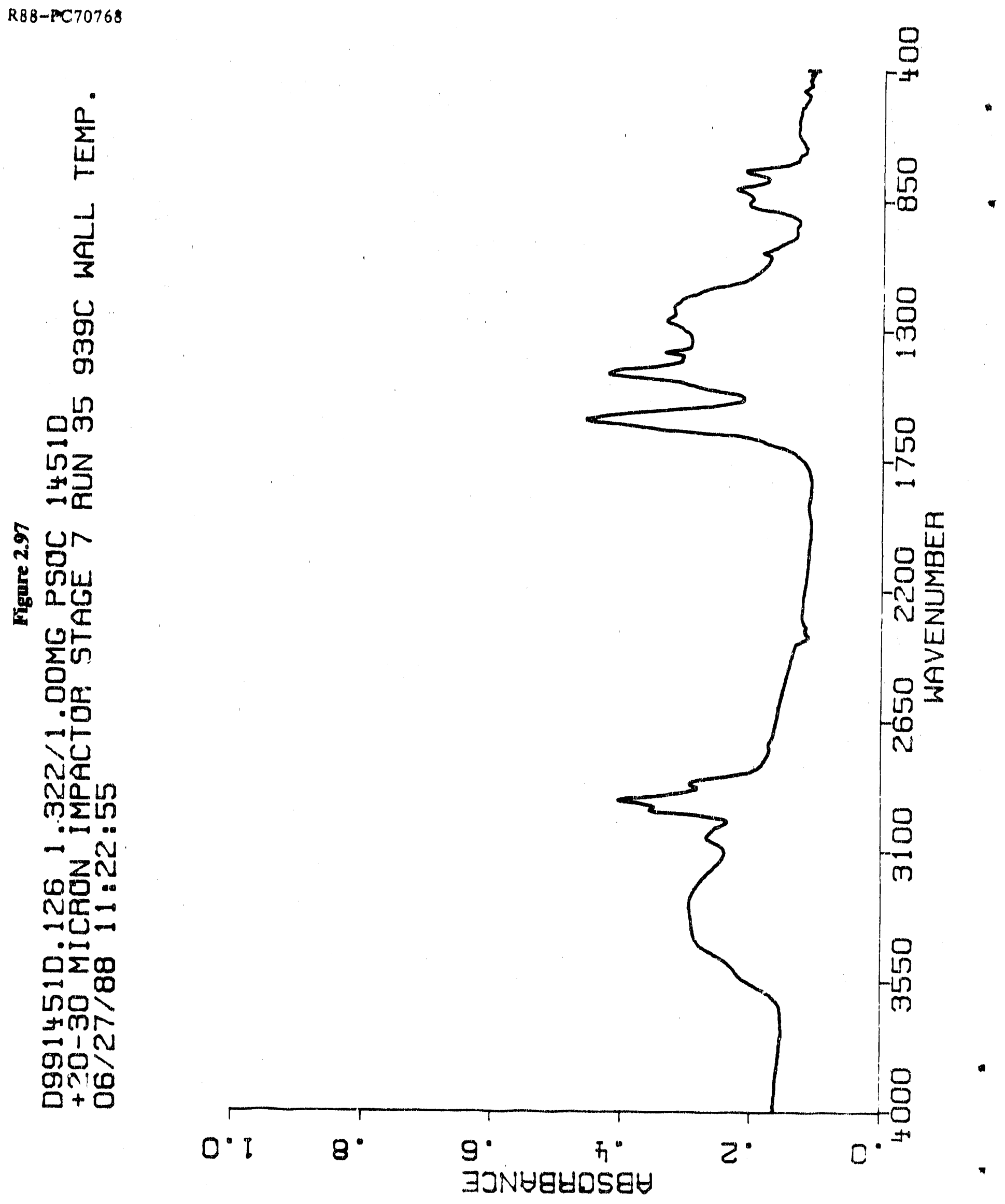




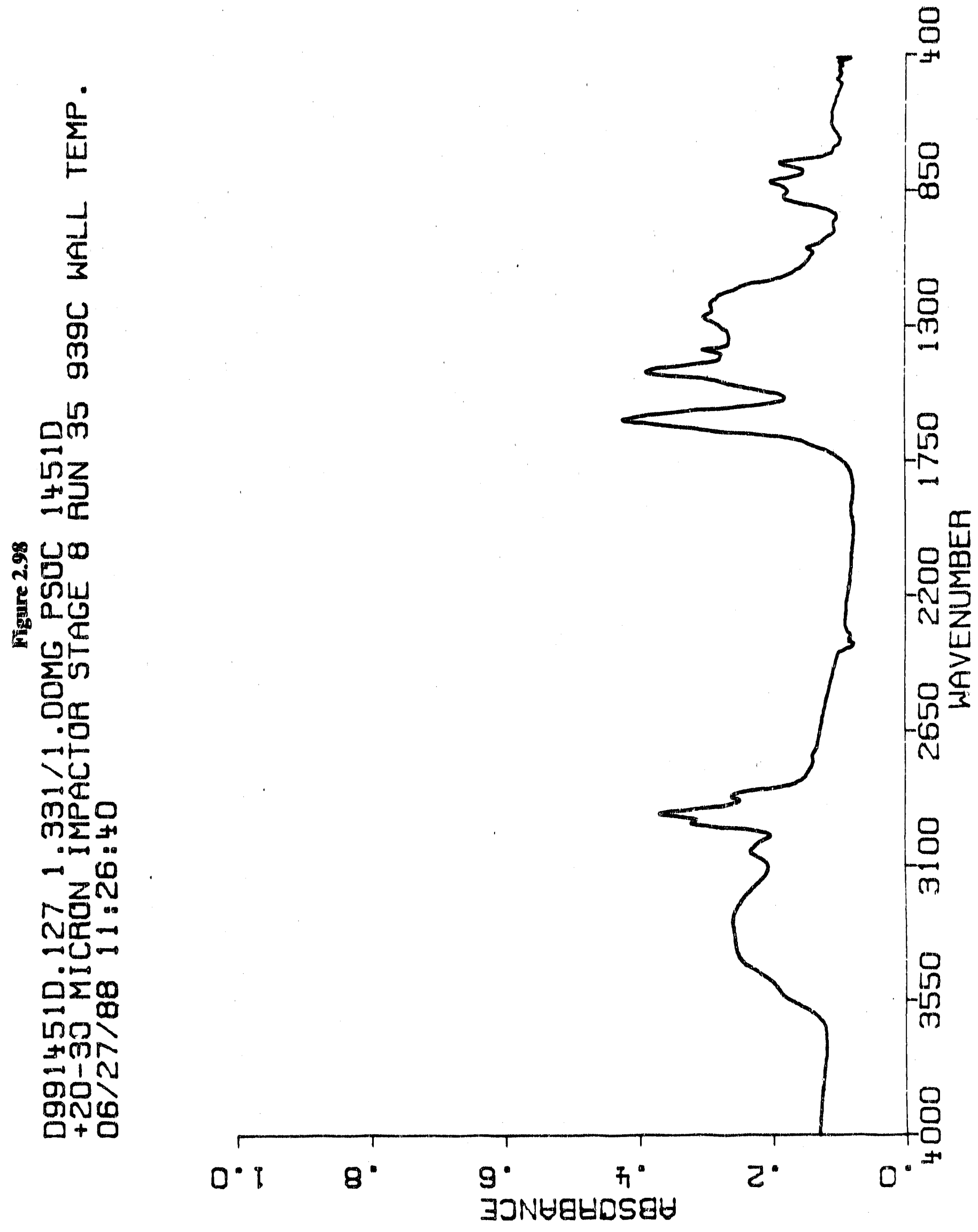



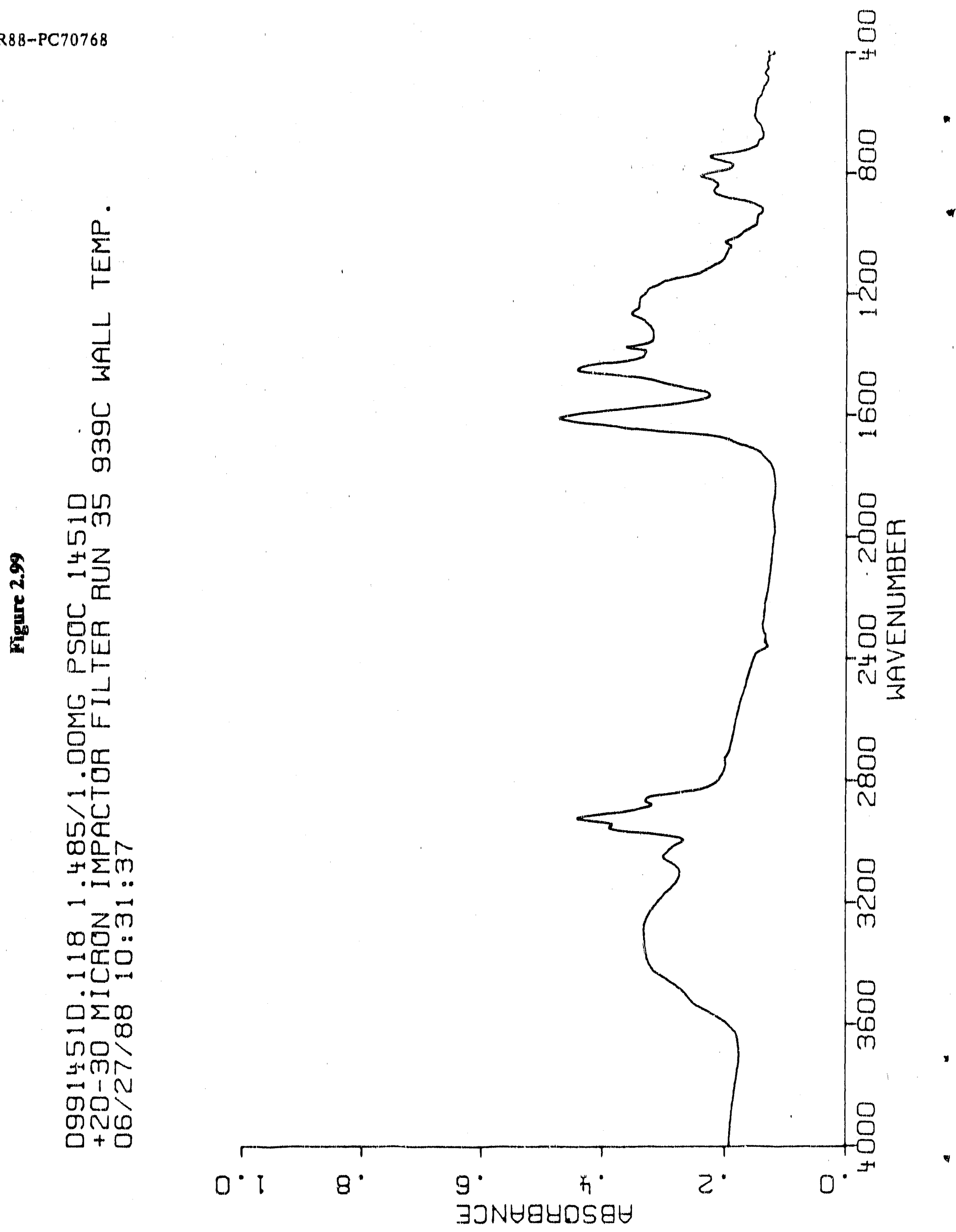


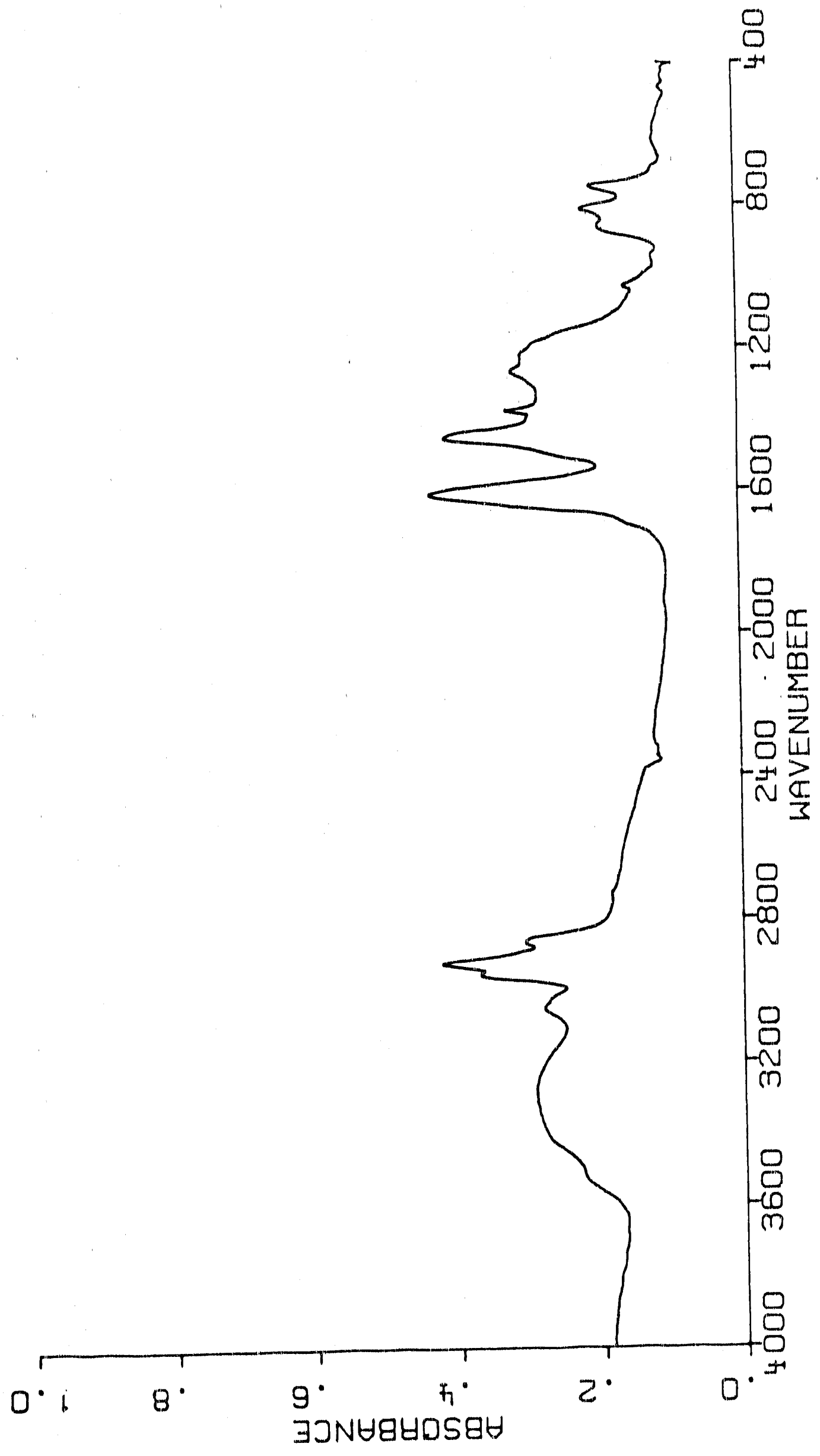




\section{TABLE 2.14 - RELATIVE TAR CAPTURE EFFICIENCY OF SAMPLING L TERS (Aerosol/Cyclone Entrainment Gas Flow Ratios: 1.6-2.0)}

\begin{tabular}{|c|c|c|}
\hline Sample & $\begin{array}{l}\text { Reactor Wall } \\
\text { Temperature (loC) }\end{array}$ & $\begin{array}{c}\text { Sample Mass Ratlos: } \\
\text { Aeresol/Cyclone Fllter Species }\end{array}$ \\
\hline PSOC $1451 D$ & 939 & 1.98 \\
\hline \multirow[t]{2}{*}{ PSOC 1520D } & 704 & 1.65 \\
\hline & 1058 & 1.85 \\
\hline \multirow[t]{3}{*}{ PSOC $1516 D$} & 704 & 1.60 \\
\hline & 939 & 2.00 \\
\hline & 1058 & 2.08 \\
\hline
\end{tabular}

\section{Size Exclusion Chromatography (SEC)}

Size exclusion chromatography (SEC) was used to determine relative molecular weight distri. butions of the tar samples. Samples were prepared by dissolving several milligrans of tar in $3-4$ $\mathrm{ml}$ of tetrahydrofuran and then filtering through a 0.5 micron filter to remove insoluble material. A series of solvents were investigated including serial combinations of solvents such as methylene chloride followed by methanol. Only THF had sufficient polarity to dissolve $100 \%$ of the tars at room temperature. SEC was performed on $500 \AA$ and $100 \AA \mu$ styragel (Waters) columns connected in serieg using tetrahydrofuran (THF) as the mobile phase at a flow rate of $1.0 \mathrm{ml} / \mathrm{min}$. UV detection at $330 \mathrm{~nm}$ was used and a uniform response with $\mathrm{MW}$ was assumed.

SEC separates molecules according to their effective size in solution. Separation according to molecular weight occurs only to the externt that solute molecule size is related to weight. Molecules of similar molecular weight but different structure, and therefore size, will olute at different retention volumes. The retention behavior is also compllcated by absorption interactions of certain condensed ring aromatic compounds with the styrene/divinylbenzene column packing. A correlation technique using SEC measurements combined with additional characterization data to account for differences in the size-MW relationship of samples has recently been presented by Rodgers, et. al. (Ref. 2.31). The molecular weights determined using this technique showed the largest deviation from FIMS measurements for coal liquefaction products, most likely due to the heteroatom content of the samples. We are presently working on including 
heteroaromaticity Into this type of correlation for use with ooal tars, However, for the prosent study, molecular weights are determined using column calibration only.

\section{SEC Calibration}

Two different SEC column callbrations have been used over the course of this Investigation. Previlous reports (Ref. 2.3 .2 and 2.33) from this laboratory have compared tar molecular welght distributions on a relative basls. The same polystyrene SEC calibration was used for all tars irrespective of the fact that the hydrogen/carbon and aromatic/aliphatic ratios were found to vary with coal rant. and extent of devolatilization. The SEC callibration was based on several polystyrene standards ( $M W=1800,3600$, $8500)$, polytsoprene $(M W=1000)$ and aceriapthene $(M W=154)$,

More recently, a number of model compounds have beon injected into the SEC in order to better define the retention behavior of the size exclusion columns. The compounds are Identified in Table 2.15 and plotted in Fig. 2.101. The best correlation of retention volume of all 44 compounds is obtained with the second order fit plotted In the flgure. Also shown are the "polystyrene" callbration curves we have used and a first order fit to aliphatic compounds.

Several observations can be made regarding the retention behavior of hydrocarbons in this column/mobiie phase system. First, the use of polystyrene calibration standards alone results in an excessively steep calibration curve which, when extrapolated to long retention times, grossly underestimates molecular weights. In order to compensate for the unavailability of low molecular weight polystyrene standards, acenapthene whs added to the "polystyrene" callbration. Second, alkanes exhibit the lowest retention volumes among ail hydrocarbons of the same molecular weight. The alkanes are "rodlike" molecules which increase in length as molecular weight increases and thus appear larger (low retention volume) relative to more compact aromatic and hydroaromatic compounds. GPC separates molecules based on their size in solution, not molecular weight. Thirt, the retention behavior of highly condensed aromatics such as perylene and coronene indicate that mechanisms other than size exclusion (for example, adsorption) are occurring. This type of inieraction with the column packing material is greatly reduced by the addition of an alkyl side chain to aromatic molecules. The out-of-plane alkyl group sterically hinders the pi-electron cloud of the aromatic group from interacting with the styrene/divinylbenzene packing. Fourth, hydrogen bonding between the tetrahydrofuran mobile phase and hydroxyl groups of the solute molecules changes the effective size of molecules in solution. This effect was accounted for in the second 
order calibration curve by adding the molecular weight of THF $(M W=72)$ to phenol, cresol and 1-napthol when determining the fit.

TABLE 2.15 - GPC CALIBRATION WTTH MODEL COMPOUNDS

\begin{tabular}{|c|c|c|c|}
\hline $\begin{array}{l}\text { Ref. } \\
\text { No. }\end{array}$ & $\begin{array}{c}\text { Compound } \\
\text { Name }\end{array}$ & $\begin{array}{c}\text { Molecular } \\
\text { Weight }\end{array}$ & $\begin{array}{l}\text { Retention } \\
\text { Volume } \\
\text { Imll }\end{array}$ \\
\hline 1 & benzene & 78 & 19.09 \\
\hline 2 & pyridine & 79 & 19.40 \\
\hline 3 & cyclohexane & 84 & 17.97 \\
\hline 4 & toluene & 92 & 16.51 \\
\hline 5 & picoline & 93 & 19.17 \\
\hline 6 & phenol & $94(166)$ & 17.81 \\
\hline 7 & ethylbenzene & 106 & 16.23 \\
\hline 8 & xylene & 106 & 18.73 \\
\hline 9 & cresol & $108(180)$ & 16.96 \\
\hline 10 & 2,2,4-trimethylpentane & 114 & 16.61 \\
\hline 11 & propylbenzene & 120 & 18.12 \\
\hline 12 & napthalene & 128 & 19.45 \\
\hline 13 & quinoline & 129 & 19.83 \\
\hline 14 & 2-methylnapthalene & 142 & 18.56 \\
\hline 15 & 1-napthol & $144(216)$ & 17.61 \\
\hline 16 & biphenyl & 154 & 18.50 \\
\hline 17 & acenaphthene & 154 & 20.35 \\
\hline 18 & 2-ethylnapthalene & 156 & 18.21 \\
\hline 19 & dodecane & 170 & 16.63 \\
\hline 20 & anthracene & 178 & 18.76 \\
\hline 21 & phenanthrene & 178 & 18.54 \\
\hline 22 & acridine & 179 & 19.24 \\
\hline 23 & anthrone & 194 & 17.50 \\
\hline 24 & tetradecane & 198 & 15.03 \\
\hline 25 & pyrene & 202 & 19.05 \\
\hline 26 & hexadecane & 226 & 14.18 \\
\hline 27 & heptadecane & 240 & 13.47 \\
\hline 28 & perylene & 252 & 20.10 \\
\hline 29 & octadecane & 255 & 15.41 \\
\hline 30 & eicosane & 283 & 13.15 \\
\hline 31 & coronene & 300 & 19.59 \\
\hline 32 & 9,10-diphenylanthracene & 330 & 16.33 \\
\hline 33 & octacosane & 395 & 14.20 \\
\hline 34 & tetratriacontane & 479 & 13.70 \\
\hline 35 & PS 517 (APS) & 510 & 14.27 \\
\hline 36 & PS 826 (APS) & 765 & 13.87 \\
\hline 37 & tristearin & 892 & 13.07 \\
\hline 38 & polyisoprene & 1000 & 12.58 \\
\hline 39 & PS 1490 (APS) & 1470 & 12.57 \\
\hline 40 & PS 2350 (WATERS) & 1800 & 11.69 \\
\hline 41 & PS 3600 (WATERS) & 3600 & 11.36 \\
\hline 42 & PS 6550 (APS) & 6100 & 11.44 \\
\hline
\end{tabular}




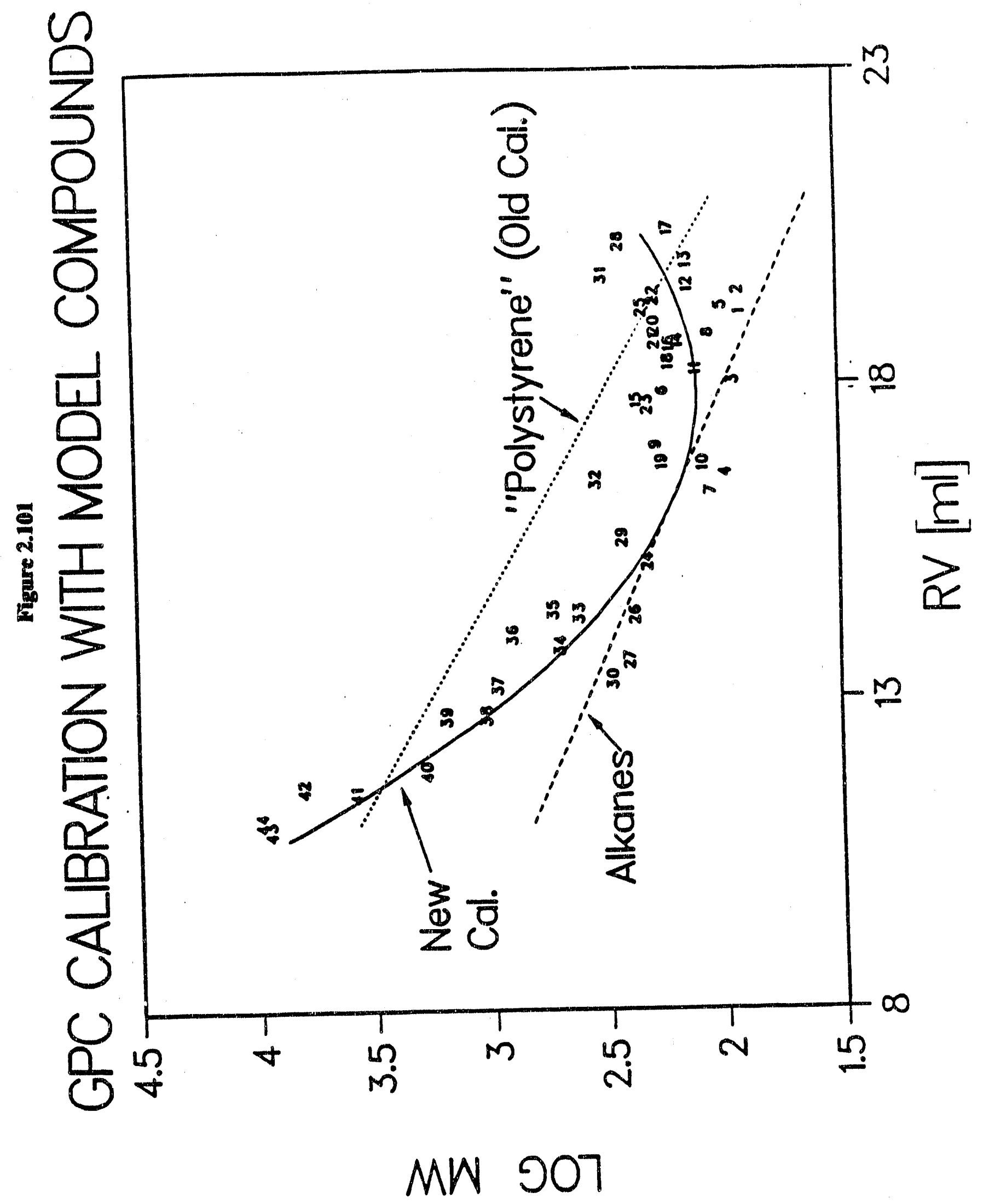




$\begin{array}{llll}43 & \text { PS } 15000 \text { (WATERS) } & 8500 & 10.74 \\ 44 & \text { PS } 9350 \text { (APS) } & 9300 & 10.89\end{array}$

The new calibration curve provides a better approximation to the retention behavior of alkanes, aromatics, alkyl aromatics and heteroatomic species than did the original "polystyrene" calibration curve. However, as illustrated clearly by Fig. 2.101 , the curve is still a rather coarse correlation of the data. The single parameter, retention volume, cannot alone correlate the retention behavior of a diverse range of molecular structure. Rodgers et. al. (Ref. 2.31) have recently shown that a much improved correlation is obtained when appropriate characterization parameters are included in the data reduction. They obtained the molar $\mathrm{H} / \mathrm{C}$ ratio from elemental analysis and the hydrogen distribution from $H$ NMR. The resulting correlation gives an average deviation of $4 \%$ for 45 pure hydrocarbons. In the future, we hope to adopt their technique by utilizing FTKR instead of NMR as well as extend it to include heteroatom containing species.

The new calibration curve was used to recalculate the molecular weight distributions of all tars studied in this investigation. The resulting MWD's are of significantly lower molecular weights than have been reported previously by this laboratory. This is because the raw chromatograms lie in the range of 11 to $20 \mathrm{ml}$ retention volume. which is precisely the range over which the new calibration gives molecular weights lower than the original "polystyrene" calibration. It should be noted that the second order calibration is not a single-valued function of molecular weight. The routines used to calculate and plot MWD's were modified to properly account for this. The MWD's are displayed using a constant molecular weight spacing (DM). Each point used to construct the curve represents the mass fraction of tar within +/-DM/2 daltons of the molecular weight of the plotted point. (The MWD has been partially integrated at each point.) This allows direct comparison of measured and predicted MWD's. The molecular weight spacing used, $D M=50$, was a compromise between resolution and CPU time in running the UTRC coal devolatilization model.

Results

HKA Bituminous Ceal. For the PSOC 1451D coal, an Appalachian high volatile bituminous coal, the ash-tracer determined, ash-free volatile yields for two particle sizes is shown in Fig. 2.102. As indicated, despite the factor of three difference in particle size, the reactor temperature serisitivity of the mass loss is very similar between the size cuts. Temperature calculations using the measured reactor heat transfer characteristics indicate this should indeed be the case. Figure 2.103 shows the relative gas yields, normalized with respect to maximum yields of each gas and plotted with respect to the peak reactor gas temperature, since gas phase reactions of tars are thought to account for substantial fractions of "coal" pyrolysis gases. It is noted that significant increases in acetylene and hydrogen cyanide gases are not observed until peak gas temperatures of $700^{\circ} \mathrm{C}$ are achieved. At lower gas temperatures, light gas yields are dominated by $\mathrm{CH}_{4}$, 
$\mathrm{C}_{2} \mathrm{H}_{4}, \mathrm{CO}$ and $\mathrm{H}_{2} \mathrm{O}$, but these gases account for only $10-15 \%$ of the total $0.20-0.25$ particle mass fraction loss observed for these reactor conditions. For this coal, tar yields dominate the mass loss at these and lower gas-particle temperatures.

\section{Tar Yields Via Nitrogen Balance Method}

Determining tar yields in a entrained flow reacior devolatilization experiment is challenging. Total volatile yields can be estimated using ash tracer techniques provided suitable precautions are taken to trace the delivered sample ash contents (See above). Reactor temperatures must be kept below the point at which mineral reducing reactions can lead to formation of inorganic species having great enough vapor pressure to escape from the char surface.

Estimating tar yields by difference, the total volatile yield from ash tracer - sum of light gases evolved, is difficult because light gases concentrations are difficult to determine quantitatively at the low concentration levels produced in entrained particle systems, particularly at low peak temperatures. In addition, quantieative determination of $\mathrm{H}_{2} \mathrm{O}$ and $\mathrm{CO}_{2}$ in such systems is difficult because of degassing of these adsorbed species from reactor walls, etc. Low rank coals generate significant quantities of these species during devolatilization.

The product separation and gas analysis system utilized in the UTRC entrained flow reactor makes determination of tar yields possible by a combined ash and fuel bound nitrogen (FBN) tracer technique. A nitrogen balance equation for devolatilization conditions (no entrained oxygen present) has the following 


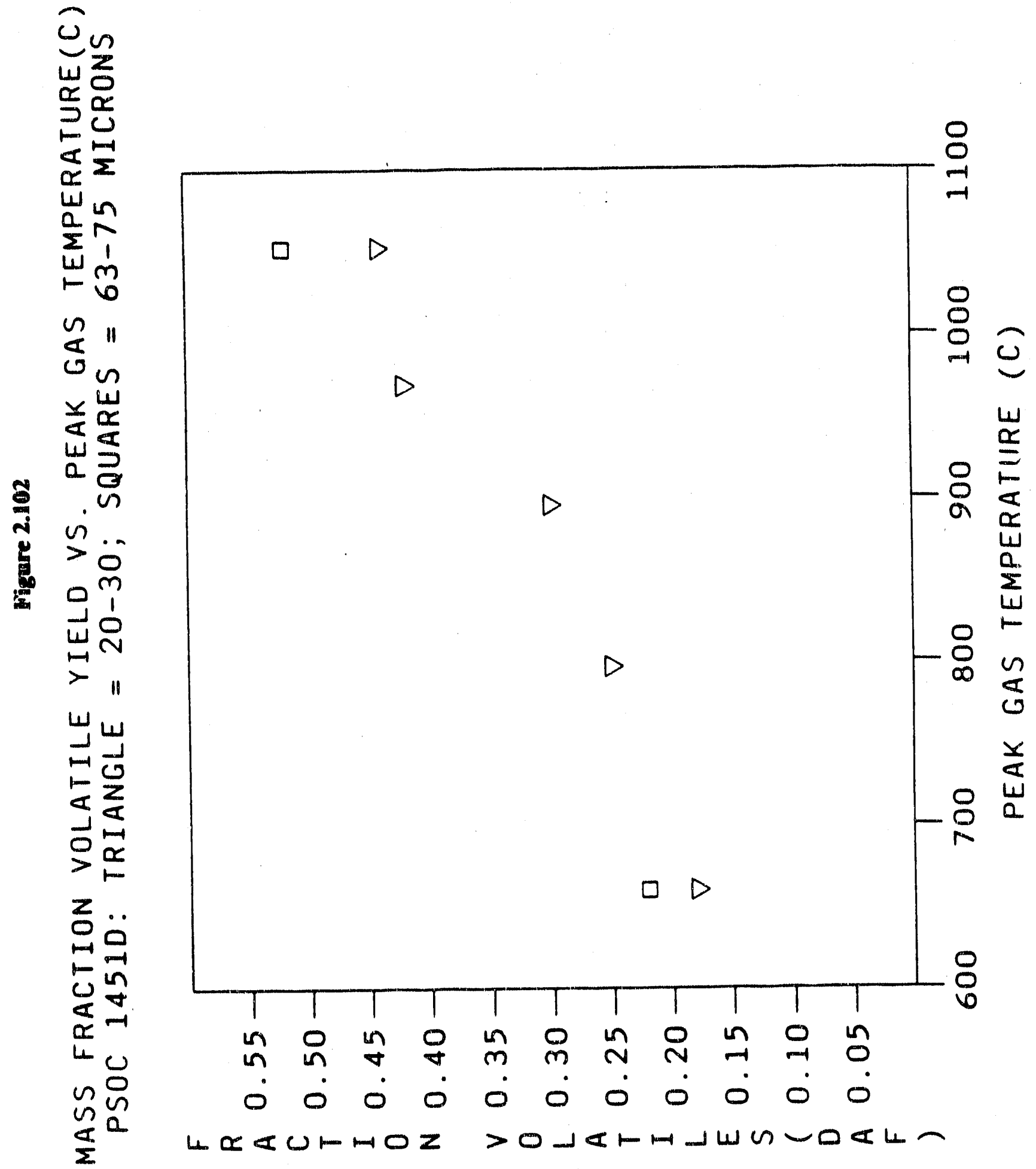




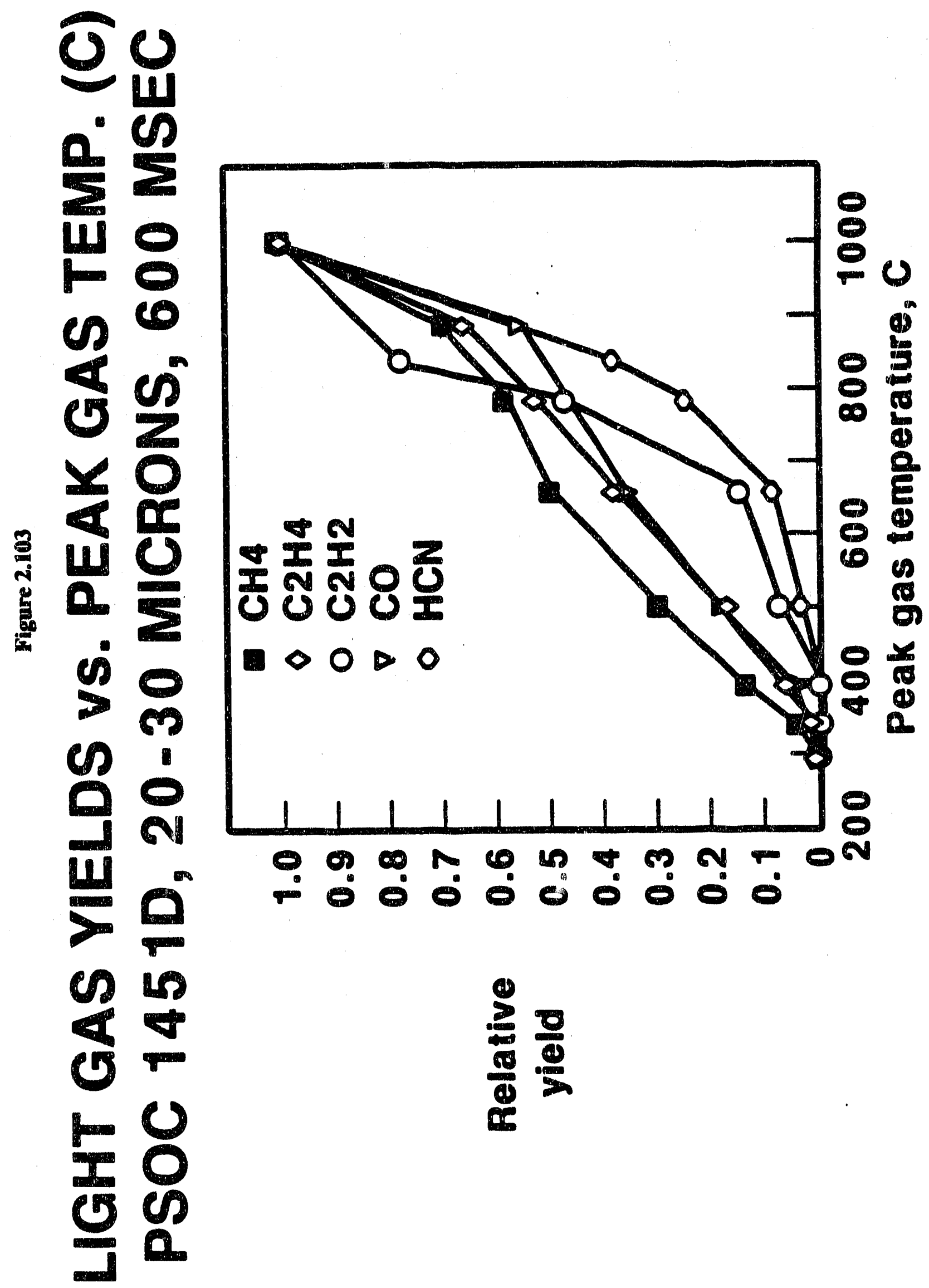


form:

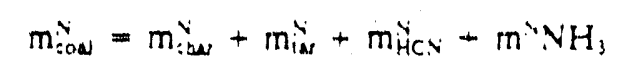

The equation assumes no FBN is evolved as a NOx species with the chemically bound oxy'gen of the parent coal. It also assumes no $F B N$ is evolved as free nitrogen, $N_{2}$, as a result of the rapid pytolysis process. The left-hand side of the above equation is the mass of coal nitrogen delivered during the devolatilization experiment. The right-hand side terms are the masses of parent coal nitrogen present in the char, tas. and light gas nitrogen products of rapid devolatilization. The nitrogen mass forms can all be expressed as mass fraction yields in equations of the following form:

$$
m_{\text {con }}^{N}=f_{\text {con }}^{N} \cdot m_{\text {con }}
$$

where $f_{\text {cou }}$ represents the nitrogen mass fraction of coal representative of that actually delivered during the experiment. The other nitrogen containing species can be similarly re-expressed. The mass fraction expression of the nitrogen balance equation becomes:

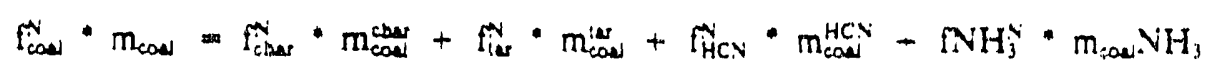

This expression is rearranged to:

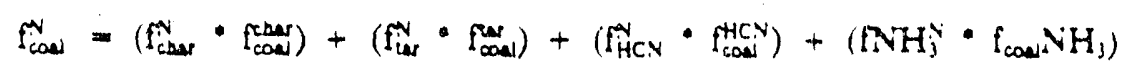

where four represents the fraction of coal transformed to char, fas the fraction transformed to tar. etc.

The mass fraction of coal transformed to char on a dry-ash-free (DAF) basis is given by the ash-tracer expression:

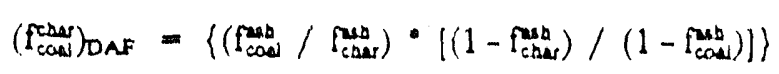


Combining the last two equations gives the following expression for the fraction of coal that evolves as tar during rapid devolatilization in the entrained flow reactor:

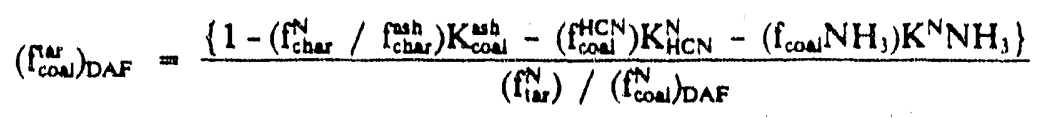

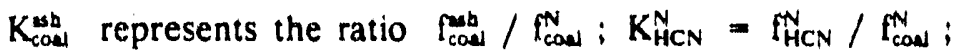

and $\mathrm{KNH}_{3}^{\mathrm{N}}=\mathrm{NNH}_{3}^{\mathrm{N}} / \mathbb{f}_{\text {cond }}^{\mathrm{N}}$.

The parent coal, char and tar $\mathrm{N}$ compositions are determined by elemental analyses of the samples collected in the separation system. The $\mathrm{CO}$ stage of the cyclone stage is defined as containing the parent coal samples obtained from cold flow runs before and after the devolatilization run. CO contains the char samples obtained in devolatilization conditions. The impactor filter is defined as containing the tar samples generated during devolatilization. Ash concentrations in the coal and char samples are determined by high temperature ash measurements made on the same samples.

Low levels of nitrogen-containing light gases are determined using the calibrated FT-IR multipass cell. In order to obtain the mass fraction of coal converted to a nitrogen-containing light gas, gas scans are taken throughout the run time, averaged and normalized with respect to amount of coal fed (determined directly by weighing the coal feeder before and after the experiment) during the measurement time.

Table 2.16 indicates the nitrogen balance determined from a series of devolatilization runs using sample PSOC $1451 \mathrm{D}$ in the entrained flow reactor. Table 2.17 shows the tar yield data for the same set of runs. Figure 2.104 shows the results in graphical form. 


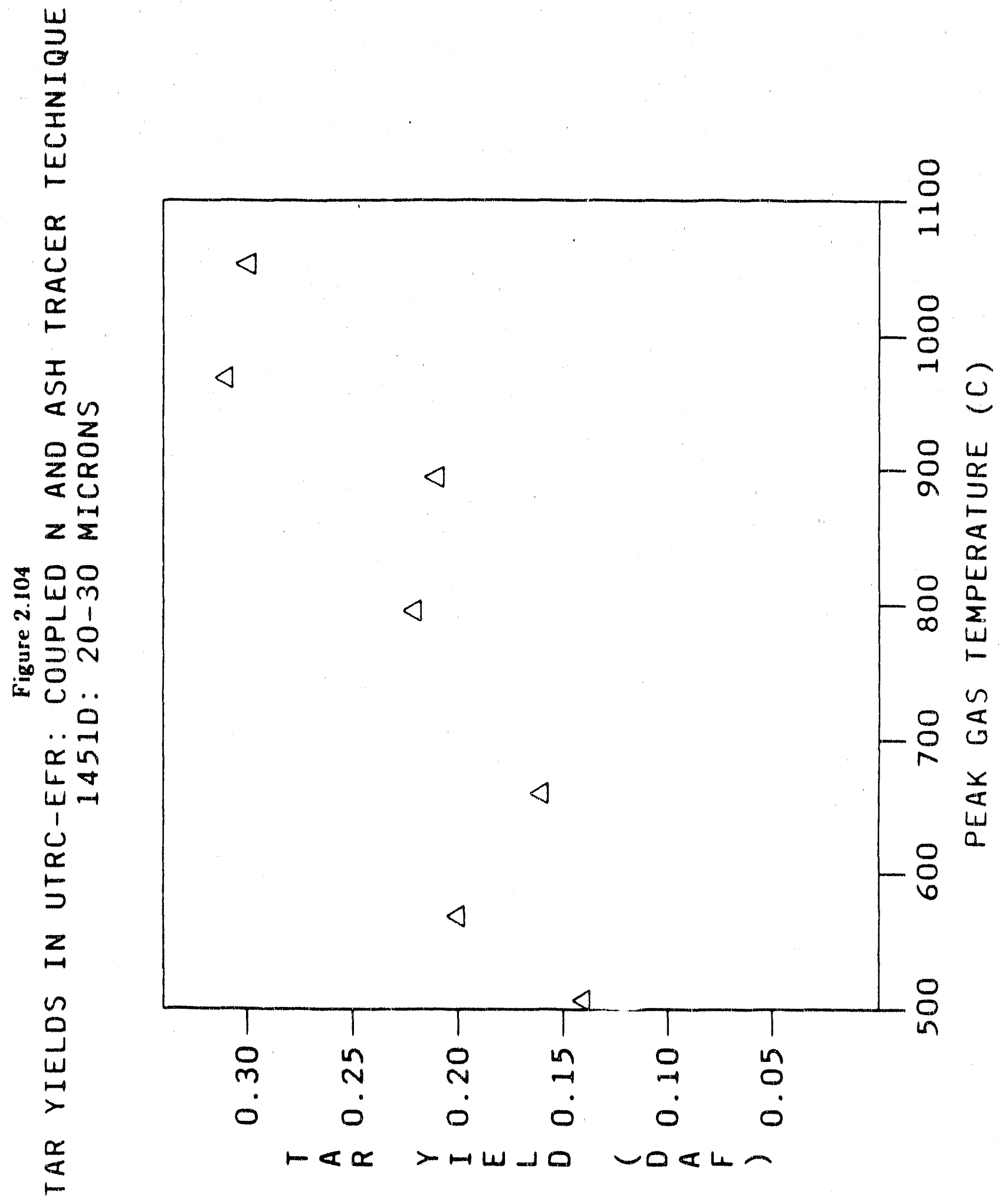




\section{TABLE 2.16 - COAL NITROGEN DISTRIBUTION IN DEVOLATILIZATION PRODUCTS \\ PSOC 1451D, 20-30 Microns}

\begin{tabular}{|c|c|c|c|c|c|}
\hline $\begin{array}{l}\text { Peak Gas } \\
\text { Temp. }\left({ }^{\circ} \mathrm{C}\right)\end{array}$ & fcoal-N & $f_{\cos -N}^{\operatorname{tar}}$ & $f_{\text {coal-N }}^{H C Y}$ & $\mathrm{f}_{\text {codi-N }}^{\mathrm{NH}_{3}}$ & $\mathrm{f}_{\text {coal-N }}^{\sum \text { products }}$ \\
\hline 450 & 0.816 & 0.145 & ND & ND & 0.961 \\
\hline 570 & 0.787 & 0.211 & $\overline{N D}$ & ND & 0.998 \\
\hline 660 & 0.840 & 0.159 & ND & ND & 0.999 \\
\hline 796 & 0.768 & 0.222 & 0,0007 & ND & 0.991 \\
\hline 895 & 0.739 & 0.224 & 0.0241 & ND & 0.989 \\
\hline 970 & 0.618 & 0.308 & 0.5060 & ND & 0.977 \\
\hline 1053 & 0.598 & 0.330 & 0.0720 & ND & 1.000 \\
\hline
\end{tabular}

\section{T BLE 2.17 - TAR YIELDS AS A FUNCTION OF REACTOR CONDITIONS PSOC 1451D, 20-30 Microns}

\begin{tabular}{|c|c|c|c|}
\hline $\begin{array}{c}\text { Reactor Wail } \\
\text { Temp. }\left({ }^{\circ}\right)\end{array}$ & $\begin{array}{c}\text { Max. Gas } \\
\text { Temp. }\left({ }^{\circ}\right)\end{array}$ & $\begin{array}{c}\text { Residence } \\
\text { Time }(\text { msec) }\end{array}$ & $\begin{array}{c}\text { TAR (DAF) } \\
\text { Mass Fraction }\end{array}$ \\
\hline 668 & 507 & 580 & 0.14 \\
\hline 704 & 569 & 545 & 0.20 \\
\hline 825 & 660 & 515 & 0.16 \\
\hline 939 & 796 & 450 & 0.22 \\
\hline 1058 & 895 & 410 & 0.21 \\
\hline 1163 & 969 & 355 & 0.31 \\
\hline 1241 & 1053 & 335 & 0.30 \\
\hline
\end{tabular}

\section{Elemental Composition and Molecular Weight Characteristics}

Examination of the elemental composition and relative MW of the tars as a function of characteristic temperature, reactor wail or peak gas temperature, indicates that the tar evolution process resembles a distillation process (Tables 2.18 , and 2.19). As indicated, the hydrogen rich, relatively lower molecular weight species devolatilize initially. As implied by the insensitivity of the total mass loss with particle size and as indicated by the temperature calculations, the elemental composition of the tars evolved from the two different particle sizes and for a particular stage of the reaction process should be similar. As indicated in Table 2.18, and 2.19 the elemental composition of the tars produced from either the 20-30 micron feed or 
63-75 micron feed are quite similar. Figure 2.105 shows the impactor filter tar species hydrogen levels observed for three different particle sizes of PSOC $1451 \mathrm{D}$ over a $900^{\circ} \mathrm{C}$ peak gas temperature range. With respect to first order effects, there is no appreclable effect of particle size on hydrogen elemental composition of the collected tars. The largest particle size, lowest temperature tars may display slightly greater hydrogen levels than the other particle sizes. But this is believed due to the greater concentrations of exinite observed in this size cut relative to the smaller cuts (Ref. 2.34 ).

A distillation-like tar evolution process would also imply changing functionality characteristics of the samples with characteristic temperature. Figure 2.106 displays the relative $-\mathrm{CH}_{2}-$ concentration of PSOC $145 I D$ tars for increasing reactor temperature. These concentrations were obtained from the infrared absorbance intensities at $2920 \mathrm{~cm}^{-1}$ observed for the impactor isolated tars (see Table 2,12). The HVA bituminous and higher rank coal tars show a gradual decrease in polymethylene structures with peak gas temperature. Lower rank coals display very polymethylene rich structures in their low temperature tars (Fig, 2.105) relative to these high rank coals. From both an elemental composition and structural characteristics perspectives, the results indicate a distillation-like tar evolution process is followed. 
TABLE 2.18 - ELEMENTAL COMPOSITION OF TARS Temperature effects

HVA bituminous coal (PSOC 145/D)

\begin{tabular}{|c|c|c|c|c|c|c|}
\hline \multirow{2}{*}{$\begin{array}{l}\text { Reactor } \\
\text { wall }\left({ }^{\circ} \mathrm{C}\right)\end{array}$} & \multirow{2}{*}{$\underset{\operatorname{gas}\left({ }^{\circ} \mathrm{C}\right)}{\operatorname{Max}}$} & \multicolumn{5}{|c|}{20 - 30 microns } \\
\hline & & $\% \mathrm{C}$ & $\% \mathrm{H}$ & $\% N$ & $\%(\mathrm{~S}+0)$ & $\mathrm{H} / \mathrm{C}$ \\
\hline 668 & 507 & 84.05 & 6.07 & 1.64 & 8.24 & 0.87 \\
\hline 704 & 569 & 84.07 & 5.94 & 1.67 & 8.32 & 0.85 \\
\hline 825 & 660 & $\begin{array}{l}84.37 \\
84.46\end{array}$ & $\begin{array}{l}5.86 \\
5.93\end{array}$ & $\begin{array}{r}1.68 \\
1.76\end{array}$ & $\begin{array}{l}8.09 \\
7.83\end{array}$ & $\begin{array}{l}0.83 \\
0.84\end{array}$ \\
\hline 939 & 796 & 84.62 & 5.55 & 1.69 & 8.14 & 0.78 \\
\hline 1058 & 895 & 85.22 & 5.40 & 1.73 & 7.65 & 0.76 \\
\hline 1163 & 969 & 85.55 & 5.27 & 1.74 & 7.44 & 0.74 \\
\hline 1241 & 1053 & 86.00 & 5.08 & 1.73 & 7.19 & 0.71 \\
\hline \multirow[t]{2}{*}{ Parent Coal } & & $\begin{array}{l}82.42 \\
81.07\end{array}$ & $\begin{array}{l}5.35 \\
5.24\end{array}$ & $\begin{array}{l}1.57 \\
1.62\end{array}$ & $\begin{array}{l}10.65 \\
12.04\end{array}$ & $\begin{array}{l}0.79 \\
0.78\end{array}$ \\
\hline & & \multicolumn{5}{|c|}{$63-75$ microns } \\
\hline 668 & 507 & 83.97 & 6.22 & 1.64 & 8.14 & 0.89 \\
\hline 825 & 660 & $\begin{array}{l}84.47 \\
84.16\end{array}$ & $\begin{array}{l}5.83 \\
5.79\end{array}$ & $\begin{array}{l}1.72 \\
1.78\end{array}$ & $\begin{array}{l}7.98 \\
8.29\end{array}$ & $\begin{array}{l}0.83 \\
0.83\end{array}$ \\
\hline 1241 & 1053 & 85.50 & 5.29 & 1.76 & 7.43 & 0.74 \\
\hline Parent Coal & & $\begin{array}{r}8.55 \\
81.86\end{array}$ & $\begin{array}{l}5.53 \\
5.43\end{array}$ & $\begin{array}{l}1.59 \\
1.66\end{array}$ & $\begin{array}{l}10.32 \\
11.02\end{array}$ & $\begin{array}{l}0.80 \\
0.80\end{array}$ \\
\hline
\end{tabular}

TABLE 2.19 - RELATTVE MOLECULAR WEIGHT CHARACTERISTICS OF HVA BIT TARS

PSOC 1451D, 20-30 Micron Feed Particles*

\begin{tabular}{|c|c|c|c|c|}
\hline $\begin{array}{l}\text { Reactor Wall } \\
\text { Temp. }\left({ }^{\circ} \mathbf{C}\right)\end{array}$ & $\begin{array}{l}\text { Max. Gas } \\
\text { Temp. }\left({ }^{\circ} \mathrm{C}\right)\end{array}$ & $\begin{array}{c}\text { Residence } \\
\text { Time (msec) }\end{array}$ & $\mathbf{M n}^{* *}$ & $\mathbf{M} \mathbf{w}^{* *}$ \\
\hline 668 & 507 & 580 & 438 & 641 \\
\hline 704 & 569 & 545 & 452 & 665 \\
\hline 825 & 6670 & 515 & 481 & 719 \\
\hline 939 & 796 & 450 & 491 & 743 \\
\hline 1058 & 895 & 410 & 518 & 801 \\
\hline 1163 & 969 & 355 & 509 & 803 \\
\hline 1241 & 1053 & 335 & 506 & 807 \\
\hline \multicolumn{5}{|c|}{$\begin{array}{l}\text { - Argon Carrier Gas } \\
\text { Tars - Species Collected on Final Filter of Impactor Train } \\
\text { - Polystyrene Calibration Curve of GPC }\end{array}$} \\
\hline
\end{tabular}




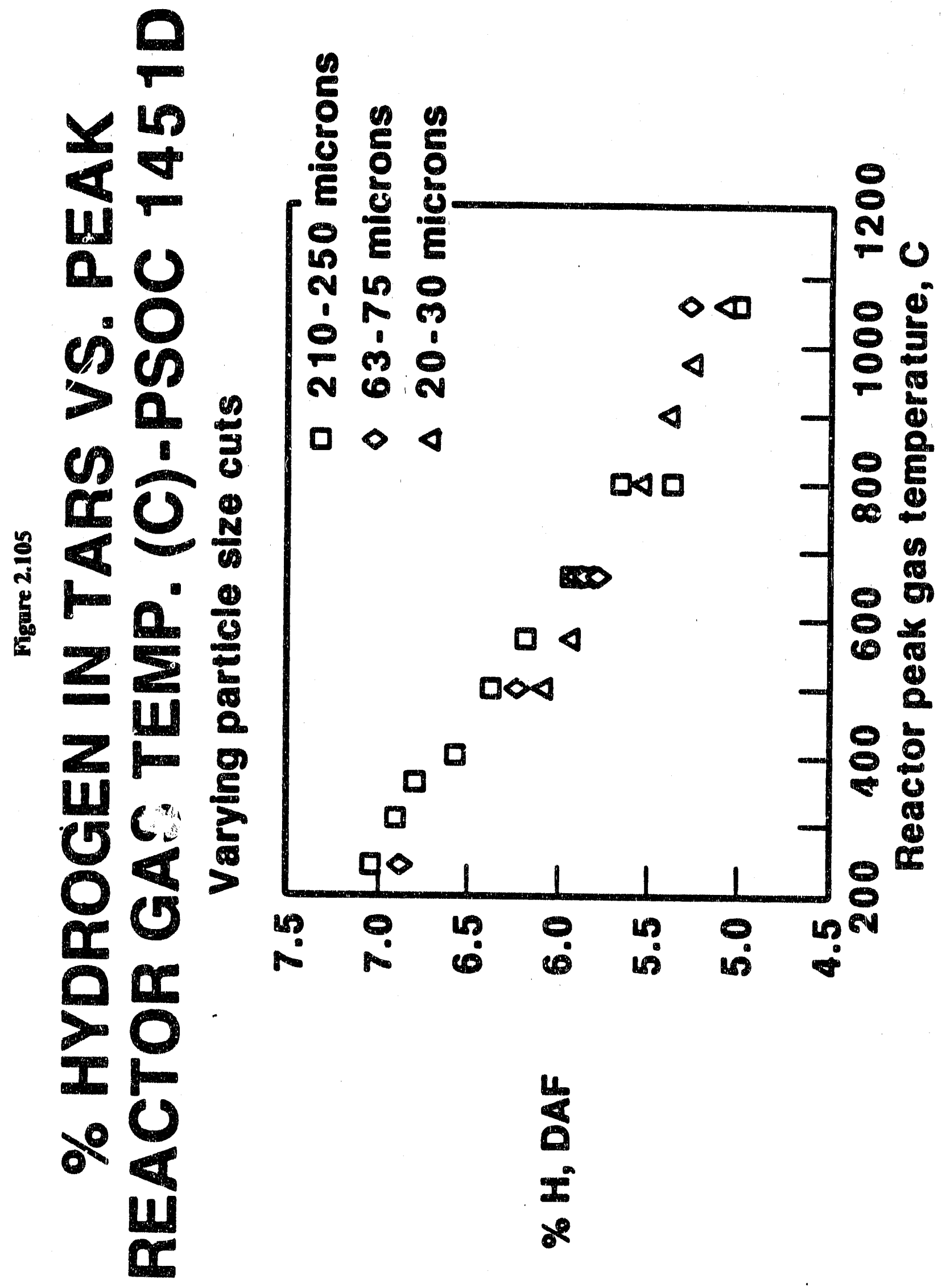




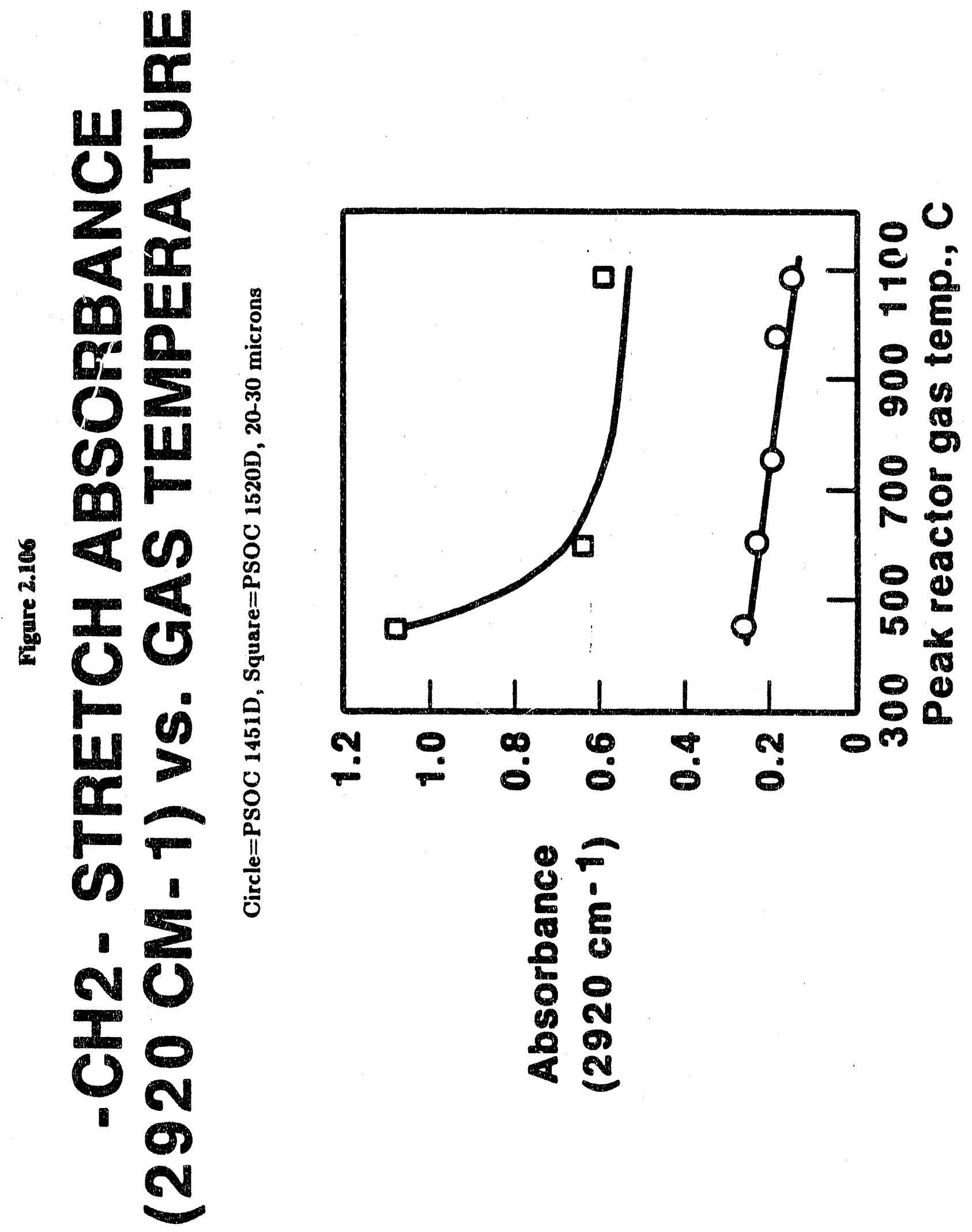




\section{R88-PC70768}

In summary, the results indicate the hydrogen level, in particular the polymethylene concentration, of the collected tars systematically decreases with peak reactor temperature as the total tar yield increases. As the hydrogen level gradually decreases, the relative molecular weight moments of the evolved tars increase to the point where the tar yield is believed to be approaching its maximum value. Lowar temperature tars contain less total oxygen and sulfur mass fractions than the tar mass evolved at higher temperatures.

Coal Rank Effects. It is desirable to determine the change in the nature of the tars produced with changes in the chemical characteristics of the parent coal, while keeping the heating conditions constant. Figures 2.107 and 2.108 are photographs indicating the visible characteristics of tars deposited on glass fiber filters at each of the peak reactor gas temperstures indicated. The general trends in appearance are obvious: For a given coal, the higher the peak gas temperature the more aromatic, carbonaceous the deposit; and for a given temperature the higher the rank characteristics of the coal, the more aromatic, carbonaceous appearing is the tar deposit. In visible reflected light the more aromatic the deposit, the darker in appearance the deposit. The low volatile bituminous tars have only a slightly brown appearance, even at the lowest temperatures, lowest loading conditions. For intermediate and high temperature condicions, the tars appear essentially black for this coal. However, at these conditions all the tars were completely soluble in THF, indicating little soot formation or coal particle fines. On the other hand the Texas lignite tars maintained a brown appearance even at the highest peak gas temperature, $1053^{\circ} \mathrm{C}$. At $507^{\circ} \mathrm{C}$ the lignite tars are a light golden brown in appearance. The darkness of the tars reflects their aromaticity, introduced either by way of the present coal or secondary reactions. For any temperature the mass deposits are greatest for the 1451D, HVA coal, implying larger tar yields from this coal type. Such variation in tar yields with coal type are indeed observed in the heated grid apparatus (see Section 2.3.2). Of course the visuai characteristics of the tars may vary not only with aromaticity but also packing density and subsidiary measurements are necessary to establish quantitative trends.

Figures 2.109 and 2.110 displays the \% $\mathrm{H}$ levels observed for each of the five coal tar types photographed (Figs. 2.107, 2.108) as well as a N. Dakota lignite (PSOC 1507D), a Utah bituminous (PSOC 1445D) and an Illinois \#6 (PSOC 1493D). The hydrogen levels for a given tar type vary significantly with reactor temperature (Fig. 2.109) or extent of tar evaluation. For a given reactor temperature the hydrogen level varies significantly with coal type (Fig. 2.110). Relative to the parent coal $\mathrm{H}$ levels, the tars collected at conditions of maximum tar yield but minimum secondary reactions $\left(825^{\circ} \mathrm{C}\right.$ wall, $660^{\circ} \mathrm{C}$ peak gas temperature), display high hydrogen levels (Fig. 2.111). As the rank characteristics of the parent coal 


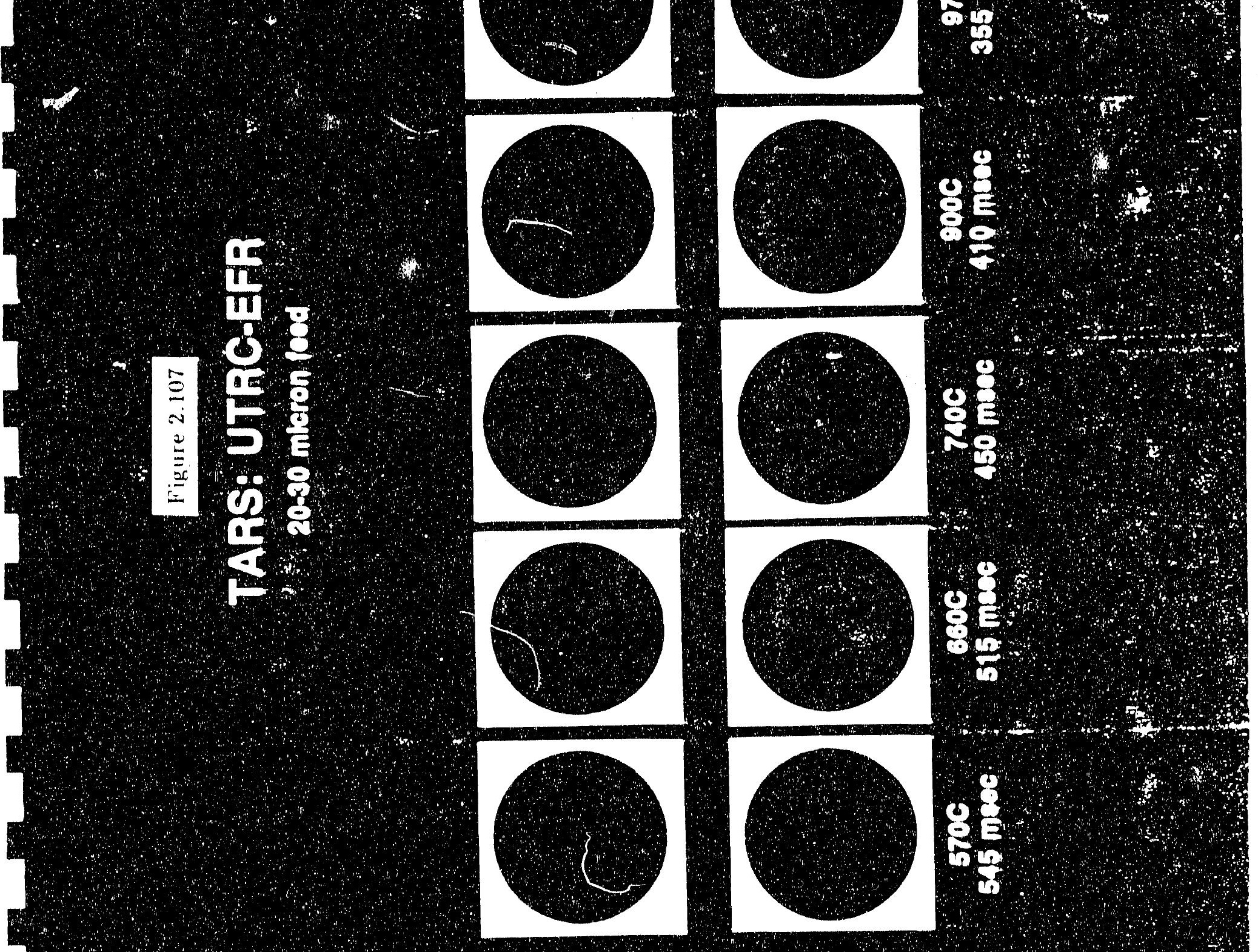




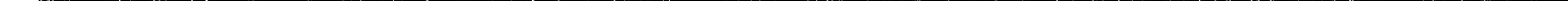


increase, the $\mathrm{N}$ ratio approaches one as an asymptotic limit. Lower temperature tars are proportionately richer in hydrogen (Fig. 2.109) for a given coal type.

Heteroatom sulfur and oxygen content at conditions of maximum "primary" tar yield show a similar asymptotic trend, but from the less than unity side (Fig. 2.112). That is, as the rank characteristic of a parent coal is increased, the $(\mathrm{S}+\mathrm{O})$ content of the tar approaches that of the parent coal as an asymptotic limit. The lower the ank of coal the more unlike the parent coal the primary tars.

\section{IR Absorbance Characteristics of Tars}

The most striking difference in the IR absorbance spectra of the low rank coal tars relative to the higher ranks resides in the polymethylene absorbance region $\left(2910-2940 \mathrm{~cm}^{-1}\right.$ ) (see Appendix A.4 for complete spectra display). The low rank coal tars generally display much greater absorbance levels in this region per unit mass of sample than the high rank coal tars (Fig. 2.113). Assuming the absorption coefficients of this band do not vary significantly with coal rank, such behavior implies increasing concentrations of $-\mathrm{CH}_{2}-$ levels with decreasing coal rank. The $-\mathrm{CH}_{2}-$ absorbance band correlates with the \% $\mathrm{H}$ level in the tars (Fig. 2.114). Another striking feature of the IR absorbance characteristics of low rank coal tars relative to the high ranks is the presence of appreciable amounts of carboxylic groups in the low rank coal tars (Appendix A.4), as evidenced by the absorbance bands in the $1700-1750 \mathrm{~cm}^{-1}$ region. For the Texas lignite (1443D) this band has greater intensity than the $1600 \mathrm{sm}^{-1}$ ban for the lowest temperature tars $\left(704^{\circ} \mathrm{C}\right.$ wall) becoming a shoulder band to the $1600 \mathrm{~cm}^{-1}$ peak for the highest temperature, most aromatic tars. The carboxylic band is practically nonexistent in the high rank tars formed at any temperature, that is, the HVA coals and higher ranks.

The highest rank tars (PSOC 1508D - MVB; PSOC 1516D - LVB) are characterized by a high degree of aromaticity as evidenced by the $700-900 \mathrm{~cm}^{-1}$ and $3000-3100 \mathrm{~cm}^{-1}$ aromatic $\mathrm{H}$ bands. The resolution and relative intensities of the peaks making up the bands attribute to the lack of ring substitution. These tars are also characterized by their relative insensitivity to formation temperatures and secondary reactions, in agreement with the elernental composition results (Fig. 2.109). This thermal and chemical stability reflects the resonance stability introduced by the degree of aromatic ring condensation in these species. Another unusual feature of the IR absorbance characteristics of these tars is the high levels of carbonyl groups (1630-1700 $\left.\mathrm{cm}^{-1}\right)$ observed in the structures. Relative to the polymethylene and methyl groups observed in the low temperature tars these species appear relatively stable at these heating conditions. 


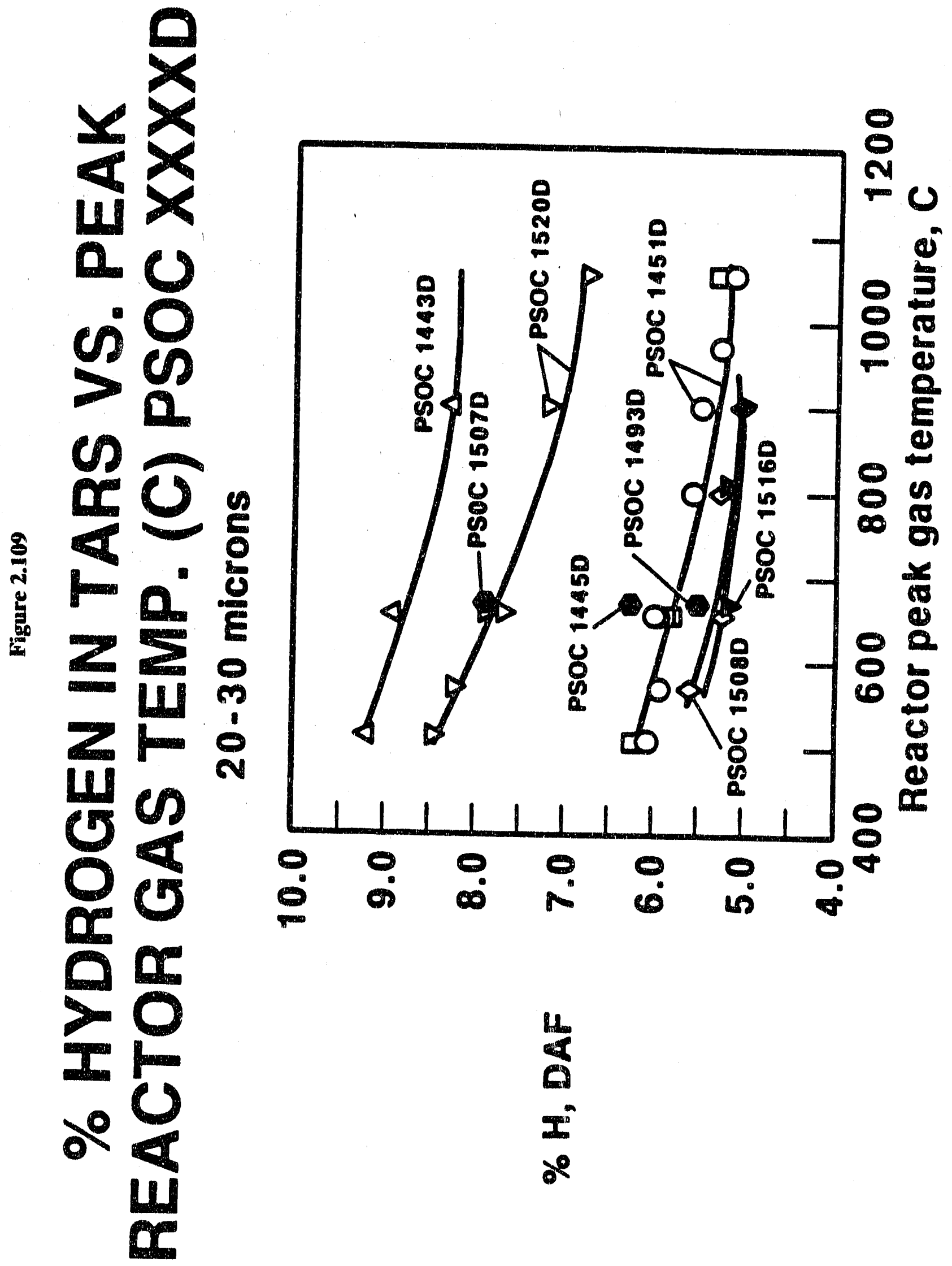




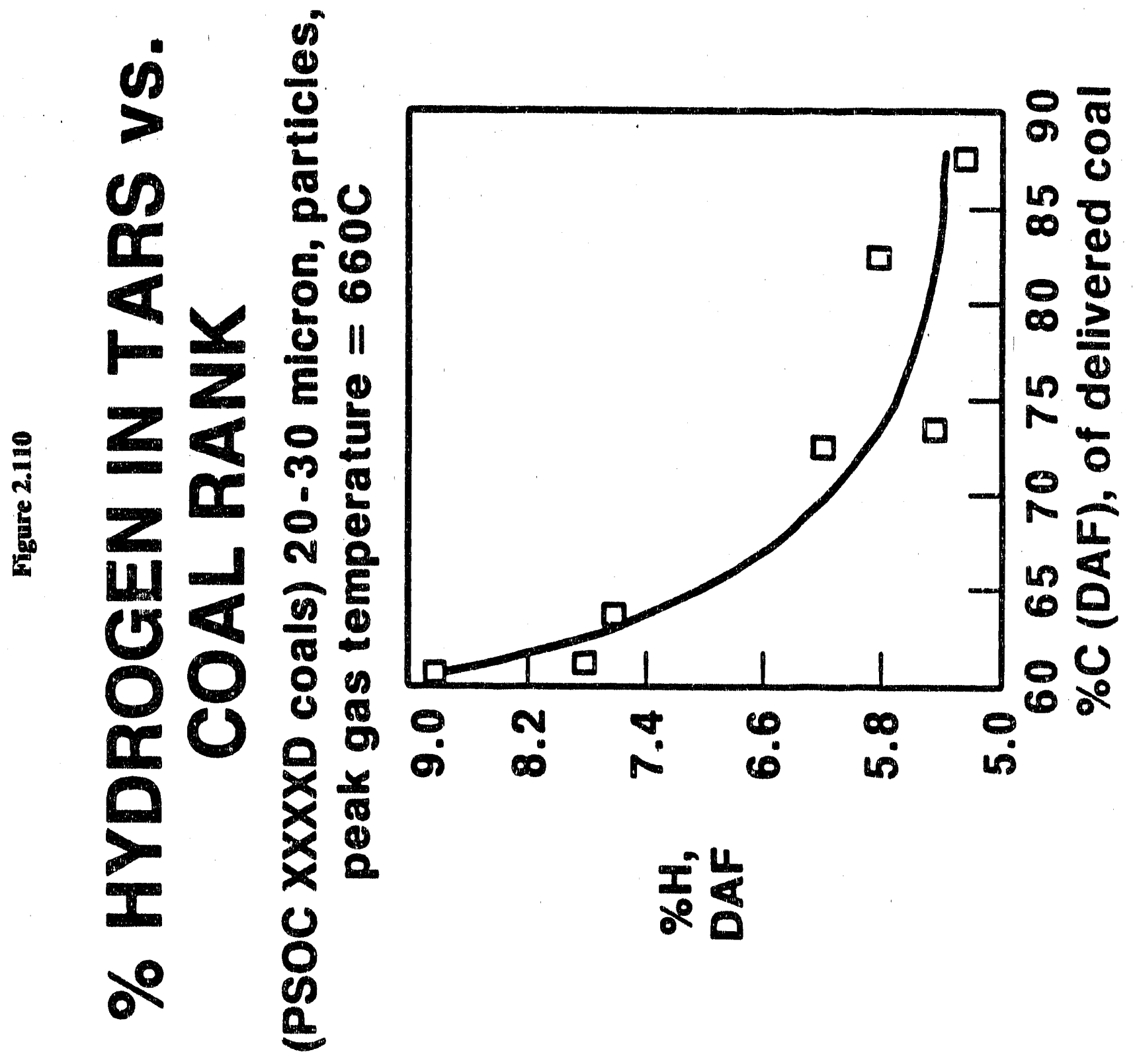




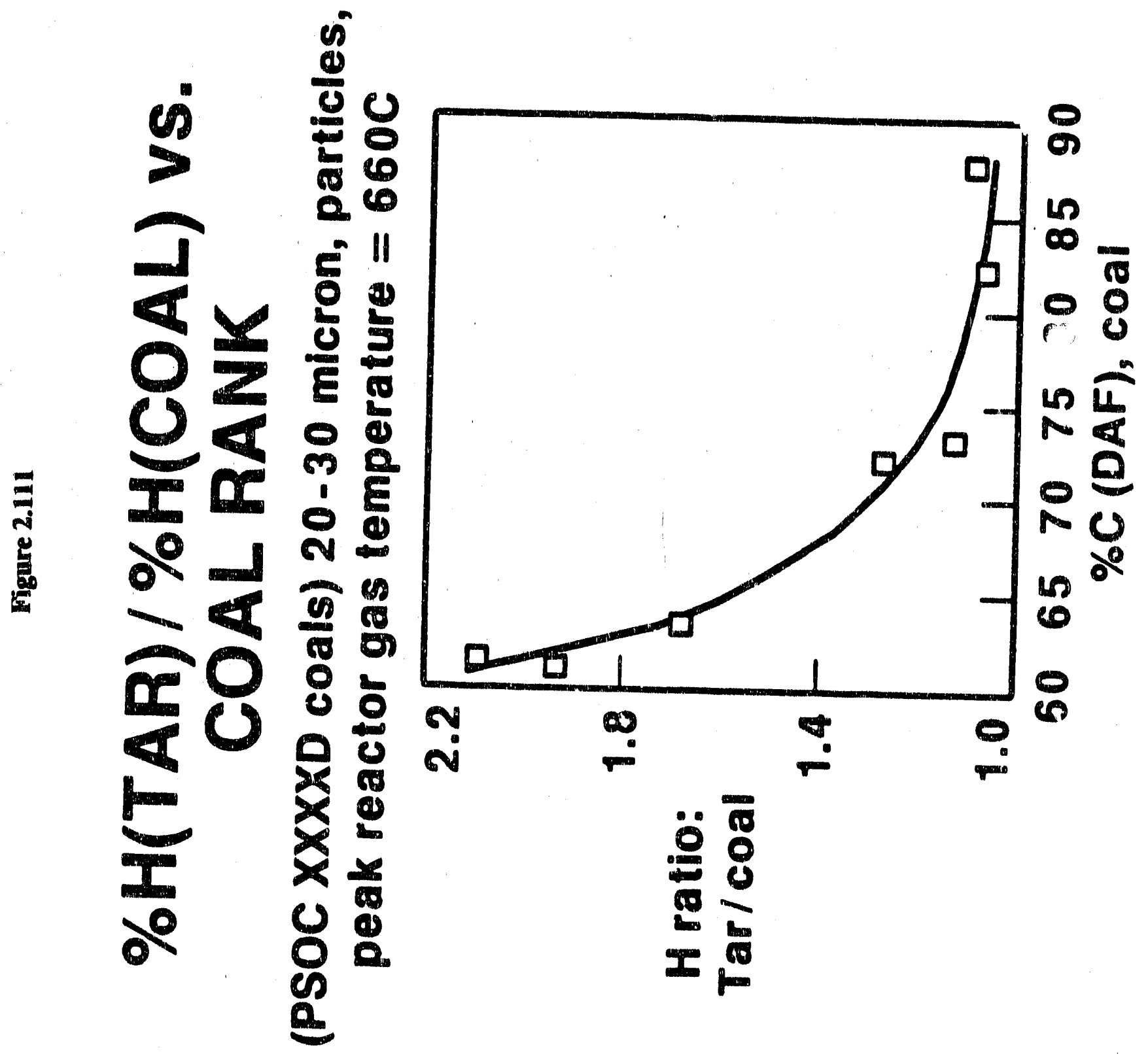




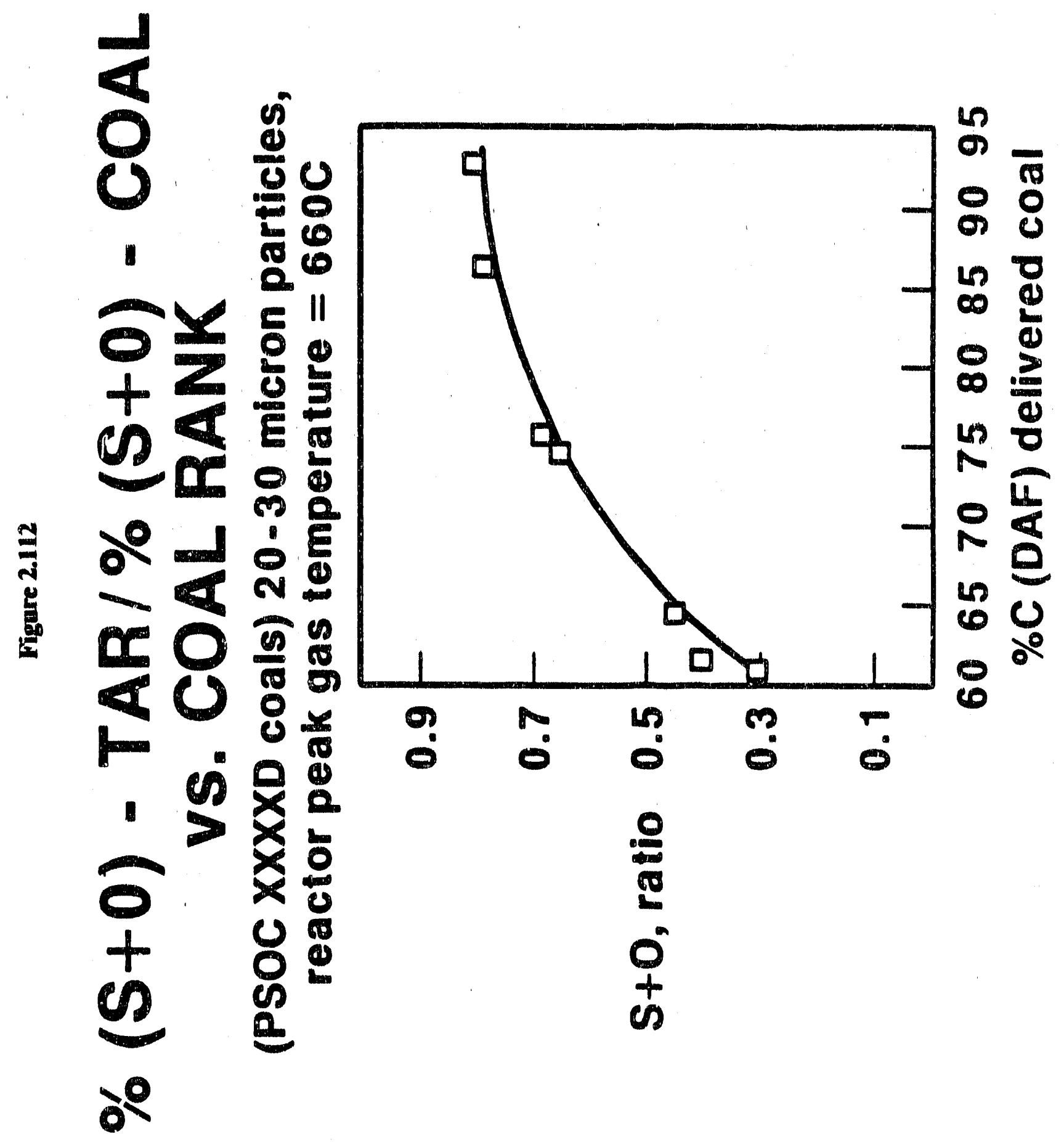




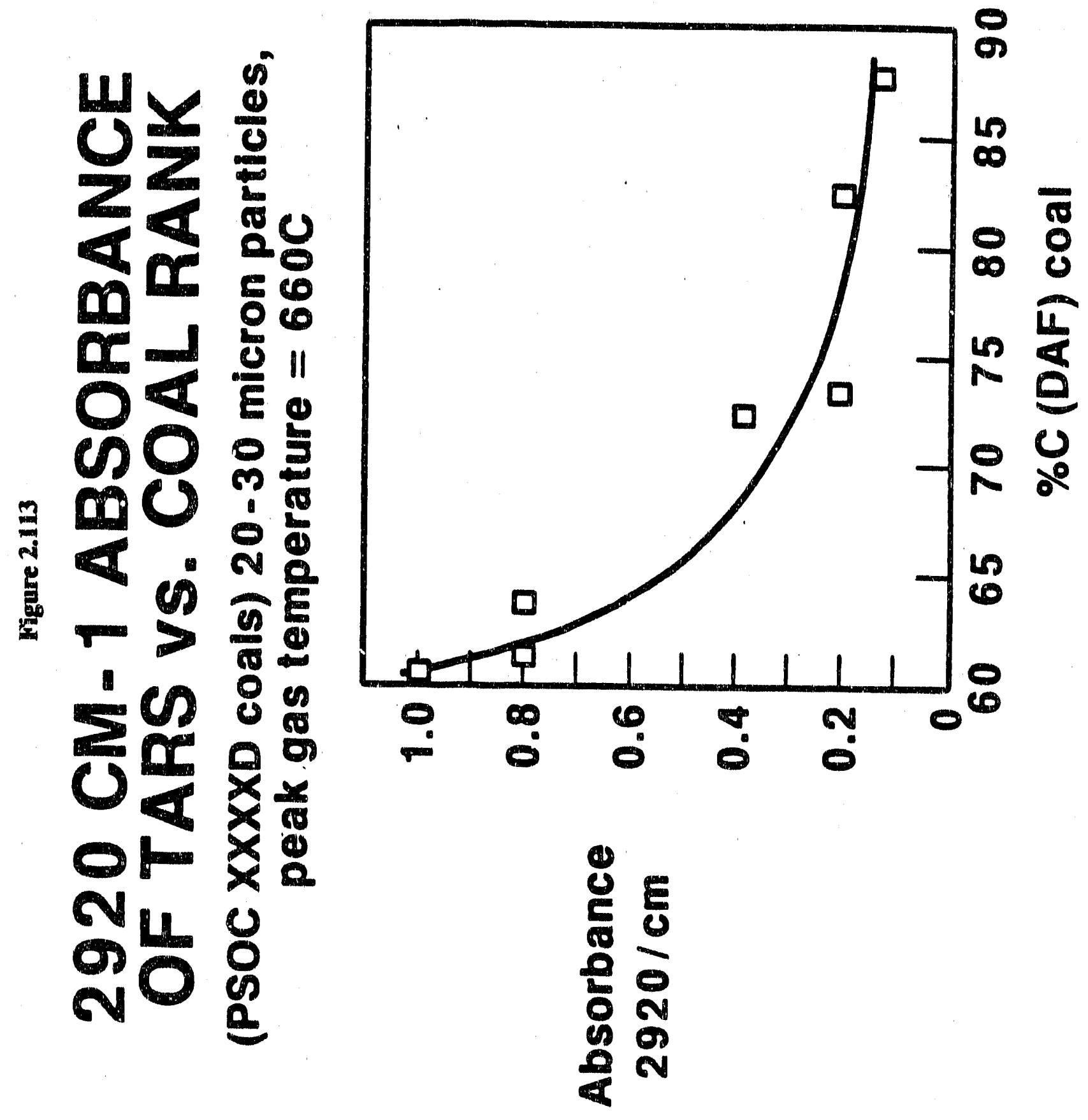




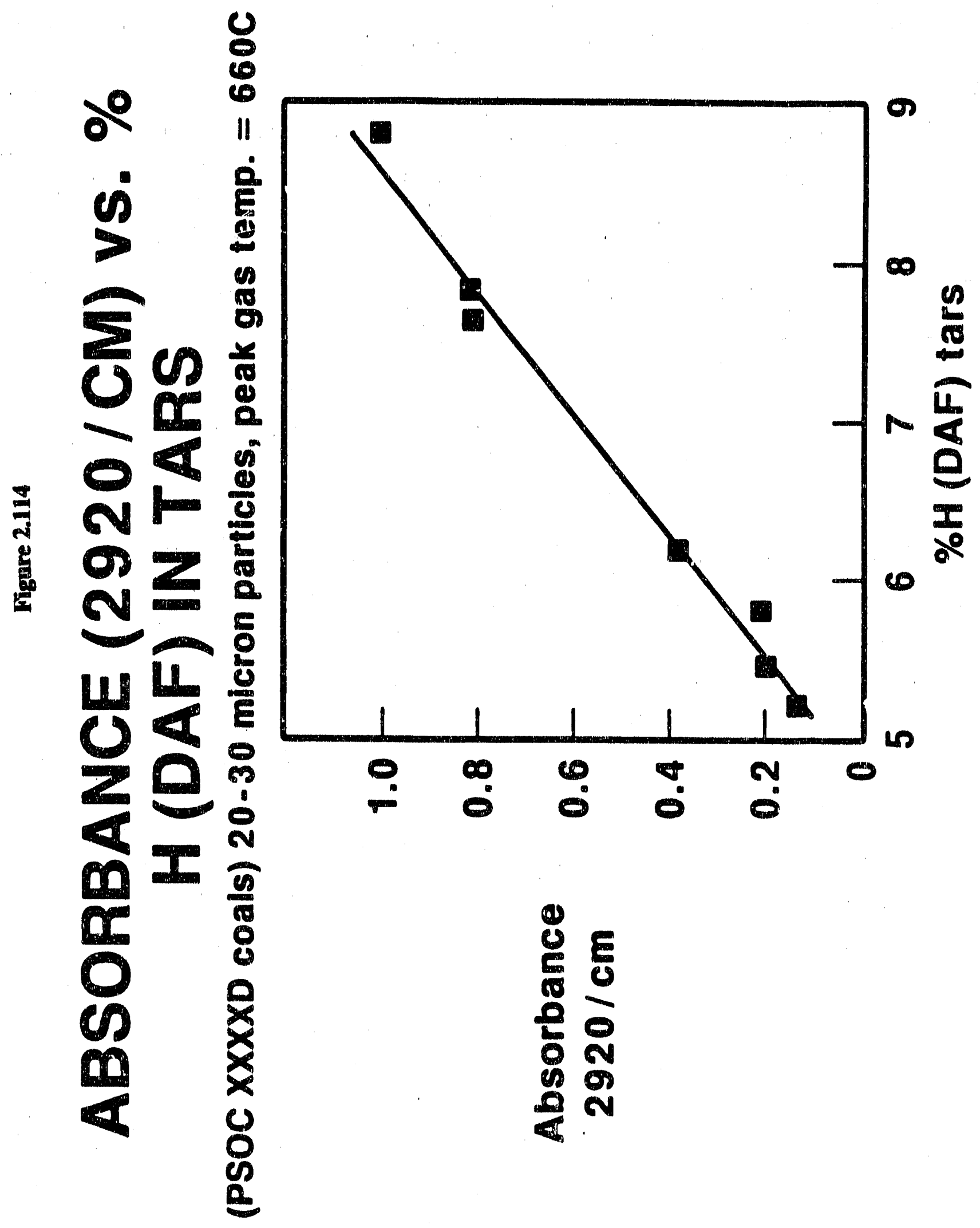




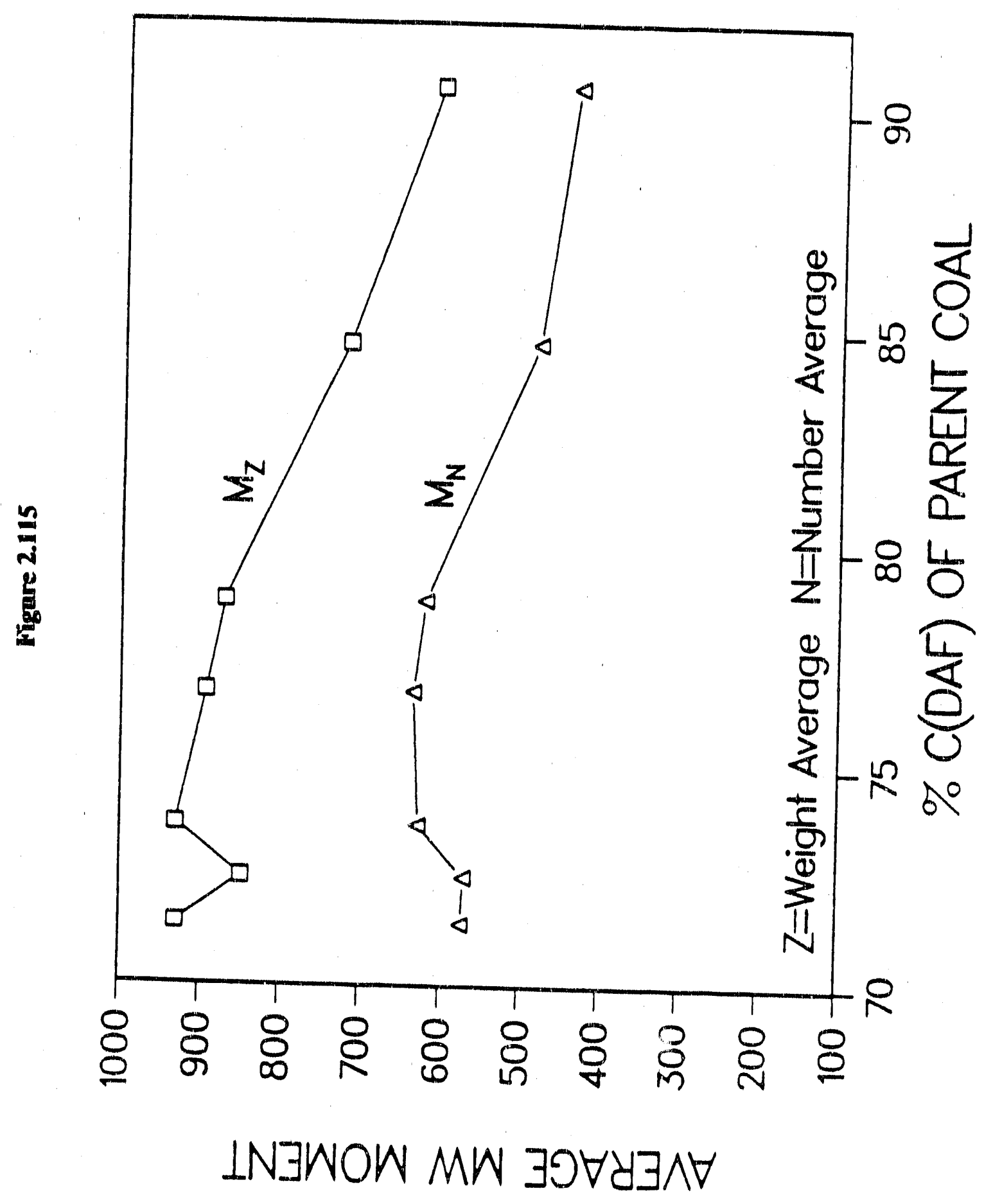




\section{MW Characteristics}

The relative difference in structural characteristics of the low temperature tars evolved from the lignite and subbituminous coals, relative to the bituminous coal tars, is again emphasized by comparing the molecular weight moments obtained by the size exclusion chromatography technique. The data in Fig. 2.115 indicate the tars evolved from the low rank coals at a particular temperature have apparently greater molecular weight moments than the corresponding high rank coal tars, based 0, styrene calibrated SEC alone. In the most elementary sense, the polystyrene calibrated SEC tech. ndicates only that aliphatic, hydrogen-rich low rank coal tars are "structurally larger" than the more aromatic bituminous coal tars with respect to a length to weight ratio parameter. These results likely reflect variation in conformational aspects of the tars as a function of rank rather than weight size or polarity differences. The long chain aliphatic tars characteristic of the low rank soals are not efficiently retained by the size exclusion column and, consequently, elute in the short retention times characteristic of heavy polystyrene standards. The molecular "weight" moments appear to be more characteristic of relative molecular geometry than actual mass size when comparing tars from a range of coal ranks. To verify this structure-retention hypothesis a series of long alkane and stearate molecules were injected in the SEC system (Figure 2.101). As expected relatively small, by mass, species gave apparenily large equivalent polystyrene masses. Figure 2.116 displays the $\overline{\mathrm{M}}_{\mathrm{w}}$ and $\overline{\mathrm{M}}_{\mathrm{n}}$ of the tars based on the broad base calibration curve of Figure 2.101 . Obviously there is a significant shift in relative MW properties. Also obvious is that some manner of a priori selection of a realistic, compound type specific calibration curve is needed.

The general observations with respect to the variations in low temperature coal tars with rank characteristics of the primary coal are indicated in Fig. 2.117, the lower rank of parent coal the more unlike the parent coal are the low temperature, primary tars. The dissimilarity appears primarily related to the aliphatic to aromatic hydrogen distribution and the oxygen-sulfur heteroatom content of the tars relative to the parent coal. Significant polymethylene concentration variations are observed with variation in coal type.

Although the nature of tars varies significantly with coal type, the phenomenology of tar evolution and gas phase reaction sequcnce does not. As in the high volatile bituminous coal, the hydrogen rich, more aliphatic, lighter molecular weight species vaporize before the heavier, more aromatic species during the evolution to the point of maximum tar yield. At gas temperatures of $700^{\circ} \mathrm{C}$ or above, gas phase reactions of pyrolysis of the polymethyiene rich tars quickly leads to ring formation in the tar species. $\mathrm{C}_{2} \mathrm{H}_{4}$ and $\mathrm{CO}$ are major light gas products of these reactions and, at still higher temperatures, $\mathrm{C}_{2} \mathrm{H}_{2}, \mathrm{CO}$ and $\mathrm{HCN}$. In short, the same light gas formation temperature pattern as indicated in Fig. 2.103 for HVA bituminous coal is 


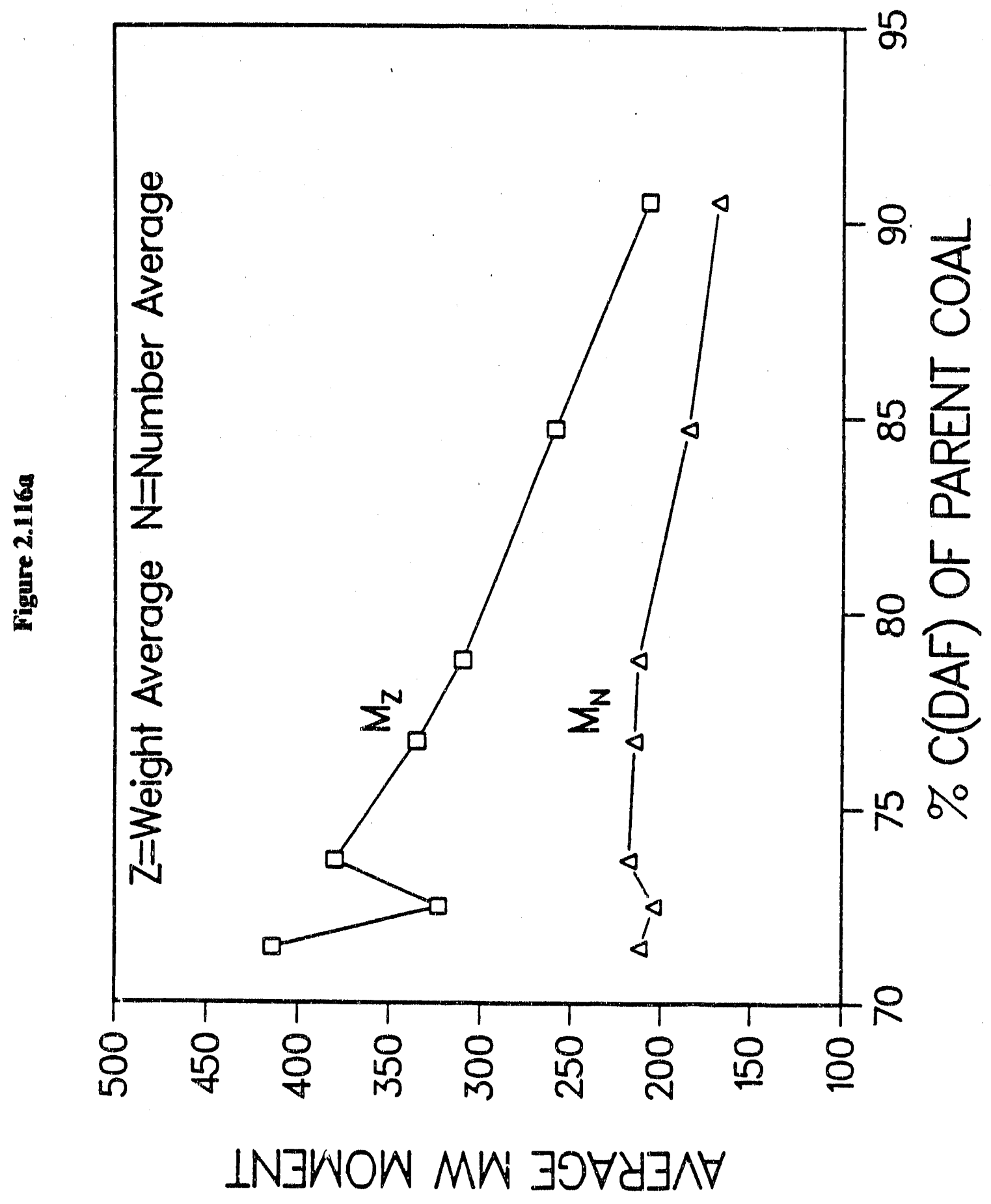




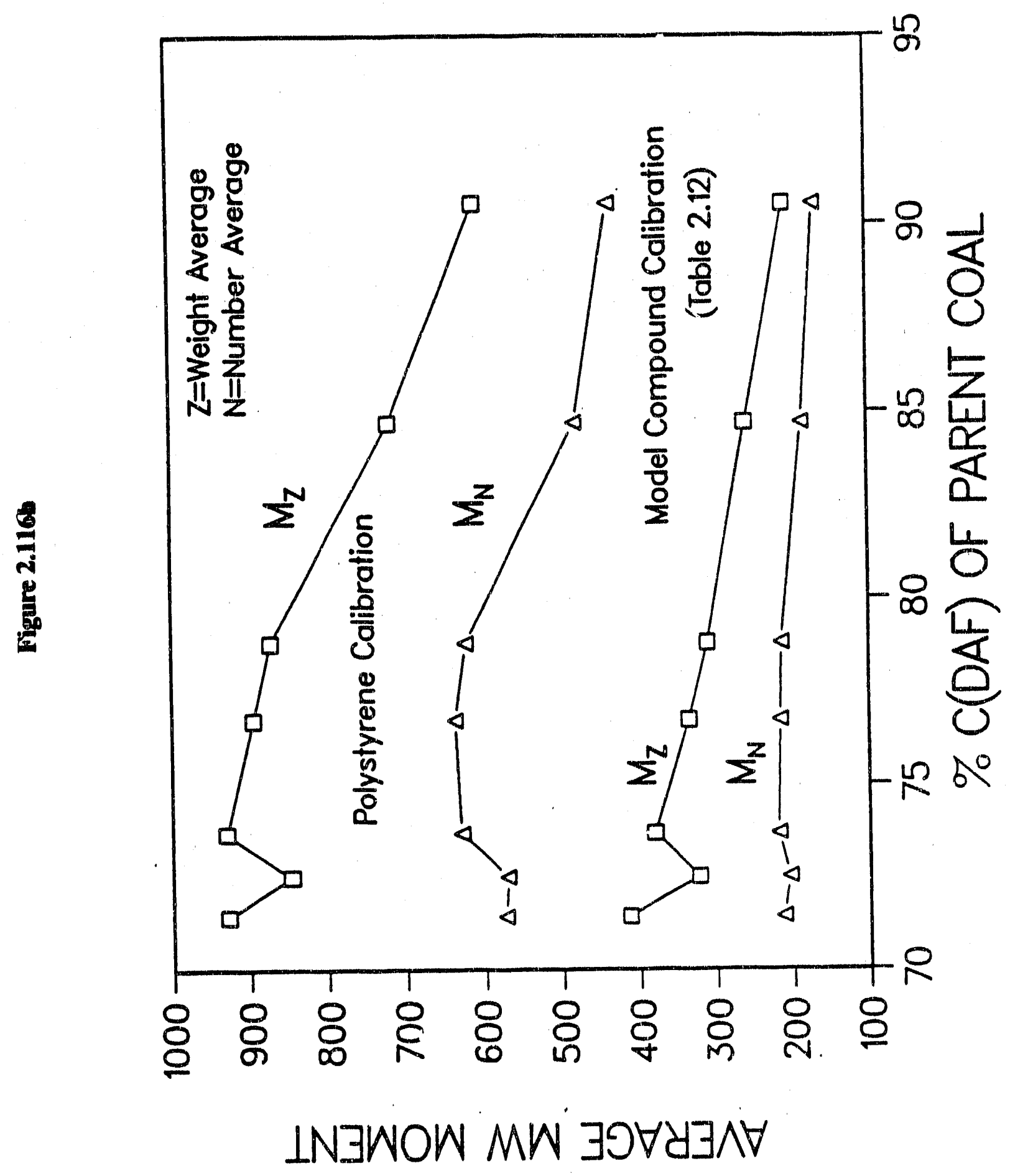




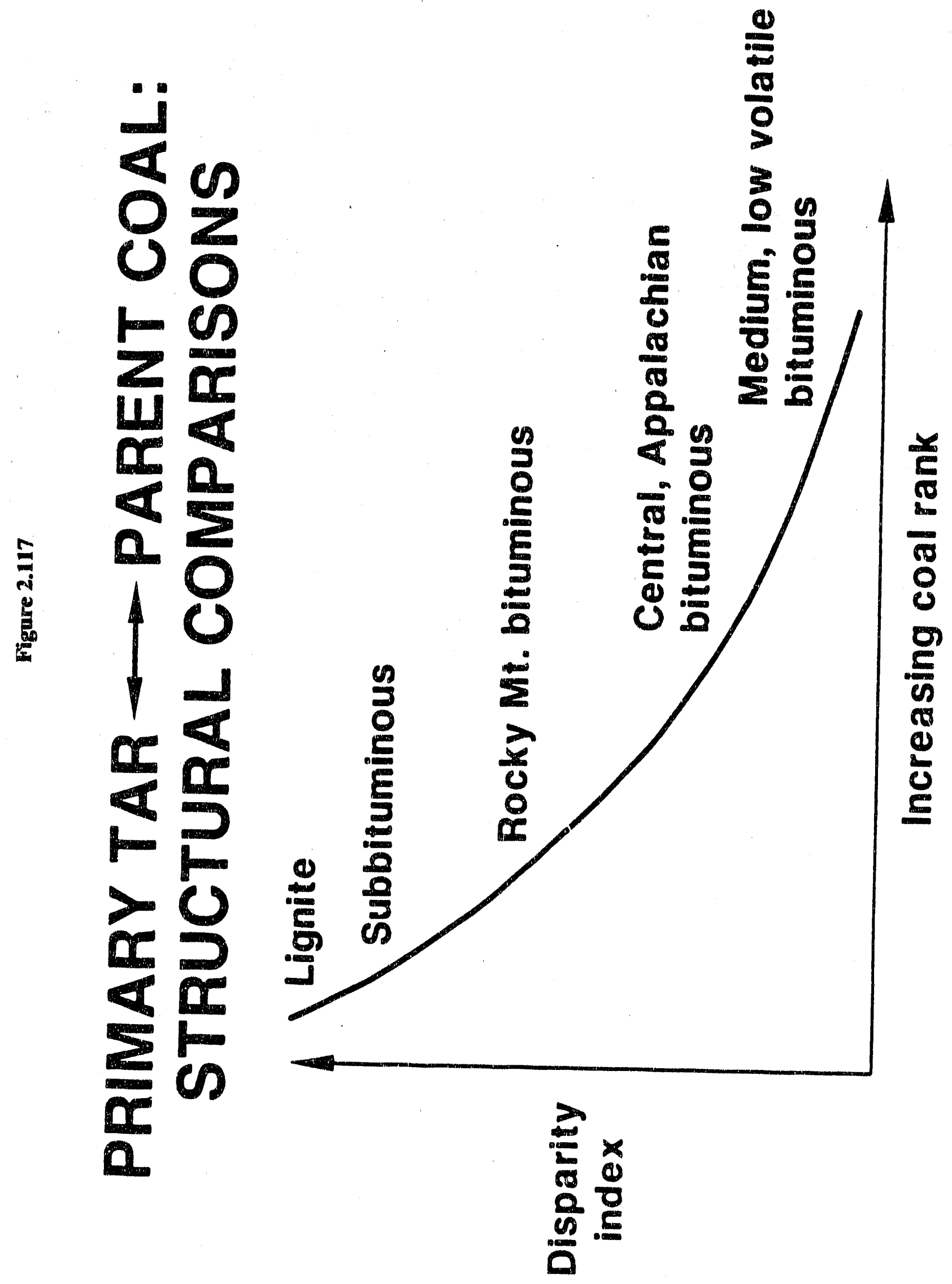


R88-PC70768

followed by the lower rank coals. However, the absolute quantities vary significantly with the nature of the low temperature tars.

\section{MW Determination and Tar Re-Vaporization Experiments}

A series of experiments designed to elucidace the vaporization temperature of coal tars under rapid heating conditions have been performed for HVA bituminous, Texas lignite, MV bituminous and Millmeran (Australian) coals. The Millmeran coal is similar to a North American subbituminous coal. Tars were generated in the UTRC entrained flow reactor at the $825^{\circ} \mathrm{C}$ wall temperature $\left(660^{\circ} \mathrm{C}\right.$ peak gas temperature) condition. The tars were then loaded onto the UTRC heated grid apparatus and re-vaporized by heating at $1000^{\circ} \mathrm{C} / \mathrm{sec}$ to various final temperatures and hold times. The tar mass loss was measured at each final temperature and the tar MWD's were determined by SEC. The mass loss data together with the number average and weight average molecular weights determined by SEC are summarized in Table 2.20 . 
TABLE 2.20 - TAR RE-VAPORIZATION EXPERIMENTS

A. PSOC 1451 D

\begin{tabular}{|c|c|c|c|c|c|c|c|}
\hline TARxx & $\begin{array}{l}\text { HOLD } \\
\text { [s] }\end{array}$ & ATM & Tf & $\begin{array}{l}\text { MASS } \\
\text { LOSS } \\
\%\end{array}$ & Mn & $C_{\text {Aw }}$ & $\begin{array}{c}\text { Trouton's Rule } \\
(75 \mathrm{cal} / \mathrm{g}) \\
\mathrm{Mn}\end{array}$ \\
\hline $\begin{array}{l}36 \\
38 \\
22 \\
21\end{array}$ & $\begin{array}{r}8 \\
20 \\
100 \\
100\end{array}$ & $\begin{array}{l}\mathrm{HE} \\
\mathrm{HE} \\
\mathrm{HE} \\
\mathrm{HE}\end{array}$ & $\begin{array}{l}320 \\
376 \\
375 \\
680\end{array}$ & $\begin{array}{l}13.6 \\
31.2 \\
50.7 \\
70.0\end{array}$ & $\begin{array}{l}166 \\
160 \\
166 \\
168\end{array}$ & $\begin{array}{l}195 \\
181 \\
191 \\
198\end{array}$ & $\begin{array}{l}166 \\
182 \\
181 \\
267\end{array}$ \\
\hline $\begin{array}{l}16 \\
26 \\
27 \\
24\end{array}$ & $\begin{array}{r}0 \\
100 \\
100 \\
100\end{array}$ & $\begin{array}{l}\text { VAC } \\
\text { VAC } \\
\text { VAC } \\
\text { VAC }\end{array}$ & $\begin{array}{l}360 \\
270 \\
350 \\
690\end{array}$ & $\begin{array}{l}64.0 \\
26.0 \\
48.6 \\
88.0\end{array}$ & $\begin{array}{l}186 \\
160 \\
167 \\
193\end{array}$ & $\begin{array}{l}255 \\
183 \\
199 \\
263\end{array}$ & $\begin{array}{l}177 \\
152 \\
174 \\
270\end{array}$ \\
\hline
\end{tabular}

B. PSOC 1443D

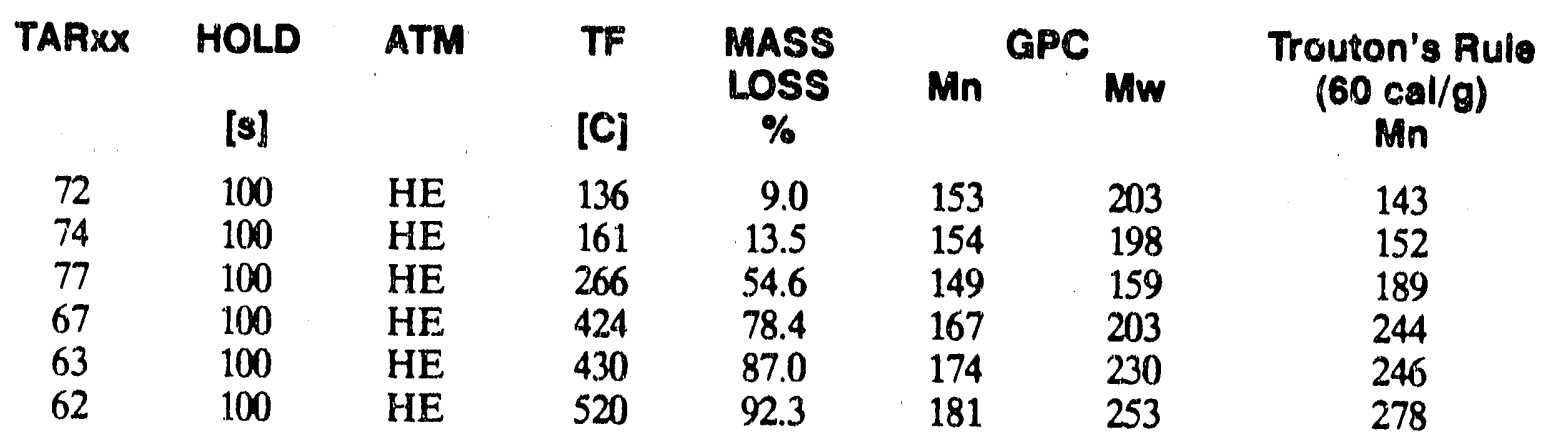

C. PSOC 1508

TARxX HOLD

[s]

$\begin{array}{ll}81 & 100 \\ 78 & 100 \\ 83 & 100 \\ 82 & 100 \\ 79 & 100 \\ 84 & 100 \\ 80 & 100\end{array}$

D. MILLMERAN
TAPXX HOLD

$\begin{array}{lr}\text { TARXX } & \text { HOL } \\ & \text { [s] } \\ 75 & 100 \\ 76 & 100 \\ 50 & 100 \\ 34 & 100 \\ 52 & 100\end{array}$

[s]

100

100

100
ATM

HE

HE

$\mathrm{HE}$

HE

HE

HE

HE

ATM

TF

[C]

HE

HE

HE

HE

HE

TF
$[C]$
246
270
388
414
494
523
670

MASS LOSS

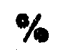

14.1

19.3

41.6

48.5

68.0

66.8

68.0

$\begin{array}{cc}\text { Mn } & \text { MPC } \\ & \\ 138 & 147 \\ 139 & 151 \\ 141 & 148 \\ - & - \\ 146 & 153 \\ 146 & 165 \\ 145 & 1.62\end{array}$

Trouton's Rule

(100 cal/g)

$\mathrm{Mn}$

109

114

139

144

161

167

$\begin{array}{ll}62 & 168\end{array}$

$\begin{array}{cccc}\begin{array}{c}\text { MASS } \\ \text { LOSS } \\ \%\end{array} & \text { Mn } & \text { MPC } & \begin{array}{c}\text { Trouton's Rule } \\ (\mathbf{7 5} \text { cal/g) } \\ \mathbf{M n}\end{array} \\ 23.2 & 149 & 175 & 134 \\ 38.4 & 155 & 166 & 157 \\ 57.3 & 171 & 204 & 177 \\ 68.7 & 174 & 212 & 202 \\ 79.7 & 175 & 219 & 298\end{array}$


Trouton's rule is a generalization of the observation that the entropies of vaporization of most non-hydrogen-bonded compounds are in the neighborhood of $21 \mathrm{cal} / \mathrm{mol} / \mathrm{K}$.

$$
\Delta S_{V A P}=\frac{\Delta H_{V A P}}{T_{b}}=\frac{\Delta h_{V A P} M_{n}}{T_{b}}
$$

The number average molecular weight of the re-vaporized tars can be determined using Trouton's rule, the known final temperature of the grid, and a value for the specific enthalpy of vaporization, as follows:

$$
M_{n}=\frac{\Delta S_{\text {vap }} \cdot T_{0}}{\Delta h_{\text {mpp }}}
$$

The specific enthalpy of vaporization is nearly constant for compounds within a compound class, varying from $30-60 \mathrm{cal} / \mathrm{g}$ for aliphatics to $75-100 \mathrm{cal} / \mathrm{g}$ for aromatics. A single value was determined for tars from each coal by fitting the molecular weight distributions calculated using Trouton's rule with those determined independently by SEC. Comparisons of the SEC and re-vaporization determined MWD's are plotted for each coal in Figs. 2.118 through 2.121. The resulting values for specific enthalpy of vaporization are in excellent agreement with values that would be expected, given the aliphatic/aromatic content of the tars inferred from elemental analysis and FTIR data. In the future, the heared grid will be used as a rapid differential calorimeter to obtain the specific enthalpy experimentally. Then, the re-vaporization experiments can be used to improve the calibration of the SEC.

Calorific Value of Primary Tars. A micro-bomb calorimeter instrument was used to determine the heating value of the primary tars $\left(825^{\circ} \mathrm{C}\right.$ wall, $660^{\circ} \mathrm{C}$ peak gas) i elitive to the parent coal. Figure 2.122 displays the measured values for some primary tars and the parent coals (PSOC XXXXD; 63-75 and 20-30 microns) received from DOE-PETC. Also shown is the calorific value of an activated carbon. The calorimeter system is calibrated with benzoic acid pellets but carbon is used as a calibration check. Both benzoic acid and carbon calibrations were within $0.3 \%$ of the theoretical values.

Due to their high aliphatic hydrogen content relative to the parent coal, low rank primary tars have relatively high calorific values, nearly $60 \%$ greater than the ash corrected parent coal value. As the rank parameter of the parent coal increases, the structural characteristics of the primary tars evolved approach 


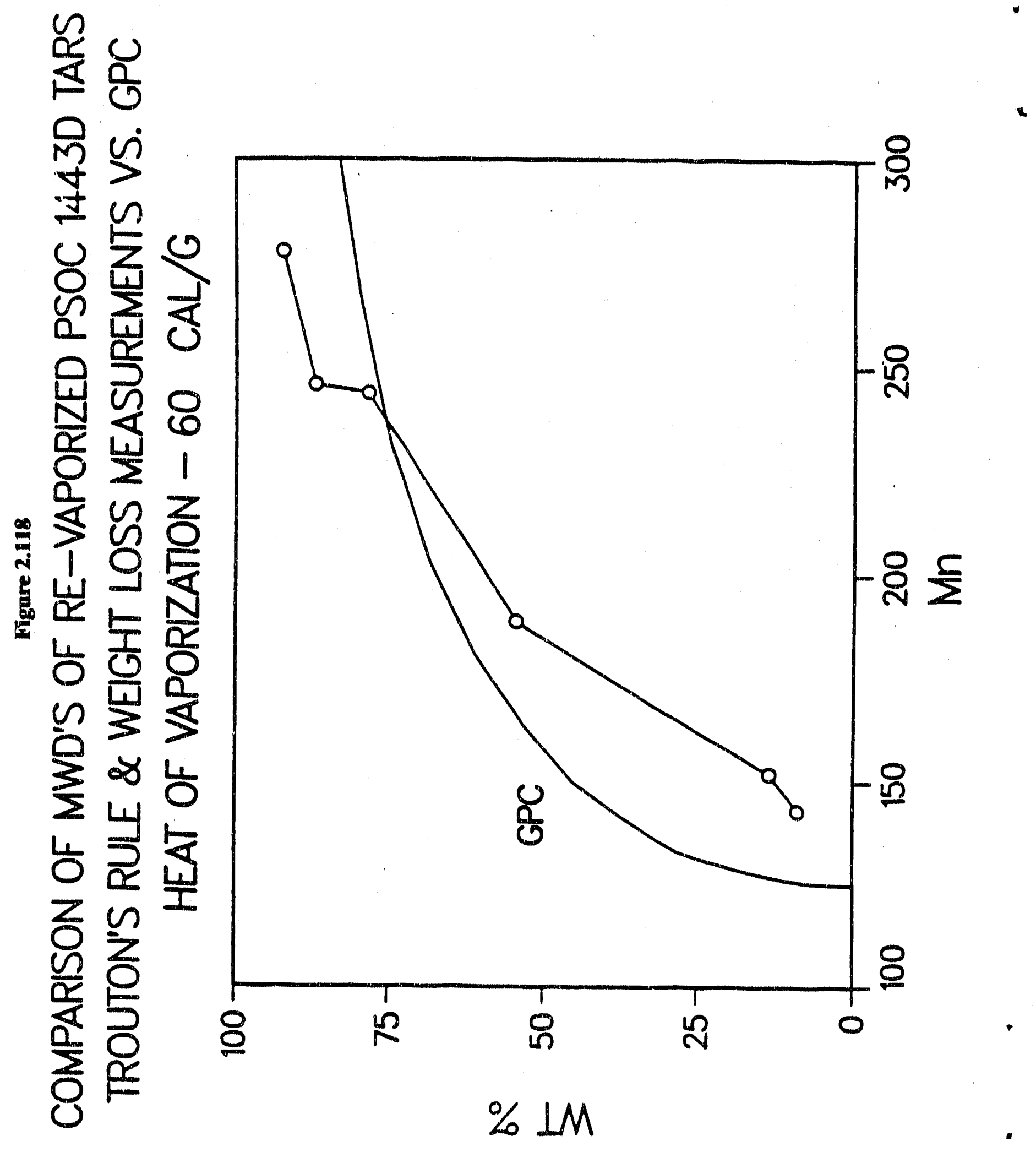




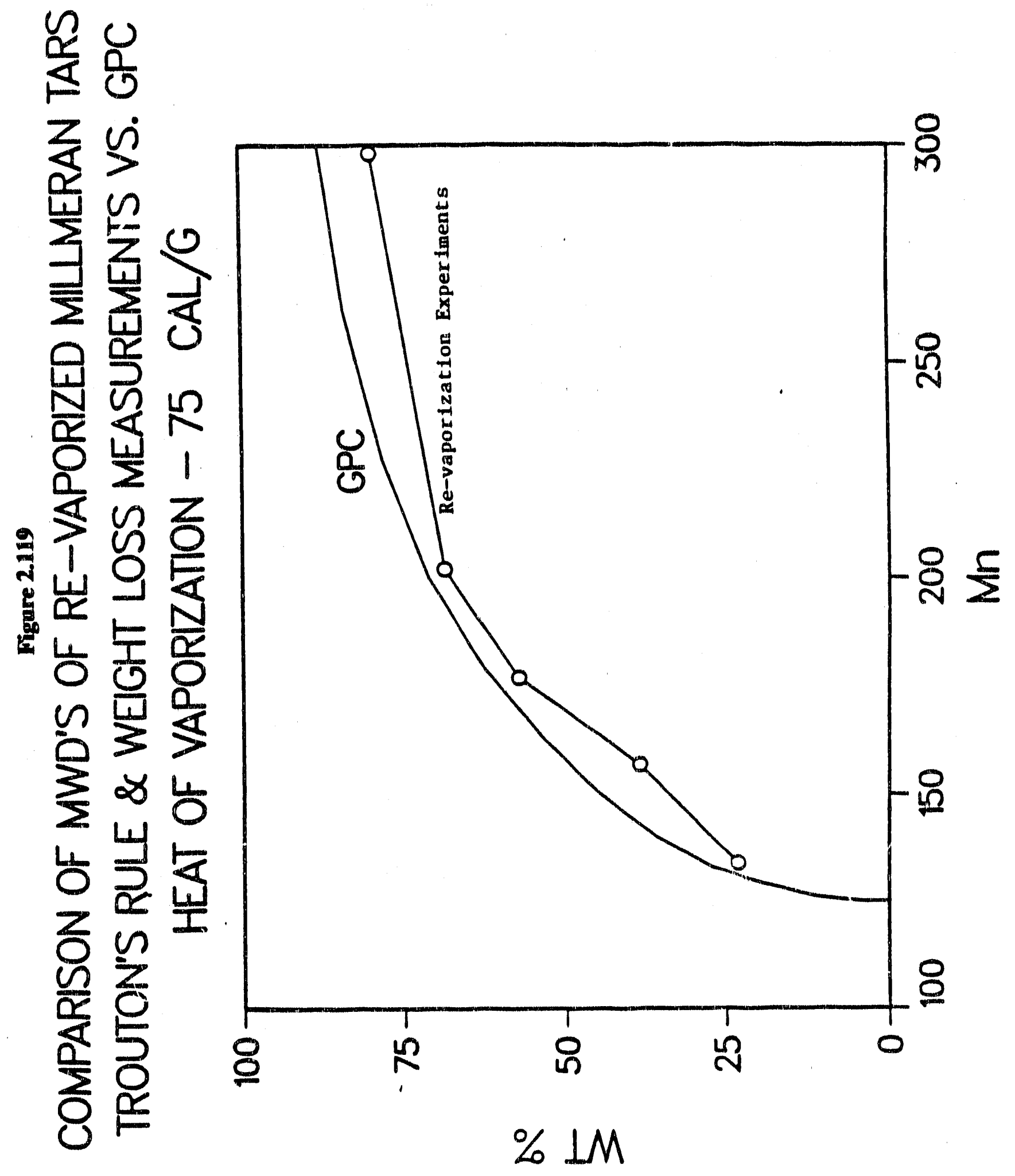


R88-PC70768

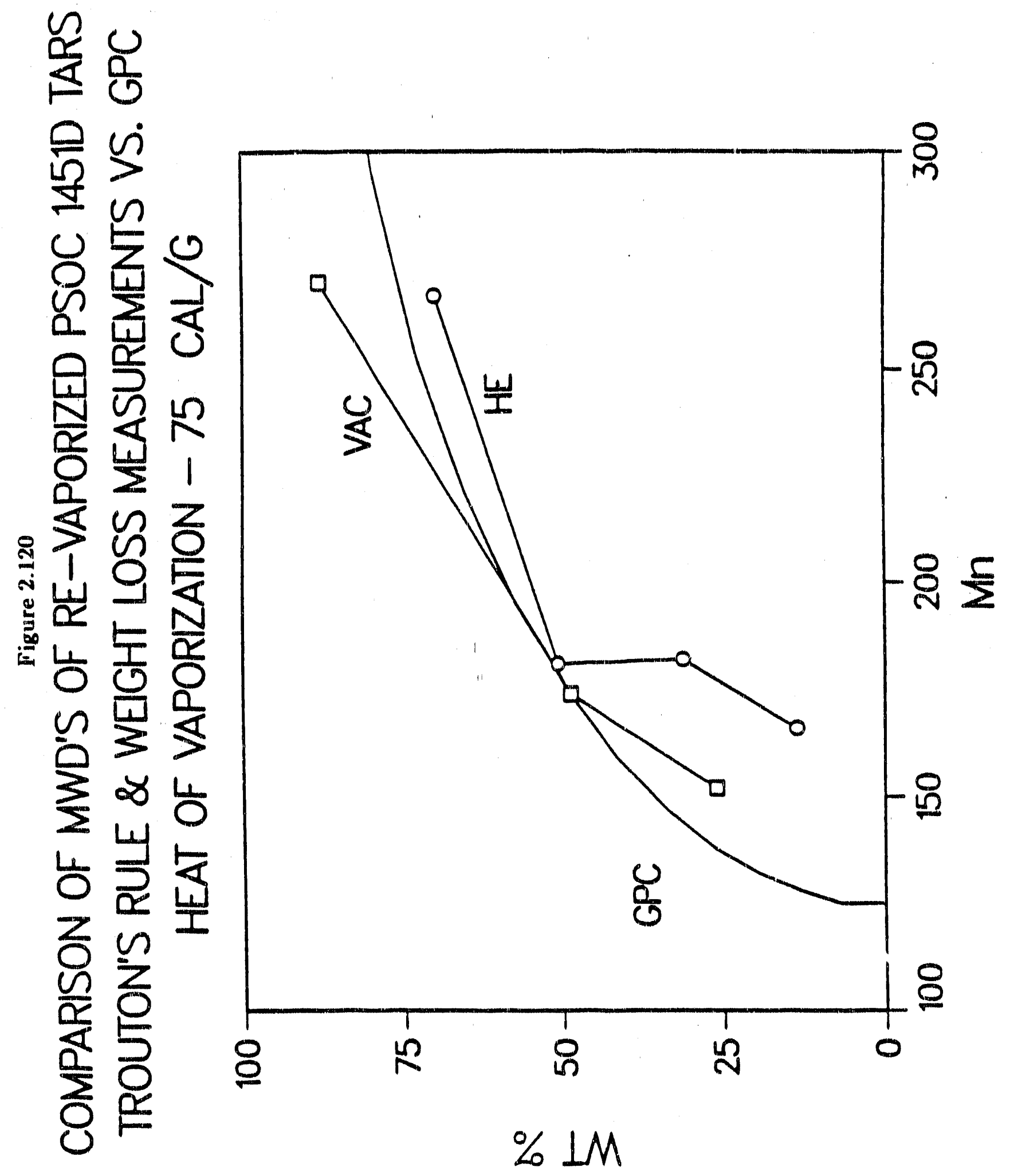




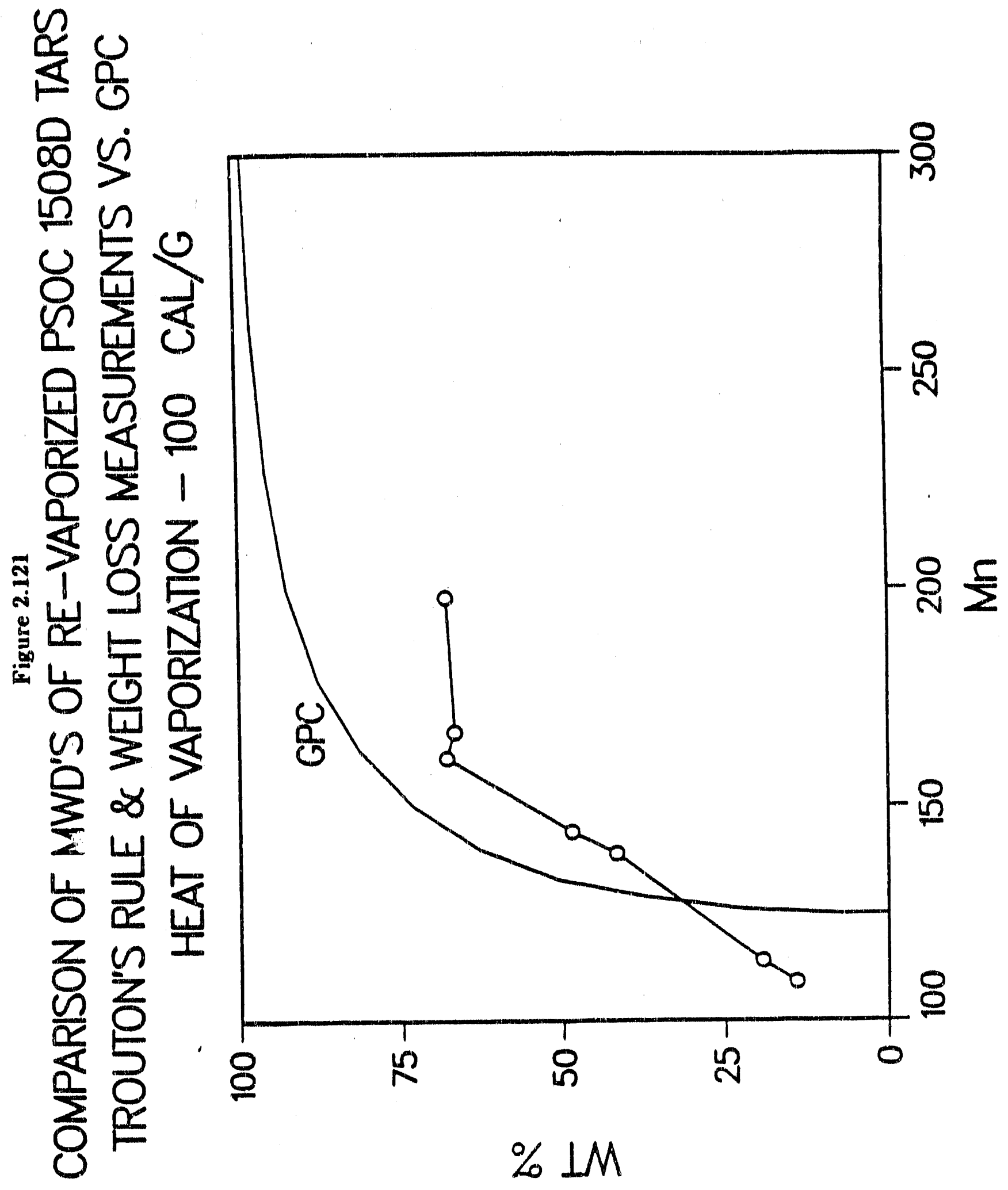




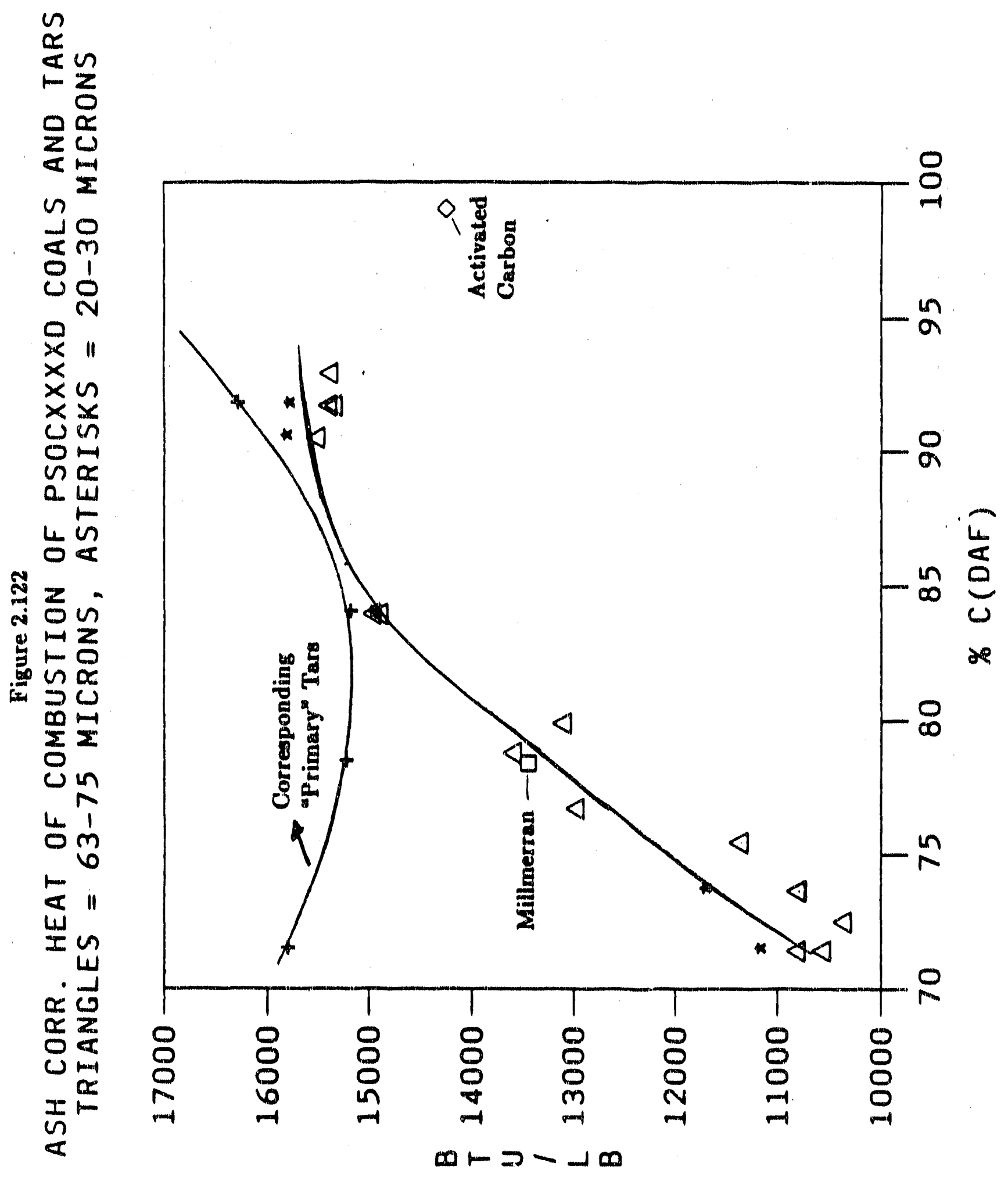


that of the parent coal (see above sections), Consequently, the mass normalized calorific values approach that of the parent coal, but are always greater due to the lower oxygen levels in the primary tars relative in the parent coal. The calorific value of the low volatile bituminous coal (PSOC 1516D) tar is greater than the $\mathrm{H}$-rlch lignite primary tars due to very low lovels of sulfur and oxygen in low volatilo bituminous tars relative to the lignite tars $(-3 \%$ vs $-13 \%)$. Even relative to the HVA tars, the LVB tars have $5-10 \%$ greater calorific values, again due to their relatively low heteroatom content,

Summary and Discussion of Results. The entrained flow reactor investigation indicates that the phencrnenology of coal devolatilization and pyroiysis is similar for a wide range of coal sanks. The phenomenology is summarized in Figs, 2.123 through 2.125 . Heavy hydrocarbons are Initially detached by physical and chemical processes within the coal particle at relatively low temperatures $\left(300-450^{\circ} \mathrm{C}\right)$. Further heating results in the extra-particle evolution of some detached heavy hydrocarbons (tars), the onset of light gas production $\left(450-650^{\circ}\right.$ ) by intraparticle pyrolysis reactions, and the detachment of more tar piecursors. The low temperature light gases consist mainly of $\mathrm{CH}_{4}$ and higher alkanes, $\mathrm{CO}, \mathrm{CO}_{2}, \mathrm{H}_{2} \mathrm{O}$ and some $\mathrm{C}_{2} \mathrm{H}_{4}$. The absolute quantities of these species vary with coal type as do the absolute ylelds of "primary" tars. Gas and particle temperatures greater than $700^{\circ} \mathrm{C}$ preferentially produce $\mathrm{C}_{2} \mathrm{H}_{2}, \mathrm{HCN}, \mathrm{CO}$ and $\mathrm{C}_{2} \mathrm{H}_{4}$. On a mass basis, the tar species dominate the Initial particle weight loss.

For any given extent of tar evolution, the lower the rank of coal, the more dissimilar the evolved tars are to the parent coal. Primary low rank coal tars appear to consist mainly of long chain aliphatic species with significant levels of associated carboxylic and carbonyl groups. As the rank index of the feed coal is increased from lignites, the low temperature primary tars approach the parent coal with respect to aliphatic and aromatic hydrogen ratio, percent hydrogen, and percent heteroatom sontent. Primary tars from bituminous coals have structural characteristics more reflective of, but never identical to, the parent coal. Corresponding observations can be made with respect to tars evolved for a given coal with respect to extent of tar evolution as the variable. That is, the tars evolved initially in the evolution process are more unllke the parent coal than the integrated sum of tars evolved at the point of asymptotic yields for a given coal. The earlier in the tar evolution process the greater the aliphatic hydrogen concentration of the tars.

Intraparticle or gas phase reactions of primary tars are rapid at particle or gas temperatures 0 $700^{\circ} \mathrm{C}$ and above, common operating temperatures of conventional entrained flow reactors. Such reactions quickly lead to the ring formation reactions of polymethylene rich low temperature tars colncidental with the evolution of the heavier tar species from the devolatilizing particle itself. Tars collected in these conditions, particularly tars collected in separatic $\eta$ systems without extensive phase separation, will appear to be more 

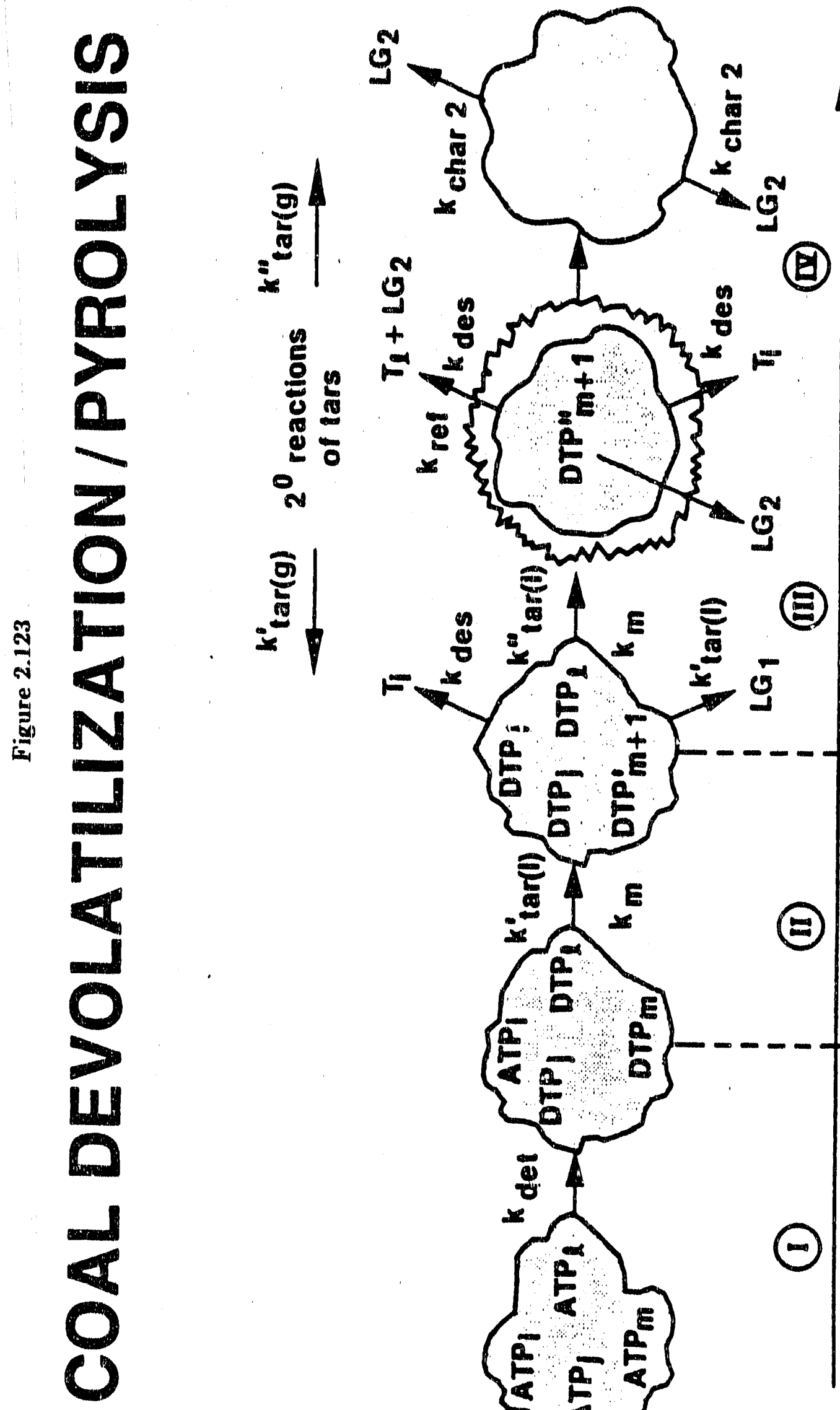

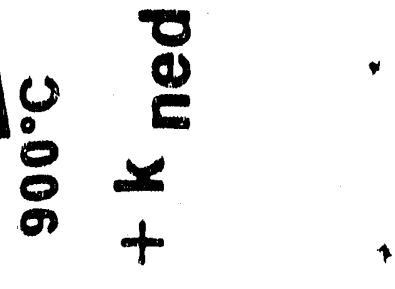

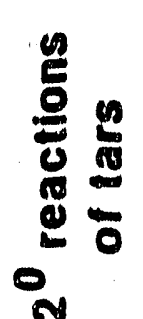

in

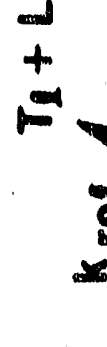

$=$
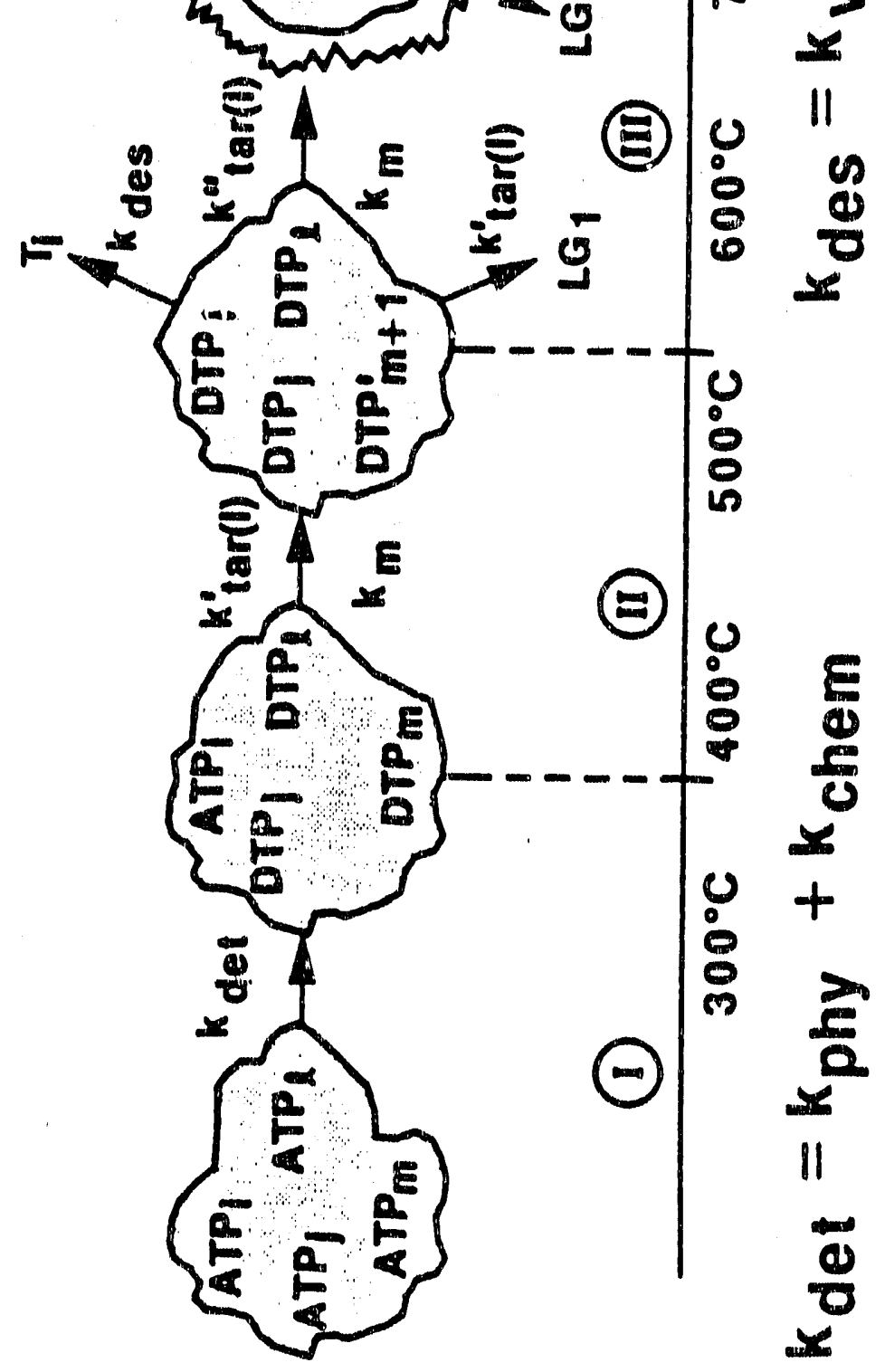


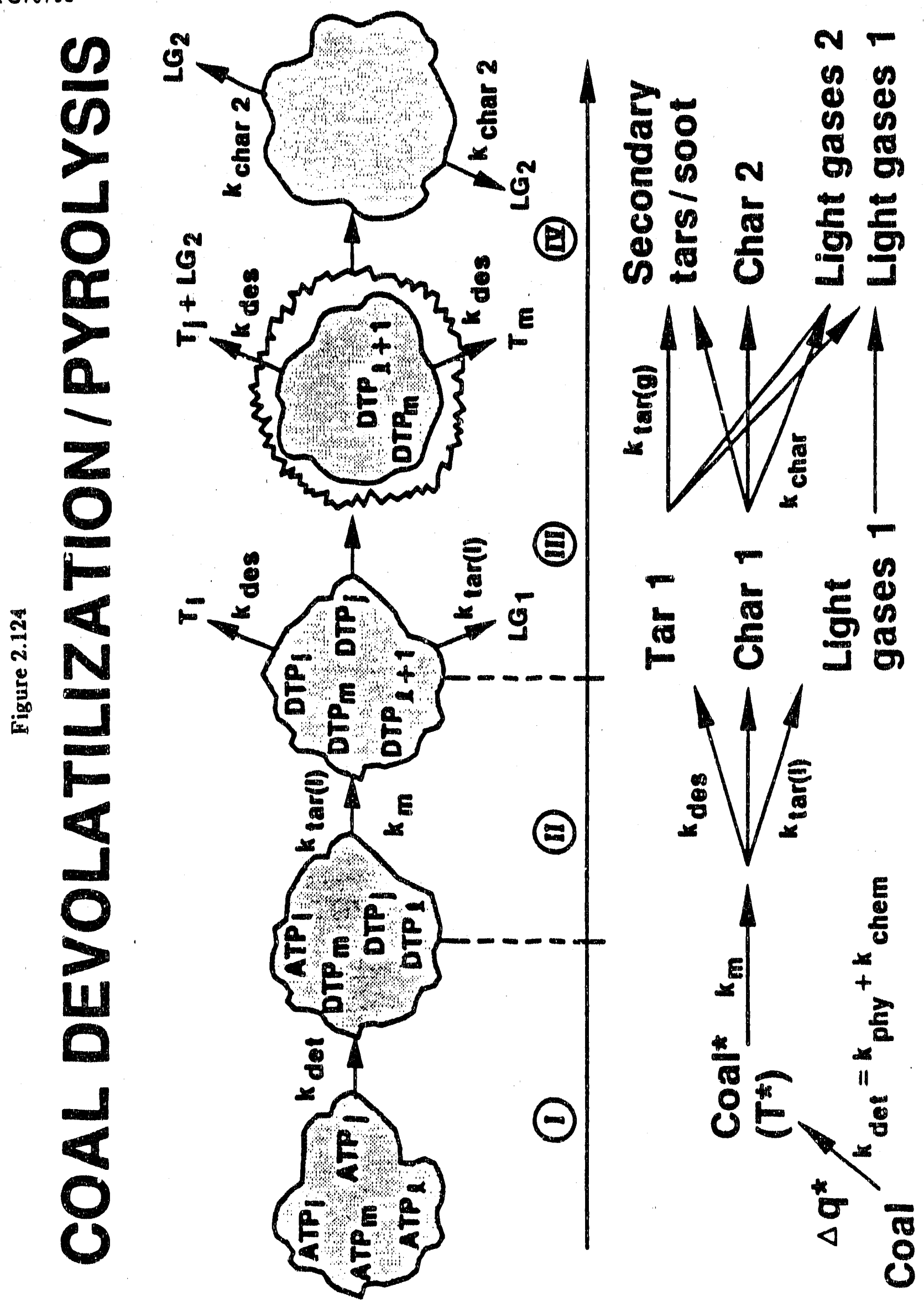




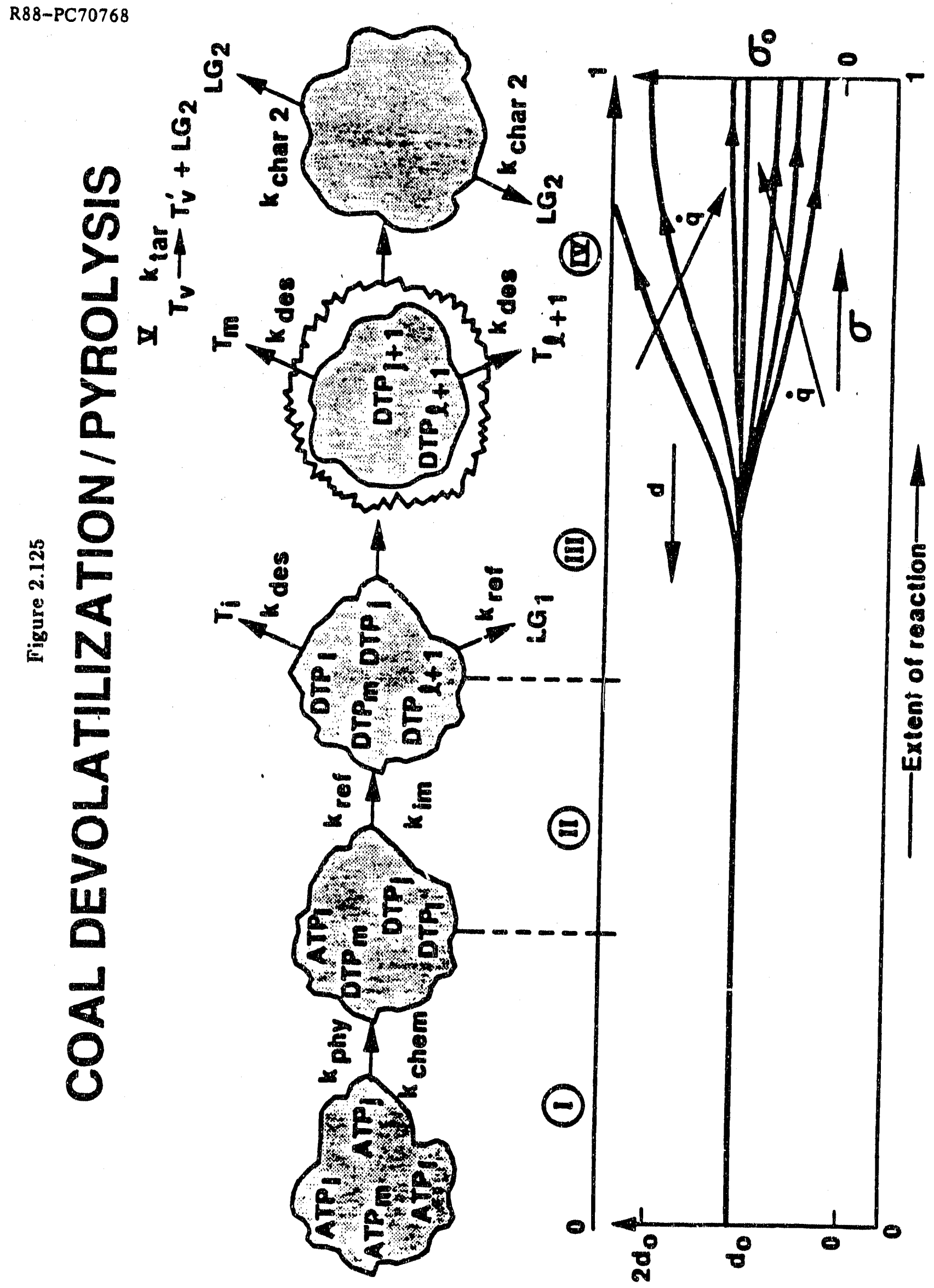

1 
like the parent coal than the primary tars originally evolved and collected in the above reactor system or other systems that minimize secondary tar reactions. Similar observations can be made with respect to tars evolved for a given coal with respect to extent of tar evolution. That is, the tars evolved initially in the evolution process are more unlike the parent coal than the integrated sum of tars at the point of maximum tar yield.

\subsubsection{United Technologies Research Center Heated Grid Investigation Heated Grid System Description}

Figure 2.126 schematically displays the heated grid system with its associated microcomputer-based, power programming and data acquisition systems. Provisions are made to routinely monitor two thermocouples, a pressure transducer, delivered current and the voltage impressed upon the grid in real time. Electrical power is delivered to the electrodes of the grid system via a programmable power supply operated in the voltage-programmed mode. Program control signals are sent to the power supply via a microcomputer controlled analog voltage (MCAV) output to the power supply. The MCAV initiates the data acquisition process in the microcomputer system utilized for monitoring the signal transducers. It also activates a solenoid valve controlling the release of cold helium gas across the length of the wire grid through a helium "spray bar" device shown, if rapid quenching is desired to "freeze" a sample at a particular stage of heating.

\section{Wire Mesh Characteristics}

Commercially available 325 mesh stainless steel (type 304 ) is used as the heating substrate in the system. The manufacturer's specifications on the screen indicate a wire diameter of $0.0014^{\prime \prime}(35.6 \mu \mathrm{m})$, an opening between wires of $0.0017^{\prime \prime}(43.2 \mu \mathrm{rn})$, and a mass/superficial area of $21.5 \mathrm{mg} / \mathrm{sq} . \mathrm{cm}$. Figure 2.127 displays a scanning electron microscope view of a section of the grid at approximately $+25 X$, with a spot welded thermocouple bead. Examination of a number of grid samples using the electron microscope revealed an average wire diameter of $36.5 \mu \mathrm{m} \pm 1.6 \mu \mathrm{m}$, with a range of 33.3 to $39.4 \mu \mathrm{m}$. Wire spacing was found to have an average value of $48.2 \mu \mathrm{m} \pm 3.1 \mu \mathrm{m}$ in a range of 42.3 to $54.2 \mu \mathrm{m}$. Table 2.21 gives the appropriate properties of the grid weave and material properties.

Figure 2.128 displays the mesh folding technique employed to create a captive area for a sample. Typical dimensions are shown as well. Small $(50-75 \mu \mathrm{m}$ bead diameter) chromel-alumel thermocouples are spot welded to the grid at locations corresponding to approximately $2.25 \mathrm{~cm}$ from each electrode clamp and $2.40 \mathrm{~cm}$ from each other. The thermocouples are welded to the grid because it was found 


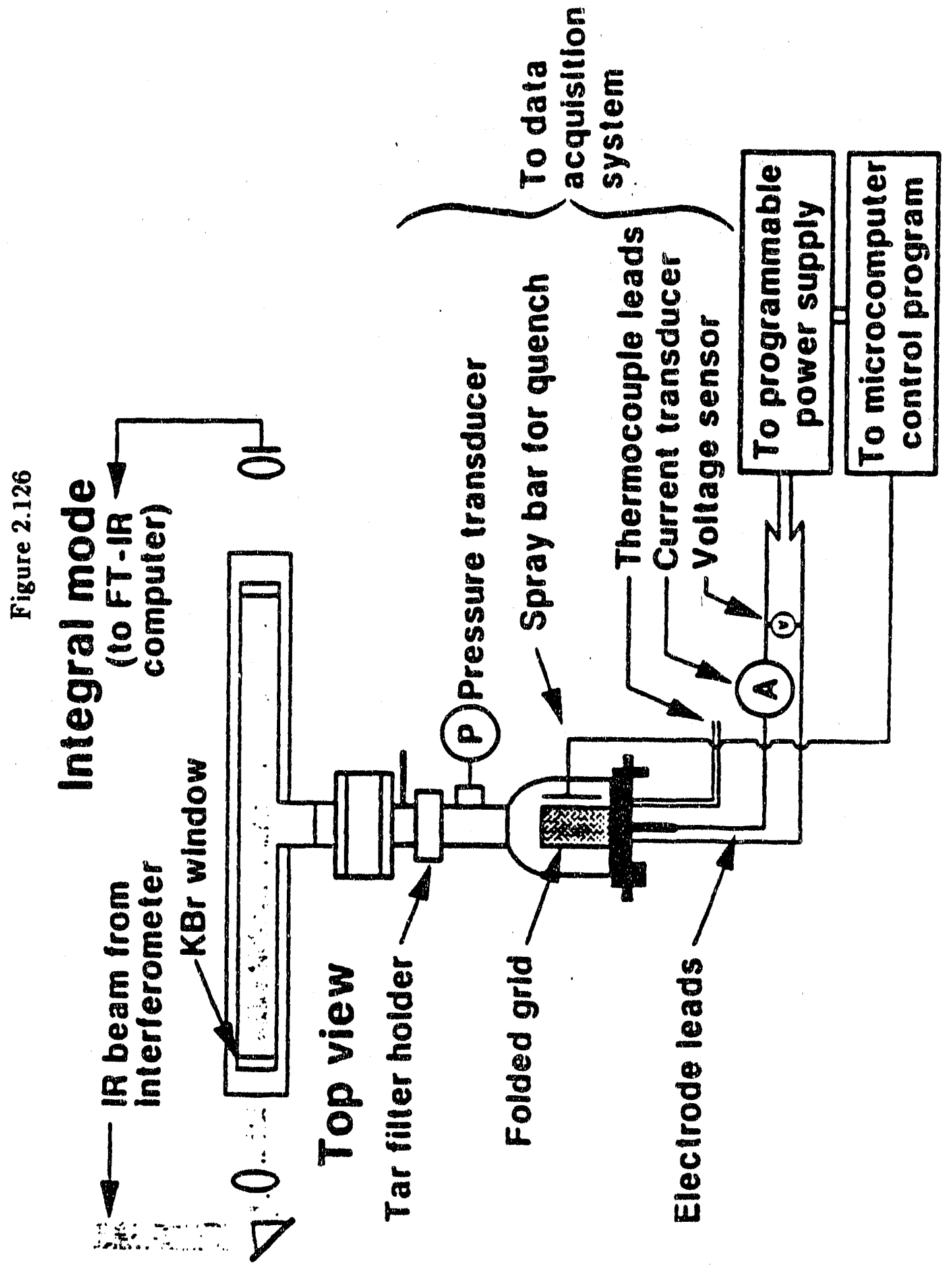

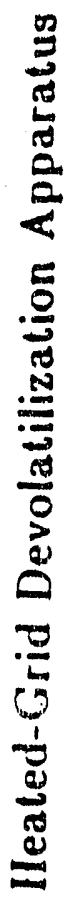


Figure 2.127

Stainless Steel Screen

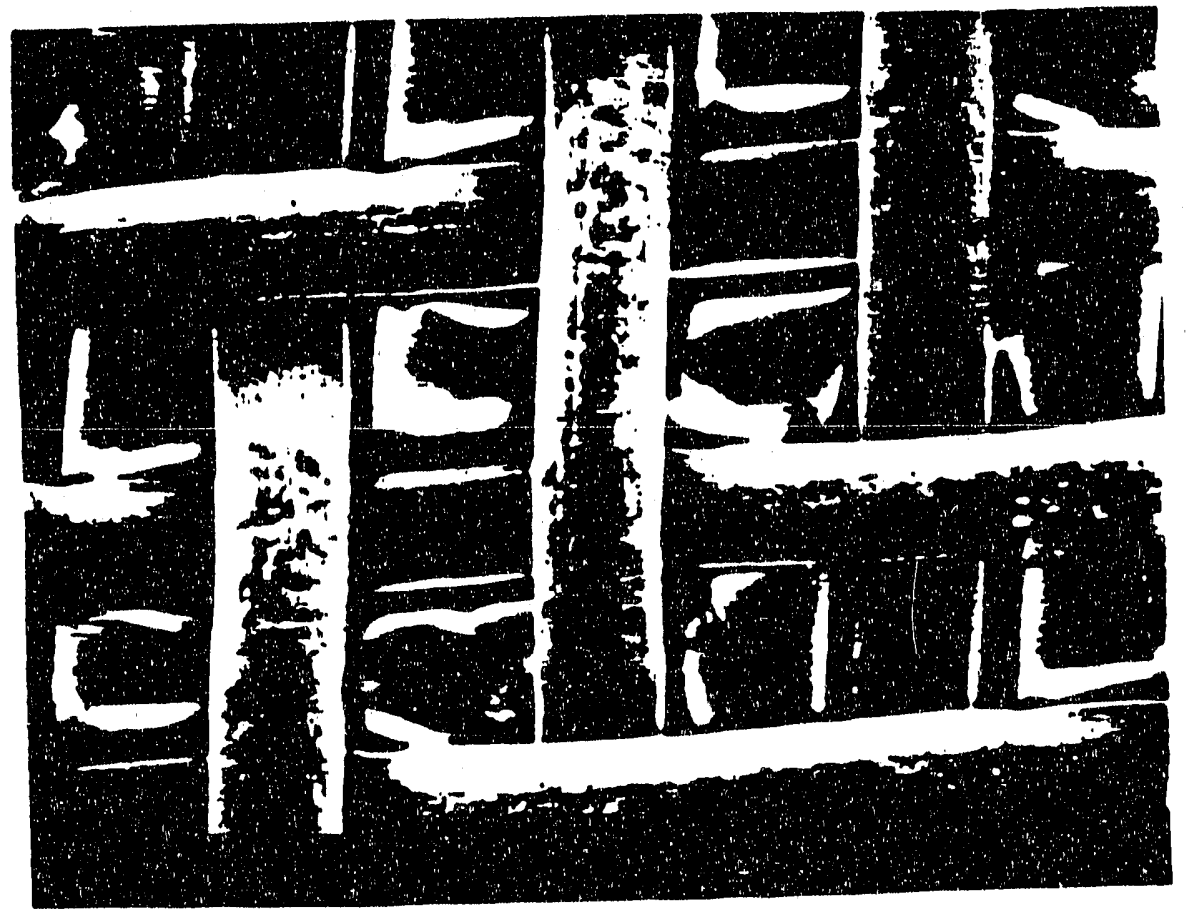

450x Screen

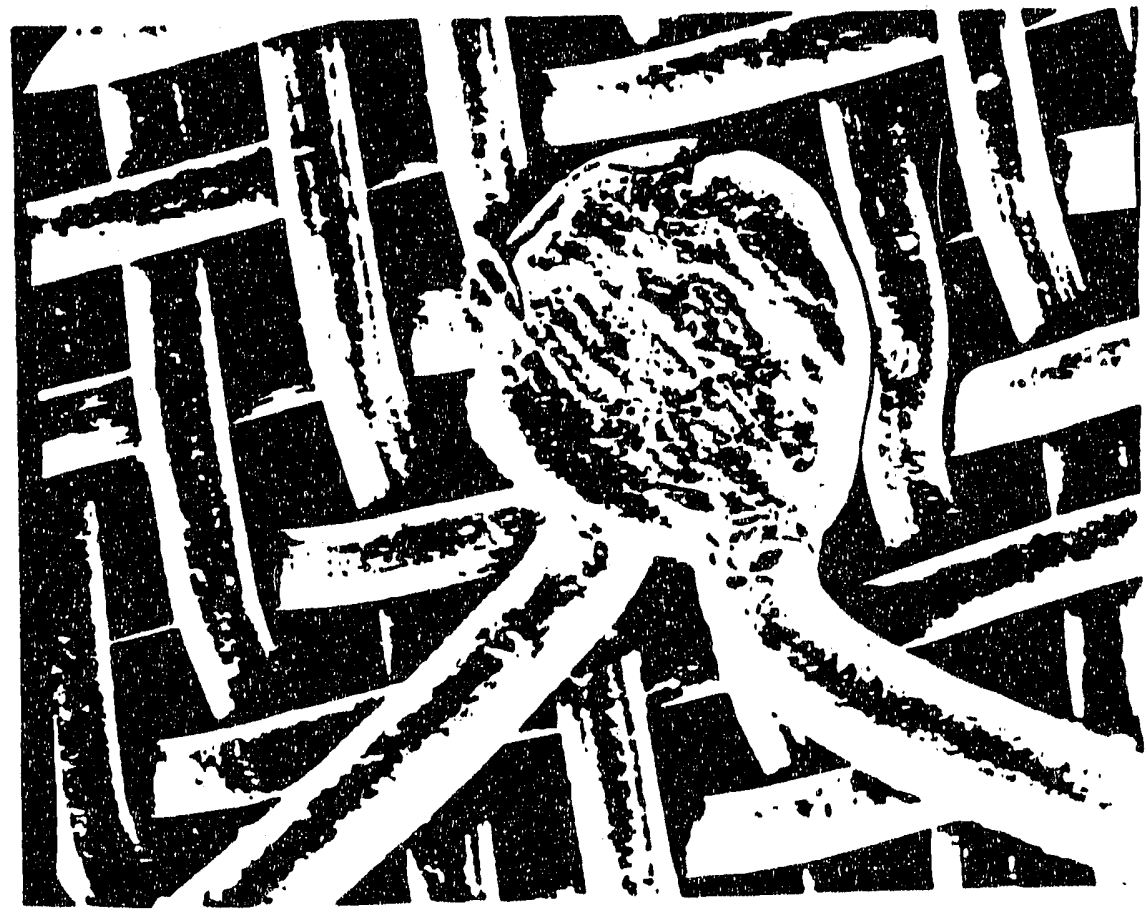

350x Thermocouple Bead 
TABLE 2.21 - PROPERTIES OF STAINLESS STEEL (Type 304) GRID MATERIAL

A. Thermophysical Properties

\begin{tabular}{lcc} 
Property & Value at $20^{\circ} \mathrm{C}$ & $\begin{array}{c}\text { Temperature } \\
\text { Dependence }\end{array}$ \\
\hline Specific Heat & 0.50 joules $/ \mathrm{g}^{\circ} \mathrm{C}$ & Increases \\
Emissivity & $0.40 \cdot 0.70$ & Increases \\
Thermal & & \\
$\quad$ Conductivity & 0.182 watt $/ \mathrm{cm}-{ }^{\circ} \mathrm{C}$ & Increases \\
Resistivity & 72 micro-ohm-cm & Increases \\
Density & $7.817 \mathrm{~g} / \mathrm{cc}$ & Constant
\end{tabular}

B. Geometric Properties

\begin{tabular}{ll} 
Property & \multicolumn{1}{c}{ Value at $20^{\circ} \mathrm{C}$} \\
\hline Strand Diameter & Average: 36.5 microns \\
& Range: $33.3-39.4$ microns \\
& Standard Deviation: 1.6 microns \\
& Average: 48.2 microns \\
Strand Spacing & Range: $42.3-54.2$ microns \\
& Standard Deviation: 3.1 microns \\
& 7.52 sq.cm. \\
Projected Geometric Area/Face & 30.09 sq.cm. \\
Total Geometric Area & 36.67 sq.cm.
\end{tabular}

C. Power Dissipation Characteristics"

\begin{tabular}{lcccc}
$\begin{array}{c}\text { Ambient } \\
\text { Condition }\end{array}$ & $\begin{array}{c}\text { Temperature } \\
\text { Range }\left({ }^{\circ} \mathrm{C}\right)\end{array}$ & $\begin{array}{c}\text { Degree } \\
\text { of Fit }\end{array}$ & $\mathrm{C}_{d}$ & $\mathrm{C}_{c}$ \\
\hline Vacuum & $25-600$ & 1 & 0.7929 & 0.8904 \\
Vacuum & $25-600$ & 4 & 0.9531 & 0.9763 \\
Vacuum & $100-1000$ & 4 & 0.9850 & 0.9925 \\
Helium & $25-600$ & 1 & 0.9689 & 0.9833 \\
Helium & $25-600$ & 4 & 0.9885 & 0.9943 \\
Helium & $100-1200$ & 4 & 0.9941 & 0.9971
\end{tabular}

- See text for description of conditions. $\mathrm{C}_{d}=$ coefficient of determination; $\mathrm{C}_{\mathrm{c}}=$ coefficient of correlation from least squares analysis of power input versus grid temperature data. 
R88-PC70768

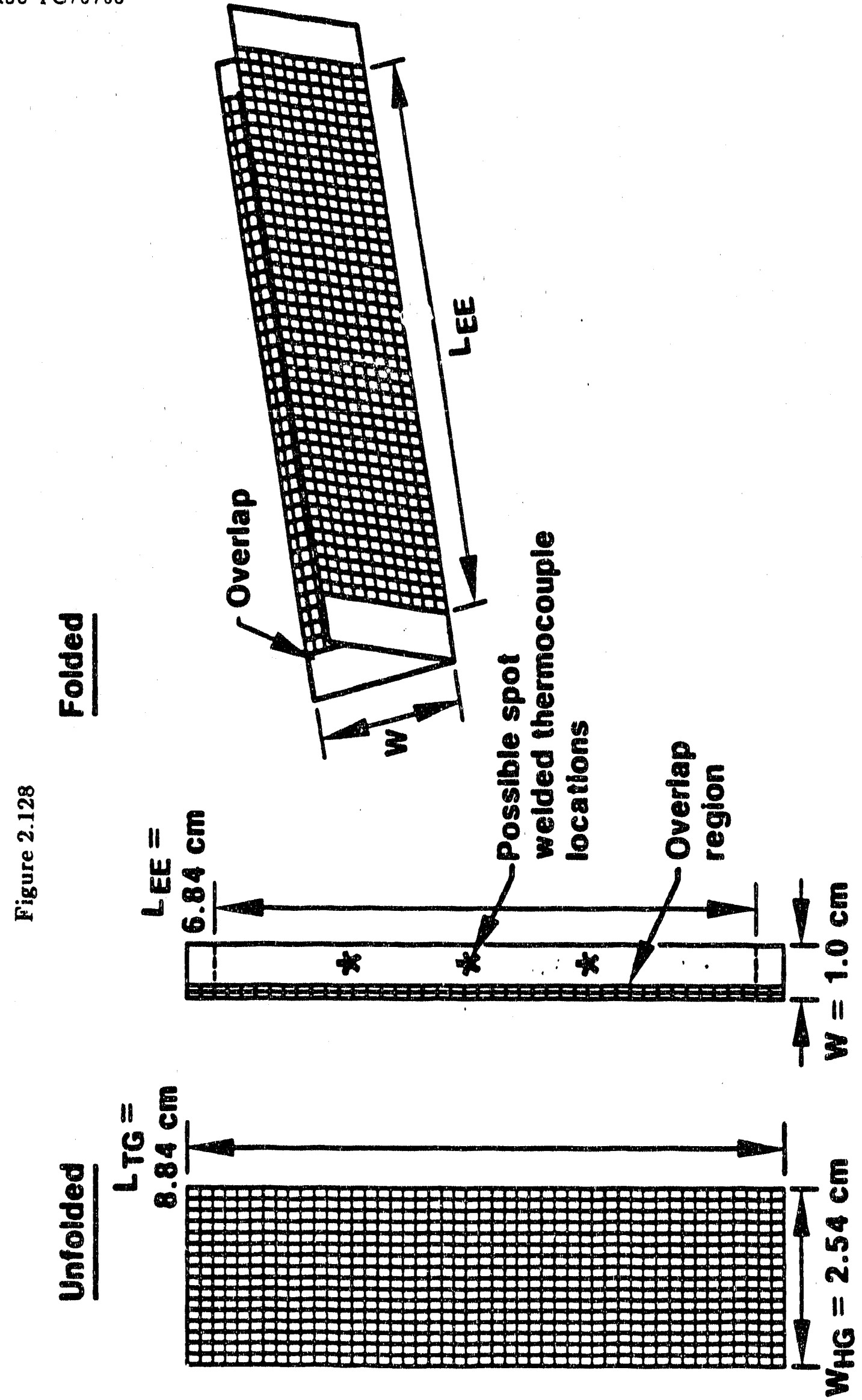


experimentally that voltages could be induced across bead diameters inserted between the folds of the screen. In the voltage programming mode, the greater the desired heating rate or hold temperature the greater the induced voltage possible. For example, a 15 volt impression across a $6.9 \mathrm{~cm}$ grid length could in theory produce a $21.7 \mathrm{mV}$ potential across a 100 micron thermocouple bead touching the grid at opposite ends of the bead, but parallel to the voltage gradient across the grid. Induced voltages across inserted thermocouple beads were common and led to the technique of spot welding the thermocouple beads to the grid at a point on a cross weave strand. This technique greatly reduces but does not altogether elliminate the problem since bead spurs sometimes touch two non-isopotential electrode to electrode strand points. The runs characterized by a voltage offset in the time-resolved thermocouple data are generally disregarded but can be used if the trouble is taken to filter out the induced offset. But such considerations point out the need to have a data acquisition system with appropriate sampling frequency. It was also noted that the thermocouple monitoring circuits must be in total electronic isolation from the power supply circuit in order to avoid resistive heating of the thermocouple leads themselves, again producing spurious temperatures in the thermocouples.

\section{Grid Substrate Power Requirements and Dissipation Characteristics}

Also shown in Figs. 2.129 and 2.130 are the curve fits for total power loss in hellum or vacuum as indicated. Both the helium and vacuum data is fit reasonably well with fourth degree polynomials with respect to grid temperature (see Table 2.21), using the entire temperature range. However, at low temperature conditions power loss in the presence of helium is better fit, as expected, with a linear power of grid temperature. The vacuum power loss continues to show better correlations of determination and correlation with a fourth degree dependence on temperature. The statistical description of power dissipation supports the modes of heat loss noted above.

\section{Power Dissipation Dependence on Ambient Gas Properties}

Since convective/conductive loss via the ambient gas is a significant dissipation mode, the effect of varying the nature of the ambient gas should be observable in the temperature response of the grid. For increasing thermal conductivity of the ambient gas, one expects lower steady state temperatures for a given power input, greater rates of cooling from a given temperature with zero power input, and small effects on a rapid transient grid temperature rise for a given power program input. Figures 2.131 and 2.132 show the current and voltage traces corresponding to the resulting temperature traces of Fig. 2.133. The temperature traces correspond to varying ambient gas conditions. The asymptotic temperatures approached, the rate of cooling to steaciy state power input conditions following the transition from ramp input, and the rate of 


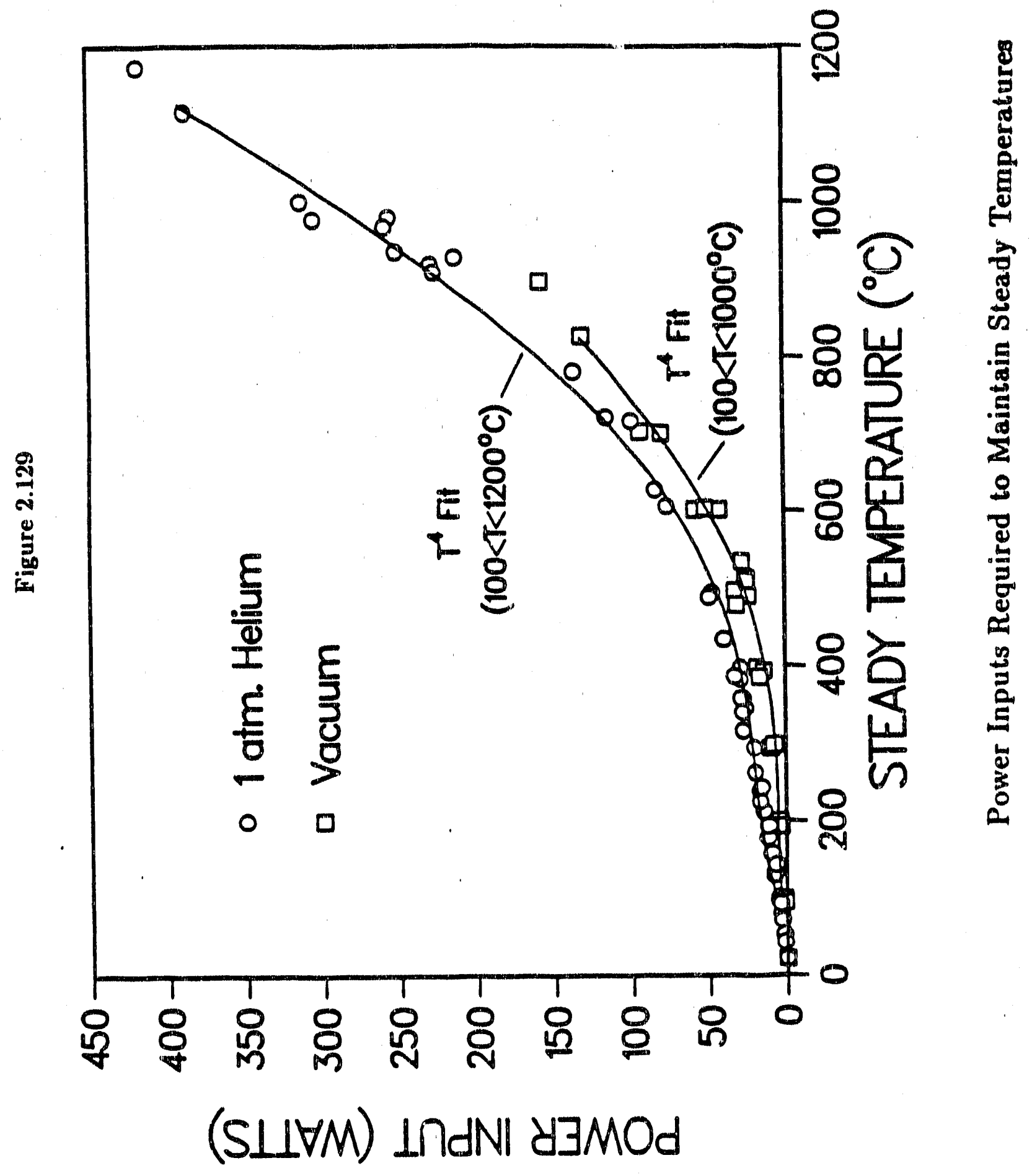




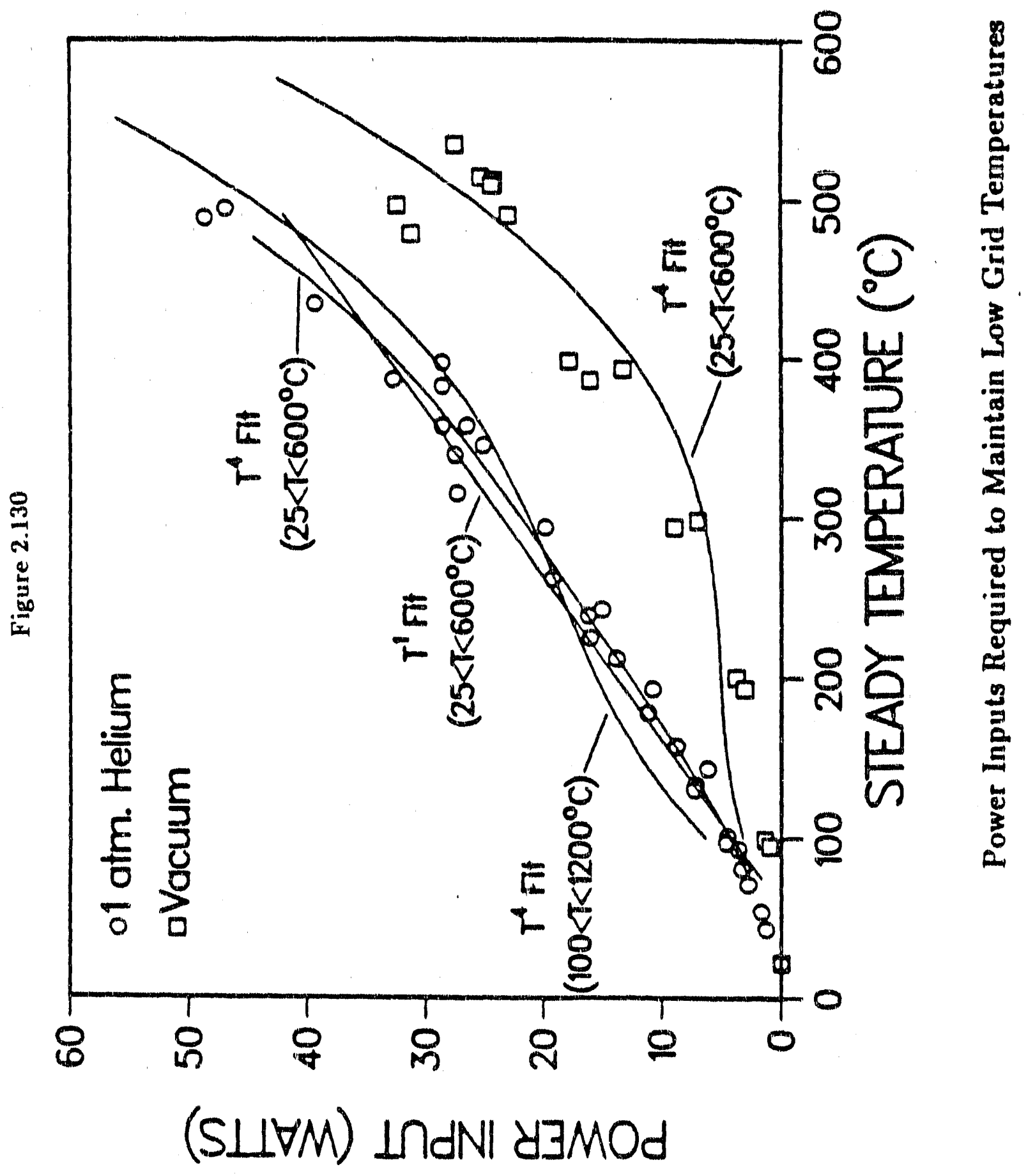


(a)
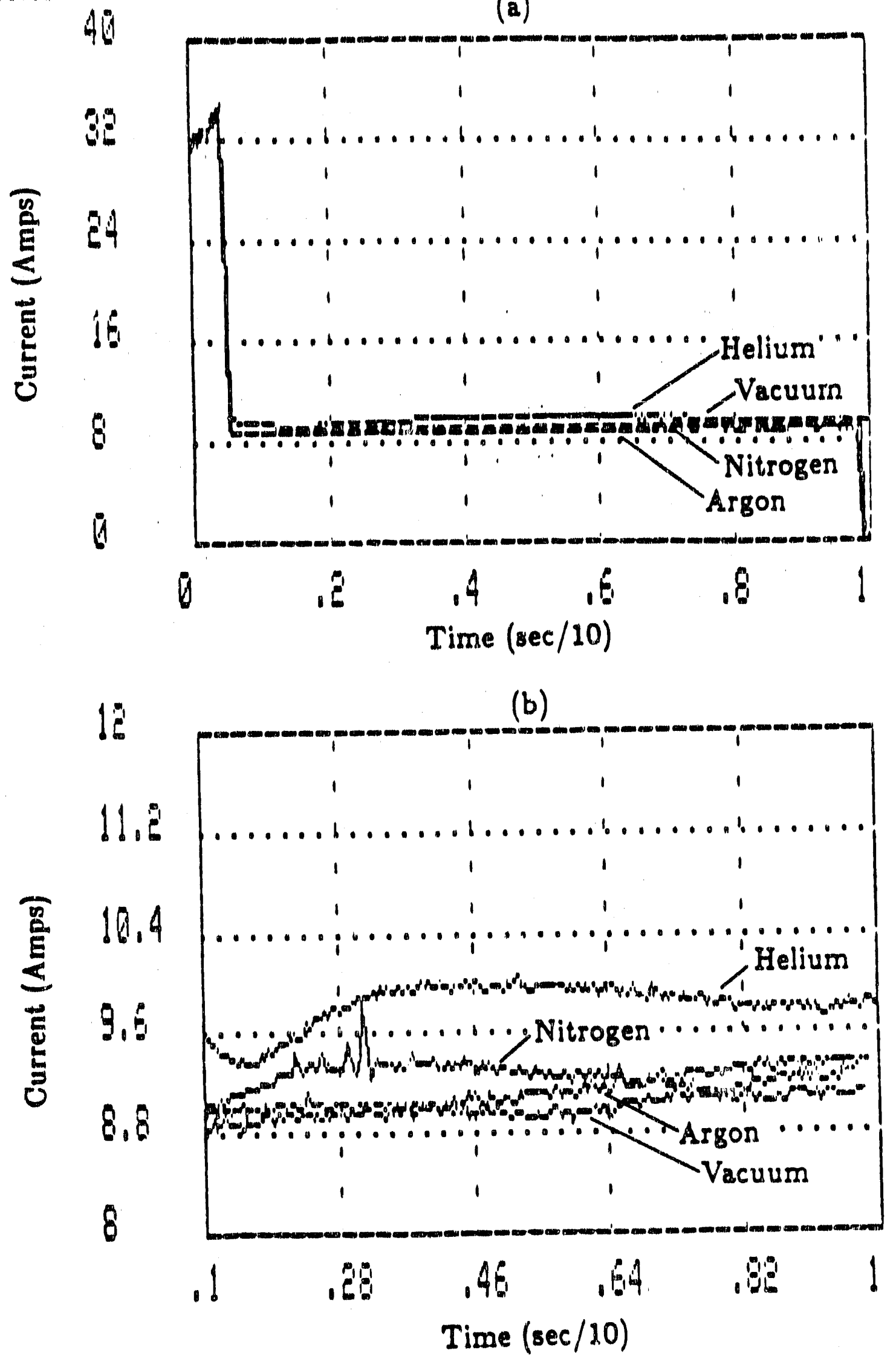

Total Current Through Grid Heated in Gases as Shown 
R88-PC70768

$\rightarrow$

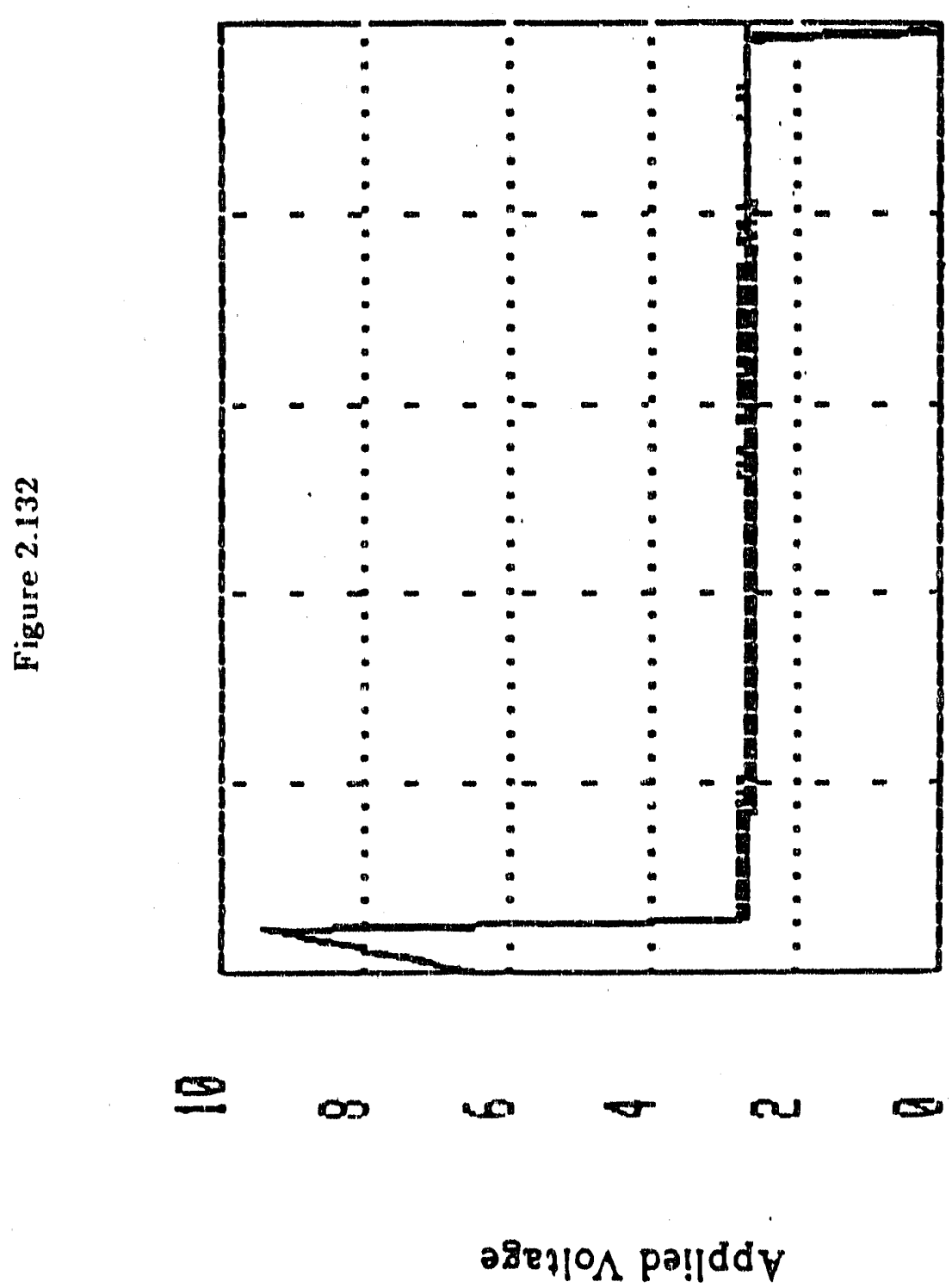

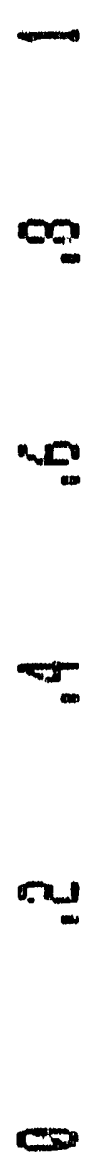

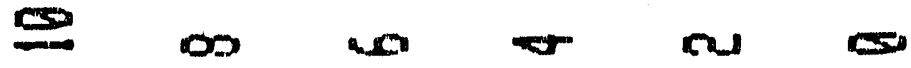

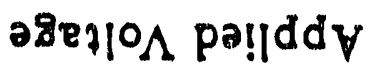

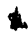


R88-PC70768

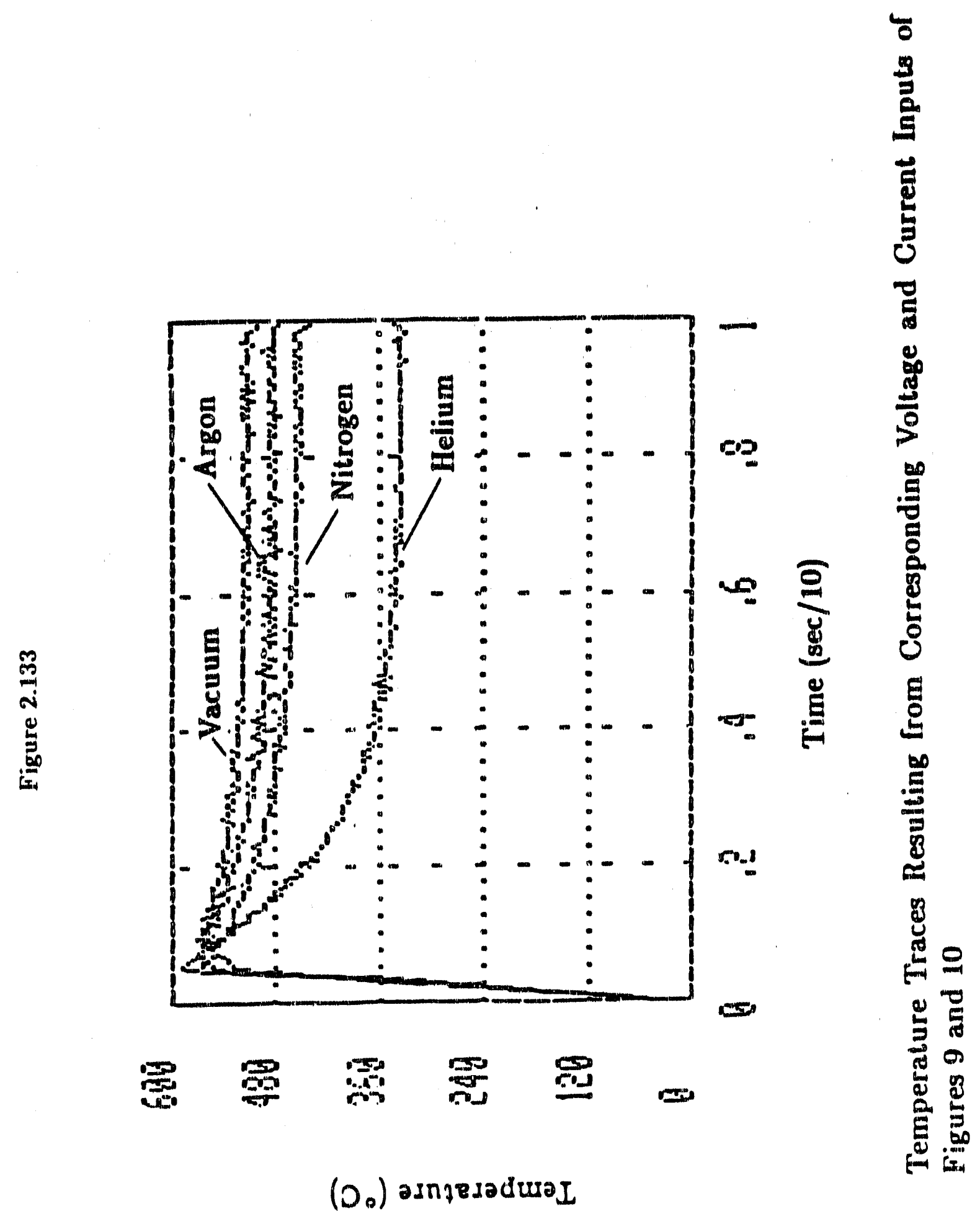


coollng from a given temperature during the power-off portion of the curves all show the expected variation In thermal conductlvity of the ambient gas, with hellum "loading" the grid to the greatest extent. Indeed, as Indicated in Fig. 2.131, for a given programmed voltage, the lower overall screen cemperature during the hold voltage cycle leads to a lower overall resistivity, permitelng slightly more current through the wire strands.

The ambient gas has a less obvious effect on the rapld heating rate of the grid substrate, due to the magnitude of the possible power dissipation relative to the grid enthalpy requirements. For example, at $450^{\circ} \mathrm{C}$. the total power dissipation in hellum is approximately 40 watts, with roughly one-half via gas conductivty, The power requirement to produce a $1000^{\circ} \mathrm{C} / \mathrm{sec}$ heating rate through the same temperature is approximately 215 watts for the grid mass employed. Loss through the hellum represents only about $10 \%$ of the total power requireinent - enthalpy and dissipation - during the transient heating period. Changing the ambitunt gas 0 other than hellum reduces the gas component loss in proportion to the relative thermal conductivity of the gas. But since the gas dissipation load only represents a small fraction of the total power requirement during rapid heating, the observable effect is slight relative to the steady state and coollng portions of the prigram cycle. As substrate heating rate is lowered, the effective thermal conductivity of the ambient gas becomes more of a factor in the grid substrate temperature trajectory.

\section{Power Dissipation Per Unit Surface Area of the Grid Surface}

The steady state and translent measurements indicate the main pathway of power loss from the grid substrate is vla the screen surface. Loss via the electrodes is not substantial relative to the total screen loss. At temperatures less than $500^{\circ} \mathrm{C}$, gas conduction and radiative losses from the screen surface are comparable in magnitude. The gas conduction component varies as expected with the nature of the ambient gas. Above $500^{\circ} \mathrm{C}$ radiation loss dominates the total power dissipation. Total power dissipation rate of the wire mesh, and therefore, its potential capability of heating a sample within its folds, varies appreciably with grid temperature. Normalizing with respect to either superficial projected screen area or total strand area Indicates power dissipation to vary from several tenths of watt/sq. $\mathrm{cm}$. at low grid temperatures to approximately 10 watts $/ \mathrm{sq} . \mathrm{cm}$. at $1000^{\circ} \mathrm{C}$.

\section{Screen, Thermocouple and Sample Thermal Coupling During Transient Heating Conditions}

Of course, the primary concern in utillizing heated wire devices for kinetic investigations is the relationship among the wire grid, thermocouple and sample temperatures during the transient heating process. "Calibration" of the heated grid device using samples of known specific heat, melting points and 
heats of fusion was performed. Figure 2.134 dlsplays the temperature profiles obtained from heating $80-100$ mesh samples of lead and bismuth on the opposite sldes of the same grid, using a two thermocouple configuration. Equal sample mass loads about the thermocouples were employed. The temperature Inflections indicate the melting phase changes associated with each pure element wherein the temperature irajectories of the local gald substrates are temporarily arrested, due to the assoclated heat reciuliement of the phase change of each material.

The temperature plateaus indicate melting points of 260 and $323^{\circ} \mathrm{C}$ for bismuth and lead, respectively. Actual melting points are reported as 271 and $327^{\circ} \mathrm{C}$. These elements have very simllar speciflc heats due to their similar atomic weights and the Dulong-Petit law $(6.55 \mathrm{cal} / \mathrm{mole})$. Similar loads were employed around each thermocouple, $100.8 \mathrm{mg}$ for bismuth and $100.6 \mathrm{mg}$ for lead, but the load intensity factors were slgnificantly different - approximately $92 \mathrm{mg} / \mathrm{sq} \mathrm{cm}$ for bismuth and $67 \mathrm{mg} / \mathrm{sq} \mathrm{cm}$ for lead. The Increased load intensity for bismuth, relative to lead, results in slight non-lsothermallties across the sample-screen interface during melting. That is, the blsmuth sample melts at the edges of the sample loading Inward toward the sample center, the location of the thermocouple. The limited power intensity generation capability of the screen surface coupled to the latent heat of fusion of bismuth exacerbates the lateral non-isothermality across the screen-sample area during the phase change.

However, the melting points and total mass loads are similar enough to allow a semiquantitative estimation of the sensitivity of the system to determining relative thermophysical properties of materials. From temperature plateau lengths, it appears the heat of fusion of $\mathrm{Bl}$ is between 2.00 and 2.10 that of $\mathrm{Pb}$. The latent heats of fusion of $\mathrm{Bi}$ and $\mathrm{Pb}$ are reported as 2.51 and $1.22 \mathrm{kcal} / \mathrm{mole}$, respectively, giving a ratio of approximately 2.06 . The reasonable accuracy in the observed melting temperature and heats of fusion ratio Irnply the local screen temperatures, as given by the spot-welded thermocouple temperatures, are representative of the sample temperatures in these heating conditions. That is, there is close coupling among thermocouple, screen and sample on a local level.

The "localness" of a sample-induced loading on a screen is also apparent by inspection of Fig. 2.135. The temperature trajectories of the aluminum (80-100 mesh) loaded and unloaded areas of the same screen are given. The data of Figs. 2.134 and 2.135 indicate that the stainless steel screen does not respond as a whole ts a given load factor. The relatively poor thermal conductivity of the mesh material forces its thermal coupling to the sample to be of a local nature, in terms of units of wire mesh spacings rather than units of total grid length 


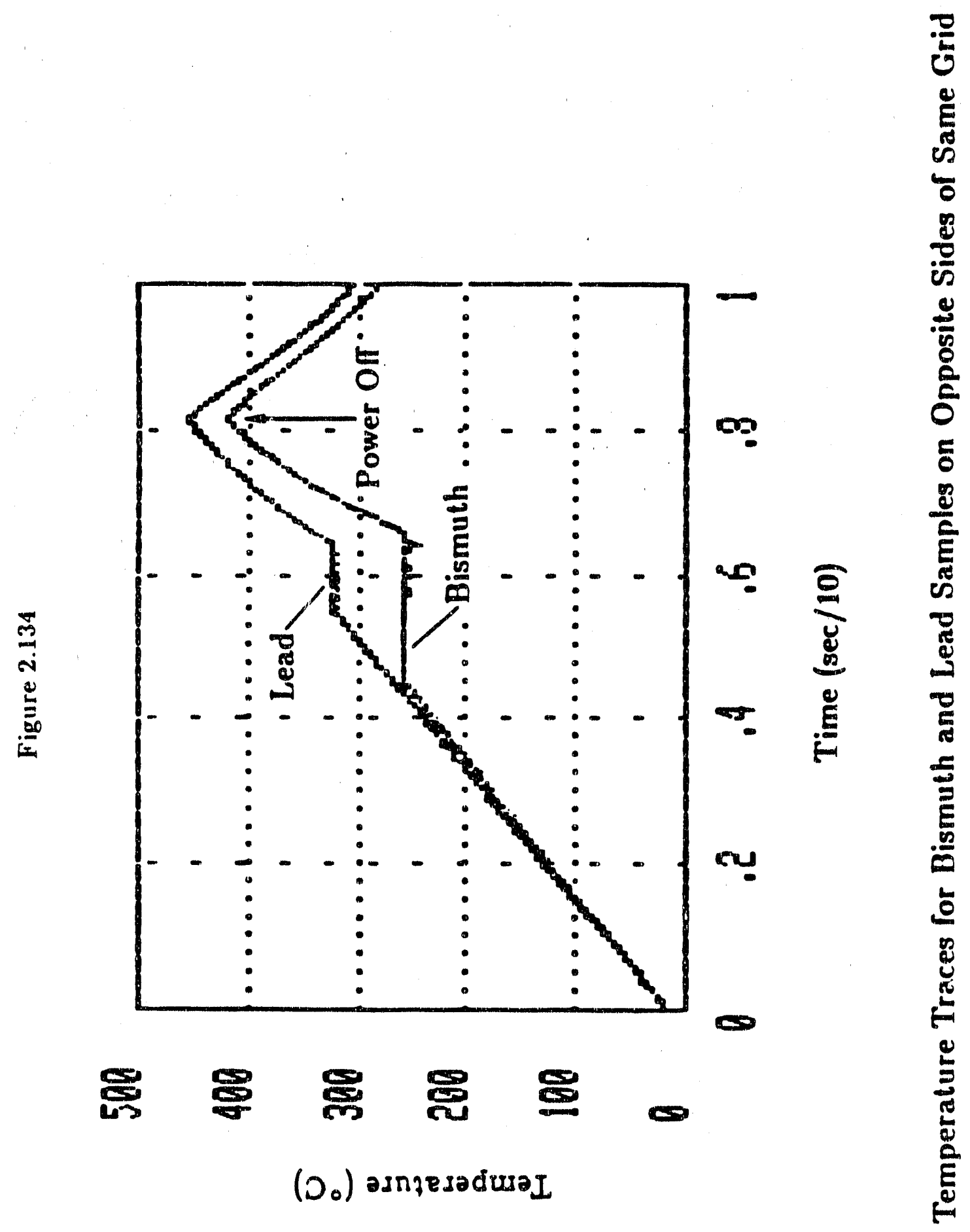


R88-PC70768

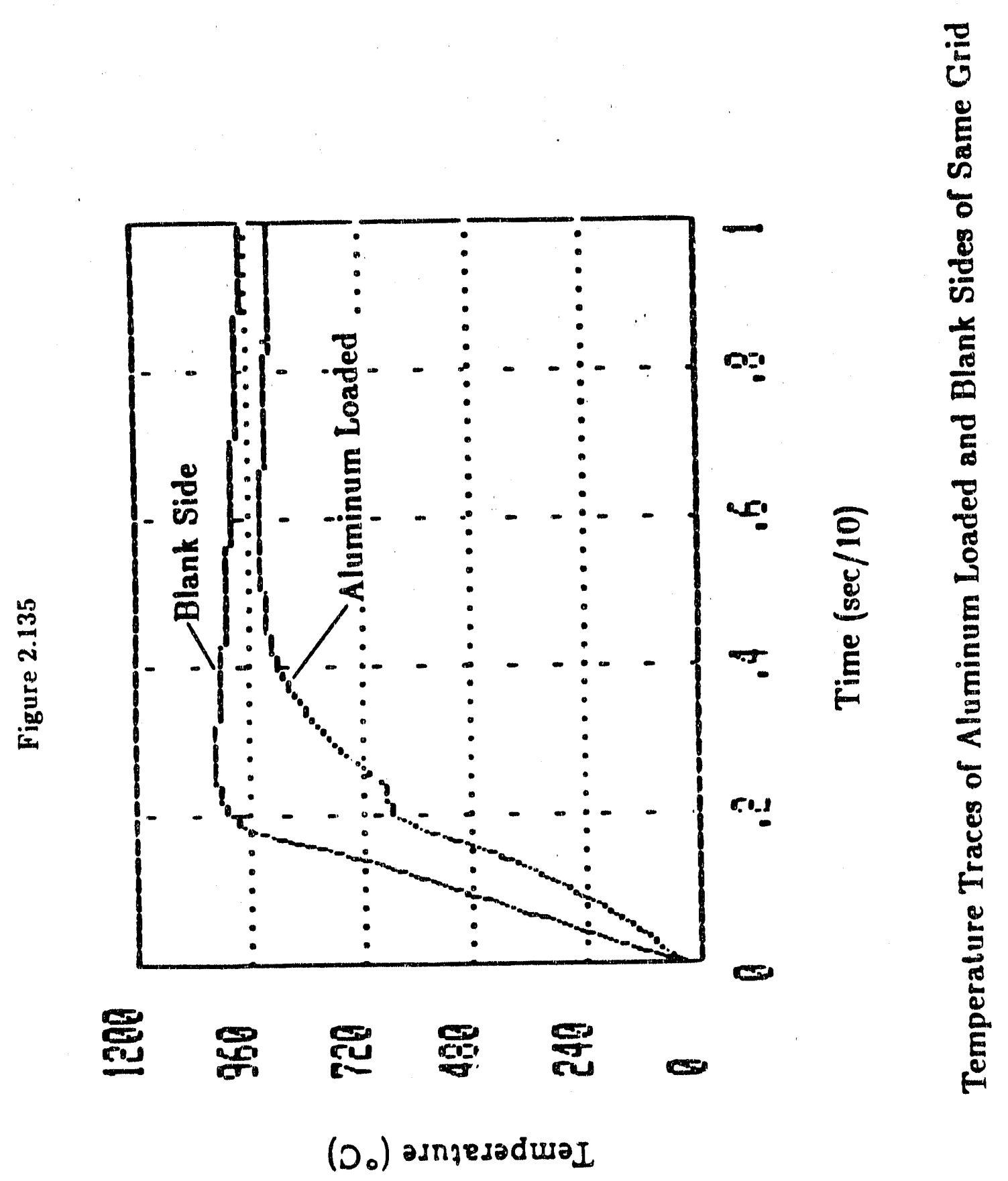


The "localness" of the coupling is also observed by changing the given local load factor for a constant sample type and power program. Table 2.22 shows the "observed" melting temperatures of aluminum in similar heating rate conditions obtained by varying the load factor around a single thermocouple. The table also shows the "observed" melting points of tin using the same load factor, to the degree possible, but varying heating rates. Lower apparent melting temperatures are obtained by locating the thermocouple in the center of a locally dense load of sample. Higher temperatures are obtained by a thermocouple bead located on the "edge" of a sample covered area or at a position several grid spacings from the sample distribution. In the former case the sample "overloads" the grid locally, given the limited heat generation capability of the wire mesh. The overload causes the sample to melt nonuniformly from an area of high heat intensity per unit mass of sample at the sample edge inward toward the sample center. The transient temperature inflection in the thermocouple occurs at a temperature lower than the actual melting temperature of the material. In the latter case, the thermocouple measures the temperature of a basically "underloaded" screen area, resulting in a thermocouple inflection at a temperature greater than the actual melting temperature or, in the extreme case, simply missing any evidence of physical change.

The above "calibration" measurements indicate the importance of local sample loading in estimating accurate sample temperature measurements from associated thermocouple measurements. More specifically, it is the sample loading per unit superficial surface area of the wire mesh, relative to the thermocouple position, that determines the observable thermocouple temperature relative to the actual sample temperature. It is observed that actual sample temperatures in rapid transient heating conditions depend on the specific heat and latent heat of fusion of the reference material relative to the substrate heat capacity and thermal dissipation properties, sample distribution relative to the thermocouple location and "programmed" heating rate. The phenomenological behavior is a result of the thermophysical properties of the stainless steel substrate relative to the corresponding properties of the sample material. However, it should be obvious from the above measurements that a properly calibrated heated grid device, coupled to appropriate instrumentation, should be capable of simultaneously providing data from which sample thermophysical and thermal decomposition properties in rapid heating conditions can be extracted. The details of such a system will be provided in a future publication.

\section{Coal Devolatilization: Tar Evolution Results}

Tar Evelution Datai Zero-Hold-Time Conditions. Figure 2.136 displays the zero-hold-time tar evolution observed for 63-75 micron particles of PSOC 1451D in one atmosphere of helium and with auxiliary quench following obtainment of the peak temperature. This UTRC data agrees most closely with 
TABLE 2.22

A. Apparent Melting Temperatures of Aluminum

Effect of Varying Load Factor (Grouped by Similar Heating Rates)

\begin{tabular}{ccccc}
$\begin{array}{c}\text { Sample Mass } \\
\text { (mg) }\end{array}$ & $\begin{array}{c}\text { Load Factor } \\
\text { (mg/sq.cm.) }\end{array}$ & $\begin{array}{c}\text { Heating Rate } \\
\left({ }^{\circ} \mathrm{C} / \mathrm{sec}\right)\end{array}$ & $\begin{array}{c}\text { Melting Temp. } \\
\left({ }^{\circ} \mathrm{C}\right)\end{array}$ & $\begin{array}{c}\text { Thermocouple } \\
\text { Location }\end{array}$ \\
\hline 32.1 & 64 & 550 & 660 & center \\
31.4 & 100 & 575 & 635 & center \\
31.4 & 100 & 600 & 630 & center \\
18.1 & 30 & 875 & 663 & center \\
31.4 & 100 & 857 & 600 & center
\end{tabular}

Effect of Varying Heating Rate (Grouped by Similar Load Factors)

$\begin{array}{lllll}31.4 & 100 & 256 & 630 & \text { center } \\ 31.4 & 100 & 575 & 635 & \text { center } \\ 31.4 & 100 & 600 & 630 & \text { center } \\ 31.4 & 100 & 857 & 600 & \text { center }\end{array}$

B. Apparent Melting Temperatures of Tin

Effect of Varying Heating Rate (for two Load Factors)

Sample Mass Load Factor Heating Rate Melting Temp. Thermocouple

\begin{tabular}{ccccc}
$(\mathrm{mg})$ & $(\mathrm{mg} / \mathrm{sq} . \mathrm{cm})$. & $\left({ }^{\circ} \mathrm{C} / \mathrm{sec}\right)$ & $\left({ }^{\circ} \mathrm{C}\right)$ & Location \\
\hline 16.7 & 50 & 80 & 230 & center \\
16.7 & 50 & 200 & 232 & center \\
30.9 & 60 & 100 & 230 & center \\
30.9 & 60 & 150 & 227 & center \\
30.9 & 60 & 200 & 233 & center \\
30.9 & 60 & 250 & 233 & center \\
30.9 & 60 & 300 & 235 & center \\
30.9 & 60 & 445 & 247 & center
\end{tabular}

1. Reported melting point of aluminum $=660^{\circ} \mathrm{C}$

2. Reported melting point of tin $=232^{\circ} \mathrm{C}$

3. Thermocouples spot-welded to screen in approximate center of sample mass distribution. 


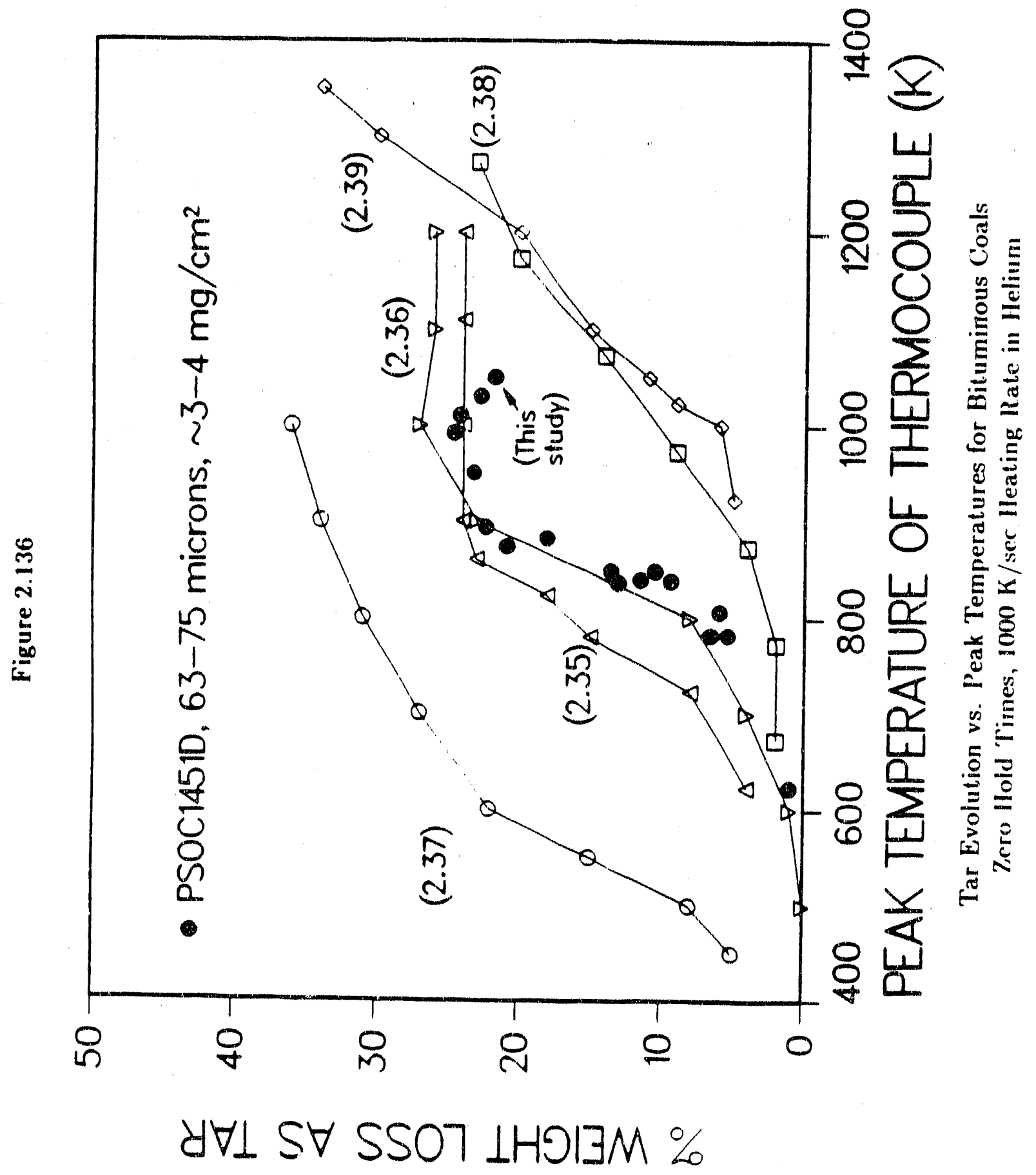


the results of Unger and Suuberg (Ref. 2.35) and Oh (Ref. 2.36). It does not agree with the results of Desypris, et. al. (Ref. 2.37), an earlier study performed by Suuberg (Ref, 2.38), or a more recent study performed by Bautista, et. al.(Ret, 2.39). Although zero-hold-time tar yields as a function of peak temperatures are not given by Gibbins (Ref. 2.40) as a function of peak temperature, the zero hold time total weight loss is reported as approximately $32 \%$, with $30 \mathrm{sec}$ hold time values only increasing to approximately $44 \%$. The tar yleld at $30 \mathrm{sec}$ in 1 atmosphere of helium is given as $32 \%$. In other words, the data of Gibbins strongly supports the Unger. Oh, UTRC results which indicate the major fraction of tar release from bituminous coals occurs between 400 and $600^{\circ} \mathrm{C}$ in these heating conditions. The tar evolution temperatures of reference 1 appear approximately 300 degrees lower, while those of references 2 and 6 appear 300 degrees higher. Since tar yields comprise the major fraction of the volatiles release from high volatile bituminous coals in these heating conditions, similar discrepancies are maintained with respect to total weight loss as a function of peak temperature. For example, the weight loss data of Niksa and Russell (Ref. 2.41) agree with the results of the earlier study performed by Suuberg (Ref. 2.38) but not those reported herein. A comprehensive analysis of the literature with respect to the temperature dependence of weight loss in heated grid apparatuses in an independent laboratory has indicated this is the case (Ref. 2.40).

Tar Evolution in Zero-Hold-Time Conditions:Sample Laad Effects. The grid heat transfer characterization tests described above with known materials revealed the "localness" of the sample load effects on the transient temperature response of the grid to a given power input. The characterization revealed the close thermal coupling among sample, grid and spot-welded thermocouples in the immediate vicinity of the thermocouple. It is the length scale of the coupling and the finite heat transfer capability of the wire mesh which introduces the uncertainty in the characterization of a distributed sample by a single thermocouple reading. Understanding of tar evolution in transient coal devolatilization is further complicated by the broad temperature ranges associated with the process itself.

The local nature of the grid-sample thermal coupling and associated load intensity effects in transient heating tar evolution experiments are demonstrated by a series of three load effect investigations using the PSOC $1451 \mathrm{D}$ coal. In the first experiment, the total mass of coal sample was yaried in two symmetric distributions on either side of a centrally-located thermocouple. A blank screen was programmed to reach a peak temperature of approximately $950^{\circ} \mathrm{C}$ and then quenched. The symmetrically loaded screen was then subjected to the same power input. Figure 2.137 displays a set of blank and screen-loaded thermocouple traces. The much higher cooling rate observed in the loaded screen thermocouple trace is due to the helium 

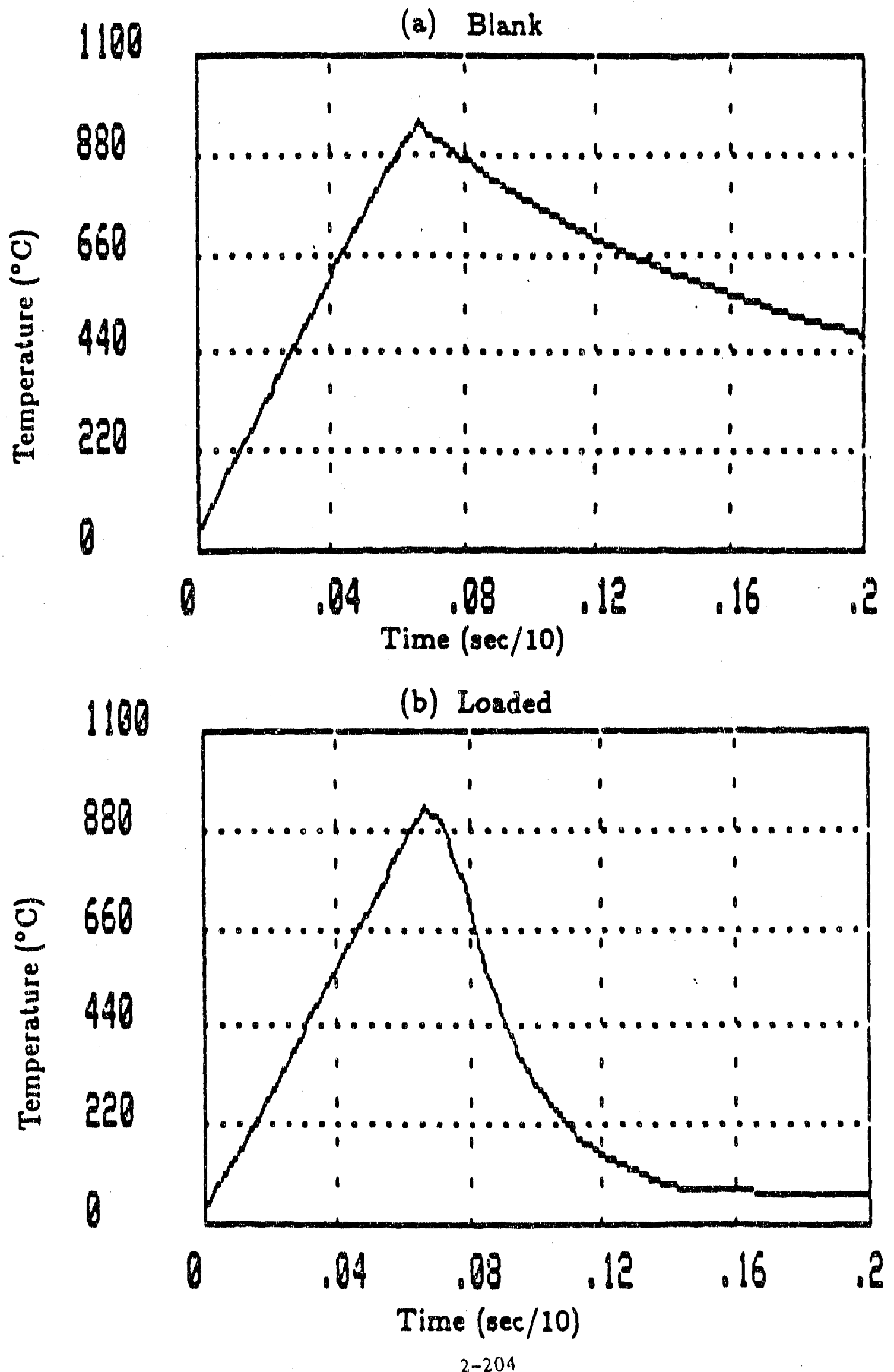

$20 \mathrm{mg}$ Coal Distritutued iñ Two $10 \mathrm{mg}$ Loads on Either Side of Thermocouple, Load factor about $5 \mathrm{mg} / \mathrm{cm}^{2}$ in Area of Load 
quench system which was not used during the blank run. Figure 2.138 shows the tar yield as a function of sample size for identical transient power inputs.

In a second series of experiments, the two thermocouple technique is employed, but the sample is loaded asymmetrically with respect to the total screen area. That is, one thermocouple is left unloaded and the other is loaded with a series of increasing sample sizes. Figure 2.139 displays the tar yield as a function of total load. Figure 2.140 shows the thermocouple traces associated with a blank screen run and a sample-loaded screen run. Comparison of corresponding thermocouples during the blank and loacled runs shows that the blank thermocouple traces (Fig. 2.140) are nearly identical, whlle the loaded thermocouple traces show a much lower local grid temperature when the coal sample is present.

In a third series of experiments, the dual thermocouple technique is utilized and the sample is loaded asymmetrically in a 2:1 mass ratio over the two thermocouples. The total mass is kept constant at $15 \mathrm{mg}$, but $10 \mathrm{mg}$ is distributed around one thermocouple and $5 \mathrm{mg}$ around the other. The same power input as in the totally asymmetric case of Figs. 2.137 and 2.140 is employed. Figure 2.141 displays the blank screen and sample loaded thermocouple traces for one of the runs.

Figure 2.142 summarizes the sample load effect investigation with respect to tar evolution by plotting the data with respect to the unloaded and loaded thermocouple traces associated with the various coal-loaded trials. In the case of the $2: 1$ asymmetric loading the tar yields are plotted with respect to a mass-averaged thermocouple reading. No loaded thermocouple traces were obtained for the symmetrically separated load cases of Figs. 2.137 and 2.138. The local nature of the grid--sample coupling is apparent in the data as is the dependence of the thermocouple reading in transient heating conditions on the local load factor. The difficulties in characterizing tar evolution by single peak thermocouple temperatures in transient heated grid, heating conditions are obvious.

The effects of load factor on zero-hold-time weight loss data is shown in Fig. 2.143 or herein the load factor is varied by a factor of three.

Tar Exglution: Varying Hold Time Data. Tar yields for $100 \mathrm{sec}$ hold times at peak temperatures achieved by $1000^{\circ} \mathrm{C} / \mathrm{sec}$ heating in helium are given in Fig. 2.144 for the PSOC $1451 \mathrm{D}$ coal in the UTRC heated grid reactor. Also shown are data for shorter hold times, and low pressure, long hold time tar yields together with the transient, zero-hold-time data for the same coal. The $100 \mathrm{sec}$ hold time results indicate ambient pressure affects the high temperature, $>600^{\circ} \mathrm{C}$, asymptotic tar yield to a greater extent than the lower temperature, but temperature sensitive tar yields. The "ultimate" low pressure tar yield appears to be 

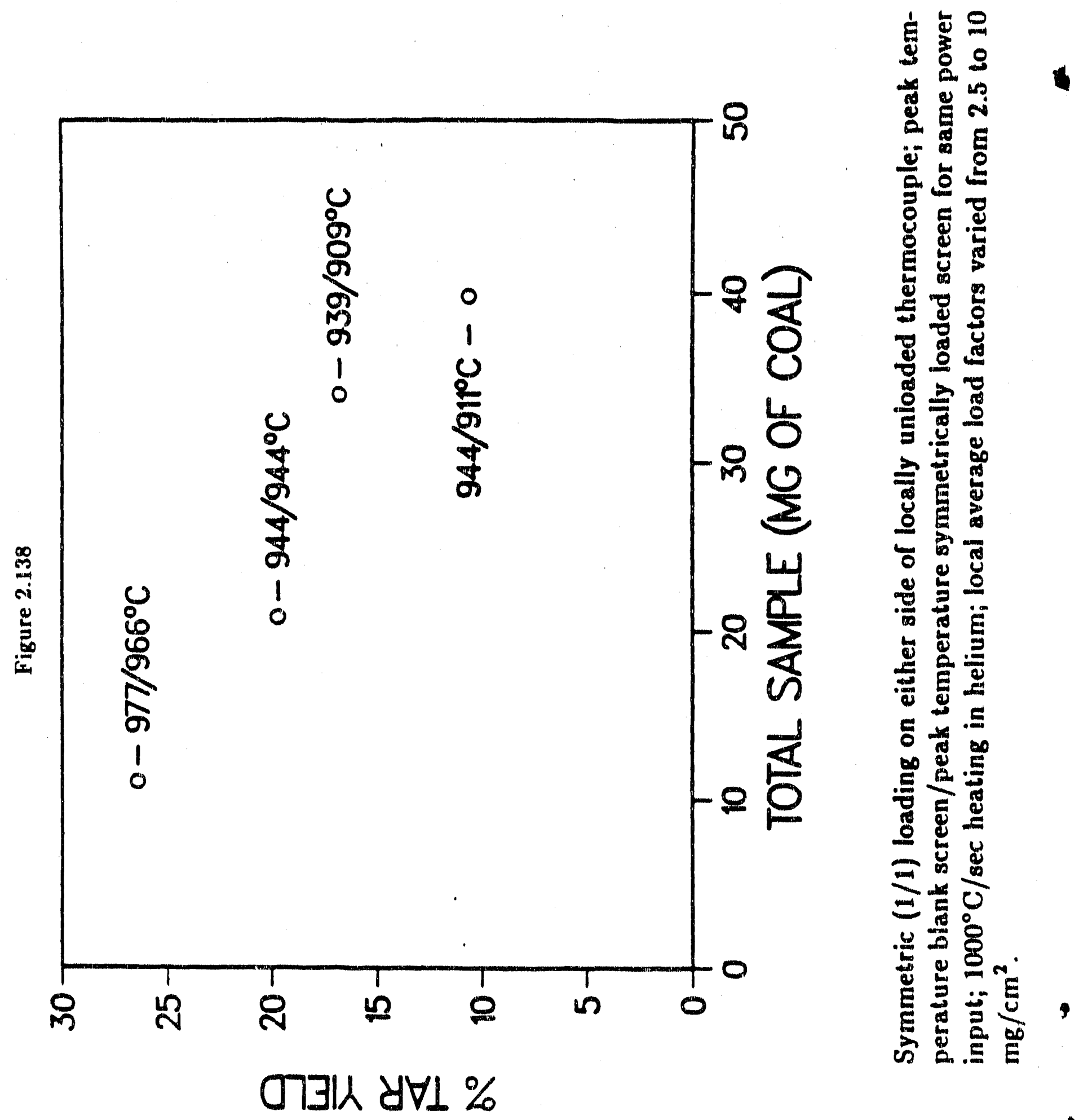

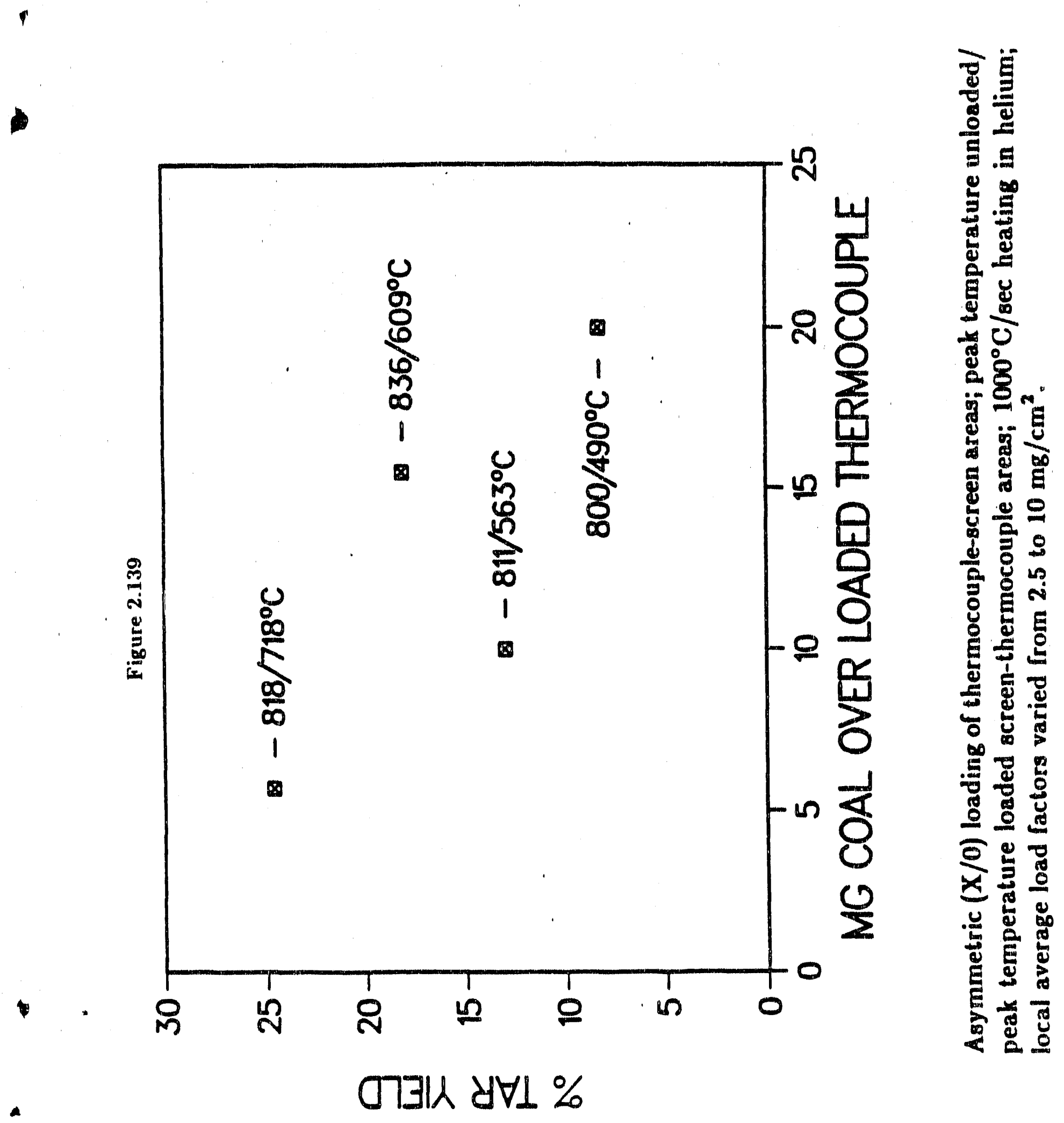


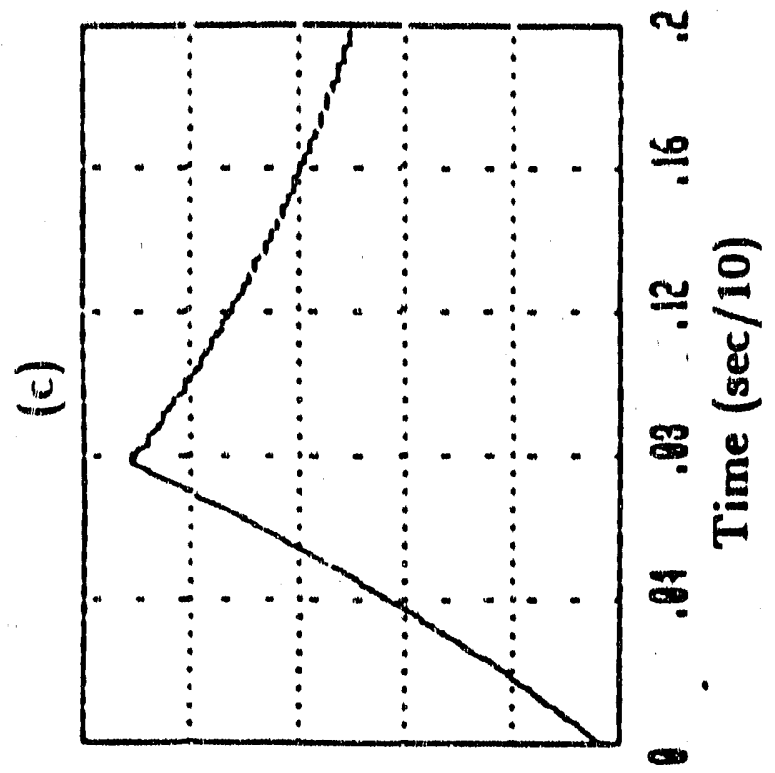

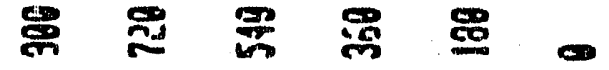
(D.) asnzesaduraj.

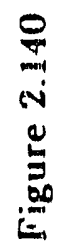

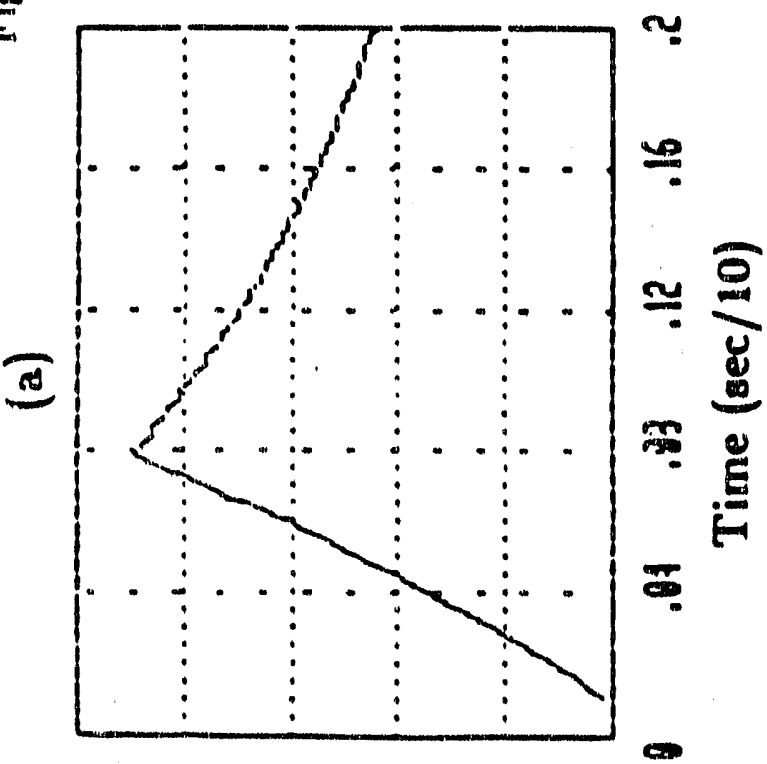

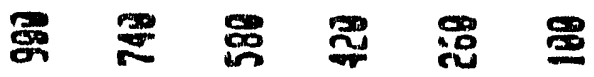
(D.) astzesaduaz

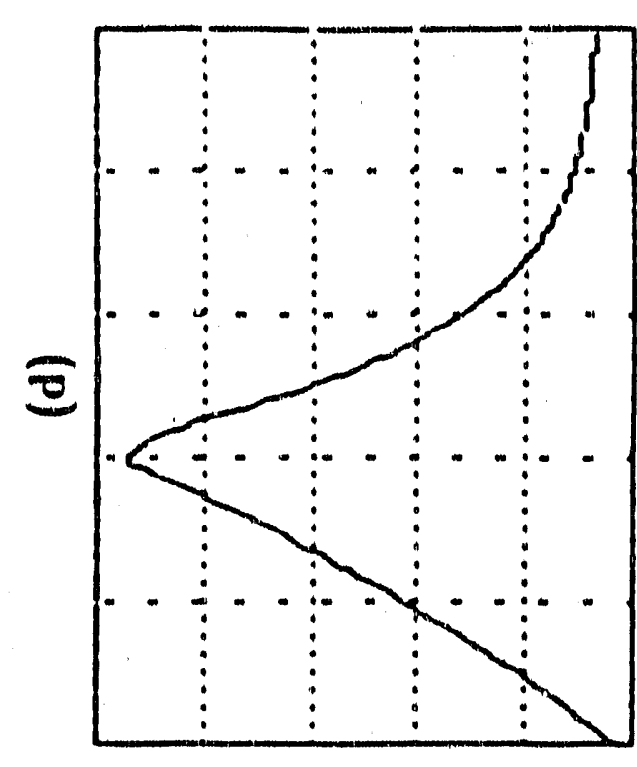

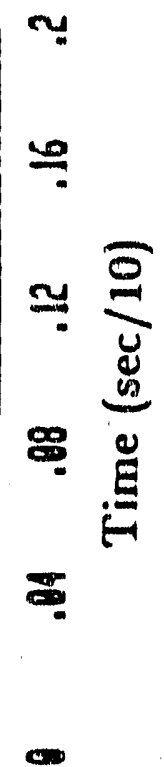

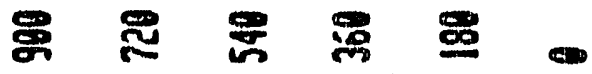

(D) asnzesoduraI

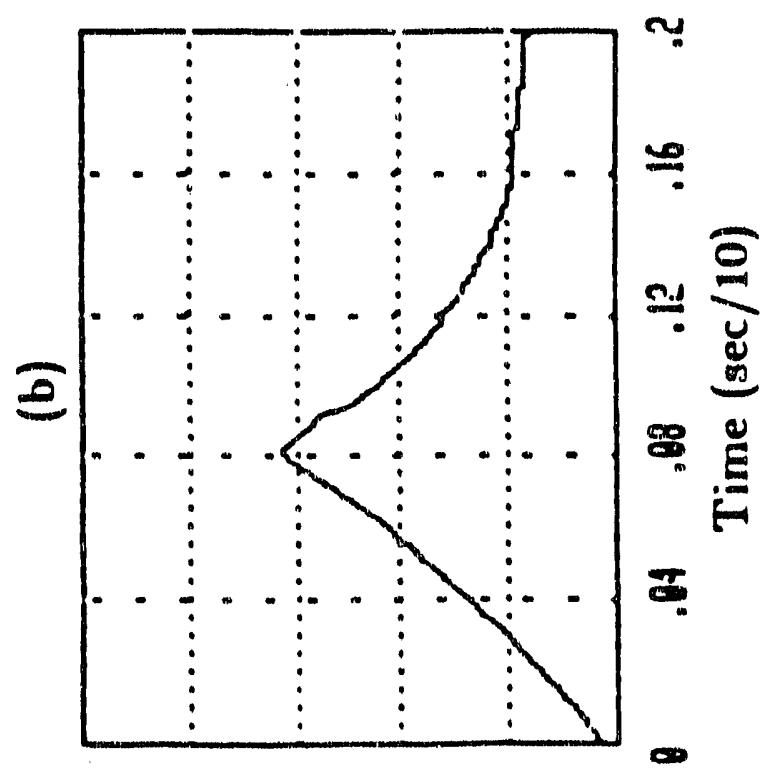

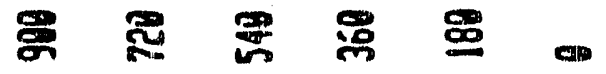

(Do) วdnzedodura

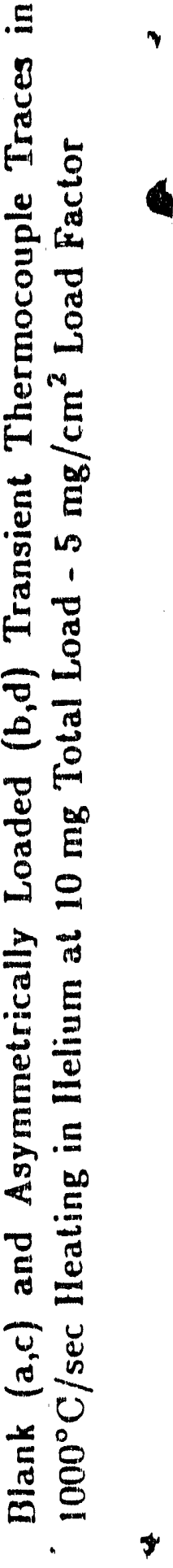

a 


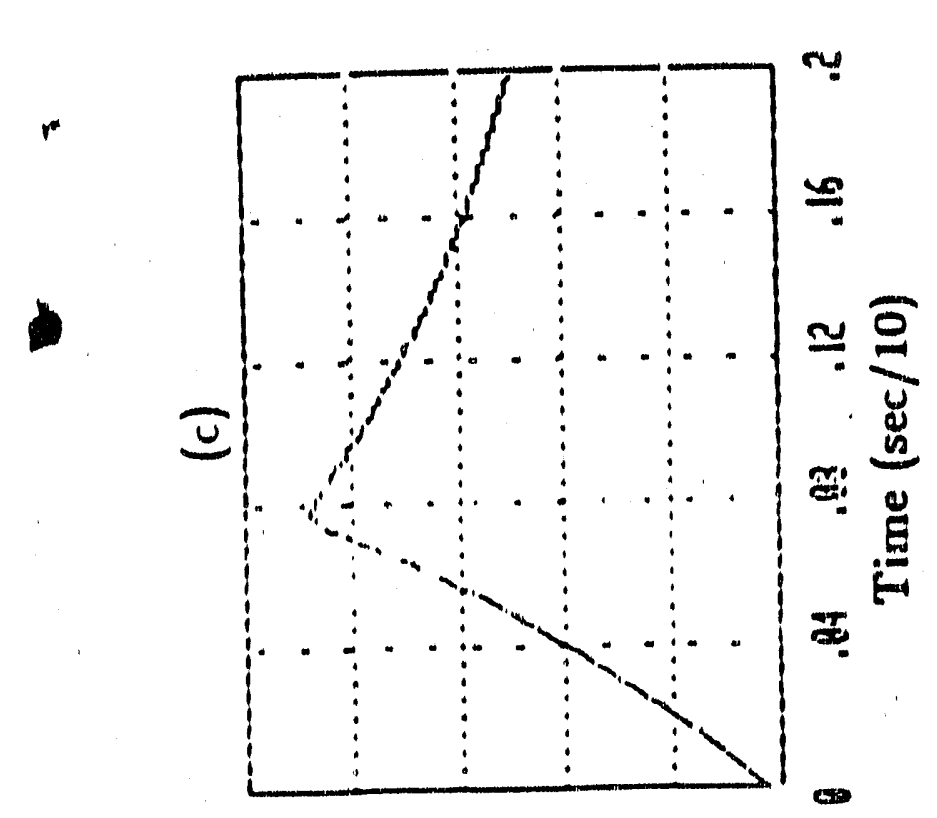

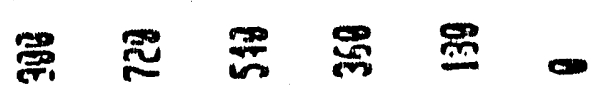

(D.) asnjesaduraj

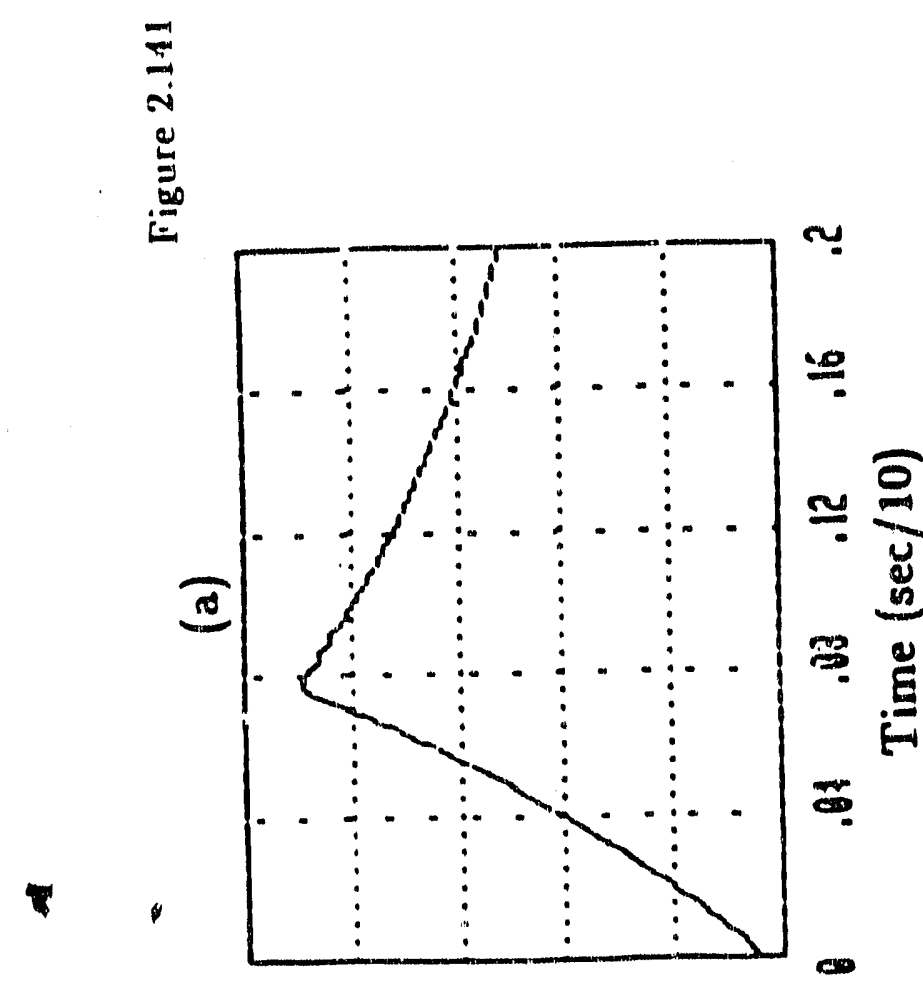

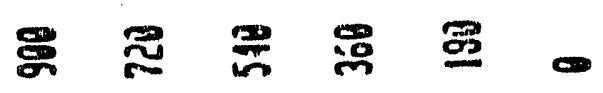

(D.) asnjesaduas

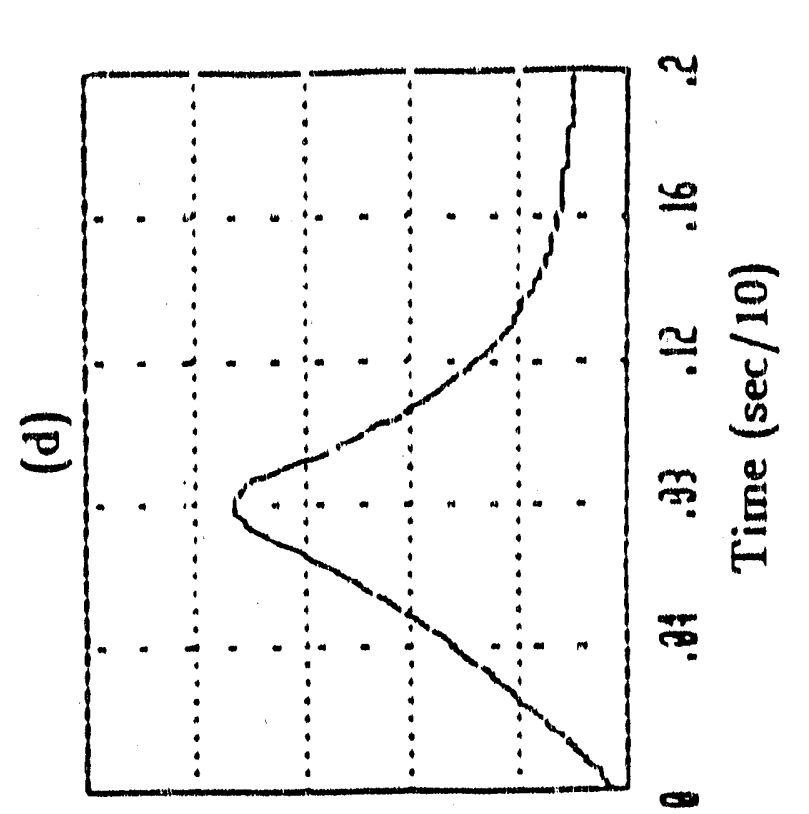

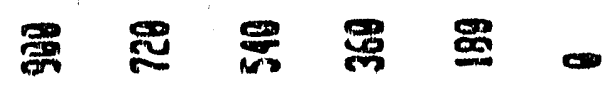

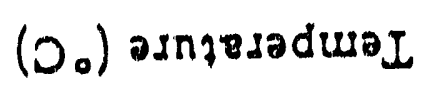

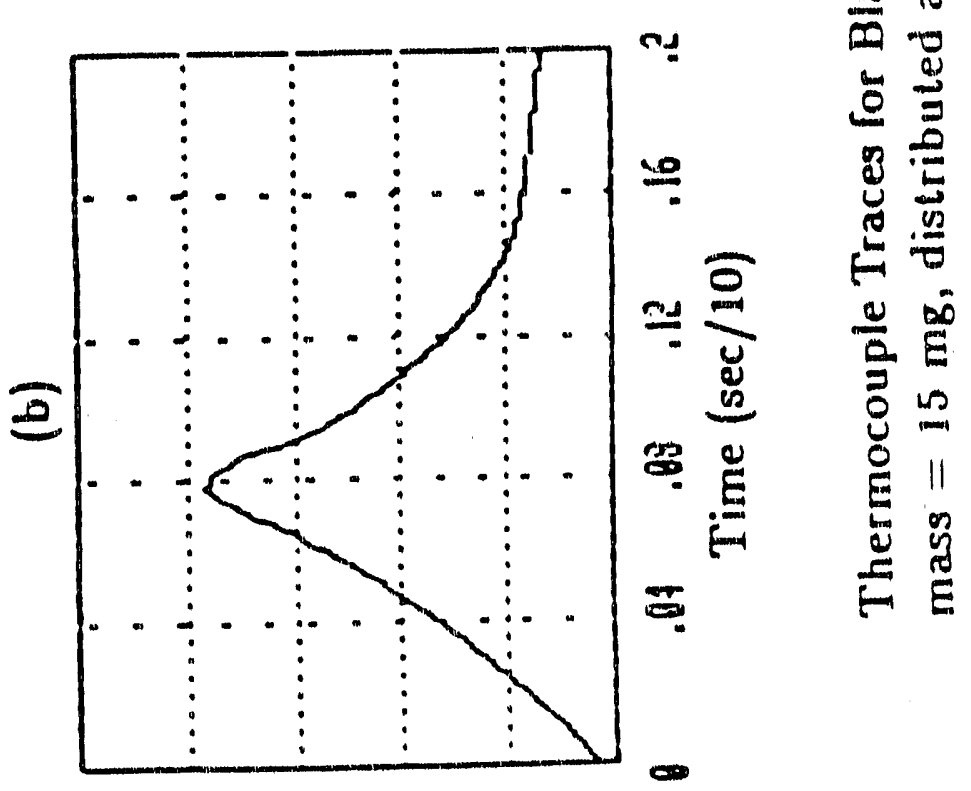

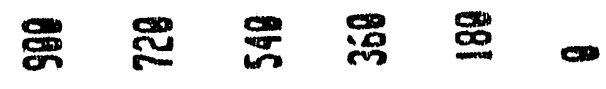

(०.) asnzraadua 


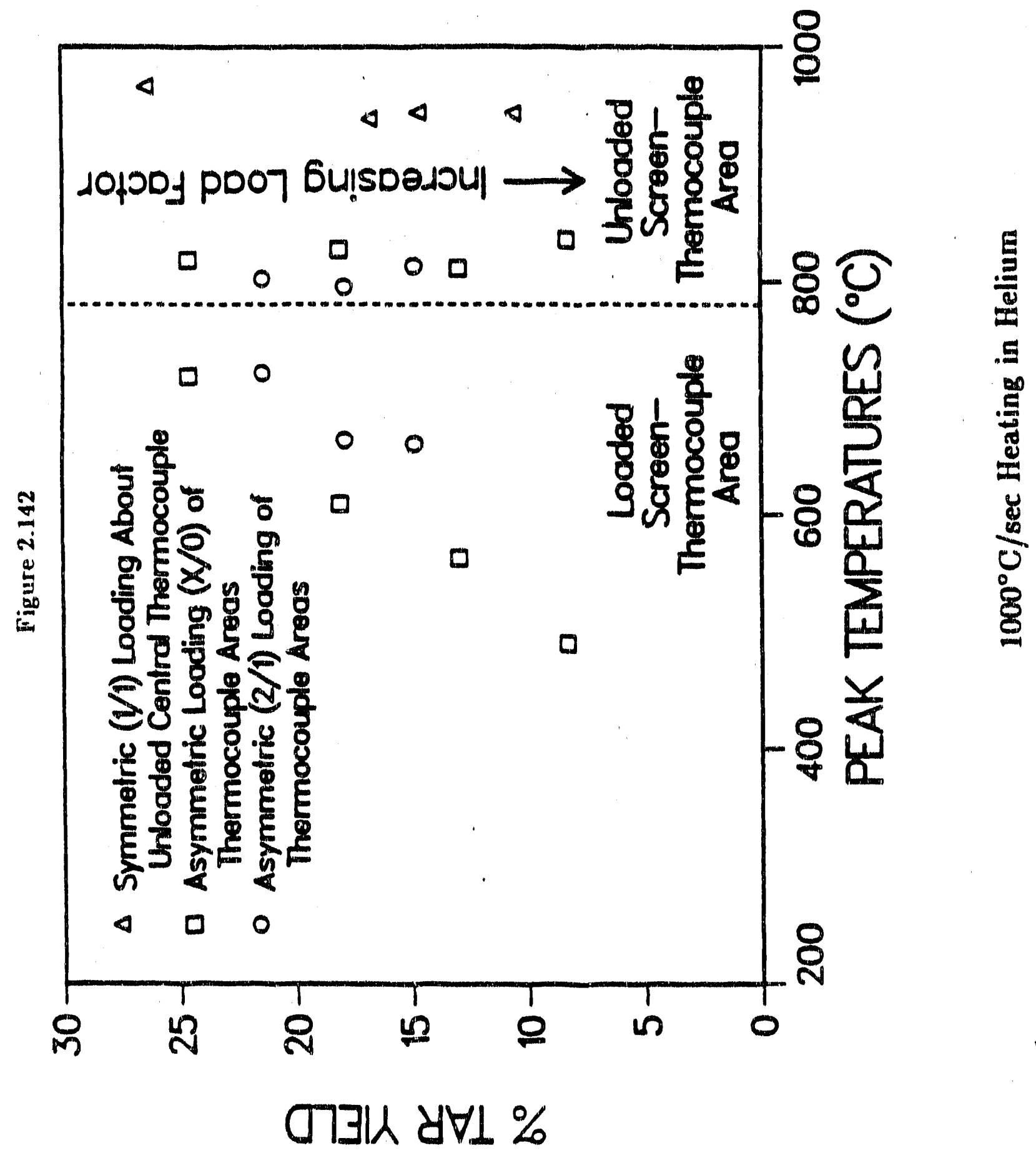


R88-PC70768

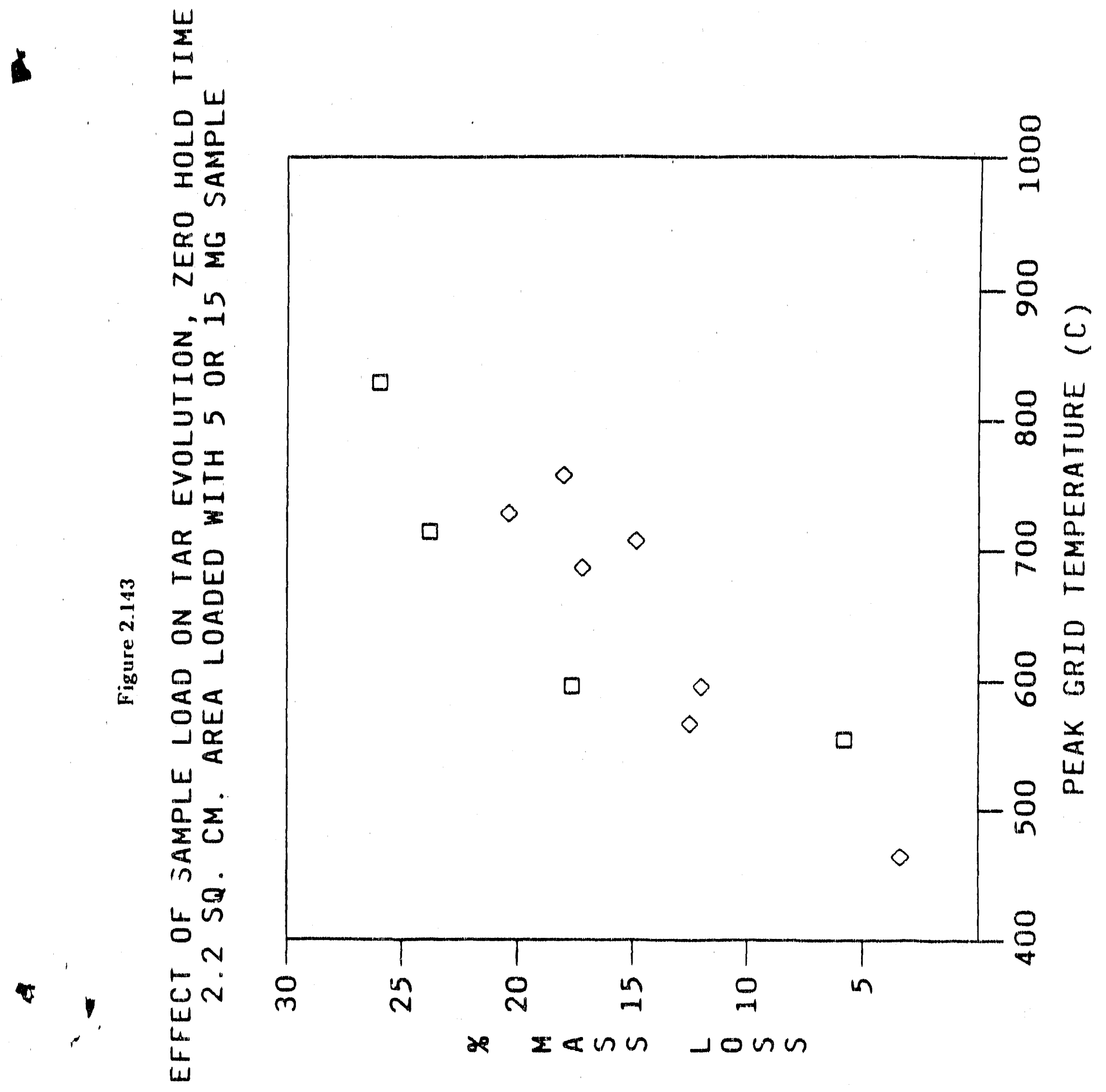




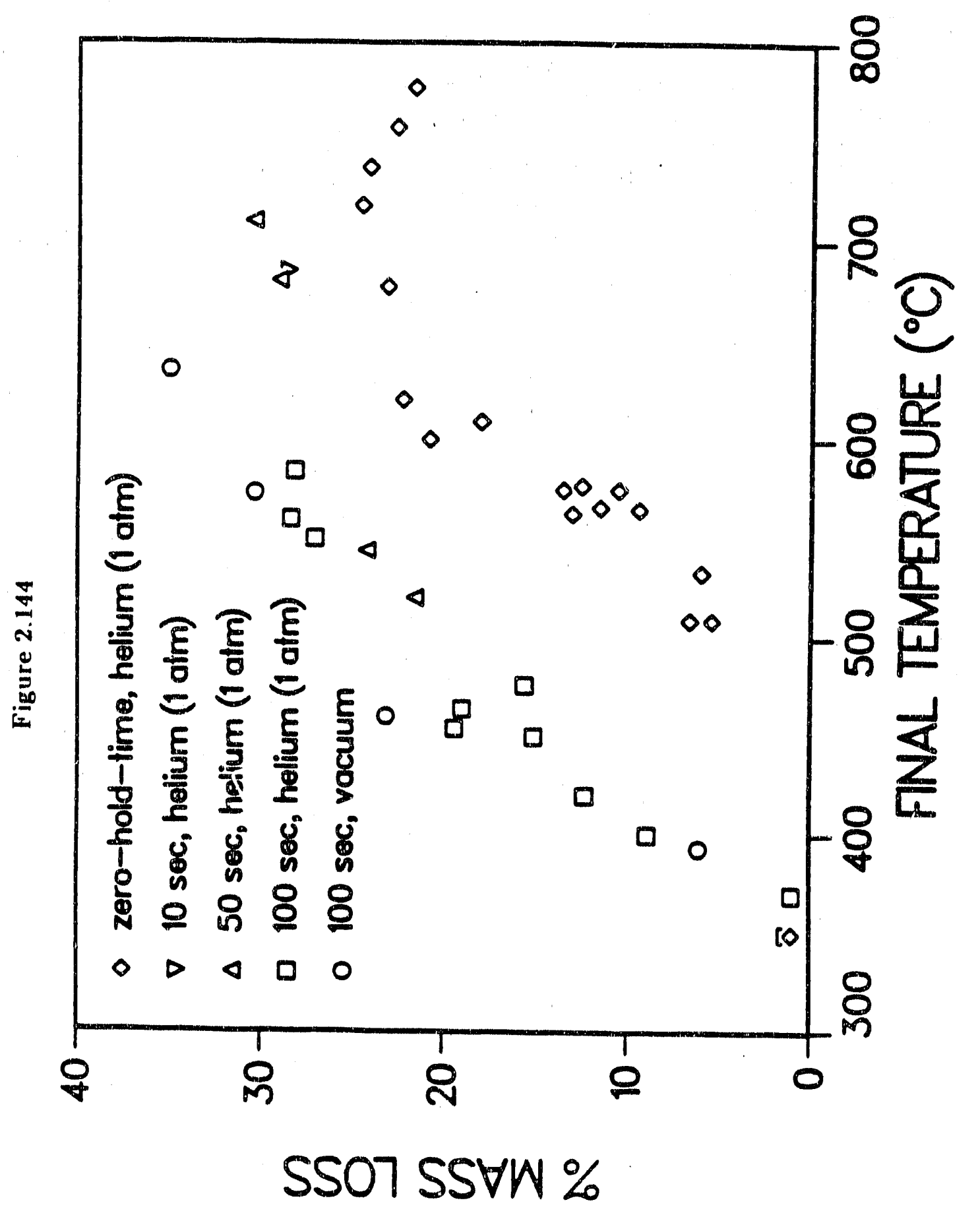

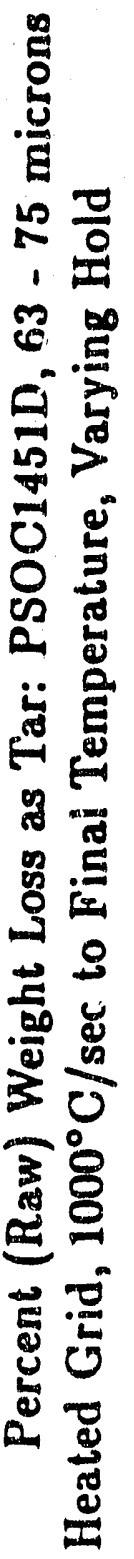


about $35 \%$ of the parent coal mass compared to $30 \%$ for one atmosphere of hellum. At hold teraperatures below $450^{\circ} \mathrm{C}$ it is difficult to distinguish between "vacuum" and atmospheric pressure tar yields. In other words, the higher temperature, heavier molecular weight tar yields appear to be influenced more by ambient pressure conditions than the low temperature, lighter tar species. Distinctions in vacuum and pressure produced tar yields become more pronounced at asymptotic particle temperatures of $500^{\circ} \mathrm{C}$ or above. There is an interphase mass transfer resistance to the evolution of high temperature, heavy molecular weight tars.

With respect to thermocouple hold time for a given thermocouple temperature, there appear to be some differences in tar yields observed for $50 \mathrm{sec}$ hold times versus $100 \mathrm{sec}$ hold times, with the longer hold times producing slightly greater yields. Whether the reduction in tar yield with decrease in hold times long relative to the zero-hold-time conditions is due to intraparticle chemical kinetic formation rates, interphase mass transfei resistance, or some combination of factors is not immediately apparent.

Intermediate temperature, $300^{\circ} \mathrm{C}$ :0 $600^{\circ} \mathrm{C}$, tar yields are obviously most sensitive to transient heating conditions. Zero hold time tar yields are a small fraction of the yields observed for 50 and $100 \mathrm{sec}$ hold times at thermocouple temperatures in this temperature span. At $500^{\circ} \mathrm{C}$ peak thermocouple temperature the zero hold time tar yield is only about 0.2 that of the corresponding long hold time yield. Differences between yields decrease with peak thermocouple temperature, the zero-hold-time yield at $600^{\circ} \mathrm{C}$ being about 0.8 that of the corresponding long hold time yield. As noted above, high temperature, zero-hold-time yields can not be made to match the long hold time yields by simply an increase in peak thermocouple temperature. Yields converge to within $20 \%$ of each other at $600^{\circ} \mathrm{C}$. For peak temperatures greater than $700^{\circ} \mathrm{C}$, it appears there may be a decrease in tar yield in these heating rate conditions. Such a decrease would be associated with high temperature pyrolysis of heavy tars which are prevented from particle desorption by mass transfex resistances.

The differences in thermocouple temperature sensitivity of tar evolution for zero versus long hold times for thermocouple temperatures less than $600^{\circ} \mathrm{C}$ is attributed in part to the same factors causing the apparent differences in temperature sensitivity among different laboratories. If average peak sampli: temperatures during the zero-hold-time experiments were 75 to 100 degrees lower than the peak thermocouple, wire inesh, temperatures, the zero-hold-time tar evolution yields would be everywhere nearly within $25 \%$ of the long hold time yields. But this is not likely the case in dispersely loaded systems. The expla aation likely lies in the different reaction networks emphasized by the different heating conditions. 


\section{Discussion of Results - Temperature Discrepancies}

The above illustrates the difficulty in assigning transient thermocouple temperatures to transiently heating coal particles during the tar evolution phase of devolatilization and the probable nature of discrepancy in reported results for similar coal types. The above results imply that empirical tar evolution rates cannot be deconvoluted without consideration of the details of the intensive and extensive heat transfer parameters of a devolatilization system. Stated more positively, a large fraction, $20-25 \%$, of the initial particle mass loss, mainly tar, is highly coupled to the grid reactor heat transfer parameters during the transient particle temperature rise from 300 to $600^{\circ} \mathrm{C}$. Substantial differences in zero-hold-time versus long hold time data within a particular apparatus appear due to differences in thermocouple versus actual particle temperature as a result of the manner in which the sample locally "loads" the wire mesh relative to the thertr.ocouple. Nevertheless, in this investigation incomplete tar yields are obtained by transiently heating to temperatures less than $600^{\circ} \mathrm{C}$. irrespective of hold times. For each intermediate temperature a major fraction of the tar yield associated with that temperature is evolved during the transient, but a significant fraction requires long hold times at the temperature, implying the strong influence of chemical kinetic and/or mass ti:nsfer phenomena in the total tar eyolution process.

Given the similarity in coal types and heating mechanism the substantial differences in reported tar evolution temperatures for zero-hold-time expariments observed in different heated grid investigations are undoubtedly more reflective of differences in local load factors and thermocouple-to-sample location than transient particle temperatures during tar evolution. Global load factors - average sample mass per unit projected area of utilized screen surface - varied significantly with investigation. For example, Oh (Ref. 2.36) used sample sizes a factor of 3 or 4 that of Suuberg (Ref. 2.38) but a screen heater with a projected. utilized surface area nearly 8 times that of Suuberg. Oh postulates (Ref. 2.36, p. 141) that the differences in global load factor probably contribute to the differences in zero-hold-time volatile yields observed in the different apparatuses.

Table 2.23 shows the iange of global mass load factors utilized by various investigators. Obviously, all the differences in transient tar evolution data can not be explained on the basis of global load factors. However, as noted in the experimental data reported above, it is the local load factor distribution relative to the thermocuple location that undoubtedly affects transient tar evolution temperatures determined by single thermocouple techniques. In transient coal devolatilization experiments, the particles load the grid in nonuniform packets, resulting in nonuniform, local load factors across the grid within a given run. In addition, high heating rate experiments cause mechanical displacement of the grid surface, changing the 
local load factors during a run. Plasticizing coals significantly change particle size and shape within the grid as they change mass, rurther complicating the local load pattern for a given sample. Thus it is not surprising that significant temperature differences are noted in the zero-hold-time data of the various investigators. It is also not surprising that there is significantly less divergence in the long hold time tar evolution data, that is, in experiments wherein thermal equilibrium is established across the screen and, therefore, between the sample, grid material and thermocouple.

\section{TABLE 2.23 - GLOBAL LOAD FACTORS}

\begin{tabular}{lclc} 
Reference & $\begin{array}{c}\text { Sample } \\
\text { Mass } \\
(\mathrm{mg})\end{array}$ & $\begin{array}{l}\text { Loaded } \\
\text { Area } \\
\left(\mathrm{cm}^{2}\right)\end{array}$ & $\begin{array}{c}\text { Global } \\
\text { Loading Factor } \\
\left(\mathrm{mg} / \mathrm{cm}^{2}\right)\end{array}$ \\
\hline Desypris et al. & $2-4$ & 5.00 & $0.4-0.8$ \\
Suuberg et al. & 10 & 5.0 & 2.0 \\
Unger \& Suuberg & 10 & 5.0 & 2.0 \\
Oh & $30-40$ & 40.0 & $0.75-1.0$ \\
Bautista et al. & 15 & 6.00 & 2.5 \\
This Study & 10 & 2.2 & 4.5 \\
Solomon \& Colket & 200 & $2.0-4.0$ & $50-100$ \\
Gibbins & $5-10$ & 1.13 & $4.4-8.8$ \\
\hline
\end{tabular}

Furthermore, there are significant differences in the manner in which temperature itself is measured. Some investigators spot weld (Ref. 2.42) electronically isolated thernocouples (this laboratory) to the grid surface itself. Others (Refs. $2.15,2.41$ ) attach the thermocouple to a wire welded to the mesh surface at a specified distance. Some investigators place the thermocouple "with" the sample between the folds of the grid (Refs. $2.35,2.37,2.38$ ), In other investigations (Refs. 2.43, 2.44) the details of the thermocouple location and attachment within or to the grid are not clearly given. Relating the transient responses of the thermocouple to the transient response of the particle for these various thermocouple-heating surface relationships is not straightforward, considering the importance of local sample load factors.

More generally, this investigation implies tar evolution in transient heating conditions can not be interpreted apart from a detailed consideration of the particular heat transfer characteristics of the reactor used in the investigation, coupled to the coal load density configurations. This is particularly true if transient temperature measurements are employed, as they must be, in estimating overall devolatilization kinetic parameters. Tar devolatilization rates in heated grid apparatuses undoubtedly reflect the limited heat transfer characteristics of the grid material coupled to specific load factors and thermocouple techniques employed to estimate the transient coal particle temperatures. 
In view of the microscale coupling among grid, sample and thermocouple in determining apparent temperatures of transient tar evolution, comparisons of kinetic parameters for tar evolution via an Arrhenius plot alone is less than informative. Such plots give derived or measured tar evolution rates in terms of associated thermocouple or estimated single particle temperature responses in transient heating conditions. In some early "comprehensive" kinetic studies (Ref. $2.43,2.44$ ), there appears to be an unawareness of the transient nature of tar evolution and either the limited heat capacity or heat transfer capability of the wire mesh itself. These investigations provided needed information into relative product distributions and elemental composition of devolatilization products, but can not be interpreted on a kinetic basis. Hypotheses on the "invariance" of the chemical kinetics of coal devolatilization with coal type can not be based on those experimental results in which the limited heating capability of the grid coupled to the relatively massive sample size dominates the observable kinetic behavior. Coal devolatilization chemical kinetics may indeed be invariant, within a given tolerance, with coal type, but those specific experiments do not provide the necessary evidence for invariant chemical control of tar evolution. If the tar evolution within a particular apparatus type is significandly sensitive to microscale heat transfer processes, then consideration of such phenomena should accompany comparisons of transient tar evolution data among reactor types.

Tar Yields vs. Coal Rank Characteristics

Figure 2.145 displays 10 second hold time data $(1000 \mathrm{c} / \mathrm{sec}$ to hold temperature) for nine of the PSOCXXXXD coals obtained. The effect of coal rank characteristics in tar yields are obvious. 


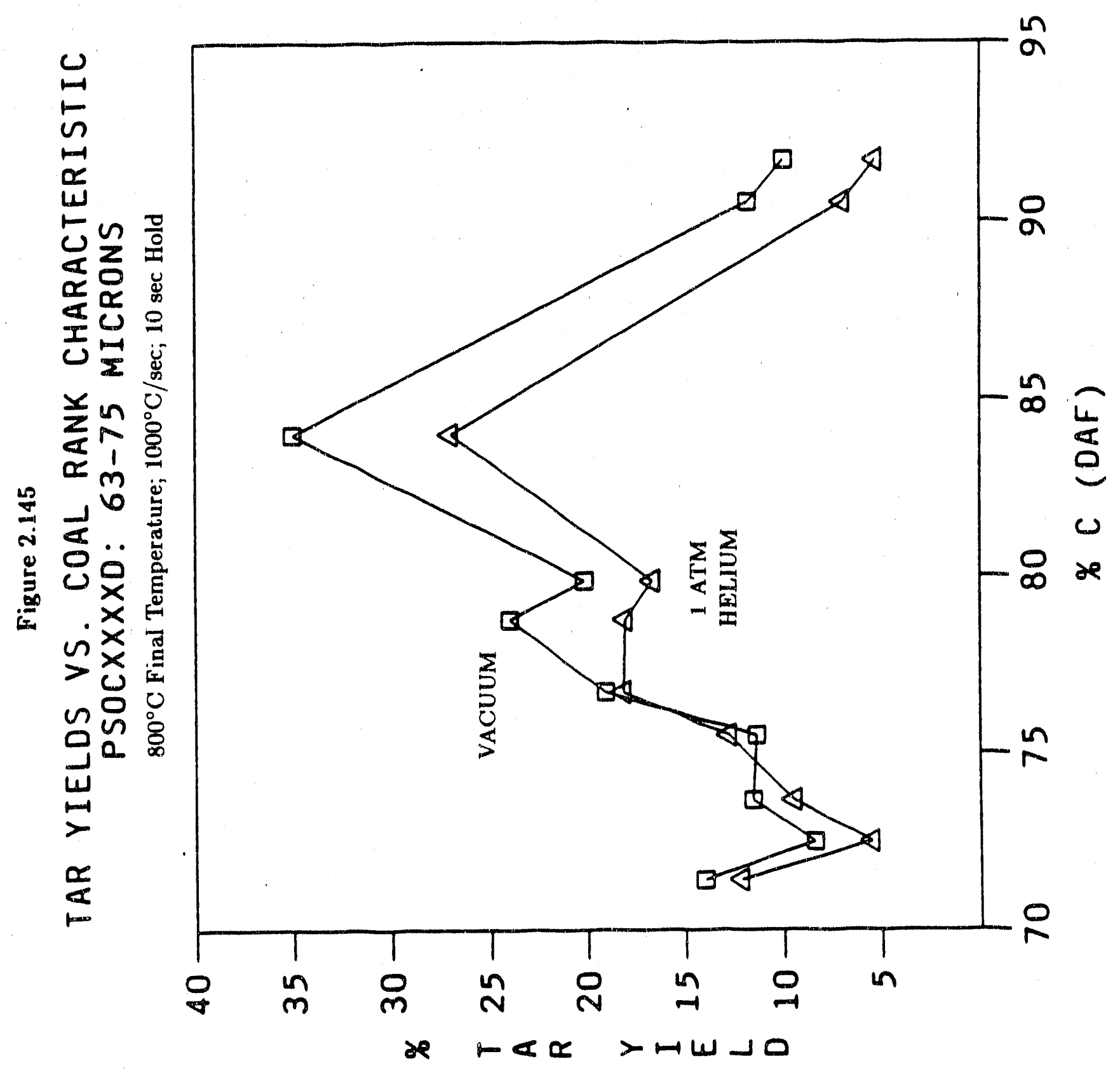




\subsection{United Technologies Research Center Flash Lamp Reactor (UTRC-FL): Devolatilization in Reactor-to-Particle Heat Flux Rates of +100 Watts/sq.cm.}

As noted in Section 2.2. pfe combustion systems can produse heat flux rates at particle surfaces in excess of 100 watts/sq.cm. High temperature $\left(T_{\text {reactor }}>1000^{\circ} \mathrm{C}\right)$ entrained flow reactor systems are capable of producing flux rates comparable to those of a pfc, but resolution of the devolatilization process either with respect to the evolution of particle mass loss in time or secondary reactions upon primary tars becomes infeasible. With respect to mass loss, the tar evolution process in such heating rate conditions occurs on a time scale comparable to the resolution in particle residence time at temperature (See Sections 2.2.1 and 2.2.2). At gas temperatures in excess of $800^{\circ} \mathrm{C}$, homogeneous secondary reactions of primary tars occur in the millisecond time interval, again beyond the residence time resolution of probe systems which must deal with solids, condensible vapors and gases.

One approach to producing high flux rates at particle surfaces, while maintaining a thermally quenching environment, has been the use of radiative pulses, broadband or single wavelength (laser) systems (Ref. 2.45-2.52). Radiation transparent gases are employed so that only the gas immediately adjacent to the particle surface, that is, the boundary layer gas, heats above ambient temperature. The "black" coal particle, on the other hand, efficiently absorbs the radiant energy and heats to devolatilization temperatures in millisecond time spans. The tars desorbed in such rapid heating experiments are immediately quenched by the cool ambient gas or reactor walls. The duration of the particle heating period is controlled by the duration of the broadband or laser pulse. To determine the transient response of pfc sized particles to such rapid heating conditions, while maintaining some ability to deconvolute particle devolatilization products, a Xenon flash lamp reactor system was established and interfaced to the FT-IR system.

A schematic of the flash lamp reactor is illustrated in Figs. 2.146 and 2.147. The time resolved pulse shape of the flash pulse is shown in Fig. 2.148. Under the range of capacitor voltage levels used in this investigation and with the particular match of lamp characteristics and driving circuit parameters, the shape of the pulse did not vary significantly. The magnitude of the irradiance level delivered to the inside of the reactor was controlled by varying the neutral density filter and/or the capacitor bank voltage levels. The real tirne irradiance levels of the flash pulse were monitored by fast response pyroelectric detectors. The detectors employed were calibrated with NBS irradiance standard lamps and a NBS traceable radiometer system used in conjunction with a chopped Argon ion laser. Pyroelectric detectors have a nearly constant. 
R88-PC70768

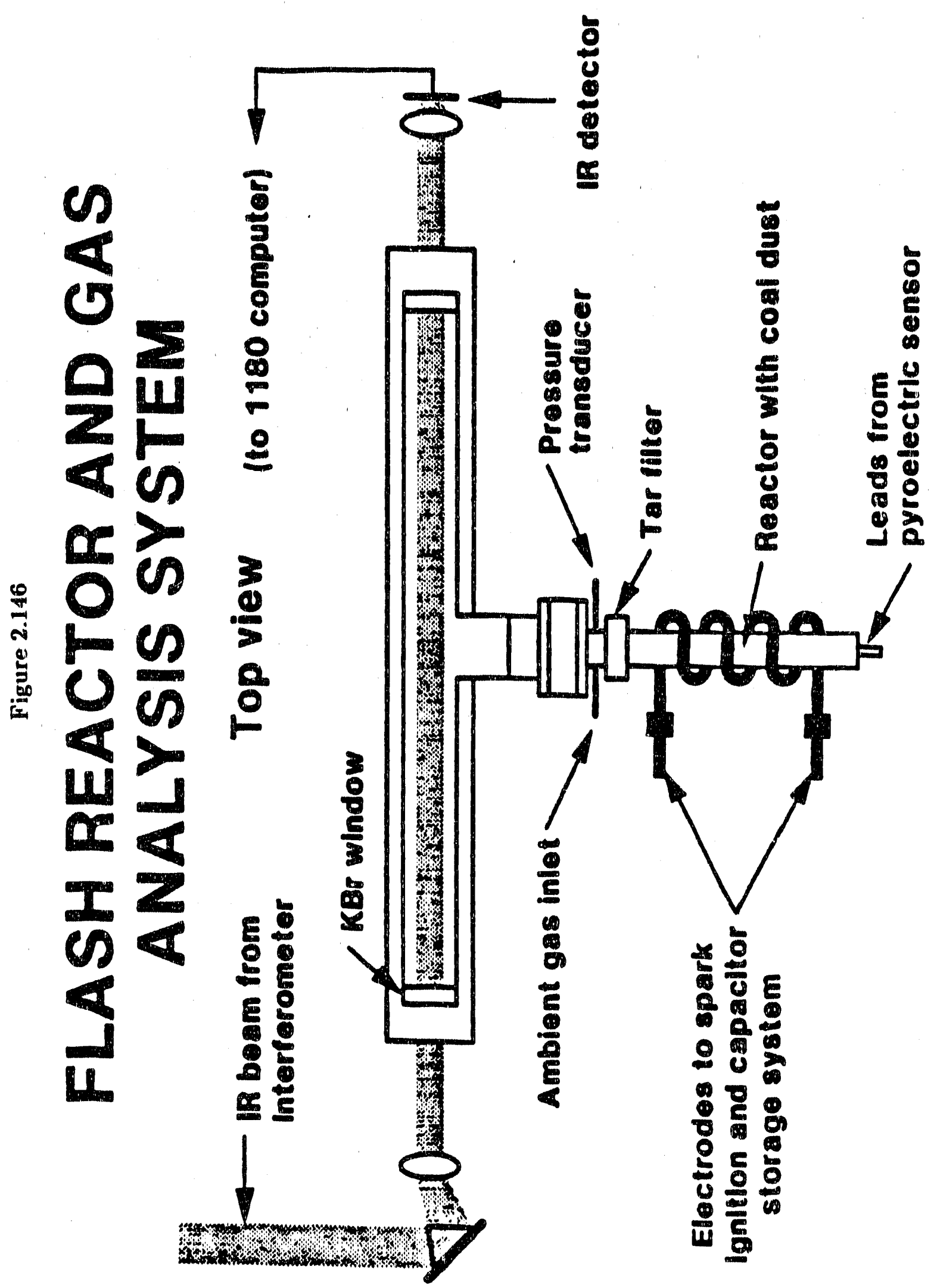



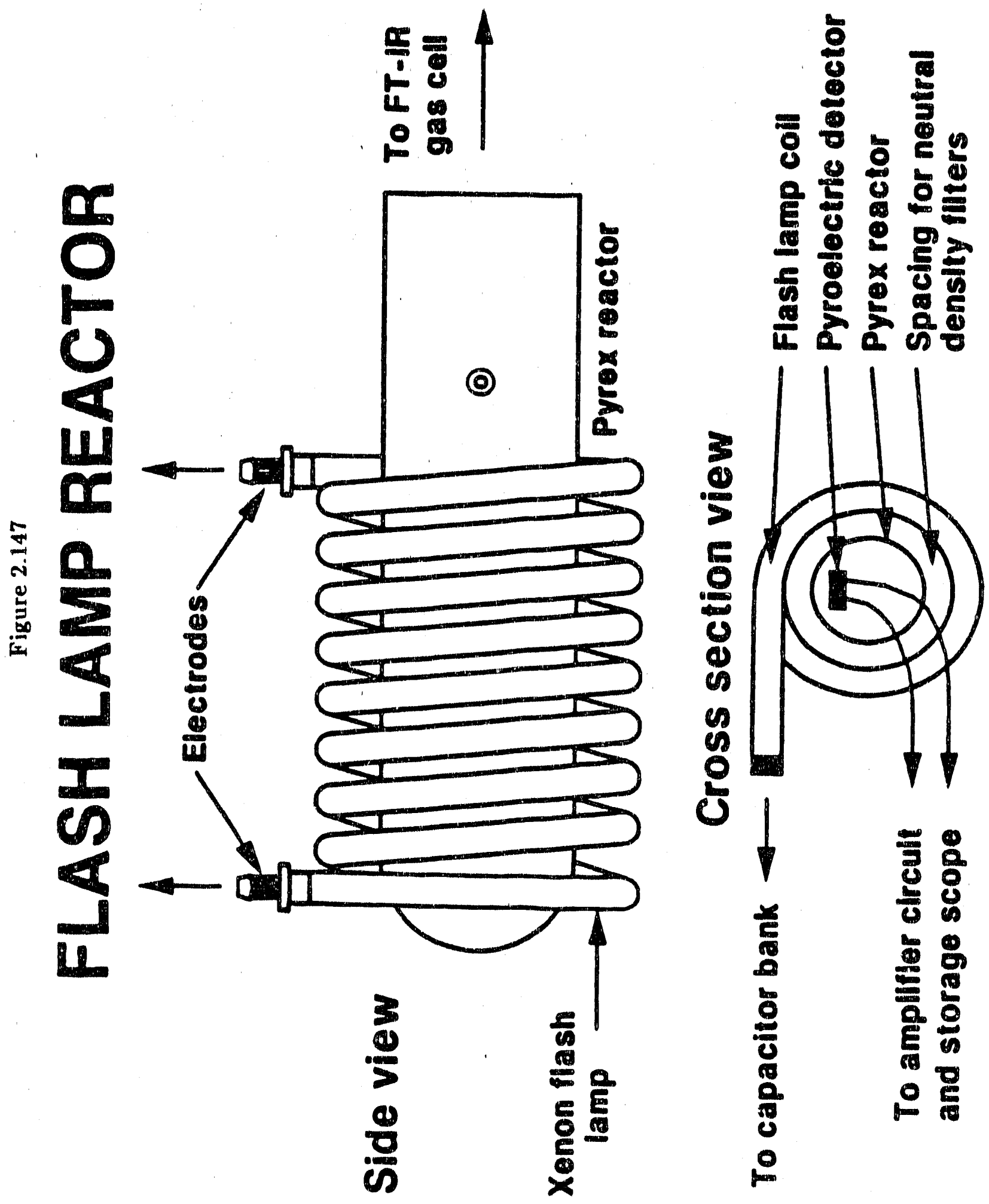
R88-PC70768

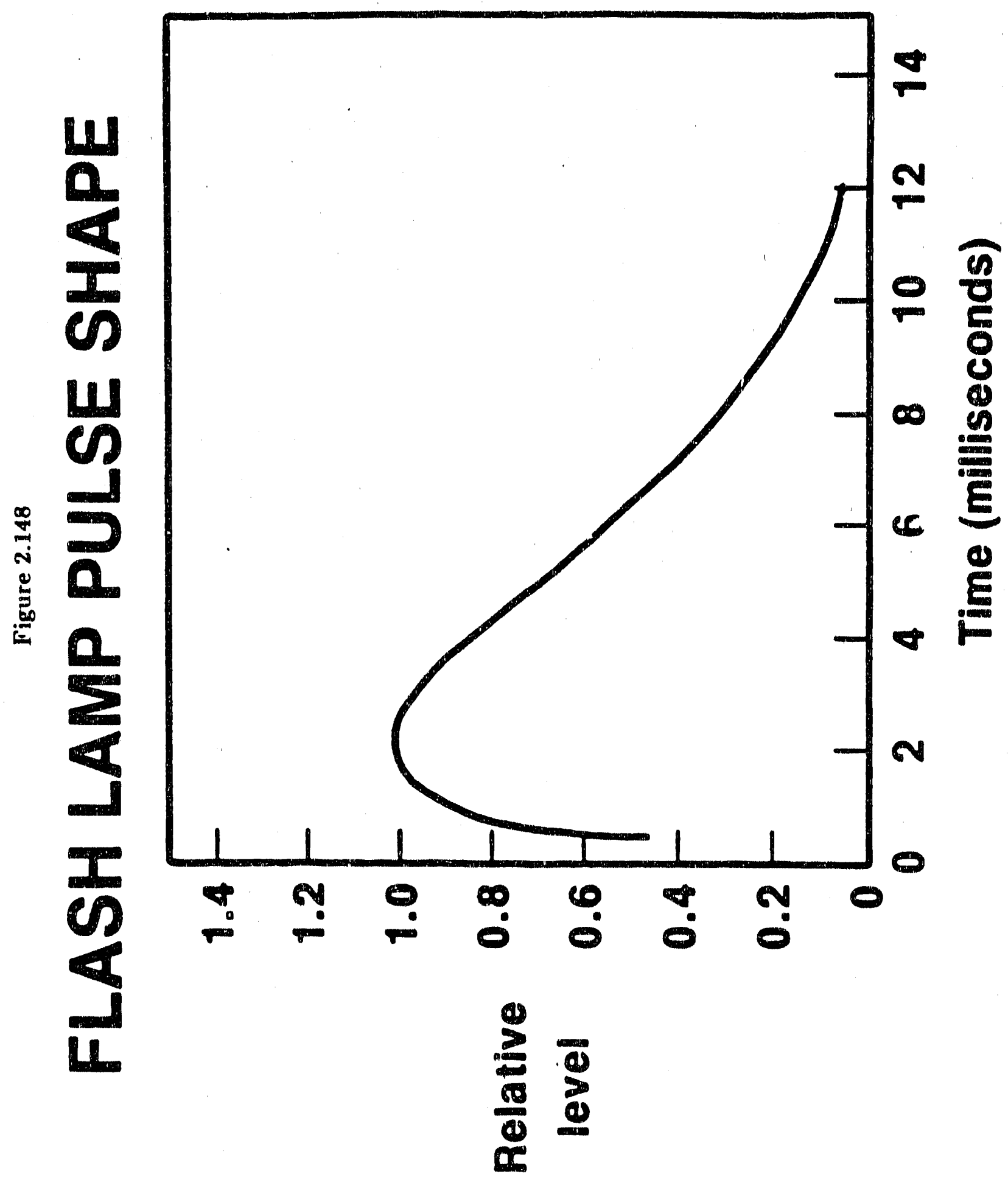


responsivity with respect to wavelength from the L'V to IR spectral regimes. Because of the possiblity of' inducing photochemical reactlons with the L'V component of the flash pulse, the reactors employed tere Fytex, as were the neutral density fllters. The delivered radiation is characterized by wavelengthe rangirg from $0 .+102.0$ microns with peak intensities hetween 0.5 and 1.1 microns. The spectral output of the liash lamp as utilized was measured using a spectroradiometer system (See Fig. 2 1+9) The relative ipesiral output dld not change appreciably within the capacitor voltage range used in this investization Characteristics of the transient pulses are indicated in Tables 2.24 and 2.25

Also shown in Tables 2.24 and 2.25 are calculated peak paricle temperatures and heating rates as a function of farticle size, ambient conditions and delivered irradiance. Figures 2.150 through $2.15+$ display :0 $\mu \mathrm{m}$ temperature profiles: Figures 2.155 through 2.157 show paricle size effects. The particle temperature trajectorles are calculated in the manner described in detail in Section 3.0. using the paricie properties given therein. Tables 2.26 through 2.29 contain data on measured product distributions at the conditions described.

Figure 2.153 displays the $\sigma_{c} \mathrm{c}$ tar yields with respect to the dry sample $(-5.5 \% \mathrm{c}$ ash as a func:ion of feak delivered irradiance (watts $\mathrm{cm}^{2}$ ) and ambient gas conditions for $-2 " 5+325$ mesh paracies. Ambient pressure is observed to have a significant influence on the magnitude of the tar sields in rapid transient heating conditions. In addition, tar yields in vacuum or argon heating conditions are maximized at lower delivered flux levels than radiant heating in the presence of helium. Tar sields in low pressure or argon conditions are maximized at approximately $35 \sigma_{0}\left(3^{\mathrm{mc}} \mathrm{c}\right.$ daf) of the parent coal at a peak irradiance eicl of -10.66 that required for helium. The peak tar yield observed in 1 atmosphere of argor or helium is approximately $20 \%(21 \%$ daf). Increasing the delivered power density beyond that required for maximum tar yield appreciably decreases the low pressure and argon tar yields, but has only a second order effect on the ambient pressure helium tar jields

Char yields slightly decrease at increased flux levels in low pressure or helium conditions whereas the: appear to increase at the highest flux levels in the presence of argon (Fig. 2.159). The increase (argon) or asymptote (vacuum, helium) in "char" yields with irradiance level is ambiguous since soot particulates are measured as char in the THF separation of tar and char. TEMI micrographs of high irradiance products reveal the presence of soot platelet structures in the THF separated species.

As observed in section 2.3 .1 , high temperature $\left(>700^{\circ} \mathrm{C}\right)$ pyrolysis reactions of tars resule in the formation of $\mathrm{C}_{2} \mathrm{H}_{2}, \mathrm{CO}$, and $\mathrm{HCN}$ gases. The decrease in tar sields with flux level and the increase in soot 


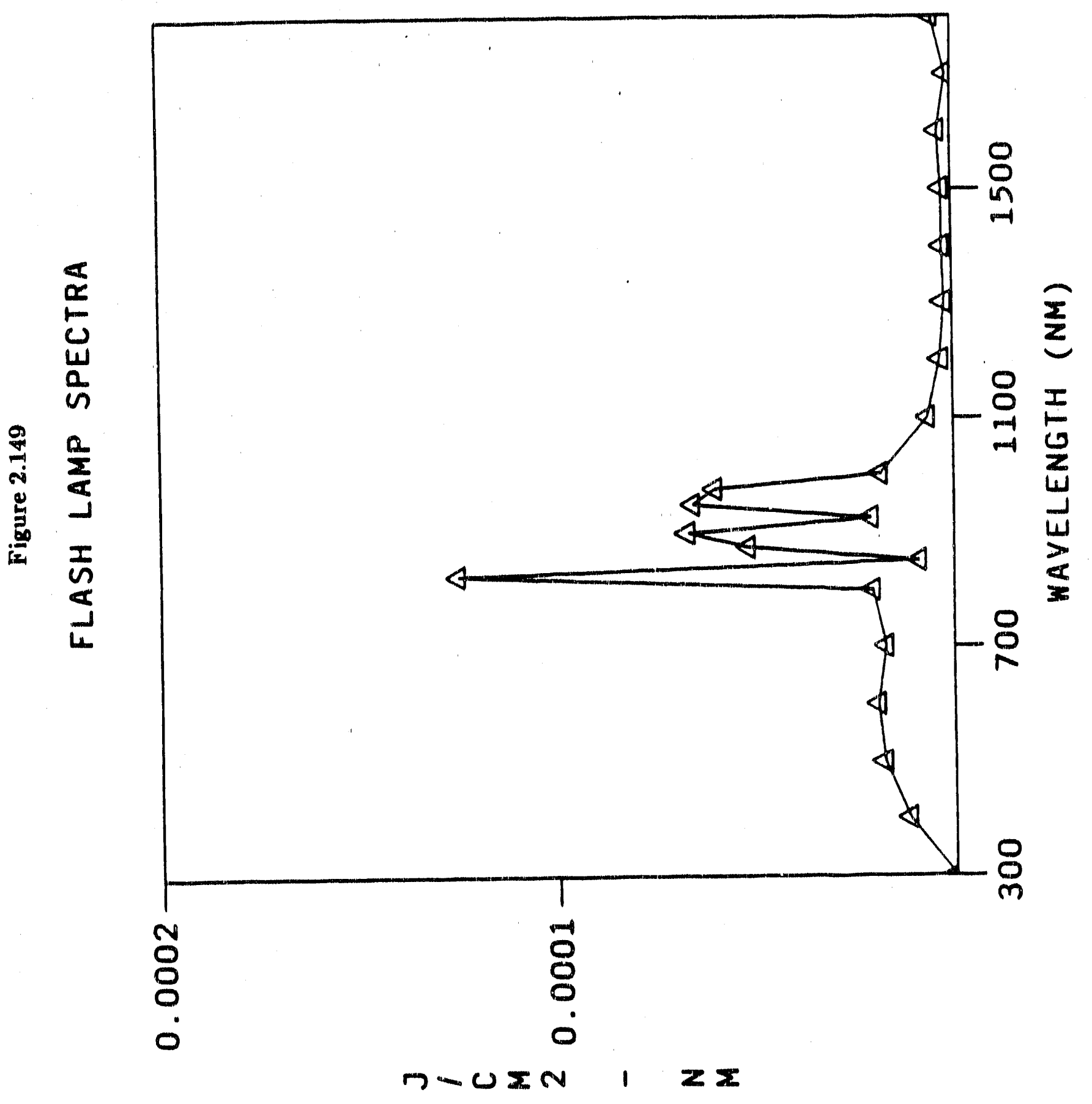


TABLE 2.24

CHARACTERISTIOS OF DELIVERED FLASH LAMP PULSES

(See Section 3.2.1 for calculation technique)

\begin{tabular}{|c|c|c|c|c|c|c|c|}
\hline $\begin{array}{l}\text { Ambient } \\
\text { Collditions }\end{array}$ & $\begin{array}{c}\text { Oapacitor } \\
\text { Bank } \\
\text { Voltage (kV) }\end{array}$ & $\begin{array}{c}\% \\
\text { NDE }\end{array}$ & $\begin{array}{c}\text { Maximum" } \\
\text { Delivered } \\
\text { Irradiance } \\
\left(w / \mathrm{cm}^{2}\right)\end{array}$ & $\begin{array}{c}\text { Time" } \\
\text { Average } \\
\text { Particle } \\
\text { Temp. }\left({ }^{\circ} \mathrm{O}\right) \\
\end{array}$ & $\begin{array}{c}\text { Averaging } \\
\text { Interval } \\
\text { (nasec) } \\
\end{array}$ & $\begin{array}{c}\text { Maximum } \\
\text { Particle } \\
\text { Temip }\left({ }^{\circ} \mathrm{O}\right) \\
\end{array}$ & $\begin{array}{c}\text { Average } \uparrow \\
\text { Heating } \\
\text { Rate }(\mathrm{C} / \mathrm{sec}) \\
\end{array}$ \\
\hline $\begin{array}{l}\text { Vacuum } \\
1 \text { atin. Ar } \\
1 \text { atm. He }\end{array}$ & $\begin{array}{c}1.5(0.5) \dagger \dagger \\
1.5 \\
1.5\end{array}$ & $\begin{array}{l}30 \\
30 \\
30\end{array}$ & $\begin{array}{l}301 \\
301 \\
301\end{array}$ & $\begin{array}{c}412 \\
399 \\
-\end{array}$ & $\begin{array}{c}35.4 \\
19.5 \\
0.0\end{array}$ & $\begin{array}{l}516 \\
471 \\
229\end{array}$ & $\begin{array}{l}5.1 \times 10^{4} \\
4.7 \times 10^{4} \\
5.0 \times 10^{4}\end{array}$ \\
\hline $\begin{array}{l}\text { Vacuum } \\
1 \text { atm. Ar } \\
1 \text { atm. He }\end{array}$ & $\begin{array}{c}1.8(0.7) \\
1.8 \\
1.8\end{array}$ & $\begin{array}{l}30 \\
30 \\
30\end{array}$ & $\begin{array}{l}478 \\
478 \\
478\end{array}$ & $\begin{array}{l}516 \\
190 \\
314\end{array}$ & $\begin{array}{c}54.1 \\
29.6 \\
3.6\end{array}$ & $\begin{array}{l}740 \\
663 \\
328\end{array}$ & $\begin{array}{l}7.3 \times 10^{4} \\
7.8 \times 10^{4} \\
6.3 \times 10^{4}\end{array}$ \\
\hline $\begin{array}{l}\text { Vacuum } \\
1 \mathrm{~atm} . \text { Ar } \\
1 \mathrm{~atm} \text {. He }\end{array}$ & $\begin{array}{c}1.5(1.0) \\
1.5 \\
1.5\end{array}$ & $\begin{array}{l}60 \\
60 \\
60\end{array}$ & $\begin{array}{l}620 \\
620 \\
620\end{array}$ & $\begin{array}{l}583 \\
550 \\
361\end{array}$ & $\begin{array}{c}66.0 \\
35.0 \\
6.2\end{array}$ & $\begin{array}{l}909 \\
808 \\
399\end{array}$ & $\begin{array}{l}9.0 \times 10^{4} \\
9.1 \times 10^{4} \\
8.3 \times 10^{4}\end{array}$ \\
\hline $\begin{array}{l}\text { Vacuum } \\
1 \text { atim. Ar } \\
1 \text { atm. He }\end{array}$ & $\begin{array}{c}1.5(1.5) \\
1.5 \\
1.5\end{array}$ & $\begin{array}{l}90 \\
90 \\
90\end{array}$ & $\begin{array}{l}009 \\
909 \\
909\end{array}$ & $\begin{array}{l}710 \\
660 \\
445\end{array}$ & $\begin{array}{l}81.5 \\
41.8 \\
8.7\end{array}$ & $\begin{array}{l}1241 \\
1080 \\
532\end{array}$ & $\begin{array}{l}1.1 \times 10^{5} \\
1.2 \times 10^{0} \\
1.0 \times 10^{0}\end{array}$ \\
\hline $\begin{array}{l}\text { Vacuum } \\
1 \text { atm. Ar } \\
1 \text { atm. He }\end{array}$ & $\begin{array}{c}2.2(2.2) \\
2.2 \\
2.2\end{array}$ & $\begin{array}{l}60 \\
60 \\
60\end{array}$ & $\begin{array}{l}1650 \\
1650 \\
1850\end{array}$ & $\begin{array}{l}953 \\
872 \\
620\end{array}$ & $\begin{array}{c}103.0 \\
51.4 \\
11.2\end{array}$ & $\begin{array}{l}2050 \\
1718 \\
829\end{array}$ & $\begin{array}{l}1.9 \times 10^{5} \\
1.9 \times 10^{4} \\
1.8 \times 10^{6}\end{array}$ \\
\hline
\end{tabular}

See Fig. 2.148 for time-resolved pulse shape.

Average over time interval for which particle temperature exceeds $300^{\circ} \mathrm{C}$.

See next column for averaging interval in msec.

$\dagger \quad$ Average heating rate calculated from ( $\mathrm{T}_{\text {particle maximum }}-20^{\circ} \mathrm{C} /\left(\mathrm{t}_{\text {maximum }}-0 \mathrm{sec}\right)$; that is, linear average of transient particle response through maximum.

$\dagger \dagger \quad$ Numbers in parentheses represent relative flux delivered.

Note: Particle temperature calculations are for an invert particle with diameter $50 \mu \mathrm{m}$, absorptivity 0.7 , and heat capacity given by the Merrick model, The vacuum condition calculations allowed for conductive losses through a gaseous tar cloud surrounding the particle. 
TABLE 2.25

\section{CHARAOTERISTIOS OF DELIVERED FLASH LAMP PIILSES $(1.8 \mathrm{kV}, 90 \%$ NDF) RELATIVE TO UHANGE IN PARTIOLE SIZE}

\begin{tabular}{|c|c|c|c|c|c|c|}
\hline $\begin{array}{c}\text { Ambient } \\
\text { Conditione }\end{array}$ & $\begin{array}{l}\text { Particle } \\
\text { Size } \\
\text { nucrons }\end{array}$ & $\begin{array}{c}\text { Maximum" } \\
\text { Delivared } \\
\text { Irradiance } \\
\left(\mathrm{w} / \mathrm{cm}^{2}\right)\end{array}$ & $\begin{array}{c}\text { Time" } \\
\text { Averago } \\
\text { Particle } \\
\left.\text { Temp. ( }{ }^{\circ} \mathrm{O}\right) \\
\end{array}$ & $\begin{array}{l}\text { Averaging } \\
\text { Interval } \\
\text { (mbec) } \\
\end{array}$ & $\begin{array}{c}\text { Maximum } \\
\text { Particle } \\
\text { Ternp }\left({ }^{\circ} \mathrm{O}\right)\end{array}$ & $\begin{array}{c}\text { Average } \dagger \\
\text { Healling } \\
\text { Rate }(\mathrm{C} / \mathrm{sec}) \\
\end{array}$ \\
\hline $\begin{array}{l}\text { Vacuum } \\
1 \text { alm. Ar } \\
1 \text { alm. He }\end{array}$ & $50 \mu \mathrm{m}$ & $\begin{array}{l}909 \\
909 \\
909\end{array}$ & $\begin{array}{l}710 \\
660 \\
445\end{array}$ & $\begin{array}{c}81.5 \\
41.8 \\
8.7\end{array}$ & $\begin{array}{c}1241 \\
1080 \\
532\end{array}$ & $\begin{array}{l}1.1 \times 10^{3} \\
1.2 \times 10^{3} \\
1.0 \times 10^{0}\end{array}$ \\
\hline $\begin{array}{l}\text { Vacuum } \\
1 \text { atm. Ar } \\
\text { l atm. He }\end{array}$ & $81 \mu \mathrm{m}$ & $\begin{array}{l}909 \\
909 \\
909\end{array}$ & $\begin{array}{l}561 \\
546 \\
455\end{array}$ & $\begin{array}{l}152.0 \\
79.5 \\
12.8\end{array}$ & $\begin{array}{l}907 \\
855 \\
556\end{array}$ & $\begin{array}{l}7.0 \times 10^{4} \\
8.1 \times 10^{4} \\
7.9 \times 10^{4}\end{array}$ \\
\hline $\begin{array}{l}\text { Vacuum } \\
1 \text { atm. Ar } \\
1 \text { atm. He }\end{array}$ & $115 \mu \mathrm{m}$ & $\begin{array}{l}909 \\
909 \\
909\end{array}$ & $\begin{array}{l}480 \\
471 \\
431\end{array}$ & $\begin{array}{c}224.0 \\
124.0 \\
17.4\end{array}$ & $\begin{array}{l}710 \\
690 \\
521\end{array}$ & $\begin{array}{l}5.7 \times 10^{4} \\
5.8 \times 10^{4} \\
6.6 \times 10^{4}\end{array}$ \\
\hline $\begin{array}{l}\text { Vacuum } \\
1 \text { atm. Ar } \\
1 \text { atm. He }\end{array}$ & $125 \mu \mathrm{m}$ & $\begin{array}{l}909 \\
909 \\
909\end{array}$ & $\begin{array}{l}465 \\
460 \\
415\end{array}$ & $\begin{array}{c}241.0 \\
133.0 \\
19.0\end{array}$ & $\begin{array}{l}609 \\
653 \\
513\end{array}$ & $\begin{array}{l}5.2 \times 10^{4} \\
5.6 \times 10^{4} \\
5.9 \times 10^{4}\end{array}$ \\
\hline
\end{tabular}

- See Fig. 2.148 for time-resolved pulse shape.

* Average over time interval for which particle temperature excesds $300^{\circ} \mathrm{O}$. See next column for averagine interval in msec.

$\dagger \quad$ Average heating rate calculated from $\left(T_{\text {partirlm maximunn }}-20^{\circ} \cap /\left(t_{\text {manxlumwn }}-0\right.\right.$ sec $)$; that is, linear average of traneient particle response through maximum.

Note: Particle temperature calculations are for an invert particle without diameter $50 \mu \mathrm{m}$, absorptivity 0.7 , and heat eapacity given by the Merrick model. The vacuum condition calculations allowed for conductive losses through a gaseous tar cloud surrounding the particle. 


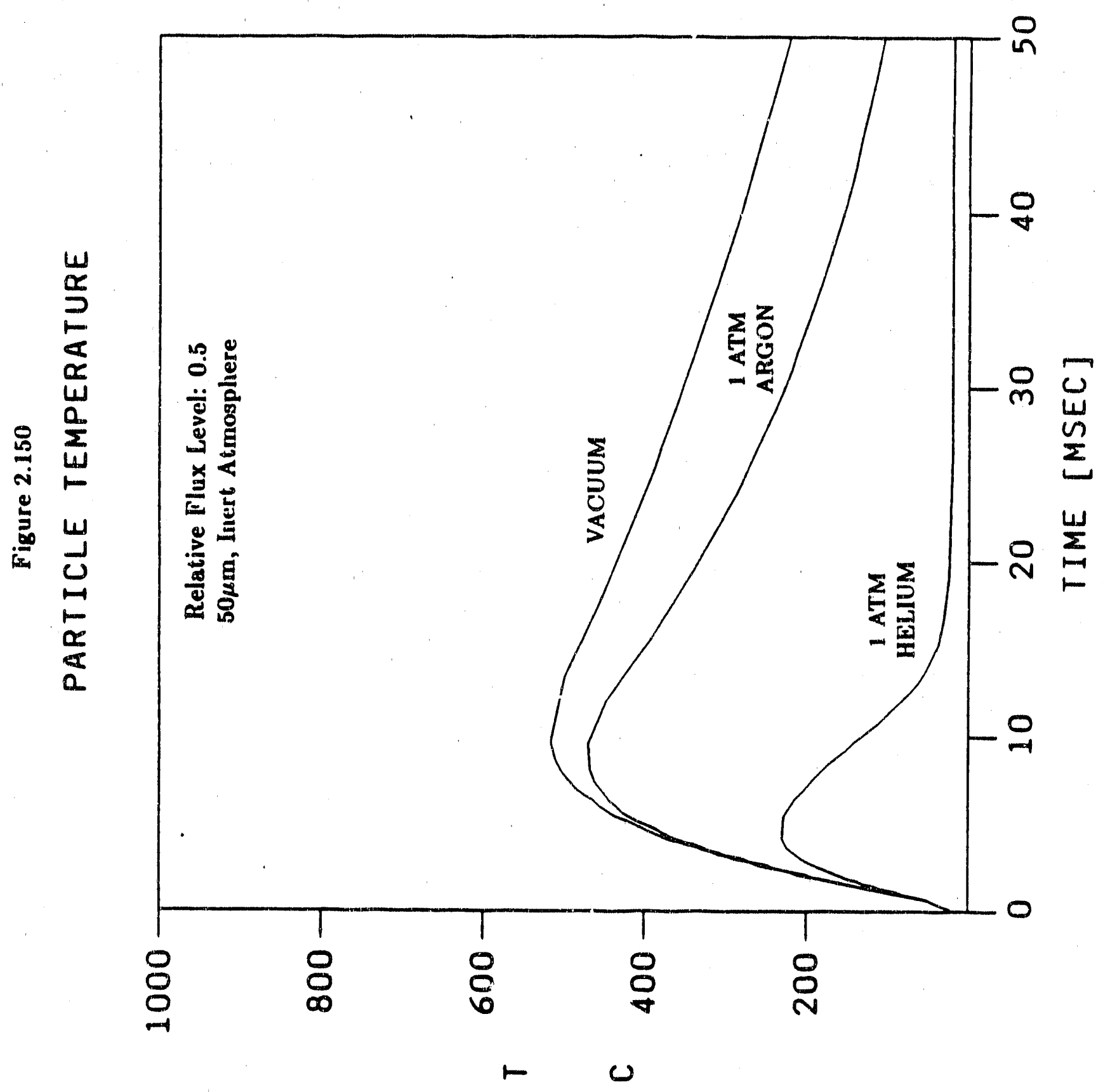


R88-PC70768

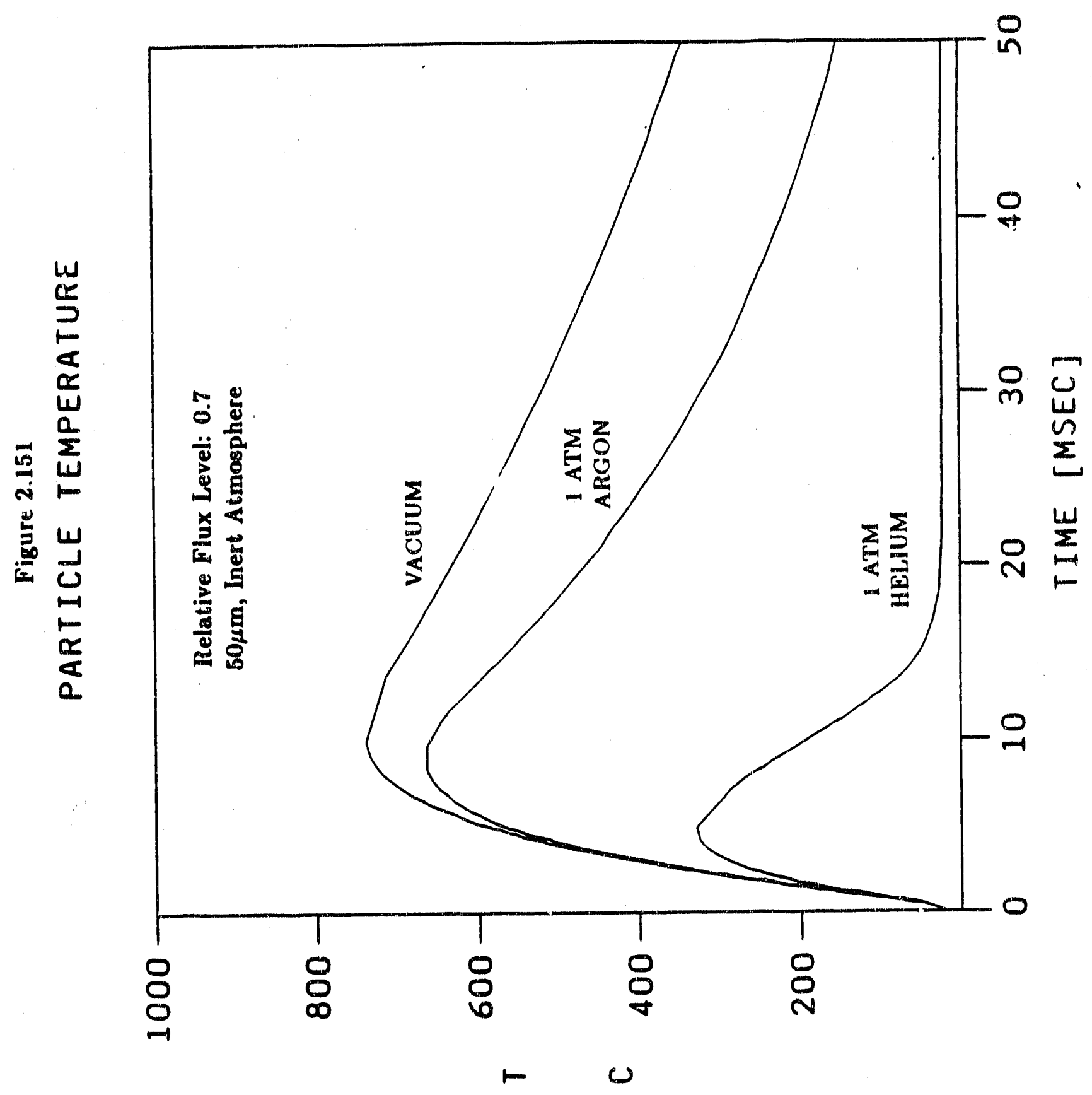




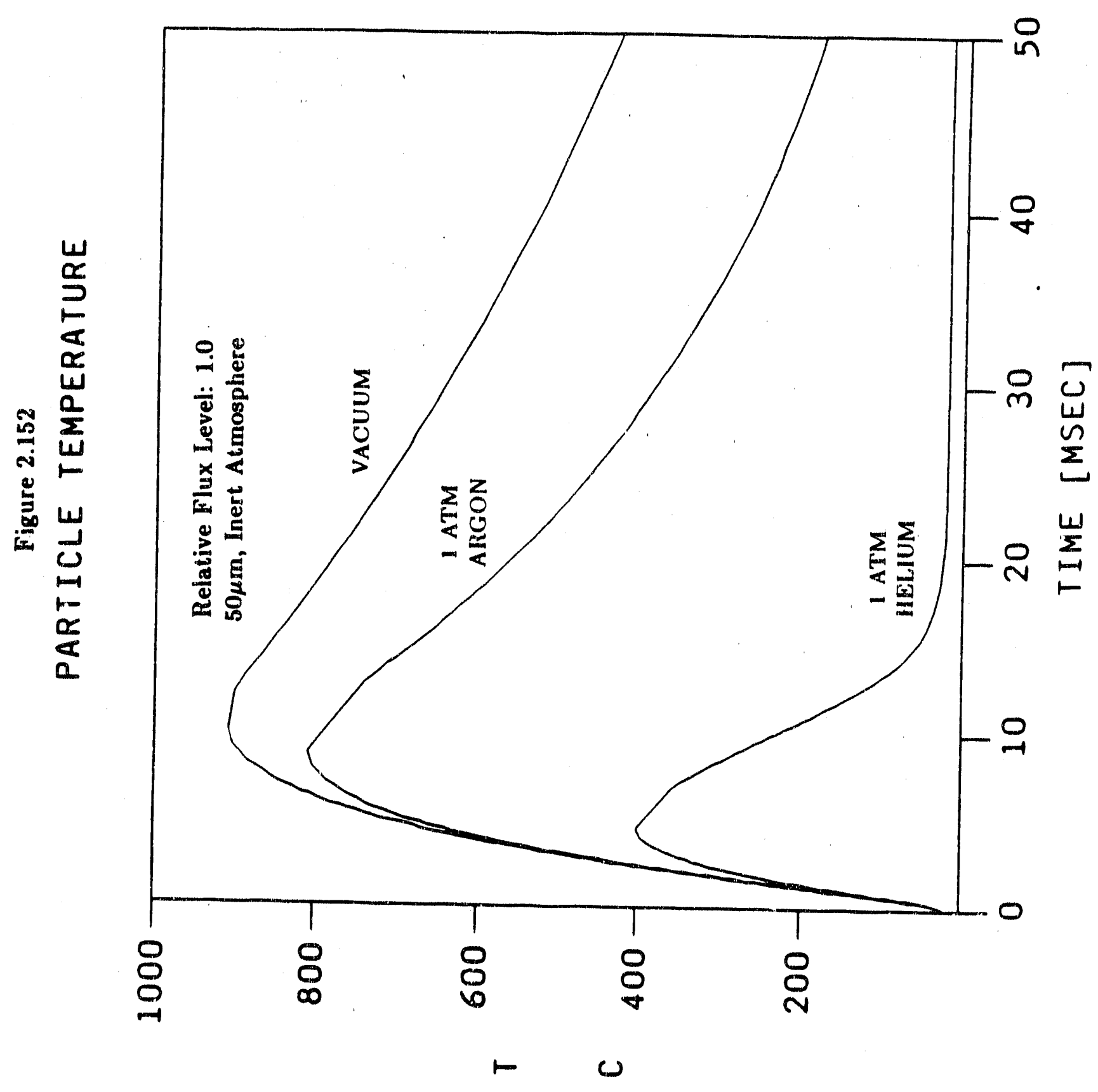




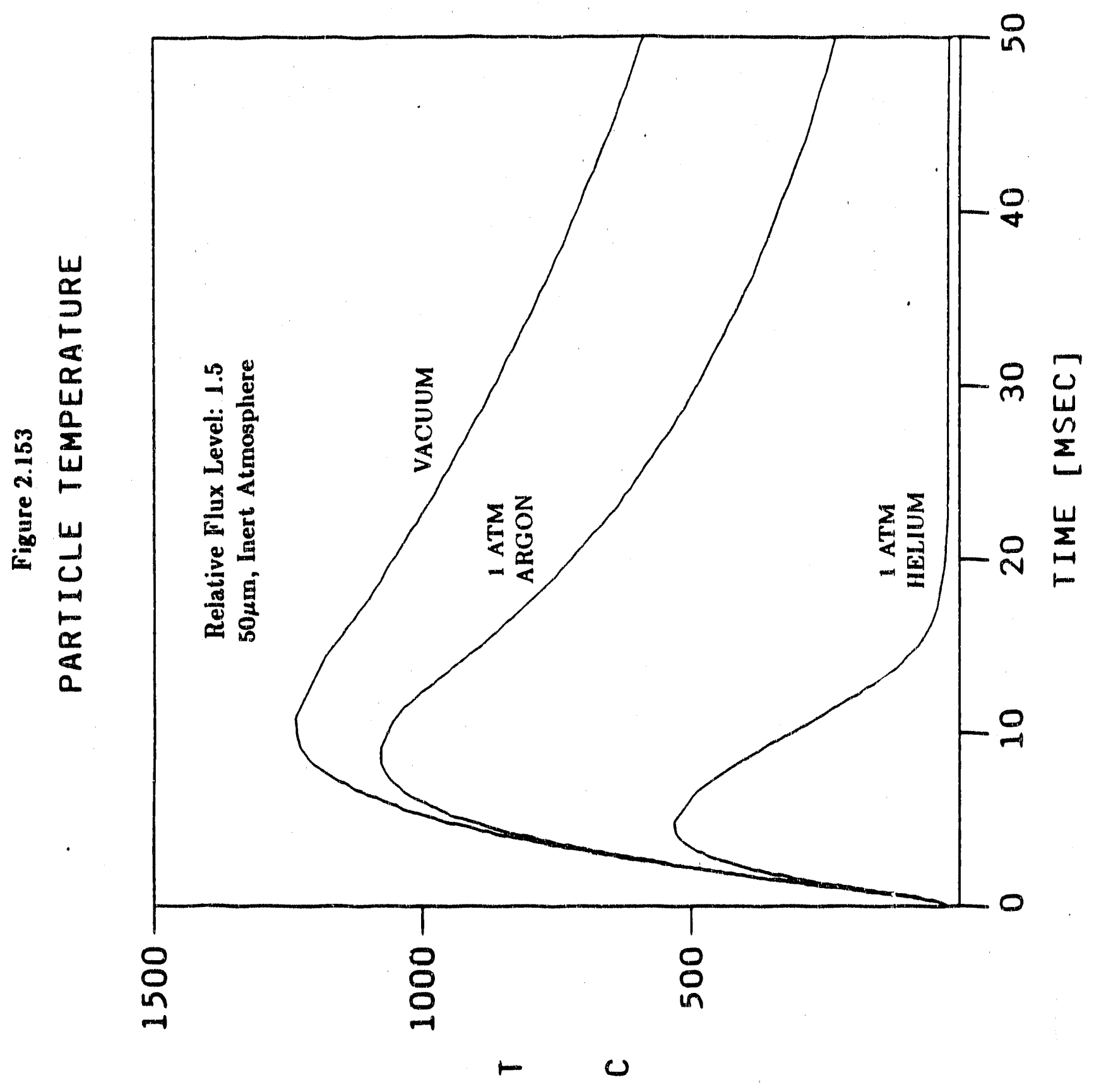




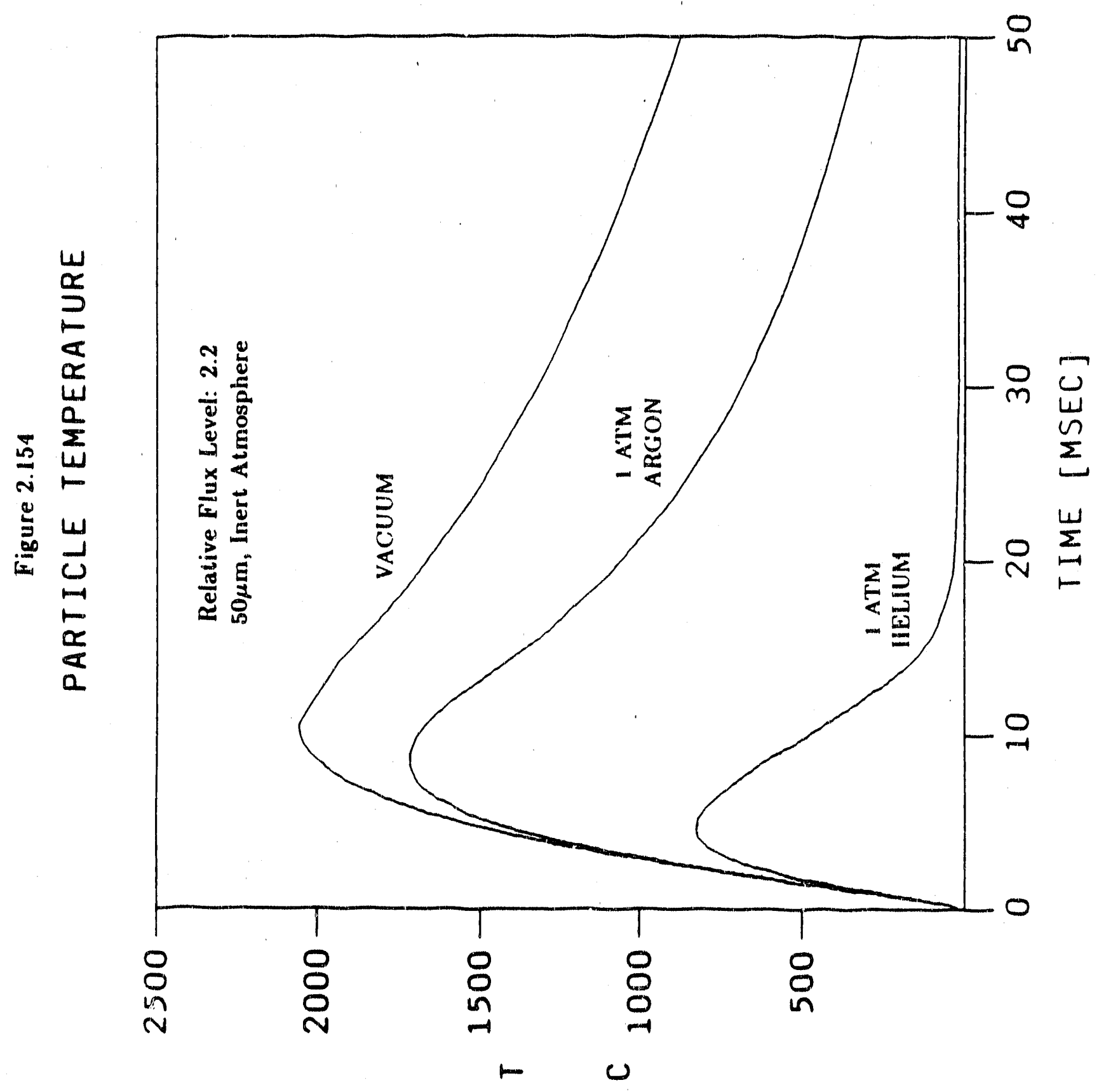


R88-PC70768
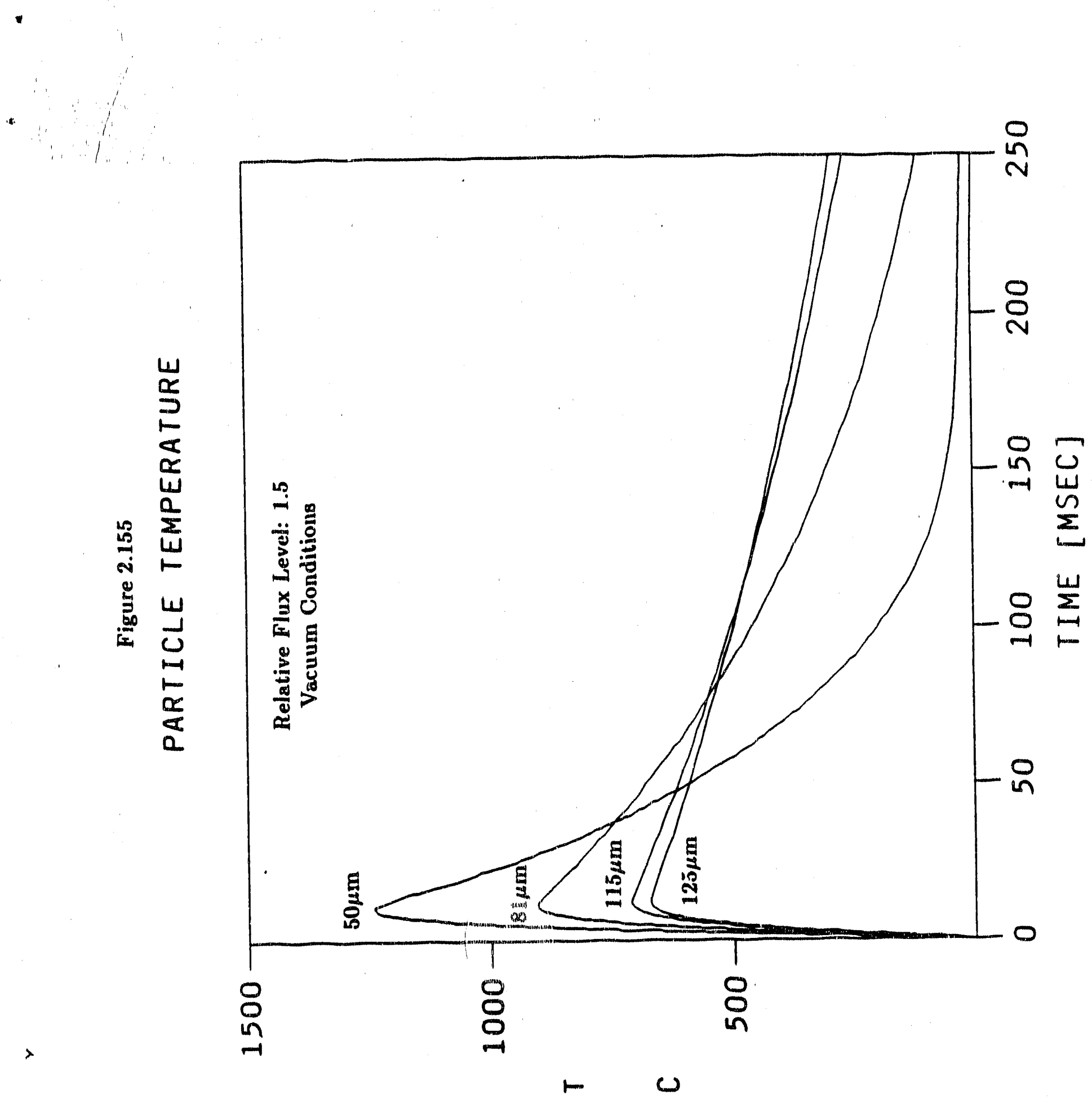


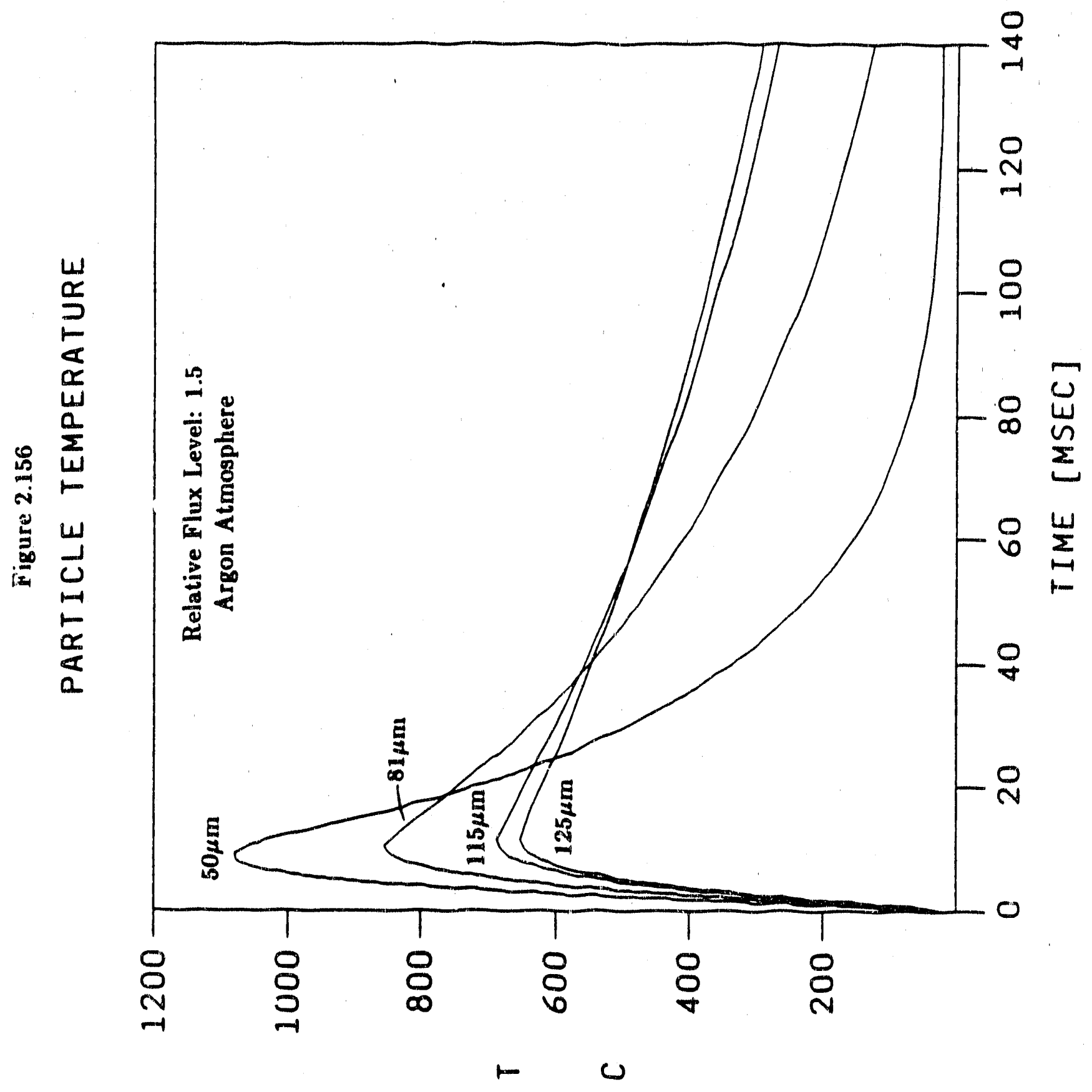




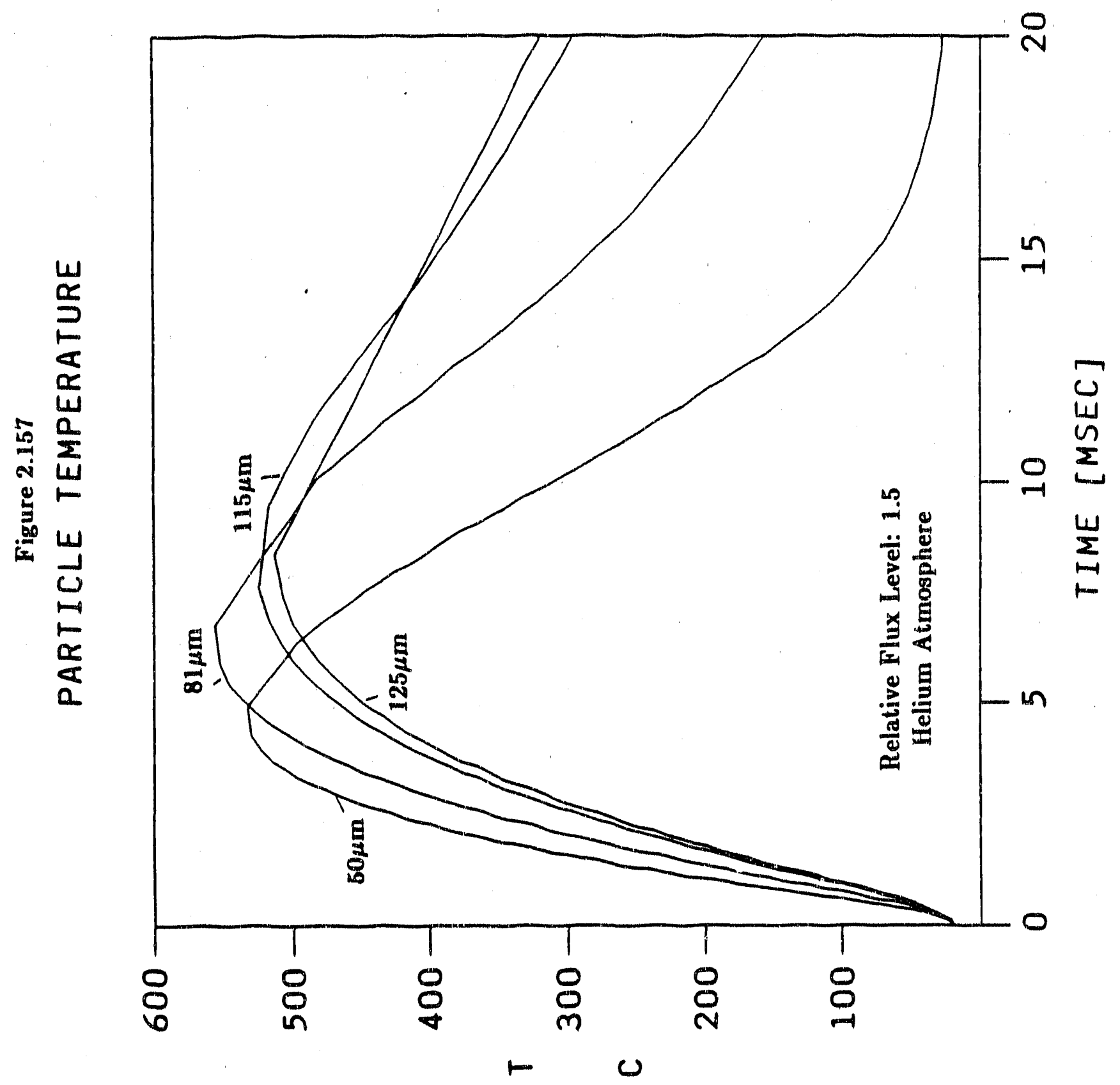


TABLE 2.26 - VOLATTLES RELEASE - PSOC 1451 (HVA BIT) FLASH LAMP APPARATUS 270/325 MESH PARTICLES

Relative Flux Level: 0.7 (1.8, KV, 30\% NDF)

Product

Char

Tar

$\mathrm{CH}_{4}$

$\mathrm{C}_{2} \mathrm{H}_{4}$

$\mathrm{C}_{2} \mathrm{H}_{2}$

$\mathrm{C}_{6} \mathrm{H}_{6}$

$\mathrm{HCN}$

$\mathrm{CO}$

$\mathrm{CO}_{2}$
Vacuum

59.0

31.0

0.13

-

$-$

$-$

0.12

0.63

\section{ATM.AR}

71). 0

19.0

0.16

$-$

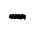

$-$

$-$

0.15

0.12
1 ATM.HE

90

6

$-$

TABLE 2.27 - VOLATILES RELEASE - PSOC 1451 (HVA BIT) FLASH LAMP APPARATUS 270/325 MESH PARTICLES (continued)

Relative Flux Level: 1.0 (1.5, KV, 30\% NDF)

Product

Char

Tar

$\mathrm{CH}_{4}$

$\mathrm{C}_{2} \mathrm{H}_{4}$

$\mathrm{C}_{2} \mathrm{H}_{2}$

$\mathrm{C}_{6} \mathrm{H}_{6}$

$\mathrm{HCN}$

$\mathrm{CO}$

$\mathrm{CO}_{2}$
Vacuum

57.0

37.0

0.25

0.09

-

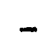

$-$

0.23

0.28

\section{ATM.AR}

59.0

24.0

0.29

0.12

0.36

-

0.47

0.69

0.12
1 ATM.HE

78

12
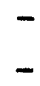

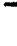

$-$ 
TABLE 2.28 - VOLATILES RELEASE - PSOC 1451

(HVA BIT) FLASH LAMP APPARATUS

270/325 MESH PARTICLES

Relative Flux Levei: 1.5 (1.5, KV, 90\% NDF)

Product

Vacuum

59.0

27.0

0.82

0.51

0.79

0.09

0.32

1.43

0.34
1 ATM.AR

63.0

18.0

0.34

0.09

1.16

$-$

0.65

3.01

$-$
1 ATM.HE

76.0

19.0

0.25

0.06

1.01

0.41

1.77

0.13

TABLE 2.29 - VOLATILES RELEASE - PSOC 1451 (HVA BIT) FLASH LAMP APPARATUS 270/325 MESH PARTICLES (continued)

Relative Flux Level: $2.2(2.2, \mathrm{KV}, 60 \%$ NDF)

Product

Char

Tar

$\mathrm{CH}_{4}$

$\mathrm{C}_{2} \mathrm{H}_{4}$

$\mathrm{C}_{2} \mathrm{H}_{2}$

$\mathrm{C}_{6} \mathrm{H}_{6}$

$\mathrm{HCN}$

$\mathrm{CO}$

$\mathrm{CO}_{2}$
Vacuum

53.0

25.0

0.66

0.01

1.41

$-$

0.56

1.68
1. ATM.AR

67.0

22.0

0.38

0.14

1.90

-

1.39

5.35

0.25
1 ATM.HE

70.0

17.0

0.75

0.23

1.48

0.17

1.11

4.44

0.14 


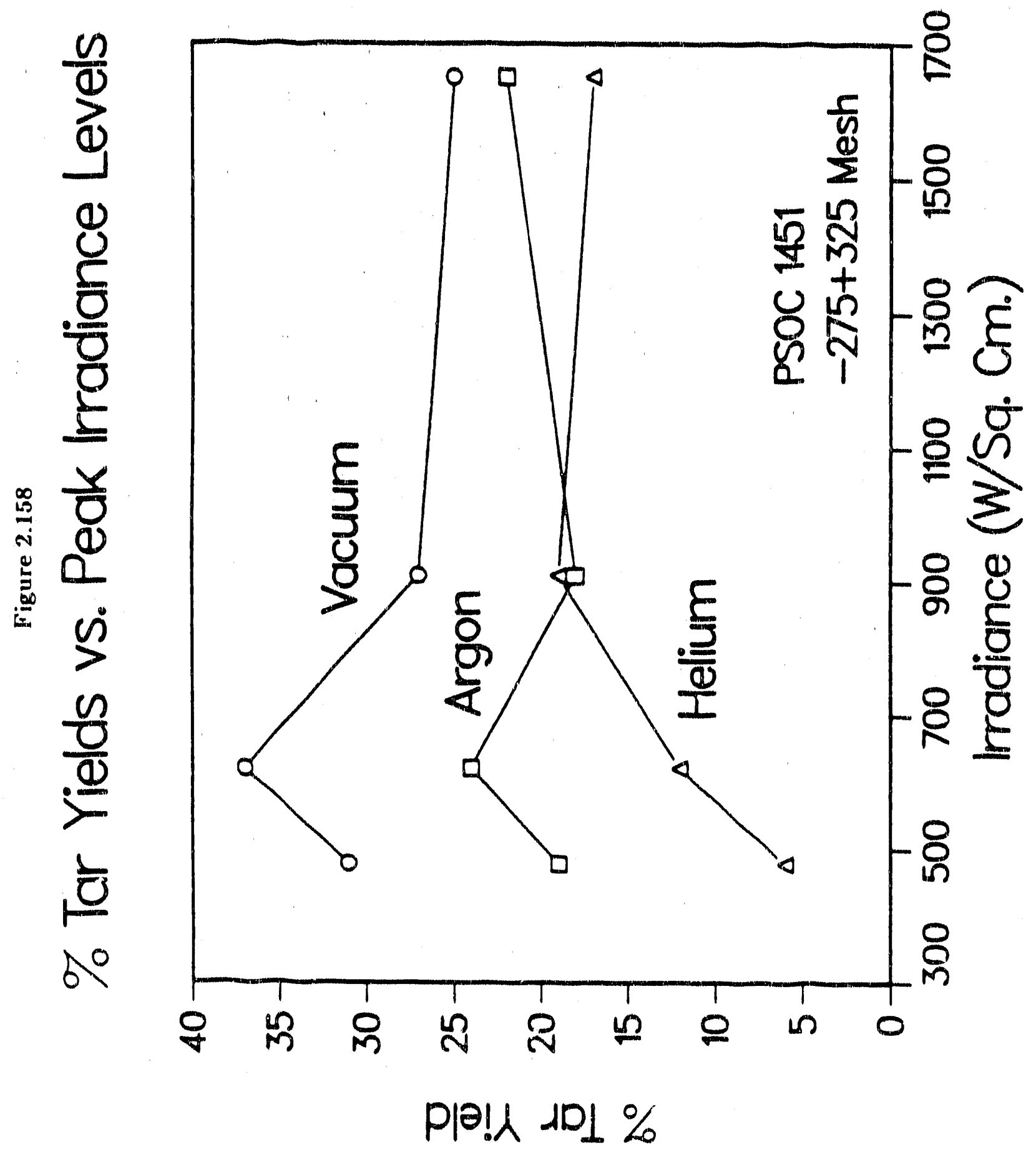




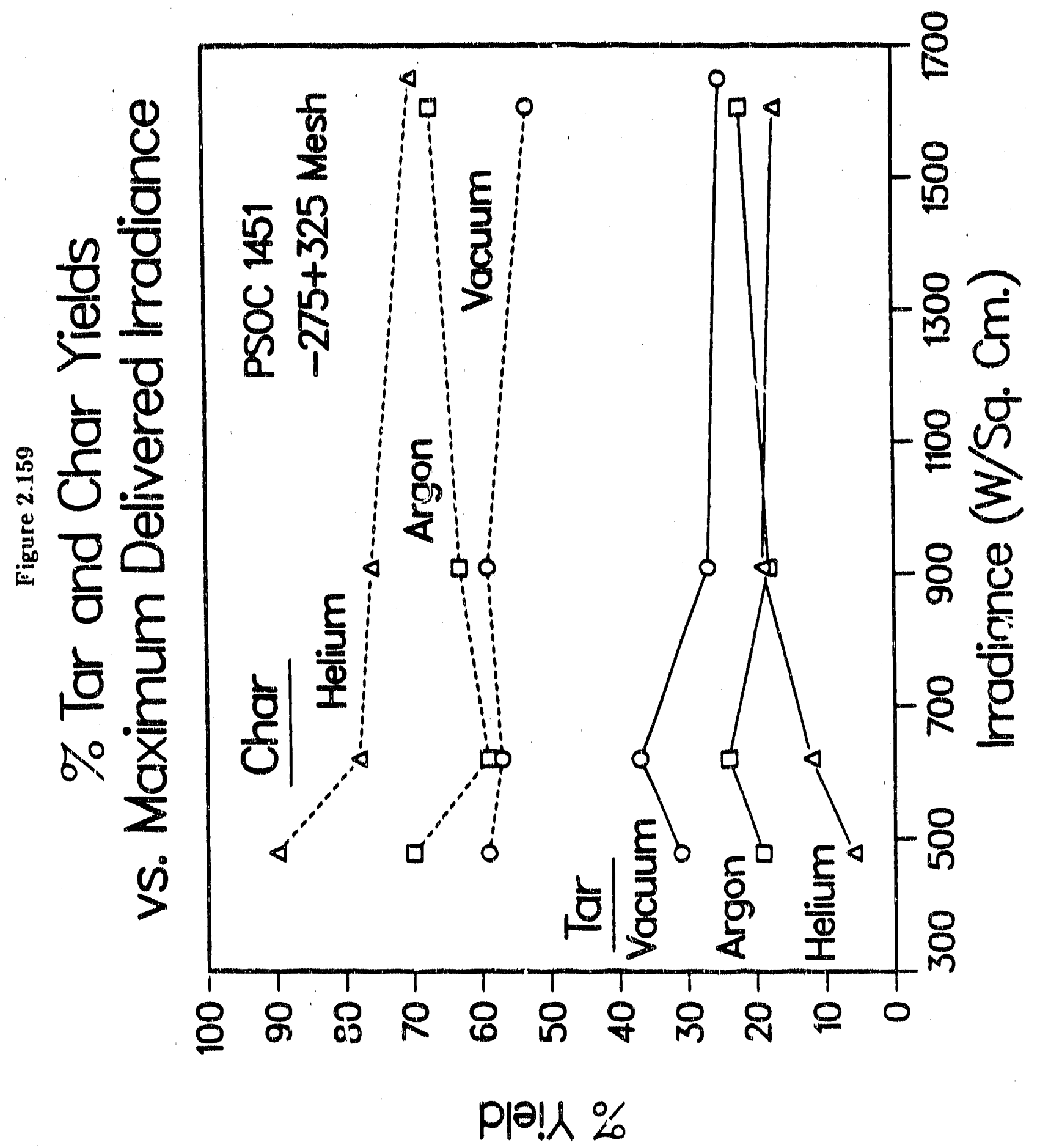


levels in the product distribution imply the onset of such high temperaeure secondary reactions of tars. Filgures 2.160 through 2.162 display the $\mathrm{CO}, \mathrm{C}_{2} \mathrm{H}_{2}$ and $\mathrm{HCN}$ yleld observed for 50 micron particles of $\mathrm{PSOC}$ 1451. As indicated, increasing the irradlance level beyond that requirod for the maximum tar yleld results in slgniflcant production of each of these gases. The results Indicate the same high temperature tar reactions observed in the entrained flow reactor system also occirr in this devolatllization system but at rates corresponding to higher transient tar temperatures, Figure 2.163 indicates the levels of $\mathrm{C}_{2} \mathrm{H}_{2}, \mathrm{CO}$ and $\mathrm{HCN}$ observed in the system are coupled.

Figure 2.164 shows the same relationship for a size range of bltuminous coal particles. This figure Indicates the levels of these gases observed at the flash lamp conditions indicated and for a range of bituminous coal particle sizes separated in the Andersen impactor train. The size cuts ranged from 1 to 15 microns and were flash heated in the presence of argon. The different size cuts produce different transient temperature profiles when subjected to the same flux pulses. The data indicate these light gas yields are correlated, that is, they are probably produced by the same high temperature pyrolysis network. Obviously, the extent of high temperature pyrolysis of potential tar mass is coupled to the presence of an ambient gas. That is, for any given irradiance pulse magnitude the level of $\mathrm{CO}, \mathrm{C}_{2} \mathrm{H}_{2}$ or $\mathrm{HCN}$ observed depends on the ambient pressure and nature of the ambient gas.

Figure 2.165 displays CO levels observed for 50 micron particles of PSOC 1451 at various irradiance levels at low pressure conditions and in the presence of one atmosphere of argon or helium. Both the absolute levels and rate of increase in CO per unit change in irradlance level vary with the nature of the ambient condltions. Similar plots could be made for $\mathrm{C}_{2} \mathrm{H}_{2}$ and $\mathrm{HCN}$ since they are produced from the same global pyrolysis network.

The data presented lllustrate the Intimate coupling among heat transfer, mass transfer and chemical kinetics In determining the observables in high temperature, high heating rate devolatilization. Ambient pressure significantly Influences the mass loss as tar. The effect is most notable at the lower flux levels. During the transient heating event, the heavy molecular weight tars that can vaporize or convect away from the particle in low pressure conditions are not able to escape in ambient prossure conditions. But, the pressure effect is not immediately determined by comparing low pressure and atmospherle pressure yields, since the nature of the ambient gas has an appreciable effect on the transient particle temperature history (See Table 2.24 or 2.25 ). Hellum has a thermal conductivity nearly an order of magnitude greater than argon and peak particle temperatures and time-averaged particle temperatures for a given irradiance pulse will be substantially lower than those achieved in argon. As a result, devolatilizing partjcles and escaping tars 


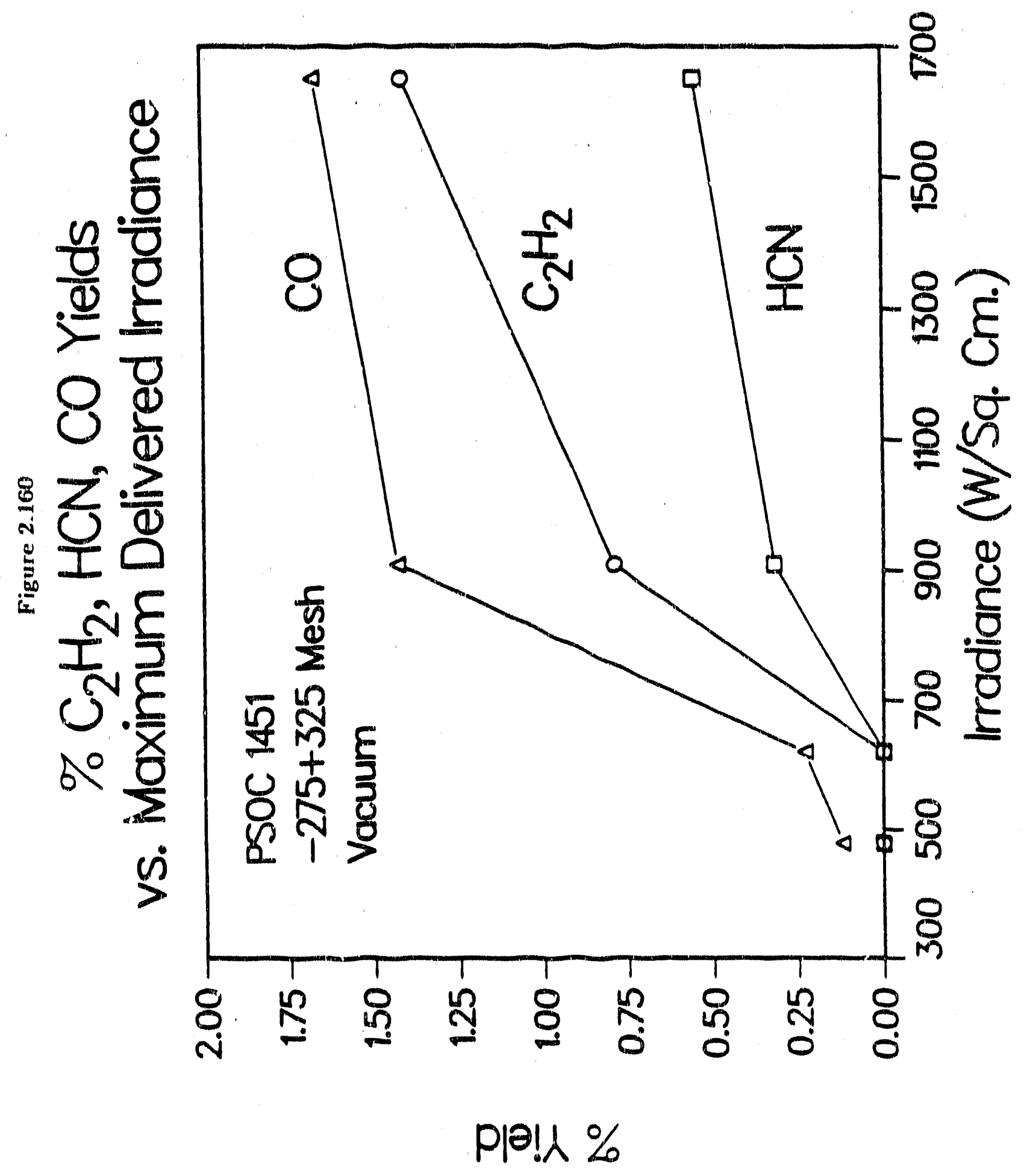




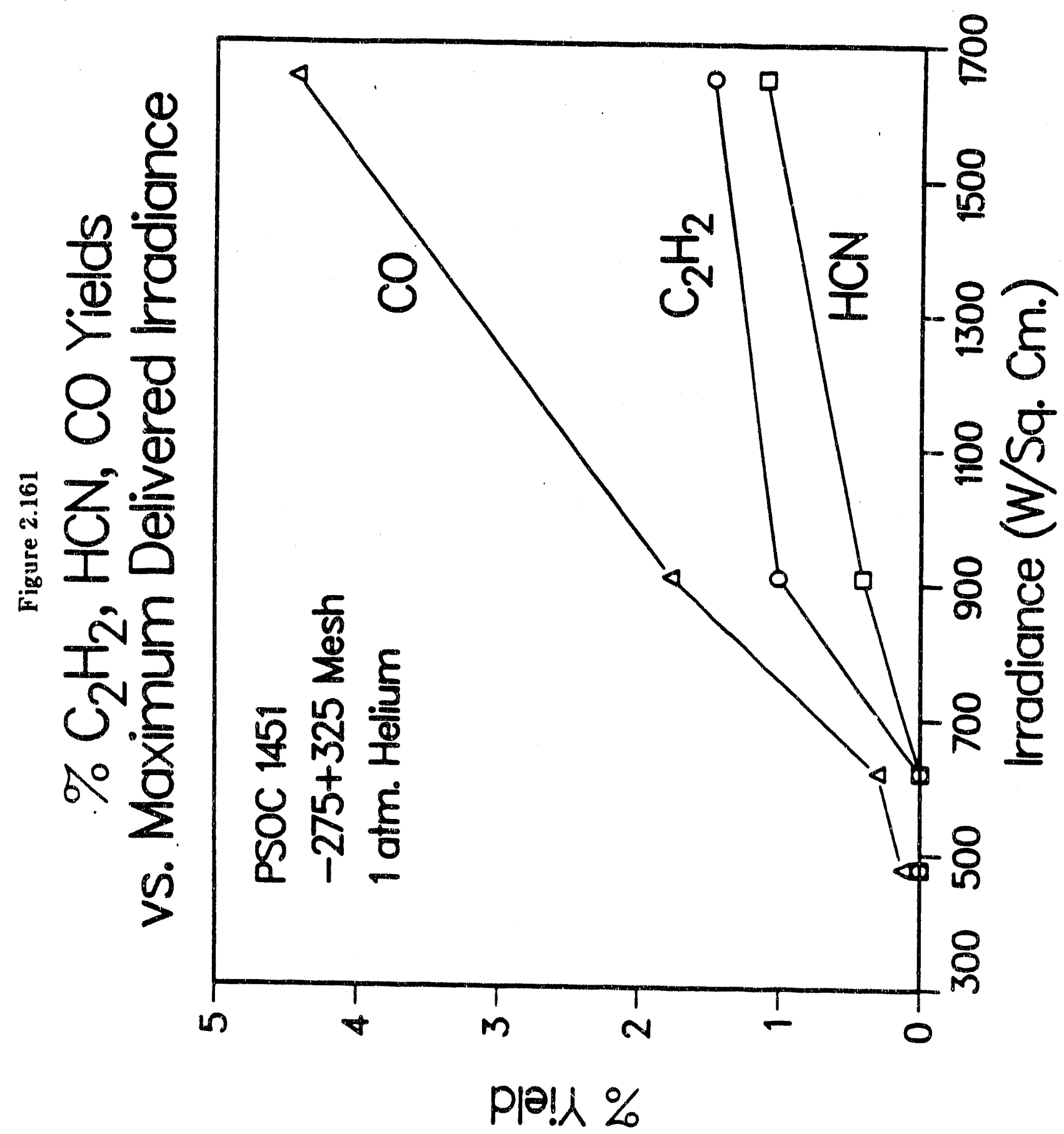




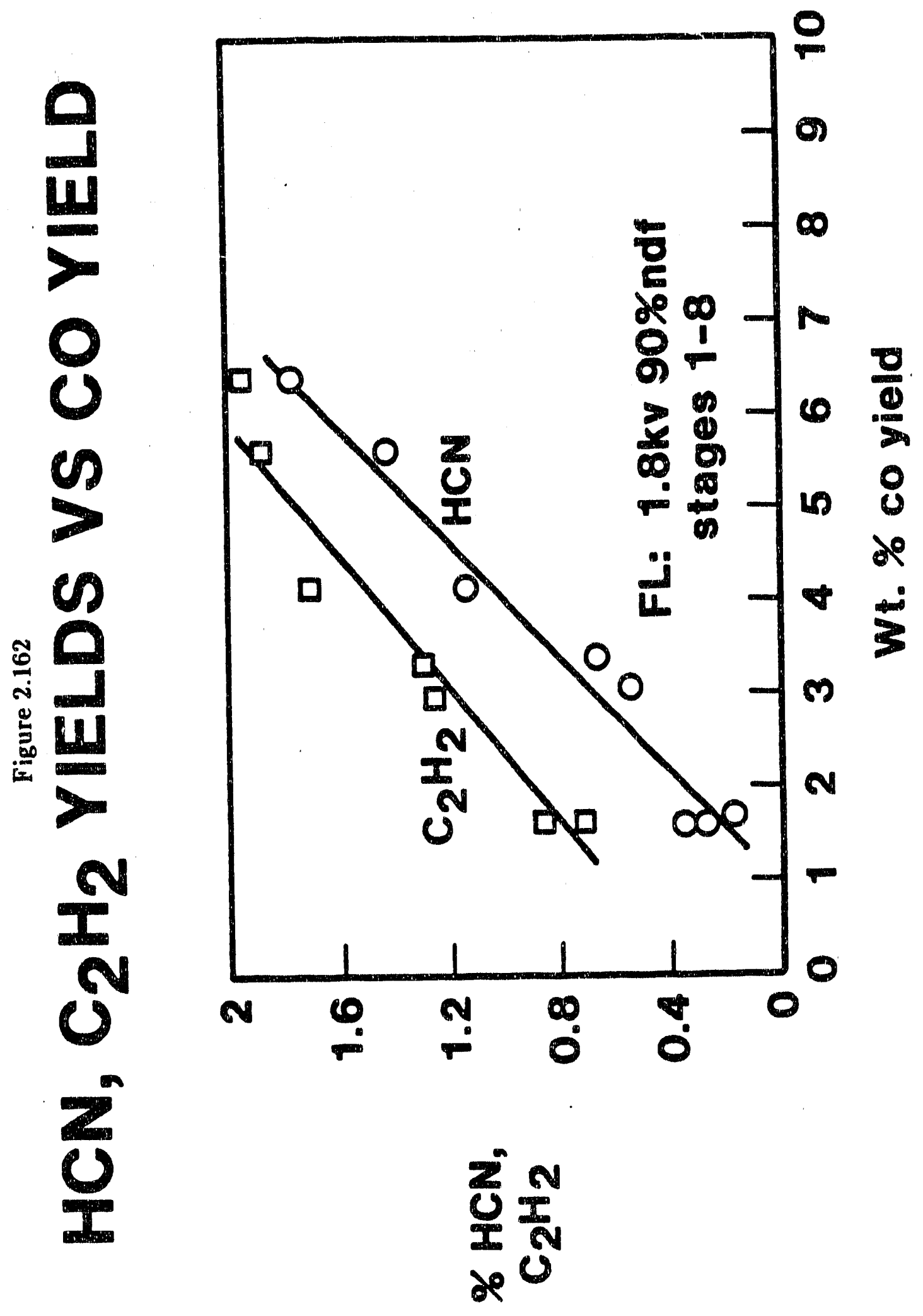




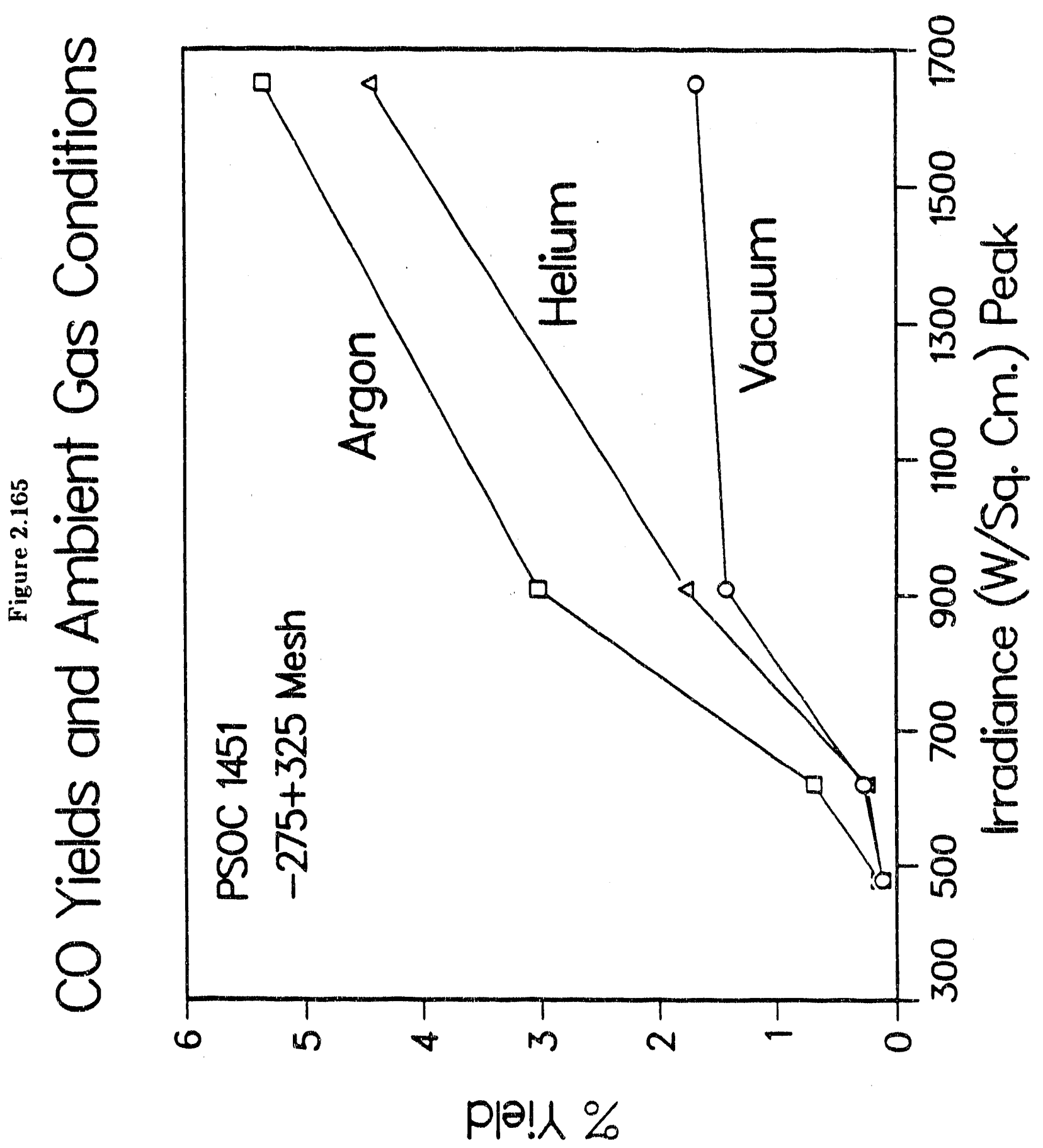


R88-PC70768

experience substantially different temperature conditions within the same ambient pressure, mass transfer resistance. The intimate coupling is again illustrated by the tar yield with respect to particle size and arnbient conditions (Fig. 2.166).

The flash lamp data can only be understood by simultaneously considering all parameter types that influence observable devolatilization behavior - heat transfer, mass transfer and high temperature pyrolysis of hydrocarbons. Increasing ambient pressure establishes an interphase mass transfer resistance to the evolution of the heavier components of the potential transient tar mass. Increasing the transient power density, the heat transfer intensity, experienced by the particle during the tar formation and evolution phase, increases the probability that the tar species will undergo high temperature pyrolysis as they evolve.

As the tars crack with increase in heating rate given an ambient pressure, a decrease in molecular weight characteristics should be ubservable. Figure 2.167 shows the effect of average power density on the relative tar molecular weight characteristics. Asids from ambient helium which has little yield at the lowest irradiance levels, the relative molecular weights show a consistent decrease with increase in irradiance level. In these rapid heating conditions to temperature of $800^{\circ} \mathrm{C}$ or above, the tars thermally crack as they are. escaping, producing lower molecular weight tar species and the high temperature light gases noted above $\mathrm{CO}_{2}, \mathrm{C}_{2} \mathrm{H}_{2}$, and $\mathrm{HCN}$. At the highest irradiance levels, soot formation reactions occur. 


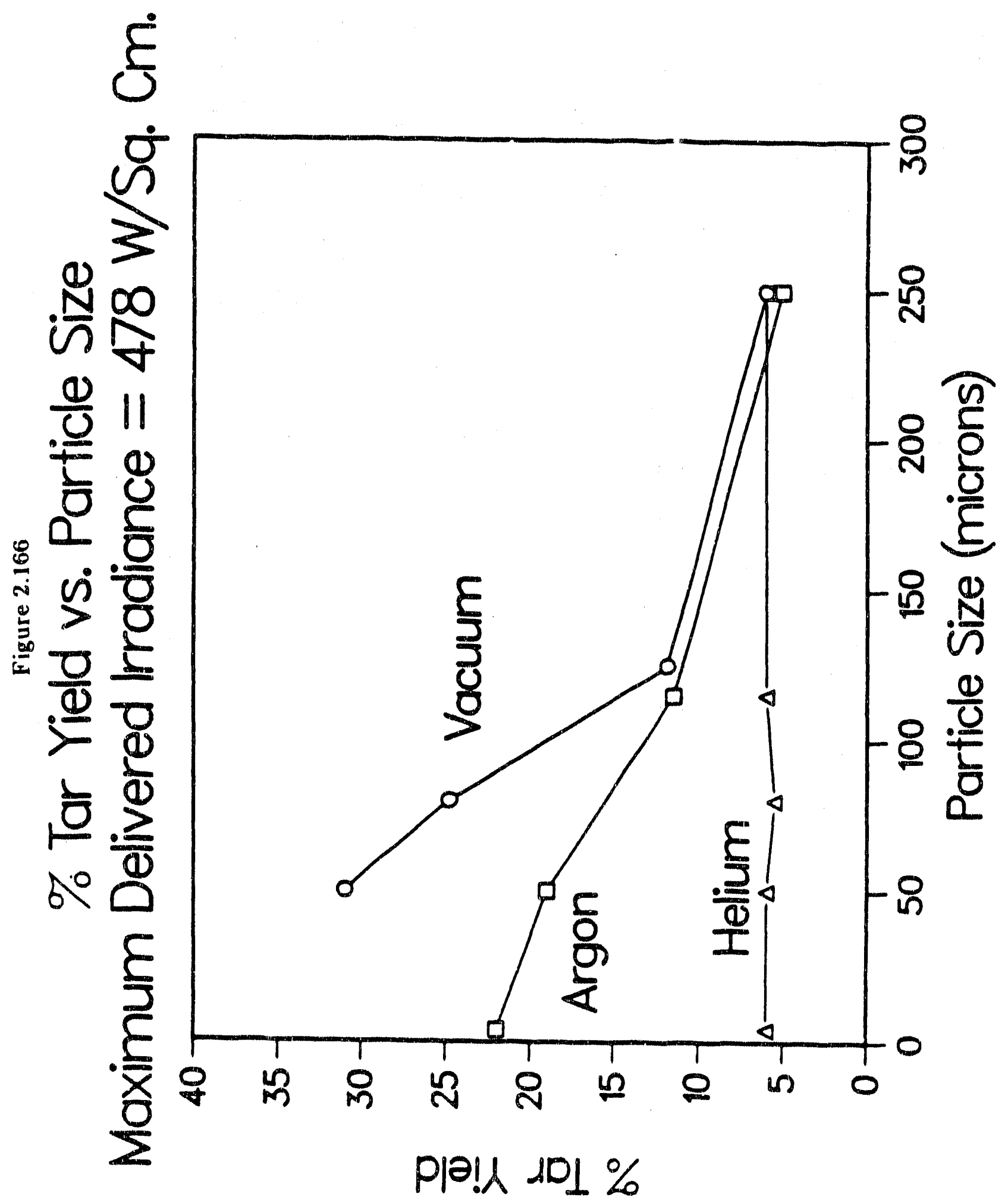


2

3

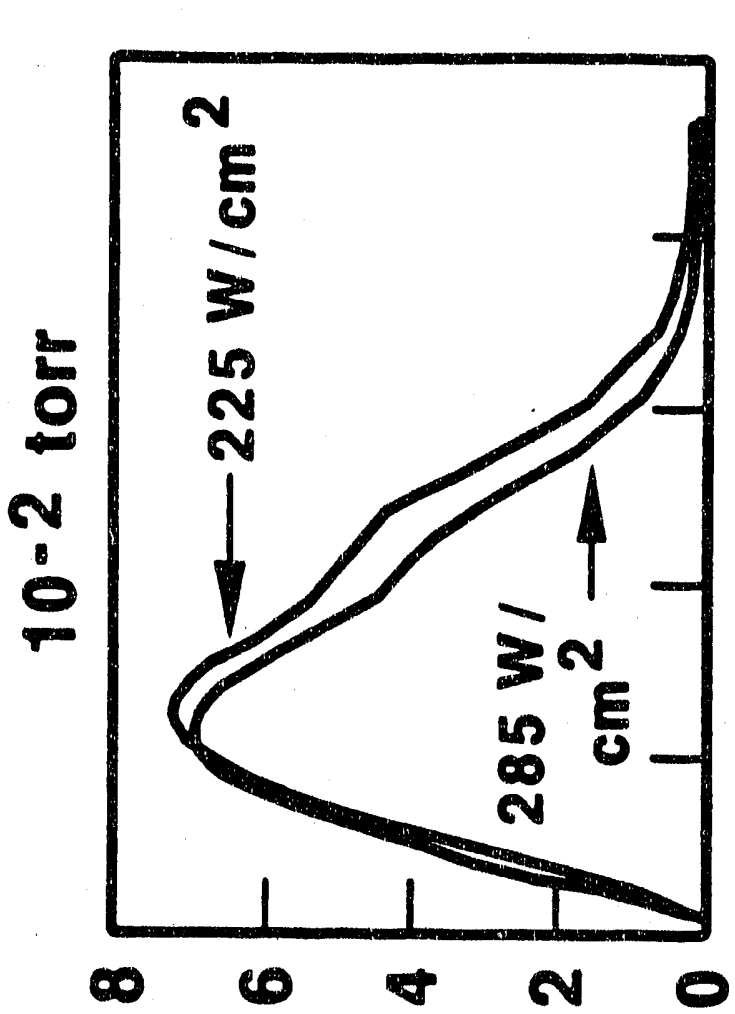

D 0 N 0

苟

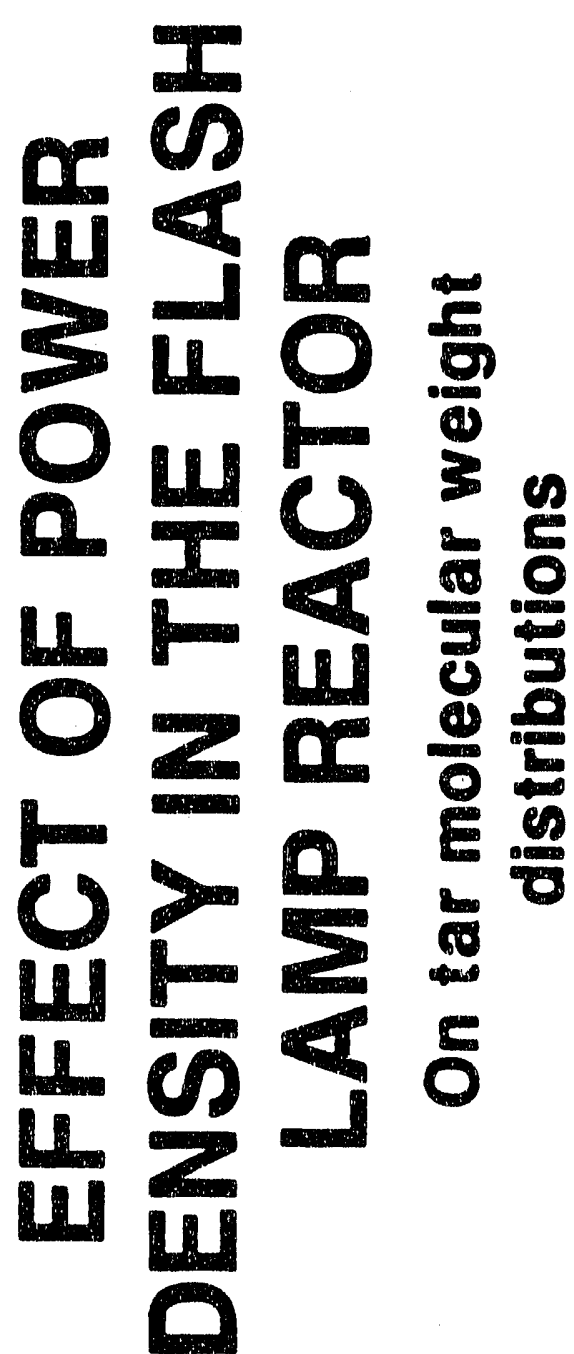

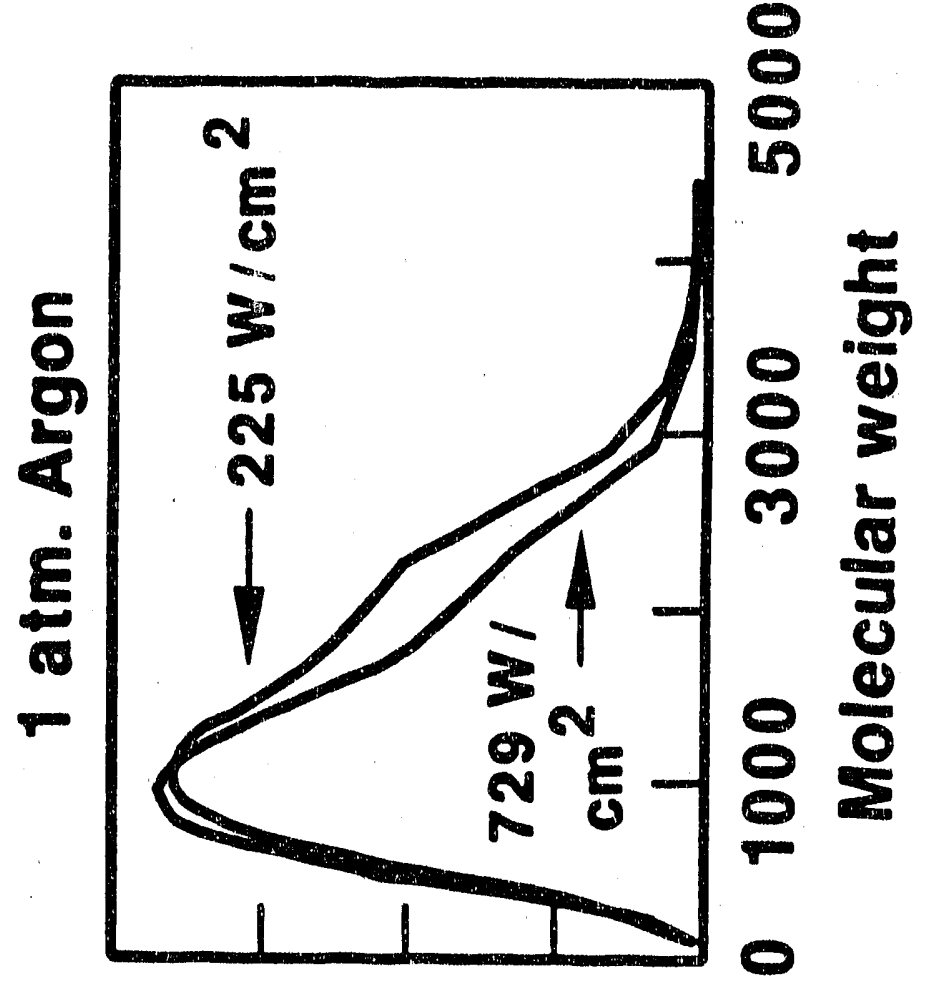

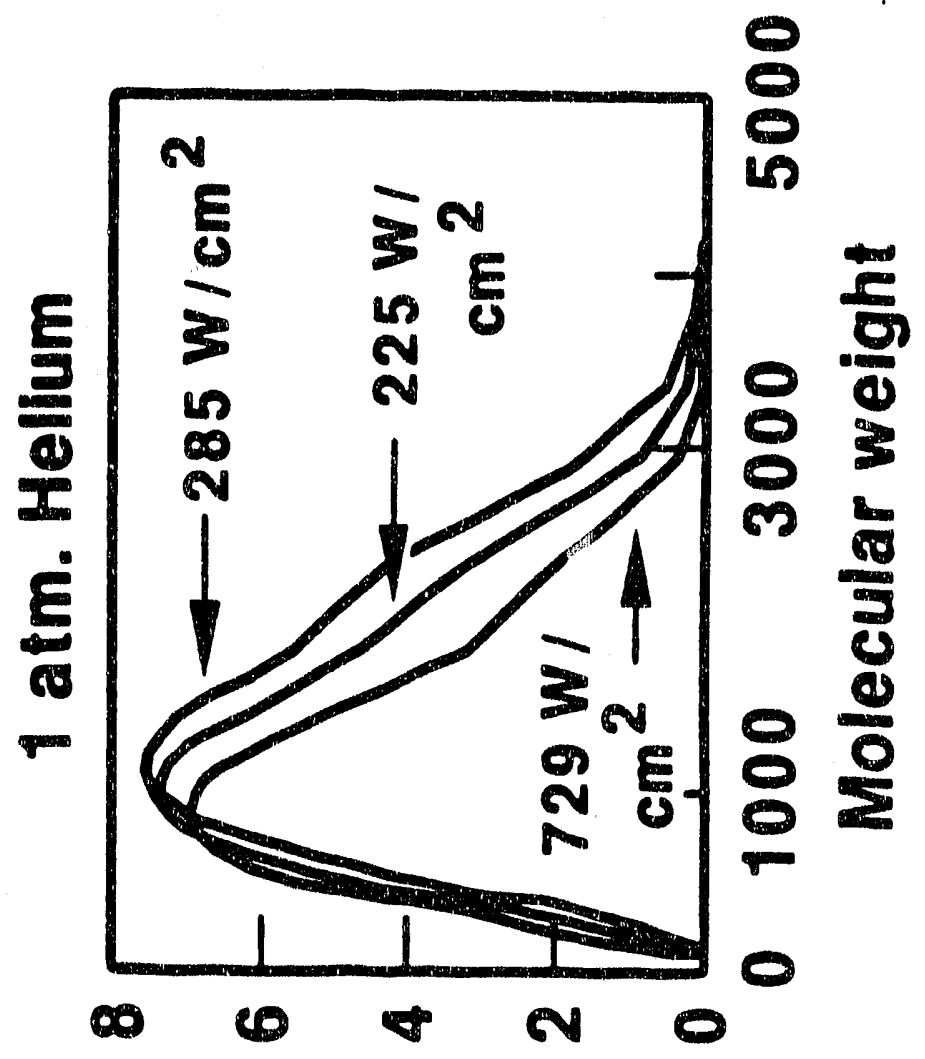




\section{SECTION 2.0 REFERENCES}

2.1 Campbell, J. H., Fuel, 57, 217 (1978),

2.2 Vanderborgh, N. E., et. al., J. of Analytical and Appiled Pyrolysis, 4, 21 (1982).

2.3 Granger, A. F. and Ladner, W. R., Combustiun and Flame, 11, 518 (1967).

2.4 Ubayakahar, S. K., et. al., Sixteenth (Intern.) Symp. on Combustion, The Combustion Institute, Pittsburgh, PA. 427 (1977).

2.5 Ballantyne, et. al., Final Report to Department of Energy, DOE/PC/30291-6, DOE-PETC (1983).

2.7 Fletcher. T.. Presented at 1988 Spring Meeting of the Western States Section of the Combustion Institute, WSS/CI 88-5.

2.8 Best, P. E., et. al., Combustion and Flame, 66, 47 (1986).

2.9 Maloney, D. J., Ph.D. Thesis, The Pennsylvania State University, University Park, PA. (1983).

2.10 Morgan, M. E., Ph.D. Thesis, The Pennsylvania State University, University Park, PA, (1983).

2.11 Tsai, C. Y., Ph.D. Thesis, The Pennsylvania State University, University Park, PA, (1985).

2.12 Scaroni, A. W., MS Thesis. The Pennsylvania State University, University Park, PA, (1979).

2.13 Daubert, T. E. and Danner, R. P., Data Compilation Tables of Properties of Pure Compounds, Design Institute for Physical Property Datä. American Institute of Chemical Engineers, (1985).

2.14 Annual Book of ASTM Standards, Vol. 05.05. American Society for Testing and Materials, Philadelphia, (1983).

2.15 Niksa, S. A., Russel, W. B. and Saville, D. A., Nineteenth Symposium (International) on Combustion. The Combustion Institute, 1151, (1983). 
2.16 Tamhankar, S. S., Sears, J. T., and Wen, C. Y., Fuel, 63, 1230, (1984).

2.17 Nsakala, N., Goetz, G. J., Patel, R. L. and Lao, T. C., Am. Chem, Soc. Div. Fuel Chem. Pre. 30(1), 221, (1985).

2.18 Scaroni, A. W., Walker, P. L., Jr. and Essenhigh, R. H., Fuel 60, 71, (1981).

2.19 Combustion, Fossil Power'Systerns, Chapter 3, (J. G. Singer, Editor), Combustion Engineering, Inc., Windsor, CT, (1981).

2.20 Fletcher, T. H. and Hardesty, D. R., Coal Combustion Science, Quarterly Progress Report, April - June, 1987b, SNLL.

2.21 Lightman, P. and Street, P. J., "Microscopical Examination of Heat Treated Pulverized Coal Particles", Fuel 47, 7, (1968).

2.22 Mahajan, O. P. and Walker, P. C., Jr., "Porosity of Coals and Coal Products", in Analytical Methods for Coal and Coal Products, (C. Karr, ed.), Chap. 4, Academic Press, New York (1978).

2.23 Satterfield, C. N., Heterogeneous Catalysis in Practice, McGraw-Hill, New York, 1980.

2.24 Fletcher, T. H. and Hardesty, D. R., Coal Combustion Science, Quarterly Progress Report, July - Sept., 1987a, SNLL.

2.25 Fong, W. S., "Plasticity and Agglomeration in Coal Pyrolysis", Ph.D. Thesis, Chem. Engr., M.I.T., (1986).

2.26 Tsai, C. Y., and Scaroni, A. W., "Pyrolysis During the Initial Stages of Pulverized Coal Combustion". Twentieth Symp. (Int'l) on Combustion, The Combustion Institute, pp. $1455,1984$.

2.27 Mackowski, M. and Wolff, E., "Microscopic Investigations of Pore Formations During Coking", Coal Science, Adv. Chem., No. 55, Amer. Chem. Sci., (1964).

2.28 Miura, S. and Silveston, P. L., "Changes of Pore Properties During Carbonization of Coking Coal", Carbon, Vol. 18, 93 (1980).

2.29 Tsai, C. Y. and Scaroni, A. W., "The Structural Changes of Bituminous 
2.30 Merrick, D., Fuel, 62, 540 (1983).

2.31 Rodgers, P. A., Creagh, A. L., Prange, M. M., and Prausnitz, J. M., Ind.

2.32 Freihaut, J. D., Proscia, W. M., and Seery, D. J., ACS Div. of Fuel Chem., Preprints, 32, 3. 129 (1987).

2.33 Freihaut, J. D., Proscia, W. M., and Seery, D. J., ACS Div. of Fuel Chem., Preprints, 33. 2. 262 (1988). (Accepted, Energy and Fueis 1988).

2.34 Maceral Analysis of PSOC1451D size cuts performed by Pennsylvania State University. Data communicated by $P$. Goldberg of DOE-PETC.

2.35 Unger, P. E. and Suuberg, E. M., Fuel, 606 (1984),

2.36 Oh, Myongsook Susan, "Softening Coal Pyrolysis", D. Sc. MIT. Dept. of Chem. Eng. (1983).

2.37 Desypris, J., Murdoch, P. and Williams, A., Fuel, 61, 807 (1982).

2.38 Suuberg, E. M., Peters, W. A., and Howard, J. B., 17th Combustion (Int.) Symposium, The Combustion Institute, 117 (1979).

2.39 Bautista, J. R., Russel, N. B. and Saville, D. A., Ind. Eng. Chem. Fundamental, 25, 536 (1986).

2.40 Gibbins, J., "Investigation of Primary Coal Pyrolysis Using a Variable Heating Rate Wire Mesh Apparatus", Ph.D. Thesis, Dept. of Chem. Eng. and Chemical Technology, Imperial College, London (1988).

2.41 Niksa, S., "Time-Resolved Weight Loss Kinetics for the Rapid Devolatilization of a Bituminous Coal", Ph.D. Thesis, Dept. of Chem. Eng., Princeton U. (1982).

2.42 Hamilton, L. H., Ayling, A. B. ana si.iboaka, M., Fuel, 58, 873 (1979).

2.43 Solomon, P. R. and Colket, M. B., 17th Symposium (Int.) on Combustion, The Combustion Institute, Pittsburgh, PA, 131 (1979).

2.44 Solomon, P. R. and Colket, M. B., Fuel, 57, 749 (1978). 
R88-PC70768

2.45 Karn, F. S., Friedel, R. A., and Sharkey, A. G., Jr., Carbon, 5, 25 (1967).

2.46 Sharkey, A, G., Jr., Shultz, J, L. and Friedel, R. A., Nature, 202, 988 (1964).

2.47 Karn, F. S., and Sharkey, A. G., Jr., Fuel, 47, 193 (1968).

2.48 Granger, A. F. and Ladner, W. R., Fuel, 49, 17 (1970).

2.49 Hertzberg, M., and Ny, Daniel, in NATO ASI Series, Series E (edited by J, Lahaye and G. Prado) 137, 104 (1987).

2.50 Ballantyne, A., et. al., Final Report DOE/PC/30291-6, DOE-PETC (1983).

2.51 Gat, N., et. al., Final Report DOE/PC/40273--4, DOE-PETC (1983).

2.52 Phenoc, Tran and Maloney, D. J., Twenty-Second Symposium (Int.) on Combustion, The Combustion Insittute (1988). 


\section{SECTION 3.0 - DEVOLATILIZATION MODELING}

The formation and evolution of heavy molecular weight hydrocarbons, tars, accounts for more than half the total mass loss of high volatile bituminous coals (Refs. 3.1-3.4). As observed in a wide range of heating conditions, the tars dominate the inltial mass loss of bituminous coal particles. The average chemical characteristics of the tars change significantly during the temperature resolved evolution process, with hydrogen-rich, lower molecular weight species evolving before the relatively hydrogen poor high molecular weight species in the latter stages. The primary tars are not collectively similar in structure to the parent coal with respect to elemental composition or functional group distributions. The earlier in the tar evolution process, the more dissimilar the tars relative to the parent coal. In addition, gas phase "secondary" reactions of tars can account for major. fractions of the light gas yields, depending on heating condicions. The distribution of the light gases and chemical characteristics of the collected tars are dependent on both the transient particle temperature and ambient gas temperature.

\subsection{General Considerations of HVA Bituminous Coal Devolatilization/Pyrolysis}

\subsubsection{Coal Structure Assumptions}

Given the observed devolatilization behavior, the following assumptions regarding coal structure are advanced in order to formulate a model for coal devolatilization:

\section{Assumption 1}

An Appalachian Province high volatile A bituminous coal consists of a distribution of aliphatic, hydroaromatic, and aromatic structures of varying size parameters and chemical composition.

\section{Devolatilization Implications}

The size parameter of most immediate relevance to coal devolatilization is the molecular weight of the molecular "unit" constituents of a coal. A molecular "unit" is a fragment of a so-called macro-molecular constituent of coal or an independent molecular species already present as such within the coal substrate. It is these molecular units that are referred to as attached tar precursors (ATP's) in the phenomenological sequence described in the next section. The molecular weight parameters are coupled to other important size parameters. For predominantly aliphatic species polymethylene chain length is significant, whereas for predominantly aromatic species the number of aromatic rings and degree of ring condensation are important structure parameters. It is these size parameters that partially determine vapor pressure properties of the tar precursor species. For example, long polymethylene chain lengths can becorne intertwined within the 
coal/char substrate, impeding their free flow to the particle surface and evaporation from the surface during devolatilization. Such conformational impedance could be phenomenologically attributed to molecular weight properties. Highly zondensed penny aromatic structures, with high interaction forces, will have lower vapor pressures than would be expected from their molecular weight alone.

The varying chemical composition characteristics of importance in determining devolatilization behavior are primarily related to the heteroatom content of the coal substrate molecular units. $\mathrm{O}, \mathrm{N}$ and $\mathrm{S}$ atoms contained in various functional groups within the molecular units impart dipole moment characteristics to the species. The polarity characteristics can make substantial contributions to the vapor pressure properties of the molecular species.

\section{Assumption 2}

The aliphatic, hydroaromatic and aromatic structures are bonded to each other by a distribution of bond types ranging from physical forces - hydrogen bonding, van der Waals interactions - to covalent bonding. The bonding distribution function is independent of the molecular unit size and composition distributions. That is, the coal is heterogeneous with respect to characteristic molecular size and bonding energies among characteristic sizes.

\section{Devolatilization Implications}

A range of hydrocarbon species by size, shape and heteroatom composition are created within the coal particle during transient heating through temperatures of $900^{\circ} \mathrm{C}+$. Relative to devolatilization observations, there is no preferential distribution of molecular sizes to a given type of bonding within the coal. That is, all sizes and composition of molecules that collectively compose the coal substrate are potentially distributed over all available bond energies, from physical to chemical. The mathematical nature of the orthogonal distribution functions describing the molecular size and bond energy functions are key unknowns. Their functional forms are, of course, key questions in the development of a comprehensive view of coal structure. For coal devolatilization the observable products (volatiles) are at least three reaction steps removed from the parent coal structure - detachment of attached tar precursors, intrapa ticle mäss transfer of detached tar precursors with possible reformation reactions, desorption of species from the particle surface (see Figs. 3.1 through 3.3). However, without a clear appreciation of the mass and bonding heterogeneity of coal structure, coal devolatilization in a wide range of heating conditions is not comprehensible with respect to conventional shemical or physical concepts. 


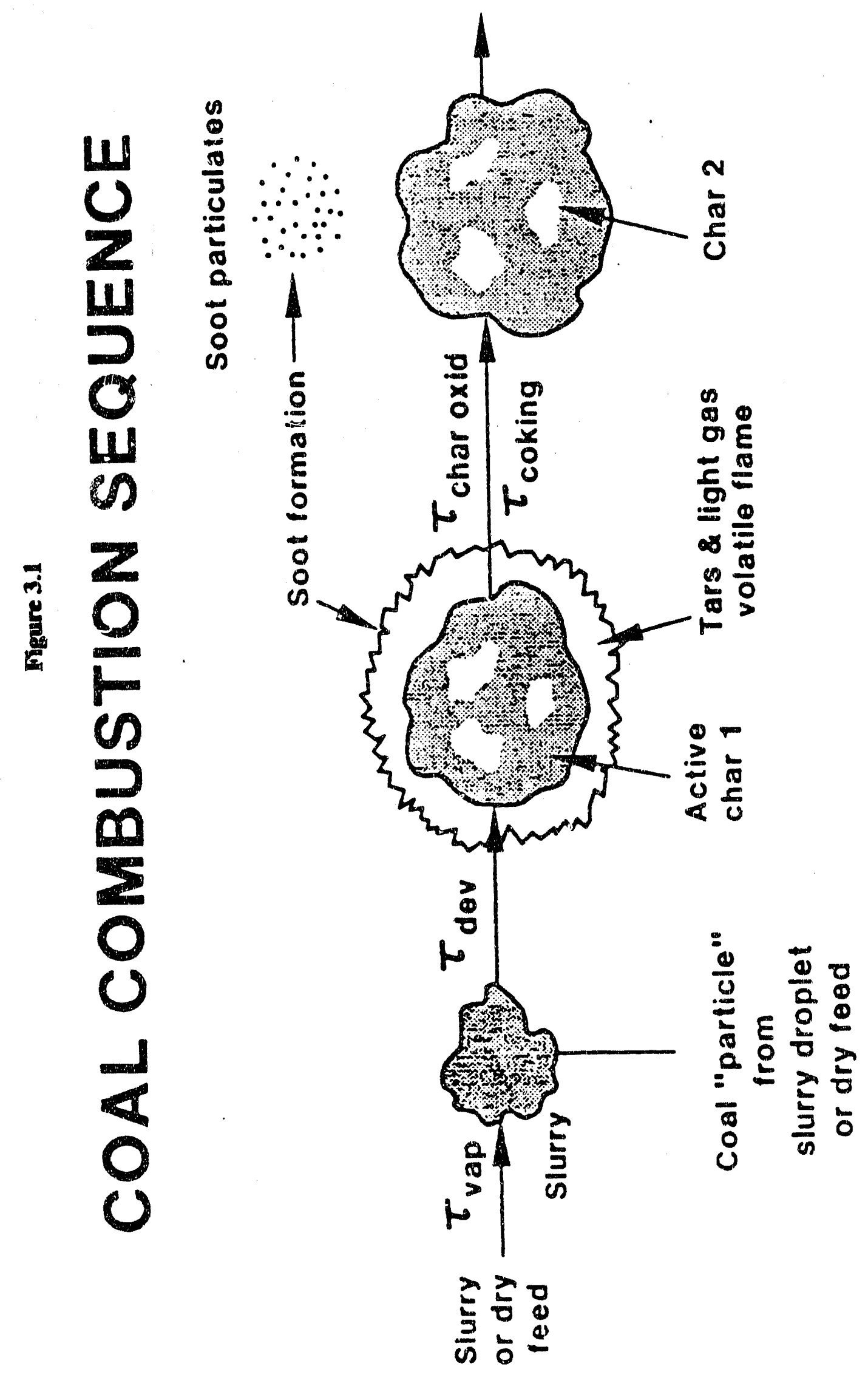




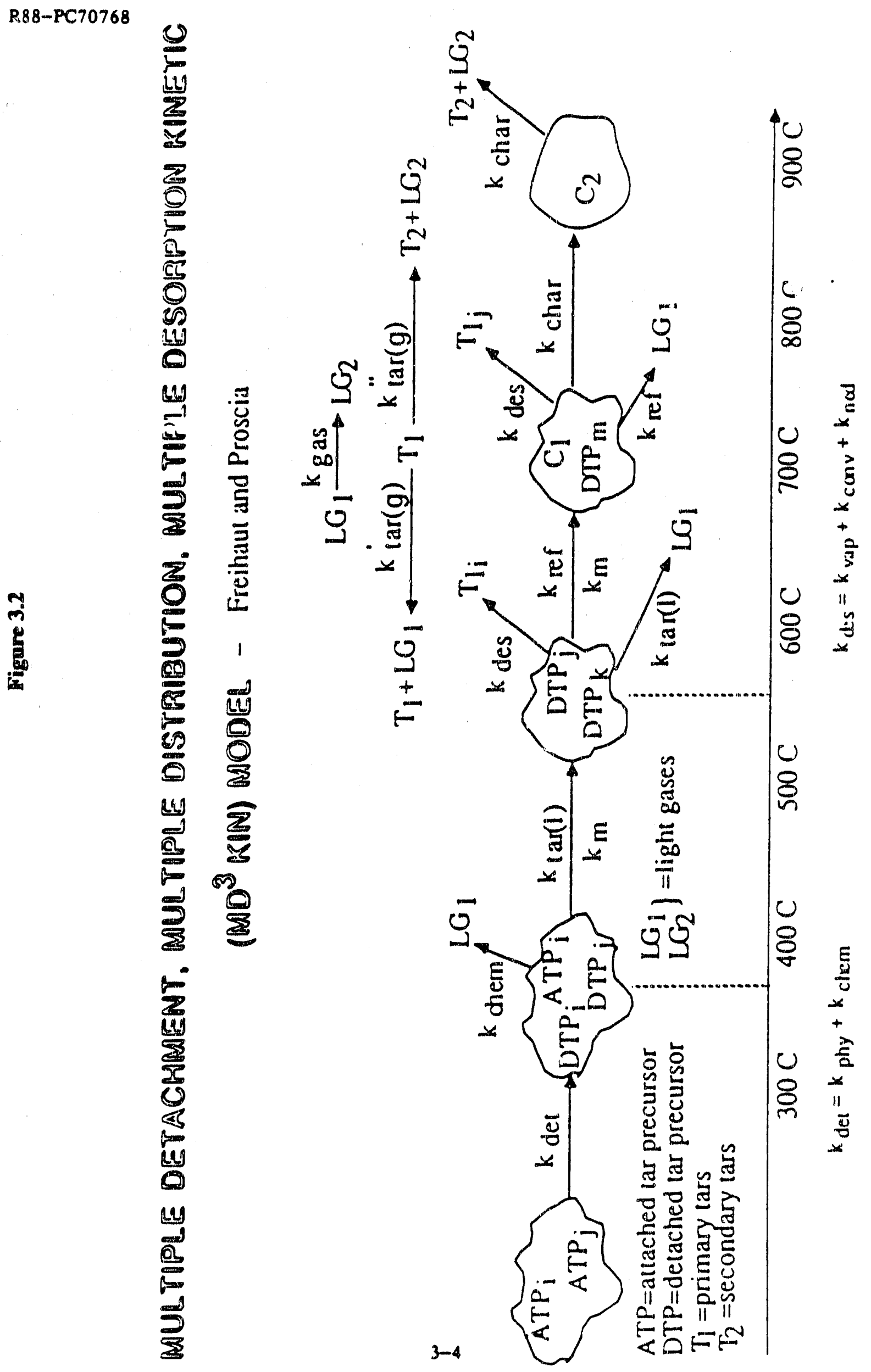




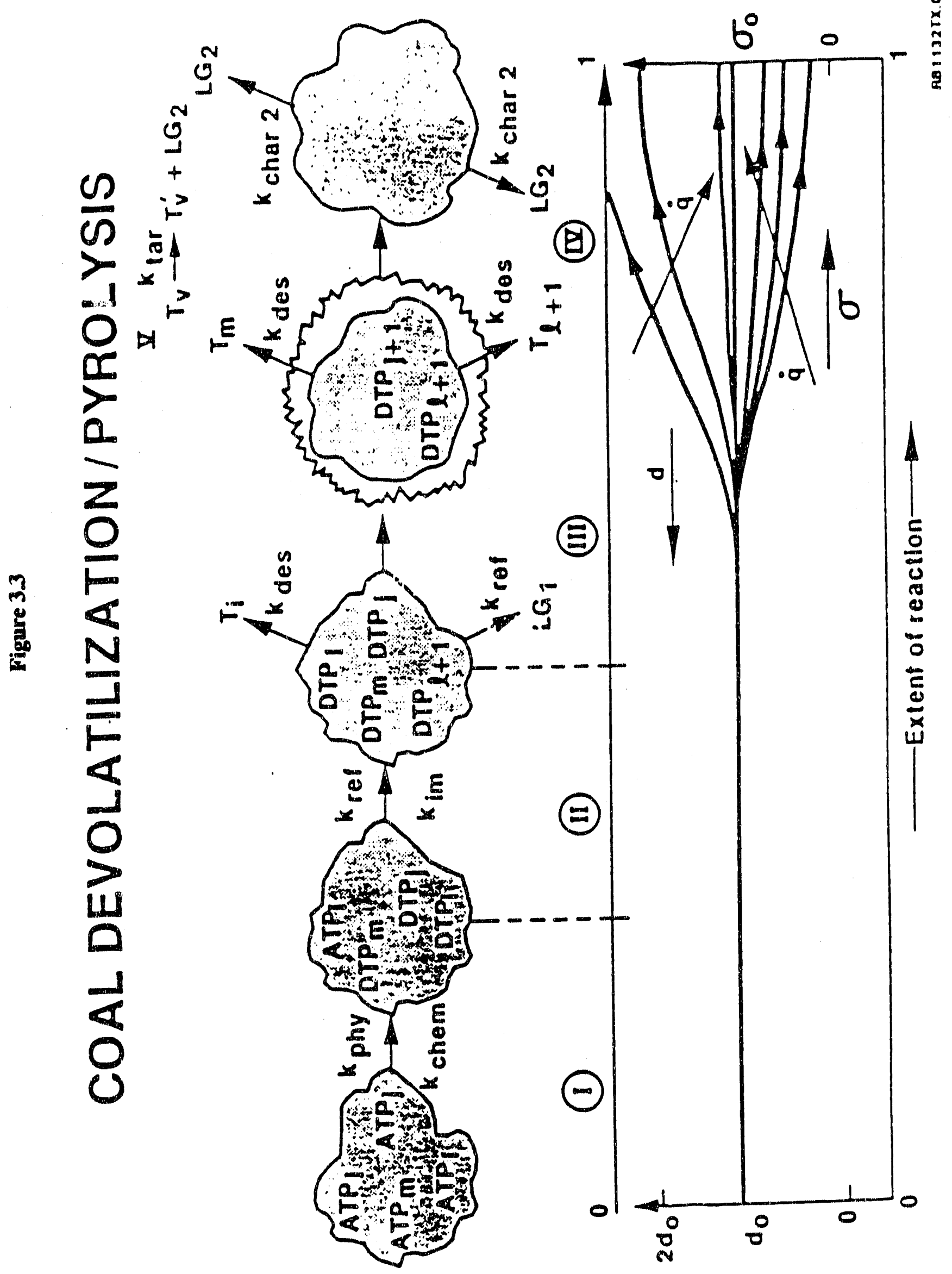




\section{Assumption 3}

The distributions of structure types and bonding types vary significantly with coal rank and geologic province - consisting primarily of covalently bonded non-aromatic structures for lignites: physically and covalently bonded hydroaromatic and aromatic structures for Appalachian province high volatile coals; and physically and chemically bonded condensed ring aromatic structures for medium volatile bituminous coals and greater rank. That is, the molecular size and composition distribution function as well as the bonding distribution functions vary significantly with coal rank characteristics. The general trend is to larger fractions of the parent coal mass incorporated by chemical covalent bonds with proportionately less physically bonded mass, the lower the rank of the parent coal. That is, the coalification process through the HVA bituminous stage of coalification is thought to partially degrade the polymeric nature of the original plant lignin and cellulose, primarily via decarbonylation, ether linkage degradation, and decarboxylation. These processes create a greater and greater portion of physically attached matter, but distributed over a wide range of molecular sizes (see assumption 2). As the coalification process continues to medium volatile bituminous and higher ranks, the aromicity and size of the aromatic ring clusters greatly increases as attached aliphalic chains are removed.

\section{Devolatilization Implication}

The above view of coal structure implies the fraction of the parent coal mass that can evolve as tars or that can be solvent extracted should pass through a maximum in the HVA bituminous coal range of ranks. Lower rank coals would require extensive pyrolytic cleavage of chemical bonds, producing mainly light gases. In addition, the coalification process would not have proceeded to the extent needed to produce large mass fractions of physically attached heavy hydrocarbons.

On these bases one would expect lower temperatures of tar evolution for lower rank coals, corresponding to smaller and more aliphatic tar species created in early stages of coalification relative to high volatile bituminous coals. The temperature of maximum tar evolution for a given coal should increase with coal rank, from a size distribution perspective alone. Higher rank coals would consist of large, condensed aromatic ring structures requiring higher temperatures to vaporize. However, once vaporized, the species should be rnore stable and exhibit less secondary reactions than lower rank coal tars, which contain greater heteroatom concentrations and diverse functionality. Convoluting the decrease in tar evolution temperature with decrease in size distribution is the lowering of the vapor pressure of low rank tars resulting from their higher heteroatom content. 


\section{Assumption 4}

The size distribution function of the molecular structures is independent of the bonding type distribution functions, that is, all riolecular unit sizes can be either chemically or physically bonded, or some combination of both.

\section{Assumption 5}

The fuel nitrogen is distri uuted uniformly throughout the mix of molecular types contained in a particular coal. That is, the fuel ritrogen serves as an internal marker of the nature of the molecular unit distribution and bond type distrib stion for a given coal rank.

\section{Devolatilization Implication}

The nitrogen distribution in the devolatilization products should mirror the hydrocarbon mass fraction distribution in the devolatilization products.

\section{Assumption 6}

The distribution of coal associated sulfur - total and organic to inorganic ratio - varies primarily with geologic province rather than rank characteristics of the parent coal.

\section{Devolatilization Implications}

For coals containing small fractions of inorganic sulfur - Rocky Mt. province, Great Plains nrovince, Gulf Coast province - the sulfur release during devolatilization should follow the coal oxygen pathways. For coals containing large fractions of inorganic sulfur - Appalachian and Central provinces - the sulfur transformation chemistry during devolatilization is complicared by intraparticle FeSx reactions.

\section{Assumption 7}

The distribution of inorganic matter among physical particulate, colloidal dispersion and chemical attachment forms varies appreciably with coal rank - low rank coals containing a larger fraction of colloidal and chemically attached forms than high volatile bituminous coals. For bituminous coals, the major mass fraction of mineral matter occurs in physically distinct particulates which are inclusions in the organic matrix of the coal.

\section{Devolatilization Implications}

Low rank, primary coal tars might be expected to contain appreciable amounts of colloidal or chemically attached inorganic species. Higher rank coal tars would contain appreciably less inorganic species since the amount of carboxylic groups and chelated functional forms are quite low in these ranks. 


\subsubsection{Phenomenological Sequence of Coal Devolatilization/Pyrolysis of a High Volatile Bituminous Coal}

Figures 3.1 to 3.3 display the sequence of the volatiles formation and release, particulate physical changes, product types and temperature and temperature regimes of an Appalachian Province, high volatile A bituminous coal. Heavy hydrocarbons are formed within (DTP = Detached Tar Precursors) the coal particle at relatively low temperatures $\left(30 ?-450^{\circ} \mathrm{C}\right)$ by physical detachment of Attached Tar Precursors (ATP) and at higher temperatures, by chemucal detachment. Liquid phase pyrolysis of DTP's results in the formation of lower molecular weight DTP's having vapor pressures great enough to escape from the particle, as well as light gases. Further heating results in the extra-particle evolution of the heavy hydrocarbons (tars) and the onset of light gas production $\left(450-650^{\circ} \mathrm{C}\right)$. Reformation reactions of DTP's, which result in the formation of char and light gases, are in competition with the liquid phase pyrolysis and desorption of DTP's. The low temperature light gases consist of mainly of $\mathrm{CH}_{4}$ and higher alkanes, $\mathrm{CO}, \mathrm{CO}_{2}, \mathrm{H}_{2} \mathrm{O}$ and some $\mathrm{C}_{2} \mathrm{H}_{4}$. High temperature char and tar gas phase reactions at gas and particle temperatures greater than $700^{\circ} \mathrm{C}$ preferentially produce $\mathrm{C}_{2} \mathrm{H}_{2}, \mathrm{HCN}, \mathrm{CO}$ and $\mathrm{C}_{2} \mathrm{H}_{4}$.

\subsection{HVA Coal Devolatilization - UTRC Model Formulation}

A mathematical model has been formulated which describes the transient devolatilization kinetics of a single coal particle exposed to transient heat transfer conditions. Measured heat transfer characteristics of the various reactors are required as inputs to the model. The particle energy balance includes terms for rate of internal energy gain, net radiative gain, net conductive gain, and energy dissipation due to heat of devolatilization. In addition to the UTRC phenomenological devolatilization model, single-step, two-step, distributed activation energy (DAEM), or the distributed-energy chain (DISCHAIN) model may be used to describe the devolatilization kinetics.

\subsubsection{Relationship to Reactor Characterization via Energy Balance Equation General Mass Loss - Particle Property Equations}

The properties of the reacting coal particle are defined as follows:

1) The particle morphology can be described by two parameters, equivalent diameter and sphericity. The particle diameter, $d_{p}$, is defined to be that of an equivalent volume sphere. The sphericity, $\psi$, is the ratio of the surface area of a sphere of the same volume as the particle to the surface area of the actual 
particle. Hence, the particle volume and surface area are given by,

$$
\mathrm{V}_{\mathrm{p}}=\frac{\pi \mathrm{d}_{\mathrm{p}}^{3}}{6}
$$

and,

$$
\mathrm{S}_{\mathrm{p}}=\frac{\pi \mathrm{d}_{\mathrm{p}}^{2}}{\psi}
$$

For the case of a spherical particle, $\psi=1$.

2) The extent of reaction is defined as

$$
u=\frac{m_{0}-m}{m_{0}}
$$

3) The remaining mass fraction is given by

$$
y=1-u
$$

4) Particle swelling can be described by

$$
d_{p}=d_{0}(1-u)^{a}
$$

5) Particle density can be described by

$$
Q_{p}=Q_{0}(1-u)^{\beta}
$$

The parameters $\alpha$ and $\beta$ are defined to be functions of extent of reaction. In addition, for softening coals, particles which are initially nonspherical in shape become nearly spherical during the swelling process. The sphericity, $\psi$, can also be defined to be a function : extent of reaction to account for this.

6) The rate of mass loss per unit superficial surface area is ciefined as

$$
R_{\mathrm{dev}}=-\frac{\dot{m}}{S_{p}}
$$

7) The particle is a gray body with $\epsilon_{\mathrm{p}}=a_{\mathrm{p}}=0.7$ as recommended by Fletcher et. al. (Ref. 3.5). 
8) Particle heat capacity is calculated using the Merrick (Ref, 3.6) model,

$$
C_{p}=Y_{d a t} C_{d a t}+Y_{a s h} C_{a s h}+Y_{\text {water }} C_{\text {water }}
$$

where the Y's are mass fractions of dry ash free coal, ash, and moisture, respectively. The heat capaoity of the dry ash free coal is given by,

$$
\mathrm{C}_{\mathrm{dat}}=\frac{8.314}{\mathrm{MW}_{\mathrm{c}}}\left[\mathrm{g}\left(\frac{380}{\mathrm{~T}}\right)+2 \mathrm{~g}\left(\frac{1800}{\mathrm{~T}}\right)\right][\mathrm{I} / \mathrm{g}-\mathrm{K}]
$$

where $g(z)=e^{z} /\left(\left(e^{z}-1\right) / z\right)^{2}$ and $M W_{c}=1 /\left(Y_{C} / 12+Y_{H}+Y_{0} / 16+Y_{N} / 14+Y_{S} / 32\right)$. The heat capacity of the ash and moisture components of the coal are given by,

$$
C_{a s h}=0.754+5.86 \times 10^{-4} \mathrm{~T} \quad[\mathrm{~J} / \mathrm{g}-\mathrm{K}]
$$

(with $\mathrm{T}$ in units of ${ }^{\circ} \mathrm{C}$ ) and

$$
C_{\text {water }}=4.187[\mathrm{~J} / \mathrm{g}-\mathrm{K}]
$$

respectively,

\section{Relationship to Specific Reactors}

Reactor-to-Particle Heat Transfar Modeling. The energy conservation equation for a devolatilizing coal particle exposed to radiative and conductive gains/losses is:

$$
Q_{p} V_{p} C_{p} T_{p}=a_{p} S_{p} I(t)-a_{r} \epsilon_{p} S_{p} \sigma T_{p}^{4}+\bar{H}_{N u} S_{p}\left(T_{B}-T_{p}\right)-\Delta H_{d e v} S_{p} R_{d e v}
$$

Substituting the definitions given above and rearranging yields:

$$
T_{p}=\frac{6}{C_{p} Q_{0} d_{0} \psi} \frac{1}{y^{a+\rho}}\left(a_{p} I(t)-a_{r} \epsilon_{p} \sigma T_{p}^{4}+\bar{h}_{N u}\left(T_{g}-T_{p}\right)\right)-\frac{\Delta H_{d e v} \dot{L}}{C_{p} y}
$$

The initial and boundary conditions used are a function of the particular reactor environment being modeled. The assumptions used to arrive at the radiarive and conductive gains/losses at the particle surface are discussed below. The gas properties used in the calculations are given in Table 3.1. 
TABLE 3.1

\section{GAS PROPERTIES}

\section{T IERMAL CONDUCTIVITY}

Monatomic Gases

$$
\lambda_{1}=(4.184)\left(1.9891 \times 10^{-4}\right) \sqrt{\mathrm{T} / \mathrm{MW}} /\left(\Omega_{\mathrm{v}, 1} \sigma^{2}\right) \quad[\mathrm{W} / \mathrm{cm}-\mathrm{K}]
$$

Polyatomic Gases (Euken approx.)

VISCOSITY

$$
\lambda_{i}=\left[C_{p_{i}}+(5 / 4)\left(8.314 / M W_{i}\right)\right] \mu_{i}
$$

$$
\begin{aligned}
\mu_{i} & =2.6693 \times 10^{-5} \sqrt{\mathrm{MW} T}\left(\Omega_{v_{1}} \mid \sigma^{2}\right) \quad[\mathrm{g} / \mathrm{cm}-\mathrm{s}] \\
\Omega_{v_{,} 1} & =1.16145\left(\mathrm{kT} / \epsilon_{i}\right)^{-.14874}+.52487 \exp \left(-.77320 \mathrm{kT} / \epsilon_{i}\right) \\
& +2.16178 \exp \left(-2.43787 \mathrm{kT} / \epsilon_{i}\right)
\end{aligned}
$$

Heated Grid_Reactor. The radiative input to a coal particle between the folds of a stainless steel heated grid is given by

$$
l(t)=\epsilon_{g r i d} d T_{B r i d}^{4}
$$

The temperature of the grid is measured in all experiments. The emissivity of the grid is a function of temperature and has been found experimentally to be:

$$
\epsilon_{\text {grid }}=0.43+1.13 \times 10^{-4} \mathrm{~T}_{\text {grid }}
$$

with $\mathrm{T}_{\mathrm{Brid}}$ in ${ }^{\circ} \mathrm{C}$. The absorptivity of the grid is assumed to be equal to the emissivity:

The condition heat transfer is calculated using a Nusselt number of two and assuming that the gas temperature in the vicinity of the grid is at the grid temperature. A correction for the effect of mass transport is applied to the convective heat transfer coefficient.

$$
\bar{h}_{N u}=\frac{N u d_{g}}{d_{p}}\left(\frac{B}{e^{B}-1}\right)
$$


with the blowing factor given by

$$
B=\frac{C_{P_{B}} \dot{u} m_{0}}{2 \pi \lambda_{g} d_{p}}
$$

Conductive losses in vacuum runs are possible due to the formation of a tar cloud in the reactor. The conduction loss through the tar cloud is estimated using a thermal conductivity value of $1.40 \times 10^{-4}$ $[\mathrm{W} / \mathrm{cm}-\mathrm{K}]$. This value has been estimated by assuming that the thermal conductivity of gaseous tar is $1 / 10$ that of liquid tar (Ref. 3.7). The importance of including this effect under high heating rate conditions, such as occur in the flash lamp, will be discussed below.

Elash_Lamp Reactor. Irradiance measurements at the flux levels used in the flash lamp have been obtained with a pyroelectric detector. These measurements are corrected for the detector absorptivity $\left(a_{\mathrm{d}}=0.9\right)$ as follows:

$$
I_{\text {actual }} \frac{I_{\text {measured }}}{a_{d}} \text {. }
$$

The reactor absorptivity, $a_{r}$, is assumed to be zero during the flash pulse and one after the pulse.

The inert gas temperature in the reactor is assumed to remain at the initial ambient temperature throughout the approximately $15 \mathrm{msec}$. flash pulse. Conduction heat transfer is calculated in the same manner as for the heated grid experiment. The conductive losses though the tar cloud in a vacuum experiment are significant. Table 3,2 lists the peak particle temperatures predicted in flash lamp vacuum runs with no concuction and with conduction through the tar cloud. If the conduction losses are not included, unrealistically high particle temperatures are predicted. In fact, the particle temperatures still appear to be somewhat high and inclusion of the effects of absorption of the incident radiative flux by the tar cloud should possibly be considered. 
TABLE 3.2

\section{PREDICTED PEAK PARTICLE TEMPERATURES [ $\left[{ }^{\circ} \mathrm{C}\right]$ FOR FLASH LAMP VACUUM EXPERIMENTS}

\begin{tabular}{ccccccc} 
& & & \multicolumn{2}{c}{ NO CONDUCTION } & GAS PHASE TAR CONDUCTION \\
RFL & KV & NDF & $10 \mu \mathrm{m}$ & $50 \mu \mathrm{m}$ & $10 \mu \mathrm{m}$ & $50 \mu \mathrm{m}$ \\
\hline 0.7 & 1.8 & 30 & 2220 & 930 & 1060 & 820 \\
1.0 & 1.5 & 60 & 2500 & 1135 & 1325 & 1005 \\
1.5 & 1.5 & 90 & 2920 & 1500 & 1810 & 1350 \\
2.2 & 2.2 & 60 & 3615 & 2280 & 2725 & 2115
\end{tabular}

Entrained Flow Reactors. The irradiance as a function of axial position in the UTRC HWHG reactor is obtained using a speciall; designed radiative flux probe. The flux measurements are corrected for the detector absorptivity $\left(a_{d}=0.92\right)$ in the same manner as for the flash lamp. The emissivity of the mullite (aluminum oxide) reactor muffle tube is calculated using:

$$
\epsilon_{\mathrm{r}}=\frac{I_{\text {aciual }}}{\sigma T_{w}^{4}}
$$

where $T_{w}$, the reactor wall temperature, is measured using a Type $R$ thermocouple compression loaded to the outer wall of the muffle tube.

The temperature of the argon entrainment gas was determined by conducting a series of temperature measurements with thermocouple beads of decreasing size. Extrapolation to zero bead size would eliminate. in principal, the radiative component of heat transfer, yielding the actual gas temperature. The measured temperatures for the two smallest bead sizes were observed to be approximately the same, indicating that either of these measurements approach that of the actual gas temperature. Figure 2.86 shows the measured gas temperature profiles for different reactor wall temperatures.

The conduction heat transfer to the particle is calculated using a Nusselt number given by:

$$
\mathrm{Nu}=2+0.6 \operatorname{Re}^{1 / 2} \operatorname{Pr}^{1 / 3}
$$

where the Reynolds number is based on the relative velocity between the particle and the gas flow. 
R88- PC70768

The particle veloclty is determined from the following force balance:

$$
m_{p} \frac{d v_{p}}{d t}=m_{p} g-Q_{g} v_{p g}+\frac{1}{2} C_{D} A_{p r} Q_{B}\left(v_{B}-v_{p}\right)\left|v_{B}-v_{p}\right|
$$

with

$$
A_{p r}=\frac{\pi d_{p}^{2}}{4}
$$

and

$$
C_{D}=\frac{2.4}{\operatorname{Re}}+\frac{6}{1+\sqrt{\operatorname{Re}}}+0.4
$$

Note tha: the projected area is given as that of an equivalent volume sphere. Although morphology influeuces the particle heating rate, since the particle experiences a uniform heat flux from all directions, the same is not true for drag because the gas flow field is essentially unidirectional. In settling velocity experiments (very low Reynolds number in a viscous, quiescent fluid), nonspherical particles orient their largest dimension perpendicular to the relative velocity vector between the particle and the fluid. However. in entrained flow reactors, the gas flow is not likely to be completely laminar, since mixing occurs between the primary and secondary gas flows. In addition, the devolatillzation prosess leads to jetting of volatiles which can cause the particles to spin. Therefore, the particles are assumed to have a random orientation relative to the velocity vector, with the result that, on average, the projected area can be approximated as that of an equivalent volume sphere.

Rearranging Eq. (3.21) gives,

$$
\frac{d v_{p}}{d t}=\frac{\left(Q_{p}-Q_{g}\right) g}{Q_{p}}+\frac{3 C_{D} Q_{3}\left(v_{B}-v_{p}\right)\left|v_{B}-v_{p}\right|}{4 Q_{p} d_{p}}
$$

An additional equation is used to determine the axtal position of the particle in the reactor, since the irradiance and gas temperatures are known as functions of position:

$$
\frac{d z_{p}}{d t}=v_{p}
$$


K88-PC70768

\subsubsection{Devolatilization/Pyrolysis Reaction Network and Mathematical Formulation}

The overali reaction network for the UTRC model of coal devolatlization is depicted in Fig. 3.4. The mathematical formulation sor each of the reactions is described in the following paragraphs.

Intra-Particle Formation of Detached Tar Precursors (DTP)

Physical Detachment. In light of the vew of coal structure postulated above, a significant fraction of the parent coal mass consists of heavy hydrocarbon species physically attached to the mix of covalently bonded structures of similar size and structure parameters. The detachment of tar precurscrs involves both physi-desorption ( $\left.k_{p h y s}\right)$ from and thermally stimulated cleavage $\left(k_{c h e m}\right)$ of the three dimensional covalent network in the parent coal structure. The physical detachment process occurs over a finite range of temperatures and is modeied with a Gaussian distribution of melting points with a mean, $T_{m}$, and a standard deviation, $\sigma_{\mathrm{m}}$. Fong et. al. (Ref. 3.8) used a mean of $623 \mathrm{~K}$ and a standard deviation of $30 \mathrm{~K}$ for Pittsburgh No. 8 seam bituninous coal. The rate for physical detachment is given by,

$$
k_{p h y s}=f_{m} \frac{1}{\sigma_{m} \sqrt{2 \pi}} \exp \left(-\frac{\left(T-T_{m}\right)^{2}}{2 \sigma_{m}^{2}}\right) \frac{d T}{d t} .
$$

where $f_{m}$ is the mass fraction of coal which is physically attached.

Chemical Detachment. Chemical detachment is postulated to be the result of the breaking of bonds between the molecular units of the coal. The mass rate of bond breaking is given by,

$$
\frac{d B_{B}}{d t}=k_{\text {chem }}\left(B^{*}-B_{B}\right) \text {, }
$$

where the rate constant for chemical detachment is given by a standard Arrhenius expression,

$$
k_{\text {chem }}=A_{\text {chem }} \exp \left(-E_{\text {chem }} / R T\right) \text {, }
$$

$B^{*}$ is the initial mass fraction of unbroken bonds in the coal and $B_{B}$ is the mass. fraction of bonds which have broken. It is assumed that broken bonds are converted to an equivalent mass of light gas $L G_{1}$ with molecular weight $\mathrm{MW}_{\mathrm{LG}_{1}}$. The light gases produced consist mainly of $\mathrm{CH}_{4}, \mathrm{C}_{2} \mathrm{H}_{8}, \mathrm{C}_{2} \mathrm{H}_{4}, \mathrm{CO}, \mathrm{CO}_{2}$ and $\mathrm{H}_{2} \mathrm{O}$.

The number of bonds which must break to liberate a detached tar precursor (DTP) from the ATP structure is most likely a function of coal type and extent of reaction. The number of bonds required to 


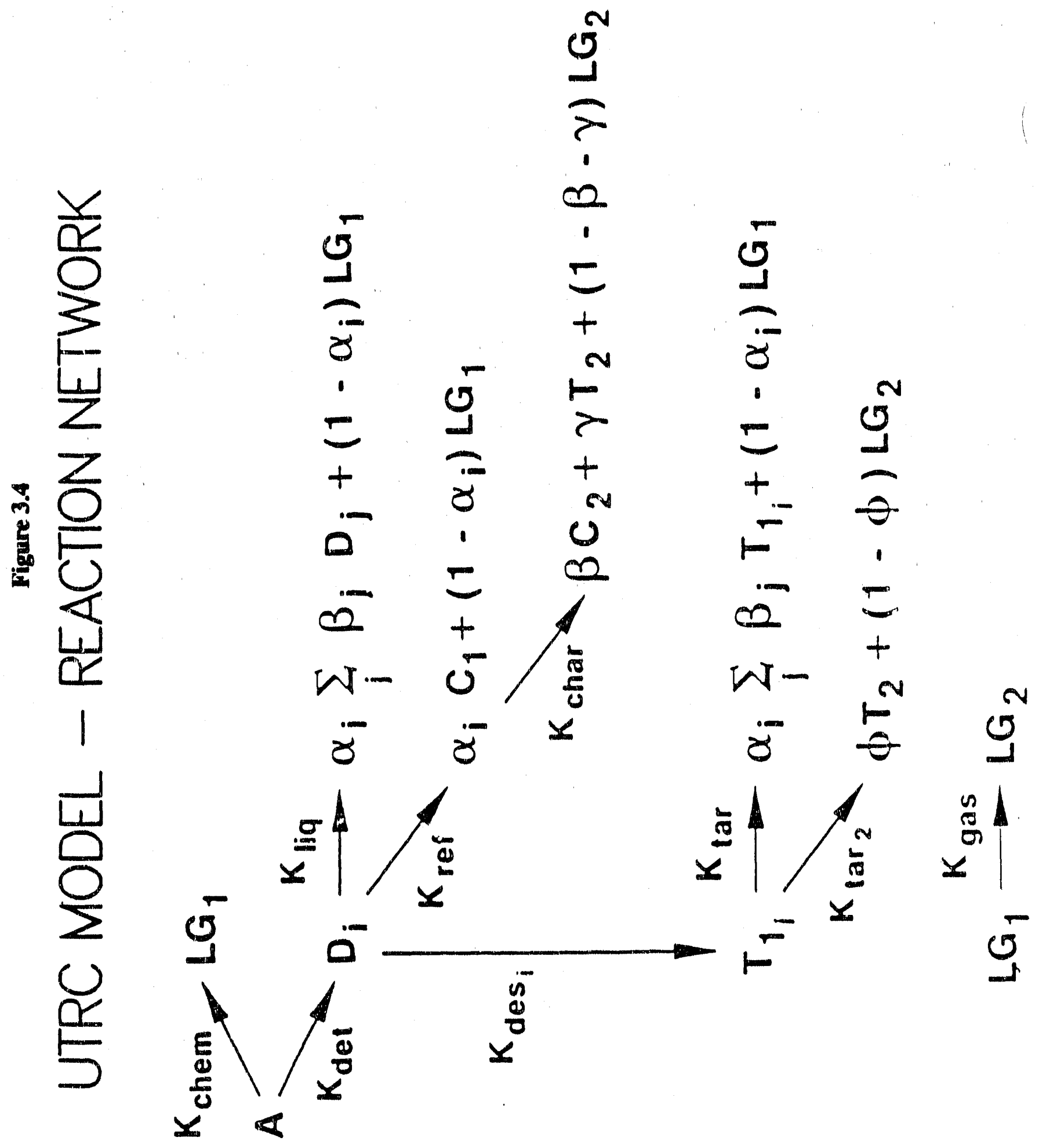


detach DTP $D_{1}$ of molecular weight $M W_{1}$ is given by the bonding distribution functi .. $N_{a}\left(M W_{1}\right)$. Investigators have used Monte Carlo methods (Ref. 3.9), linear chain statistics (Ref, 3.10), and percolation theory of Berhe lattices (Ref. 3.11) to model the disintegration of infinite lattices into clusters of finite size. These models have all assumed that the structure of coal can be represented by an average lattice structure. Refinements to these models should allow for multiple structure types within a particular coal. Results from such modeling of lattice disintegration can be used to determine correlations for the bonding distribution. $N_{B}\left(M W_{1}\right)$, as a function of coal type and extent of reaction. The present modeling effor uses a bonding distribution given by

$$
N_{B}\left(M W_{1}\right)=\frac{n_{0} M W_{1}}{M W_{s}}
$$

where $n_{b}$ is the number of bonds per lattice site which must be broken and $M W_{1} / M W_{3}$, the ratio of the molecular weight of $D_{1}$ to that of a site, gives the number of sites in the cluster. This bonding distribution simply states that, for constant $n_{b}$, the number of bonds which must be broken to liberate a DTP is proportional to the molecular weight of that DTP.

In addition to the bonding distribution, the molecular weight distribution of the DTP's is needed to determine the rate of chemical detachment. The weight distribution of DTP's is given by $f_{D}\left(M W_{1}\right)$ and will be described in the next section. The total number of bonds which must break to detach a unit mass of $D$ (where $D=\Sigma D_{1}$ ) is given by,

$$
N B_{101}=\sum_{i=1}^{n} \frac{f_{n}\left(M W_{1}\right) N_{B}\left(M W_{1}\right)}{M W_{1}}
$$

Note that for the simplified bonding distribution given in Eq. (3.29). NBtot reduces to $n_{b} / M W_{3}$.

Now, to determine the rate of chernical detachment, the rate of bond breaking is divided by the total number of bonds which must break to liberate a unit mass of $D$,

$$
\left(\frac{d D}{d t}\right)_{\text {chem }}=\frac{d B_{B} / d t}{M W_{L G_{1}}} \frac{1}{N B_{t o t}}
$$


where the number of bond breaks per second has been obtained by dividing the mass rate of bond breaking by the molecular weight of each bond. Finally, the rate of chemical detachment for each DTP of molecular weight $M W_{1}$, is given by,

$$
\left(\frac{d D_{i}}{d t}\right)_{\text {chem }}=f_{D}\left(M W_{1}\right)\left(\frac{d D}{d t}\right)_{\text {chem }} .
$$

DTP Molecular Weighe Distribution. The detachment process, whether physical or chemical, results in the formation of DTP's of a range of molecular weights. Tars of the widest MW range are ouserved in vacuum flash lamp experiments. The molecular weight distribution (MWD) of these tars will be used to approximate the MWD of the DTP's within the coal. The observed shape of the tar MWD's can be fairly well represented by a gamma distribution function.

$$
f_{N}\left(M W_{1}\right)=\frac{\left(M W_{1}-\gamma\right)^{a-1}}{\beta^{a} \Gamma(a)} \exp \left[-\left(\frac{M W_{1}-\gamma}{\beta}\right)\right]
$$

with $f_{N}=$ the number of molecules with weight $M W_{1}$. The parameter $y$ fixes the origin where $f_{N}$ is zero, that is, $\gamma=M W_{0}$, the lower limit of the observed MWD. $\Gamma(\alpha)$ is the gamma function. The parameters $\alpha$ and $\beta$ are determined by equating the first and second moments of the distribution function to the number and weight average molecular weights of the observed distribution,

$$
\begin{gathered}
M W_{N}=\alpha \beta+\gamma, \\
M W_{W}=\frac{a(a+1) \beta^{2}+2 a \beta \gamma+\gamma^{2}}{a \beta+\gamma} .
\end{gathered}
$$

Equation (3.33) gives the number distribution; the weight distribution needed for comparison with MWD's determined by size exclusion chromatography (SEC) is given by,

$$
f_{D}\left(M W_{1}\right)=\frac{M W_{1} f_{N}\left(M W_{1}\right)}{a \beta+\gamma} \Delta M
$$

where the weight distribution has been normalized using $M W_{N}$ and partially integrated by multiplying by the size of the molecular weight interval $\Delta M$. 
R88-PC70768

Thus, the weight distribution of detached tar precursors, $f_{D}$, is given by $\mathrm{Eq} .(3.36)$ with appropriate selection of the parameters $a_{D}, \beta_{D}$ and $\gamma_{D}$ (the $D$ subscript has been added here to avold confusion with other parameters which will be introduced later).

\section{Desorption of Detached Tar Precursors = Tar Evolution}

The desorption $\left(k_{d e s}\right)$ of heavy hydrocarbons from the particle surface to the surrounding gas phase may occur by a variety of transfer modes: heavy hydrocarbon vaporization $\left(\mathrm{k}_{\mathrm{vap}}\right)$, nonequilibrium desorption $\left(k_{n e d}\right)$, convective entrainment in escaping gases ( $\left.k_{\text {conv }}\right)$. The activation energy for the vaporization rate is taken as the molar enthalpy of vaporization.

$$
E_{\mathrm{vap}_{\mathrm{i}}}=\Delta \mathrm{H}_{\mathrm{vap}_{\mathrm{i}}}=\Delta h \cdot M \mathrm{~W}_{\mathrm{i}}
$$

with $\Delta h$, the specific enthalpy of vaporization, approximately constant for hydrocarbons (varying from 75-100 cal/g for aromatics to $30-60 \mathrm{cal} / \mathrm{g}$ for aliphatics). The vaporization rate for a DTP with molecular weight $M W_{i}$ is given by,

$$
k_{v_{\text {vap }}}=A_{\text {vap }} \exp \left(-E_{v_{\text {app }}} / R T\right) .
$$

The doninane mode of transport in any one set of devolatilization conditions appears to depend heavily on the mode and ate of heat flux to the particles. Conditions which enhance vaporization and/or convective transfer involve cracking reactions of tar precursors (see below) which produce higher vapor pressures speci.s and light gas byproducts.

The detached tar precursors must be transported to the particle surface $\left(k_{1 m}\right)$ before they can be transferred to the boundary layer surrounding the particle and thereby to the ambient field. However, the equations presented heie do not account for intraparticle mass transfer resistance.

\section{Liquid Phase Pyrolysis of Detached Tar Precursors and the Production of Low Temperature Light Gases.}

Within the particle, the detached tar precursors undergo cracking reactions $\left(k_{119}\right)$ which yield light gases and lighter molecular weight detached tar precursors, 
R88-PC70768

$$
\mathrm{D}_{1} \rightarrow a_{1} \sum_{j=1}^{1} \beta_{i} \mathrm{D}_{1}+\left(1-a_{1}\right) \mathrm{LG}_{1}
$$

with $D_{1}=$ DTP species with molecular weight $M W_{1}$ and,

$$
a_{1}=\frac{M W_{1}-M W_{L O_{1}}}{M W_{1}}
$$

where $M W_{L O_{1}}$ is the average molecular weight of light gas species $L G_{1}$.

The model presently assurnes that these cracking reactions redistribute the mass of cracked $D_{1}$ equally among all lower molecular weight intervals as well as into lower molecular weights within the same molecular weight interval $\left(D_{i}\right.$ to $\left.D_{1}\right)$, therefore, $\beta_{1}=1 / \mathrm{i}$. The cracking of tar precursors io smaller molecular weights eventually produces tar species having vapor pressures great enough to escape the particle subserate. The light gases produced by the cracking reactions consist mainly of $\mathrm{CH}_{4}, \mathrm{C}_{2} \mathrm{H}_{6}, \mathrm{C}_{2} \mathrm{H}_{4}, \mathrm{CO}, \mathrm{CO}_{2}$ and $\mathrm{H}_{2} \mathrm{O}$.

Reformation Reactions of Detached Tar Precursors Leading to the Formation of Char and Low Temperature Light Gases

In competition with cracking reactions which yield lighter molecular weight DTP's and light gases, are reformation reactions $\left(k_{r e t}\right)$ of the detached tar precursors which yield char and light gases,

$$
D_{1} \rightarrow a_{1} C_{1}+\left(1-a_{1}\right) L G_{1}
$$

The rate of these reformation reactions, relative to the cracking reactions, is dependent on the mode of transport of DTP's to the particle surface and the temperature of the surrounding intraparticle substrate. It is expected that measurable light gas production will be associated with any significant pyrolytic reactions (whether cracking or reformation) of the detached tar precursors. The same light gases are produced by the reformation reactions as the cracking reactions above.

\section{High Temperature Char Solid State and Tar Gas Phase Pyrolysis Reactions}

Char Degassing. The completion of the tar evolution process is followed by the pyrolytic, degassing reactions of the residual "virgin" char ( $\left.k_{\text {char }}\right)$,

$$
\mathrm{C}_{1} \rightarrow \beta \mathrm{C}_{2}+\gamma \mathrm{T}_{2}+(1-\beta-\gamma) \mathrm{LG}_{2}
$$

These reactions occur as the initial char seeks to achieve its thermodynamically preferred graphitic--like structure. The main gases produced in these relatively slow reactions are $\mathrm{CH}_{4}, \mathrm{CO}, \mathrm{H}_{2}$ and $\mathrm{HCN}$. 
Gas Phase Secondary Reactions. Low temperature $\left(<700^{\circ} \mathrm{C}\right)$ reformation and cracking reactions of tar precursors produce the light gas structures noted above. Analogous to the cracking reactions of the DTP's $\left(k_{1, q}\right)$, tars undergo similar cracking reactions in the gas phase $\left(k_{t a r}\right)$, the principal difference being a reduction in rate due to the much lower number density in the gas phase. These low temperature, gas phase cracking reactions yield light gases and lighter molecular weight tars,

$$
T_{1 i} \rightarrow a_{i} \sum_{j=1}^{1} \beta_{i} T_{1 i}+\left(1-a_{1}\right) L G_{1}
$$

where the definitions for $a_{i}$ and $\beta_{\mathrm{j}}$ are the same as given previously for the case of DTP cracking. The same light gases are produced by gas phase tar cracking as for condensed phase DTP cracking.

High temperature $\left(>800^{\circ} \mathrm{C}\right)$ pyrolytic reactions of tars $\left(\mathrm{k}_{\mathrm{tar}_{2}}\right)$ produce soot precursors, soot, $\mathrm{H}_{2}, \mathrm{CO}, \mathrm{C}_{2} \mathrm{H}_{2}$ and $\mathrm{HCN}$,

$$
\mathrm{T}_{1} \rightarrow \phi \mathrm{T}_{2}+(1-\phi) \mathrm{LG}_{2}
$$

where $T_{1}=\Sigma T_{1 j}$.

Light gas species undergo pyrolytic reactions in the gas phase $\left(\mathrm{k}_{\mathrm{gat}}\right)$ as follows,

$$
\mathrm{LG}_{1} \rightarrow \mathrm{LG}_{2}
$$

\section{Summary of Kinetic Rate Equations}

The kinetic reaction system used to model coal devolatilization is depicted in Fig. 3.4. The ordinary differential equations which describe the net rates of production of each species in the model are listed below:

$$
\begin{aligned}
& \frac{d B_{B}}{d t}=k_{\text {chem }}\left(B^{\prime}-B_{B}\right) \\
& \frac{d A}{d t}=-k_{d e t}-\frac{d B_{B}}{d t}
\end{aligned}
$$




$$
\begin{aligned}
& \text { with } \quad k_{d e t}=k_{p h y t}+\frac{d B_{B} / d t}{M W_{L G_{1}}} \frac{1}{N B_{t a t}} \\
& \frac{d D_{1}}{d t}=f_{D}\left(M W_{1}\right) k_{d e t}-\left(k_{d e s_{1}}+k_{r e l}+k_{11 q}\right) D_{1}+\sum_{j=1}^{n} a_{1} \beta_{1} k_{11 q} D_{j} \quad 1=1 \ldots n \\
& \frac{d T_{11}}{d t}=k_{d e 1_{1}} D_{1}-\left(k_{1 a r}+k_{\operatorname{tar}_{2}}\right) T_{1_{1}}+\sum_{j=1}^{n} a_{j} \cdot \beta_{j} k_{t a r} T_{11} \quad i=1 \ldots n \\
& \frac{d T_{2}}{d t}=\gamma \quad k_{\text {char }} C_{1}+\phi \quad k_{\text {tar } 2} T_{1} \\
& \frac{d L G_{1}}{d t}=\frac{d B_{B}}{d t}+\sum_{i=1}^{n}\left(\left(1-a_{1}\right)\left(k_{\text {ret }}+k_{l, q}\right) D_{1}\right)+\sum_{i=1}^{n}\left(\left(1-a_{1}\right) k_{\text {tar }} T_{11}\right)-k_{g a t} L G_{1} \\
& \frac{d L G_{2}}{d t}=(1-\beta-\gamma) k_{c h a r} C_{1}+(1-\phi) k_{\text {tar }} T_{1}+k_{s a s} L G_{1} \\
& \frac{d C_{1}}{d t}=\sum_{i=1}^{n} a_{1} k_{r e t} \quad D_{1}-k_{c h a r} C_{1} \\
& \frac{d C_{2}}{d t}=\beta \quad k_{\text {char }} C_{1}
\end{aligned}
$$

\subsubsection{Results and Kinetic Parameters}

\section{Results for Idealized Conditions}

The UTRC coal devolatilization model has been exercised for constant heating rate conditions of 10 . $10^{2}, 10^{3}, 10^{4}, 10^{5}$, and $10^{8} \mathrm{C} / \mathrm{sec}$. The parameter set used for these calculations is summarized in Table 3.3. The mass fractions of each of the species tracked by the model are plotted versus particle temperature in Figs. 3.5 to 3.10. The attached tar precursors (A) are seen to detach by physical melting at $300-400^{\circ} \mathrm{C}$ at all heating rates, whereas the temperature range of chemical detachment shifts to higher temperatures at higher heating rates. Formation of char $(\mathrm{Cl}$ and $\mathrm{C} 2)$ from detached tar precursors (D) is seen to be significant only at heating rates lower than $1000^{\circ} \mathrm{C} / \mathrm{s}$. This is a consequence of the lower activation energy of the reformation reaction relative to that of the vaporization rate. (Note that the remaining attached tar precursors can also be considered char.) The primary tar (T1) evolution process mirrors the detachrnent process; there is an initial burst of tar representing the fraction of the physically detached DTP's 


\section{TABLE 3.3 - UTRC MODEL PARAMETERS}

\begin{tabular}{|c|c|}
\hline $\begin{array}{l}\text { MELTFRAC } \\
\text { MELTMEAN } \\
\text { MELTSIGMA }\end{array}$ & $\begin{array}{r}.07 \\
623 \\
30\end{array}$ \\
\hline $\begin{array}{l}\text { FBRIDG } \\
\text { BONDSSITE }\end{array}$ & $\begin{array}{r}.17 \\
3.2 \\
\text { COAL UNIT }\end{array}$ \\
\hline $\begin{array}{l}\text { WTMON } \\
\text { WTBP.IDG } \\
\text { WTLG1 }\end{array}$ & $\begin{array}{l}72 \\
20 \\
20\end{array}$ \\
\hline ALPHAD & $\begin{array}{r}263 \\
\text { DTP's }\end{array}$ \\
\hline $\begin{array}{l}\text { BETAD } \\
\text { GAMMAD } \\
\text { MWINIT } \\
\text { DI }\end{array}$ & $\begin{array}{r}559 \\
125 \\
150 \\
50\end{array}$ \\
\hline $\begin{array}{l}\text { ACHEM } \\
\text { ECHEM }\end{array}$ & $\begin{array}{r}1.0 \mathrm{E} 13 \\
45241\end{array}$ \\
\hline $\begin{array}{l}\text { ALIQ } \\
\text { ELIQ }\end{array}$ & $\begin{array}{r}1.0 \mathrm{E} 13 \\
45241\end{array}$ \\
\hline $\begin{array}{l}\text { AVAP } \\
\text { EVAP }\end{array}$ & $\begin{array}{r}1.0 \mathrm{E} 13 \\
75\end{array}$ \\
\hline $\begin{array}{l}\text { AREF } \\
\text { EREF }\end{array}$ & $\begin{array}{l}7.3 \mathrm{E5} \\
20000\end{array}$ \\
\hline $\begin{array}{l}\text { ACHAR } \\
\text { ECHAR } \\
\text { BETA }\end{array}$ & $\begin{array}{r}1.0 \mathrm{E} 10 \\
66500 \\
.82\end{array}$ \\
\hline GAMMA & 0.0 \\
\hline ATAR & $1.0 E 10$ \\
\hline ETAR & 45241 \\
\hline ATAR2 & $1.0 \mathrm{E} 13$ \\
\hline $\begin{array}{l}\text { ETAR2 } \\
\text { PHI }\end{array}$ & $\begin{array}{r}66500 \\
0.9\end{array}$ \\
\hline $\begin{array}{l}\text { AGAS } \\
\text { EGAS }\end{array}$ & $\begin{array}{r}1.0 \mathrm{E} 17 \\
88400\end{array}$ \\
\hline
\end{tabular}

MASS FRACTION OF COAL WHICH MELTS
[K] MEAN OF MELTING POINT GAUSSIAN
[K] STD DEVIATION

FRACTION OF COAL MASS WHICH IS BRIDGE MASS NO. OF BONDS/SITE WHICH MUST BREAK TO FREE A MW OF A COAL UNIT SITE (amu) MW OF A BRIDGE (amu) MW OF LG1 (amu)

MWD PARAMETERS FOR GAMMA DISTRIBUTION OF

BASED ON MWD OF VAC FL TAR 1451709B (amu) USING NEW MODCOM GPC CALIBRATION (amu) FIRST MW INTERVAL (28 INTERVALS ARE USED) (amu) SPACING OF MW INTERVALS (amu)

\section{BRIDGE BREAKING RXN}

PRE-EXPONENTIAL $\left(\mathrm{sec}^{-1}\right)$

DTP CRACKING RXN ACTIVATION ENERGY (cal)

DTP CRACKING RXN

PRE-EXPONENTIAL ACTIVATION ENERGY

VAPORIZATION RATE HEAT OF VAPORIZATION [CAL/GM] PRE-EXPONENTIAL $\left(\sec ^{-1}\right)$ DTP REFORMATION RXN PRE-EXFONENTIAL ACTIVATION ENERGY

CHAR DEGASSING RXN PRE-EXPONENTIAL $\left(\mathrm{sec}^{-1}\right)$ ACTIVATION ENERGY (cal) FRACTION OF C1 CONVERTED TO C2 BY CHAR DEGASSING FRACTION OF C1 CONVERTED TO T2 BY CHAR DEGASSING

$\begin{array}{ll}\text { LOW TEMP TAR PYROLYSIS } & \left.\text { PRE-EXPONENTIAL ( } \mathrm{sec}^{-1}\right) \\ \text { RXN } & \text { ACTIVATION ENERGY (cal) } \\ \text { HIGH TEMP TAR PYROLYSIS } & \text { PRE-EXPONENTIAL ( } \mathrm{sec}^{-1} \text { ) } \\ \text { RXN } & \text { ACTIVATION ENERGY (cal) } \\ \text { FRACTION OF T1 CONVERTED TO T2 BY TAR2 RXN } \\ \left.\text { GAS SPECIES PYROLYSIS RXN PRE-EXPONENTIAL (sec }{ }^{-1}\right) \\ \text { ACTIVATION ENERGY (cal) }\end{array}$


Figure 3.5
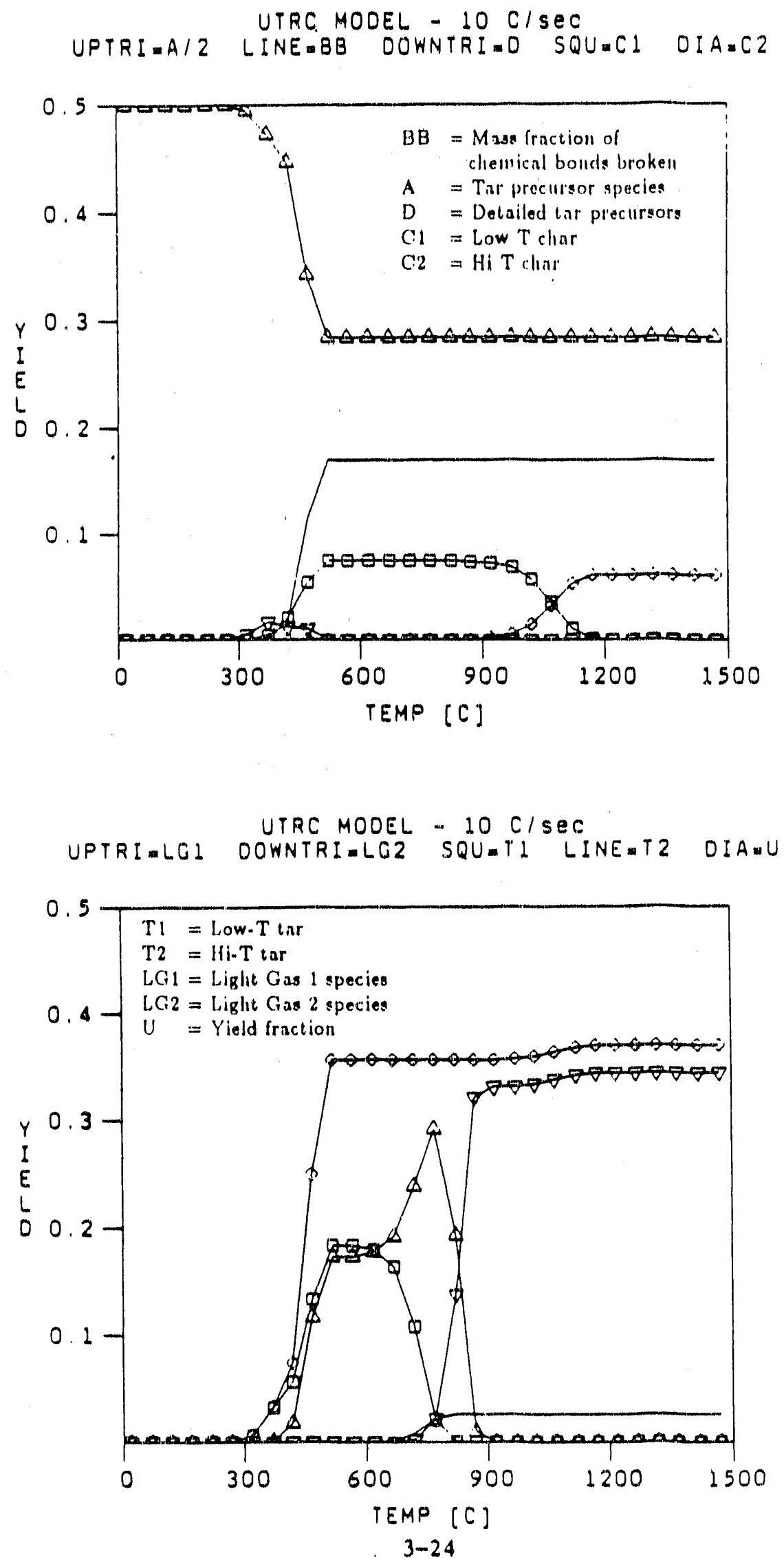
Figure 3.6
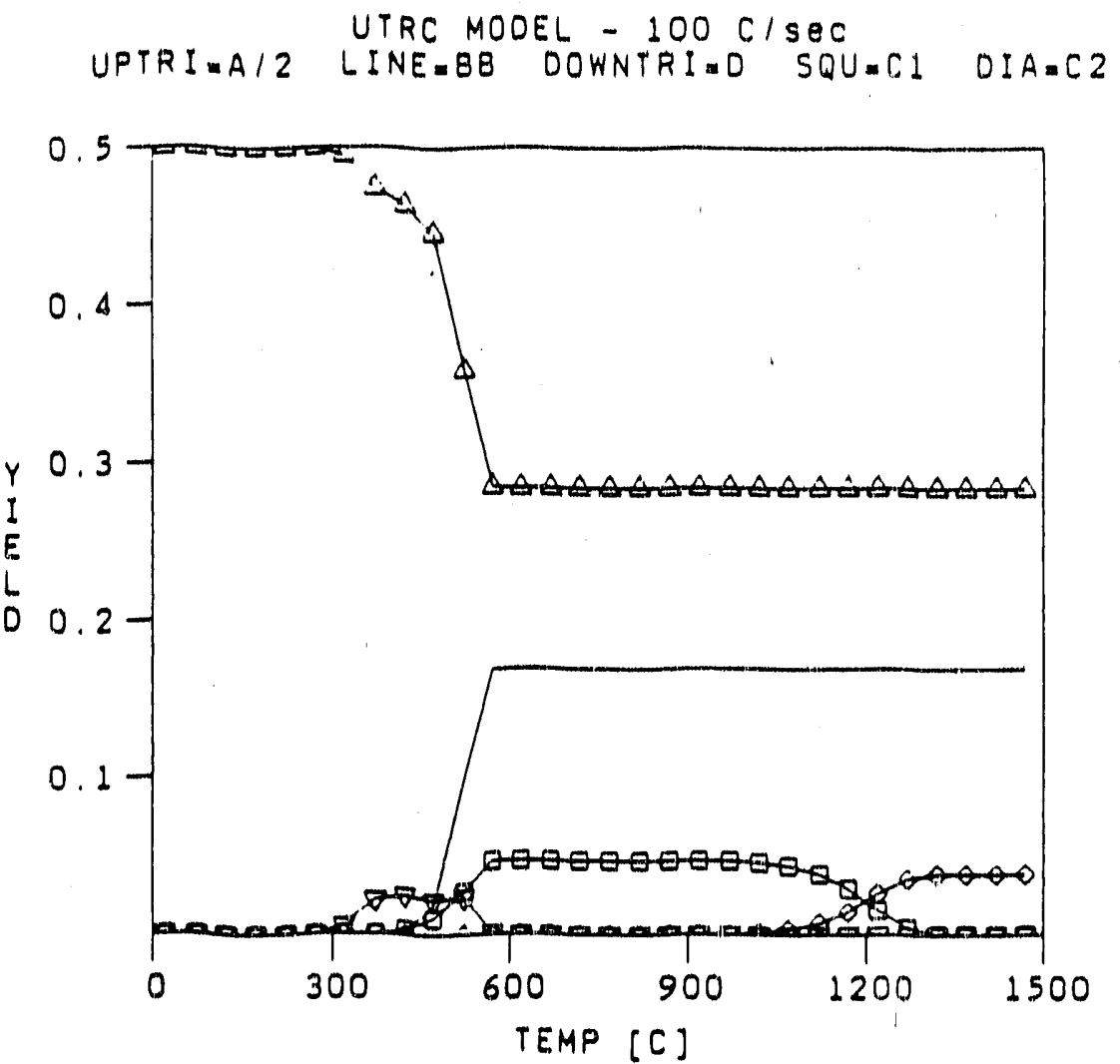

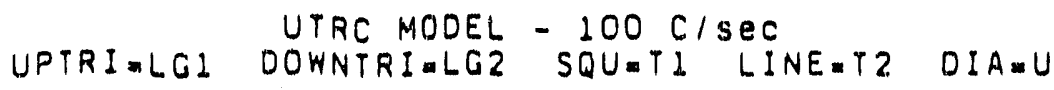

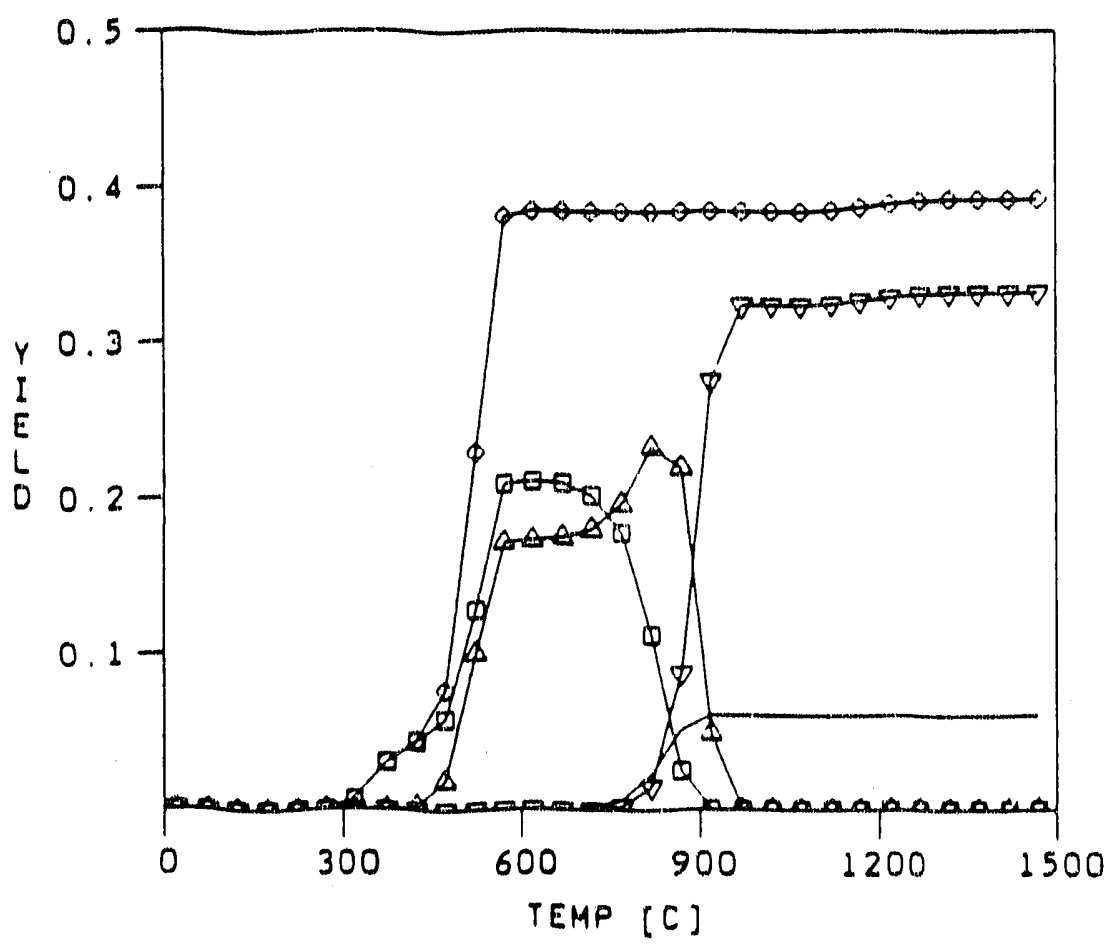


Figure 3.7

UTRC MODEL - $1000 \mathrm{C} / \mathrm{SeC}$

UPTRI=A/2 LINE=BB DOWNTRI=O SQUECL OIAECI
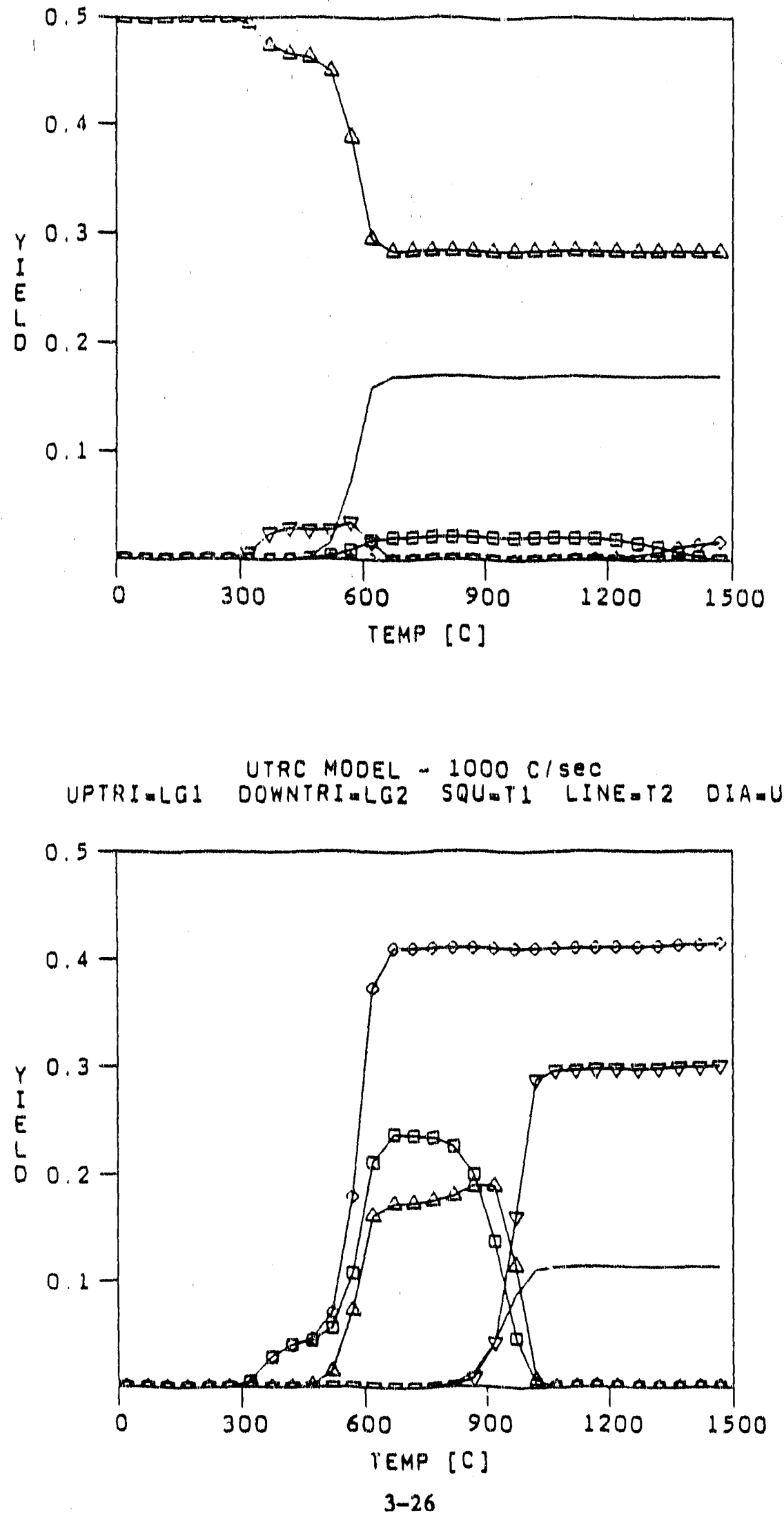
Figure 3.8

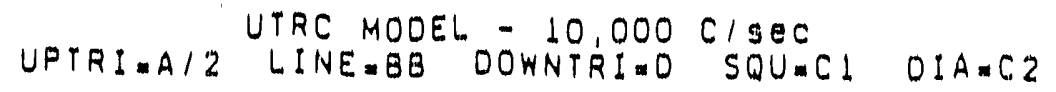

a

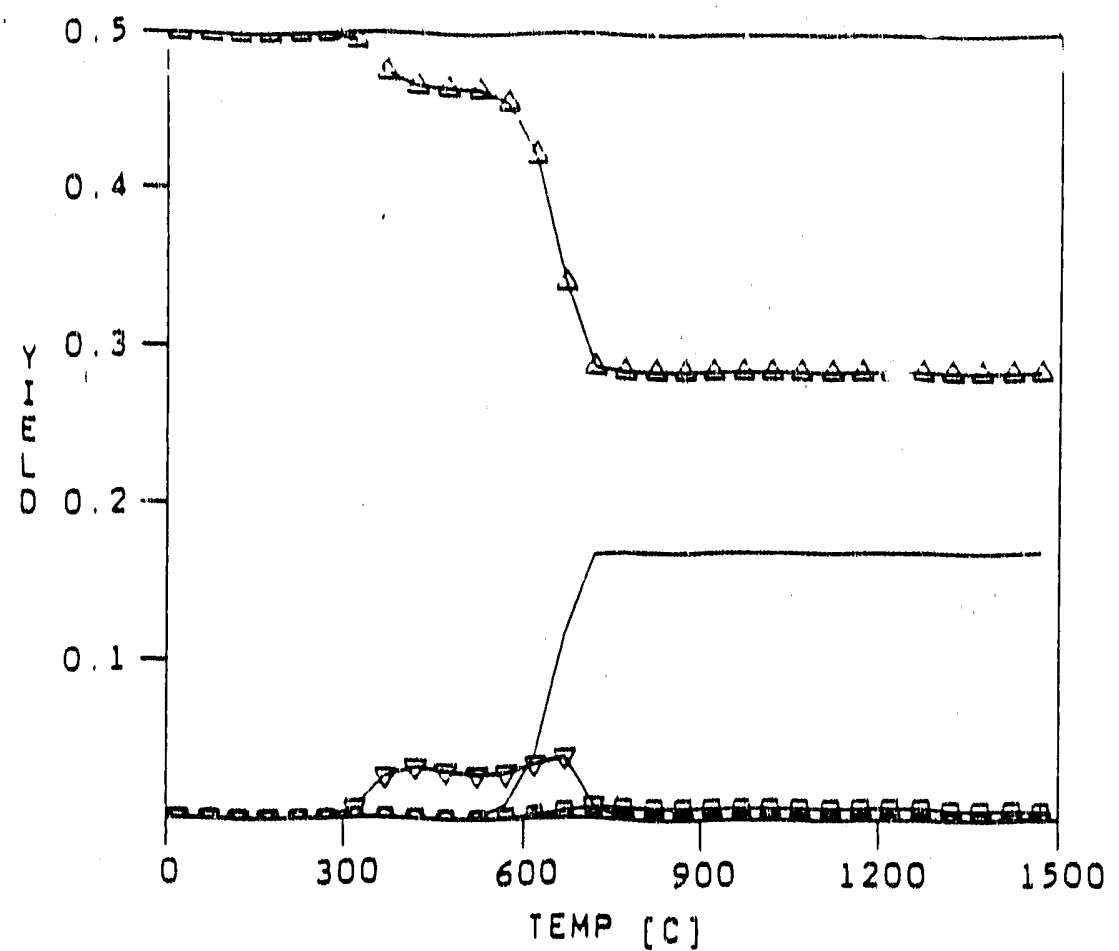

UTRC MODEL - $10,000 \mathrm{C} / \mathrm{seC}$

UPTRIILLI DOWNTRIMLGL SQU-TI LINENT2 DIA=U

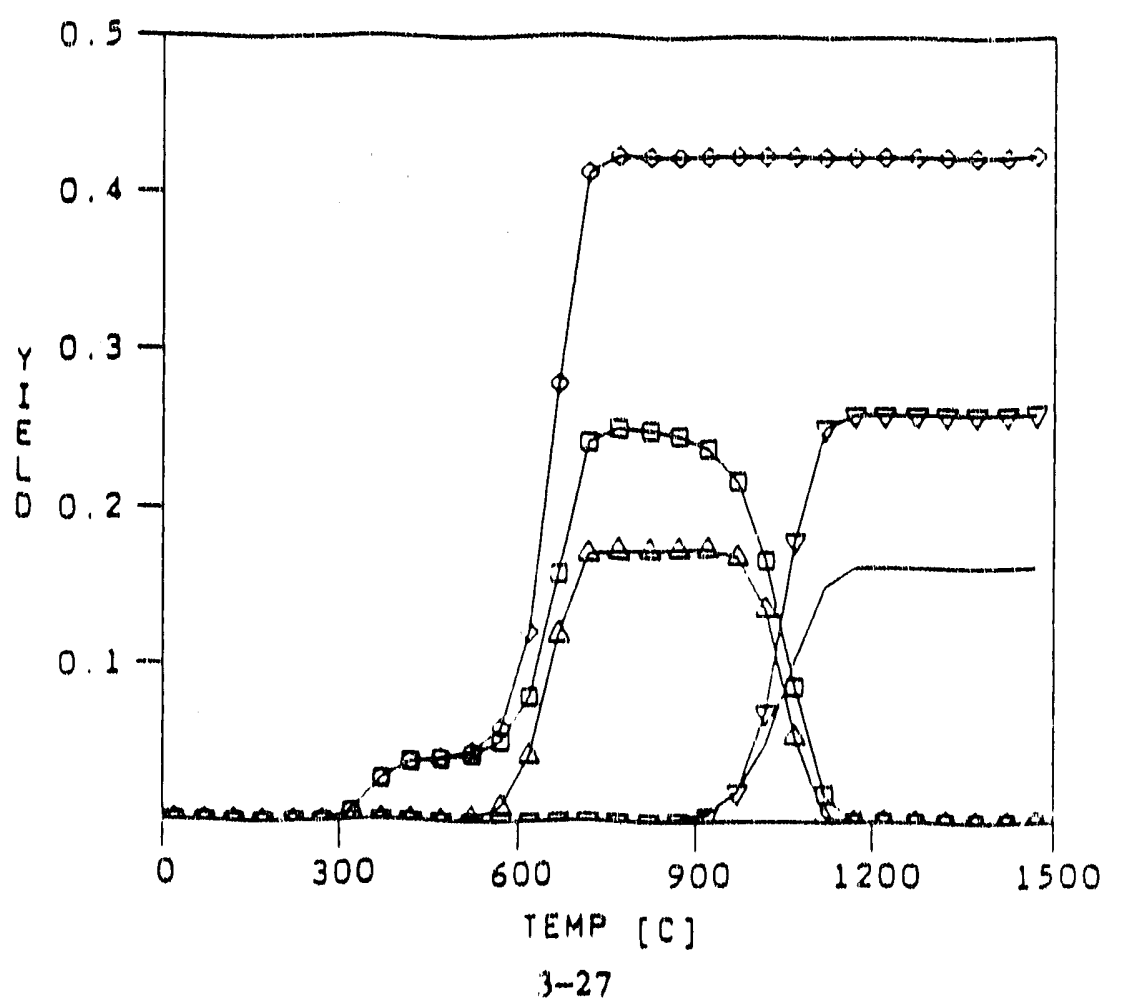


Figure 3.9
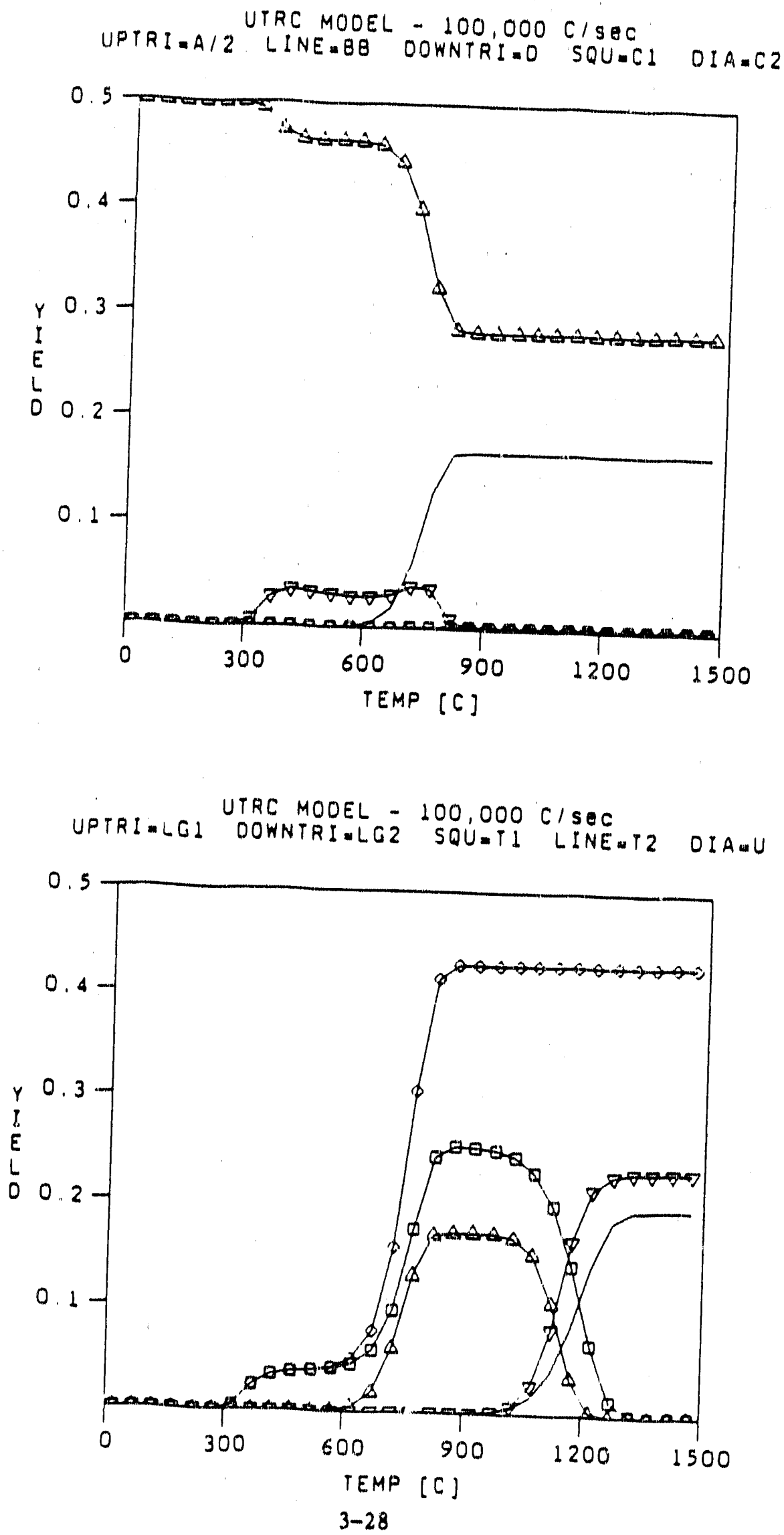
Figure 3.10

$r$
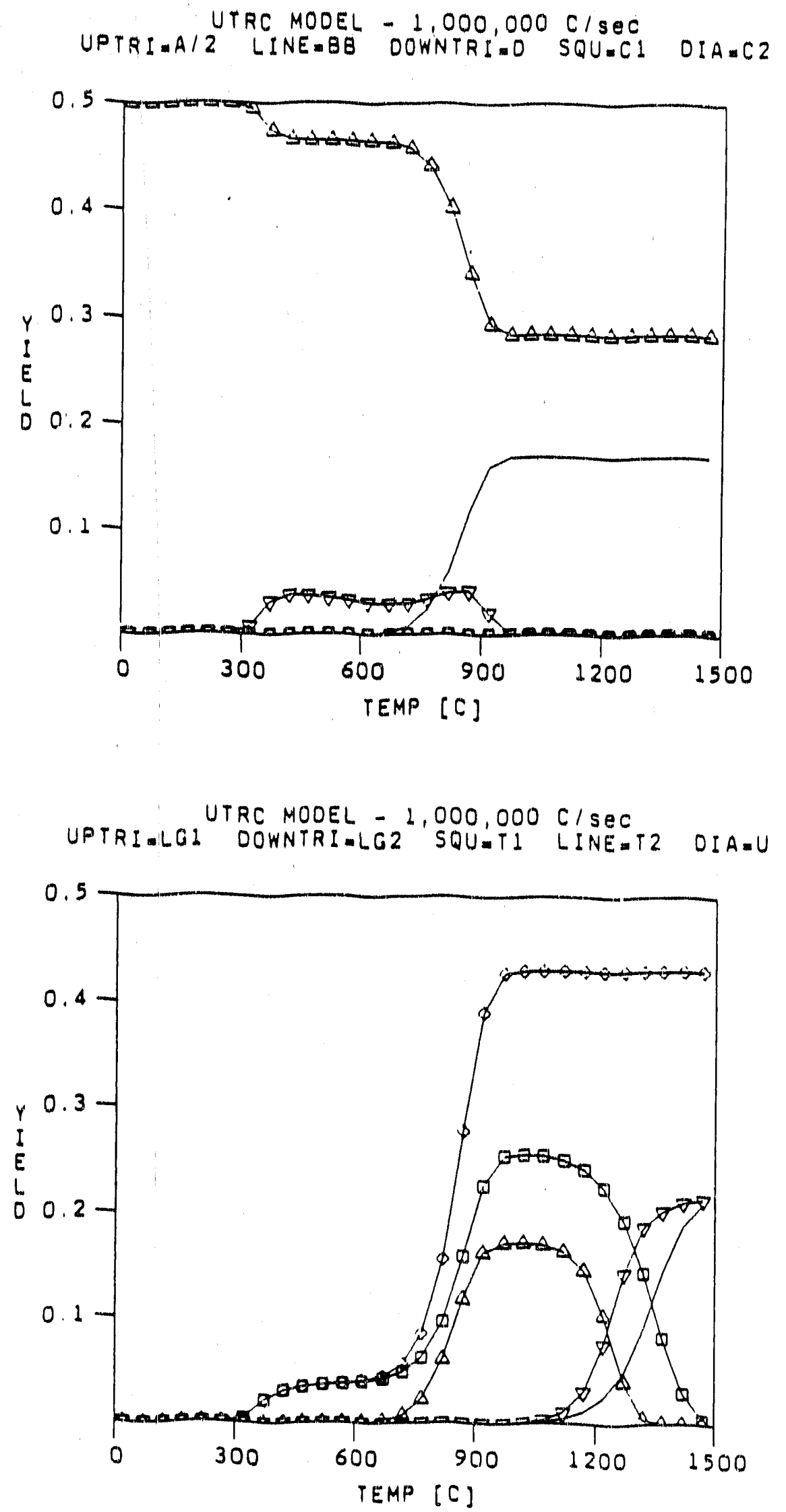
which are of low enough molecular welght to vaporize at $300-400^{\circ} \mathrm{C}$. There is little bulldup of DTP's within the particle due to the cracking reactions which rapidly redistribute the higher molecular welght DTP's into lower molecular weights which are able to vaporize at these temperatures. The major release of tars occurs concurrent with the chernical detachment process, again with no significant accumulation of DTP's within the particle. We have found that significant buildup of detached tar precursors will occur if it is assumed that the detachment process results in a much heavier molecular weight distribution of the DTP's than has been used for these calculations. Finally, at higher temperatures, the onset of char degassing, tar secondary reactions, and gaseous species pyrolysis reactions occur. The evolution of total mass loss shifts to higher temperatules and the ultimate yleld increases with increasing heating rate (Fig. 3.11).

The curves for detached tar precursors (DTP's) and primary tars (T1) In Figs. 3.5 to 3.10 are actually summations over all molecular weight Intervals tracked by the model. Figures 3.12 and 3.13 are plots of the DTP and T1 MWD's as they evolve in time for the $1000^{\circ} \mathrm{C} / \mathrm{s}$ heating rate case. The initial MWD of DTP's, at detachment, is also shown in Fig. 3.12 for comparison. As the ATP's detach, whether physically or chemically, their mass is distributed using this initial DTP MWD. The cracking, reformation and vaporization processes all act to alter this initial MWD, resulting in the DTP MWD's shown in Fig. 3.12 and 3.13. The DTP MWD is seen to consist mostly of heavier molecular weight species, the lighter species having teen depleted by vaporization. The tar MWD's shift to heavier molecular weights as the particle temperature rises and larger species are able to vaporize. Above $690^{\circ} \mathrm{C}$, secondary reactions set in and begin to crack the tars to lower molecular weights.

\section{Modeling Specific Experimental Results}

Healed Gerid. A series of zero-hold-tirne heated grid runs conducted in one atmospliere of helium at $1000^{\circ} \mathrm{C} / \mathrm{s}$ using 63-75 micron PSOC $1451 \mathrm{D}$ were modeled using the UTRC coal devolatilization model (see Table 3.4). This set of data was chosen over other heated grid, entrained flow reactor and flash lamp data because it allows for the most reliable particle temperature estimates. The parameter set which resulted in the best fit to the data is summarized in Table 3.3. Results for gas, tar and total yields are ploted against final temperature in Fig. 3.14. The agreement between experiment and prediction is excellent, of course, since the parameters were adjusted to obtain the fit shown. Parameters which were determined by this fitting procedure are: the fraction of the coal which physically detaches, the mass fraction of bridges, and the number of bonds per site which must break to allow chemical detachment of a coal unit. All other parameters have been deternined independently or estimated from literature values, as will be described further below. 
Figure 3.11

- EXTENT OF REACTION FOR VARIOUS HEATING RATES $10100100010,000100,0001,000,000 \mathrm{c} / \mathrm{s}$

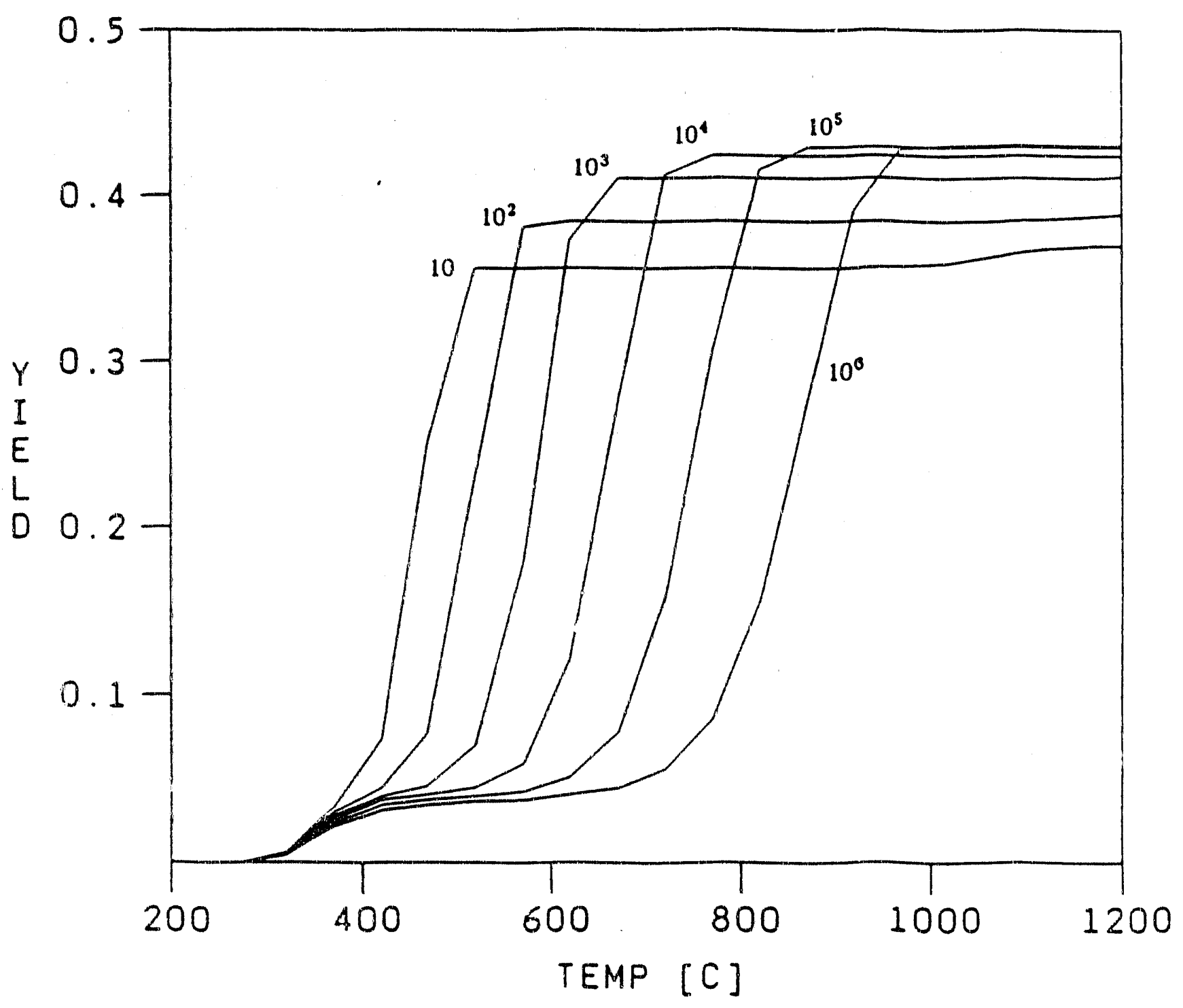


Figure 3.12

DTP MWD

$1000 \mathrm{C} / \mathrm{s}$

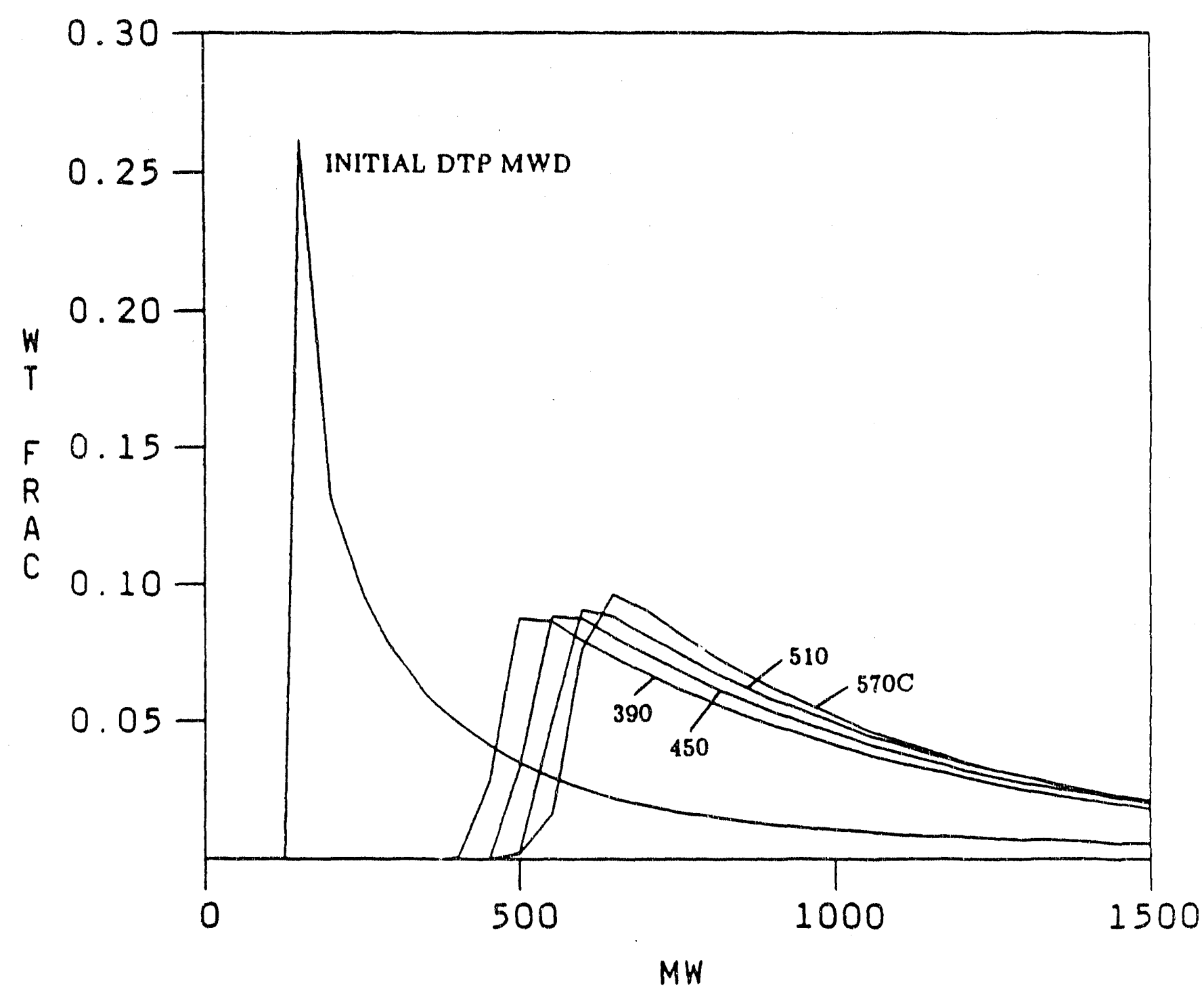


Figure 3.13

TAR MWO

$1000 \mathrm{c} / \mathrm{s}$

$+$
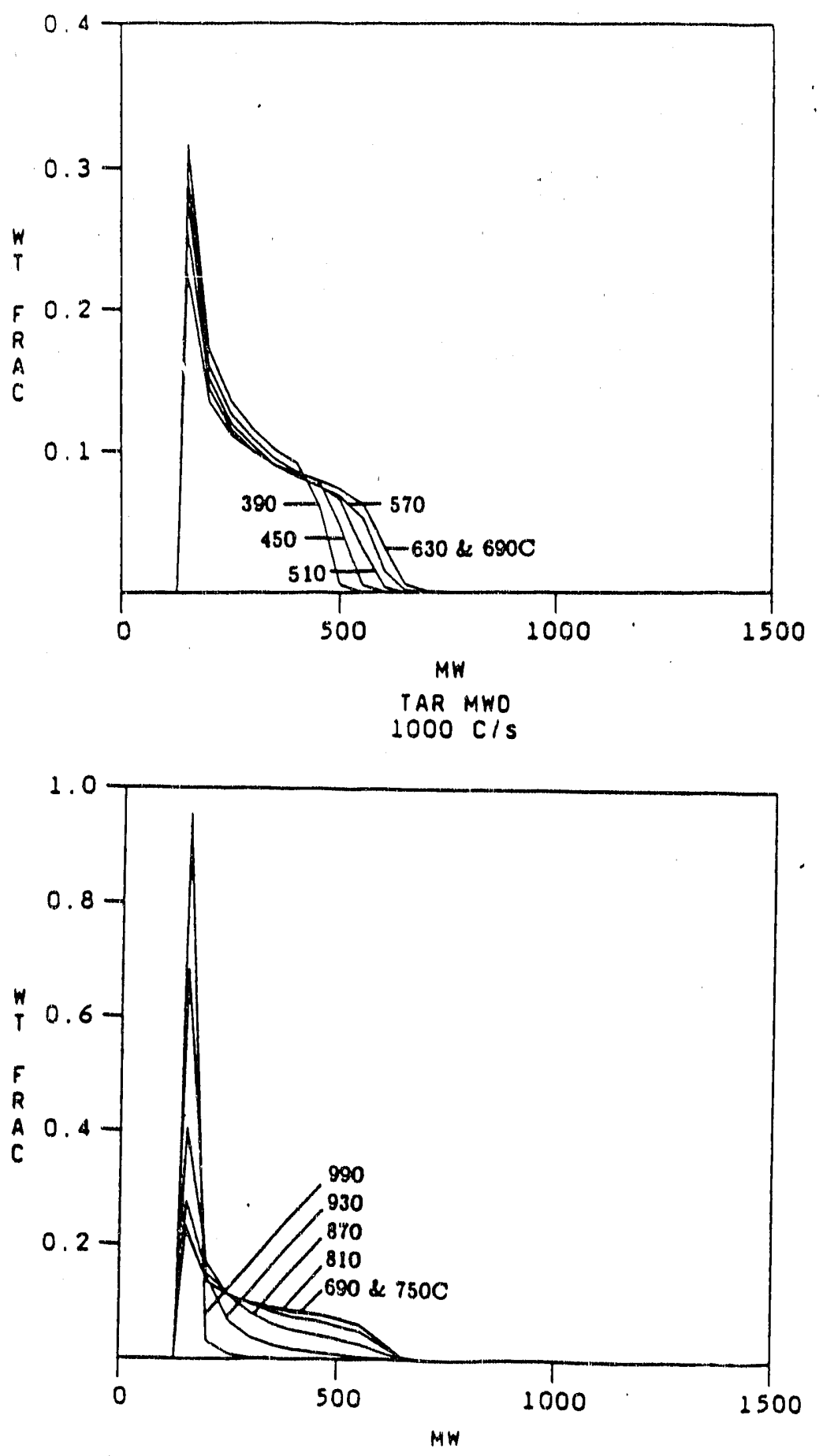


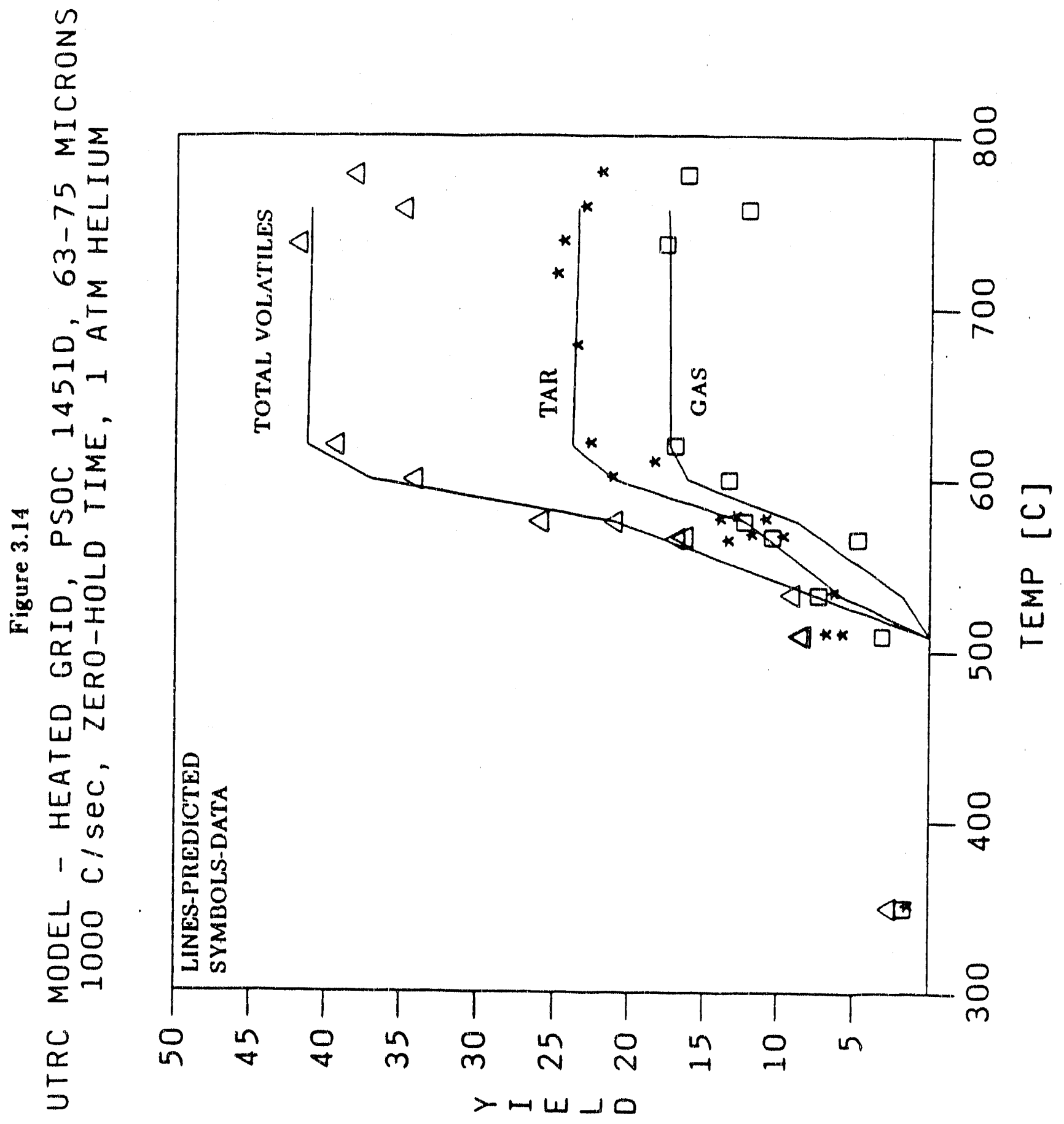




\section{TABLE 3.4 - HEATED-GRID RUNS}

$\begin{array}{cc}63-75 \text { micron, PSOC } 1451 \mathrm{D} \\ \text { Zero-Hold-Time, } 1000^{\circ} \mathrm{C} / \mathrm{sec}, 1 \text { Alm. Helium } \\ \text { RUN ID } & \text { Tmax } \\ & {\left[{ }^{\circ} \mathrm{C}\right]} \\ - & 350 \\ 458 & 509 \\ 457 & 509 \\ 444 & 533 \\ 447 & 565 \\ 455 & 566 \\ 451 & 575 \\ 452 & 575 \\ - & 577 \\ 459 & 600 \\ 446 & 620 \\ 448 & 737 \\ 449 & 757 \\ 450 & 777\end{array}$

The results presented above are based on performing a separate simulation for each heated grid experiment using the measured heat transfer conditions. It was observed that the actual (loaded thermocouple) heating rate in this set of experiments consistently averaged $850^{\circ} \mathrm{C} / \mathrm{sec}$ for each run. therefore a single constant temperature ramp calculation was performed. The resulting predicted yields (Fig. 3.15 ) fit the data set as well as the previous individual simulations. Using the $850^{\circ} \mathrm{C} / \mathrm{sec}$ simulation, the predicted tar MWD's at various final temperatures are compared to experimental GPC MWD's in Fig. 316. Unfortunately, the tar MWD'S were not measured by GPC for this set of heated grid runs; instead GPC results for three typical atmospheric pressure heated grid tars are plotted for comparison. The heating conditions used to generate these tars all used a $1000^{\circ} \mathrm{C} / \mathrm{sec}$ heating rate with the following variation in hold time and temperature: 1) $800^{\circ} \mathrm{C}$ for $\left.2.5 \mathrm{sec}, 2\right) 600^{\circ} \mathrm{C}$ for $10 \mathrm{sec}$, and 3) $550^{\circ} \mathrm{C}$ for $2 \mathrm{sec}$ followed by $800^{\circ} \mathrm{C}$ for $.5 \mathrm{sec}$. The tars, as measured by GPC, match predicted tars at a temperature of $900^{\circ} \mathrm{C}$, after significant loss of the high molecular weight components has occurred as a result of secondary reactions. Zero-hold-time, tar MWD data are needed to determine if appreciable cracking reactions are actually occurring during the hold time, as the comparison implies, or if the model is overestimating the heavy molecular weight components in the tars. The close similarity of the three measured tar MWD's may be due to a lack of sensitivity of the GPC technique or may be evidence for desorption mechanisms which are not strongly dependent on molecular weight. 


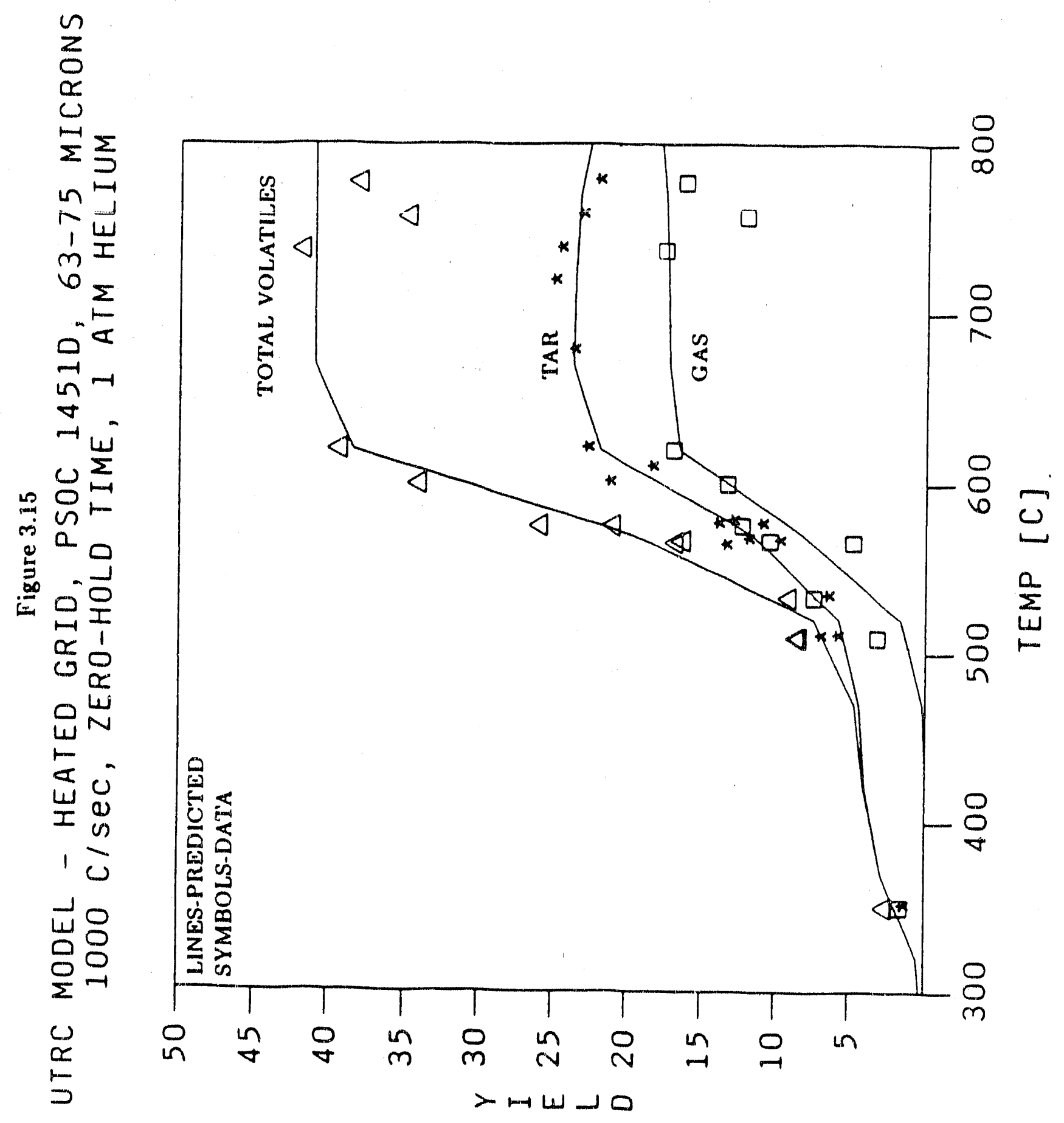


Figure 3.16

COMPARISON OF TAR MWD'S PREDICTED FOR 850 CISEC HEATINC RATE WITH TYPICAL MEASURED TAR MWO'S AT ATMOSPHERIC PRESSURE

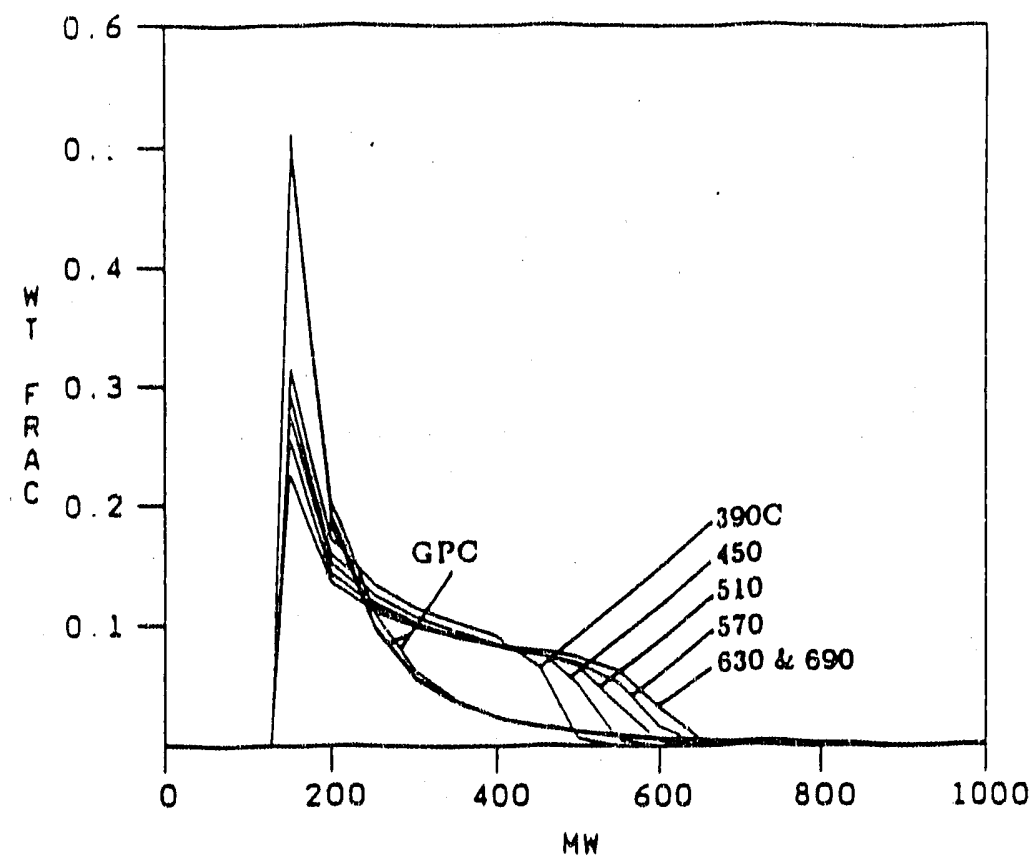

COMPARISON OF TAR MWO'S PREDICTED FOR $850 \mathrm{C} / \mathrm{SEC}$ HEATING RATE WITH TYPICAL MEASURED TAR MWD'S AT ATMOSPHERIC PRESSURE

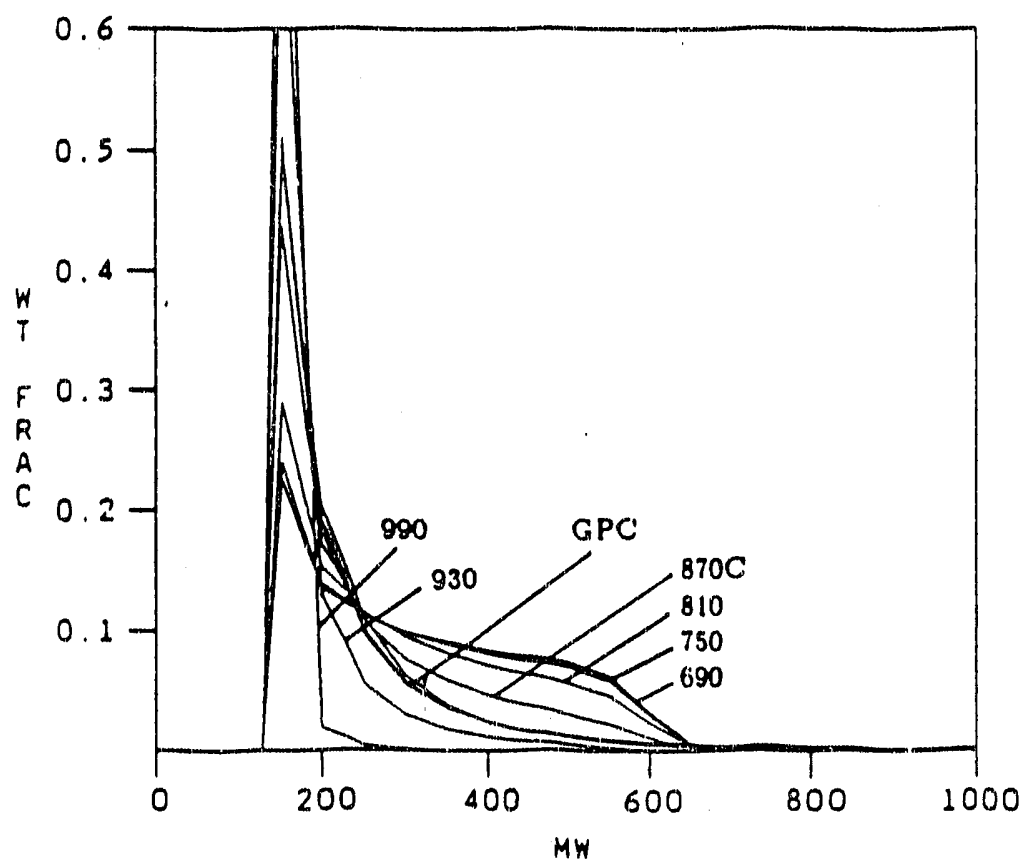


Entrained Flow Reactor. The devolatilization model was used to simulate the conditions of a series of UTRC entrained flow reactor runs. The experiments, summarized in Table 3.5, were conducted in an argon entrainment gas using 25 micron PSOC $1451 \mathrm{D}$ coal. The model parameters used are thes determined by fitting heated grid data, as explained above. Gas, tar and total volatlle yields are plotted ys peak gas temperature in the reactor in Fig. 3.17. No experimental data is shown for the lowest temperature runs since quantitative yields were not determined. Also, only total volatile yields are presented for the three highest temperature runs because gas and tar yields could not be reliably quantified. The model predicts the initial appearance of gas and tar yields near $500^{\circ} \mathrm{C}$ correctly. Recall that the heated grid data used to determine the model parameters covered a temperature range of $300-800^{\circ} \mathrm{C}$. Limiting the comparison of model and experiment to this ternperature range, it is seen that tar yields are only slightly overpredicted whereas the predictions for gas yields are high by a factor of three. At higher temperatures, where the model is in fact being extrapolated, the total yield is in agreement with the available data.

\section{TABLE 3.5 - ENTRAINED FLOW REACTOR RUNS}

\section{0-30 micron, PSOC 1451D, 20.6 SLPM ARGON} Collection probe $36 \mathrm{~cm}$ from inlet

Max Wall
Temp $\left[{ }^{\circ} \mathrm{C}\right]$

462

593

668

704

825

939

1058

1163

1241

Max Gas
Temp $\left[{ }^{\circ} \mathrm{C}\right]$

310

446

507

569

660

796

895

969

1053

$$
\begin{aligned}
& \text { Max Particle } \\
& \text { Temp }\left({ }^{\circ} \mathrm{C}\right)
\end{aligned}
$$

305

449

512

573

661

799

902

980

1067
Residence Time (msec)

815

719

670

635

600

520

474

417

385

The major discrepancy between the model predictions and the entrained flow reactor data is the gross over prediction of gas yields. Comparison of the heated grid and entrained flow reactor data sets (Fig. 3.18) reveals that the tar and, especially, gas yields are lower at a given temperature in the EFR. The heating rate in the entrained flow reactor is on the order of five times higher than in the heated grid runs, which, of course, results in a proportionally shorter residence time required to attain a given final temperature. The residence time effect is accounted for in the model by calculating the particle velocity through the reactor. The velocity calculations assume plug flow of the entrainment gas through the reactor, with the gas velocity at any point determined from the total gas mass flow through the reactor and the measured centerline gas 


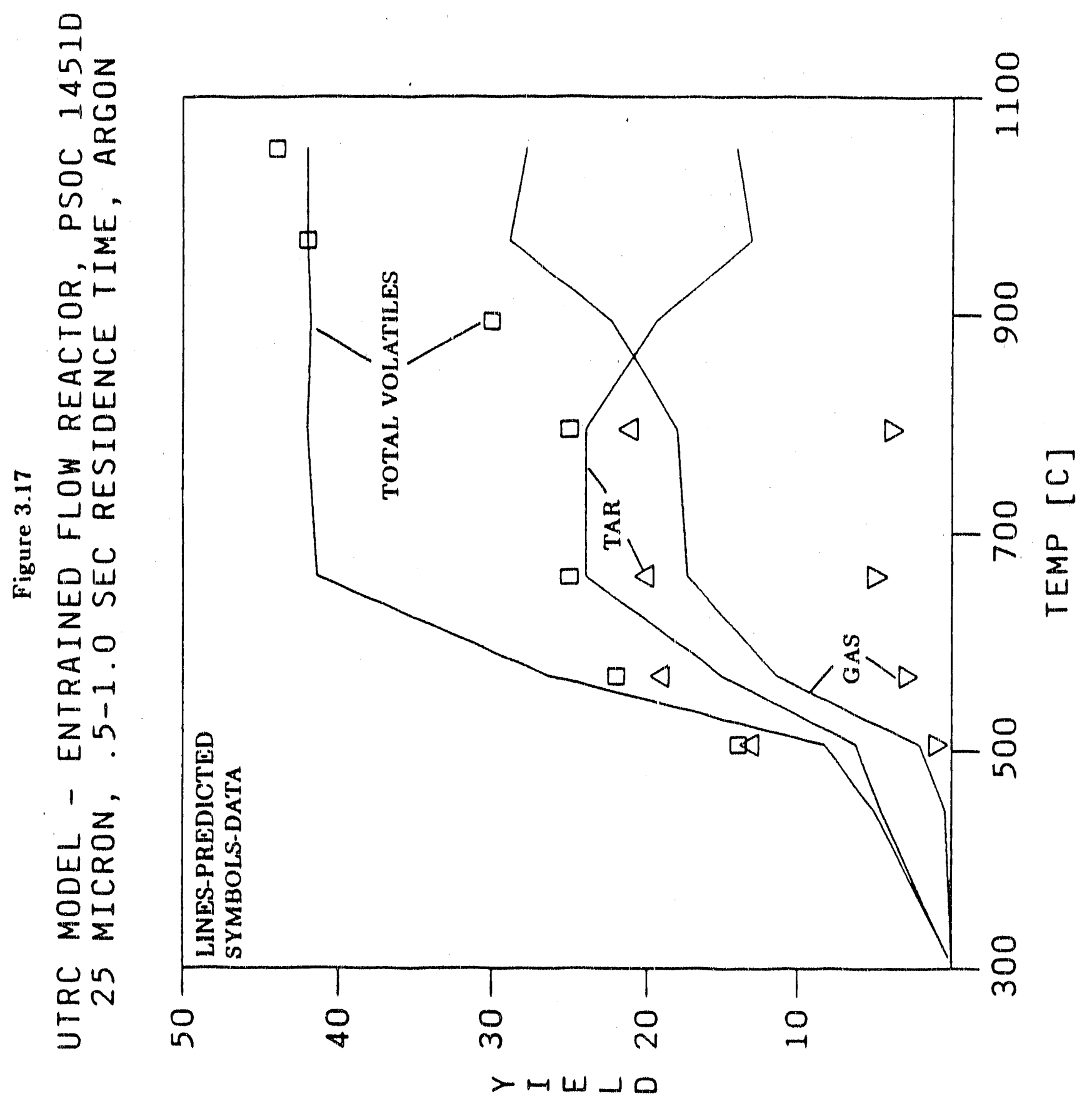




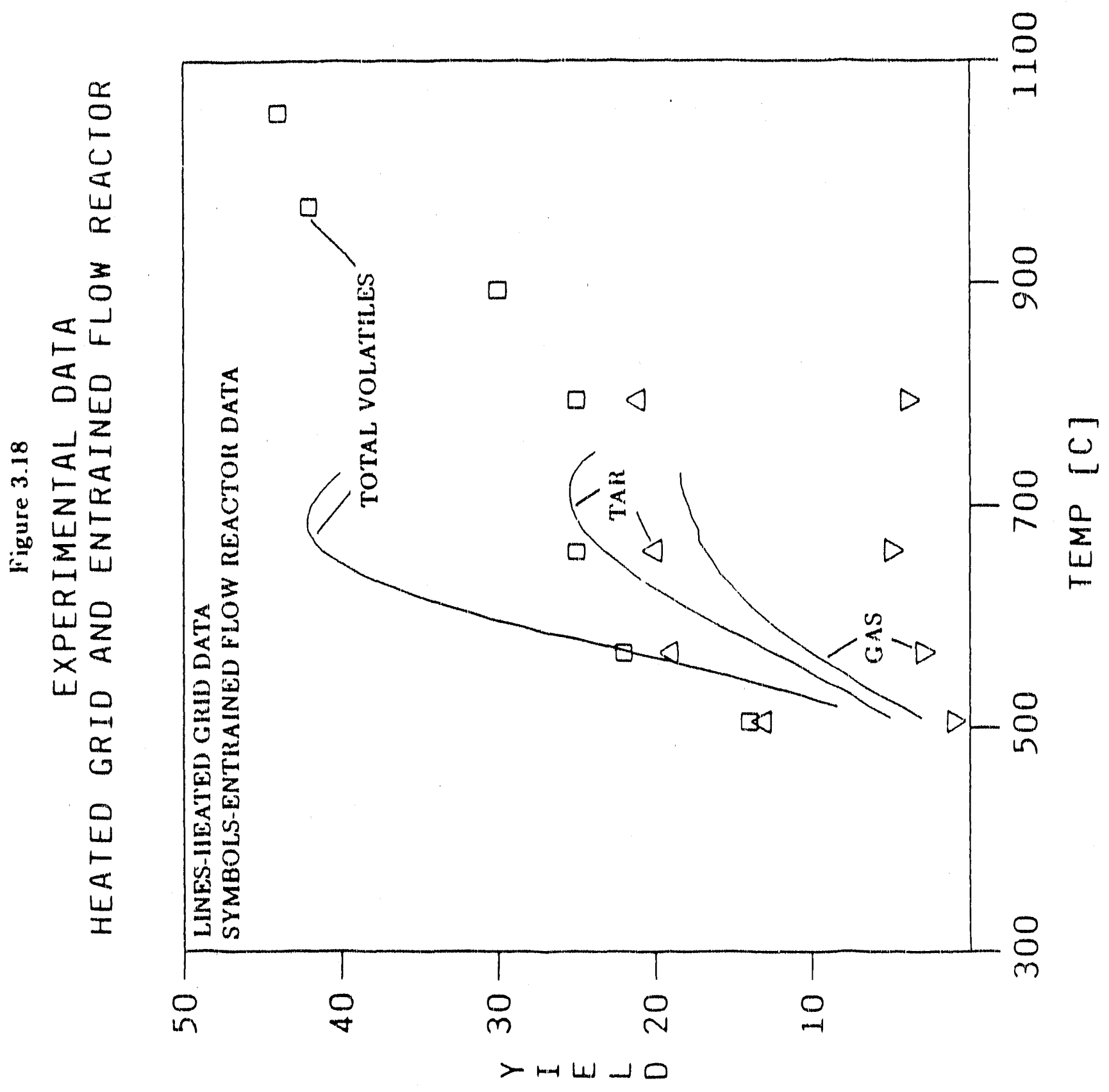


temperature at that point. In actuallty, the full length of the reactor is within the entrance regton of developing thermal and momentum boundary layers, with the result that the coal particles most likely spend less time in the high: temperature regton of the reactot than predicted by the plug flow model, Two-dimensional modeling of the flow field will be necessary to enable accurate prediction of coal devolatilization in the entralned flow reactor.

Elash Lamp. The flash lamp experiments llsted in Table 3.6 were modeled with the UTRC coal devolatilization model. The temperature used to characterize a given run is the calculated peak temperature. Tar ylelds are underpredicted at temperatures below $750^{\circ} \mathrm{C}$ and overpredicted at higher temperatures (Fig. 3.19). Quantitative gas yields were not determined experimentally; therefore, only calculated gas ylelds are shown in the figure. The model predictions allow for tar desorption by vaporization only, other mecharisms such as convective entrainment and nonequilibrium desorption are thought to be Important, especlally at the hlgh heating rates encountered in the flash lamp experiments. The flash lamp tar MWD's measured by GPC are significantly heavier than those of heated grid and entrained flow reactor experiments. This evidence lends additional support to the hypothesis that desorption mechanisms other than vaporization, phenomena that are independerit of molecular weight, are indeed occurring. The observed reduction in tar ytelds at the highest heating condition, together with qualitative analysis of the gas composition which shows larger amounts of $\mathrm{HCN}$ and $\mathrm{C}_{2} \mathrm{H}_{2}$, indicates that tar secondary reaction 3 are significant at the highest heating condition. The model, using the current parameter set (Table 3.3), does not predict the onset of secondary reactions until temperatures near $1000^{\circ} \mathrm{C}$ at heating rates of 10,000 to $100,000^{\circ} \mathrm{C} / \mathrm{sec}$ (see Figs, 3.8 and 3.9). It is posslble that the model is underpredicting the particle temperature, and therefore the position of the experimental tar yield daic is incorrectly shifted to lower temperatures. However, it is also possible that a different reaction pathway is being followed at these higher heating rates which cannot be described by a parameter set clerived from data obtained at lower heating rate conditions. More data and better estimates for particle temperature at high heating rates will be necessary in order to improve the predictive capability of the model. 
Figure 3.19

UTRC MODEL - FLASH LAMP

PSOC 14510, 49 MICRONS, I ATM HELIUM

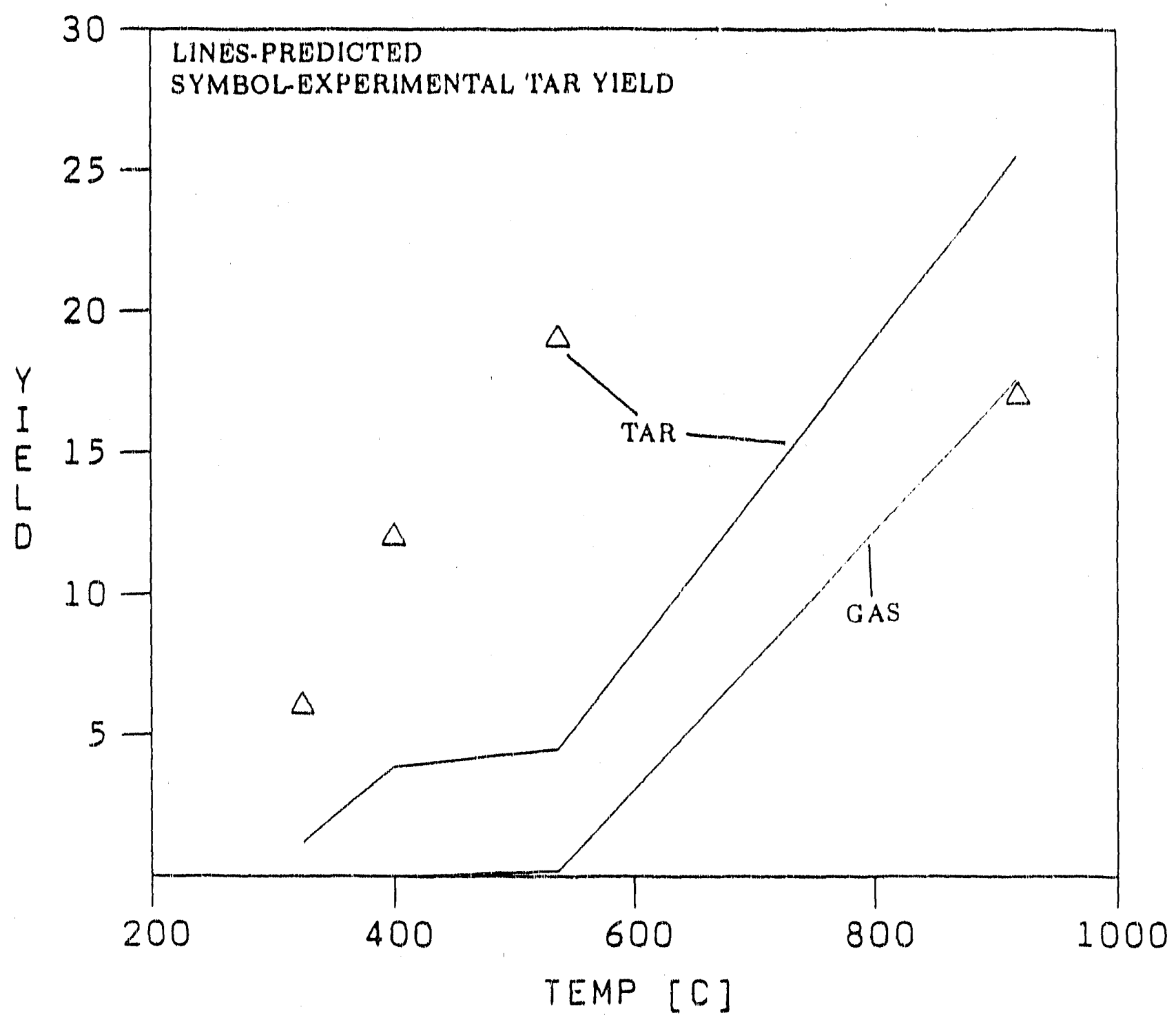




\section{TABLE 3.6 - FLASH LAMP RUNS}

$\$ 9$ micron, PSOC 14SID. I Atm. Helluin

$\begin{array}{cccc}\begin{array}{c}\text { Initial } \\ \text { Voltage }\end{array} & \begin{array}{c}\text { Noutral } \\ \text { Density } \\ \text { Filter } \\ {[\%]}\end{array} & \begin{array}{c}\text { Peak } \\ \text { Radiative } \\ \text { Flux } \\ {\left[\mathrm{W} / \mathrm{cm}^{2}\right]}\end{array} & \begin{array}{c}\text { Peak } \\ \text { Particle } \\ \text { Temp }\end{array} \\ {[\mathrm{KV}]} & 30 & 478 & {\left[{ }^{\circ} \mathrm{C}\right]} \\ 1.8 & 60 & 620 & 325 \\ 1.5 & 90 & 909 & 401 \\ 1.5 & 60 & 1650 & 537 \\ 2.2 & & & 918\end{array}$

\section{Kinetic Parameters}

Tar_Precuwsor PhysicaL Detachment. Fong et. al. (Ref. 3.8) determined pyridine extract yields of Pittsburgh seam No. 8 bituminous coal which had been devolatilized in a heated grid reactor. The pyridine extractables are used as a measure of the amount of detached tar precursors prosent in the coal. Both physical melting and primary pyrolysis are assumed to result in the formation of the DTP's. They fit the data using a Gaussian distribution for the fraction of the coal which melts with a mean of $623 \mathrm{~K}$ and standard devlution of $30 \mathrm{~K}$. A pyridine extract yield of $27 \%$ for the raw coal was reported and was used to represent the fraction of the coal which undergoes physical melting. The power of the pyridine solvent and the fact that the extractions were performed at the boiling point of pyridine $(389 \mathrm{~K})$ contribute to the possibility that the high extract yields observed were partially the result of chemical breakdown of the raw coal. Extract yields for PSOC 1451 were obtained at UTRC using room temperature tetrahydrofuran extraction in an ultrasonic bath. The extract ylelds averaged $11 \%$ after 30 minutes, and $23 \%$ after 2 days, of extraction. In order to fit the heated grid data for tar yields at low temperatures it was necessary to use a value of $7 \%$ for the fraction of coal which melts. The higher values suggested by the results of the extraction studies, when used in the model, result in excessive release of low molecular weight tars. (Only low molecular weight DTP's can vaporize at these low temperatures.) An alternative explanation would be that the initial molecular welght distribution of the DTP's is shifted to much heavier weights than we have used in the model. (Recall that a vacuum flash lamp tar MWD was used to represent the initial DTP MWD.) Then, the mass of DTP's within the light molecular weight end of the DTP distribution would be decreased. However, comparison of GPC results for vacuum flash lamp tars and THF extract from raw coal reveal little difference in the measured MWD's (Fig. 3.20),

Chemical Defachment. DTP Cracking and Tar. Pyrolysis. The mass rate of detachment of coal units caused by chemical bond breaking is a function of the instantaneous bonding structure of the coal 


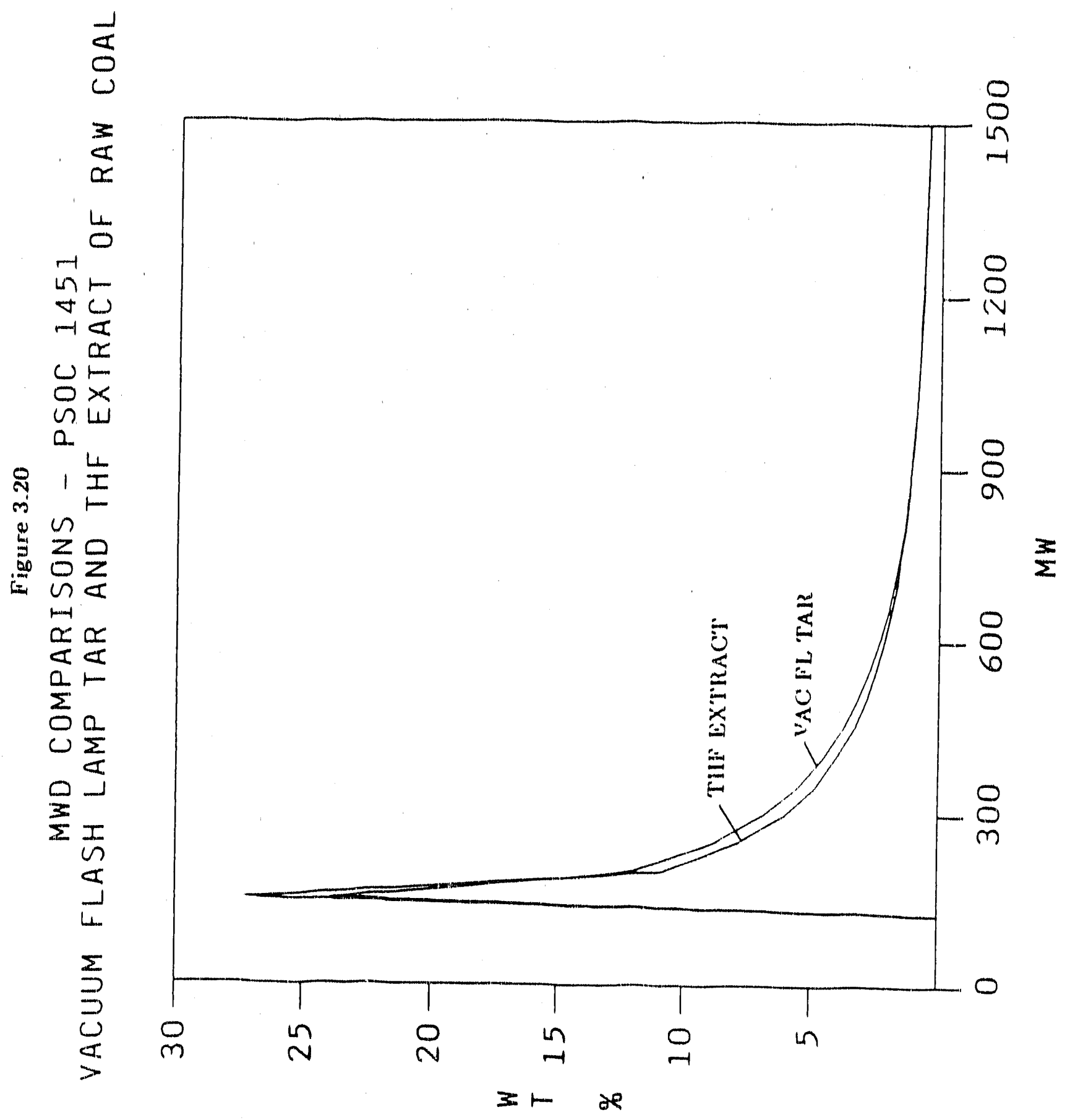


matrix as described previously (see Section 3,2). The rate constant for the sond breaking process underlying chemical detachment is given by a standard Arthenius expression. The same bond breaking processes are responsible for the intraparicle cracking of the DTP's and the gas phase pyrolysis of tar. The same types of bonds are breaking, wherher shey are atrached to coal units which ar:" part of the "infinite" coal matrix (ATP's), to coal units within a DTP, or within an escaping tar molecular. It is recognized that a range of bond types exist with differing bond energies which can be accounted for by using a distributed activation energy model. However, for the present. a single activation energy rate formulation has been used to limit the CPU time requirernents of the model. Analysis of mass lCss data from heated grid, flash lamp and entrained flow reactors results in an overall temperature sensitivity which is fit by an activation energy of $45.241 \mathrm{cal} / \mathrm{mole}$. This value is similar to that used by other investigators for bond breaking rates in HVA bituminous coals (Table 3.7). The pre-exponentials for the condensed phase reactions, ArP detachment and DTP cracking, are assumed to be $1 \times 10^{13}$, while that for the tar pyrolysis reaction is taken as $1 \times 10^{10}$ to account for the lower number density in the gas phase.

\section{TABLE 3.7 - COMPARISON OF BOND BREAKING RATES IN VARIOUS MODELS}

\begin{tabular}{|c|c|c|c|c|}
\hline MODEL & A & $\underset{[\mathrm{cal} / \mathrm{mol}]}{E}$ & $\sigma$ & REF. \\
\hline DAEM & $1.07 \times 10^{10}$ & 48720 & 9380 & Anthony et. al. (3.12) \\
\hline DAEM & $2.0 \times 10^{9}$ & 43000 & 5500 & Niksa (3.13) \\
\hline DISCHAIN & $2.0 \times 10^{10}$ & 40000 & 7000 & Niksa (3.13) \\
\hline FLASHTWO & $1 \times 10^{11}$ & $\$ 7000$ & 5000 & Niksa $(3.14)$ \\
\hline FLASHTWO & $3 \times 10^{7}$ & 38000 & 7000 & Niksa (3.15) \\
\hline$D V C-F G$ & $4 \times 10^{85}$ & 55400 & 2000 & Solomon et. al. (3.9) \\
\hline$C P D$ & $4 \times 10^{15}$ & $\$ 5400$ & 2000 & Grant et. al. (3.11) \\
\hline UTRC & $1 \times 10^{13}$ & 45241 & 0 & This study \\
\hline
\end{tabular}

Tar Deserotion. Desorption can occur by vaporization, convective entrainment and nonequilibrium processes as described previously. The rate equation for vaporization uses a specific enthalpy of vaporization of $75 \mathrm{cal} / \mathrm{gm}$ for an HVA bituminous coal. This value was obtained by fitting tar revaporization data using Trouton's nule with the MWD's measured by GPC (see Section 2.3.1). The total heat of devolatilization was also set equal to $75 \mathrm{cal} / \mathrm{gm}$. that is. the hedt of vaporization is assumed to be the dominant energy sink in the 
devolatilization process. The pre-exponential for the vaporization rate was estimated at $1 \times 10^{13}$ based on calculations of the accommodation coefficient and Debye vibrational frequency which bracket the A-factor in the range $10^{12}$ to $10^{14}$. Working submodels for convective entrainment and nonequilibrium desorption are not yet available.

Kinetic Regimes of Tar Devalatilization and Pyralysis. Tar evolution measurements in the EFR and $\mathrm{HG}$ apparatuses are used to estimate the tar evolution rate constants. The temperature sensitivity of the appearance of $\mathrm{C}_{2} \mathrm{H}_{2}$ and $\mathrm{HCN}$ in the EFR and $\mathrm{HG}$ apparatuses is used to estimate the high temperature ( $\mathrm{T}>700^{\circ} \mathrm{C}$ ) cracking reactions of the heav; hydrocarbon species. The estimated kinetic parameters are indicated in Table 3.8. An Arrhenius rate constant type plot of the rate constants are showen in Figure 3.21. The horizontal lines in the rate constant plot represent the apparatus heating rate constants. These are obtained by dividing the $300^{\circ} \mathrm{C}$ paricle temperature change - the temperature differential associated with a major fraction of tar evolution (See Section 4.0) - by the theoretically possible particle heating rate that can be established in a particular devolatilization system.

\section{TABLE 3.8 - ESTIMATED KINETIC PARAMETERS OF TAR EVOLUTION AND PYROLYSIS FOR HVA BITUMINOUS COALS}

\begin{tabular}{|c|c|c|c|}
\hline Phenomenon & $\begin{array}{c}\text { Activation } \\
\text { Energy } \\
\text { (kcal) }\end{array}$ & $\begin{array}{c}\text { Pre-Exponential } \\
\left(\sec ^{-1}\right)\end{array}$ & $\begin{array}{l}\text { Estimated } \\
\text { From }\end{array}$ \\
\hline Tar Devolatilization & 45.24 & $1.0 E+13$ & UTRC-HG \\
\hline High Temperature Pyrolysis of Tars & 66.5 & $1.0 \mathrm{E}+13$ & $\begin{array}{l}\text { UTRC-FL } \\
\text { UTRC-EFR }\end{array}$ \\
\hline Tar Incorporation into Char Product & 20.0 & $1.0 \mathrm{E}+06$ & UTRC-HG \\
\hline
\end{tabular}

As noted. the ovservable tar evolution phenomenology is dependent on the relative devolatilization and pyrolysis kinetic rates in the context of the overall heating rate established by the reactor system. For example, in $\mathrm{HG}$ heating conditions of $1000^{\circ} \mathrm{C} / \mathrm{sec}$ to $700^{\circ} \mathrm{C}$ or greater, tar evolucion is primarily chemical kinetic or vapor-pressure controlled at particle temperatures below $550^{\circ} \mathrm{C}$, that is $k$-tar evolution $\ll$ $k$-heating rate imposed. However, as the particle temperature exceeds $550^{\circ} \mathrm{C}$ the tar evolution rate becomes dominated by the heat transfer rate of the system, $k$-heating rate $\ll k$-tar evolution. Thete is no secondary tar pyrolysis in the gas phase since the tars are evolved into a cold gas environment. Figure 3.22 indicates that $\mathrm{C}_{2} \mathrm{H}_{2}$ is not generated in these dispherse phase heated grid experiments and $\mathrm{HCN}$ yields are very slight. As the tar evolution phase continues to the heavier species, mass transfer limitations influence 


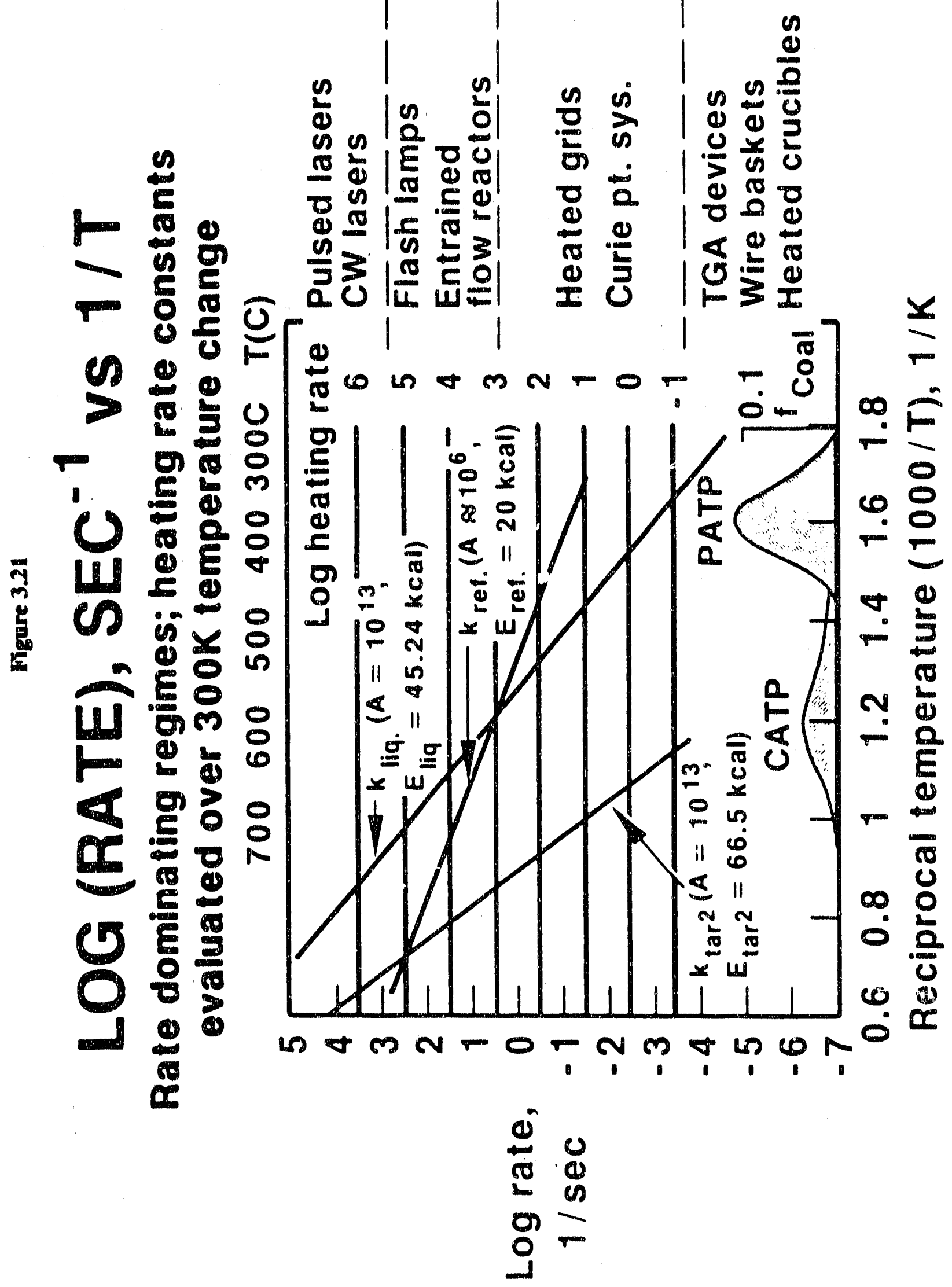




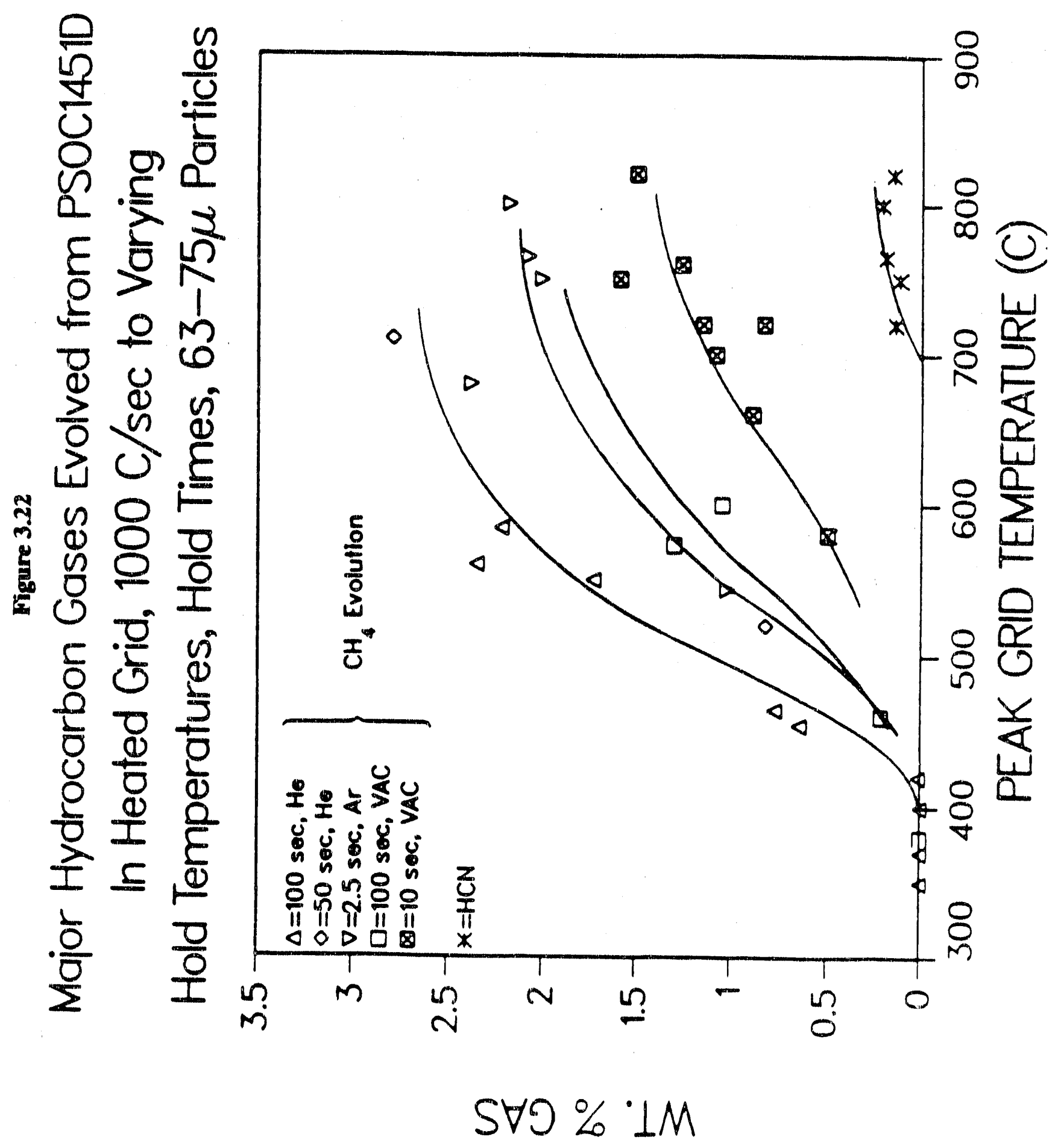


the rate of tar evolution, particularly in ambient pressure conditions. Intraparticle pyrolysis of these heavier, aliphatic-poor tars are responsible for the low yields of HCN observed at high particle final temperatures. The steep temperature sensitivity of the tar pyrolysis process limits the amount of $\mathrm{HCN}$ that can be evolved at these temperatures from the limited residual intraparticle heavy tars.

In the UTRC EFR wherein particle heating rates of the order of $5000^{\circ} \mathrm{C} / \mathrm{sec}$ are obtainable for peak particle temperatures of $800^{\circ} \mathrm{C}$ or greater, yields of $\mathrm{C}_{2} \mathrm{H}_{2}$ and $\mathrm{HCN}$ are greater than that observed for the same coal in the HG apparatus. In the UTRC EFR system opearated at high temperatures, tars evolved early in the devolatilization process are subjected to some residence time in hot gases in this reactor. Relative to the zero-hold-time HG experiments, the devolatilizing particle also spends a greater fraction of time at temperatrues above $700^{\circ} \mathrm{C}$ and less time at temperatures below $700^{\circ} \mathrm{C}$. In other words, the heavy hydrocarbon fraction of the potential tar yield has a greater probability of high temperature pyrolysis in the UTRC-EFR than the UTRC-HG.

A very different picture emerges in conventional entrained flow reactors wherein wall and gas temperatures are matched and heating rates of the order of 10,000 to $100,000^{\circ} \mathrm{C} / \mathrm{sec}$ are possible. Such reactors undoubtedly produce signficant overlap in the tar evolution and gas phase pyrolysis reactions for a given weight loss extent. Such reactors are generally operated at wall and gas temperatures 0 $800^{\circ} \mathrm{C}$ and above to achieve large enough mass loss to trace by ash tracing techniques. An entrained flow reactor using 50 micron particles and an operating temperature of $1000^{\circ} \mathrm{C}$ would produce a particle heating rate of $50,000^{\circ} \mathrm{C} / \mathrm{sec}$. Particle heating times would be of the order of $10-15 \mathrm{msec}$ and the tar evolution time would be of the order of msecs or lower. Homogeneous tar pyrolysis reactions would be of the order of $15-20$ msec. If the minimum experimentally resolvable particle/tar residence time is $50-100 \mathrm{msec}$, the entire tar evolution and secondary pyrolysis process would be convoluted.

Very intense, irradiance heating (flash lamps, lasers) would give behavior intermediate to that of the HG and conventional EFR's. For example, pulse heating a particle to $800^{\circ} \mathrm{C}$ in a cold gas environment would be expected to produce a burst of the more volatile tars and some light gases, but low yields of gases symptomatic of high temperature tar pyrolysis. The low yields of $\mathrm{C}_{2} \mathrm{H}_{2}$ and $\mathrm{HCN}$ are due to the cold quench gas environment and the short particle time at high temperatures. However, pulse heating the particle to $1000^{\circ} \mathrm{C}$ or greater would "turn on" the temperature sensitive tar pyrolysis reactions leading to these gases. The heavy tars would crack within the heating particle or in the hot boundary layer around the particle as 
they attempt to evolve. Such an understanding predicts very different yield ratios of tar, $\mathrm{C}_{2} \mathrm{H}_{2}$ and $\mathrm{HCN}$ with ambient gas conditions. This is indeed observed (See Flash Lamp results of Section 2.0).

It is obvious from these considerations that the apparent tar evolution kinetics vary substantially with reactor system because of the mix of potential evolution and pyrolysis pathways avallable to these heavy hydrocarbons. The specific reactor heat and mass transfer parameters amplify a particular weighted set of tar kinetic parameters by determining the time-temperature trajectory followed by a coal particle and the tar species. The observable phenomenology is the result of the coupling realized among the chemical characteristics of the tars (parent coal) and the transport properties of the devolatilization system.

DTP Reformation to Char. Heated grid experiments consisting of a $60 \mathrm{sec}$ hold at intermediate temperatures near $500^{\circ} \mathrm{C}$ followed by a ramp and hold to a higher final temperature result in reduced tar and increased char yields relative to experiments which ramp directly to the same final temperature. Reformation reactions involving the reattachment of DTP's to the coal matrix are occuring. The activation energy for the reformation reaction is estimated to be $20,000 \mathrm{cal} / \mathrm{mol}$. A low actiyation energy supports the hypothesis that active sites are involved in the reaction mechanism. A pre-exponential of $7.3 \times 10^{5}$ is obtained by matching the rate of DTP reformation with the rate of DTP cracking at $500^{\circ} \mathrm{C}$, the temperature at which char formation is observed to become significant.

Char Degassing and High Temperature Tar Pyrolysis. Gas species such as $\mathrm{C}_{2} \mathrm{H}_{2}$ and $\mathrm{HCN}$ (LG $\mathrm{LG}_{2}$ ) are evolved by both char degassing reactions and by high temperature tar pyrolysis. The activacion energy for the release of these gases, determined from analysis of the temperature sensitivity of the formation of these gases in the entrained flow and flash lamp reactors, is $66,500 \mathrm{cal} / \mathrm{mol}$. It is not possible to distinguish between the char degassing and tar pyrolysis reactions with the available experimental data. Therefore, both reactions are assumed to have an activation energy of $66,500 \mathrm{cal} / \mathrm{mol}$. Tar yields reach a maximum near particle temperatures of $700^{\circ} \mathrm{C}$ and decrease at higher temperatures coincident with an increase in $L_{2}$ species. Hence, it is evident that the rate of tar pyrolysis becomes competitive with tar desorption near particle temperatures of $700^{\circ} \mathrm{C}$. The MWD of the DTP's remaining in the coal at this temperature covers a range from about 500 to 1500 daltons with a weight average molecular weight of about 900 (see Fig. 3 12). Therefore. the mass average vaporization rate for the DTP's will have an activation energy given by 75 $\mathrm{cal} / \mathrm{gm} \times 900 \mathrm{gm} / \mathrm{mol}=67,500 \mathrm{cal} / \mathrm{mol}$. Therefore, for the tar pyrolysis rate to become competitive with the desorption rate of the heavy tars, a pre-exponential of about $1 \times 10^{13}$ is necessary. The pre-exponential for 
the char degassing reaction was assumed to be three orders of magnitude lower because of steric hindrance of the active sites on the chars.

LightGas Pyrolysis. The light gases $\left(\mathrm{LG}_{1}\right)$, evolved as a result of bond breaking in the coal matrix, in the DTP'S, and in the tars, are pyrolyzed in the gas phase to secondary gas products ( $\left.\mathrm{LG}_{2}\right)$. Approximate values for the Arrhenius parameters for the decomposition of alkanes are $1 \times 10^{17}$ and 88,400 for the pre-exponential and activation energy, respectively (Ref. 3.16).

\subsection{Comparison to Other Model Formulations}

\subsubsection{One-Step Model}

The one-step model proposed by Badzioch and Hawksley (Ref. 3.17) utilizes a single Arrhenius rate expression to represent the conversion of unreacted coal to volatiles and residue:

$$
\begin{gathered}
C O A L \rightarrow V+R \\
d V / d t=k\left(V^{*}-V\right) \\
k=A \exp (-E / R T)
\end{gathered}
$$

where $V^{*}$ is the ASTM proximate analysis volatile matter yield. Given sufficient time at temperature the one-step model will always predict the same yield regardless of temperature or heating rate.

\subsubsection{Two-Step Model}

The two-step model (Refs. 3.18 and 3.19) consists of two competitive reaction steps, one predominating at low temperatures and the other at high temperatures:

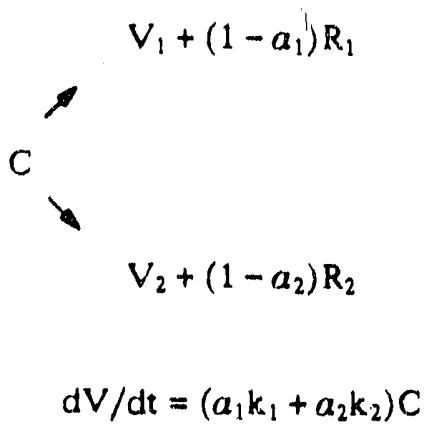

where $V_{i}=$ volatiles, $R_{i}=$ char residue, and $C=$ unreacted coal. The two-step model allows for the prediction of volatiles yields that change as a function of temperature and heating rate. 


\subsubsection{Distributed Activation Energy Model (DAEM)}

Anthony et. al. (Ref. 3.12) proposed that coal devolatilization is the result of numerous independent chemical reactions with each type of bond breakage given by a simple first-order irreversible rate equation:

$$
d V_{1} / d t=k_{1}\left(V_{1}^{\prime}-V_{1}\right)
$$

The rate of total volatiles production is obtained by summing the contribution from each reaction or integrating over all values of activation energy where it is assumed that the $k_{1}$ 's all have the same pre-exponential $k_{0}$. The result for a Gaussian distribution of activation energies with mean $E_{o}$ and standard deviation $\sigma$ is:

$$
\frac{d V}{d t}=\frac{V^{\prime}}{\sigma \sqrt{2 \pi}} \int_{E_{0}-2 \omega}^{E_{0}+2 \sigma} A \exp (-E / R T) \exp \left(-\int_{0}^{1} A \exp (-E / R T) d t^{\prime}\right) \exp \left(-\frac{\left(E-E_{0}\right)^{2}}{2 \sigma^{2}}\right) d E
$$

Since the ultimate yield is an input parameter, the DAEM model can not predict volatiles yield a priori.

\subsubsection{Distributed-Energy Chain Model (DISCHAIN)}

Niksa and Kerstein (Refs. 3.10 and 3.13) have devised a model which is based on the macromolecular configuration of coal as a linear straight chain. The model classifies coal into components as follows: aromatic nucleii linked by bridges into chains, labile bridges (B), peripheral groups ( $P$ ), isolated nucleii or monomers $(M)$, char $(C)$, gas $(G)$, and tar $(T)$. The bridge dissociation reaction rate is clescribed using a distributed activation energy. The rate equations used in the DISCHAIN model are summarized in Table 3.9. DISCHAIN predicts gas, tar, and char yields. 
TABLE 3.9 - DISTRIBUTED ENERGY CHAIN MODEL (DISCHAIN)

\begin{tabular}{|c|c|c|c|}
\hline $\mathrm{B}$ & labile bridges/Initial bridges (Bo) & & $B(0)=1$ \\
\hline $\mathrm{C}$ & stable char links/Bo & & $C(0)=0$ \\
\hline $\mathrm{T}$ & $\operatorname{tar} / \mathrm{Bo}$ & & $T(0)=0$ \\
\hline$P$ & periphera! groups/init, periph./bridges & (Po/Bo) & $P(0)=2$ \\
\hline$G$ & light gases/Po/Bo & & $G(0)=0$ \\
\hline M & free aromatic units/Bo & & $M(0)=0$ \\
\hline $\mathrm{D}$ & char caps/Bo & & $D(0)=0$ \\
\hline $\mathrm{H}$ & pure char chains/Bo & & $\mathrm{H}(0)=0$ \\
\hline REACTION & $\begin{array}{c}\text { A FACTOR } \\
s^{-1}\end{array}$ & \multicolumn{2}{|c|}{$\begin{array}{c}\text { ACTIVATION ENERGY } \\
\mathrm{cal} / \mathrm{mole}\end{array}$} \\
\hline bridge dissociation & $2 \times 10^{10}$ & \multicolumn{2}{|c|}{$40,000(a=7,000)$} \\
\hline tar formation & $8 \times 10^{2}$ & \multicolumn{2}{|c|}{30,000} \\
\hline char formation & $1 \times 10^{6}$ & \multicolumn{2}{|c|}{25,000} \\
\hline gas formation & $1 \times 10^{3}$ & \multicolumn{2}{|l|}{10,000} \\
\hline \multicolumn{4}{|c|}{$f(E)=\frac{1}{\sigma \sqrt{2} \pi} \exp \left[-\left(E-E_{0}\right)^{2} / 2 \sigma^{2}\right]$} \\
\hline
\end{tabular}

$$
\begin{aligned}
& d B / d t=-\int_{B_{0}-2 a}^{E_{0}+2 \sigma} k_{B} \exp \left[-\int_{0}^{t} k_{B} d t^{\prime}\right] f(E) d E \\
& \mathrm{dC} / \mathrm{dt}=-\mathrm{k}_{\mathrm{c}} \mathrm{M}(2 \mathrm{H}+2 \mathrm{~B}(1-\mathrm{B})+\mathrm{M}) \\
& \mathrm{dT} / \mathrm{dt}=-2 k_{\mathrm{T}} \mathrm{M} \\
& d P / d T=-k_{G} P+a_{B} / P_{0}(-d B / d t) \\
& \mathrm{dG} / \mathrm{dt}=-\mathrm{k}_{\mathrm{G}} \mathrm{P} \\
& d M / d t=-2(1-B)(1-D /(2 B(1-B)) d B / d t \\
& =-(2 M+2 B(1-B)+2 H) /(M+2 B(1-B)+2 H) d C / d t \\
& =-1 / 2 \mathrm{dT} / \mathrm{dt} \\
& \mathrm{dD} / \mathrm{dt}=-\mathrm{k}_{\mathrm{c}} \mathrm{M}(2 \mathrm{~B}(1-\mathrm{B})-\mathrm{D})+(\mathrm{D} / \mathrm{B}) \mathrm{dB} / \mathrm{dt} \\
& d H / d t=-(D / B) d B / d t+k_{c} M^{2}
\end{aligned}
$$




\section{SECTION 3.0 REFERENCES}

3.1 Sanberg, E. M., Peters, W. A. and Howard, J. B., Ind Eng. Chem. Proc. Design and Div. 17, 37 (1978),

3.2 Arendt, P. and Von Heek, K. H, Farel, 60, 779 (1981).

3.3 Freihaut, J, D., Zabielski, M. F., and Seery, D. J., Nheteenth Symposium (Int.) on Combustion, 1159 (1982).

3.4 Wei-Chun Xu and Akira Tomita, Fuel, 66, 626 (1987).

3.5 Fletcher, T.H., Baxter, L.L. and Ottesen, D.K., 1987 International Conference on Coal Science, ed. Moulin, J.A., Nater, K.A. and Chermin, H.A.G., Elsevier, New York, p. 945. 1987.

3.6 Merrick, D., "Mathematical Models of the Thermal Decomposition of Coal, 2. Specific Heats of Reaction," Fuel 62:540 (1983).

3.7 The Coal Tar Dáta Book, 2nd Edition. The Coal Tar Research Association, Oxford Road, Gomersal, Leeds, Great Britain, p. A.2-7, (1965).

3.8 Fong. W. S., Peters, W.A. and Howard, J.B., "Kinetics of Generation and Destruction of Pyridine Extractables in a Rapidly Pyrolysing Bituminous Coal," Fuel 65:251 (1986).

3.9 Solomon, P.R., Hamblen, D.G., Carangelo, R.M., Serio, M.A. and Deshpande, G. V'., "A General Model of Coal Devolatilization," Combust. Flame 71:137 (1988),

3.10 Niksa, S. and Kerstein, A.R., "The Distributed-Energy Chain Model for Rapid Coal Devolatilization Kinetics. Part I: Formulation," Combust. Flame 66:95 (1986).

3.11 Grant, D.M., Pugmire, R.J., Fletcher, T.H. and Kerstein, A.R., "A Chemical Model of Coal Devolatilization Using Percolation Lattice Statistics," ACS Div, of Fuel Chem. Preprints, 195th National Meeting, Toronto, Canada 33 2:322 (1988).

3.12 Anthony, D.B., Howard, J.B., Hottel, H.C., and Meissner, H.P., "Rapid Devolatilization of Pulverized Coal," Fifteenth Symp. (Int.) on Comb., The Combustion Institute. Pittsburgh, P. 1303, (1975). 
3.13 Niksa, S." "The Distributed-Energy Chain Model for Rapid Coal Devolatllization KInetics. Part II: Transient Welght Loss Correlations," Combust, Flame 66:111 (1986).

3.14 Niksa, S., "Modeling the Devolatilization Behavior of High Volatile Bituminous Coals," Twenty-Second (Internat.) Symposium on Cornbustion. The Combustion Institute. (1988).

3.15 Niksa, S., "Rapid Coal Devolatilization as an Equilibrium Flash Distillation," AICHEJ, to appear (1988).

3.16 Hucknall, D.J., "Chemistry of Hydrocarbon Combustion," p. 329, Chapman and Hall, New York, (1985).

3.17 Badzloch, S. and Hawksley, P.G.W., "Kinetics of Thermal Decomposition of Pulverized Coal Particles," Ind. Eng. Chem. Process Des. Develop., 9(4):521 (1970).

3.18 Kobayashi, H., Howard, S.B. and Sarofilm, A.F., "Coal Devolatilization at High Temperatures," Sixteenth Symp. (Int.) on Comb., The Combustion Institute, Pittsburgh, p. 411, (1976).

3.19 Ubhayakar, S.K., Stickler, D.B., Von Rosenberg, C.W., Jr. and Gannon, R.E., "Rapld Devolatilization of Pulverized Coal in Hot Combustion Gases," Sixteenth Symp. (Int.) on Comb., The Combustion Institute, Pittsburgh, p. 427, (1976). 


\section{SECTION 4.0 - ENGINEERING KINETICS OF COAL DEVOLATILIZATION}

\subsection{Introduction}

This section describes the development and structure of an englneering rato equation for coal pyrolysis that can be used in a model of a pulverized coal (p.c) flame. An "Engineering Rate Equation" is one that is a deliberately constructed simplification for it to be tractable in a larger model construct (the p.c flame), but that nevertheless describes behavior with necessary and sufficient accuracy for the Intended purpose. In this Instance, the intended purpose is to predict the volatlle matter (VM) release rate, the main constituent composition of the pyrolysis products (tar, char, and light gases), and the functional dependence of these parameters on heatirig rate, final temperature, particle size, and the like.

The incentives for the development of these equations derive from soveral different sources. The principal one is the demand for increasing precision In flame models that are used for predicting coal combustion and burnout; and, in turn, this is requiring improved precision in the model elements, of which pyrolysis is a dominant component in the early stages of any coal flame. There is also increasing interest in the staging involved in the release of different components, with the tar fraction being particularly important In the early (lower temperature) stages of pyrolysis as this is the primary source of smoke, carbon particle, formation in the flame, and $\mathrm{FBN}$ to $\mathrm{NO}_{x}$ reactions in pfe firing.

The development described in this report was, of necessity, a two stago process. The first requirement was the development of an adequate and sufficiently detailed description or model of a single pyrolyzing particle. The second stage, as noted above, was simplification of the model in such a way that it still described behavior with "the necessary and sufficient accuracy for the intended purpose". This is what we present in this report.

\subsection{Analytical Procedure and Task Listing}

The need for an adequate and sufficiently detailed description of a single pyrolyzing particle, l.e. the first development stage, arose primarily from the inadoquacy of the existing models, but it was compounded by inconsistencies in the available data: for example, values of activation energy for a single pyrolysis step have been reported that range from 10 to $70 \mathrm{Kcal} /$ mole. There is no dearth of pyrolysis models, but their general and common shortcoming, as discussed in more detall below, is the question of uniqueness. The different models adequately describe the behavior of the specific experimental conditions for which they were developed, and under which they were validated, but they generally fall in prediction when 
R88-PC70768

extripolated to different experimental conditions. The experimental and fundamental modeling sections of this investigation (Sections 2.0 and 3.0) have addressed the underlying causes for these apparent dlscrepancies.

The inconsistencies in the data base also dertve in part from the different models used. Without a unique (and accepted) model the "velocity constants" in each model are best thought of as empirical fitting factors. When that is the case it is not surprising that fitting factors with the same name (such as activation energy) will vary with the fltting equation - l.e. model - used, even when applled to the same set of experimental data. A further possible complication that has been argued in the literature is in error of measurement as the source of some varlabillty in the reported kinetic constants. Wrille that is undoubtedly so to some extent (see Section 2.0. Appendix $C$, and Section 4.7.1), our approach here has been to take all the data avallable at face value.

In constructing an approach to this problem it became ovident to us that the focus in the past had been predominantly on the extraction of rate constants from experimental data: this was essentially an Inductive process with experiments contributing substantially during development of the theory. On that account, much less attention had been given to the Influence of temperature gradients in the particles, and possible transport delays in the particles after generation. Thus, the focus of attention was generally on the "differential" behavior of the particles, that is to say, the local behavior in time, point by point through time.

The alternative, chosen for this study, is to focus on the "integral" behavior, that Is to say, the overall behavior or total pyrolysis time. This decision carried a number of dopendent requlrements. The primary model had to be a total study of a single pyrolyzing particle in unsteady state heating with diffusion as a clelay factor in the VM escape. The model predicted the differential (poine in time) behavior, but the primary objective was the total pyrolysis time. To this was added, during development of the program, the important intermediate stage of the tar release time.

The reason for choosing the integral behavior, total pyrolysis time or time to complete a stage of pyrolysis, was that this provided the best means: first, of compiling an experimental data base that included results from all methods of experiment; and second, of comparing prediction with experiment without necessarily being limited to study of one experimental method.

An additional element of this approach was that the model developed was not to be under constrained. This is the key requirement for developing a model that has sufficient clairn to uniqueness, and as we shall show in what follows, it is our bellef that this objective has been met. 
R88-PC70768

To execute this plan, a set of 7 tasks was dovised as listed hereunder.

Task 1 Analysis of thermal and pyrolysis behavior of a particle heating under an unsteady state condition using one-step, first-order reaction kinetics.

Task 2 Compilation of a data base of experimental values of total pyrolysis times, VM compositions, and simllar relevant data for different particlo sizes, temperatures, heating rates, coal ranks, and the like.

Task 3 Use of the model of the pyrolyzing particle as it heats up to predict total pyrolysis times. Comparison of the predicted times with those avallable in the literature.

Task 4 Review of more elaborate models and comparison of the models with each other by calculating such propertles as VM evolution rates for different sized particles at different temperatures.

Task 5 Substitution of the one-step, first-order pyrolysis model with a more elaborate inodel and repetition of Task 3 to determine the influence of the choice of model on the prediction of pyrolysis times, and the effect on the accuracy of agreement with experiment.

Task 6 Modification of the most promising model on the basis of the predlctions and comparison with the data base.

Task 7 Test of the model for sensitivity to the parameters in it with the objective of establishing the simpiest possible rate equations that will predict pyrolysis behavior both at the differential level and integrated level - with necessary and sufficient accuracy for use in flame models. This target equation is the required Engineering Rate Equatiol..

\subsection{Experimental Data Base}

The data base compiled for these investigations included several different sources but primarily focused on the total pyrolysis times for coal particles heated in a range of environments, and for sizes ranging from $5 \mu \mathrm{m}$ to $2.5 \mathrm{~cm}$. Figure 4.1 summarizes these on a plot of pyrolysis time against particle size. This figure shows some marked characteristics. The most significant one is the different trend structure for the data values above and below $500 \mu \mathrm{m}$. Above $500 \mu \mathrm{m}$, the trends are markedly evident with pyrolysis time rising 


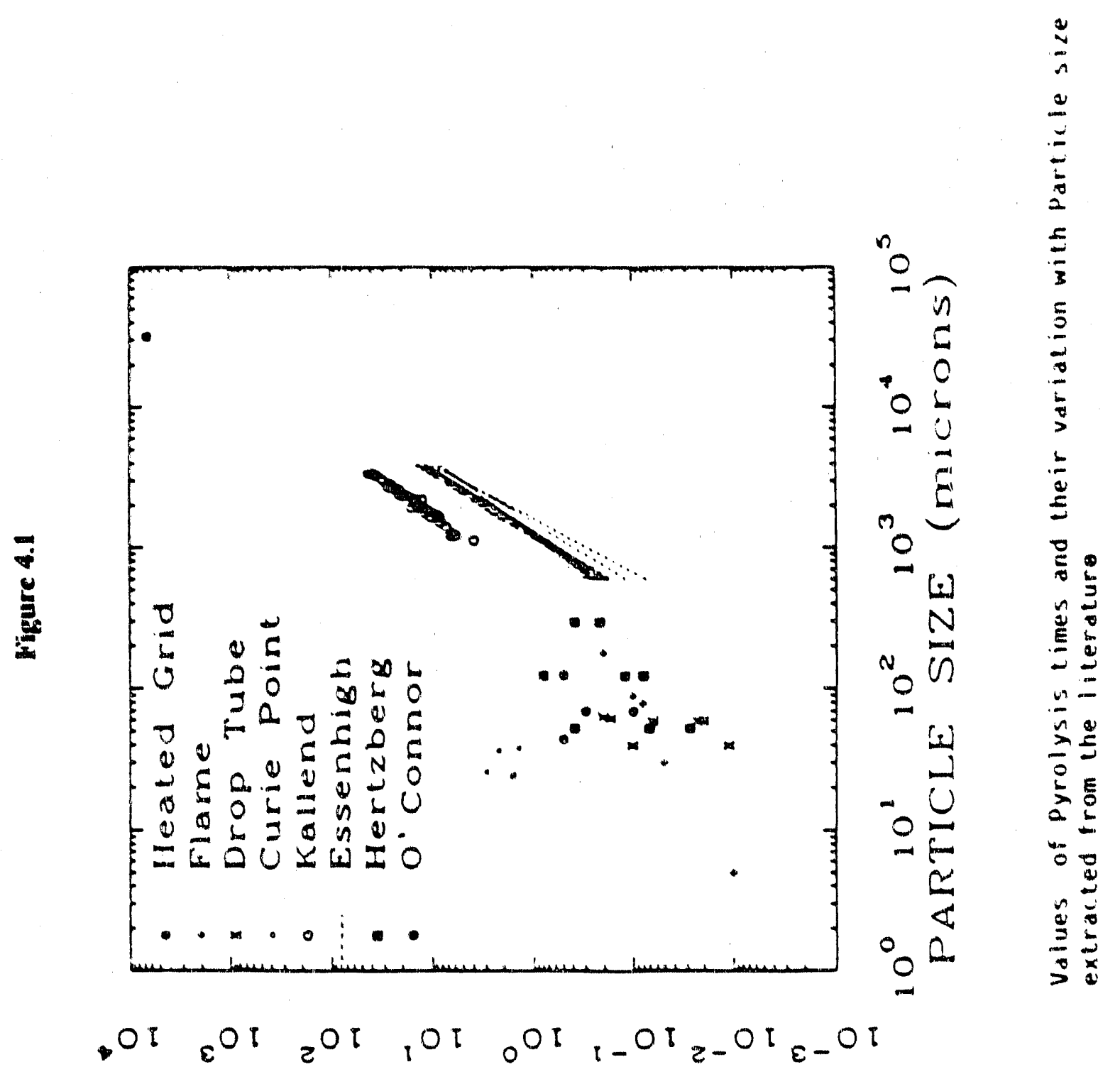

(s) JWIL SIS.XTOadd 
roughly in proportion to $d^{2}$, and with the two data sets less than half an order or magnitude apart. This contrasts strongly with the pattern for the smaller particles where the predicted pyrolysis time is found, as we shall show later, to be substantially independent of diameter; but, experimentally, the range in total pyrolysis times is nearly 3 orders of magnitude (over a range of one order of magnitude in diameter (mostly) between 20 and $2.00 \mu \mathrm{m}$ ). Superficially, there appears to be a dogleg in the data trends, but we now believe this is more apparent than real. In the Results Section we show comparisons with prediction. The principal factors governing this spread in times for the smaller particles appear to be: (final) reaction temperature and the temperature-time ramp of the heating source (notably for heated grid). Coal rank does not appear as a particular factor at this time; rank may account for as much as a factor of 2 difference under roughly comparable heating conditions, but this is less than second order compared with the 2 to 3 decades range due to the other factors.

The sources of the total pyrolysis lime data were as follows. All the values (totaling nearly 700) for particles greater than $500 \mu \mathrm{m}$ were for burning captive coal particles. Most were obtained by Essenhigh (Ref. 4.1) - 650 values - and by Kallend and Nettleton (Ref. 4.2) - 35 values - measured in oxidizing atmospheres (see Table 4.1). O'Connor (Ref. 4.3) reported one typical value for pyrolysis of 1 " to $11 / 2$ " cubes (being more concerned with the coke formation). Below $500 \mu \mathrm{m}$, about $1 / 3$ of the values were from flame data, that is, also measured in oxidizing atmospheres, (Refs. 4.4-4.8); the rest were from drop-iube (Refs. 4.9-4.14), heated-grid (Refs. 4.15-4.17), curie-point (Ref. 4.18) experiments, or laser irradiation of small $(<300 \mu \mathrm{m})$ fixed particles (Ref. 4.19). Table 4.2 summarizes the data values for the smaller particle sizes, with additional data on the heating rates and ambient temperatures; it will be noted that the majority of the particle heating rates are reported as in the region of $10^{4} \mathrm{~K} / \mathrm{s}$.

The actual determination of the pyrolysis times depended on the experimental method. For the larger-sized, captive particles, the results were reported as total combustion times of volatiles and, equating combustion with pyrolysis time $\left(t_{v}\right)$, the empirical relationship established with diameter was

$$
t_{v}=K_{v} d_{o}^{n}
$$

The values of $K_{v}$ and $n$ obtained by Essenhigh (Ref. 4.1) and by Kallend and Nettleton (Ref. 4.2) are given in Table 4.1. As this shows, the values of $\mathrm{n}$ were about 2, in agreement with a simple model developed by Essenhigh (Ref. 4.1) based on the Darcy equation for transfer through a porous medium (Ref.4.20). The values of $K_{v}$ for Essenhigh's data were mostly about $100 \mathrm{cgs}$ units; for Kallend and Nettleton's data it was just 
over $300 \mathrm{cgs}$ units: this is due to small but crucial differences in the experimental methods, as discussed later (Eection 4.7.2).

The pyrolysis times for the smaller particles were mostly obtained by a somewhat different method. In most cases, including the flames, profiles of volatile matter (VM) release or loss were reported, and these profiles were used to estimate the values listed in Table 4.2 by taking the time from $1 \%$ loss to $99 \%$ loss. generally using the original authors trend-line or calculated curves as the basis for the estimations. The estimations are considered to be within $10 \%$ accuracy. which is a trivial error compared to the broad spread in all the data values.

TABLE 4.1 - VALUES OF THE VOLATILE COMBUSTION CONSTANTS $\left(K_{v}\right.$ and $\left.n\right)$. (SOURCE: REF 4.1)

(The errors in $K_{v}$ are between 2 at.d $5 \%$, the errors given against $n$ are in percentage.)

\begin{tabular}{llccc} 
& COAL. & VM\% (d.a.f) & $\mathrm{K}_{\mathrm{v}}$ (c.g.s units) & $\mathrm{n}$ \\
\hline 1. & Stanllyd & 9.9 & 44.6 & $1.82 \pm 4.18 \%$ \\
2. & Five ft. & 14.9 & 80.0 & $2.32 \pm 4.37 \%$ \\
3. Two ft. Nine & 28.8 & 120.0 & $2.63 \pm 3.33 \%$ \\
4. Red Vein & 23.3 & 86.6 & $2.19 \pm 4.22 \%$ \\
5. Garw & 30.6 & 96.8 & $2.06 \pm 2.14 \%$ \\
6. Silkstone & 41.5 & 91.6 & $2.19 \pm 3.86 \%$ \\
7. Winter & 39.3 & 93.6 & $2.24 \pm 3.18 \%$ \\
8. Cowpen & 40.2 & 91.4 & $2.15 \pm 3.28 \%$ \\
9. High Harel & 40.7 & 134.0 & $2.2 .8 \pm 2.79 \%$ \\
10. Lorraine & 40.2 & 98.9 & $2.14 \pm 2.55 \%$
\end{tabular}

(Source Ref.)

1. Gelding

30.0

325.8

$1.96 \pm 4.06 \%$ 
TABLE 4.2 - PYROLYSIS TIMES FROM DROP-TUBE (DT) HEATED-GRID (HG), AND FLAME (F) EXPERIMENTS.

\begin{tabular}{|c|c|c|c|c|c|}
\hline $\begin{array}{l}\text { Investigators } \\
\text { [Ref. 4.xx] }\end{array}$ & $\begin{array}{l}\text { Part. Size } \\
\text { (microns) }\end{array}$ & $\begin{array}{l}\text { Htg. Rate } \\
(\mathrm{K} / \mathrm{s})\end{array}$ & $\begin{array}{l}\text { Pyrolysis } \\
\text { Time (s) }\end{array}$ & & $\begin{array}{l}\text { Ambient } \\
\mathrm{p}(\mathrm{K})\end{array}$ \\
\hline Anthony [15] & $53-83$ & $\begin{array}{l}10^{4} \\
3 \times 10^{3}\end{array}$ & $\begin{array}{l}0.1 \\
0.3\end{array}$ & HG & 1273 \\
\hline Nsakala [11] & 64 & $8 \times 10^{3}$ & 0.2 & DT & 1100 \\
\hline Niksa [17] & 125 & $10^{2}-10^{4}$ & 0.5 & HG & 1200 \\
\hline Kobayashi [9] & $37-44$ & $>10^{4}$ & 0.1 & DT & 2100 \\
\hline Howard [4] & $<200$ & $10^{4}$ & 0.2 & F & 1700 \\
\hline Smoot $[6]$ & 30 & $10^{4}$ & 0.05 & $\mathrm{~F}$ & 1200 \\
\hline Thring [7] & $<100$ & $10^{4}$ & 0.1 & F & - \\
\hline Ubhayakar [14] & $<74$ & $>10^{5}$ & 0.011 & DT & 1500 \\
\hline Seeker [5] & 80 & $5 \times 10^{4}$ & 0.08 & $F$ & 2050 \\
\hline Desypris [16] & $\begin{array}{l}126 \\
44\end{array}$ & $3 \times 10^{3}$ & $\begin{array}{l}0.5 \\
0.5\end{array}$ & HG & 1400 \\
\hline Maloney [10] & 62 & $10^{4}$ & 0.17 & DT & 1273 \\
\hline Solomon [13] & $\begin{array}{l}53-74 \\
44-74 \\
44-74\end{array}$ & $\begin{array}{l}10^{4} \\
3 \times 10^{4} \\
4 \times 10^{4}\end{array}$ & $\begin{array}{l}0.064 \\
0.02 \\
0.023\end{array}$ & DT & $\begin{array}{l}1000 \\
1100 \\
1200\end{array}$ \\
\hline Kelin [18] & $\begin{array}{l}36.2 \\
37.6 \\
23.7 \\
24.5 \\
25.6\end{array}$ & $\begin{array}{l}800 \\
900 \\
900 \\
1000 \\
900\end{array}$ & $\begin{array}{l}2.25 \\
1.42 \\
1.68 \\
1.6 \\
2.93\end{array}$ & $\begin{array}{l}\text { Curie } \\
\text { Point }\end{array}$ & $<1250$ \\
\hline Marshall [8] & 5 & $10^{5}$ & 0.01 & F & 1600 \\
\hline Hertzberg [19] & $\begin{array}{l}53,125 \\
53,125,310\end{array}$ & $\begin{array}{l}51-65 \mathrm{~W} / \mathrm{cm}^{2} \\
23-270 \quad .07 \\
320-360 \quad .028\end{array}$ & $\begin{array}{l}.38, .8 \\
.12, .38 \\
.08, .22\end{array}$ & $\begin{array}{l}\text { laser } \\
\text { irradiated }\end{array}$ & \\
\hline O'Connors [3] & $1-1.5^{\prime \prime}$ & - & 6720 & Captive & 1100 \\
\hline
\end{tabular}

An additional set of target data was provided by Freihaut (Ref. 4.10, 4.14, 4.22-4.34) for the release of the tars, estimated to be the fraction of volatiles lost between onset of pyrolysis $\left(-300^{\circ} \mathrm{C}\right)$ and about $650^{\circ} \mathrm{C}$. It was typically about $1 / 3$ to $1 / 2$ of the total volatiles. 
For coals exhibiting large overall tar yields (pfc coal types) the experimental results presented have indicated mass loss phenomena are not simply either transport or chemically controlled. The chemical characteristics of the parent coal determine the asymptotic yields, elemental composition, molecular types and molecular size characteristics of the potential "primary" tar species. The mass and heat transport related parameters of the system determine the characteristics of the actual tar species evolved, collected and characterized. From an engineering kinetics point of view the initial problem is empirical prediction or correlation of particle mass loss rates as a function of heating conditions, not detailed predictions of chemical characteristics of evolved volatiles.

\section{Characteristic Time Approach}

The comprehensive coupled heat transfer and chemical kinetic salculations presented (Appendix C) indicate the apparent disparity in particle mass loss kinetic schemes can not be explained on the basis of intraparticle non-isothermalities alone. The experimental results indicate interphase non-isothermalities among reactor/associated thermocouple measurements and actual transient particle temperatures during rapid devolatilization do contribute to apparent kinetic parameter discrepancies. Research is proceeding in which efforts are made to measure particle group temperatures (Ref. 4.35) or single particle temperatures (Ref.4.64) during devolatilization. However, in rapid heating experiments, a substantial fraction of paricle mass is lost before accurate in situ particle or particle group iemperatures can be obtained. That is, a major fraction of the asymptotic tar yield is complete before time resolved particle temperatures can be made. The engineering problem of developing predictive rates would only be partially alleviated if such measurements could be made, since the complexity of coal structure allows an almost unlimited number of devolatilization models to account for a given mass loss. The need for a simplified empirical description of the dynamics of particle mass loss for pfc modeling applications remains.

Accepting the phenomenology (see Sections 2.0 and 3.0) of particle mass loss for high tar yielding coals as a given, the engineering kinetics problem reduces to developing predictive or correlating expressions for each of the principal phases of particle mass loss in pfc heating conditions: I) intraparticle tar formation: 


\section{R88-PC70768}

II) light tar devolatilization; III) heavy tar pyrolysis and devolatilization; IV) char degassing. In terms of characteristic times, the total devolatilization time is expressed as:

$$
\begin{aligned}
& t_{\text {particle }}=t_{1}+t_{11}+t_{1 n}+t_{N} \\
& \text { devolatilization }
\end{aligned}
$$

and

$$
{ }^{t} \text { devolatilization } \approx t \text { volatiles combustion }
$$

The engineering problem reduces to three tasks: 1) determining the time scale of each phase relative to the others and the volatiles combustion phase of pfc;2) ascertaining the dominating phenomena within each phase; 3) developing predictive, empirical expressions from avallable data for each phase.

Determining relative time scales allows one to ascertain the significance of each phase from a combustion time point of view, and, as a resule, the effort, if any, to be employed in developing predictive correlations.

The experimental results of this investigation (Section 2.0) and others indicates that Phase IV, char degassing, is a slow process relative to either of the two tar devolatilization phases or volatiles combustion times in pfc systerns. Mathematically.

$$
\begin{aligned}
& t_{V V} \gg t_{1}+t_{11}+t_{11} \Rightarrow t \text { volatiles } \\
& \text { combustion }
\end{aligned}
$$

Although important from fundamental understanding and fuel nitrogen chemistry perspectives, developing rate correlations for this phase relative to pfc modeling and furnace codes is not necessary. Char degassing times at temperatures of $800-1000^{\circ} \mathrm{C}$ and above are of the order of several seconds or greater, comparable to or greater than total particle combustion times in typical pfe boiler systems.

$$
\begin{aligned}
& t \text { char }>t \text { paricle } \approx t \text { volatiles } \quad+t \text { char } \\
& \text { degassing combustion } \\
& \text { combustion combustion }
\end{aligned}
$$


In addition, char degassing accounts for only -0.10 mass fraction of the particle, compared to $0.40-0.50$ evolved during Phases I, II and III. In view of these considerations an empirical formulation of particle mass loss rate expressions reduces, as a first approximation, to:

$$
\begin{aligned}
& t_{\text {devolatilization }} \quad \approx t_{1}+t_{11}+t_{111} \\
& \begin{array}{lll}
\approx t & +\mathrm{t} & +\mathrm{t} \\
\text { intraparticle } & \text { light } & \text { heavy tar } \\
\text { tar formation } & \text { tar } & \text { and pyrolysis } \\
& \text { evolution } & \text { gas evolution }
\end{array}
\end{aligned}
$$

Ascertaining the dominating phenomena of each phase is necessary in order that the correct parameters are employed in attempts to develop correlations. It is now well established that coupled chemical and transport phenomena exist in each phase of devolatilization of coals that yield significant quantities of tar. That is, chemical kinetic, mass transport and heat transport factors all contribute to one or more of the observables during rapid devolatilization. Figure 4.2 a illustrates a typical sigrnoid particle mass loss rate $(\mathrm{dm} / \mathrm{dt})$ curve as a function of time and with the four phases of mass loss indicated. As indicated in the figure, asceraining the dominating phenomena in each of the phases is essential to establishing engineering rate expressions.

Because of the intimate coupling among intrinsic, chemical, parameters and extrinsic, transport related, parameters in determining observables during devolatilization, the development of practical rate expressions is necessarily a cyclic, spiral approach process. Figure $4.2 \mathrm{a}$ indicates heat transfer $(\dot{Q}, \dot{q})$, mass transfer $\left(H_{m}, h_{m}\right)$, and chemical kinetic processes $\left(k_{d e l}, k_{c h e m}^{\prime}, k^{\prime \prime}{ }_{c h e m}\right)$ are involved in each phase. The perceived dominating phenomenon in each phase is indicated by capital case letters. Heat transfer parameters are estimated to be primarily responsible for overall particle mass loss rates during the initial 0.15 -0.25 mass fraction devolatilization. Mass transfer phenomena are thought to dominate the next -0.15 mass fraction loss, whereas char degassing, determined by chernical kinetic pyrolysis rates, controls the asymptotic approach to the final particle mass loss. These estimations of the dominating influence in each phase are derived from consideration of the experimental results of this investigation as well as those found in the literature. The general phenomenological model noted in Fig. $4.2 \mathrm{a}$ and $4.2 \mathrm{~b}$ may be viewed relative to Figs. 3.2, 3.3 and 3.4, wherein more chemical detail is given. The chemical detail is necessary in distinguishing fundamental models of devolatilization but not for development of engineering expressions of "mass loss", a particularly non-specific caregory. 


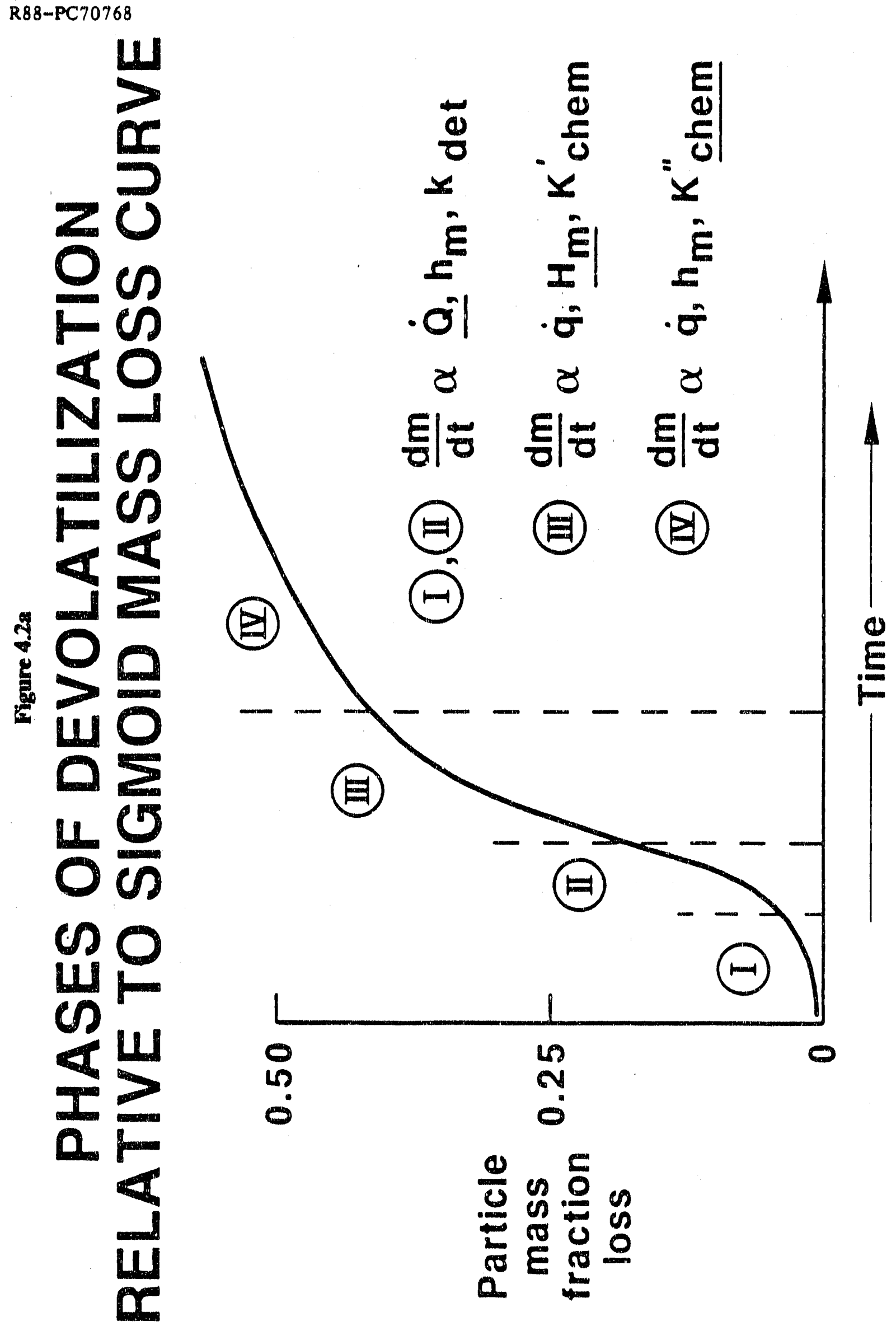




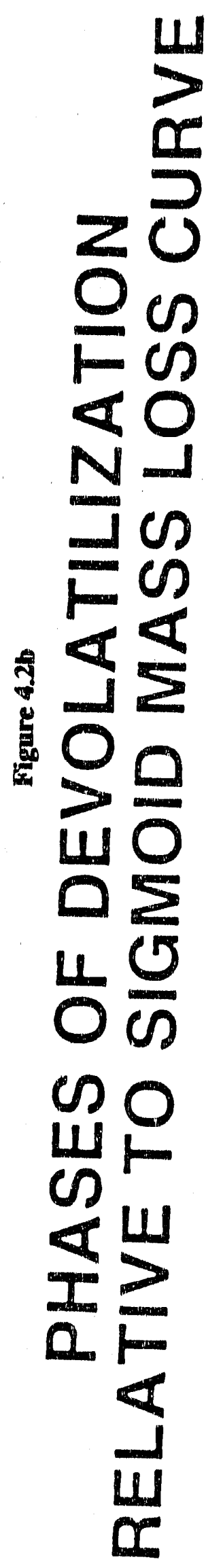

3
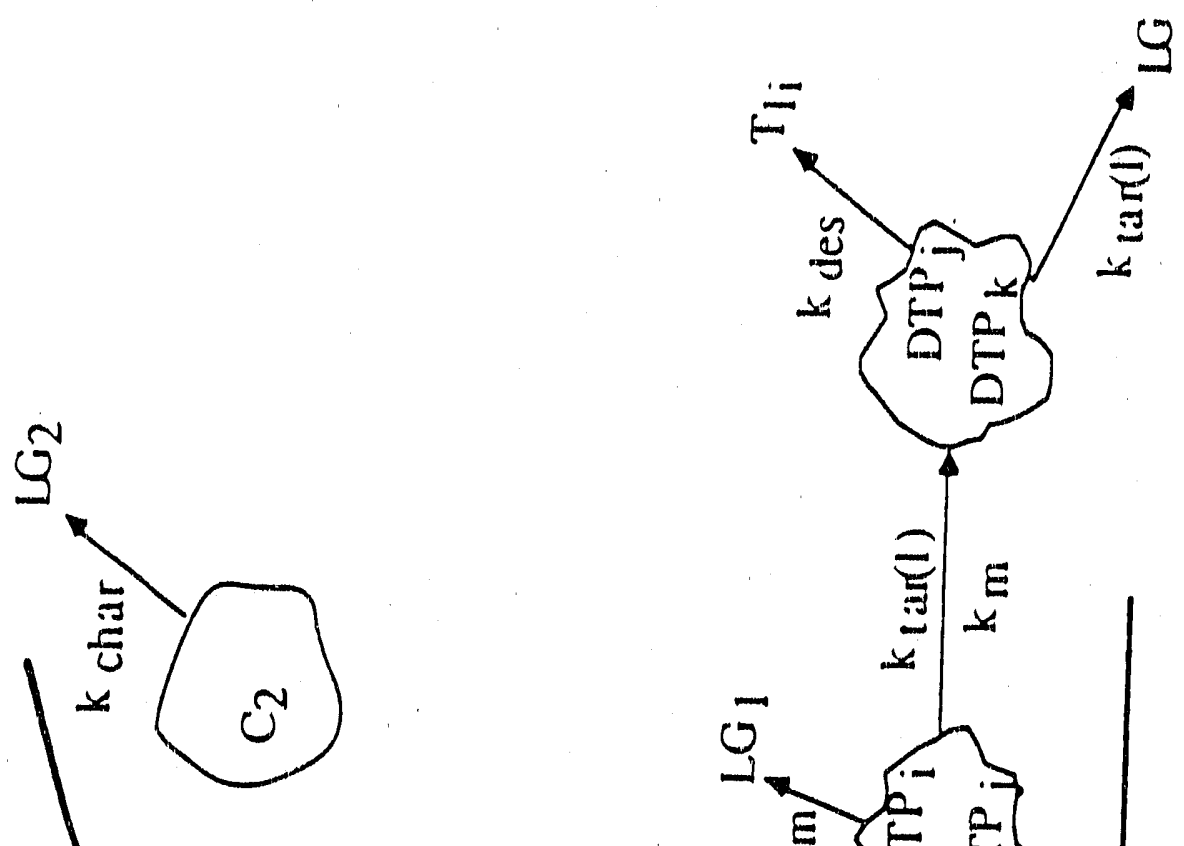

5.

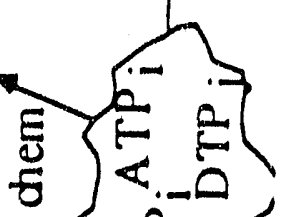

$=$
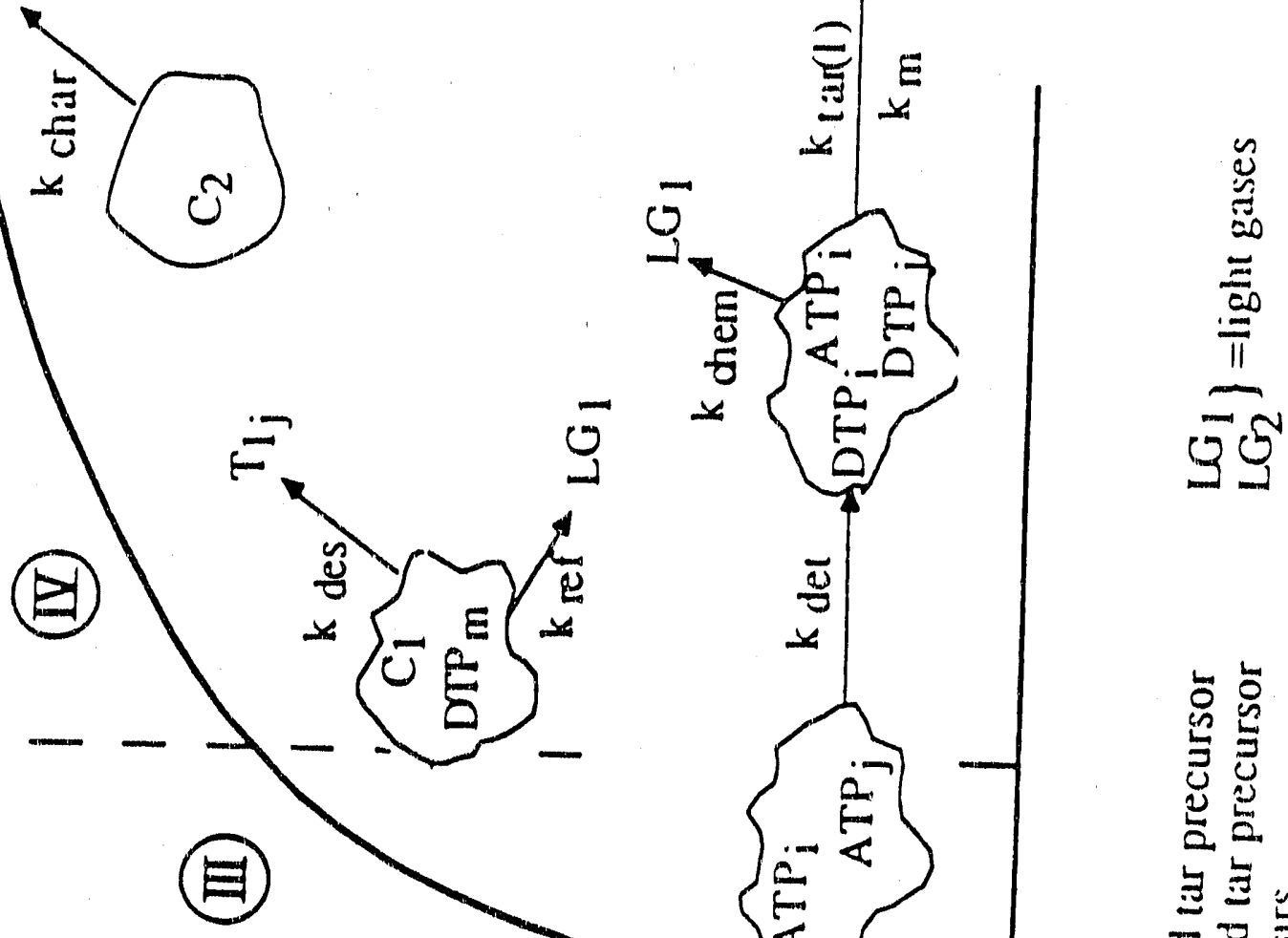

5
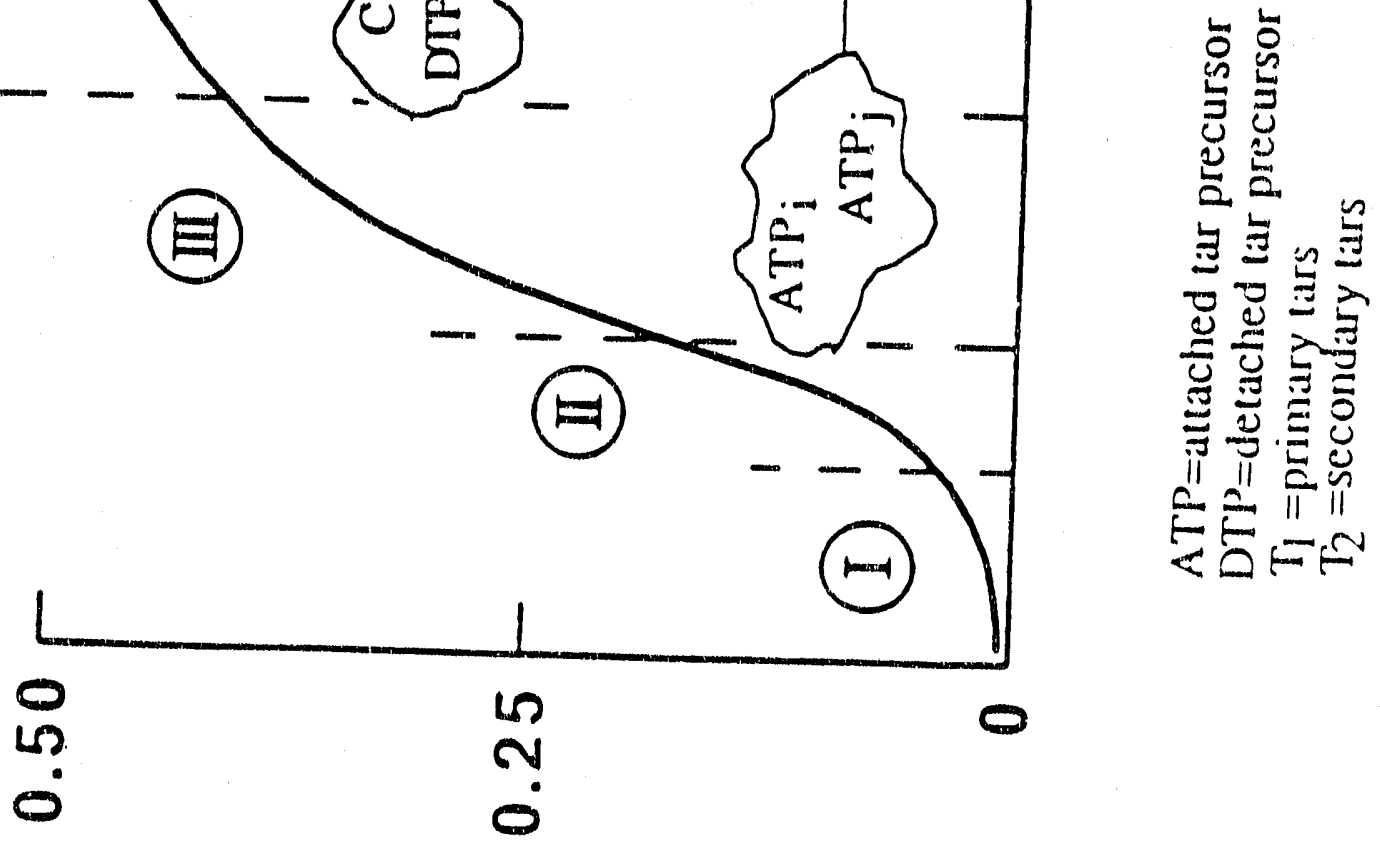

एक

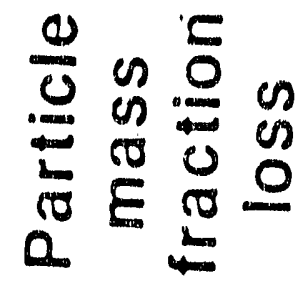


The possible coupling among heat transfer parameters, and devolatilization rates is obvious from the energy balance equation for a particle subjected to radiative and conductive/convective heating:

$$
\sigma_{S B}\left(a_{1}\right)_{p}\left(T_{w}^{d}-T_{p}^{d}\right)+\left(\hbar_{N u} S_{p}\right)\left(T_{s}-T_{p}\right)=(Q C V)_{p} T_{p}+\Delta h_{d e v} S_{p} \quad R_{d e v}
$$

where,

$$
r_{\text {dey }}=-\left(f_{\substack{\text { car } \\ \text { tar }}}\left(\frac{V}{S}\right)\right){ }_{p} k_{\text {dev }}
$$

Normalizing with respect to the superficial surface area of the particle, $S_{p}$ :

$$
\sigma_{\mathrm{SB}} a_{\mathrm{p}}\left(\mathrm{T}_{\mathrm{w}}^{4}-\mathrm{T}_{\mathrm{p}}^{4}\right)+\bar{h}_{\mathrm{Nu}}\left(\mathrm{T}_{\mathrm{z}}-\mathrm{T}_{\mathrm{p}}\right)=\left(Q \mathrm{Qc}\left(\frac{\mathrm{V}^{\prime}}{\mathrm{S}}\right)\right)_{\mathrm{p}} \mathrm{T}_{\mathrm{p}}+\Delta \mathrm{h}_{\mathrm{dev}} \mathrm{R}_{\mathrm{dev}}
$$

In the case of no particle gas velocity differential:

$$
\sigma_{S B} \alpha_{p}\left(T_{w}^{4}-T_{p}^{4}\right)+\left(\frac{2 k_{g}}{d_{p}}\right)\left(T_{8}-T_{p}\right)=\left(Q c\left(\frac{V}{S}\right)\right)_{p} T_{p}+\Delta h_{d e v} R_{d e v}
$$

This equation represents the energy balance in terms of energy density components. The left hand side (LHS) of equation 4.10 represents the reactor-particle heat transfer process in terms of its radiative and convective components. The RHS of the equation indicates the energy density input in terms of the internal energy of the particle, and the component needed to devolatilize the particle. From an engineering perspective the energy density balance during Phases I, II and III is the concern, the tar formation and evolution phases that are of concern.

For example, at a transient particle temperature of $773 \mathrm{~K}$ in an isothermal $\mathrm{N}_{2}$ carrier stream at $1073 \mathrm{~K}$ surrounded by isothermal alumina walls $(e=0.6)$ at $1073 \mathrm{~K}$ a $100 \mu \mathrm{m}$ coal particle would be experiencing a radiative flux density of -2.3 watts $/ \mathrm{cm}^{2}$ and a convective component of 36.3 watts $/ \mathrm{cm}^{2}$. Such a power density would result in an instantaneous particle heating rate of $-1.3 \times 10^{4} \mathrm{C} / \mathrm{sec}$ of an inert particle. If tar release occurs via a mechanism having an overall rate constant of $-60 \mathrm{sec}^{-1}$ at $873 \mathrm{~K}$ $\left(E_{A C T}=45 \mathrm{kcal}, \mathrm{k}_{\mathrm{o}}=10^{13} \mathrm{sec}^{-1}\right)$ its half-life would be of the order $11-12 \mathrm{msec}$, comparable to the time required to heat the particle through the tar evolution temperatures $(773 \mathrm{~K}$ to $973 \mathrm{~K}$ ). Aside from being beyond the experimental time resolution capability of most devolatilization reactors operating in such 
heating conditions, such rapld tar evolution procosses could further convolute experimental analyses by introducing a perturbation to the standard energy balance equation. A heat of devolatilization of $419 \mathrm{~J} / \mathrm{g}$-tar (nominal heat of vaporization of aromatic species) coupled to a $k_{\text {dev }}$ of $60 \mathrm{sec}^{-1}$ introduces a 17-18 watts $/ \mathrm{cm}^{2}$ instantaneous heat sink leaving a net energy density to heat the particle of -20 watts $/ \mathrm{cm}^{2}$. Such an energy density could heat a particle at only $7 \times 10^{30} \mathrm{C} / \mathrm{sec}$.

The deviation in transient particle temperature trajectory relative to an inert particle would not be directly observable in an entrained flow reactor measurement. The limited temporal resolution of such reactors and the velocity of the tar devolatilization process in the flux fields of such reactors characterized by isothermal reactor temperatures of $800^{\circ} \mathrm{C}$ or above convolutes the mass loss process. However, subtle changes in heat transfer related parameters should produce some observable change in the global time of particle mass loss as tar in such reactors. This is observed to be the case (Section 2.1.1) in the PSU-EFR reactor wherein changes in feed particle size or thermal conductivity of feed stream gas produce correspor.ting changes in initial particle mass loss times. The engineering implication of the above considerations is that a tar evolution process is stimulated in a bituminous coal provided asymptotic partcle temperatures of $600^{\circ} \mathrm{C}$ or greater are generated by a reactor. That is, a tar formation and evolution pathway is always available to bituminous coals, irrespective of heating conditions. Heating conditions determine the chemical nature and rate of tar species release during the transient particle heating, but some tar formation and release pathway is available from the almost unlimited devolatilization routes.

Recognizing the lack of chemical detail and mechanistic information in such an approach these considerations suggest tar evolution, initial particle mass losis, times may be correlated by a heat transfer index. Arate of tar formation and evelutionis assumed to vary with reactor conditions. It is established that some form of tar evolution can occur in response to heating conditions. Ignoring the reaction effects on the energy density balance of equation 4.10 , an apparent heating rate index is defined as the LHS divided by the average diameter of the coal particles utilized in the reactor, that is, the average net flux rate density at the particle surface during its 300 to $600^{\circ} \mathrm{C}$ temperature rise, normalized with respect to particle size.

$$
\text { Apparent Heating Rate Index }=\frac{\left\langle Q_{\text {nel }} w / \mathrm{cm}^{2}\right\rangle}{\langle\mathrm{d}, \mathrm{cm}\rangle} 300^{\circ} \mathrm{C}
$$

Obviously $\dot{Q}_{n e s}$ varies significantly with reactor type (Fig, 2.1) as will the particle size of the feed. Again the underlying assumption is that seme form of tar release can occur, provided particle temperatures of $600^{\circ} \mathrm{C}$ 
or greater are achleved. The chemlcal nature, mode of tar release and tar formation reaction network are not assumed invariant. On the contrary, they are assumed to be able to adjust rapldly to the conclition of heating. If the heat transfer process of the devolatilization reactor is thought of as producing a strain on the coal particles, the tar devolatilization pathway is the strain rellef process of the coal particle. Due to lts chemical complexity, bituminous coal has an almost unlimited set of strain rellef mechanisms via tar release. The implication of the above is that tar evolution times will correlate with the apparent heating rate Iridex. Figure 4.3 displays the observed, experimentally estimated, Initjal particle mass loss, tar release, times for subbituminous and bituminous coals plotted versus the apparent heating rate index. By "initial" is meant the first $20 \%$ of the particle mass loss, which generally is observed to be dominated by tar species for such coals. For a bituminous coal such a mass loss accounts for $60-75 \%$ of the potential transient tar yleld of such coals (see Sections $2.3 .1,2.3 .2,2.4 .0$ ),

$\left(\dot{Q}_{n+1}\right)$ is generally estimated from the detalls of the reactor description using coal properties cliscussed above (Section 3.0). For example, in the PSU-EFR the wall gas temperature and gas composition are clearly defined, leading to transient estimates of $\mathrm{Q}_{\mathrm{rot}}$ such as found in Fig, 2.14. In the Granger and Ladner (Ref. 4.32) flash lamp experiments the transient total radiant flux profiles are giverı along with the particle size characteristics of the coal and ambient gas characteristics. Maloney (Ref.4.34) provides extremely fine detail of his unique suspended particle laser devolatllization experiments.

As the realization of the importance of heating condition on observables has increased, Investigators have increased the reactor details provided, enabling reactor-particle heat transfer characterization. The initial tar release times are estimated directly from the tar evolution data for heated grid and flash lamp studies or the initial partlcle riass loss in the case of entrained flow weight loss studies. The empirical correlation between initial tar release and heat transfer index is appasent. Within the experimental resolution, tar formation and evolution from bituminous and subbituminous coals correlates directly with heat transfer intensity. Unfortunately, as noted above, thero is substantial evidence indicating significant changes in mode of tar release and the chemical nature of the tars with heating rate. Consequently, such a correlation can be employed to estimate particle response times in pfe firing conditions, but not the combustion properties of the volatiles. These must be determined from subsidiary measurements. 


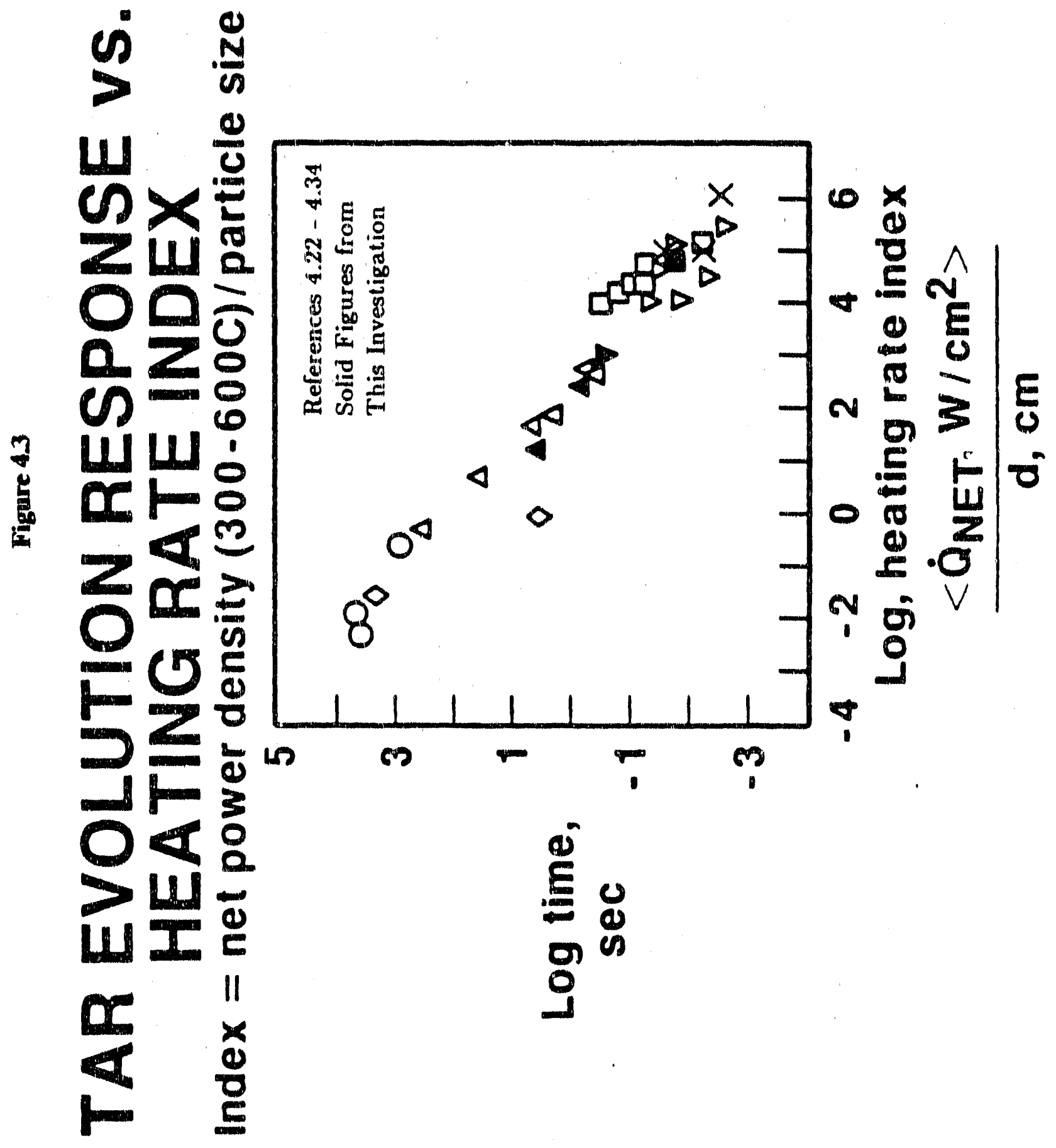


From Eq. $(4,7)$, it can be shown that the time it takes to drive an inert $\left(\Delta h_{\text {dov }}=0\right)$ partlcle of clameter d from temperature $T_{1}$ to temperature $T_{2}$, an experiementally determined temperature range for the light tar release, is given by:

$$
t_{1 !}=\frac{\left.\left\{\frac{\left\langle\rho_{p}\right\rangle\left\langle C_{p}\right\rangle}{6}\right\}(\Delta T)\right|_{T_{1}} ^{T_{2}}}{\left(Q_{\text {Def }} / d_{p}\right)_{T_{1}}^{T_{2}}}
$$

where $Q_{p}$ and $C_{p}$ represent the average particle density and heat capactidy during the temperature excursion. Specifically, the average particle density is taken as the arithmetic average of the initial particle density and a particle that has lest $25 \%$ of its mass without swelling. The average particle heat capacity is determined from the equations given above. Putting specific average values in place gives the following equation for devolatilization times:

$$
t_{11}=\frac{k}{\left\langle Q_{\text {Det }} / d_{p}\right)_{T_{1}}^{T_{2}}}
$$

where $Q_{\text {net }}$ is the net, time-averaged power density in watts $/ \mathrm{cm}^{2}$ at the surface of a particle of $\mathrm{d}$ centimeters during the heating process. " $\mathrm{k}$ " is a constant incorporating the average particle density and heat capaclty and a given temperature interval of interest. For example, $k$ is approximately $105 \mathrm{~J} / \mathrm{cc}$ for a particle having an average density of $1.22 \mathrm{~g} / \mathrm{cc}$ and heat capacity of $1.71 \mathrm{~J} / \mathrm{g}-{ }^{\circ} \mathrm{C}$ over a $300^{\circ} \mathrm{C}$ temperature excursion.

The dovolatilization process is assumed to be thermally neutral and the initial mass loss occurs in a linear fashicn over the temperature change considered, that is, the rate of mass loss can be represented as a constant during this phase. Of course, experimental evidence indicates that this is not the case. Rather, the tar evolution rate for high tar yielding coals is a maximum around $400-450^{\circ} \mathrm{C}$ for apparent particle heating rates less than $1^{\circ} \mathrm{C} / \mathrm{sec}$ and has a fairly narrow temperature width at half naximum. The time interval of release is appreciable since $\Delta t=$ Heating Rate $\Delta T$. The instantaneous maximum rate of tar evolution shifts to higher apparent particle temperatures with increasing heating rate, the width at half-maximum of differential mass loss curve becornes spread over a greater temperature interval, but the tar evolution in absolute time units becomes less. In no case, however, can the light tar release be pushed substantially above $600-650^{\circ} \mathrm{C}$, except perhaps in some laser driven experimerits in which instantaneous net irradiance levels of 
1000 watts $/ \mathrm{cm}^{2}$ or greater are reporter. In no case can the onset of detectable tar release be pushed below $375^{\circ} \mathrm{C}$

Given these empirically determined constraints on $T_{1}$ and $T_{2}$, the bracketing temperatures ri phase II tar release. Eq. $(4.12)$ can be used to calculate the tar evolution times expected from enerby balance considerations alone. Figure 4.4 displays the energy-balance-estimated tar evolution times calculated from use of Eq. (4.12) and employing the temperature endpoints indisated. Table 4.3 compares the data fit parameters to the corresponding energy balane parameters.

Obviously, the eneroy balance considerations alone provide a reasonable description of the data but tend to overestirnace the tar devolatilization cimes av lower heating race indices and underestimate at bigher value more intease heating conditions. Of course, the uncertainties involved in experimental measurements and time resolution as well as extracting pyrolysis times from presented data rather than raw data must be considered. Given this reservation, it appsars that ransienteneroy balance sonsiderations alone do not mircor the statitical fit as the extremes of experimentai sonditions.

TABLE 4.3 - LINEAR COEFFICIENTS; $\log \left(t_{11}\right)=m^{*} \log (H R I)+b$

\begin{tabular}{lcc} 
Equation & $\mathrm{m}$ & $\mathrm{b}$ \\
\hline Least Squares Fit of Data & -0.8198 & +1.899 \\
Energy Balance. $300-600^{\circ} \mathrm{C}$ & -1.0000 & +2.021 \\
Energy Balance, $300-700^{\circ} \mathrm{C}$ & -1.0000 & +2.121 \\
\hline
\end{tabular}

In the low heating rate index conditions the fall off in tar evolution times relative to the energy balance predictions is believed due to the coking rate incorporation of some of the tars into the char matrix (See Modeling: Section 3.0).

At the highest intensil; heating conditions the observed tar evolution times are greater than that predicted on energy balance considerations alone. That is, in these crreditions there does seem to be an additional contributing resistanc to the evolution of tar species the considered in the simplistic heat transfer analysis. The nature of the resistance - chernical kineti transfer inhibition, vaporization energy requirements - is not immediately apparent. However, the single-sided heating exper nents may 


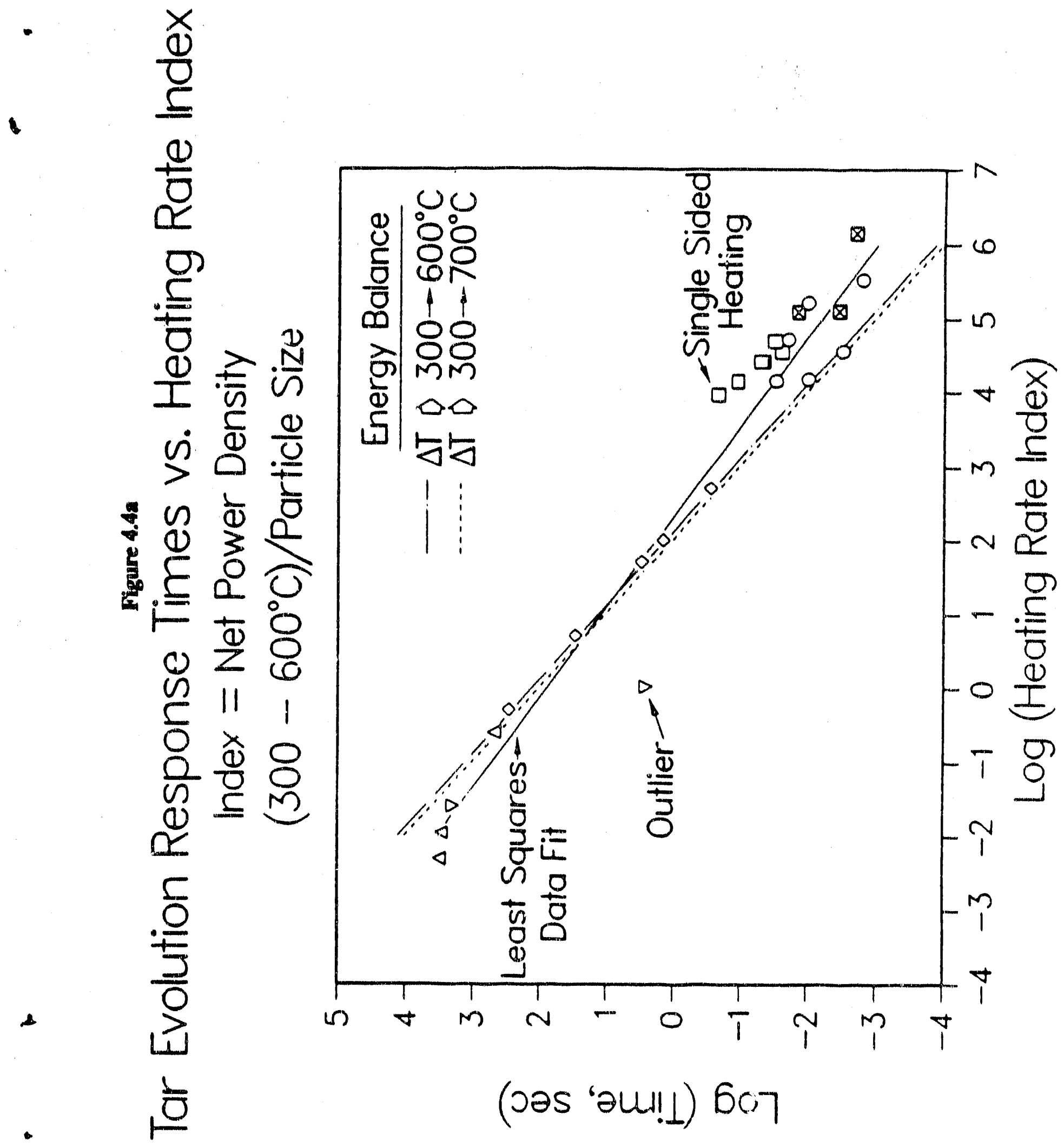




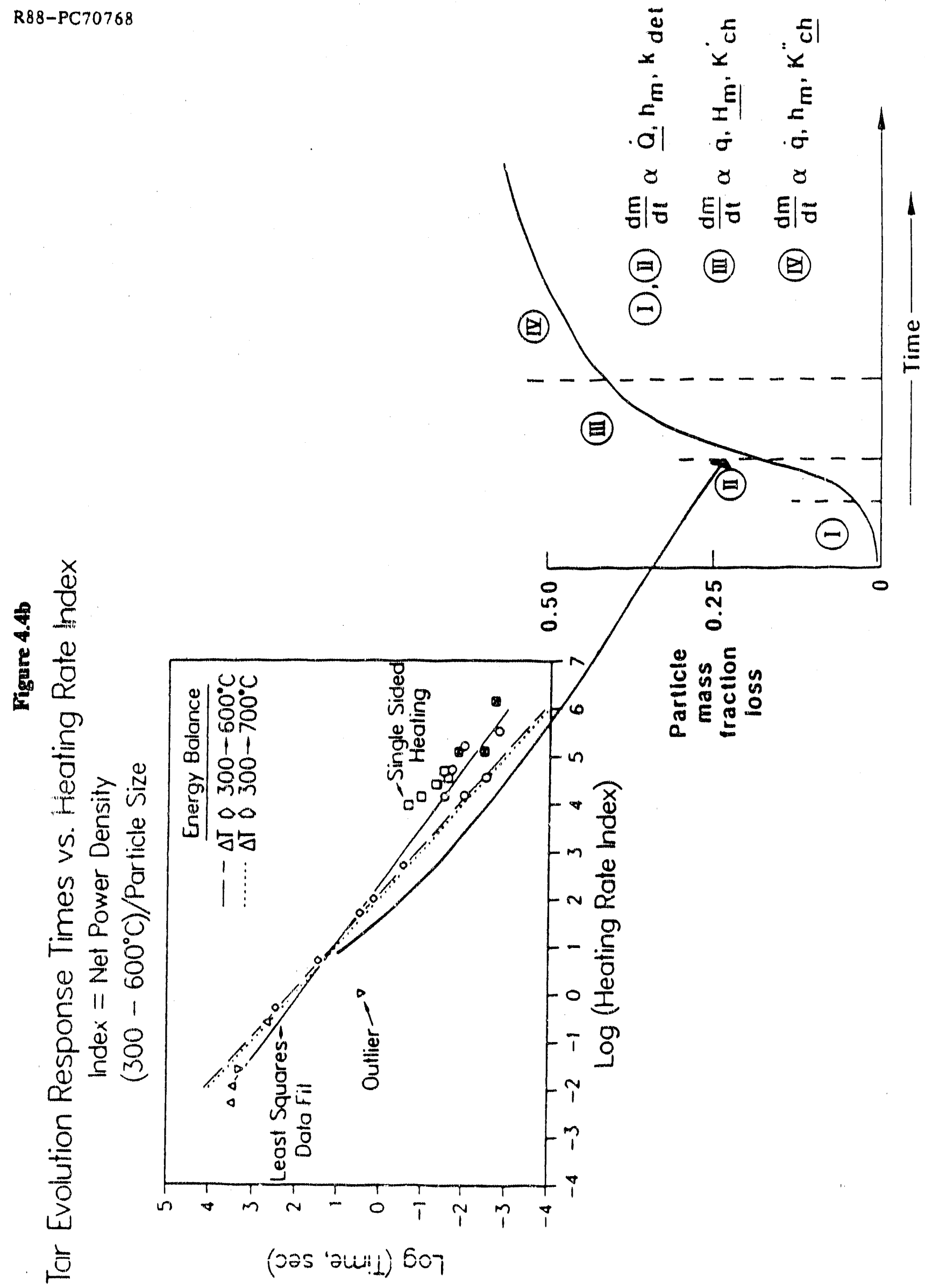


provide a clue. These experiments consistently indicate mass evolution times which are greater than either the data fit line or the energy balance calculations. In this case it is known from the asymmetric heating of the particles that the observed mass evolution times are influenced by the heat transfer process. It is not unlikely that similar factors in entrained flow systems - mixing times of coal carrier gas with hot entrainment gas, nonuniformity of laser beam density, etc. - could be influencing observable devolatilization times relative to the calculated energy balance times. Both the energy balance calculations and the estimations of experimental heating rate indices assume perfect symmetric particle heating and step functions in heat transfer boundary conditions with the experimental apparatus. This is not akely the actual case.

In any case, an empirical method has been developed which indicates the tar evolution response is directly correlated to the conditions of heating, as a first approximation. The correlating expression is:

$$
\log \left(t_{H I}\right)=-0.8198 \cdot \log (H R I)+1.8998
$$

where $t$ is the phase II tar evolution, particle mass loss, time and HRI is the heating rate index as defined above. Table 4.4 displays typical examples of expected response times for given HRI values and the possible experimental conditions having the given HRI. The time refers to the phases illustrated in Figs. 4,2a,b. Figure $4.2 \mathrm{~b}$ displays the relationship of the characteristic light tar evolution to the total mass loss process.

Residence time restrictions on some reactors make them impractical for investigating tar evolution since the particle can not be maintained in the hot zone for sufficient time. 
TABLE 4.4 - EXPECTED INDUCTION AND INITIAL TAR EVOLUTION TIMES: PHASE I AND PHASE II OF MASS LOSS DEVOLATILIZATION SEQUENCE

\begin{tabular}{|c|c|c|c|c|c|}
\hline 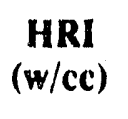 & $\begin{array}{c}\langle d\rangle \\
\text { (microns) }\end{array}$ & $\begin{array}{l}<Q_{\text {now }}> \\
(w / s q ~ c m)\end{array}$ & Reactor System* & $\underset{(\mathbf{m s e c})}{\mathbf{t}_{\mathbf{I I}}}$ & $\begin{array}{l}t_{1}+I_{1} \\
(\mathrm{msec})\end{array}$ \\
\hline $10^{2}$ & 100 & 10 & $\mathrm{HG}$ & $250-300$ & $500-600$ \\
\hline $10^{4}$ & $\begin{array}{l}10 \\
20 \\
40\end{array}$ & $\begin{array}{l}10 \\
20 \\
40\end{array}$ & $\begin{array}{l}\text { EFR, RF } \\
\text { EFR, RF } \\
\text { EFR, RF }\end{array}$ & $40-50$ & $80-100$ \\
\hline $10^{5}$ & $\begin{array}{r}1 \\
10 \\
20 \\
40\end{array}$ & $\begin{array}{r}10 \\
100 \\
200 \\
400\end{array}$ & $\begin{array}{l}\text { EFR, RF } \\
\text { EFR, PL, FL, CW } \\
\text { PL, FL, CW } \\
\text { PL, FL, CW }\end{array}$ & $5-10$ & $10-20$ \\
\hline $10^{6}$ & $\begin{array}{r}1 \\
10 \\
20 \\
40\end{array}$ & $\begin{array}{r}100 \\
1000 \\
2000 \\
4000\end{array}$ & $\begin{array}{l}\text { EFR, PL, FL, CW } \\
\text { PL, FL } \\
\text { PL, FL } \\
\text { PL, FL }\end{array}$ & $0.5-1.0$ & $1-2$ \\
\hline
\end{tabular}

$\mathrm{HG}=$ Heated Grid Devices, EFR $=$ Entrained Flow Reactors, $\mathrm{RF}=$ Radiative Field Flow Reactors, $\mathrm{PL}=$ Pulsed Lasers, $\mathrm{FL}=$ Flash Lamps, $\mathrm{CW}=$ Continuous Laser Systems

Some data compilations also included tabulations of velocity constants and kinetic parameters (activation energies and frequency factors). Velocity constant tabulations have been made by numerous investigators, and notably by Howard (Ref. 4.37) and by Solomon (Ref. 4.35, 4.36), with values presented on A.rrhenius plots. Those plots showed that there were wide variations both in absolute values and in the temperature trends (activation energies) in reported values. Reasons advanced for these variations have included: the variable nature of coal, and natural trends with rank; and the differences between the static and dynamic analyses (Ref. 4.38). Another factor affecting variations in $k_{\mathrm{o}}$ and $E$ can be random error. However, Nsakala (Ref. 4.11) has shown that the two kinetic parameters generally have a considerable degree of autocorrelation. This is a plot of $\mathrm{E}$ against $\log \mathrm{k}_{\mathrm{a}}$ for values reported by many principal experimentalists, and it was used as a starting point in matching constraints with degrees of freedom without which there can be no convergence to uniqueness. One end result of the present study is a revision of this graph, as shown later.

\subsection{Physical Model for Engineering Heat Transfer Times}

The physical model we have used as the basis for the mathematical formulation (Appendix B) is that of a particle plunged into an enclosure containing an inert or reactive gas whose temperature is rising. Heat 
transfer can be jointly by conduction (convection) and by radiation. This model was chosen to represent as wide a range of practical or laboratory experimental conditions as possible.

In all relevant systems, coal particles can be burned in only a limited number of ways. They can be held captive in a thuratiai feld, or injected into quiescent hot gas as small packets or as single particles, or they can be entraine inith a flowing stream. Captive particles were used by Essenhigh (Ref. 4.1), by Kallend and Nettleton (Ref, 4.2) and by Zghoul and Essenhigh (Ref.4.39), for particles above $300 \mu \mathrm{m}$; this can also describe the heated-grid experiments, and can include the new electrostatic field levitation experiments for suspending single particles without physical attachment. The injection of single particles or small packets into stationary air in electric tube furnaces, however, has mainly been used for ignition studies (Ref. 4.40 4.43) although both pyrolysis and burn-out times were measured photographically by Orning in 1942 (Ref. 4.44). (Physically-attached particles (Refs. 4.45 - 4.47), Heated Grid (Ref. 4.48) and TGA methods (Ref. 4.49) have also been used in ignition studies though information from those experiments on pyrolysis is limited or not obtained). Drop tube experiments use entrained flow; entrained flow also describes the behavior of laboratory--scale flames (Refs. 4.4, and 4.50), and of pulverized coal fired boilers or furnaces where the cold jet of primary air carrying the coal particles is heated by turbulent exchange with hot, entrained combustion products.

Thus, in most cases, the primary thermal field is due to convection/conduction from the ambient gas at a constant or rising temperature. In every specific case, the detailed calculation of the temperature-time profile of the ambient gas is highly complex, but for the purpose of establishing the pattern of influence on the coal particles, the behavior in these calculations is sufficiently approximated by writing

$$
T_{B}-T_{0}=\left(T_{m}-T_{0}\right)\left[1-\exp \left(-t / r_{B}\right)\right]
$$

where $\tau_{g}$ is a characteristic time for the gas temperature $T_{8}$ to heat from anbient at $T_{0}$ to a maximum at $T_{m}$; this maximum can, if necessary, be interpreted as the flame temperature. This equation may have to be used with some care with some of the heated grid conditions where the temperature ramps up to $T_{m}$ almost linearly and is then held constant, so that $\mathrm{dT} / \mathrm{dt}$ is $\mathrm{n}$ ( $\mathrm{c}$ continuous at the transition between the two heating st.ages.

Past studies have shown that radiation was generally found to be important only in quite limited circumstances. It is certainly dominant in the so-called Type II one-dimensional flames (Ref. 4.51 ); but it 
has generally been found to be of only second order importance in jet flames where the recirculation provides up to $90 \%$ or more of the ignition energy (Ref.4.52). For the radiation fleld included in the model in the present study, this is described by a constant background (i.e. wall) temperature; in some cases, such as for the heated-coil experiments, a view factor is incorporated. The radiative contribution calculated from the model, however, was generally found to be second order or trivial, in agreement with the results of the past studies already noted; it was usually of the greatest significance for the larger particles. Specifically, for captive particles in the size range 1 to $3 \mathrm{~mm}$ (Ref. 4.39), the radiation was found to increase from a relatively minor to the dominant mode of heat transfer as particle size increased from the smallest to the largest.

The complete physical model is, thus, a particle that is heating, jointly, by radiation from a constant field and by conduction from a gas at temperature $T_{B}$ with a $T_{B}-t$ profile described by Eq. (4.15). Even in the heated grid the estimation is that gas conduction is the principal mechanism of heat transfer, and Eq. (4.15) still applies. The characteristic time, $\tau_{\mathbf{g}}$, is used as a preset adjustable parameter; specifically, for very small values of $\tau_{b}, T_{b}$ is effectively constant and equals $T_{m}$. For the particle, the total thermal field, both inside and outside the particle, is treated in unsteady state. In this respect it differs, we believe, from most or all previous unsteady state models where approximations were used for either the exterial or the internal fields. Inside the particle, assumed spherical, this is divided into concentric shells; and pyrolysis in each shell is described in the first part of the calculation by a one-step, first-order rate equation, at a rate specified by the local temperature for that shell in the particle. This is later modified to a Two-Component Model for coal pyrolysis. Escape of the volatiles formed is assumed to be governed by permeability diffusion, using an assumed diffusion or Darcy-type permeability coefficient (Ref, 4.20) as an adjustable parameter to esta' 'iish the effects of diffusional hold-up in the particle. Volatile trapping by cracking is not included at this time, but incorporating this in the model would be relatively simple in principle.

The selection of the one-step, first-order pyrolysis assumption was based on concern for requirements for uniqueness, for which there must be a match between constraints and degrees of freedom. Our target was either an exact match in constraints or an overconstrained set, as any consequent mismatch between prediction and experiment, then, will usually provide clues as to the constraint to be modified. The first-order, one-step assumption adopted here is the simplest phenomenological - and thus general postulate; and it has been widely used with considerable success for many purposes. More elaborace 
assumptions commonly invoke or imply specific mechanlstic bases for which there is only arguable or no Independent supporting evidence.

\subsection{Results I: Differential Behavior}

In reviewing the expected behavior of the heating, pyrolyzing particle it was evident that there was the possibility that very fast heating could create a highly-reactive, high-temperature shell around an almost Inert core. If this happened experimentally then, clearly, assumptions that reaction was uniform through the particle could generate rate constants that could be grossly in error. Examination of this possibility thus became one of the particular reasons for this theoretical development.

\subsubsection{General Characteristics: Inert Particle}

The first calculations were for an inert particle so that the thermal response could be examined without the complications of or inierference by the pyrolysis. Attention was first focused on the temperature response, and Fig. 4.5 is typical of the curves obtained. The two most evident characteristics are the (1-exp) type of response so that there is a steadily diminishing heating rate $(\mathrm{dT} / \mathrm{dt})$ as time progresses. An additional factor is the slightly different response of the surface and center where, as can be expected, the center lags the surface; in this case it is by a relatively small amount, but in some cases it can be substantial, Figure 4.6 shows the magnitudes of the difference more clearly by using a logarithmic time scale; this shows that the difference can be as much as 500 degrees. This difference is primarily a function of the ambient (limit) gas temperature $\left(T_{m}\right)$. This dependence is shown in Fig.4.7 where the plot now is for the temperature difference between surface and center $(\Delta \mathrm{T})$, but using the local heating rate ( $\mathrm{dT} / \mathrm{dt}$ ) as the stand-in for time. (where the heating rate falls with time so that the time scale is running in the $-x$ direction): the dependence of $\Delta T_{\max }$ on $T_{m}$ is quite clear.

Figure 4.7 shows that the maximum $\Delta T$ values can be as high as $700 \mathrm{~K}$, and for gas temperature up to $2000 \mathrm{~K}$, the difference can be as high as 1000 degrees. Physically, following the temperature profile through the particle, the temperature jump is found to occur mostly near the surface of the particle so that there is a thin shell at the surface with a dramatic difference in temperature across it. These results do, indeed, show that there can be a high temperature shell around a low timperature core; and, clearly, this could be a possible source of error or of reported differences between investigators if reaction was confined to such a shell but the surface temperature was assumed to be constant through the particle, as this would underestimate the true isothermal rate taken at the surface temperature. Conversely, it would overestimate the true isothermal rate if taken at the center temperature. 
Figure 4.5

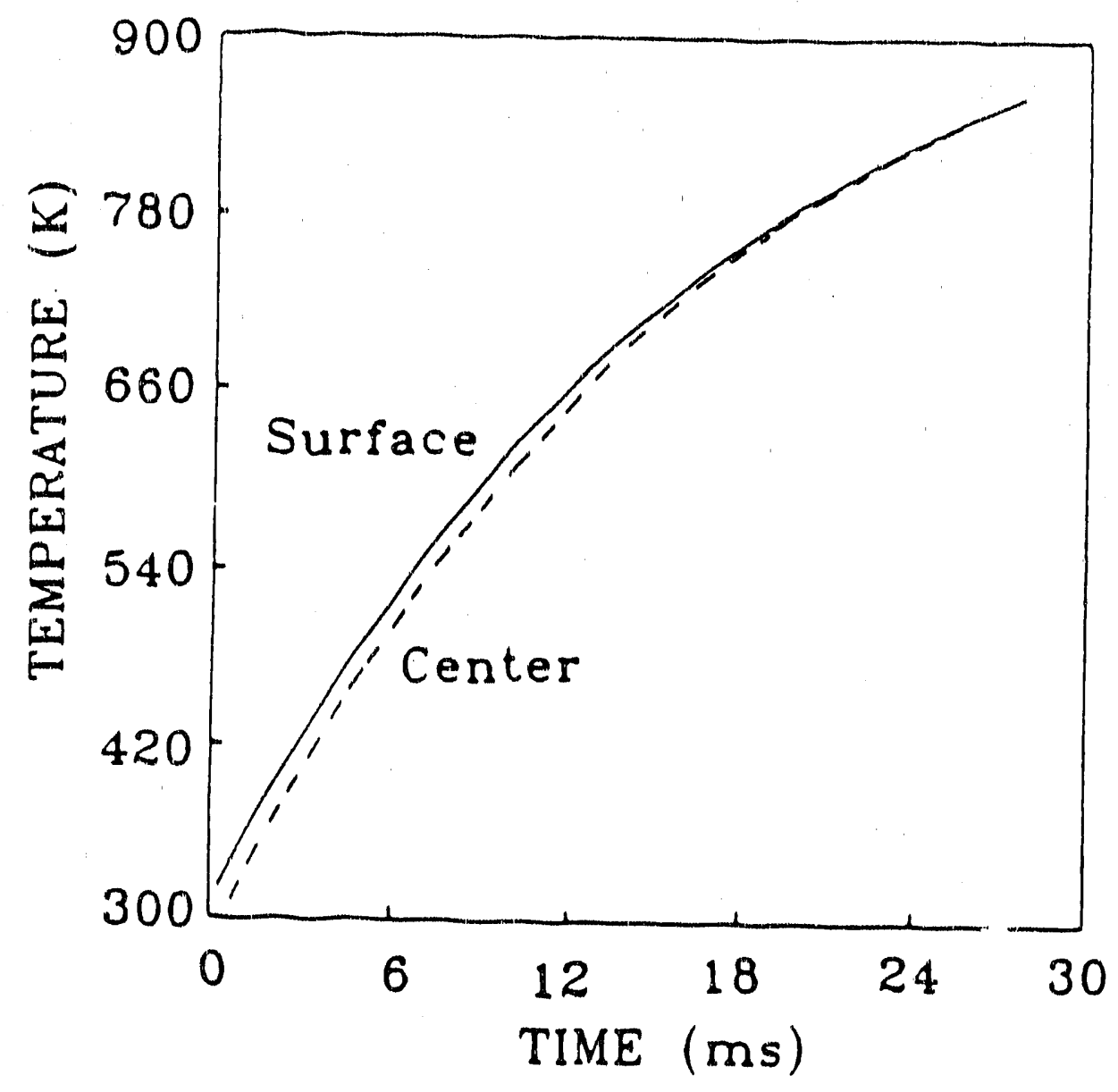

Temperature response of a pyrolyzing coal particle for a maximum gas temperature of $1000 \mathrm{~K}$. The particle size is 50 microns. 
Figure 4.6

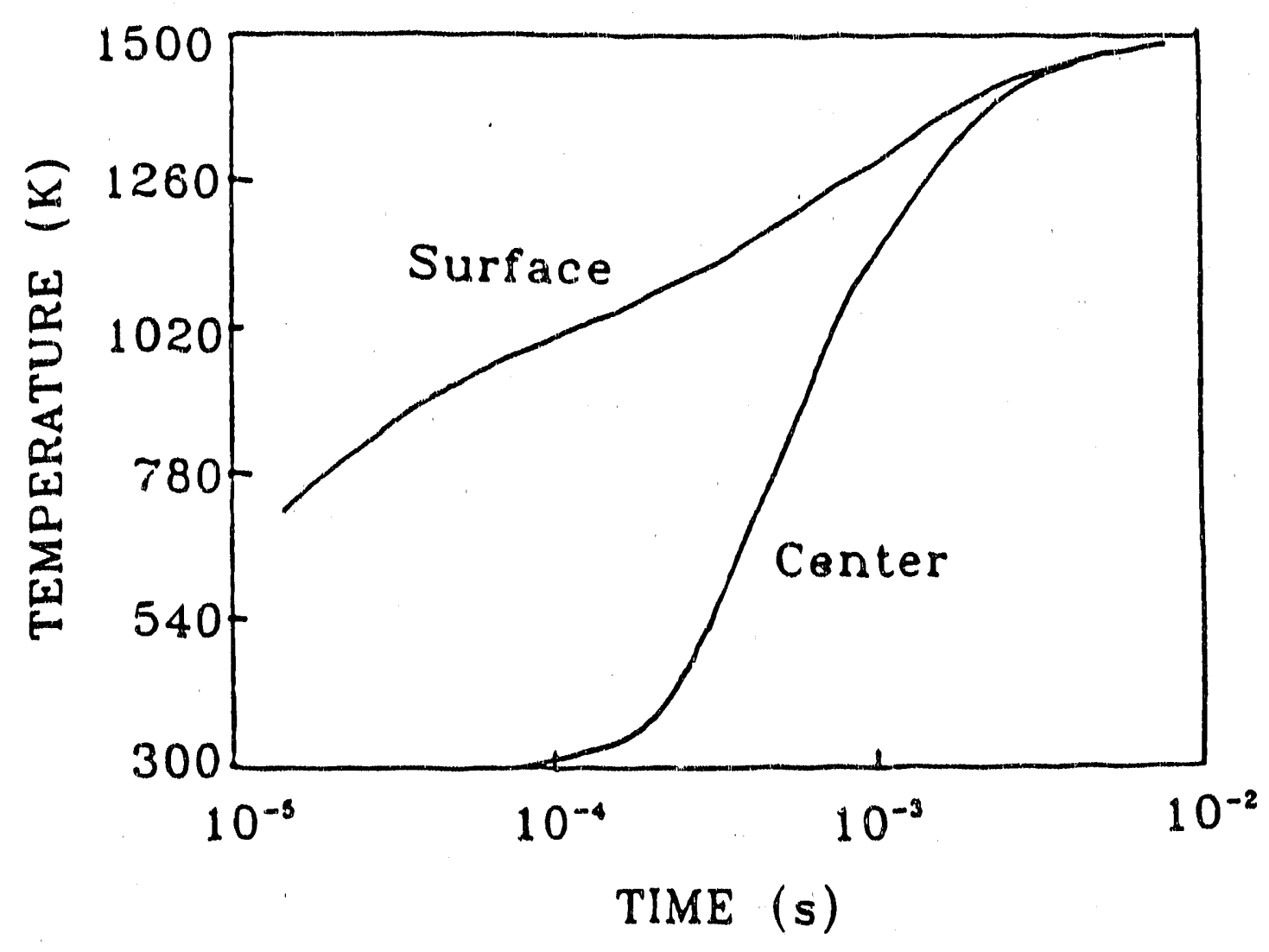

Temperature rise at the surface and the center of a 50 micron particle. The gas temperature is $1500 \mathrm{~K}$. 
Figure 4.7

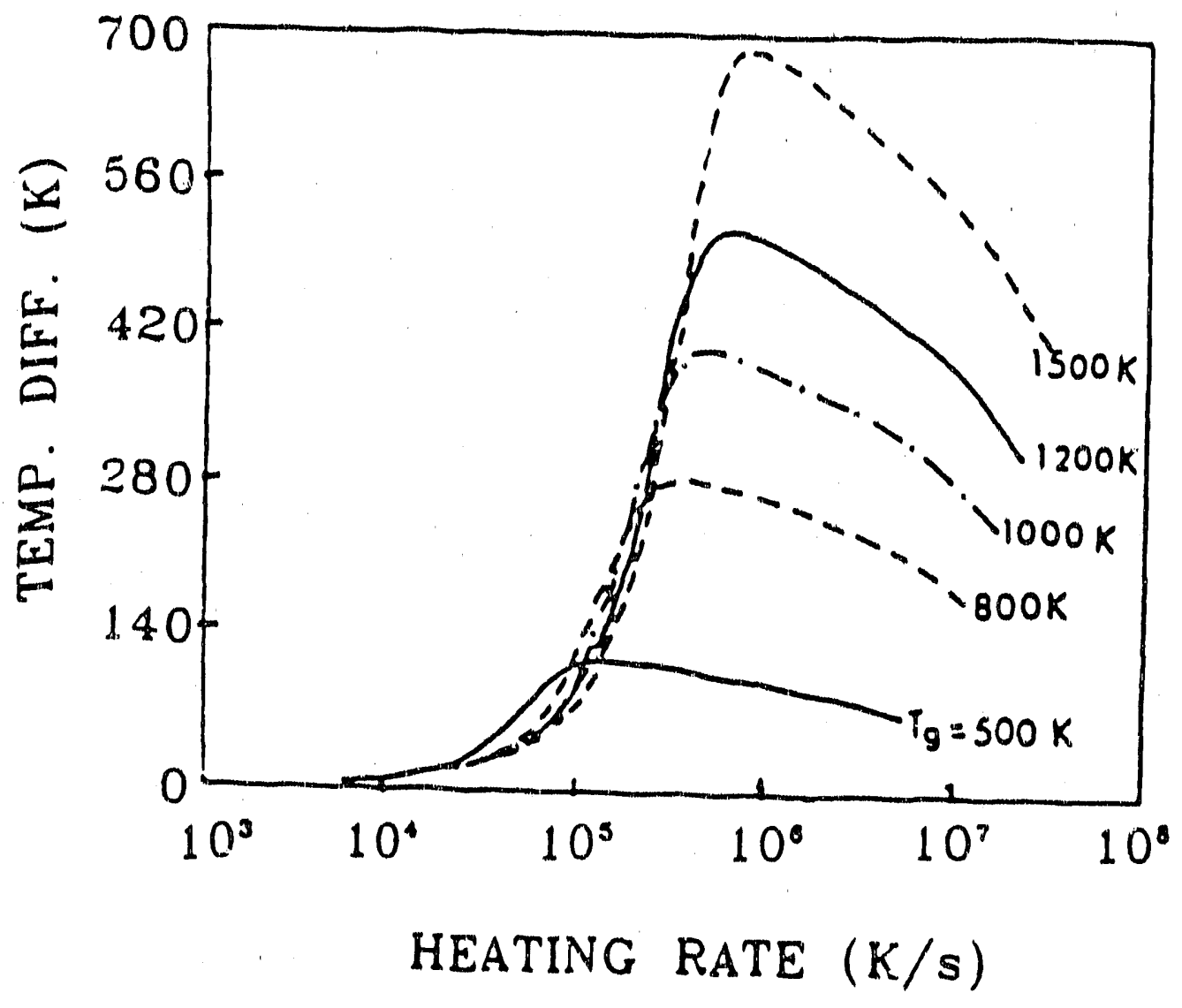

Variation of temperature difference between the surface and the temperatures of $500,800,1000,1200$, and $1500 \mathrm{k}$. 
In fact, however, this may be more of a possible than an actual concern. The reason is that the time during which $\Delta \mathrm{T}$ is very high is also very short, so that there is little reaction over this time period. This becomes more evident from Fig, 4,8 which is the plot of heating rate agalnst time. Figure 4.7 shows that, for $T_{m}=1500 \mathrm{~K}$, the maximum $\Delta T$ occurs when the heating rate has dropped to $10^{\circ} \mathrm{K} / \mathrm{s}$, and $F / g, 4.8$ shows that this takes only $0.1 \mathrm{~ms}$. After one millisecond, the heating rate has dropped to $10^{6} \mathrm{~K} / \mathrm{s}$, and $\Delta \mathrm{T}$ ' Is down from $700 \mathrm{~K}$ to about $125 \mathrm{~K}$. Thus the possible effect on the reaction rate is substantially reduced. This polnt is reexamined in a different way in the subsection following. We should emphasize, nevertheless, that the calculations have not yet been sufficiently wide-ranging to rule out an important effect under all possible conditions of practical interest.

Figure 4.8 also brings out two other points. The first is the very high initial values of heating rate, up to $10^{8} \mathrm{~K} / \mathrm{s}$ when the "average" value, as estimated from the Fig. 4.5 type of curves, can be very much lower, In Flg, 4.5 it can be estimated as roughly a 500 degree rise in $20 \mathrm{~ms}$, or $25,000 \mathrm{~K} / \mathrm{s}$, which is a typical value for many jet-flame systems, but very much lower than the Initial Instantaneous value (by 4 orders of magnitude),

The second point indicated by Fig. 4.8 is the roughly linear fall in heating rate on this double-log plot. With appropriate selection of an origin, this integrated to the expression given as Eq. (B.30). This is, thus, an alternative to a (1-exp) as an operational equation to describe the heating of the particle when a simple tractable expression is required. This figure emphasizes particularly well the difficulties or impossibility of specifying a characteristic heating rate, as an independent parameter, in the majority of condltions.

\subsubsection{Pyrolyzing Particle}

\section{General Characteristics}

Like the te: perature response, the weight loss response for the pyrolyzing particle is also a slgmoid. We show first some general results for two different sizes of particle (large and small), including the different particle temperature responses. These are shown in Figs. 4.9 and 4.10 for, respectively, a $500 \mu \mathrm{m}$ and a 20 $\mu \mathrm{m}$ particie. In Fig. 4.9, the onset of pyrolysis is about $0.4 \mathrm{~s}$ after the start of heating when the temperature had reached about $700 \mathrm{~K}\left(400^{\circ} \mathrm{C}\right)$. The temperature continued to rise through the pyrolysis, reaching nearly $1000 \mathrm{~K}$ as the computation terminated. This is quite characteristic of virtually all the calculations carried out for the larger particles: namely that the temperature continued to rise throughout the whole or a substantial part of the pyrolysis reaction. However, with particles small anough, pyrolysis was essentially isothermal, as illustrated in Fig. 4.10 for Identical conditions to those for Fig. 4.9 except for the reduction in particle size. 
Flgure 4.8

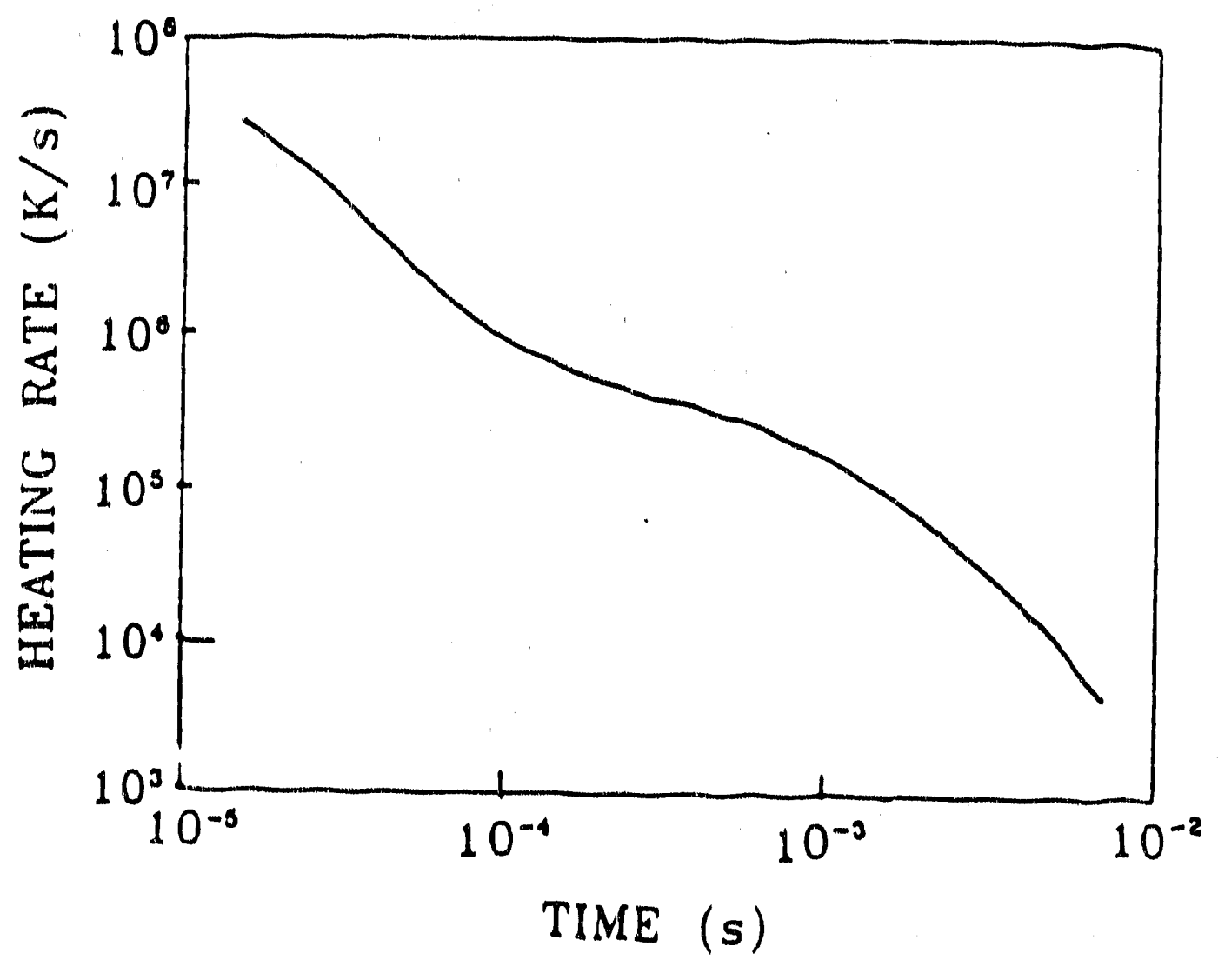

Variation of instantaneous heating rate (dT/dt) with time for a gas temperature of $1500 \mathrm{~K}$ and particle size of 50 microns. 
Figure 4.9

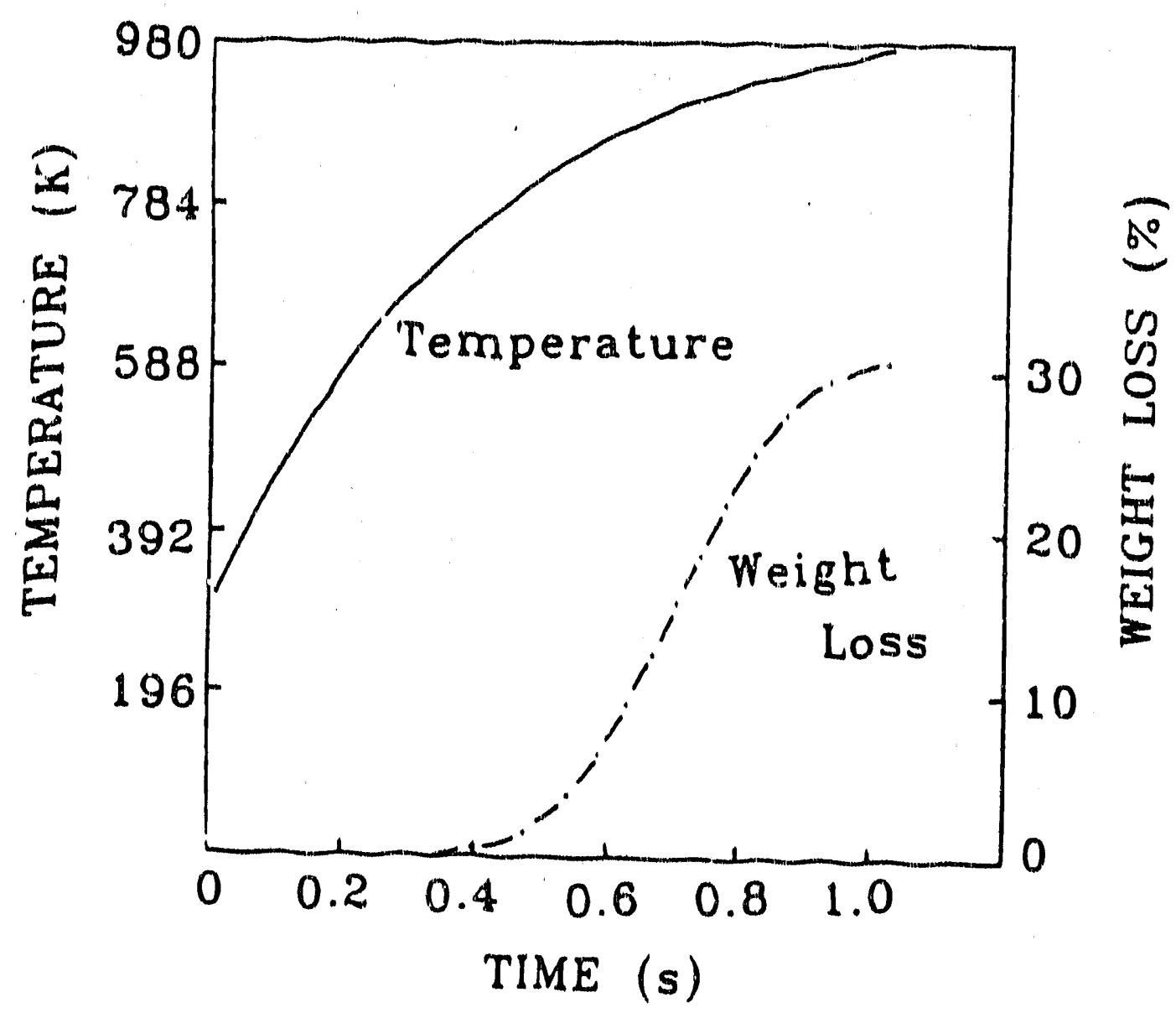

Temperature rise and percentage weight loss with time for a 500
micron particle. 
Figure 4.10

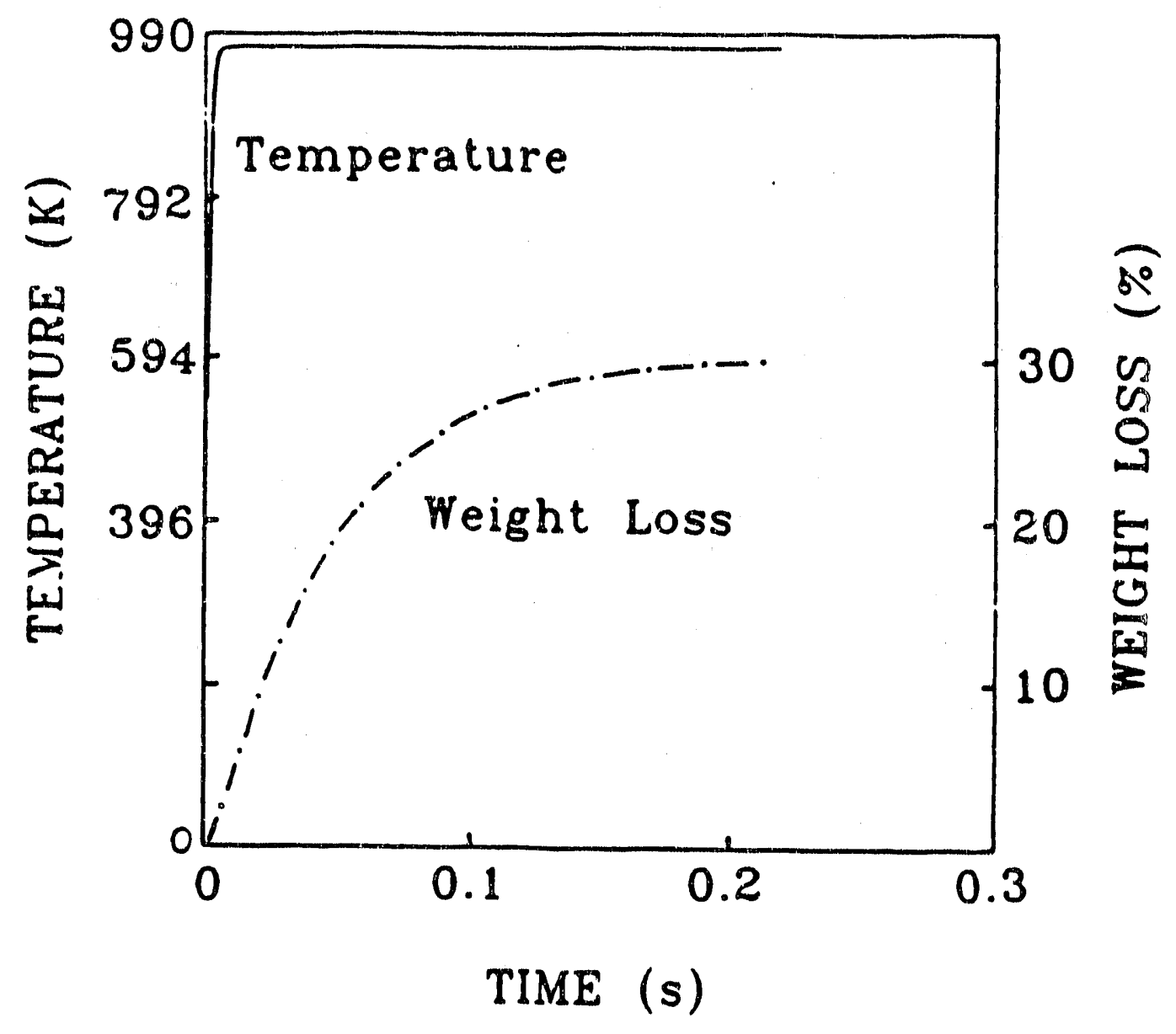

Temperature rise and percentage weight loss with time for a 20 micron particle. 
In more detail, Fig. 4.11 now shows a similar sigmoid but, in this instance, compared with experimental data to show ability of the model to describe the internal details. This was chosen at random from available possible examples: this is por curve-fitted to the specific experimental clata; the curve is independently calculated from the developed model which was fit to a broad range of other data. It supports the general insensitivity of coal rank as a factor governing pyrolysis rates and times.

A common alternative method of presentation of these data is the weight loss as a function of temperature, as a substitute for time, as this gives directly the temperatures of pyrolysis onset and termination. Figure 4.12 for a $40 \%$ VM particle is typical, again showing the common sigmoid shape; it is this shape that requires the somewhat arbitrary determination of onset and termination of pyrolysis to be set at $1 \%$ and $99 \%$ of weight loss.

These methods of data presentation, however, do not indicate in any way the possible influence of non-isothermality in the particle. This refers to the effect of the temperature gradient through the particle leading to erroneous or ambiguous rates, as discussed above. This effect can be represented, however, using a parallel to the Thiele analysis for internal reaction for a porous particle. We define a Reactivity Ratio as the ratio of the (actually computed) rate when there is a non-isothermal temperature distribution through the particle to the rate for an isothermal particle at the same surface temperature. Figure 4.13 shows a typical result for the Reactivity Ratio plotted against the surface temperature of the particle. The graph shows clearly the significant influence of non-isothermality through the whole of the temperature history, from $300 \mathrm{~K}$ and $1100 \mathrm{~K}$, with the Reactivity Ratio as low as 0.4 at the lowest temperatures. However, the graph also shows the $1 \%$ and $99 \%$ weight-loss points, showing clearly that the Reactivity Ratio is very much higher (about 0.85 in this case) at the start of significant onset of pyrolysis, and rising to unity (with the temperature still rising in this instance) when the fraction pyrolyzed was still relatively small (the scale for weight loss between $1 \%$ loss and $99 \%$ is highly nonlinear). This and numerous additional calculations do show that the non-isothermality can play a part in modifying the pyrolysis rates, and this should be a factor to be included in any evaluation of experimental data involving extraction of rate constants. For most experimental conditions, however, it would appear to be more of a second order than a dominant factor.

\section{Effect of Heat of Pyrolysis}

The effect of heat of pyrolysis on the temperature-time history of the particle is shown in Fig. 4.14. It can be seen in this figure that changing the value of heat of the pyrolysis has no effect on the initial temperature rise until the temperature of the particle has reached about $850 \mathrm{~K}$, essentially because the mass of coal decomposed - and thus the corresponding thermal load due to pyrolysis - is small in this region. It 
Figure 4.11

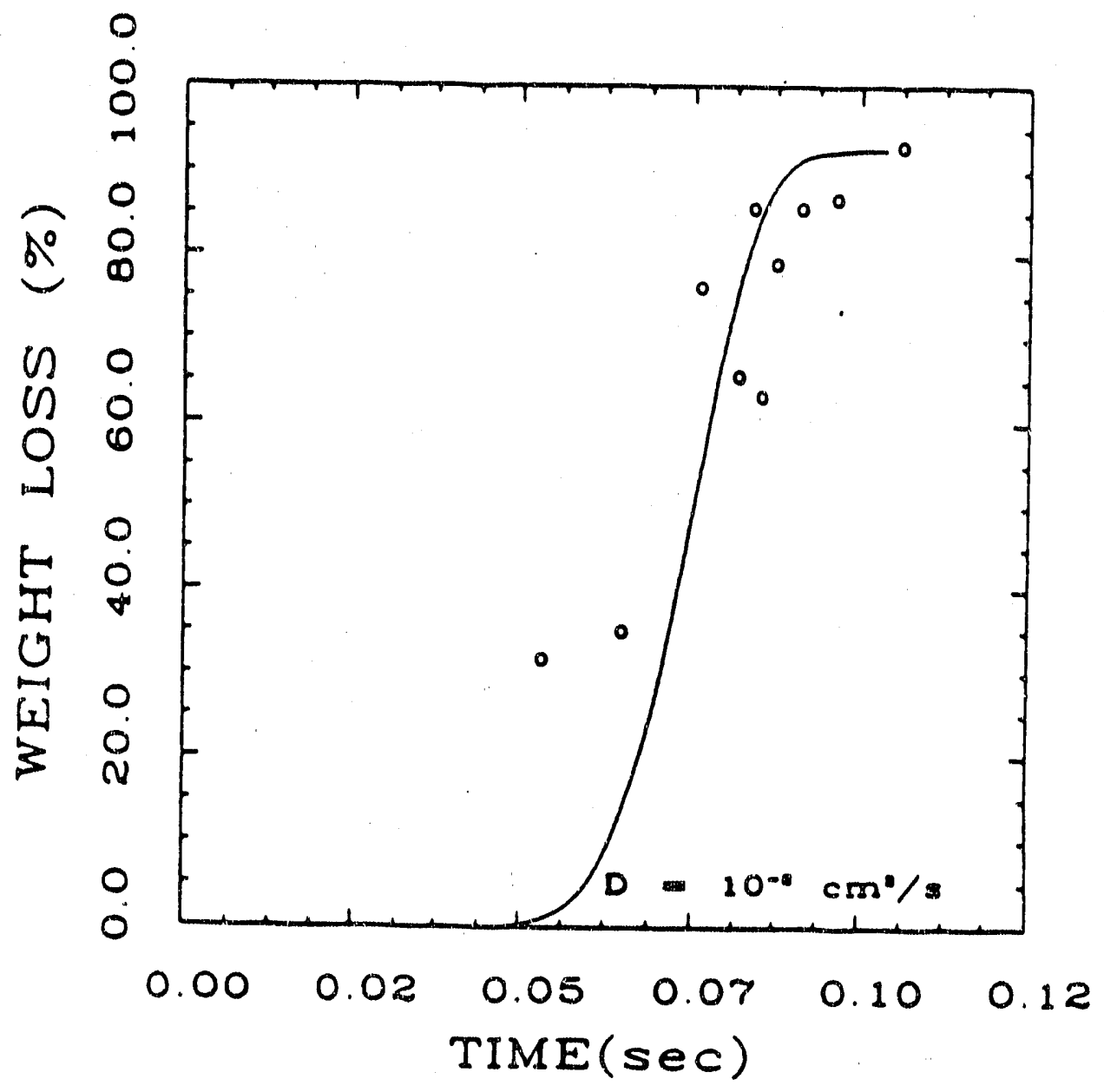

Release of volatile matter with time: Comparison of the experimental data (Source: Ref.4.15) with theoretical prediction using an activation energy of $35 \mathrm{kcal} / \mathrm{mole}$ and diffusion coefficient of $0.01 \mathrm{~cm}^{2} / \mathrm{s}$. 
Figure 4.12

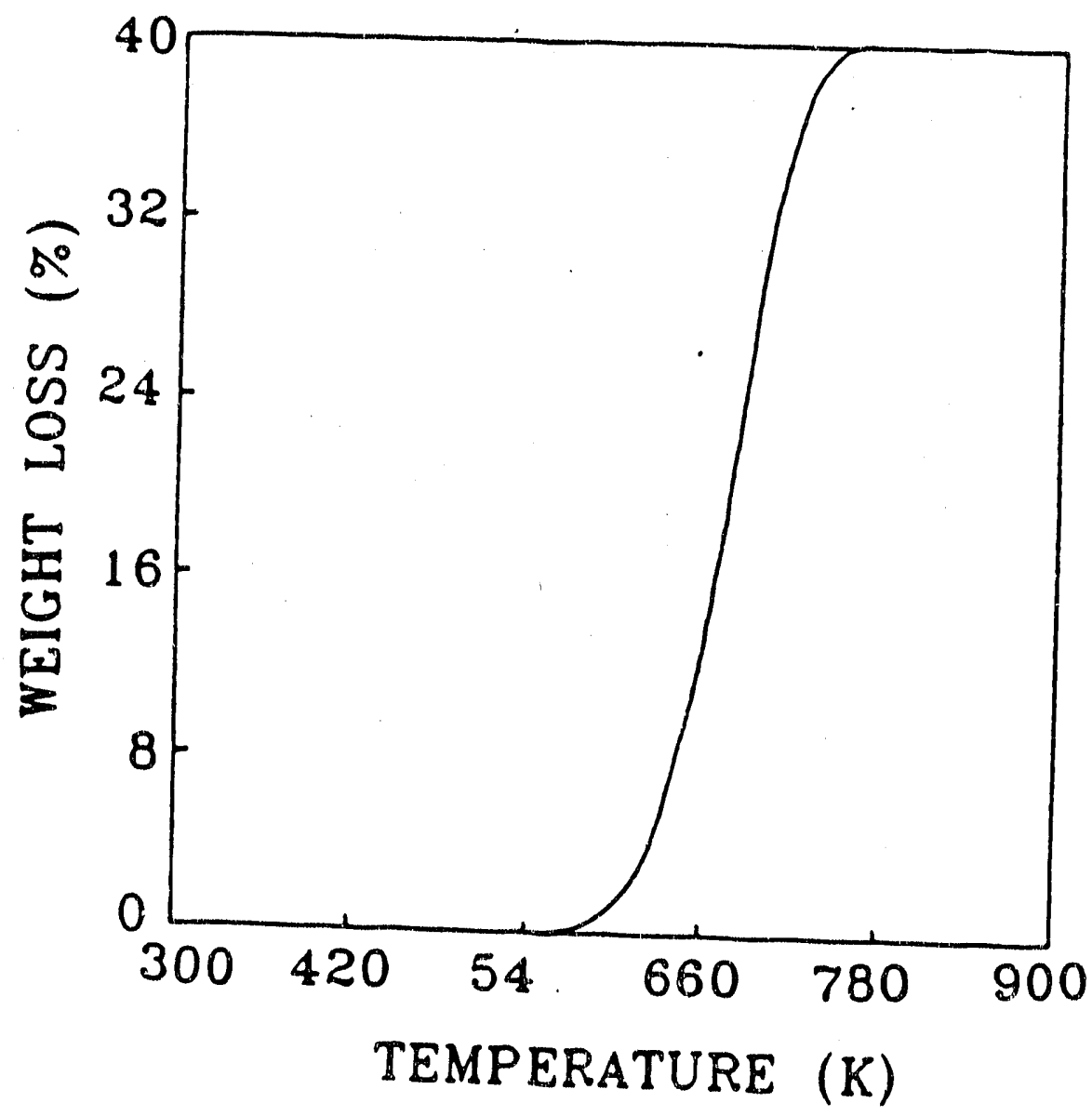

Volatile Matter release with time. Values of acivation energy pre-exponential factor and particle size are $25 \mathrm{kcal} / \mathrm{mole}, 10^{8}$ $s^{-1}$ and 50 microns respectively. 
Figure 4.13

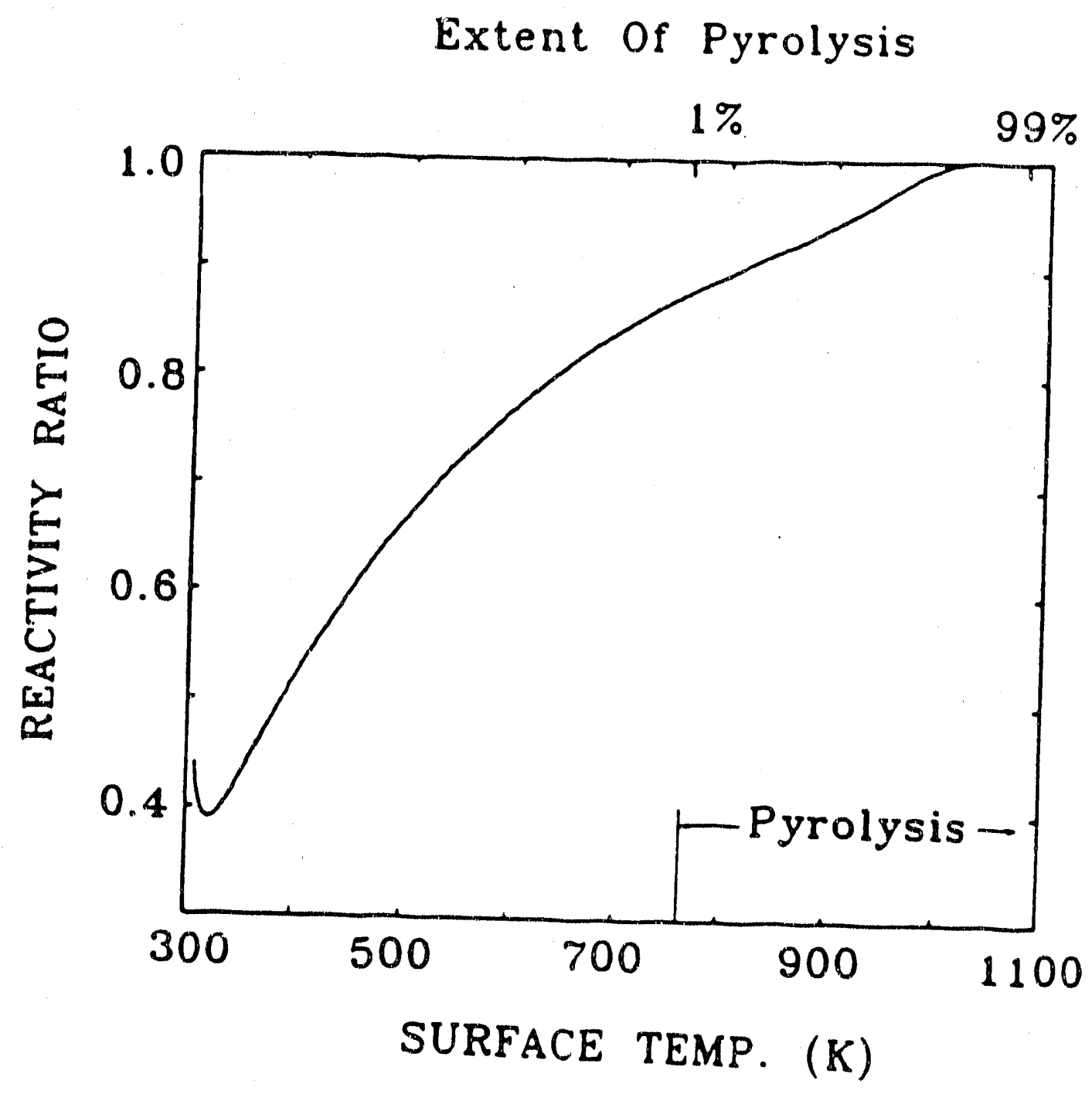

Variation of reactivity ratio with particle surface temperature
for a 200 micron particle. 
R88-PC70768

Figure 4.14

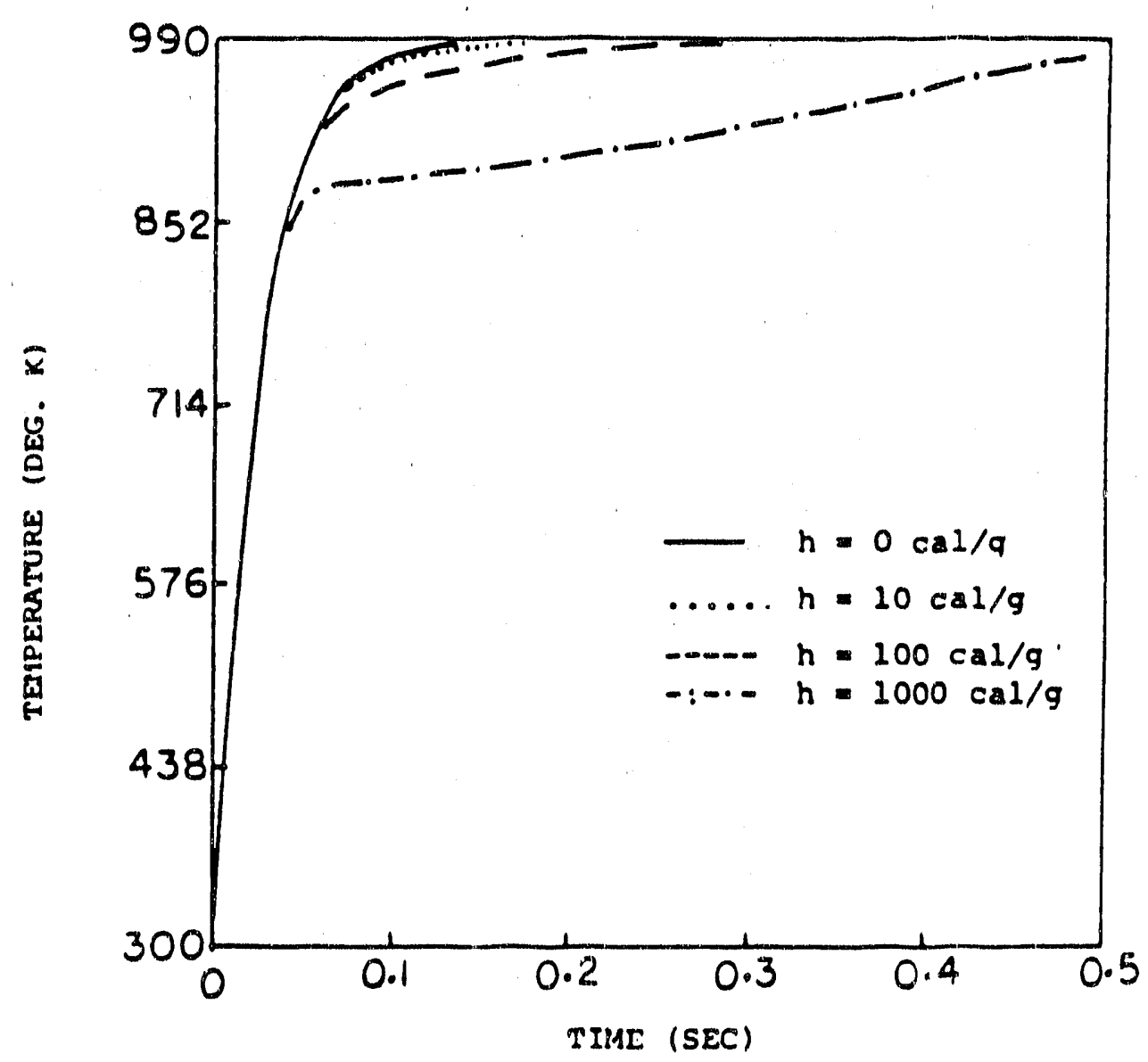

Temperature-time history for a 100 microns particle held between two electrically heated spiral coils for different heat of pyrolysis. 
can also be seen that the deviation after $850 \mathrm{~K}$ is more significant with increasing heat of pyrolysis. This means that, with an increase in the value of $h_{p}$, the temperature during pyrolysis would decrease, thus decreasing the rate of pyrolysis.

It has been reported in the literature that pyrolysis is an endothermic reaction with the value of heat of pyrolysis close to about $100 \mathrm{cal} / \mathrm{gram}$. At these low values of heat of pyrolysis, the effect on the $\mathrm{T}-\mathrm{t}$ response is not significant from an integral time perspective and this can be seen in Fig. 4.14 as only a slight deviation from the zero heat of pyrolysis curve. However, the effect of $h_{p}$ could become significant at very low heatirig rates.

\subsubsection{Combustion}

\section{- Particle Response}

Figures 4.15 to 4.18 illustrate the effect of combustion. In Fig. 4.15, the gas temperature rises almost instantaneously to a value of $800 \mathrm{~K}$ which is a little below the ignition temperature. The temperature-time profile is then characteristic of a reactive particle under such conditions, with the temperature rising to a point of inflection a little above the gas temperature, and then jumping rapidly (the Thermal Explosion response). This simulates, for example, the behavior believed to occur in the ignition experiments reported by Chen et. al. (Ref. 4.41) and Brooks and Essenhigh (Ref. 4.42).

In Fig. 4.15 the average heating rate was below $10^{\circ} \mathrm{C} / \mathrm{sec}$. Under these conditions, the values of the temperature differences between the surface and the center were too small for the two temperatures to appear on this scale as two distinct curves. The curves are more distinctly seen in Fig. 4.16 where the heating rate has been increased by increasing the gas temperature to $1500 \mathrm{~K}$. In Fig. 4.16 the temperature of the gas rises to $1500 \mathrm{~K}$ with a characteristic time $\left(\tau_{\mathrm{B}}\right)$ of $3 \mathrm{~ms}$. Under these conditions, the particle temperature rise is more or less linear up to the ignition temperature. The point of inflection is impossible to detect by eye, but the temperature jump is clearly in evidence, showing that the ignition occurs at a temperature well below the gas temperature (unlike that seen in Fig. 4.15). Theoretically, the point of inflection (ignition temperature) is independent of heating rate.

Figure 4.17 shows the variation of $\Delta \mathrm{T}$ with time. As can be seen from this figure, the maximum value of $\Delta \mathrm{T}$ is about $10^{\circ} \mathrm{C}$, which is very low compared to the value of $280^{\circ} \mathrm{C}$ for an inert particle under the same conditions. The effect of reaction on $\Delta T$ is clearly substantial. It can also be seen in Fig. 4.17 that $\Delta T$ falls to zero at a temperature close to the ignition temperature, and then goes negative after ignition as the center temperature rises at a faster rate than the surface temperature. This is because of the fact that after ignition 
Figure 4.15

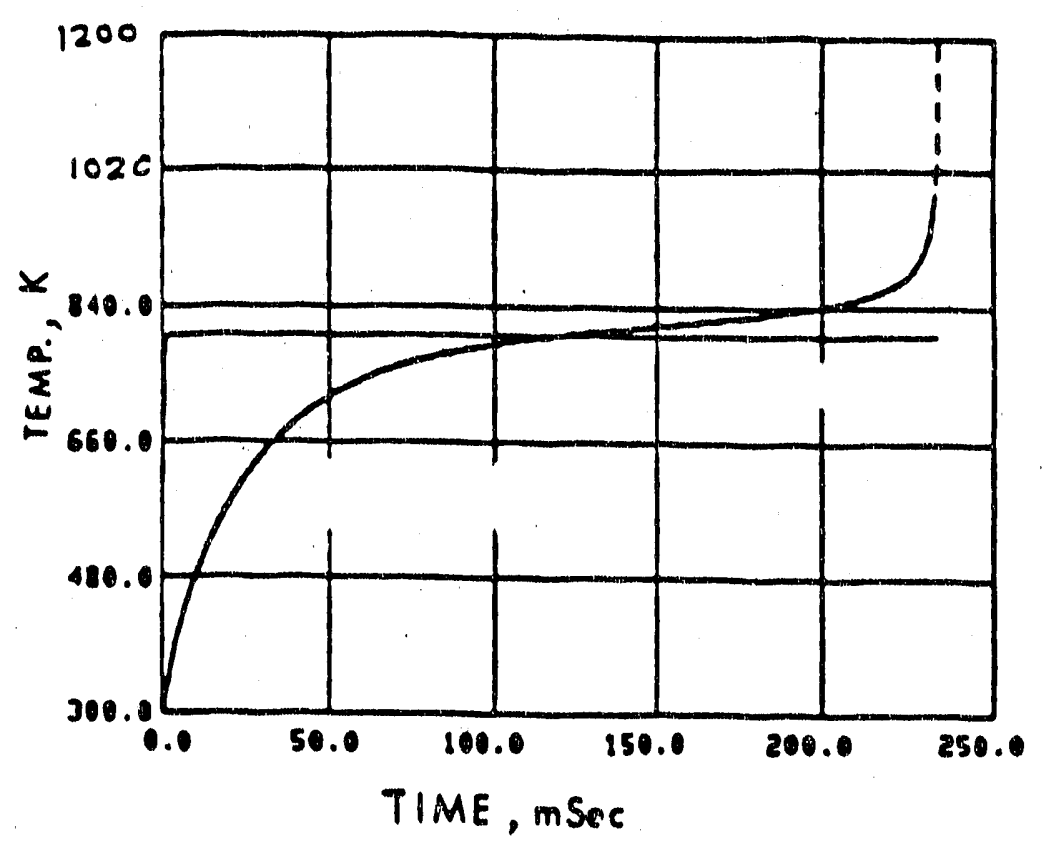

Temperature rise of a burning particle for a maximum gas temperature of $800 \mathrm{~K}$ and particle size of 50 microns. Characteristic heat-up time of gas is $3 \mathrm{E}-4 \mathrm{millisec}$. 
Figure 4.16

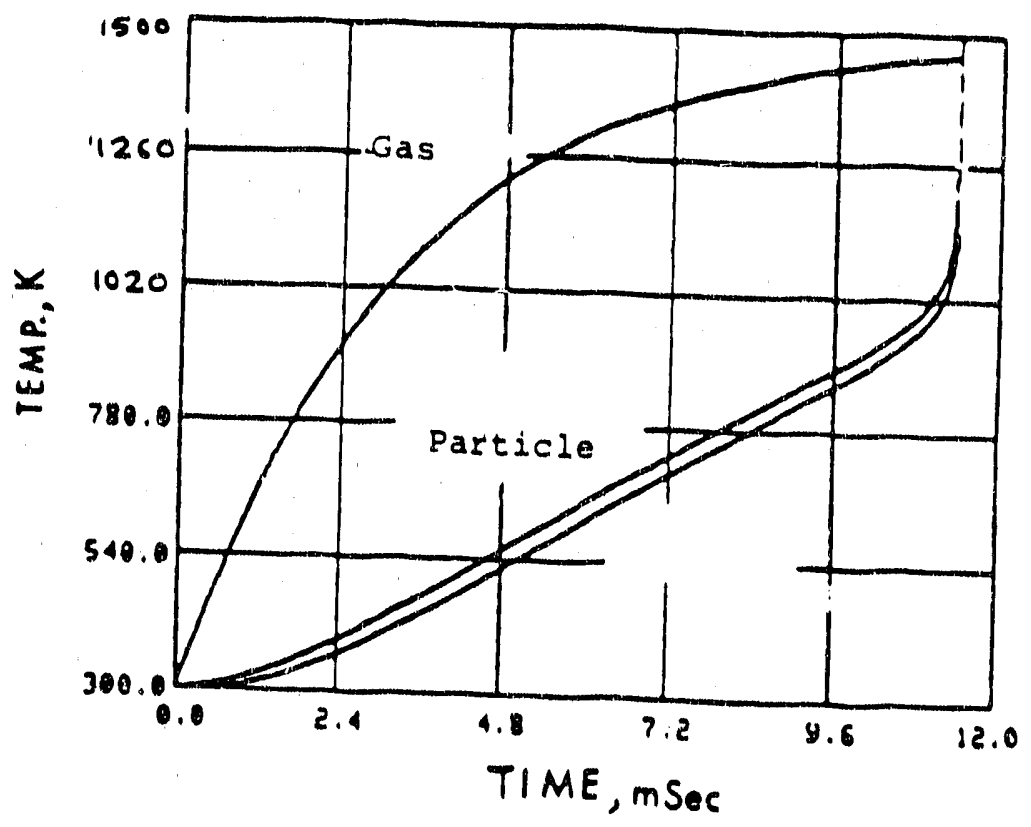

Temperature rise of a burning particle for a maximum gas temperature of $1500 \mathrm{~K}$ and a particle size of 50 microns. Characteristic heat-up time of gas is 3 mililisec. 
Figure 4.17

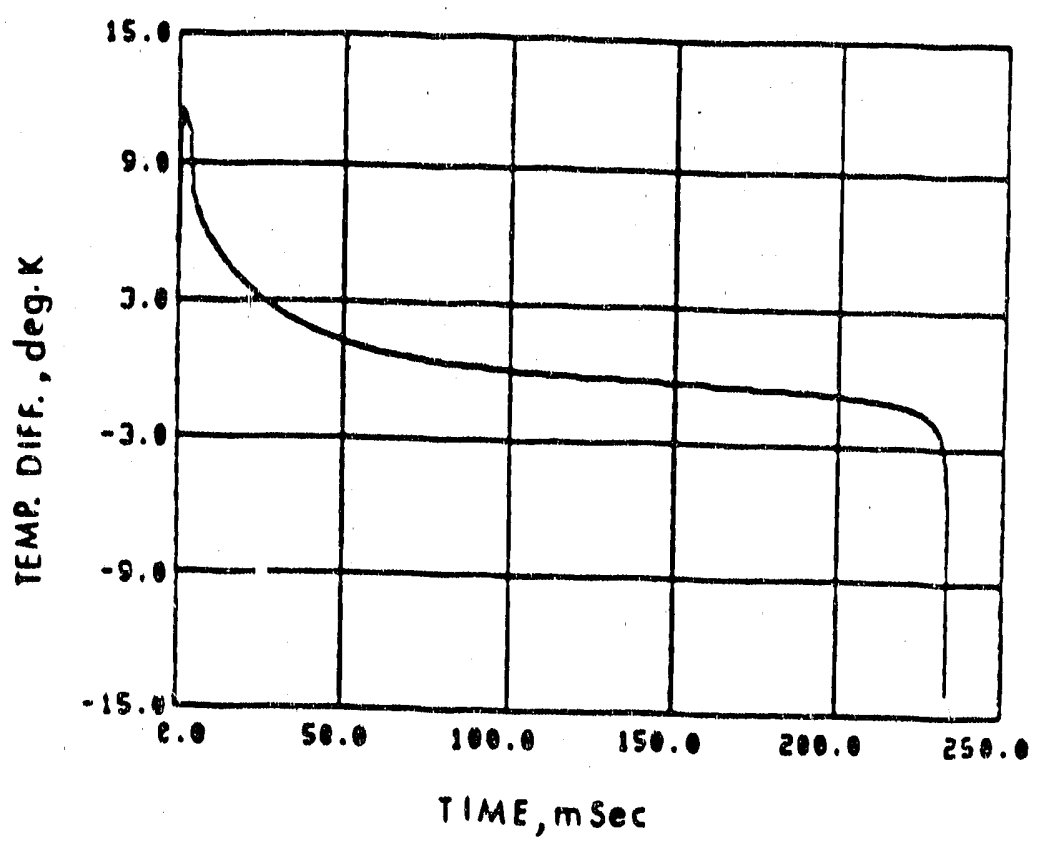

Variation of temperature difference between surface and center of a burning particle with time for a maximum gas temperature of $800 \mathrm{~K}$. 
the surface, being at a higher temperature than the gas, loses heat to the gas surrounding the particle, and then the temperature profile within the particle is inverted.

The variation of $d T / d t$ with temperature can be seen in Fig. 4.18. The $d T / d t$ curve goes throligh a minimum where the temperature at the minimum can be interpreted as the Ignition temperature as discussed by Chen (Ref. 4.41), and Brooks (Ref. 4.42).

\section{Ignition}

The results of the preceding section show the significance of the internal reaction at the moment of ignition.

Recent measurements of ignition temperatures by Chen (Ref. 4.41) and Brooks (Ref. 4.42) yielded values in the range 300 to $450^{\circ} \mathrm{C}$. Some additional calculations to those described in the last section were carried out to see how far it was possible to predict ignition temperatures from the combustion reactions for comparison with the recent measurements, and to determine the sensitivity of the behavior to changes in ambient conditions. The ignition temperaturos obtained in these calculations were 100 to 200 degrees higher than the measured values. The adopted activation energy of $40 \mathrm{Kcal} / \mathrm{mole}$ was close to one of the measured values, but the frequency factor lowered the calculated values of Ignition temperatures and it was possible to bracket the experimental values.

In the past, there has been some controversy regarding the ignition mechanism, whether it is heterogeneous or homogeneous. Experimentally determined values of temperatures at which significant pyrolysis sets in are in the region of $400^{\circ} \mathrm{C}$ for a bituminous coal at low heating rates. These temperatures rise as the heating rate increases. The overlap of ignition and pyrolysis temperatures support the possibility of heterogeneous combustion in some circumstances. In particular, if ignition starts heterogeneously, the rapid jump in temperature at the center of the particles, at or following ignition, could be responsible for onset of rapid pyrolysis, starting at the center; and the pyrolysis products would then flush the particle clear of oxygen to establish an "oil-drop" type of flame around the particle.

\subsection{Results II: Integrated Behavior}

The principal target of the model predictions is the data compilation of Figs. 4.1 and 4.3, Figs. 4.19, 4.20, and 4.21 illustrate three of four prediction sets presented in this Section; Fig. 4.4 is the fourth set. Additional prediction sets for the total pyrolysis times are given in earlier reports (Refs. 4.53 and 4.54 ) with a wider range of values of the key coefficients; the values used in this section have been. selected as the best 
Figure 4.18

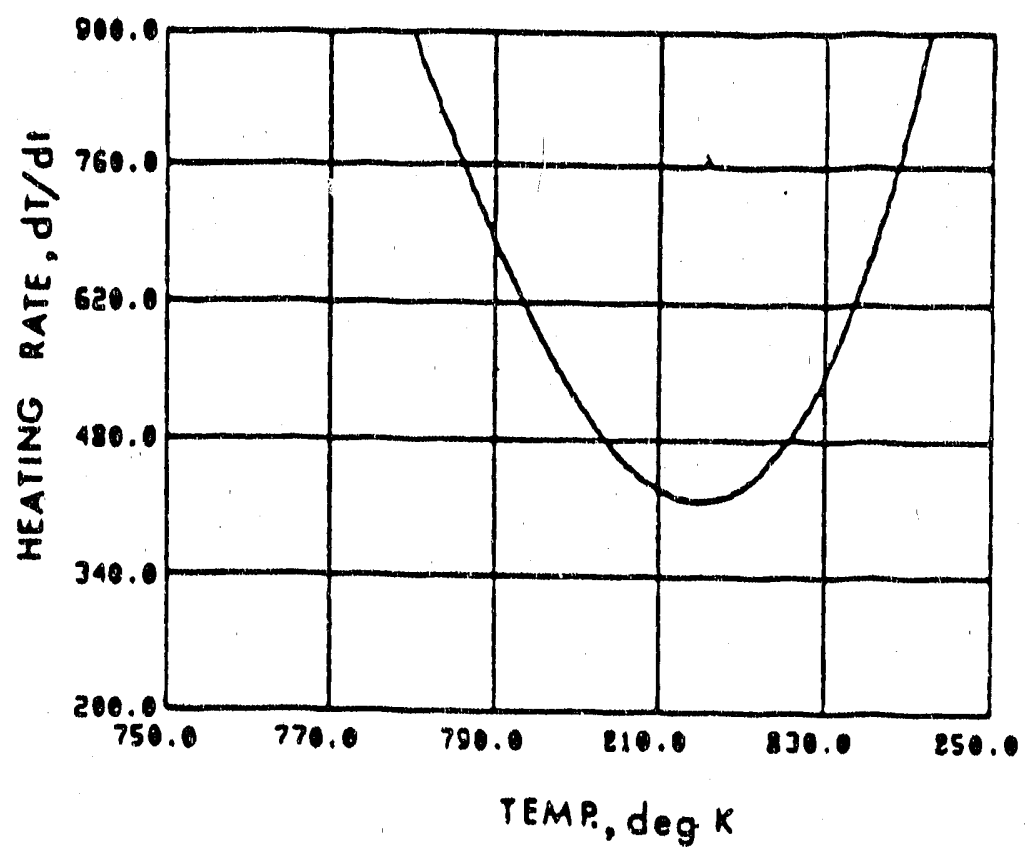

Variation of instantaneous heating rate with surface temperature for a maximum gas temperature of $800 \mathrm{~K}$ and particle size of 50 microns. 
Figure 4.19

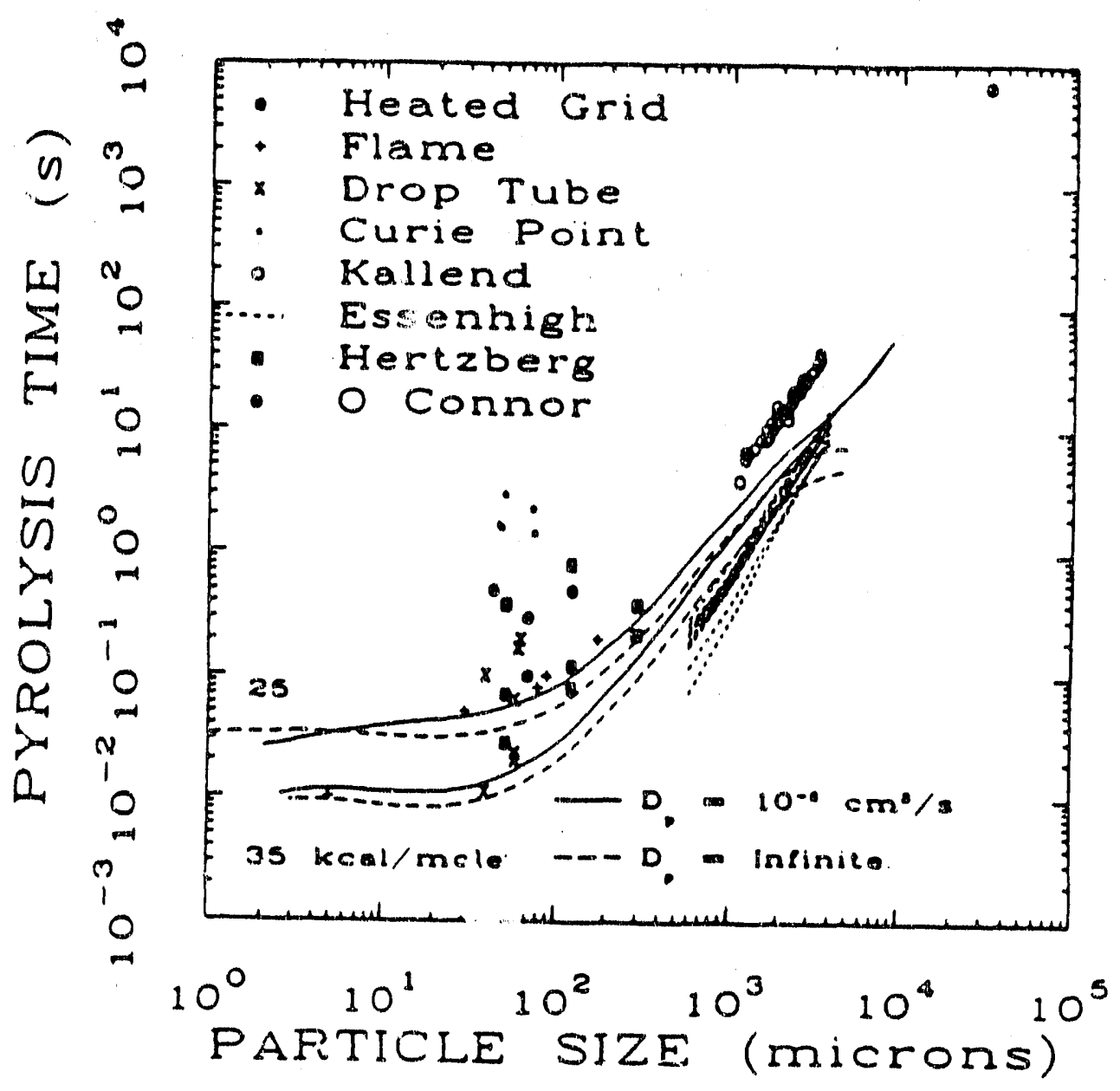

Variation of pyrolysis time with particle size: Comparison of experimental data with theoretical predictions for different activation energies $\left(25\right.$ and $\left._{2} 35 \mathrm{kcal} / \mathrm{mole}\right)$. Values of diffusion coefficients used are $0.01 \mathrm{~cm}^{2} / \mathrm{s}$ (solid lines) and $\infty$ (dashed curves). 


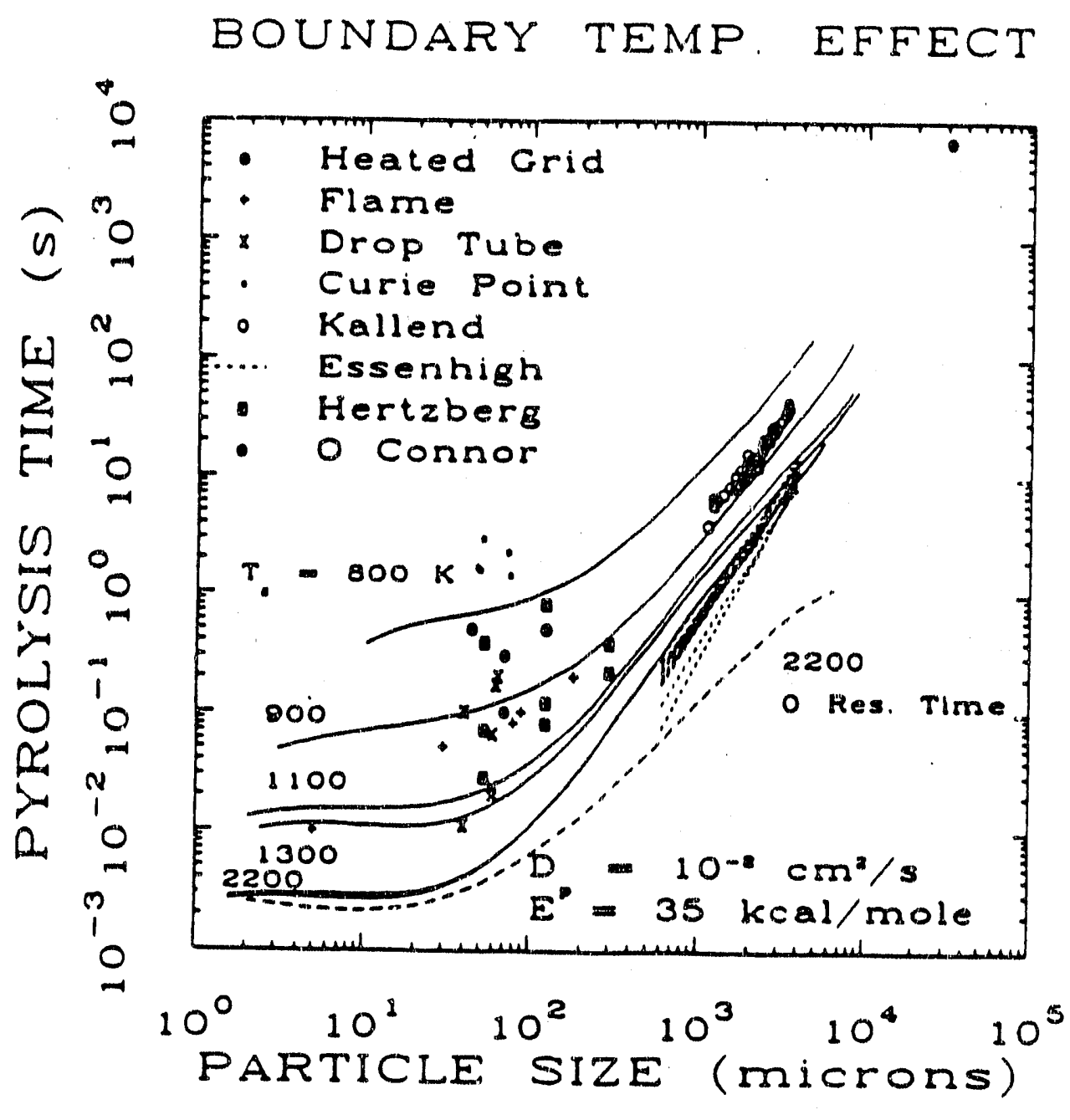

Variation of pyrolysis time with particle size for ambient gas temperatures of (1) 800, (2) 900, (3) $1100,(4) 1300$, (5) 2200 , and (6) $2300 \mathrm{~K}$. The dashed curve shows the variation for ambient temperature of $2200 \mathrm{~K}$ and instantaneous escape of VM. 
Figure 4.21

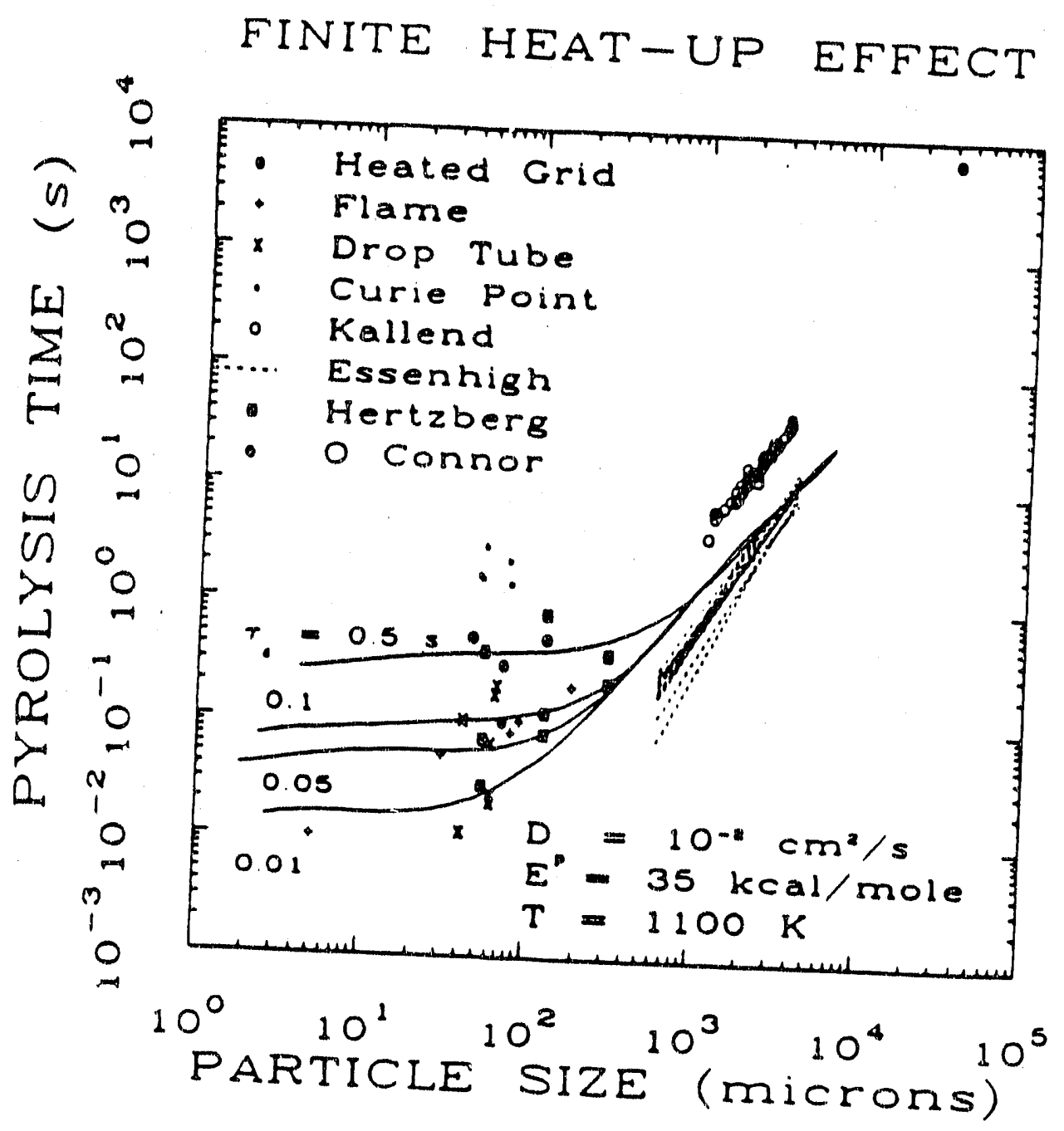

The effect of characteristic heat-up time of ambient variation of pyrolysis time with particle size ambient $\left(\tau_{q}\right)$ on the are: (1) $0.5 \mathrm{~s},(2) 0.1 \mathrm{~s}$, (3) $0.05 \mathrm{~s}$ (4) size. The values of $T$ k]. 
fit at this time. in the first of the two earlier reports we examined primarily the effect of varying the kinetic constants; in the second, we examined the sensitivity to the diffusion coefficients. In examining the influence of these two factors, in particular, we found that there were insufficient constraints for the degees of freedom in the system and it was possible to obtain adequate fits to the data over a wide range of coefficient values, but at the expense of seeing the onset of pyrolysis vary over an impossible range of temperatures, from roughly $200^{\circ} \mathrm{C}$ to $6000^{\circ} \mathrm{C}$. We have, accordingly, reduced the degrees of freedom in the present calculations by selecting baseline conditions and impusing on these conditions a default pyrolysis-onsec temperature of $400^{\circ} \mathrm{C}$, with the option to change that value for sensitivity studies. This eliminates the possibility, at this time, of predicting a rank-dependent pyrolysis temperature; but this will be possible when sufficiently accurate values of the relevant kinetic constants can be provided from independent sources. However, the effect of heating rate ori tite pyrolysis-onset temperature, outside the baseline conditions, is examined in one of the sections following (Section 4.6.5).

\subsubsection{Prediction of Pyrolysis Times: (1) Influence of Diffusion and Activation Energy}

These are examined in Fig. 4.19, which illustrates a number of critical points. The four lines in this figure represent the calculated pyrolysis times using 2 activation energies ( 25 and $35 \mathrm{Kcal} / \mathrm{mole}$ ) and 2 values of the diffusion coefficient $\left(0.01\right.$ and $\left.\infty \mathrm{cm}^{2} / \mathrm{s}\right)$. The dashed lines are for the immediate escape of the volatiles, and the solid lines are for diffusionally delayed escape. The characieristics of all four lines is as noted earlier (Section 4.3): there is a particle size independence below, roughly, $100 \mu \mathrm{m}$; and there is a strong size dependence above that (almost a $\mathrm{d}^{2}$ variation). The effect of diffusional delay then does play a small role at the smaller sizes, but this becomes dominant and then controlling at the largest sizes. When there is assumed to be immediate escape of the volatiles the (dashed) lines show a strong size dependence from 100 to $1000 \mu \mathrm{m}$, but the curves flatten out again, predicting that the pyrolysis times for large particles should be independent of particle size, which contradicts experiment. The introduction of the diffusional escape limitation (solid lines) not only returns the predicted lines to a rough parallel with the experimental trend lines, but the lines for the two activation energies also merge, showing that the escape is then dominated by diffusion.

A third, related point is the relative magnitude of the diffusional effect at different diameters. Below $100 \mu \mathrm{m}$, the increase in pyrolysis time due to diffusional delay is 20 to $30 \%$. At $1000 \mu \mathrm{m}$, it has only increased to 50 to $60 \%$; but above that, it increases rapidly to more than an order of magnitude at $1 \mathrm{~cm}$. In the middle particle size range, it appears that the dominant fictor is heat transfer, with this replaced by diffusional escape as already noted, bove $1000 \mu \mathrm{m}$. The reason for the reduced influence of heat transfer 
in the largest size range is still unclear. but does seem to be associated with the increasing significance of radiation so that the flux intensity increases fast enough to offset the reduced conduction flux with increasing diameter.

The effect of activation energy is the inverse. The separation of the calculated lines is greatest at the smaller diameters; it drops steadily with increasing diameter, and vanishes, as already noted, at the largest diameters when the diffusional escape is included. Notabiy, however, the range of small-particle pyrolysis times carınot be matched without invoking unrealistic values of $E$ and $D_{i}$.

\subsubsection{Prediction of Pyrolysis Times: (2) Effect of Ambient Temperature}

The ambient temperature was kept constant in the calculations used for Fig. 4.19; it was then varied and examined separately, and the results are shown in Fig. 4.20. In the first instance, the intention was to select the ambient conditions most appropriate to the experimental method (by adjustment of gas and radiating enclosure temperatures). As sensitivity factors, however, these did not, in fact, vary so very much from one experiment to another; and the constant temperature lines were then found to present a fairly clear pattern, as shown in Fig. 4.20. For these calculations, the activation energy and diffusion coefficient were set at $35 \mathrm{Kcal} / \mathrm{mole}$, and $0.01 \mathrm{~cm}^{2} / \mathrm{s}$, respectively. The temperatures selected were $800,900,1100,1300$, 2200 , and $2300 \mathrm{~K}$ respectively (approximately $500,600,800,1000,1900$, and $2000^{\circ} \mathrm{C}$ ). The value of $2200 \mathrm{~K}$ was selected as being a good average value for the adiabatic flame temperature for a wide range of hydrocarben fuels.

This figure shows that part of the 2 to 3 orders of magnitude spread in the pyrolysis times can be accounted for by a change in ambient temperature, although its influence is somewhat exaggerated in Fig. 4.20 because the range chosen for the calculations substantially exceeds that used in the experiments. The experimental range would be more like $800^{\circ} \mathrm{C}$ to $1500^{\circ} \mathrm{C}(1100 \mathrm{~K}$ to $1800 \mathrm{~K})$, with the flame data obtained at higher temperatures and the other experimental data mostly at the lower values. Such a band covers only about one order of magnitude in the pyrolysis times; it rather clearly bounds only the lower half of the data set for the smaller range of the particles $(<100 \mu \mathrm{m})$, but it lies right between the two sets of large particle data.

\subsubsection{Prediction of Pyrolysis Times: (3) Effect of Ambient Heating Rate}

For the calculations already described the ambient temperature was set as constant (or more accurately, the characteristic heating time, $\tau_{8}$, in Eq. (4.12) was set at a very low value). This is reasonably accurate for drop tube and flame data where the particle heating rates are generally in excess of $10,000 \mathrm{~K} / \mathrm{s}$. 
Heated grid data, however, generally involve slower heating rates, with $1000 \mathrm{~K} / \mathrm{s}$ as a common value. Significantly, in Fig. 4.1 the heated grid data lie above all but the Curie point measurements, by roughly an order of magnitude.

The calculated effect of ambient heating rate is shown in Fig. 4.21 for four different characteristic times ranging over a factor of 50 , for the same final temperature $(1100 \mathrm{~K})$. The shortest of these times corresponds approximately to the heating rate conditions found in flames $\left(\tau_{\mathrm{g}}=0.01 \mathrm{~s}\right)$; and the curve for $\tau_{\mathrm{g}}=0.1$ approximates the heated grid conditions. This figure clearly supports the difference in ambient heating rate as a major factor in contributing to the spread in times for the smaller particles. It is also particularly significant that this parameter is essentially eliminated as an important factor for particles above $500 \mu \mathrm{m}$. This is of some minor importance with regard to the different methods of operating the very similar methods of experiment used by Essenhigh (Ref. 4.1) and by Kallend and Nettleton (Ref. 4.2). Kallend and Nettleton preheated their coils before inserting the particles; Essenhigh did the opposite. These calculations suggest that the difference in times is not due to the different system heat-up rates.

Overall, the predicted times in all three Figs. 4.19, 4.20, and 4.21 do show a rough degree of fit particularly with regard to the general trends, and to the values for the larger particles $(>100 \mu \mathrm{m})$; the times for the smaller particle sizes tend to be underpredicted. The extent to which the fit can be improved still further is discussed below.

\subsubsection{Prediction of Pyrolysis Times: (4) Variation with Heating Rate}

It appears from the scatter in data in the small particle region $(<200 \mu \mathrm{m})$ that the times in this region show no regular trend with the independent variables such as the ambient gas temperature or the particle size. It was also noticed that (Figs. 4.19, 4.20,4.21) a small variation in the value of $\tau_{8}$ can give larger variation in pyrolysis times compared to the variation in temperature. It appeared that pyrolysis times would show a more definite trend as a function of the heating rates; this is evident from the plot of variation in pyrolysis time with estimaced overall heating rate as shown in Fig. 4.22 and 4.23 . In this figure, the experimental data are seen to be concentrated at whole values of heating rates. This could possibly be because of rounding-off of the heating rates to the nearest order of magnitude and the actual rates could be overestimated or underestimated by as much as half an order of magnitude. 


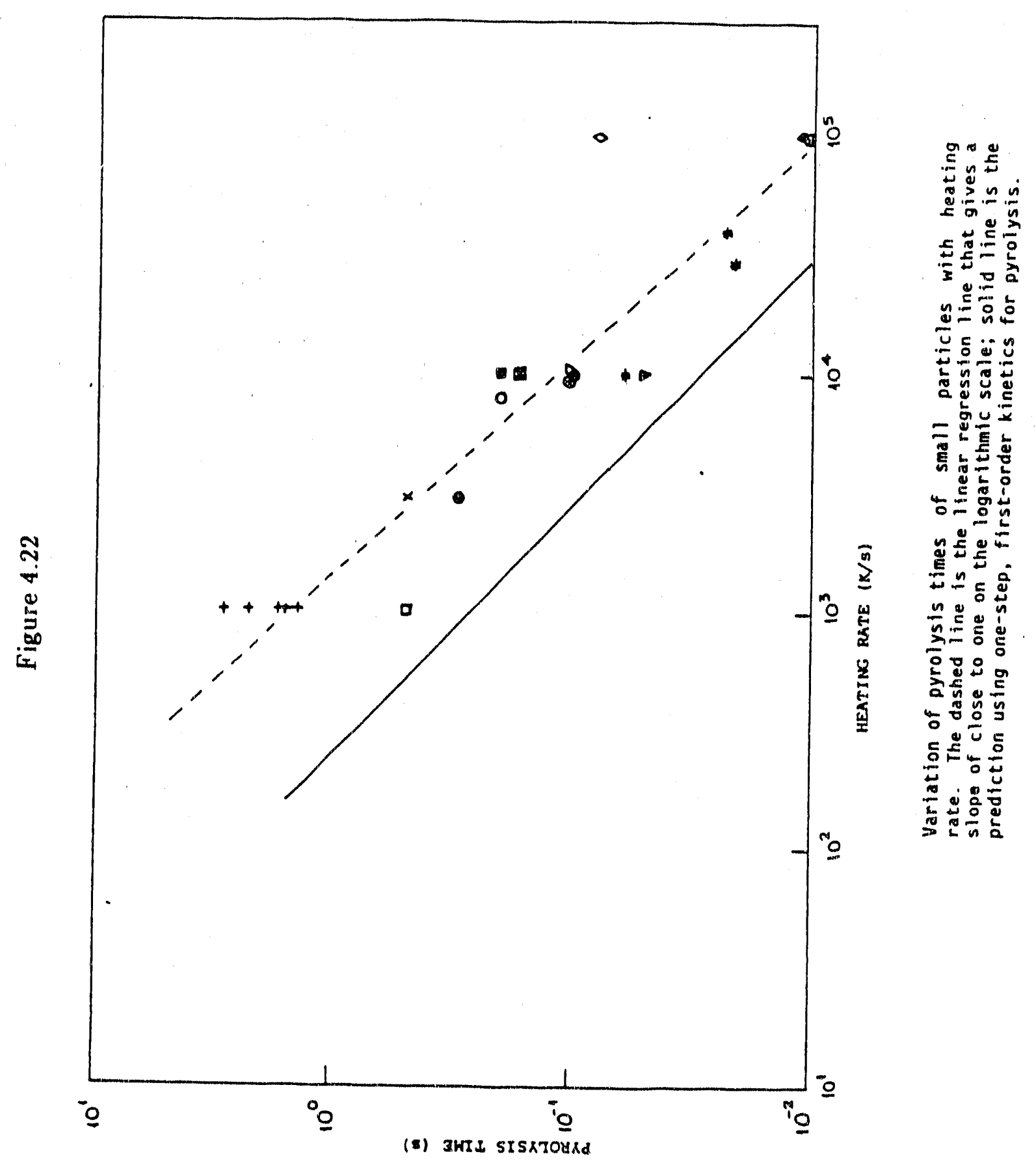


R88-PC70768

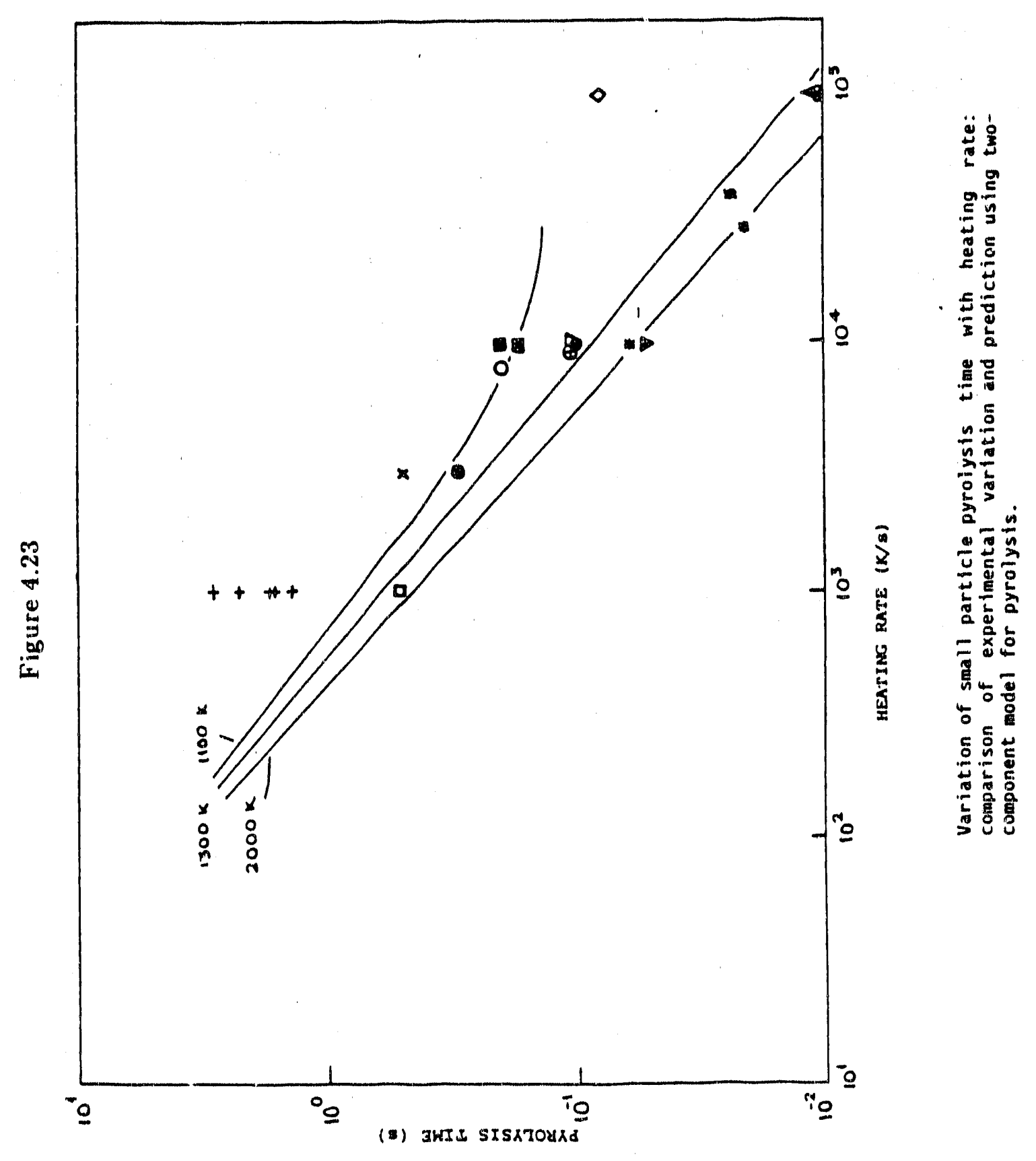


R88 PC70 768

The trend in data in Fig. 4.24 show that pyrolysis times are inversely related to the heating rate by the relation

$$
t_{p}=(\text { const. }) /(d T / d t)_{\text {avs }} \text {. }
$$

The simple relation which appears to be empirical could then be used to estimate the order of pyrolysis times of small paricles, If an approximate value of the heating rate is known. This equation can possibly go into the required engineering rate equations, to be used more as a guideline rather than to actually estimate the times for pyrolysis.

Figure 4.21 also shows the predicted variation in pyrolysis time with average heating rates of the particles using a first-order, one-step reaction model for pyrolysis. It is seen from the prediction that the use of this model predicts the trend, with a slightly lower slope, but, underpredicts the pyrolysis times by as much as half to one order of magnitude.

The constant underprediction of pyrolysis times of small particles (Figs. 4.19, 4.20,4.21, and 4.22) and good prediction of tar release times (Fig. 4,3,4,4) using the one-step, first-order pyrolysis model led us to believe that we needed a more elaborate model that would predict the times for pyrolysis of small particles. Based on the phenomenological model establisned (see above) and the coal constitution hypothesis (discussed in more detail in Section 4.7.5) a Two-Component Model was selected to represent pyrolysis. According to this model, the reaction can be represented as

Coal $\left\{\begin{array}{l}\text { Component I }-k_{p} \rightarrow \text { Tar } \\ \text { Component II }-k_{p} \rightarrow \text { Metaplast }-k_{m} \rightarrow \text { Char }+v \text { Gils }\end{array}\right.$

This represents tar and gas formation from two independent parallel reactions; the kinetis for tar release is the same as in the earlier one-step reaction, so that the tar release time is not affected, and choosing values for Component II kinetics such that the gas release is delayed to a higher temperature, thus increasing the overall pyrolysis time. This model extension is clescribed in Section 4.8 .

The variation in pyrolysis time with average heating rate using the above model is shown in Fig. $\$ .23$ for gas temperatures of 2000,1500 , and $1300 \mathrm{~K}$. The predicted lines show an inverse linear dependence of pyrolysis times on heating rates for all temperatures except for $1300 \mathrm{~K}$. At high enough heating rates, the 
Figure 4.24

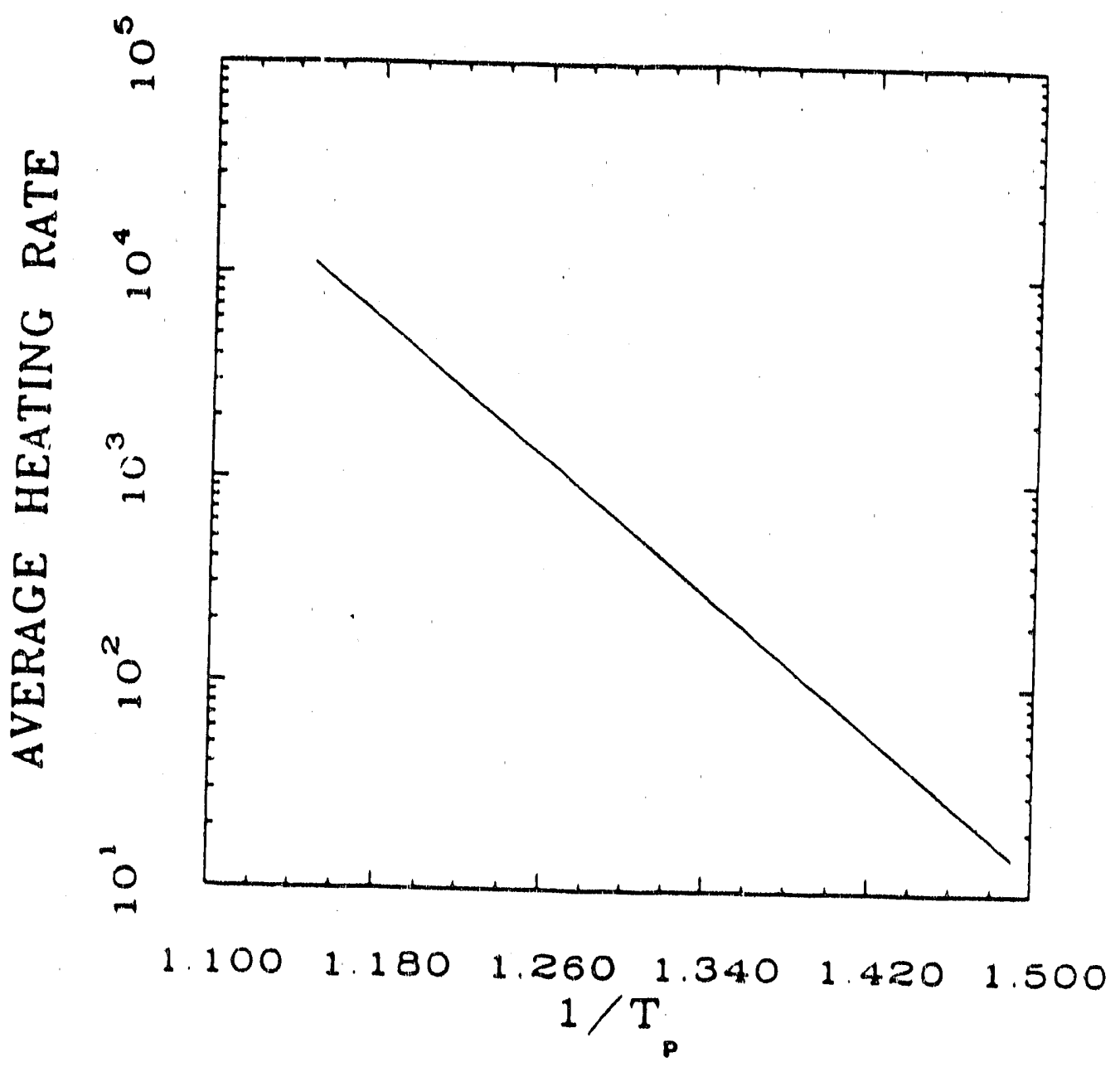

Variation of logarithm of average heating rate with inverse of temperature at the onset of pyrolysis $\left(1 / T_{p}\right)$. 
particles heat up to the final temperature before sigrilficant pyrolysis occurs, and the rest of the pyrolysls takes place at a constant temperature. Under these conditions the times for pyrolysis would be Inclependerit of the heating rates as is shown by the predicted line for $1300 \mathrm{~K}$ at heating rates greater than $10^{4} \mathrm{~K} / \mathrm{s}$. This figure also shows the relative insensitivity of the pyrolysis times of small particles to the final gas temperatures, compared to the effect of the heating rate itself.

\subsubsection{Prediction of Tar Rolease Time}

The data trend and prediction fit for the tar release time have already been given in Figs, 4.3 and Fig. 4.4, using data provided by Freihaut (Ref. 4.10, 4.14,4.22-4.34): these are plots of tar release time against a "Heating Rate Index" (HRI) defined below. The activation energy and diffusion coefficient values used were the same as for Flgs. 4.20 and 4.21. The tar release time was based on the estimate that the tar yield was about $30 \%$ of the total volatile yield. An alternative proposed is that the tar yield is the quantity released between onset of pyrolysis and about $650^{\circ} \mathrm{C}$. Figure 4.4 has a particular significance in comparison with Figs. 4.19,4.20, and 4.21 with regard to the accuracy of prediction. Figure 4.4 shows that the accuracy of the tar release time prediction is superior to that of the total pyrolysis time. This is an impcrtant factor, as discussed below (Section 4.7.5), in evaluating the success and/or deficiencles of the moclel.

The importance of the Heating Rate Index as a determinant of other factors can also be shown by allowing the pyrolysis onset temperature $\left(T_{p}\right)$ to float with heating rate instead of being held $0400^{\circ} \mathrm{C}$, after selection of kinetic parameters for baseline conditions. With the kinetic parameters held co $1 s t a n t, T_{p}$ then varies with heating conditions. Using, as before, $1 \%$ mass loss to define $T_{p}$, a set of data tabulations of $T_{p}$ for differene (average) Heating Rate Index values was constructed by calculation from the full unsteady-state model. These values were then found to generate Arrhenius plots, as shown in Fig. 4.24, by plotting In (avg. HRI) against $1 / T_{p}$, with the slope returning an activation energy close to the (constant) value used in the model calculations.

This can be partially justified as a limit to behavior by the following considerations. Using the one-step, first order rate equation on which Eqs. (B.7) and (B.17) are based, then

$$
\begin{aligned}
d V / d t & =k_{0}\left(V_{0}-V\right) \exp (-E / R T) \\
& =(d V / d T)(d T / d t)
\end{aligned}
$$


R88-FC70768

At $1 \%$ mass loss Eq. $(4.18)$ can be written

$$
\left(d T^{\prime} / d t\right)_{1 \%}=\left\{k_{0}\left(V_{0}-V\right) /(d V / d T)_{1 \%}\right] \exp \left(-E / R T_{p}\right)
$$

or by taking logarithms

$$
\ln (d T / d t)_{1 \%}=\ln \left[\left(0.01 V_{0}\right) /(d V / d T)_{1 \%}\right]-E / R T_{p}
$$

and the straight line of Fig. 4.24 implies that

$$
(d T / d t)_{1 \%} \propto(d T / d t)_{u v e}
$$

and that $\ln (d V / d T)_{1 \%}$ is temperature insensitive. To the extent that these may be good empirical generalizations, they are of substantial value for approximation purposes in flame models.

\subsubsection{Kinetics Constant Values}

The fitting determinations of the kinetic constants as described above now allows us to update Fig. B.3. This is shown in Fig. 4.25, Fig. B.3, was constructed by Nsakala (Ref. 4.11) by adopting initial values of the pair $k_{0}$ and $E$, and then calculating the variation of $E$ with $k_{0}$ such that the extent of pyrolysis at a fixed heating rate was $1 \%$ at the same temperature; the calculation was then repeated for $5 \%$ and $10 \%$ loss. The experimental values of reported coefficients which were then mapped on to that graph mostly straddled the three lines, as shown in Fig. B.3.

This procedure has, essentially, been repeated to obtain Fig. 4.25 with the differences that: the line is calculated for only $1 \%$ loss; the two lines shown are for instantaneous loss and diffusion-controlled loss; and the coupling between $\mathrm{E}$ and $\mathrm{k}_{0}$ is obtained by the restriction that onset of pyrolysis (for Component $\mathrm{I}$ ) takes place at $400^{\circ} \mathrm{C}$. The temperature value used as a constraint for the second component is $600^{\circ} \mathrm{C}$.

It is not clear whether the range of experimental values is just error of measurement, or whether it represents real variations due to such iactors as coal type, method of experiment, and the like. Clarification of this point will aid interpretation immeasurably, 
Figure 4.25

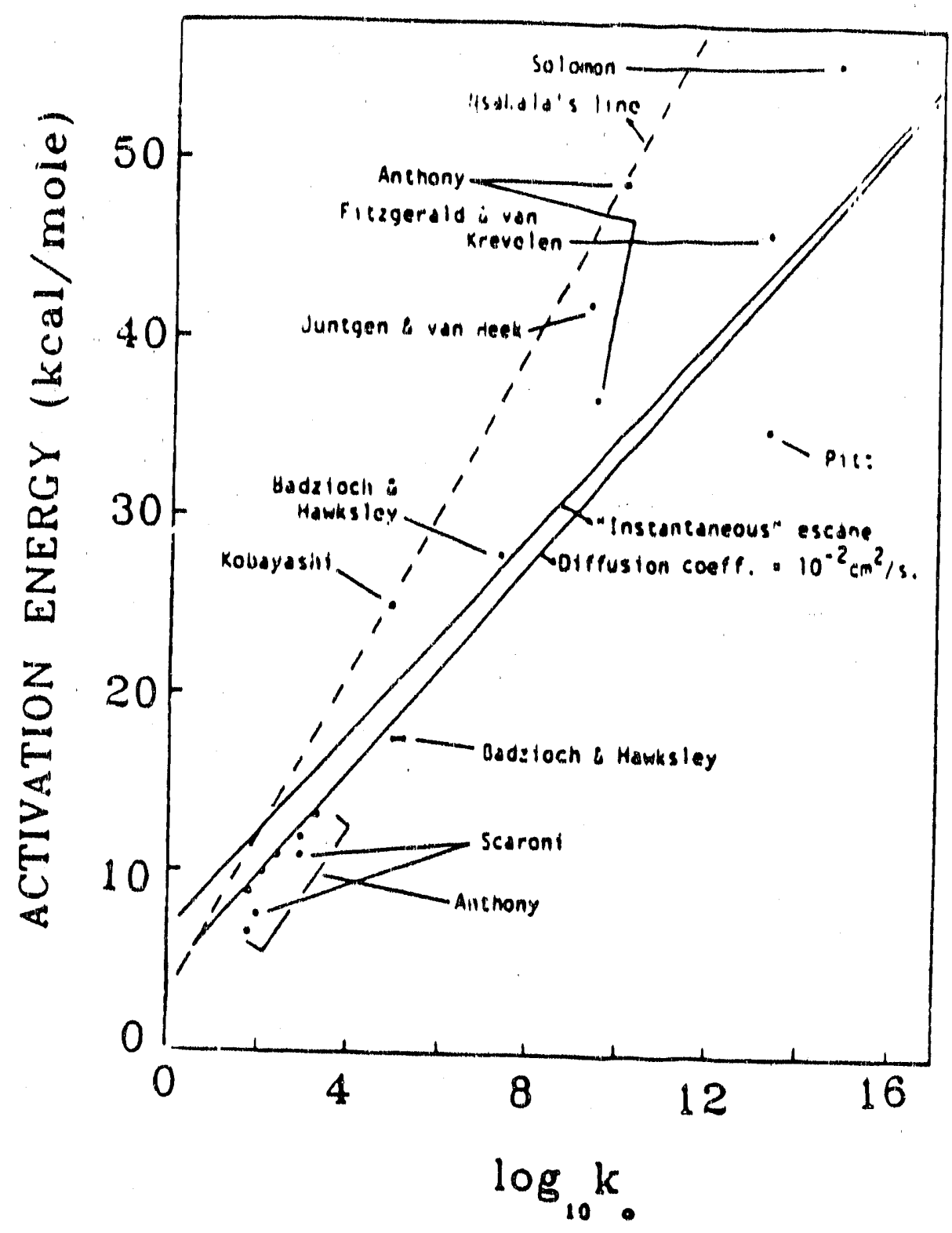

Variation of activation energy with pre-exponential factor. The calculations assume that $1 \%$ volatile loss occurs at $400{ }_{C}$. T Line 1: "Instantangous" escape of UM, Line 2: Diffusion Coefficient of $0.01 \mathrm{~cm}^{2} / \mathrm{s}$, Dashed Line: Nsakala's line for $\beta=1 \%$ 


\subsection{Data and Model Evaluation}

The results of he analysis developed in this Section are mostly summarized in Figs, 4.1, 4.3 and 4.19 to 4.23. Broadly speaking, there is a general support by the experimental results for the predicted curves; but It is equally clear that there is also some mismatch in detall which raises important quesilons. The best match in the trend lines is undoubtedly in the size range above $500 \mu \mathrm{m}$. The absolute magnitudes are still not quite as good as could be desired; but the greater discrepancies that are more difficult to account for are in the size range 20 to $200 \mu \mathrm{m}$. These are the points that need to be examined. The sources of the discrepancies must lie either with errors of measurement if the calculations are accurate, or with errors of assumption if measurements are accurate. There is reason to believe that it is some combinution of both. The argument that follows is structured to show that the equation system used in the initial part of the calculation was overconstrained: an additional degree of freedom was required and the logic of the argument limits this to Extension of the mechanism steps from one to two.

\subsubsection{Accuracy of Measurement}

It is possible for there to be some errors of measurement either in the pyrolysis times or in the particle sizes. With regard to the first, the pyrolysis times, in general, are more likely to be underestimated, not overestimated, particularly in the case of the captive particles. However, it is also unlikely that the errors are more than 10 or $20 \%$, and even a $50 \%$ error would not be seen on Figs. 4.19 and 4.20 as much of a shift where the $y$-axis has a logarithmic scale of 5 decades. Moreover, the fit to the calculated curves would generally get worse in such a case since the correction to an underestimate would move the points upwards.

For the drop tube, flame experiments, and (large) captive particles, there is no basis to challenge the particle size. The heated grid expcrimerits, however, may be more arguable. The weight of sample and dimensions support the general view that the particles are in a monolayer. If they are touching and are able to fuse together, it might be argued that the governing diametes to represent the sample response is greater than the nominal particle size. Even so, the increase would have to be $50 \%$ or more to improve the fit with prediction to any reasonable degree. Figures 4.21 and 4.22 , however, do support the view that the general location of these data is most probably due to the slower heating rates in this method of experiment.

The same argument regarding size may apply to the Curie-Point experiments. In those experiments, the particles were formed into a slurry and the Curie point sensor was dipped into the slurry to form a coat. From the weight of sainple an the dimensions of the sensor and coating $(0.5 \mathrm{~mm}$ and $20 \mathrm{~mm})$, the dimension (thickness) of the coating is estimated as equal to the diameter of a single particle. Tho layer is 
only heated from one side, however; and, on that basis, if we regard a single particle heated on one side as roughly equivalent to a particle of twice that diameter heated on both sides, these data then conform more readily with the rest. Accordingly, between Figs. 4.1 and 4.19 , the data points have been moved to reflect this argument.

\subsubsection{Captive Particle Data}

These two groups of measurements, for particles above $500 \mu \mathrm{m}$ (Ref. 4.1, 4.2), present a special case of some importance. Both the pyrolysis times and particle sizes are considered to be reasonably accurate. The experimental systems were very similar. Essenhigh (Ref. 4.1) used two flat (horizontal) spirals of electrically heated resistance wire, $20 \mathrm{~mm}$ dia and $15 \mathrm{~mm}$ apart with the particle held between them so that the particles were in the radiant field of both coils and in the upward convecting thermal field of the lower coil. Without the heated air from the lower coil the particles would not ignite. Kallend and Nettleton used an identical system, but using only the lower coil. We now know from recent measurements, however, that removal of the upper coil completely changes the convect :e field of the heated air rising from the lower coil (in addition to halving the radiation field). We cannot account totally for the factor of 3 difference in the pyrolysis times in the two groups of experiments, but these differences in the thermal fields account for a significant fraction of that difference. As discussed above, however, effective differences in coil heating time are probably not a factor.

Kallend and Nettleton also measured particle temperatures using thermocouples set into the particles, and they reported that the temperatures were surprisingly constant at about $400^{\circ} \mathrm{C}(700 \mathrm{~K})$ for most of the pyrolysis, and the effective ambient gas temperature for referencing in Fig. 4.20 will be above that. Figure 4.20 shows that these data are bracketed by the calculated curves at $800 \mathrm{~K}$ and $900 \mathrm{~K}\left(500\right.$ and $600^{\circ} \mathrm{C}$ ) and we believe these values are reasonably accurate.

In Essenhigh's experiments (Ref, 4.1) the presence of both coils helped to confine the VM flame around the particle at a stand-off distance that could never be more than one or two particle diarm" is away for the larger particles; this is substantially different from the Kallend and Nettleton setup. This creates gas iemperature gradients close to the particle that could be equivalent to very much higher temperatures at the "infinite" distance from the particle assumed in the model. Figure 4.20 shows that the curves for gas temperatures of 2200 and $2300 \mathrm{~K}$ (about 1900 and $2000^{\circ} \mathrm{C}$ ) provide some degree of match with the experimental data using the diffusion confficient of $0.01 \mathrm{~cm}^{2} / \mathrm{s}$. The dashed line then shows the predicted behavior at the same temperature with infinite speed of escape; this now underpredicts the time by as much 
as an order of magnitude, but it does show that the data can be bracketed by calculation using realistic values of ambient conditions.

Overall, the large particle data are in reasonably good agreement with the calculations, particularly for the Kallend and Nettleton data, using the presently selected coefficients.

\subsubsection{Ambient Temperature Effects}

If the calculations are reasonably accurate then the effect of ambient temperature and the rate at which it rises provide the best basis at this time to account for the one or two orders of magnitude in the range of experimental values below $500 \mu \mathrm{m}$ (and also above that diameter, as discussed ahove). With very rapid heating, the lower bound of the small particle experimental data is the band 800 to $1000^{\circ} \mathrm{C}(1100$ to $1300 \mathrm{~K})$; the predictions at flame temperatures are on the low side, but not too unreasonably so. The temperatures required for matching predictions to the main body of the drop tube and flame data, however. do seem to be too low and this we now helieve is due to the reaction (pyrolysis) model assumptions, as discussed below. This objection also applies to the heated grid data, but the discrepancy for this method of experiment is clearly due in part to the slower ambient heating rates as shown in Fig. 4.21.

\subsubsection{Effects of Coefficient Adjustment}

The evaluation above does indicate that the predicted pyrolysis times for the smaller particles shown in Figs. 4.20 and 4.21 are too short, possibly by as much as half to one order of magnitude. The agreement with the larger particles is substantially better for the most part, probably because the diffusion is starting to dominate the VM escape and prediction becomes much less sensitive to the kinetic coefficient values.

Where the fit needs to be improved, this can nominally be done by adjustment of the coefficients values, but only at the probable expense of requiring pyrolysis onset temperatures that are cutside the rarige of reasonableness or reality, and/or that require use of kinetic constants ( $k_{0}$ and $E$ ) that lie substantially outside the range of values supported by Fig: 4.25 . This last is not impossible, of course, but it would seem to be a constraint that should not be abandoned without good reason. (One such reason might be the need to correct the velocity constant values for heating rate as discussed in Appendix B.2.) However, any such changes would also have to be consistent with the relative trend and absolute values of the tar release shown in Fig. 4.4. Thus, there are reasonable constraints to forbid such arbitrary adjustment of the coefficients. Hence, although an additional degree of freedom is evidently needed, it is not reasonably available from coefficient adjustment and must be sought elsewhere. 
To emphasize the point being made here: the use in a model of an arbitrary number of degrees of freedom without matching con traints will always allow "fitting" of the model to the existing experimental data: but such "agreement" is no clear support for the model, which lacks uniqueness, and the model is not necessarily of predictive value outside the testing range of the fitting data. Only a sufficiently constrained model can be considered unique. Our objective here, as described earlier, was to develop a model that is either just constrained or overconstrained. Our results now show that at least one additional degree of freedom is required. We do not see that this exists in the arbitrary adjustment of any of the physical or chemical parameters (e.g. rate coefficients). Thus, the most probable source of the overconstraining is the (deliberately) over-simple pyrolysis model. In the subsection following we describe the basis for selecting a Two-Component Model for coal pyrolysis.

\subsubsection{The Two-Component Model of Coal Pyrolysis: A Derivation from Coal Constitution}

At this time the most commonly used model for a more complex pyrolysis system is based on the distributed activation energy assumption (Ref. 4.15) first proposed by Pitt (Ref. 4.55). The assumption, however, ic essentially empirical and has no particular mechanistic or constitutional basis beyond the postulate that production of a range of different products can imply an array of reactions. Uniqueness is very difficule to establish, and there are also many alternative pyrolysis models with equal validity; Lbhayakar (Ref. 4.14) has listed 5 groups of models representing 10 different subgroups (this listing is reproduced in Ref. 4.56).

The best alternative to that is considered to be a two-step model based on the Clark and Wheeler (Ref. 4.58). Two-Component Hypothesis of coal constitution; we show below that the two approaches have a significant degree of similarity. The particular relation of this Hypothesis to combustion was reviewed by Essenhigh and Howard (Ref. 4.59). The Two-Component Hypothesis has been interpreted (Ref. 4.60) in terms of the process of coalification represented by the Componeni I being transformed into Component II. The two components are then presumed to pyrolyze in different ways, with different products; and Table illustrates a recent update (Ref. 4.61) for the relation of constitution, pyrolysis, and coal formation proposed in 1958 (Ref. 4.62). This has also been used as the basis for a model to predict the variation of carbon ring structure with carbon percentage as a measure of rank (Ref. 4.60) (also updated recently, (Ref. 4.63)). This pyrolysis model assumes two independent componerits that can pyrolyze as noncompeting independent reactions: thus there is no rank effect except to the extent that this is introduced a prior by appropriately ratioing the proportions of the two components, nor is there any effect of heating rate or other operating conditions on the total VM yield, for the same reason. 
This can be compared with the phenomenological model, interpeted in Table $4.5 \mathrm{~b}$. This illustrates a coal "unit" being thermally reduced to "fragrnents" (D) of the same essential composition as the coal, at a kinetically controlled rate; the "fragments" in turn transform into tar $(H)$ and metaplast $(M)$ in a "flash distillation" disproportionation step where the proportioning between $\mathrm{H}$ and $\mathrm{M}$ is assumed to be governed by the local temperature and pressure conditions; the metaplast, in turn, reacts to light gases $(G)$ and char in a fixed molar ratio, $v$. The final VM yield is determined by the disproportionation reaction of $D$ into $H$ and $M$ : the ratioing of metaplast into light gases and char is fixed, but the overall proportioning into char and volatile products is changed by the flash distillation conditions of the "fragments" decomposition. If this ratioing was fixed and not variable, the tar formation would correspond kinetically to the Component I decomposition in Table 4.5a; and the light gases and char formation would correspond kinetically to the Component II decomposition, though in two consecutive kinetic stages instead of one. Consequently, we can add in the more complex pyrolysis processes illustrated by Tables $4.5 \mathrm{a}$ and $4.5 \mathrm{~b}$ in two steps: first, allowing the overall pyrolysis to proceed in two independent steps, with preset ratioing between the relative proportions; second, by incorporating the additional variation governing the disproportioning of the fragment breakup. For the development of the Engineering Rate Equation, we only need at this time implementation of the first of these two steps, as shown next. 


\section{TABLE 4.5}

(A) COALIFICATION, CONSTITUTION, AND PYROLYSIS OF COALS OR THE TWO-COMPONENT HYPOTHESIS

(a) Coalification (Coal Formation)

Stage I: up $\frac{10}{\text { Coallifation reaciton - Iransiormation of Component }}$

Transition: $05.0 \%$

Transition: $\frac{85.0 \% \text { to } \frac{92.5 \% \mathrm{C}}{\text { Stage l goes to completion - the natural }}}{\text { and point of this is Hirseh's pertect oliquile }}$
structure at $90 \% \mathrm{C}$ (minimum porosity).

Graphitization - condensation and coalescing of lamellae (Component II); end point, oraphite. The "liquid" structure breaks up, and the intermediate structures lormed are
less perfect.

(b) Constitution and Pyrolysis

\begin{tabular}{ccc}
\hline & (b) Constitution and Pyrolysis \\
\hline Material Decomposing & Temperature Range, deg. C & Product \\
\hline Material liquated out & Up 10 decomposition, $T$, & Molsture; absorbed and
\end{tabular}

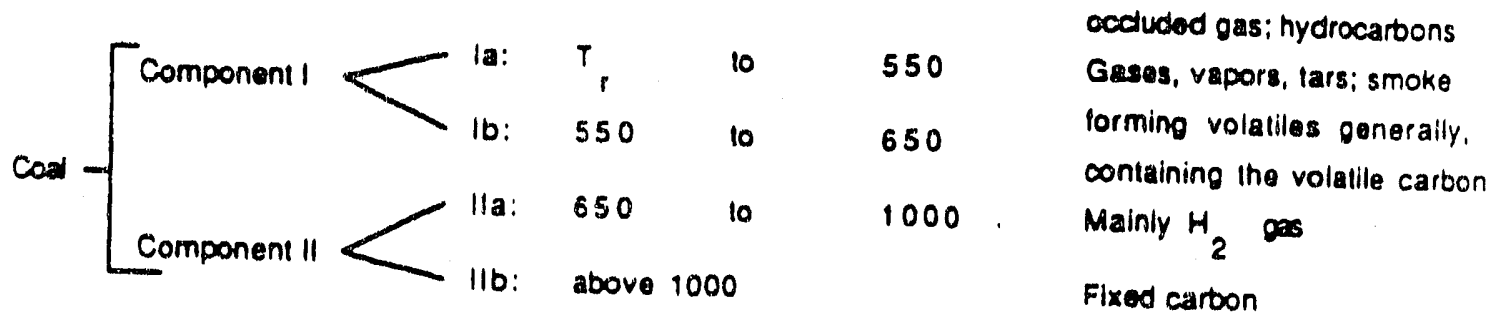

Pyrolysis Model Comparisons: Simplitied Model

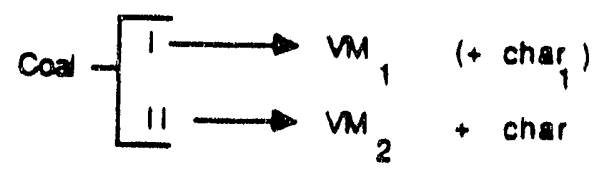

is oquivalent to above model with $V M_{1}-10+16$ and Char,-0 .

[B] PHENOMENOLOQICAL MODEL

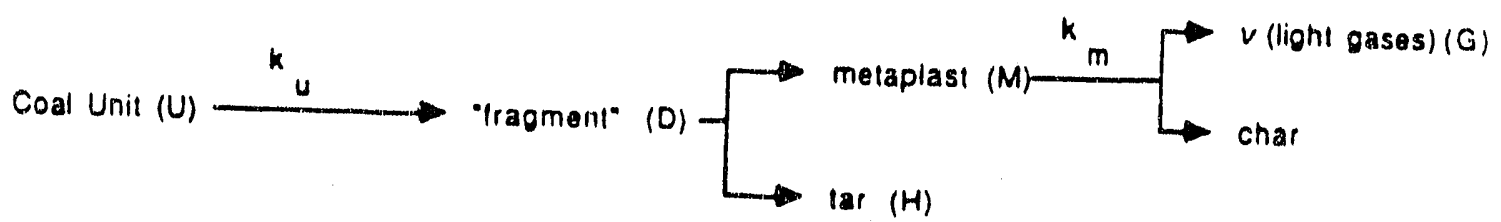




\subsection{Engineering Rate Equation}

The Engineering Rate Equation is by definition a simplification of a sufficiently complete model but with the constraints that the predictions shall be of necessary and sufficient accuracy. The final development of the working equation thus requires two stages. The first stage is implementation of the additional development step of the complete model identified above. The second stage is the simplification process.

\subsubsection{Two-Component Predictive Model}

The approach adopted is discussed and explained in Section 4.7.5. We use preset ratioing, as described in Section 4.6.4, of the proportion between tar, now equated with Component I of the Clark and Wheeler model, and the metaplast, equated with the Component II of the Clark and Wheeler model. With these identifications, the Component I pyrolysis is a one-step process, and the Component II is a sequential two-step process. We already haye, then, in the model a sufficient description of the Component-I/tar behavior, together with experimental verification of that behavior and determination of the relevant kinetic constants. This also provides us with the kinetic constants for the first stage of the Component-II to metaplast pyrolysis. All that is missing is the pair of kinetic constants for the metaplast pyrolysis into light gases and char.

To obtain the missing pair of kinetic constants we adopted the same approach, in principle, that we used for the first pair, as described in Appendix B and 4.6.6. The starting point was to assume that the relevant kinetic constants for the metaplast pyrolysis would follow the same auto-correlation shown in Fig. 4.24. The actual values on the autocorrelation range were then selected by imposing the requirement that $1 \%$ pyrolysis of the metaplast would occur at about $600^{\circ} \mathrm{C}$. The basis for this restriction was the summary statement of behavior for Component II provided in Table 4.5a.

With these additions, the completed model was then used to predict total pyrolysis times for the actual conditions reported by all investigators, and Fig. 4.26 shows the comparison between the predicted and experimental values, for all available data points for particles less than $100 \mu \mathrm{m}$. The calculations were restricted to this smaller particle size range for three reasons. First, it is the size range showing the greatest discrepancy between calculation and experiment; second, above $100 \mu \mathrm{m}$ the kinetics are progressively less important and predictive accuracy improves; third, in p.c. flames, which are the primary target of this work, only 1 to $5 \%$ of the p.c. particles are greater than $100 \mu \mathrm{m}$ in most cases.

Figure 4.26 shows now reasonably good agreement between prediction and experiment. Only 2 data points are significantly displaced, but the agreement overall is considered very good in view of the 
Figure 4.26

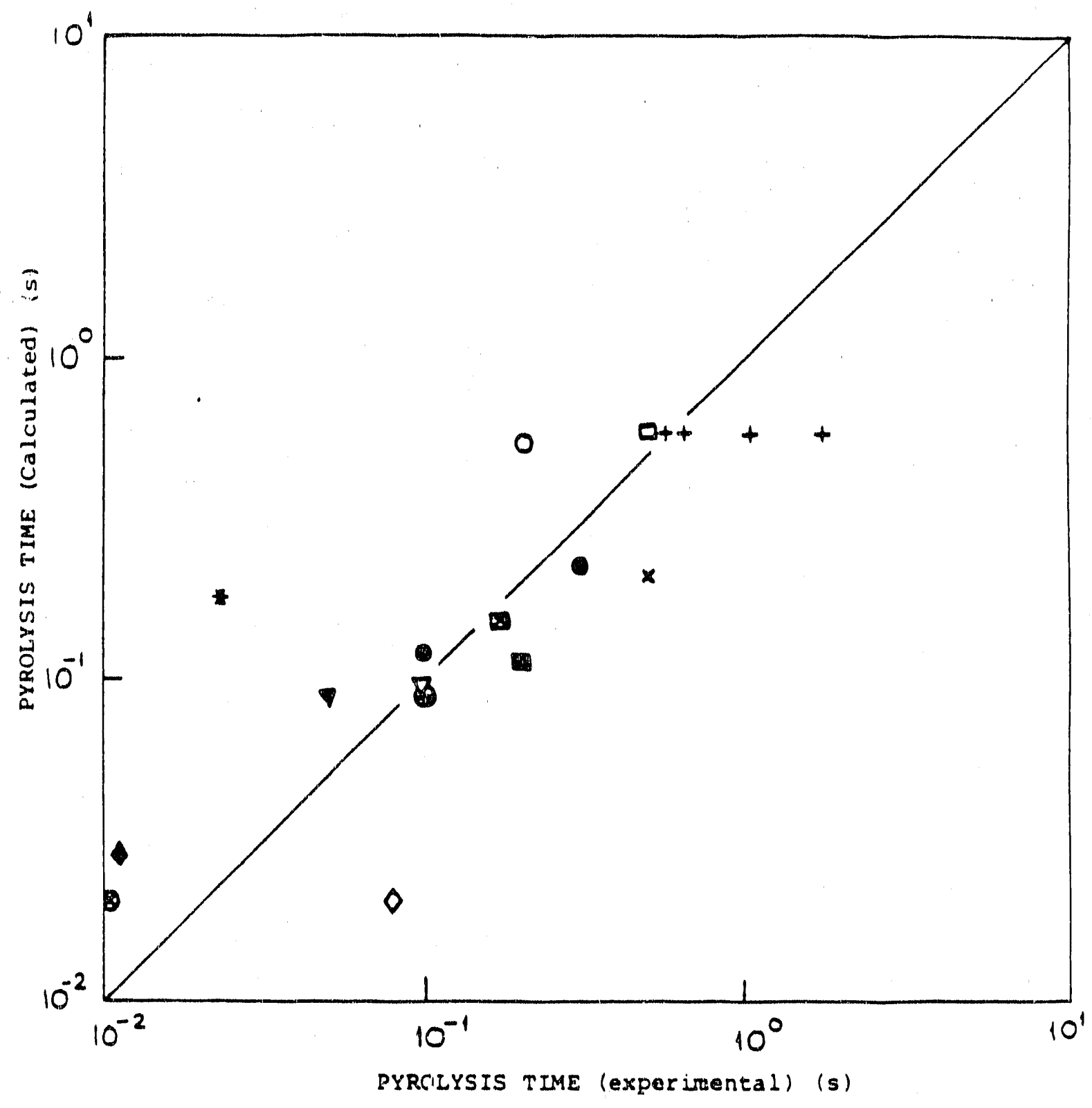

Comparison of pyrolysis time data with theoretical prediction using a two-component hypothesis and a total unsteady state analysis. 
uncertainties in the sources of data and the inevitable errors of assumption incorporated in any model. The values shown range over about $2-1 / 2$ orders of magnitude and are reasonably balanced either side of the $45^{\circ}$ line. With this agreement we feel that the plimary model is reasonably complete and accurate.

\subsubsection{The Simplified Model}

The need for simplification for incorporation in flame models is self-evident in view of the 8-hour CPU time of the complete model, fur one particle. The model was simplified in the following ways.

(1). The simplifications are confined to the heat transfer (physical) behavior, with the exterided (Two-Component) kinetics left unchanged. Diffusional escape, however, is assumed to be infinitely fast.

(2) The physical behavior is largely described by so-called lumped-parameter relations.

(3) The thermal behavior inside the particle is obtained by setting the particle thermal conductivity to infinity so that temperature gradients inside the particles are eliminated.

(4) Heat supply to the particle is provided by radiation (generally small) and by conduction only, with $\mathrm{Nu}=2$, and assuming quasi-stationary thermal response in the boundary layer.

With these changes, total pyrolysis times were calculated from both models, and the comparison is shown in Fig. 4.27, for final gas temperatures of 1300.1500 , and $2000 \mathrm{~K}$. As expected, there are minor to significant errors in the comparative predictions. In all cases, the simplified model underpredicts the pyrolysis times. The errors are greater for the slower heating rates (which give more time for the model differences to show up), and thus for the lower final temperatures which are generally related to lower heating rates. Analysis of these results shows that the surface temperature initially rises faster using the unsteady state model, but this is more than offset by the lower interior temperature with the result, as shown in Fig. 4.27, that the pyrolysis time is longer.

The effective temperature is, therefore, lower than either the surface temperature in the unsteady state model, or the (uniform) temperature in the simplified model. To correct for this, the calculated temperature was arbitrarily reduced by a constant amount at each time step. With a reduction of 2 degrees, the comparisons between the two models are shown in Fig. 4.28. The small residual error is substantially less than the error of experiment shown in Fig. 4.26. On this basis we conclude that the simplified model is an adequate representation of the detailed model, and likewise of the real pyrolysis behavior, so long as the temperature is appropriately corrected. 
Pigure 4.27

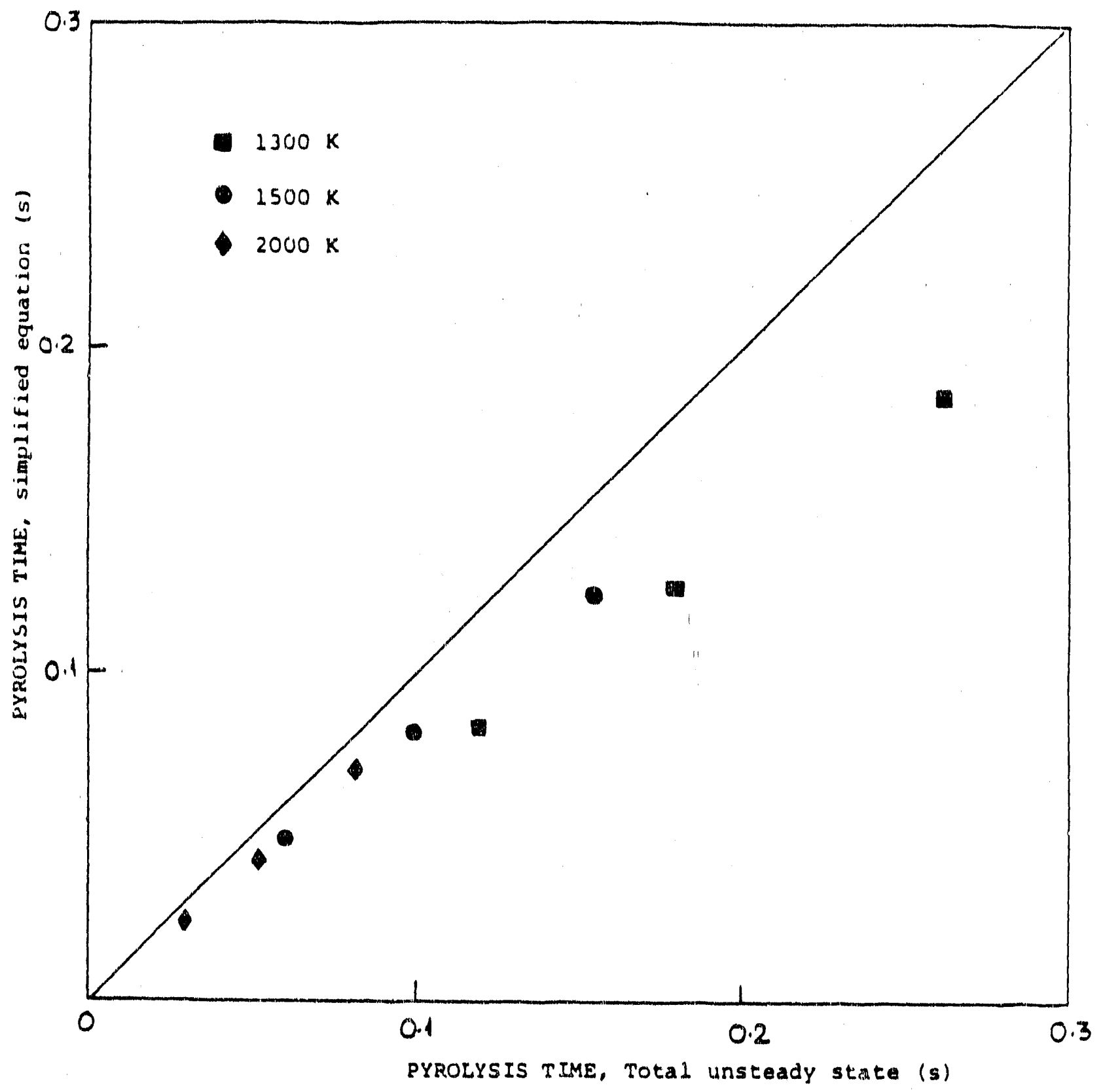

Comparison of predicted pyrolysis times using total unsteady state analysis and using simplifted heat transfer model for final gas temperatures of 2000,1500 and $1300 \mathrm{~K}$. 
Figure 4.28

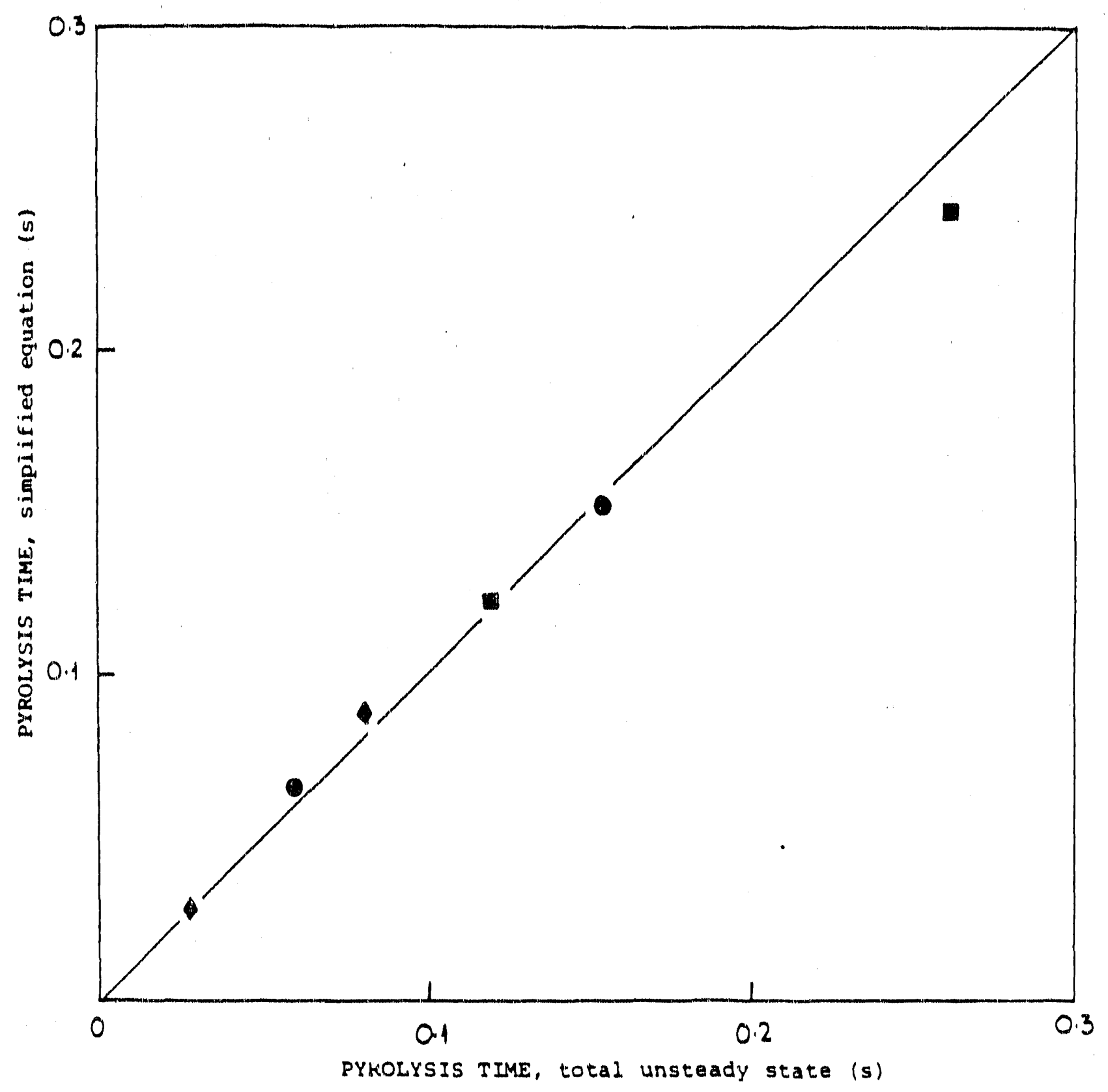

Comparison of predicted times for pyrolysis using total unsteady state analysis and using simplified equations with a correction factor of $2 \mathrm{~K}$ for temperature. 


\subsubsection{Recommended Kinetic Equations}

From this evaluation the recommended reaccion sequence is the scheme given as Eqs. (4.14) and (4.15) in Section 4.6.4, representing the enhanced Twa-Component scheme (see Table 4.5). The common velocity constant for the tar and metaplast formation is defined as the primary constant, $k_{u}$ and the velocity constant for the char and light gas formation is defined as the secondary, reaction velocity constant, $k_{m}$. In each case these have the standard relations

$$
k=k^{0} \exp (-E / R T)
$$

The parameters selected for the two velocity constants at this time are

$$
\begin{array}{ll}
k_{u}^{0}=3 \times 10^{10} \mathrm{~s}^{-1} & E_{u}=35 \mathrm{kcal} / \mathrm{mole} \\
k_{m}^{0}=10^{\prime} \mathrm{s}^{-1} & E_{m}=30 \mathrm{kcal} / \mathrm{mole}
\end{array}
$$

If $\mathrm{Cl}, \mathrm{CII}$, and $\mathrm{M}$ are the mass fractions of the two components and the metaplast then the relevant rates are given by

$$
\begin{aligned}
& d[C I] / d t=-k_{u}[C I] \\
& d[C I I] / d t=-k_{u}[C I I] \\
& d(M) / d t=+k_{u}[C I I]-k_{m}[M]
\end{aligned}
$$

Finally, in the split between char and gas the value of $v=0.2$ is used. 


\section{SECTION 4.0 REFERENCES}

4.1 Essenhigh, R.H., J. Eng, for Power, 85, pp.183-190, (1963),

4.2 Kallend, A.S., Nettleton, M.A., Sonderdruck aus $\gg$ Erclol und Kohle. Erdgas, Petrochemle $\ll 19$, pp, 354-356, (1966).

4.3 O'Connors, J,G.. Thring, M.W., Hulse, C., Perry, M.C., Proc. Conference on Sclence in the Use of Coal, Inst. Fuel, London, paper \#22, pp, c25-c33, (1958),

4.4 Howard, J.B., Essenhigh, R.H, I \& EC Process Design and Development, 6, pp, 74-84, (1967).

4.5 Seeker, W.R., Samuelsen, G.S., Heap, M.P., Trolinger, J.D., Proc, 18th Symp. (Intl,) on Comb., The Comb, Inst., pp. 1213-1226, (1981).

4.6 Smoot, L.D., Horton, M.D., Williams, G.A., Proc, 16th Symp. (Int.) on C'omb., The Comb. Inst., pp. 375-387, (1977).

4.7 Thring, M.W., Hubbard, E.H., Proc, 2nd Conference on Pulverized Fuel, Inst. Fuel, London, Paper \#4, (1957).

4.8 Marshall, W.F., Palmer, H.B., Seery, D.J., J Inst. Fuel, 37, pp. 342-349, (1964),

4.9 Kobayashi, H., Howard, J.B., Sarofim, A. F., Proc. 16th Symp. (Int.) on Combustion. The Comb. Inst., pp. 411-425, (1977).

4.10 Maloney, D.J., Jenkins, R.G. , Proc. 20th Symp. (Iritl.) on Comb., The Comb. Inst. pp. 1435-1443, (1984).

4.11 Nsakala, N.Y., Essenhigh, R.H., Walker, P.L., Comb. Sc, and Tech, 16, pp. 153-163, (1977),

4.12 Scaroni, A.W., Walker, P.L., Essenhigh, R.H., Fuel, 60, pp. 71-76, (1981),

4.13 Solomon, P.R., Serio, M.A., Carangelo, R.M., Markham, J.R., Fuel, 65, pp.182--193. (1986).

4.14 Ubhayakar, S.K., Stickler, D.B., Von Rosenberg, F.W., Gannon, R.E., Proc. 16th Symp. (Intl.) on Comb., The Comb. Inst. pp. 427-436, (1977). 
4.15 Anthony, D.B., Howard, J.B., Hottel, H.C., Melssner, H.P., Proc. 15th Symp. (Int,) on Comb., The Comb. Inst. pp. 1303-131\%. (1975).

4.16 Desyprls, J., Murdoch, P., Willams, A., Fuel, 61, pp. 807-816, (1982).

4.17 Niksa, S., Heyd, L.E., Russol, W. B., Saville, D. A., Proc, 20th Symp, (Int.) on Comb. The Comb. Inst. pp. 1445-1453, (1984),

4.18 Kelin, G., Mingchuan, Z., Hanxian, G., Proc, International Speclallsts' Meeting on Solld Fuel Utilization, Portuguese Section of the Combustion Institute, Lisbon, Portugal, (1987)

4.19 Hertzberg, M., Zlochovor, I.A., Cont, R.S., Cashdollar, K.L., Prepr, ACS (Div. Fuel Chem.) 32 (3), pp, 24-41, (1987)

4.20 Darcy, H. "Les Fontaines Publlques de la Ville de Dijon", Paris, Victor Delmont, (1856).

4.21 Freihaut, J, D., Proc, AR \& TD Contractors Review Mtg., U.S, DOE, (1987),

4.22 Campbell, J.H., Fuel, 57, 217 (1978),

4.23 Arendt. P, and Van Heek, K.H., Fuel, 60, 779 (1981),

4.24 Serio, M., et, al., Ind. Eng, Chem, Res., 26, No, 9, 1831 (1987)

4.25 Carangelo, R.M., et, al., Fuel, 66, 960 (1987).

4.26 Gibbins, J., PhD, Thesis, Imperial College, Dept. of Chem. Eng., (1988).

4.27 Present Investigation: UTRC.

4.28 Peters, W, and Bertling, H., Fuel, 44, 317 (1965).

4.29 Hertzberg, M., et. al., Amer. Chem. Society - Div, of Fuel Chem., 32, No. 3, 8 (1987)

4.30 Ballantyne, $A_{1}$ et. al., Final Report DOE/PC/30291-6, DOE/PETC (1983).

4.31 Gat, N., et. al., Final Repor, DOE/PC/40273-4, DOE/PETC (1983).

4.32 Granger, A, F., and Ladner, W. R., Fuel, 49, 17 (1970).

4.33 Badzioch, L. and Hawksley, P.G.W., Ind. Eng. Chem. Process Design and Dev., 9. No. 4, $521(1970)$. 
4.34 Phuoc, Tran. X. and Maloney, D. J., 22nd Symposiurn (Int, on Cnmbustion, Combustion Institute (1988).

4.35 Soloman, P, R. and Hamblen, D. G., Progress in Energy and Combustion Sclence, 9, 323 (1984),

4.36 Soloman, P. R, and Serio, M. A., NATO ASI Series, No, 137, ed, by Lahage and Prado, G. 126 (1986).

4.37 Howard, J.B., Chap. 12 in Chemistry of Coal Utilization, Second Supplementary Vol. (Ed. M. A. Ellot), John Wiley and Sons, Inc. (1981).

4.38 Howard, J.B., Fong, W.S., Peters, W.A., in "Fundamentals of the Physical Chemistry of Pulvertzed Coal Combustion" (Eds. J, Lahaye and G. Prado), Martinus Nishoff, Publishers, Dondrecht, pp. 77-97, (1987).

4.39 Zghoul, A.M., Essenhigh, R.H., Proc 2nd Annual Pittsburgh Coal Conference, Univ. Pittsburgh and Pittsburgh Energy Technology Center (U. S. DOE), 658-665 (1985).

4.40 Cassel, H.M., Llebmann, I., Comb. and Flame, 3, 167 (1959).

4.41 Chen, M., Fan, L.S., Essenhigh, R. H., Proc. 20th Symp. (Internat.) on Comb., The Comb. Inst., Pittsburgh, PA, pp. 1513-1521 (1984).

4.42 Brooks, P. J., Essenhigh, R.H., Proc. 21 st Symp. (Internat.) on Comb., Munich, (1986) (In press).

4.43 Seixas, J.P.S., Essenhigh, R.H., Comb. and Flame, 66, pp. 215-218, (1986),

4.44 Orning, A. A., Trans. ASME, 64, 497 (1942).

4.45 Bandyopadhyay, S., Bhaduri, D.B., Comb. and Flame, 411 (19/2),

4.46 Karcz, H., Kordylewski, W., Rybak, W., Fuel, 59, 799, (1980).

4.47 Kordylewskl, W., Kruczek, H., Rybak, W., Comb. Sci. and Technol.; 26, 157-160 (1981),

4.48 de Soete, G.G., Rev. de l'Institut Francais du Petrole, 40, 649-670 (1985).

4.49 Tognotti, L., Malotti, A., Petarca, L., Zanelli, S., Comb. Sci and Technol., 44, 15-28 (1985). 
4.50 Howard, J.B., Essenhigh, R.H., Proc 11 th Symp. (Internat.) on Comb., The Comb. Inst., Pittsburgh, PA, pp. 399-408 (1967).

4.51 Xieu, D.V., Masuda, T., Cogoli, J.G., Essenhigh, R.H., Proc. 18th Symp. (Internat.) on Comb., The Comb. Inst., pp. 1461-1468 (1981).

4.52 Beer, J.M., Proc. Second Symp. on "Flame and Industry", Inst. Fuel (London), pp. c1-c11 (1962), also J. Inst. Fuel, 67, 286-313 (1964).

4.53 Misra, M.K., Essenhigh, R.H., "Pyiviytic Eehavior of Coal Particle: Effect of Unsteady State Heating and Temperature Gradients". Paper \#10 presented at the Spring Technical Meeting, Central States Section, The Combustion Institute, Chicago IL. May, 1987.

4.54 Misra, M.K., Essenhigh, R.H., ACS (Div. of Fuel Chem.) Prepr., 32, No. 3, pp. 59-67 (1987).

4.55 Pitt, G.J., Fuel, 41, 267 (1962).

4.56 Ubhayakar, S.K., "Pyrolysis of Coal", AVCO-Everett Res. Lab. (Inc.) Rep. \#AMP538, July, 1977.

4.57 Essenhigh, R.H., Ch. 19 in Chemistry of Coal Utilization; Second Supplementary Vol. (Ed. M.A. Elliot), John Wiley and Sons. Inc. (1981).

4.58 Clark, A. H., Wheeler, R.V., Trans. Chem. Soc., 103, 1754 (1913).

4.59 Essenhigh, R.H., Howard, I.B., "Combustion Phenomena in Coal Dusts and the Two-Component Hypothesis of Coal Constitution”. Monograp/ 1231 in Penn. State Studies Series, The Penn. State Univ., Univ. Park PA, (1971).

4.60 Ayre, J.L., Essenhigh, R.H., Sheffield Univ. Fuel Soc. J., 8, p. 44 (1957).

4.61 Essenhigh. R.H., Ch. 3 in Coal Conversion Technology (Eds. C.Y. Wen and E.S. Lee), Addison-Wesley Pub. Co., (1979).

4.62 Essenhigh, R.H., Proc. Conf. Sci. in the use of Coal, Inst. Fuel (London), p. A-74 (1958).

4.63 Scaroni, A.W., Essenhigh, R.H., Prepr. ACS (Div. of Fuel Chem.), 23(4), pp. 124-134 (1978).

4.64 Fletcher, T., "Time Resolved Temperature Measurements of Individual Coal Particles During Devolatilization". Presented at 1988 Spring Meeting of the Western States Section of the Combustion Institute, March 21, 1988. 


\section{SECTION 5.0 - SUMMARY, CONCLUSIONS, SUGGESTIONS FOR FUTURE WORK}

This investigation represents a multilaboratory, coordinated experimental and analytical investigation of coal devolatilization using carefully screened coal samples provided by DOE personnel. Engineering kinetics (Essenhigh, Ohio State U.), fundamental modeling (Howard and Peters, MIT) and experimental investigations (Jenkins, Penn State U.) and (Freihaut, Proscia and Seery, UTRC) are included. At the same time, Fletcher (Sandia Labs.) and Maloney (DOE-METC) initiate coal devolatilization experiments using the same coal samples. An entire set of coals ranging from Texas lignite to anthracite were selected; however, most work concentrated on the HVA bituminous samples as a reference coal. In one "simple" stroke, the "unusual" coal sample argument is eliminated due to the concerted efforts of DOE-PETC personnel.

For a reaction system as complex as coal, an initial frame of reference needs to be explicitly formulated in order to establish a context for interpretation of results. The "working hypotheses" of this investigation are:

1. The apparent discrepancies in reported devolatilization rate phenomena are the result of three hidden assumptions employed by those reading the literature:

a. Coal is essentially a three dimensional covalently bonded polymer.

b. There is "A" devolatilization pathway and this exists independent of conditions of heating.

c. Transient temperature trajectories assigned to coal particles are acceptably accurate for kinetic model development.

2. A systematic, underlying consistency exists in coal devolatilization and this underlying consistericy is traceable via a close examination of tar evolution and structural characteristics. That is, tar yields, chemistry and properties are the internal tracers to examine the phenomenology and kinetics of coal devolatilization. The distribution of coal $\mathrm{N}$ serves as a subsidiary chemical tracer of the devolatilization path followed by a particular coal type in a particular reactor.

3. Coal phenomenology can best be understood by viewing coal structure as consisting of a distribution of physical and chemical bonding networks. 
4. An underlying consistency exists in coal devolatilization phenomena for all coal ranks. But the consistency is the expression of the interaction of intrinsic parameters of the coal with the extrinsic parameters, heat and mass transfer conditions, established by the reactor system. A coal devolatilization mechanism or kinetic pathway does not exist apart from the conditions of heating. That is, devolatilization is a dynamic property. A specific devolatilization path is the result of the interaction of a coal type, having a wide range of potential thermochemical thermophysical responses, to a given heat and mass transfer field, that is, the conditions of heating established by a specific reactor.

5. For the reasons noted above, the underlying consistency of coal devolatilization, the basis of a comprehensive model, can only be determined by a use of range of well defined heating conditions and a range of well-defined coal types.

\section{Significant Findings of the Investigation}

\section{Influence of Reactor System Characteristics and Experimental Technique on Devulatilization Observables}

Because of the recognized equivalent importance of heat transfer conditions on observables, well characterized reactors spanning a range of heating conditions were employed to perform the investigations. With respect to the influence of experimental conditions on the observables of devolatilization, the UTRC investigation established the following:

1. Inaccurate Transient Temperature Measurements Account for a Significant Fraction of the Apparent Discrepancy in Devolatilization Kinetic Behavior of Bituminous Coal (Figs. 2.136, 2.142 and Appendix D.1):

Temperature measurements and subsequent heat transfer analysis made with a unique heated grid device in the UTRC investigation demonstrated temperature differences as great as $300^{\circ} \mathrm{C}$ can exist among various portions of a transiently heated wire mesh during tar evolution. Local coal sample load factors influence the local transient temperature response of the heating medium, the grid surface. Uncontrolled sample distributions relative to a single thermocouple measurement are demonstrated as the probable cause of the $600^{\circ} \mathrm{C}$ variation in temperature distributions in published heated grid tar evolution data. The inaccuracy in previous temperature measurements is shown to be a major contributing factor in the apparent discrepancies in tar evolution rates reported in the literature. 
Underlying the inaccuracy of previous measurements was the failure of some investigators to realize the significant coupling among the local heat transfer field and the particle temperature during the main phase of devolatilization, tar evolution. The temperature insensitivity of early heated grid work is shown to be the result of the inaccurate transient temperature measurements. Temperature insensitivity arguments based on depolymerization via a set of distributed activation energies have no measurement basis. The premises of Solomon's comprehensive model are shown to have absolutely no experimental basis relative to his early heated grid work.

Accurate estimates of HVA bituminous coal tar evolution temperatures in such heating conditions indicate the initial phase of tar evolution occurs at temperatures below $600^{\circ} \mathrm{C}$ for heating rates of $1000^{\circ} \mathrm{C} / \mathrm{sec}$ or lower. The rate of tar evolution varies with heating rate as does the temperature of maximum tar evolution rate, indicating close coupling among intraparticle tar formation, pyrolysis and rate of evaporation. With accurate temperature measurements, the tar evolution rate in a heated grid apparatus is shown to be adequately fit with a single activation energy ( $45 \mathrm{kcal}$ ) and pre-exponential $(1.0 \mathrm{E} 13)$. It is interesting to note that recent work done by Suuberg and Howard at MIT incorporates a mass loss rate constant having a single activation energy of $50 \mathrm{kcal}$ and a pre-exponential of $1.0 \mathrm{E}+13$ for a bituminous coal.

2. Particle Feed Characteristics Can Vary Dynamically In Entrained Flow Reactor Systems Having Significant Effects on Apparent Mass Loss Results (Table 2.12):

In operating the UTRC-EFR and establishing mass loss by the ash tracer technique, it was noted that the mineral matter content of the feed coal could change significantly over a period of several experiments. Such changes led to negative mass loss data while significant quantities of tar were being generated. This phenomenon was observed despite the fact that DOE-provided, aerodynamically separated, narrow size range feeds were utilized in a feeder operated on aerodynamic principles. It was noted that ash decerminations had to be performed in cold flow conditions before and after each run to obtain accurate mass loss determinations. These findings offer a possible explanation for the wide variation in mass loss kinetics observed for entrained flow reactors over the same temperature range.

3. A Unique Entrained Flow Reactor System with On-line Gas Analysis and Tar Separation Permitted Deconvolution of the Tar Evolution and Secondary Reaction Networks (Figs. 2.81 through 2.114 , Figs. 2.123 through 2.125, Figs. 3.2 through 3.5 , Figs. 4.2 through 4.4, Appendix D.2): 
A unique tar separation system and on-line gas analysis system allowed the determination of the separate temperature regimes of tar evolution and secondary reactions. The experimental results again indicated that the observables - tar yield and characteristics, light gas yields and composition - from a given reactor system, entrained flow reactor, depends significantly on the condltions of heating. The secondary reaction temperature regimes of tar pyrolysis determined independently by CSIRO using very different heating systems were confirmed with the additional information that nitrogen evolution chemistry is intimately coupled to the high temperature secondary reactions of tars.

By systematically varying parent coal type, the underlying consistency in the phenomenology of tar evolution, irrespective of coal rank, as well as the significant differences in tar chemistry and properties with coal rank were demonstrated. The data provide unique and unprecedented experimental guides for devolatilization modeling.

4. A Unique Flash Lamp Apparatus Verified the Temperature Regimes of Tar Evolution and Secondary Reactions-Indicating Consistency in Coal Devolatilization Phenomenology and Apparently Disparate Irradiance Heating Data (Figs. 2.146 through 2.167):

By varying the irradiance/particle size ratio in a calibrated flash lamp apparatus, it was again demonstrated that the observables of devolatilization are intimately coupled to the transient conditions of heating as noted below. By establishing a reactor system having a broad range of irradiance/particle size applicability, the apparently disparate range of devolatilization behavior observed in published radiant heating investigations is demonstrated to be basically consistent. That is, apparently diverse behavior is the result of slight changes in irradiance heating conditions which selectively emphasize a particular devolatilization pathway or subset of all possible pyrolytic responses of coal, for example, tar cracking vs. intact tar evolution.

5. The Unique Capabilities of the Heated Grid and Entrained Flow Reactors Were Utilized to Develop A New, More Accurate Approach to Characterizing Molecular Weight Properties of Coal Tars (Figs. 2.118 through 2.121):

By using a combination of elemental analysis, infrared absorbance analysis and vaporization properties on the heated grid device, and size exclusion measurements, it was demonstrated that a single size exclusion calibration technique could not be employed to determine the molecular weight properties of tar species from different coal samples. Tar structures vary from primary aliphatic to condensed aromatic structures 
depending on coal type or reactor operating conditions. One must a priori determine what type structures dominate in a particular sample before applying a particular retention volume to size correlation.

The Phenomenology of Tar Evolution: Effects of Coal Rank, Reactor Temperature, Particle Size and Extent of Evolution on Tar Properties

Because of the central role of tars in developing a comprehensive model of coal devolatilization, measurements of particle temperature during tar evolution, tar ctaracterization for a range of coal ranks, extent of tar evolution, and heating conditions, and the determination of tar evolution kinetic parameters is emphasized. The major findings to date of the UTRC study of tar evolution phenomenology are as follows:

1. For a given set of heating conditions and extent of tar evolution, the lower the rank of the parent coal the more dissimilar the "primary," immediately quenched, tars relative to the "average" parent coal structure, as indicated by elemental composition or infrared absorbance properties. In general, the lower the rank characteristics of the coal, the greater the concentration of polymethylene-like structures in the primary tars (Figs. 2.113, Appendix C.2).

2. For a given coal type and a given set of heating conditions, the primary tars evolve in a definite sequence - the earlier in the tar evolution process the more hydrogen rich, lower molecular weight the tars (Figs. 2.109 through 2.111).

3. For a given coal type, the yield, physical and chemical characteristics and rate of particle mass loss as "primary" tars varies significantly with rate of heating and peak particle temperature achieved (Figs. 2.142, 4.143, 4.2 through 4.4).

4. In general, maximizing tar yields for a given coal requires transient particle heating to particle temperatures in excess of $600^{\circ} \mathrm{C}$. The higher the apparent particle heating rate, that is the greater the transient heat flux to the particle, the larger the molecular weight characteristics of the integrated tar mass, although a distillation-like process appears followed in all but most intense heating conditions. Factors such as particle size and ambient pressure appear to have second order influence on the yields or chemical characteristics of the major fraction of the potential tar yield, provided account is taken of the effect changes in these parameters have on transient heat transfer (Figs. 4.3, 2.102, $2.105,2.142,2.143,2.158,2.166,2.167)$. 
5. The initial $60-75 \%$ of particle mass loss as tar correlates well with the reactor to particle heat flux rate, provided particle temperatures in excess of $600^{\circ} \mathrm{C}$ are achleved. However, the nature and yield of tars can vary appreciably, indicating very different overall intraparticle chemistry and tar desorption processes are followed in different heating conditions (Fig. 4.3, 4.4).

6. Tar evolution in the $550-700^{\circ} \mathrm{C}$ particle temperature range involves desorption of large molecular weight species relative to species evolved at lower temperatures. The molecular weight and thermally labile structural characteristics of such species immediately establish competitive reaction processes that determines their fate - intraparticle pyrolysis fragmentation and/or intraparticle coking yersus intact desorption. Intact desorption requires net reactor-to-particle surface heat transfer rates of the order of 100 watts $/ \mathrm{sq} . \mathrm{cm}$ (Table 2.19, Appendix C.2, Fig, 2.167) and is favored by low pressure conditions.

7. Extensive heat transfer characterization of coal devolatilization reactor systems indicates that heat transfer rates required for non-equilibrium, intact desorption of the large, detached molecular weight species can not be achieved in conventional fixed bed reactors wire baskets, heated grids, low temperature fluid bed systems, etc. Such heat transfer rates are only achieved in high temperature flow reactors or radiation heating - flash lamp, laser desorption - experiments (Fig. 2.01).

8. Gas phase, "secondary" pyrolysis reactions of primary tars from all coals initiate around $600^{\circ} \mathrm{C}$, producing mainly methane, water, carbon dioxide, carbon monoxide and ethylene between 600 and $800^{\circ} \mathrm{C}$. At $700^{\circ} \mathrm{C}$ and above, gas phase pyrolysis networks leading to the formation of acetylene, carbon monoxide, ethylene, benzene and hydrogen cyanide dominate the observable gases (Figs. 2.103, 2.160 through 2.165, 3.2 through 3.04, Appendix D.2, D.3).

9. The change in gas phase products as a function of residence time of the primary tars in the hot zone of the reactor, or the particle vicinity, correlates with the change in tar structure properties - elemental composition, infrared absorbance, molecular weight and THF solvent solubility. By gas phase secondary reactions, "primary" tars of coals can approach average structural features similar to but never identical to the parent coal (Figs. 2.109 through $2.112,2.117$ ). 
10. Paricle size studies using the heated grid and a specially designed entralned flow reactor also indicate the importance of heat transfer conditions in establishing the rate of particle mass loss as tar. Tar yields and chemical characteristics for a given reactor appeared relatively insensitive to particle size, given knowledge of any maceral distribution changes with particle :ize (Figs. 2.102, 2.105).

11. Experiments performed on a conventional entrained flow reactor at PSU indicate that HVA bituminous coals show the same sensitivity to changes in heat transfer parameters as observed earlier by Maloney. However, the lower rank coal display lower initlal mass loss rates than bituminous coals. The decrease in initial mass loss rate correlated with the decrease in potential tar yield from lower rank coals (Flgs, 2.28 through 2.31, 2.104, 2.145).

12. MIT studies using the Sandia EFR indicate that intraparticle bubble formation occurs early in the devolatilization process, resulting in significant swelling during the first phase of particle mass loss (Fig. 2.55 through 2.74 ).

13. In view of the above coupling observed among intrinsic and extrinsic parameters in determining tar evolution rates and characteristics, comparisons of mass loss kinetic rate constants over a wide range of heating conditions and without respect to observed tar characteristics is less than informative. Such comparisons can even be misleading in the sense that the underlying assumption is that the same chemical kinetic processes are followed with equal magnitude in a wide range of heating conditions.

14. Extensive heat transfer calculations performed independently by MIT (Appendix $C$ ) and Ohio State (Section 4.0) personnel indicate that intraparticle temperature gradients were not significant in most experimental conditions, provicled the initial and boundary conditions of the experiment were assumed to simulate the mathematical boundary conditions. In addition, such calculations also showed negligible temperature difference between a reactor thermocouple and a coal particle in real time, provicled an idealized set of heat transfer boundary conditions could be established within an experiment and the tar evolution process is slow enough to allow the ideal boundary conditions to be established around the particle. These requirements are, of course, mathematically feasible but experimentally unrealizable in rapid heating to particle temperatures in excess of $500^{\circ} \mathrm{C}$. 
Conceptual Understanding of Coal Structure and Devolatilization Sequence Following From Above:

1. Comparisons of datil generated In this program with that generated in a wide range of heating conditions with similar HVA bituminous coals indicate the following conceptual model of tar forrnation, evolution and reactions provides an adequate basis for understanding the tar devolatllization process and tar propertles observed in a wide range of reactor conditions (Figs, 3.2 through 3,4):

I. Physical Detachment of Tar Precursors $\left(300-450^{\circ} \mathrm{C}\right)$

II. Chemical Detachment of Tar Precursors $\left(400-550^{\circ} \mathrm{C}\right)$

III. Intraparticle Pyrolysis/Reformation of Detached Tar Precursors $\left(450^{\circ} \mathrm{C}+\right)$

IV. Extraparticle Evolution of Tar Precursors via Vaporization, Convection, Non-equilibrium Desorption $\left(300-700^{\circ} \mathrm{C}\right)$

V. Low Temperature Secondary Reactions of Tars Coincidental with Char Degassing $\left(600-800^{\circ} \mathrm{C}\right)$

VI. High Temperature Secondary Reactions of Tars Coincidental with Char Degassing $\left(700^{\circ} \mathrm{C}+\right)$

2. With respect to particle weight loss, the HVA bituminous coal devolatilization process is best understood as a four phase process (Figs. 4.2a, 4.2b, 4.5):

1. Induction Period to Initial Tar Release

11. Initial Heat Transfer Controlled Phase of Devolatilization

III. Residual Tar Evolution Phase

IV. Char Degassing

Phases I and II are primarily heat transfer controlled and account for 50-60\% of the particle mass. Phase III is mass transfer and chemical kinetics controlled. Interphase mass transfer Inhibits the release of large molecular weight hydrocarbons associated with the late stages of tar evolution. Intraparticle pyrolysis reactions generate enough light gas and smaller molecular weight tars enabling tar escape via vaporization 
and convective oxpulstion with gases through bubble formation. Phase III is slow relative to Phase I+II and represents the change in slope of the wh. loss vs. time curve from concave up to concave down Ir. :he transition to the asymptotic approach to final weight loss. Phase IV represents the slow char dega Ing Indlcated by asymptotic nature of the final $10 \%$ weight loss in devolatilization experiments. Phase IV is ery slow relative to phases I, II and III. It should be noted that the total weight loss process, Irrespecti: of experimental configuration, is always the result of coupled chemical and transport processes. Or...all kinetics will change with conditions of heating because it is the conditions of heating that ampllfy the importance of a particular set of tar reactions (see above) or phase of mass lass.

3. The results imply that the correct view of coal structure is that of a three dimenstonal macromolecular entanglement containing a wide range of moleoular sizes bonded throughout the entanglement by a wide range of physical and chemical bond strengths.

4. Relative to a HVA bituminous coal, lower rank coals dlsplay tar evolution and weight loss phenomenology more symptomatic of purely polymeric materials. That is, these coals have structural parameters that produce devolatillzation behavior more symptomatic of polymer pyrolysis - light gas evolution is always competitive with tar evolution, the initial tar burst is not clearly heat transfer controlled (Figs. 2.28 through $2.31,2.104,2.145$ ).

5. Relative to a HVA bituminous coal, higher rank coals display tar evolution patterns similar to the HVA coal but tar yields are lower, indicating less material is present or is generated within the parent coal structure possessing molecular weight capable of vaporizing during the weight loss process (Fig. 2.104, 2.145).

\section{Related Investigations Performed at Other Laboratories:}

Maloney devised an ingenious experiment to Investigate the devolatilization of a single coal par sle pulsed by a laser beam. By observing the evolution and condensation of tar mists outside the particle surface. he was able to establish to three separate time periods of heavy hydrocarbon devolatilization. In general these correlate well with the phases noted above.

Hertzberg performed supported particle, asymmetric heating of single particles using long pulses of a $\mathrm{CO}_{2}$ laser. His data indicated the particle mass loss to be simply correlated by heat transfer considerations, wherein the net flux at the particle surface establishes a pyrolysis wavefront through the paricle. The characteristic mass loss times are assumed to correlate with the pyrolysis wave propagation time. However. 
Hertaberg observes different asymptotic mass loss values depending on the net flux to particle size ratio and no product deconvolution is reported. These results are quantitatively consistent with stages 1 and II.

In entralned flow reactior systems, both Fletcher at Sandia and Solomon at AFR have attempted to make in situ particle temperature measurements during devolatilization. Fletcher established a sophisticated, truly single particle technique which is able to make its first in situ measurement on particles $650^{\circ} \mathrm{C}$ or hotter. Unfortunately, this is after the majority of tar evolution (30\% of the parent particle mass). However, the technique demonstrates that tar evolution occurs rapidly during such heat transfer conditions. Fletcher observes, almost parenthetically, in reporting his results that the stream mixing in the front end of his reactor may affect his observable mass loss rate. This is a significant observation in view of the above understanding of tive particle mass loss process.

Solomon actually measures a particle cloud temperature for bituminous coal. It is Interesting to note that the particle mass loss rate constant developed by Fletcher at Sandia Laboratory (Livermore) and the tar evolution rate constants developed by Solomon (at AFR) agree fairly well with the UTRC tar evolution rate constant developed using the calibrated heated grid apparatus.

\section{Future Work:}

Tar evolution rate constants for varying coal ranks need to be established as do low temperature tar intraparticle coking reactions.

In order to quantify the influence of interphase mass transfer resistance in the middle and late stages of tar evolution the molecula $\%$ elght and vapor pressure characterization of tars produced from varying coal ranks and extent of reaction should be systematically pursued. Because of the significant changes in tar structure with rank and extent of reaction, a technique using type classification, vaporization property measurements and size exclusion techniques in a coordinated manner is essential.

Significant differences with respect to the point at which mass transfer resistance becomes dominant in the mass loss kinetics exist. This needs to be finally clarified as a function of extent of reaction and coal type

A more tractable model of particle swelling needs to be developed as well as a model that will predict char reactivity as a function of extent of devolatilization. These are important parameters in burnout.

The kinetics of soot formation from tar needs to quantified. Does the UTRC hi-T tar pyrolysis kinetics serve to predict overall soot formation rates? The soot yield/tar mass input needs to be quantified for combustor modeling. 


\section{R88 - PC70768}

Finally, experimenis should begin to be used as model discriminators. That is, models should begin to be required to predict the results of a pardcular experiment - e.g. tar yleld, tar molecular weight distribution, tar H/C, swelling parameter - rather than fit the data after the fact. Critical experiments should be defined by the model developers that would allow experimental verfification or testing of a model. 

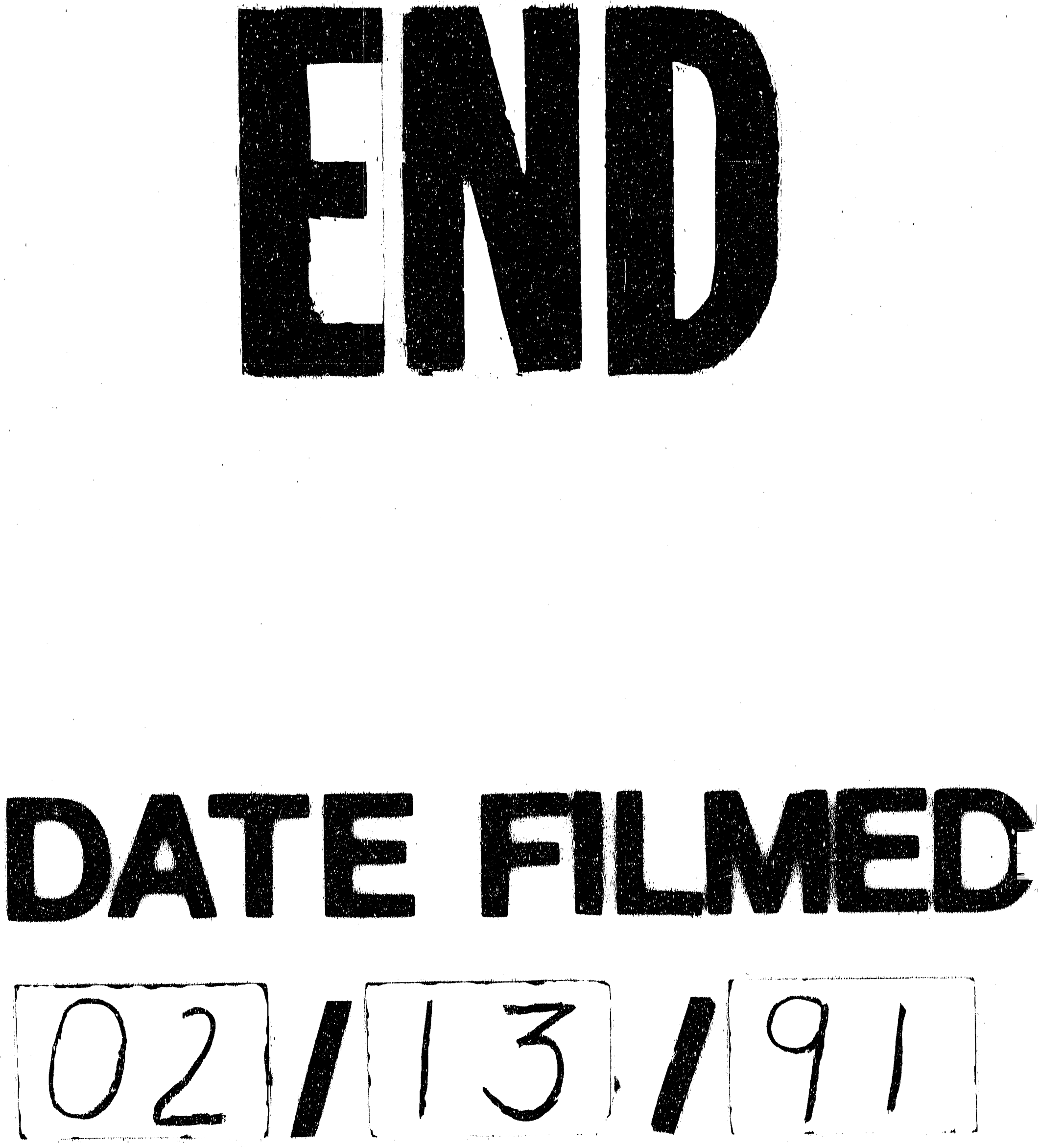
